


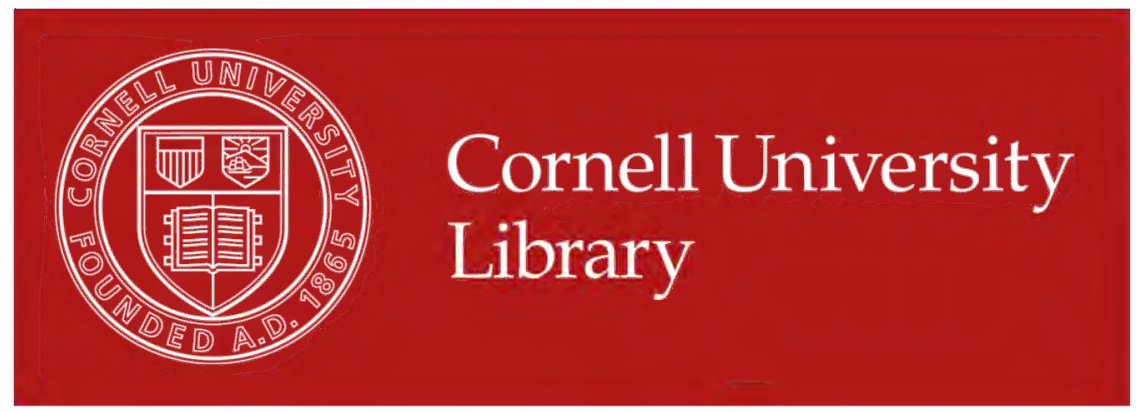

The original of this book is in the Cornell University Library.

There are no known copyright restrictions in the United States on the use of the text. 


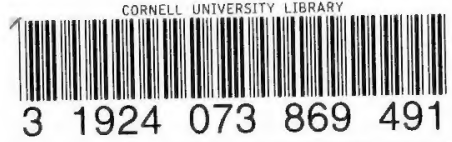







\section{Production Note}

Comell University Library produced this volume to replace the irreparably deteriorated original. It was scanned at 600 dots per inch resolution and compressed prior to storage using CCITT/ITU Group 4 compression. The digital data were used to create Cornell's replacement volume on paper that meets the ANSI Standard Z39.48-1992. The production of this volume was supported by the United States Department of Education, Higher Education Act, Title II-C.

Scanned as part of the A. R. Mann Library project to preserve and enhance access to the Core Historical Literature of the Agricultural Sciences. Titles included in this collection are listed in the volumes published by the Cornell University Press in the series The Literature of the Agricultural Sciences, 1991-1996, Wallace C. Olsen, series editor. 




\section{COUNTRY LIFE EDUCATION SERIES}

Edited by Charles William Burkett, recently Director of Experiment Station, Kansas State Agricultural College; Editor of American Agriculturist

TYPES AND BREEDS OF FARM ANIMAL.'

By Charles S. Plumb, Ohio State University

PRINCIPLES OF BREEDING

By Eugene Davenport, University of Illinois

FUNGOUS DISEASES OF PLANTS

By Benjamin Minge Duggar, Cornell University

SOIL FERTILITY AND PERMANENT AGR ICULTURE

By Cyril George Hopkins, University of Illinois

PRINCIPLES AND PRACTICE OF POULTR $Y$ CULTURE

By John Henry Robinson, Editor of Farm-Poulsry Other volumes in preparation 



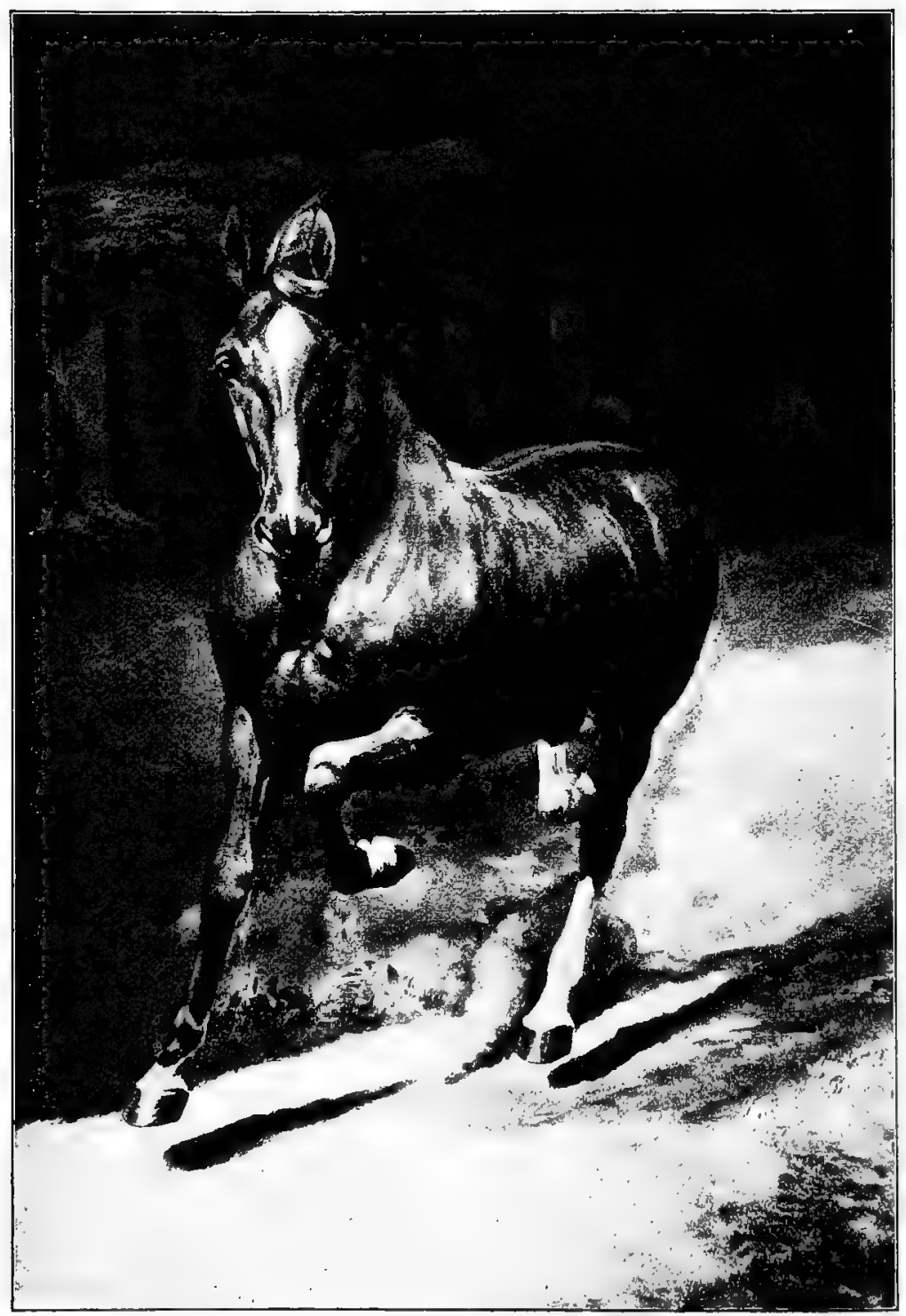

Langton Performer 242 (4844). A famous Hackney sire. Owned by F. C. Stevens of New York. From a photograph of a painting 


\title{
TYPES AND BREEDS OF FARM ANIMALS
}

\author{
BY \\ CHARLES S. PLUMB \\ Professor of Animal husbandry in the College of Agriculture \\ of tile Ohio State University
}


Entered at'Stationbrs' Hale

COPYRIGHT, 1906

BY CHARLES S. PLUMB

ALI. RIGHTS RESERVED

613.1 


\section{FOREWORD}

The need for such a volume as this will no doubt be best expressed by a demand for it on the part of live-stock students. The author, however, desires to call attention to the fact that not since 1888 has a volume devoted to the breeds of horses, cattle, sheep, and swine been published in America. The most recent work devoted to the breeds entirely omitted a consideration of the horse. Further than this but very few books have thus far been published in the English language that have been strictly breed studies.

This book differs somewhat from others that have preceded it. A number of breeds have received recognition for the first time, these being the ass, the mule, the angora and milch goats, - all animals of importance in certain localities. The more important or better known breeds have received more detailed consideration than those which may be regarded as the lesser known, and have been so ranked in the make-up of the book. In numerous instances much new historical information has been gathered. During the past twenty years a great amount of evidence bearing on breed merit has been secured at the agricultural experiment stations, at expositions, on race courses, and at fair grounds. In the breed reviews in this work much of this recent evidence is given a place. Brief consideration is also given to some of the more important foundation families or tribes, and to individual animals that have made a deep impression upon the breed. The author has taken the liberty of commenting on the weak as well as on the strong points of the breeds, but this has been done in a nonpartisan spirit, in harmony with the views of capable critics.

In the preparation of this volume a wide range of breed literature has been consulted. Following the breed discussion of each group is given a list of reference works to which the author is indebted for helpful information. Some of these are 
prefixed by an asterisk (*), as especially worthy the attention of the student. Numerous pamphlets, the stud, herd, and flock books of many breeding associations, and the documents of the United States Department of Agriculture and of various experiment stations have contributed materially to this work. Special recognition is here given of the great amount of important information regarding the breeds, published in the volumes of such valuable journals as the Breeders' Gazette, the old National Live Stock Journal, the Live Stock Journal (England), the Journal of the Royal Agricultural Society of England, the Journal of the Highland and the Agricultural Society of Scotland, as well as numerous other excellent live-stock and agricultural periodicals published in America and elsewhere. All these have contributed materially to such value as this book may possess.

Much of the material in this volume has been submitted in manuscript or proof to the frank criticism of many eminent breeders, that justice might be rendered each breed. While many of the illustrations are from photographs taken by the author at home and abroad, not a few are contributed by generous breeders and friends, for which credit is given elsewhere. The author is especially grateful to his associate, Dr. Carl W. Gay, for helpful suggestions and assistance.

These brief studies of the types and breeds of farm animals are naturally far from complete. They are intended for the student or the stockman who sees the long road of education before him. The subject-matter is arranged with some regard to systematic grouping, with the hope that it may in a measure meet the requirements of the class room, the teacher, and the practical stockman on the farm.

CHARLES S. PLUMB

OHio STATE University

Columaus, Ohio 


\section{CONTENTS}

Chapter

PAGE

1. The Prehistoric Horse . . . . . . . I

II. The Arab Horse . . . . . . . 7

III. The Thoroughbred . . . . . . . . I4

IV. The American Saddle Horse . . . . . 26

V. The Roadster Type . . . . . . . 33

VI. The American Trotter . . . . . . 36

VII. The Pacer . . . . . . . . . . . 49

VIII. The Orloff Trotter . . . . . . . 54

IX. The Coach or Carriage Horse Type . . . . $5^{8}$

$X$. The Hackney . . . . . . . . 63

XI. The French Coach . . . . . . . 72

XII. The German Coach . . . . . . 8I

XIII. The Cleveland Bay . . . . . . . 86

XIV. The Draft Type . . . . . . . . 92

$\mathrm{XV}$. The Percheron . . . . . . . . 98

XVI. The French Draft . . . . . . . III

XVII. The Clydesdale . . . . . . . . II4

XVIII. The Shire . . . . . . . . . 124

XIX. The Belgian . . . . . . . . . I33

XX. The Suffolk. . . . . . . . . 140

XXI. Ponies . . . . . . . . . . 146

XXII. Shetland Pony . . . . . . . 150

XXIII. The Ass . . . . . . . . . . 155

XXIV. The Mule . . . . . . . . I6I

XXV. Beef Type of Cattle . . . . . . . . I69

XXVI. The Shorthorn . . . . . . . . I75

XXVII. The Polled Durham . . . . . . . 197

XXVIII. The Hereford . . . . . . . 201

XXIX. The Aberdeen Angus . . . . . . . 213

$X X X$. The Galloway . . . . . . . . 225

XXXI. The Sussex . . . . . . . . . 234

XXXII. The West Highland . . . . . . 238

XXXIII. Dairy Type of Cattle . . . . . . . . 243

XXXIV. The Jersey . . . . . . . . . 249

XXXV. The Holstein-Friesian . . . . . . . 264

XXXVI. The Guernsey . . . . . . . . 276

XXXVII. The Ayrshire . . . . . . . . . 287 
Chapter

XXXVIII. The Dutch Belted 296

XXXIX. The French Canadian

300

XL. The Kerry

303

XLI. Dual-Purpose Type of Cattle.

307

XLII. The Red Polled.

309

XLIII. The Devon

319

XLIV. The Brown Swiss

326

XLV. The Merino or Fine-Wool Type of Sheep . . . 333

XLVI. The American Merino

339

XLVII. The Delaine Merino

357

XLVIII. The Rambouillet .

366

XLIX. The Mutton Type of Sheep. . . . . . 375

L. The Southdown.

378

LI. The Shropshire

387

LII. The Oxford Down

395

LIII. The Hampshire Down

. 402

LIV. The Dorset Horn

408

LV. The Cheviot

. 415

LVI. "The Suffolk Down

421

LVII. The Tunis

425

LVIII. The Leicester

429

LIX. The Cotswold .

437

LX. The Lincoln

443

LXI. The Kent or Romney Marsh : . . . . . . 450

LXI1. The Black Faced Highland ' . . . . . 452

LXIII. The Angora Goat . . . . . . . . 455

LXIV. The Milch Goat . . . . . . . . 460

LXV. The American Type of Pig . . . . . . . 467

LXVI. The Berkshire . . . . . . . . 472

LXVII. The Poland-China . . . . . . . 484

LXVIII. The Chester White . . . . . . . 497

LXIX. The Duroc-Jersey . . . . . . . . 505

LXX. The Cheshire . . . . . . . 514

LXXI. The Victoria . . . . . . . . . 518

LXXII. The Essex . . . . . . . . 521

LXXIII. The Small Yorkshire . . . . . . . 525

LXXIV. The Suffolk . . . . . . . $53^{\circ}$

LXXV. The Bacon Type of Pig . . . . . . 532

LXXVI. The Large Yorkshire or Large White . . . 536

LXXVI1. The Tamworth . . . . . . . 545

LXXVIII. The Thin Rind or Hampshire . . . . . 551

INDEX • . . . . . . . . . 555 


\title{
TYPES AND BREEDS OF FARM ANIMALS
}

PART I - THE HORSE, ASS, AND MULE

\author{
CHAPTER I \\ THE PREHISTORIC HORSE
}

The existence of the prehistoric horse, in the light of comparatively recent investigations, has become thoroughly well known and comprehended by scientific men. The discoveries of the Whitney expedition, under the direction of the American Museum of Natural History of New York, have provided a wealth of most valuable material in this field. ${ }^{1}$

The first discovery of the prehistoric horse in America was made by Mitchell in 1826 near the Navesink Highlands in New Jersey, and caused great discussion. About I850 Dr. Leidy made similar discoveries in Nebraska. Following these came further finds, until late in the nineteenth century the wide distribution of this early horse in North and South America was well understood. Geographically speaking, these remains have been found all over the Southern States, in the Northeastern and Middle States, in California and Oregon, and in greatest abundance in the so-called Bad Lands of Nebraska, Wyoming, and South Dakota.

1 The author's discussion of this subject is based on the published researches of the American Museum of Natural History, and especially the writings of Professor H. F. Osbom of Columbia University and Dr. W. D. Matthew of the American Museum. The Century Magazine, November, 1904, has a valuable contribution on this subject by Professor Osborn. 
The world-wide distribution of the horse in prehistoric times is now well understood. Besides the references to discoveries in North America, fossil remains have been found in Patagonia, South America, and in earth and sand deposits in various parts of Europe which existed previous to the Glacial period. In I90 I most interesting discoveries were made of drawings of horses in the cave of La Mouthe, France, which it is believed date back to the Stone Age. These drawings were partly cut in rock and

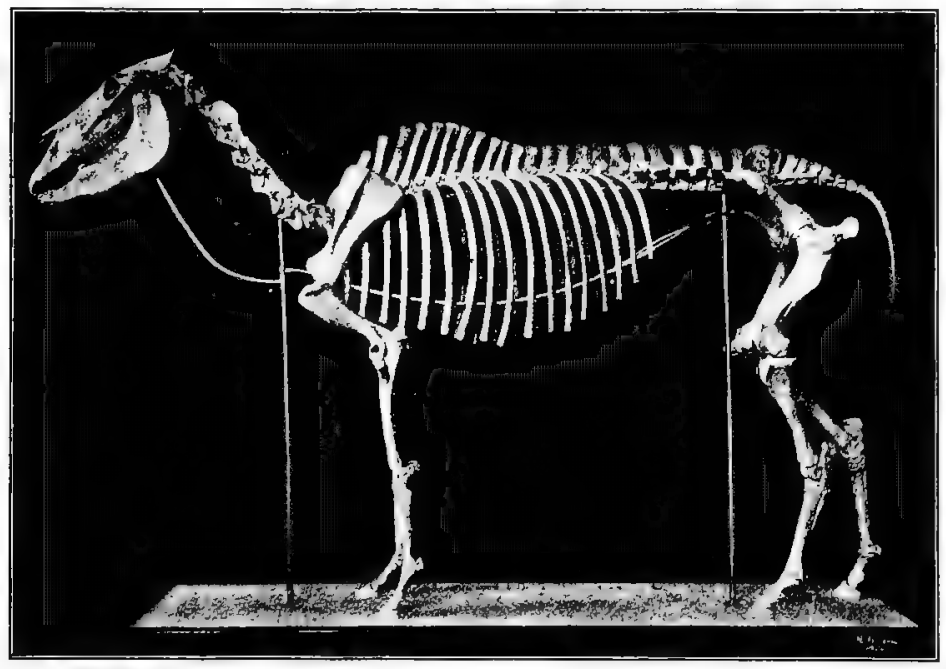

FIG. I. Skeleton of prehistoric horse from Lower Pleistocene of Texas, in American Museum of Natural History. Reproduced by courtesy of the American Museum

partly made in ocher, and represented animals associated with the chase. These cave drawings are very clear, and show a horse with no forelock and a head with Roman-nose character, also one with a head similar to that of the Celtic pony. From the evidence left in the caves of France it is thought a larger type of horse lived toward the south, while farther north a smaller form existed. It is also fairly well established that the ass was known in Europe at this period.

The evolution of the horse from the prehistoric to present form covers geological ages of time and represents a passing of 
perhaps three million years. Careful investigation and discoveries show that animals of the horse class existed in the Lower Eocene period and gradually passed upward through twelve stages of development in the course of geological time, becoming more and more developed toward the present-day type as the geological periods became more and more recent. These various forms properly grouped may be briefly described as follows:

1. Hyracotherium. Existed in Lower Eocene period. Only the skull has been found. The teeth display six rounded knobs or cusps on upper molars and four on lower. Found only in London Clay, England.

2. Eohippus. From Lower Eocene period. Teeth vary some from above. Fore foot has four complete toes and splint of a fifth. Hind foot has three toes and splint. Found in Wyoming and New Mexico. Were about size of fox terrier, and known as "dawn horses."

3 and 4. Protorohippus and Orolitppus. From Middle Eocene period. In these animals the splints have disappeared, leaving the complete toes, as in Eohippus. The crests on the molars are more apparent, and the last premolar has become almost like the molars. This type was about the size of a small dog, perhaps fourteen inches high. The Protorohippus was discovered in 1880 in Wyoming.

5. Epilippus. From Upper Eocene period. Only incomplete specimens have been found. The teeth have gone through changes with more crescents and crests, with another premolar tooth becoming like the molars. There are four toes in front and three behind, but the central toe in each is larger and stronger and more important than the side toes.

6 and 7. Mesohippus. From Oligocene period. There are three toes on each foot and a splint representing the fifth toe of the fore foot. The middle toe is now much larger than it was in the preceding, the side toes bearing but little weight of the body. Three of the premolars have also become like full molars. In the Middle Oligocene is found one species about the size of a coyote, or eighteen inches high, while in the Upper Oligocene is another species as large as a sheep. 
8. Anchitherium. From Lower Miocene period. Is much like Mesohippus, but is larger and has the crests of the teeth sornewhat higher and more complete. This form may not be in direct line of descent, but may be a side branch. Found in both Europe and America.

9. Parahippus and Hypohippus. From Middle Miocene period. The tooth crests in Parahippus are much higher, the upper molars are changing in form, and a second pair of crescents is formed. Hypohippus is off the direct line of descent. A complete skeleton of this form, now in the American Museum, was discovered in 1901 in Colorado. This species attained the size of a Shetland pony. The fore foot has small rudiments of the first and fifth toes, but there is no splint of the fifth, as in Mesohippus. The second and fourth toes lightly touch the ground. It has been called the "forest horse," and is supposed to have lived on lowlands and in forests.

Io. Protohippus. From Middle and Upper Miocene period.

I 1. Pliohippus. From Middle and Upper Miocene period.

In this stage the crowns of the upper molars have become much longer, the two pairs of crescents on the upper molars are complete, with two half-separated cusps within the inner pair. The valleys between the crests have become filled with cement, so that with the wear of the teeth the edges of hard enamel are backed inside by dentine and outside by cement. Thus the tooth surface has a series of enamel ridges always projecting somewhat above the grinding surface, because the softer material on each side wears down into hollows, yet never breaks off. This makes an efficient medium for grinding grass. In these two forms of horse, notably Protohippus, the crowns of the teeth are not as long as in the modern horse. The feet in these two have but one toe touching the ground. The side toes are complete, but are more slender than in the earlier stages and are apparently useless. In some species of Pliohippus they have almost disappeared. Horses at this period were about forty inches, or ten hands, high.

Hipparion. From Pliocene period. This is similar to Protohippus, but with larger and more complicated tooth patterns. In this period some horses have three toes and others one.

12. Equus. From Pleistocene period and Recent. This is the stage of the modern horse. The side toes are gone but are 
represented by splints on fore and hind foot. On the fore foot no trace remains of the little nodules which in Protohippus represented the first and fifth toes. The crowns of the teeth are much longer and the teeth have changed otherwise. The skull has lengthened and the horse is much larger.

Tracing the development of this prehistoric horse, we find that the animal gradually increases in height, the number of toes reduces to one on each foot, while the teeth increase in length

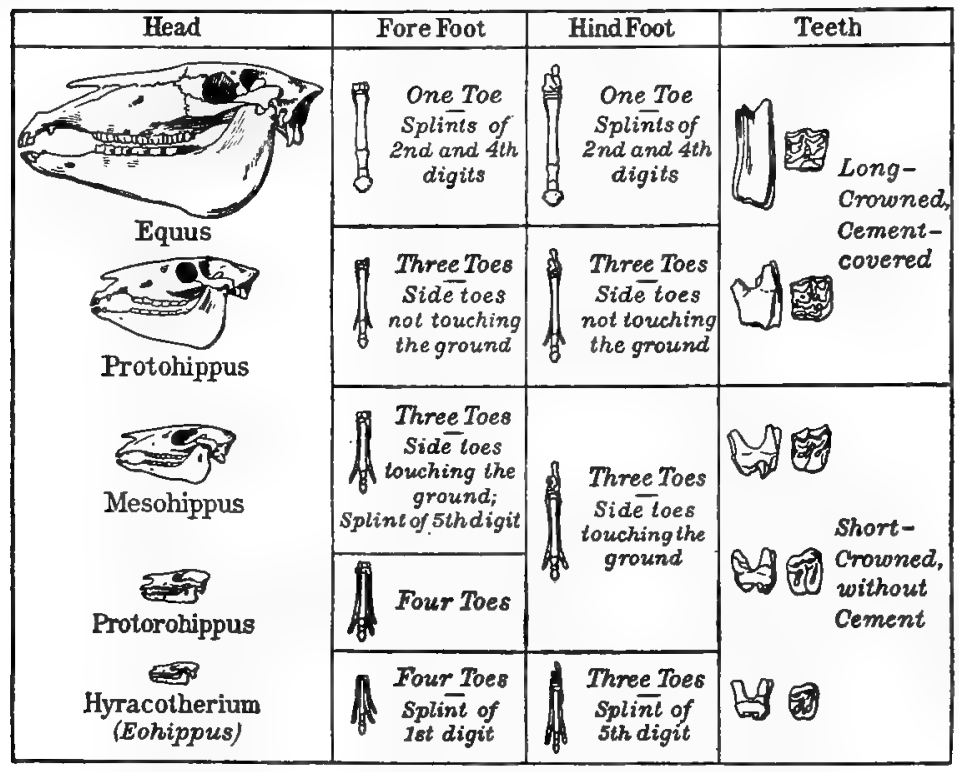

Fig. 2. Comparative drawings of skulls, feet, and teeth of prehistoric horse, showing evolutionary development. Reproduced by permission from Guide Leaflet No. 9, American Museum of Natural History

and crown development. The tooth of the modern horse may be an efficient grinder for twenty-five or thirty years, while that of the prehistoric one, from shortness of crown and lack of enamel and dentine, perhaps would not serve over ten or twelve years.

The color of the prehistoric horse is not known, but it is supposed to have been more or less striped, like the zebra, though not brilliantly colored. The groundwork of this color was presumably dun or khaki. 
The first association of man with the prehistoric horse so far as discovered existed in the Paleolithic or Stone Implement Age. It is assumed that man first hunted horses for food, then drove them, and finally used them for riding and then as beasts of burden. The bones of human beings have been found in connection with prehistoric horse remains in South America, but not in North America. In Europe man and the prehistoric horse were without doubt associated.

The connecting link between the prehistoric horse and the horse of modern times is assumed to be the present form of the zebra,

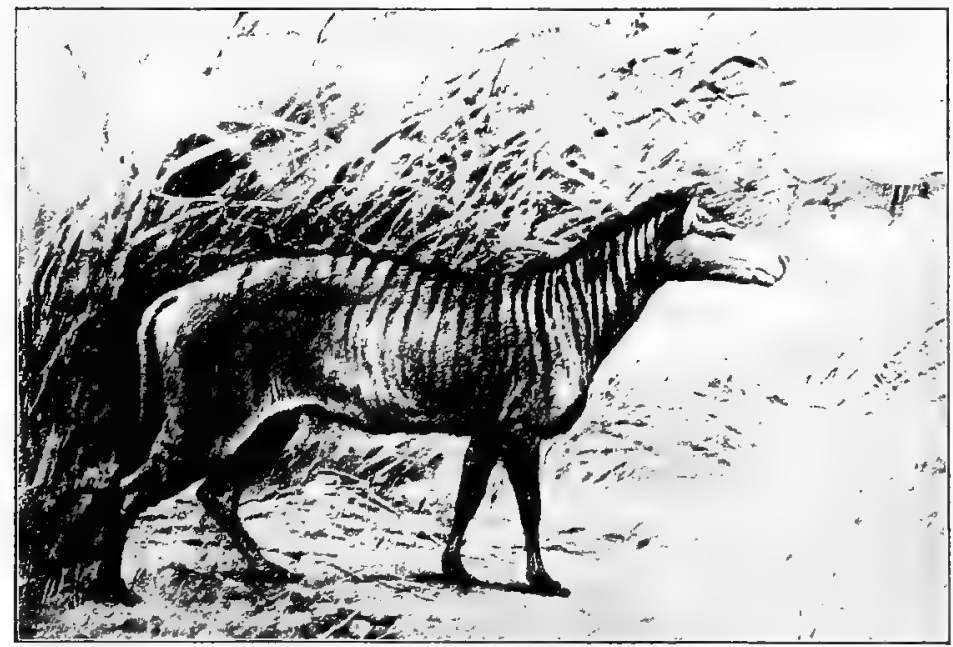

FIG. 3. Restoration of the four-toed horse. Photograph from original water color by C. R. Knight, based on mounted skeleton sixteen inches high, in American Museum of Natural History

the wild ass of Asia and Africa, and Przewalskii's horse. The latter was discovered by Poliakoff in I88I on the desert of Zungaria in western Mongolia in Asia. It has been assumed that this type of wild pony, standing forty inches high, is quite similar to the horse as known by prehistoric man thirty thousand years ago. The European cave drawings show a strong resemblance to the Przewalskii horse, and it is probable that from such an ancestry has come the Norwegian, Irish, and other ponies of northern Europe, and the wild horse of Mongolia and China. 


\section{CHAPTER II}

\section{THE ARAB HORSE}

The influence of the Arab horse upon the improvement of the present-day breeds is well recognized among. students. As early as the reign of King James I of England (I603-I625) Arab horses were introduced into that country and crossed with light horse stock. Between I 700 and I800 many Oriental horses found their way to England, and these had a most important influence in improving the Thoroughbred. The so-called "Royal Mares" imported by Charles II (I 660-I685) became foundation stock in the best of British light horse blood, their descendants reaching great distinction. From the Darley Arabian imported in 1706 is descended the best of Hackney blood to-day. According to Joseph Osborne, since the time of James I one hundred and sixty-four Oriental sires of known record have been taken to England

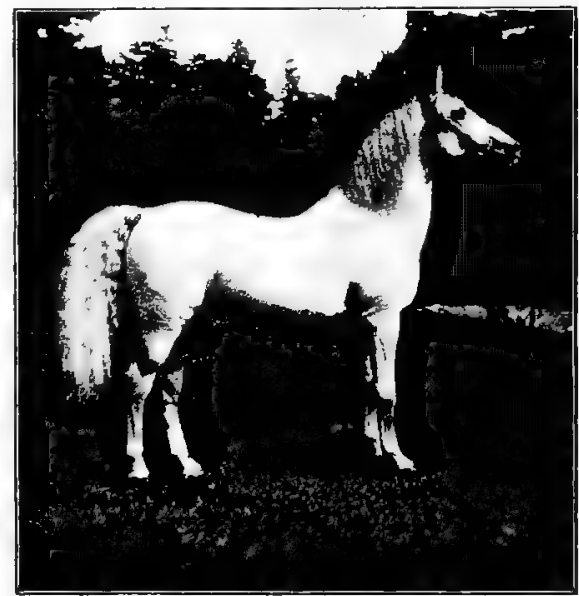

Fig. 4. Shahwan, an Arab stallion bred by Ali Pacha Sherif, of Egypt. Used in stud by W. S. Blunt, Esq., England. Imported in 1895 by J.A.P. Ramsdell, Newburg, N.Y. Photograph from Mr. Ramsdell

and used in service. This list includes ninety Arabs, thirty-six Barbs, thirty-two Turks, four Persians, and two horses of unknown ancestry. Arab horses have also been used for centuries in improving the horses of continental Europe, even up to the draft type. Much of the quality produced in the early Percheron 
came from the Arab, while the French have set a high value on this horse in producing half-breds and improving coach horses.

In 1522 the Turks invaded Hungary five hundred thousand strong, which number, so history informs us, included three hundred thousand horsemen. With the defeat of the Mohammedans they were driven from the country, but they left large numbers of Arabian horses behind. From that time Arab horse blood has been in use in the stables of Hungary, and a Bedouin of the desert, thoroughly familiar with the breed, is attached to the Hungarian army as master of horse, his duty being to select the best Arabian horses for the royal studs. These studs were established in 1785 and have since been maintained. In addition to the royal studs, there are some one hundred and fifty private studs in which are to be found five thousand Arab mares of purest blood. Russia and Germany have also used the Arabian in the stud. It is said that no less than two hundred Arab stallions belonging to the French government were at the free service of owners of mares in Algiers in Africa in 1895, this being a French colony.

The native home of the Arab horse is Arabia, a vast country some fifteen hundred miles long and from five hundred to one thousand miles wide, lying east of the Red Sea, with its northern extremity not far from the east end of the Mediterranean. The Arab horse, however, is found in great numbers in Turkey, Persia, and parts of northern Africa, notably the Sahara region.

The origin of the pure Arabian has been the cause of much discussion in print. Major Upton and Lady Anne Blunt, however, have given the most definite and satisfactory information on this subject. These persons made special trips to Arabia, where careful studies were made of the horse of the people, concerning which we learn much in their writings. " Major Upton lived among the Bedouins for months and spoke their language.

The best Arabian horses are found in the desert region, among the migratory Bedouin tribes, of which there are several groups. The most powerful of these are the Shammar race of

1 Gleanings from the Desert of Arabia, by Roger D. Upton, London, 1881; The Bedouin Tribes of the Euphrates, by Lady Anne Blunt, 2 vols., London, 1879; A Pilgrimage to Nejd, by Lady Anne Blunt, 2 vols., London, 1881. 
Mesopotamia in the north and to the east of the Euphrates, visited by the Blunts, and the Anezah in the south, studied by Major Upton. The latter race have the best horses, a fact generally recognized by Bedouins.

The Arabs are descendants of Ishmael, who, according to tradition, inherited a valuable horse of the Kuhl race. The Anezah tribe descended in a direct line from Ishmael, through Sheik Salaman, who lived about 1635 B.c. (four generations removed from Ishmael), and who owned five famous mares. From this ancestry has come the purest and best Arab horse blood. This race was in existence many centuries before the time of Mohammed.

The Arabian words " keheilan" and " keheilet " have a special application to the horse. These words are derived from the word "kuhl," which means antimony, material with which Arab women blacken their eyebrows and eyelashes. Upton claims to have discovered that the entire race of pure-bred horses among the Anezah had black skins irrespective of color of hair. This accounts for the use of the words "keheilan" and "keheilet," the former meaning a male and the latter a female of pure blood whose lineage can be traced without a break to the five mares of Salaman. The Anezah Bedouin declines to recognize any animal as keheilan or keheilet, the pedigree of which does not go back to the five mares in question, the five being designated as Al Khamseh.

Five great families of Arabian horses descended from foundation stock tracing to the five mares Al Khamseh are as follows:

I. The descendants of Keheilet Ajuz.

2. The Maneghi, with three sub-families.

3. The Hadban, with five sub-families.

4. The Jelfon, with two sub-families.

5. The Homdani, with two sub-families.

From the first-named family comes the most distinguished Arab blood. The word "ajuz" means old woman. This family descends from a mare that dropped a filly colt when on a long and hard journey, her owner being hard pressed by an enemy. The colt was left where foaled, and the owner of the mare after much difficulty reached his own people. To the surprise of the 
camp the young filly came in also a few hours after, having followed her dam. The story goes that she was given into the care of one of the old women of the tribe, whence came her name, Keheilet Ajuz ("the mare of the old woman "), that she lived to become the most famous mare ever seen on the desert, and from her are descended the choicest of pure Arabian horses. It is claimed that nineteen families descend from her, five through mares and fourteen through stallions. Some even believe that eight other families also should be credited as her descendants.

The families of Arabian horses descended from Keheilet Ajuz that are recognized as of superlative merit, are the following :

(I) Seglawi, comprising the three sub-families, the Seglawi Jedraän, Seglawi Obeiri, and Seglawi Al-Abd. This is one of the choicest families.

(2) Abeyan. There are seven sub-families. This family received its name from a high carriage of tail.

(3) Dalman. There are four sub-families.

(4) Abu Arkab. There are three sub-families.

The following families are also regarded by some as descendants of Keheilet Ajuz :

(5) Rishon; (6) Radban; (7) Twaissan; (8) Milliah, with sub-families in each case.

The history of the Arab horse in America is not very extensive, though dating back many years. No doubt many horses called Arabian were not of that breed, but were of Oriental ancestry. About I765 an Arab stallion named Ranger was imported to New London, Connecticut. A half-bred, gray son of Ranger was used by General Washington during the Revolutionary War. Ranger was later taken to Virginia, where he became known as the Lindsay Arabian. The first volume of Bruce's American Studbook contains a list of forty-two Arab stallions imported into the United States between I 760 and I 860 , besides twelve Arab mares, four Barb stallions and two Barb mares. There were some famous animals imported years ago. Honorable A. Keene Richards of Kentucky made two journeys to Arabia with Troye, the animal painter. They visited among the Anezah and brought back to America some splendid Arabian horses, the blood of which occupies a place of prominence in 
the Gold Dust family of trotters. The Arab horses Maanake Hedgrogi and Liklany Gidran were sent as a gift to $\mathrm{Wm} . \mathrm{H}$. Seward, Umbark to President Martin Van Buren, and Linden Tree and Leopard to General U. S. Grant. In I 838 a large consignment of both stallions and mares was brought to the United States by Commodore J. D. Elliott of the United States Navy.

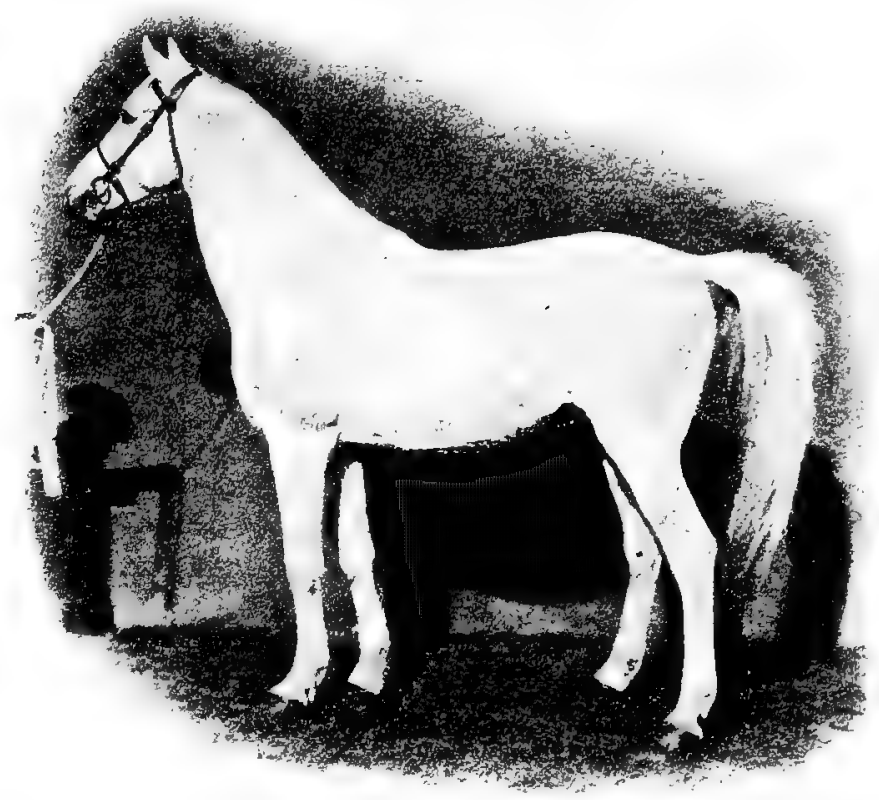

Fig. 5. Cunningham, an Arab stallion owned by Sir Walter Gilbey, Bart., England. A winner of races in Egypt and England. From photograph from Sir Walter Gilbey, Bart.

Important studs of Arab horses in England and America during recent years are worthy of mention. In England Major Upton until his death maintained a pure Arab stud, as also did Henry Chaplin, Minister of Agriculture. Both of these studs were sold. Sir Wilfred Blunt and his wife, Lady Anne Blunt, brought to England from Arabia some eighteen pure Arab mares and two stallions. Besides these Rev. F. F. Vidal and Miss Ethelred - Dillon also have studs in England. In the United States 
Randolph Huntington of Long Island, New York, Peter Heyl of Milwaukee, Wisconsin, and J. A. P. Ramsdell of Newburg, New York, have maintained notable Arab studs in recent years.

A few notable Arab horses of pure breeding that have become famous are the stallions Kismet, El Emir, Maidan, Kouch, Kars, Shahwan, Cunningham, and Himyarite. The mares Haidee, Keziah, Naomi, and Nazli are among the most important modern females of the breed.

The characteristics of the Arab horse. The head represents very superior character and intelligence, the forehead being broad and prominent, and the head tapering toward the nose more than with other breeds. The nostrils are prominent, the eyes fairly so, the ears delicate and pointing inward, and the general head expression lean and representing high spirit. The neck is of medium length and sustains the head most gracefully. Captain Hayes states that the shoulders of the Arab slope well, though from the saddle point of view they are often too thick, while the withers incline to be rather low and broad. The body is fairly short, and is usually deeply ribbed; the back is well sustained, and the loins are broad and muscular. The croup tends to be high, sometimes making specimens of the breed appear higher here than at the withers. The tail sets high and is carried with style. The quarters are long and deep, but the gaskins and hocks hardly equal those of the Thoroughbred. The legs and feet are very superior. For his size the strength of the Arabian horse is remarkable, this being due in part to large development of muscle of loin and arm, whereby he becomes a superior burden carrier. The Arab has a great constitution and extraordinary staying power. $\mathrm{He}$ is not noted so much for speed as for endurance, as he is not nearly the equal of the Thoroughbred or American trotter for rapid speed. Yet the Arab will perform long journeys across country with comparative ease, such as require great staying power. In height the Arab ranges from I 4 to $14 \frac{1}{2}$ hands, so that he stands at the boundary line between pony and horse. Many of the most famous Arabs brought to England were ponies. Esa bin Curtis, a large importer of Arabs to Bombay, is credited with the statement that the best Arabs did not, as a rule, exceed 14 hands $1 \frac{1}{2}$ inches to $14 \frac{1}{2}$ hands high. 
In color there is some variation, for there are bays, whites, grays, chestnuts, and blacks, the latter being least common of all.

The value of the Arab in cross breeding is preëminent. Wherever used he has transmitted constitution, quality, intelligence, and style in a marked degree. His value to horse stock in the past has been incalculable. Not only this, but European governments, even of to-day, recognize the value of an Arabian cross to instill the qualities above referred to into depleted stock. As an example of this crossing, in 1899 it is stated that the French government mated sixty Thoroughbred mares with pure Arabian stallions at the national stud at Pompadour. The object was to obtain Anglo-Arab stallions for service in the government studs. These cross-bred stallions are usually placed in low, soft districts, where the horses are coarse and of inferior bone. The progeny from such stallions have more refinement and quality than those obtained by other matings. At the present time one important use for Arab sires is breeding to Welsh, New Forest, Exmoor, or similar ponies to produce cross-breds for polo playing.

The registration of Arab horses is provided for in the American Studbook, and in the General Studbook of Great Britain. There is no special organization for the promotion of this breed. 


\section{CHAPTER III}

\section{THE THOROUGHBRED}

The history of the Thoroughbred is so closely associated with the improvement of the modern horse that much consideration should be given it.

The horse in England prior to Queen Elizabeth's reign was mainly of the draft type, coarse and strong. We know little of his general merits. He was used in war for chariots and as a saddle horse. The early Romans brought horses to England in the fifth century, and so did the succeeding Normans and others. Early in the thirteenth century King John imported one hundred stallions from Flanders. Edward III, during the fourteenth century, brought to England, it is stated, over fifty Spanish horses at a cost of over eight hundred dollars each. Henry VIII maintained a royal stud, had laws enacted regarding horse breeding, and imported from Turkey, Spain, and Naples. Yet during all these years the prevailing horses were burden bearers with the exception of a few of greater speed, known as running horses. The use of heavy armor in the army had justified breeding a horse of this type.

Systematic horse racing in England was first introduced by James I. During the reign of Queen Elizabeth (1558-1603) the use of armor grew to be unpopular, though the use of horses changed but little. James I, succeeding Elizabeth, was not warlike in temperament, and the use of armor passed away during his reign. Not only this, but James established the race course, gave attention to horse breeding, and imported from the Orient. He established a code of regulations from which the modern race course has derived its foundation. James imported an Arabian stallion from the Orient through an English merchant named Markham, for which he paid five hundred pounds. This horse was much ridiculed and had no special importance in improving 
racing stock. Charles I (1625-I649), the son of James I, established racing at Newmarket and Hyde Park, while his son, Charles II, whom British authors credit with first creating the Thoroughbred, brought many horses from the Orient and was a great promoter of the race course. Two Barb mares which Charles II imported took very high rank among the brood mares of England and were named the "Royal Mares."

From the time of James I up to the present day each British ruler has patronized the race course and has promoted horse breeding. Since the time of this monarch about one hundred and sixty-four Eastern sires have been imported into England. From this desire for the running horse and the race has been developed the Thoroughbred, which for a hundred years or more has been bred with reasonable purity.

Three foreign horses introduced into England during the formation period of the Thoroughbred exercised an important influence worthy of special mention. These were the following:

1. The Godolphin Barb, also known as the Godolphin Arabian, was probably foaled in Barbary about I 724. Later he found his way to France, and for a time was used to haul a water cart. About I 728 he was taken to England and presented to Lord Godolphin. He was used in the stud with great success. His blood contributed in a most important degree to founding the Thoroughbred.

2. The Byerly Turk, the saddle horse of Captain Byerly, used later in the seventeenth century in the wars of William in Ireland, was probably brought to England in 1689. He was very famous as a sire and horses descended from him are known as Byerly Turk horses.

3. The Darley Arabian, supposed to be a pure Arabian, was bought at Aleppo, Syria, by a Mr. Darley. He was brought to England in I 706, late in Queen Anne's reign, as a gift to Mr. John B. Darley, of Aldby Park, near York. He was bay in color with blaze on face and white on three feet, and stood about 15 hands high. To this horse can be traced the choicest Thoroughbred blood.

These three Oriental horses preceded the development of the Thoroughbred, yet their blood had a potent fundamental influence in establishing the breed which followed. 
Three English-bred horses of great prepotency, important in founding the Thoroughbred, stand out as really great ancestors of the modern speed horse. They are the following :

I. Herod (King Herod). This horse was born in 1758 and was bred by the Duke of Cumberland, a brother of George II. He was used on the race course for a time and was then retired to the stud. He is said to have sired 497 prize winners on various race courses, and it is estimated that they won for their owners $£ 201,505$, or over one million dollars. Herod was a direct descendant of the Byerly Turk.

2. Matchem. One of the important sons of the Godolphin Barb was named Cade. He proved to be an indifferent race horse, but a great breeder, due to his superior blood and conformation. Matchem, his best-known son, became a great racer as well as a prominent sire. It is stated that he made a record on the Beacon course at the rate of a mile in I.44. He also became well known for the excellence of his progeny in speed quality, for he sired 354 sons and daughters that were winners of races. Matchem was born in 1748 and died in $I 781$.

3. Eclipse. The Darley Arabian was the sire of two great horses in their day, notably Flying Childers, also known as The Devonshire, and Bartlett's Childers. The former was a chestnut horse with four white feet, and was the fastest horse on the English turf up to his time. Bartlett's Childers was never trained to race, but was used in the stud instead. A grandson of his, named Marske, bred to the mare Spiletta, was the sire of Eclipse, foaled in 1764 during a great eclipse from which he takes his name. From two points of view this horse may be regarded as perhaps the greatest in history, one as a racer the other as a progenitor of racers. He was bred by the Duke of Cumberland, and at the sale of his stud brought 75 guineas. $\mathrm{He}$ was five years old before going on the turf, running first at Epsom. In his second race, at York, he distanced his competitors. In I 769 Dennis O'Kelly bought him for 1650 guineas $(\$ 8250)$. As a racer he distanced some of the best horses of his time. Finally, as no one would race against him, he closed his racing career of seventeen months by walking over the Newmarket race course for the King's Plate in October, I770. 
In 1779 O'Kelly was asked by one of the Bedford family for his price on Eclipse, and he replied that "all Bedford Level would not purchase him." From another person he asked \$125,000 and an annuity of $\$ 2500$ for life.

Eclipse won eleven King's Plates and O'Kelly cleared $£ 25,000$ on him. In historical descriptions of this horse he is said to have been about $5_{5} \frac{1}{4}$ hands high; his shoulders were very low and oblique and thick above, while he stood high behind. He had a great loin, very long quarters, and powerful and long thighs and fore arms, and his stride was very wide. He was so thick-winded that he could be heard some distance. He was of fine disposition, and in a race he took his own gait, rushing along with his head down, indifferent to his jockeys, who found it impossible to hold him in. Eclipse sired 334 winners of races. $\mathrm{He}$ died in 1789 , aged twenty-five years. This horse was a direct descendant of the Darley Arabian, and the very best of British and American racing-horse blood traces its course from these two great sires.

Of these three English-bred stallions Eclipse as a breeder was most important, at least in the male line of descent, while Matchem was least so. The influence of both the Oriental and English sires on the creation of the Thoroughbred as a breed has been very profound, but without doubt numerous females have had an important part. However, much less is known of the personality and breeding of the mares than of the sires. C. Bruce Lowe, in an elaborate study of speed lines of many great Thoroughbreds, compiles a list of forty-four important foundation mares. At the head of that list he places first, Tregonwell's Natural Barb Mare; second, Burton's Barb Mare; third, Dam of two True Blues.

The Thoroughbred derives his origin from the union of Arabian, Barb, and Turkish blood with the lighter type of English horse. From this amalgamation came great stamina, remarkable speed, unusual endurance, and great symmetry of form.

The names of many famous Thoroughbreds appear during the history of the breed. The following are worthy representatives, all of them famous racers and most of them great breeders. The dates after their names indicate the years of foaling. 
Prominent British Thoroughbreds and their sires and dams: Squirt, I732, by Bartlett's Childers, out of the Snake mare; Pot-8-os, 1773, by Eclipse, out of Sportsmistress; Woodpecker, I 773, by Herod, out of Misfortune ; Highflyer, I 774, by Herod, out of Rachael ; Sir Peter Teazle (also known as Sir Peter), I 784 , by Highflyer, out of Papillon; Waxy, I790, by Pot-8-os, out of Maria by Herod; Whalebone, 1807, by Waxy, out of Penelope ; Tramp, 1810, by Dick Andrews, dam by Gohanna; Whisker, I 8 I 2, by Waxy, out of Penelope ; Sir Hercules, I826, by Whalebone, out of Peri; Touchstone, I831, by Camel, out of Banter; Irish Bird Catcher, 1833, by Sir Hercules, out of Guiccioli; Gladiator, 1833, by Partisan, out of Pauline; Faugh-a-Ballagh, 184 I, by Sir Hercules, out of Guiccioli ; Orlando, 1841, by Touchstone, out of Vulture; The Baron, I 842 , by Irish Bird Catcher, out of Echidna; Stockwell, I849, by The Baron, out of Pocahontas; Kingston, 1849, by Venison, out of Queen Anne; King Tom, I 85 I, by Harkaway, out of Pocahontas ; Blair Athol, I86I, by Stockwell, out of Blink Bonny; Hernit, I864, by Newminster, out of Seclusion; Robcrt The Devil, 1877, by Bertram, out of Cast Off ; Bend Or, 1878, by Doncaster, out of Rouge Rose; St. Simon, I $88 \mathrm{I}$, by Galopin, out of St. Angela ; Isinglass, I 890 , by Isonomy, out of Deadlock; Persimmon, I893, by St. Simon, nut of Perdita II ; Flying Fox, I 896, by Orme, out of Vampire; Diamond Jubilee, I897, by St. Simon; Rock Sand, I900, by Sainfoin, out of Roquebrune.

Prominent British Thoroughbreds imported to America: Shark, I77I, by Marske, dam by Snap; Diomed, I777, by Florizel, out of Sister to Juno; Buzzard, 1787, by Woodpecker, out of Daughter of Alexander; Sarpedon, 1828, by Emilius, out of Icaria ; Glencoe, 1831, by Sultan, out of Trampoline ; Leamington, I853, by Faugh-a-Ballagh, out of Daughter of b.m.; Bonnie Scotland, 1853, by Iago, out of Queen Mary; Australian, I 858, by West Australian, out of Emilia; Phaeton, 1865, by King Tom, out of Merry Sunshine; Prince Charlie, 1869, by Blair Athol, out of Eastern Princess ; Rayon d'Or, 1876, by Flageolet, out of Auracaria; St. Blaise, 1880, by Hermit, out of Fusee; Kingston, 1882, by Flageolet; Ormonde, 1884, by Bend Or, out of Lily Agnes; Sysonby, 190I, by Melton, out of Optime. 
Prominent American Thoroughbreds: Sir Archy, I 805, by Diomed, out of Castianira ; American Eclipse, I8 I4, by Duroc, out of Miller's Damsel; Boston, 1833, by Timoleon, out of Sister to Tuckahoe; Lexington, I850, by Boston, out of Alice Carneal; Norfolk, I860, by Lexington, out of Novice; Emperor, 1860, by Leamington; Longfellow, 1867, by Leamington, out of Nantura; Enquirer, I 867 , by Leamington, out of Lida; Tom O'Chiltree, I872, by Lexington, out of Katona; Parole, I 874, by Leamington, out of Maiden; Himyar, I875, by Alarm, out of

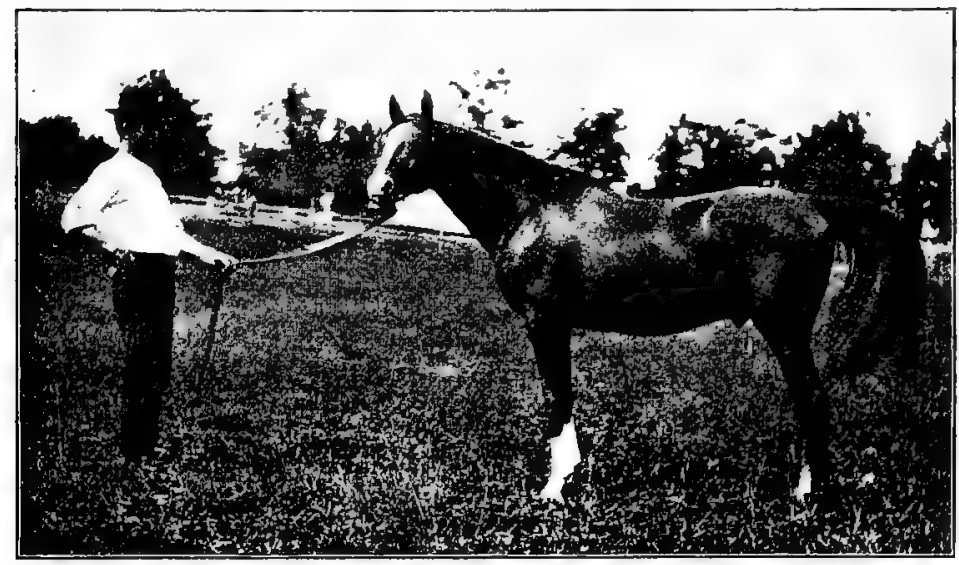

FIG. 6. Hanover, a Thoroughbred stallion. A great racer, starting in fifty races, winning thirty-two, and securing $\$ 120,912$ in prize money. The leading sire of prize winners in $1895,1896,1897$, and 1898 . In stud at McGrathiana, Lexington, Kentucky. From photograph by author

Hira; Spendthrift, 1876, by Australian, out of Aerolite; Luke Blackburn, I877, by Bonnie Scotland, out of Nevada; Foxhall, I878, by King Alfonso, out of Jamaica; Iroquois, I 878 , by Leamington, out of Maggie B.B. ; The Bard, I 883, by Longfellow, out of Brademante; Firenzi, I 884 , by Glenelg, out of Florida ; Hanover, 1884, by Hindoo, out of Bourbon Belle; Emperor of Norfolk, I 885, by Norfolk, out of Marian; Salvator, r886, by Prince Charlie, out of Salina ; Hamburg, I89 I, by Hanover, out of Lady Reel.

Importations of Thoroughbreds to America were made at a comparatively early date, and some of the most famous horses 
of the breed found their way to the United States during the eighteenth century. The brief and incomplete list of Thoroughbreds imported, which precedes this statement, represents a list of sires and racers of the most distinguished character. The first Thoroughbred to come to America is said to have been the horse Bulle Rock, imported to Virginia in 1730 . Diomed, who won the first Derby ever run, was imported in 1797 at twenty years of age. Messenger, imported in 1788 , as a Thoroughbred to improve the running horse, became a distinguished progenitor of trotters. Fearnought, I775; Buzzard, 1787; Shark, I77I ; Alderman, I 787 ; Pantaloon, I 778 ; Highflyer, 1784 ; Saltram, I 780 ; and Matchem, 1773, represent eminent early importations. The men of Virginia, South Carolina, Maryland, and Kentucky, from very early days, showed great interest in Thoroughbreds and promoted the race track. In 1760 the first track in America, known as the Newmarket course, was established at Charleston, South Carolina, on which were held many enthusiastic races.

The conformation of the Thoroughbred is distinctive. The head should be fine and lean and moderately small, showing breeding; eyes prominent and intelligent; ears of medium size, not too wide apart, and carried in a lively manner. The neck should be long, the upper part from withers to poll being about twice as long as the lower part from point of shoulder to larynx, and strongly muscular. The shoulder should slope obliquely back, be covered with muscle, and come back to form high, fairly close, long withers; no collar heaviness should be noticeable. The chest tends to narrow rather than broad conformation, with good depth, yet able authorities prefer a broad rather than deep and narrow chest. The body should be rather circular in type, with a depth at the withers rather less than half the height, with a length equal to the height at withers and croup; the back and loins should be comparatively broad, level, and muscular; the ribs well sprung and of enough depth to show good feeding capacity. The croup tends to be long, rather level, curving gracefully, with the tail attached medium high and carried gracefully. The hind quarter is one of the features of the Thoroughbred, being long, strongly muscled, exhibiting great driving power; the gaskins or lower thighs should be broad. The fore leg should be muscular 
and strong in arm and long and wide in fore arm, with comparatively little width between the legs. A rather broad, strong knee, supported by a short flat cannon bone extending well back, is desirable. The hind leg at the hocks ought to be deep, clean, free from fleshiness, and be supported by a short, flat, clean cannon bone. The pastern joints should be smooth, placed true, and in harmony with the leg as a whole. The pasterns should not be straight but rather long and slanting, yet strong, clean, and springy, being carried at an angle of about 45 degrees. The feet should be of medium size, wide and high at the heel, concave below, and be carried straight and true. In order to secure speed it is essential that the knees and hocks move smoothly and freely and that this movement be true.

The height of the Thoroughbred ranges from $14 \frac{1}{2}$ to $16 \frac{1}{2}$ hands, but 15 to $15 \frac{1}{2}$ is most approved. It is probable that this breed has increased in height with its development. Nearly fifty years ago Rous argued that a gain of a hand had occurred during the preceding hundred years. Sir Walter Gilbey states that "from an average height of 14 hands in 1700 the breed has been graded up to an average of 15 hands $2 \frac{1}{2}$ inches in the year $1900 . "$

The color of the Thoroughbred is variable. Bays and browns are most common and most popular, though chestnuts are common, while blacks, sorrels, grays, and roans occur.

The weight of the Thoroughbred is quite variable, but in general ranges from 900 to 1050 pounds.

In temperament the Thoroughbred is nervous and mettlesome, being endowed with great spirit and endurance in the race.

The distribution of the Thoroughbred is world-wide in regions where light horses for speed purposes prevail. This is noteworthy in Great Britain, France, Germany, Australasia, Argentine Republic, and the United States.

Prices at which Thoroughbreds have sold cover a wide range of high figures, this breed, in fact, leading all others in this respect. The highest price paid up to 1906 is for the stallion Flying Fox, sold for 37,500 guineas $(\$ 187,500)$ at the sale of the Duke of Westminster in 1904. Flying Fox was taken to France for stud purposes. Late in I905 King Edward VII of England sold the stallion Diamond Jubilee for $\$$ I 50,000 to Señor Ignacio 
Correas of the Argentine, South America. Ormonde sold for $\$$ I 50,000, and Cyellene, another English Thoroughbred, recently sold for \$150,000. Among other high prices at which Thoroughbreds have changed hands are the following: Rock Sand, $\$$ I 2 5,000; Water Cress, \$7 I,000; Hamburg, \$60,000; Nasturtium, \$50,000; Norfolk, \$40,000; Kentucky, $\$ 40,000$; Iroquois, $\$ 34,000 ;$ Rayon d'Or, $\$ 33,000$; Bonnie Scotland, $\$ 30,000$; and Luke Blackburn, $\$ 20,000$.

The speed record of the Thoroughbred is faster than that of any other horse. Races with this breed are run under the saddle, with jockeys up. A light, skillful jockey is needed in the saddle.

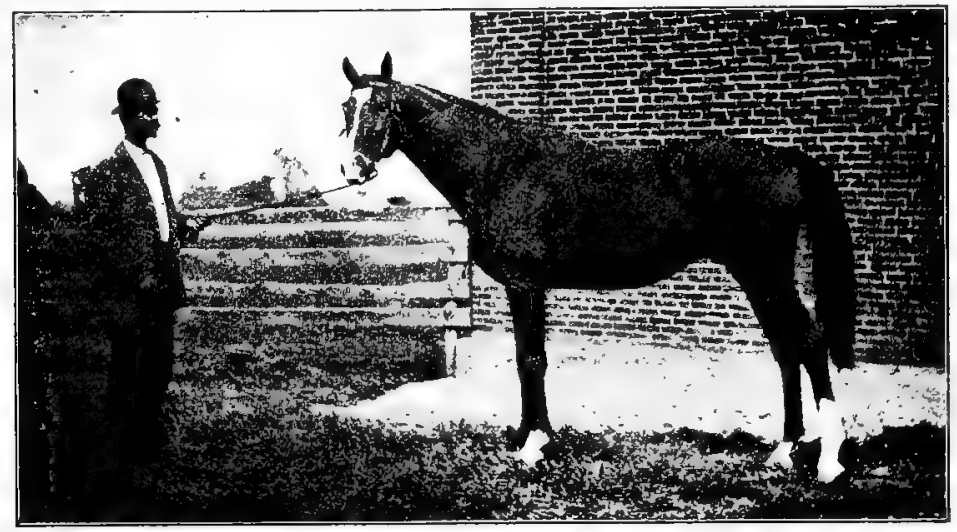

FIG. 7. Lamplighter, a prominent Thoroughbred sire and racer owned by Milton Young, Lexington, Kentucky. One of the leading sires of 1904 and 1905 prize winners. From photograph by author

A very satisfactory jockey weight is I Io to II 5 pounds, but many great races have been won with weight up to 125 pounds. The fastest record by a Thoroughbred is that of $1.35 \frac{1}{2}$ by Salvator on a straightaway track of one mile, in 1890 , at Monmouth Park, New Jersey. On the Harlem standard track, in I903, Dick Wells ran a mile in I.37호․ Only a few days before Alan-a-Dale had passed around the Washington Park track, making the mile in $1.37 \frac{3}{5}$. In 1855 Lexington ran four miles in $7.19 \frac{3}{4}$, winning $\$ 20,000$ in a race against time. In $1876 \mathrm{Ten}$ Broeck, in a race against time, lowered the four-mile record to 7.1 $5 \frac{3}{4}$. This same year he made a mile in $1.39 \frac{3}{4}$, which was the 
record for about thirteen years. In I88 I Luke Blackburn, a very famous runner, then four years old, made a mile at Jerome Park in 1.45 . In 1880 he also made a record of 2.34 for a mile and a half, which was not lowered for many years.

Records by Thoroughbreds are made at a running gait under the saddle. In England there are three so-called classic races each year, the Derby, Oaks, and St. Leger. Each of these races is very old. The first Derby in England was run at Epsom, May 4, I780. In 1784 the distance was increased from one mile to one and one-half mile. The following are the English Derby racing records, since I 890 :

\begin{tabular}{|c|c|}
\hline $\begin{array}{l}1890 \\
1891\end{array}$ & $\begin{array}{l}\text { Sainfoin, by Springfield, } 2.49 \text { I-4. } \\
\text { Common, by Isonomy, 2.56 4-5. }\end{array}$ \\
\hline 1892 & Sir Hugo, by Wisdom, 2.44 . \\
\hline I 893 & Isinglass, by Isonomy, 2.43 . \\
\hline I 894 & Ladas, by Hampton, $2.454-5$. \\
\hline 89 & Sir Visto, by Barcaldine, $2.433-5$. \\
\hline 1896 & Persimmon, by St. Simon, 2.42 . \\
\hline 1897 & Galtee Moore, by Kendal, 2.47 . \\
\hline 0 & Jeddah, by Janissary, 2.37 \\
\hline 399 & Flying Fox, by Orme, $2.3^{8} 2-5$ \\
\hline 100 & Diamond Jubilee, by St. Simon, 2.42 . \\
\hline $0 \mathrm{I}$ & Volodyovski, by Florizel, 2.40 4-5. \\
\hline & Ard Patrick, by St. Florian, $2.42 \mathrm{I}-5$. \\
\hline & Rock Sand, by Sainfoin, 2.42 4-5. \\
\hline & St. Amant, by Frusquin, $2.454-5$. \\
\hline & \\
\hline
\end{tabular}

In America one of the great running races of the year is the Suburban Handicap, of one and one-fourth miles, run at Sheepshead Bay, New York. The following are the more recent records of that annual event, showing the weight of jockey, time and money won by the winning horse:

1890 Salvator, 127 lbs., $2.064-5$; \$690o.

I891 Loantaka, II o lbs., 2.07 ; \$9900.

I892 Montana, II 5 lbs., 2.07 2-5; \$17,750.

1893 Lowlander, I05 lbs., 2.06 3-5; \$1 7,750.

I 894 Ramapo, I 20 lbs., 2.06 I-5; \$1 2,070.

I 895 Lazzarone, I 5 lbs., $2.074-5$; \$4730.

I 896 Henry of Navarre, 128 lbs., $2.07 ; \$ 5850$.

I 897 Ben Brush, 123 Ibs., 2.07 I -5 ; $\$ 5850$. 
1898 Tillo, I I 9 lbs., 2.08 I $-5 ; \$ 6800$.

I 899 Imp, I I 4 lbs., 2.08 2-5; \$680o.

1900 Kinley Mack, I2 5 lbs., 2.06 4-5; $\$ 6800$.

I901 Alcedo, I I 2 lbs., $2.093-5 ; \$ 7800$.

1902 Gold Heels, I 24 lbs., 2.05 I-5; $\$ 7800$.

1903 Africander, I 10 lbs., 2.10 2-5; \$16,490.

I 903 (Renewal) - Water Boy, 12 lbs., 2.04 3-5; \$9900.

1904 Hermis, 127 lbs., 2.05; \$17,000.

I 905 Beldame, I 23 lbs., 2.05 2-5; \$ 6,800 .

Famous Thoroughbred sires of winning stock. Each year a record is made of the sire of Thoroughbreds winning the most races. The table on the opposite page shows the American records from 1870 to date.

Lexington proved to be a wonderful horse. In twenty-one seasons he sired 600 horses of which 236 were winners of races. During fifteen years they won a total of $\$ I, I 59,32 I$. The influence of Lexington was very far-reaching, and he may be regarded as one of the very greatest of American Thoroughbreds.

The two imported horses, Leamington and Bonnie Scotland, left a strong impress on running-horse blood. The former was used in the stud in England, and in 1865 was purchased for $\$ 7500$, by Mr. Cameron and brought to America. A daughter of his in Ireland, Miss Theo, proved to be a great brood mare. Parole, a son, became a famous racer.

The American-bred horse, Hanover, by Hindoo, was one of the more celebrated Thoroughbreds in recent American history. Foaled in 1884 , he early showed great speed and became a turf favorite. As a sire he attained the first rank.

A Thoroughbred studbook, known as the General Studbook of Great Britain is published in England. In America The American Studbook for Thoroughbreds is maintained by the American Jockey Club, with headquarters in New York. 
THE THOROUGHBRED

\begin{tabular}{|c|c|c|c|c|c|}
\hline YEAK & NAME & AGE & WINNERS & $\begin{array}{l}\text { RaCes } \\
\text { Won }\end{array}$ & $\begin{array}{c}\text { AMOUNT } \\
\text { WON }\end{array}$ \\
\hline 1870 & Lexington & 20 & 35 & 82 & $\$ 120,360$ \\
\hline 1871 & Lexington & $2 \mathrm{I}$ & 40 & 102 & 109,095 \\
\hline 1872 & Lexington & 22 & 28 & 82 & 71,515 \\
\hline 1873 & Lexington & 23 & 23 & 71 & 71,565 \\
\hline 1874 & Lexington & 24 & 23 & 70 & 51,889 \\
\hline 1875 & Imp. Leamington & 22 & 18 & 32 & 64,518 \\
\hline 1876 & Lexington & 26 & 12 & 34 & 90,570 \\
\hline 1877 & Imp. Leamington & 24 & 21 & 49 & 41,170 \\
\hline 1878 & Lexington & 28 & 16 & $3^{6}$ & 50,198 \\
\hline 1879 & Imp. Leamington & 26 & 24 & 56 & 70,837 \\
\hline 1880 & Imp. Bonnie Scotland & 24 & 35 & 137 & 135,700 \\
\hline $188 \mathrm{I}$ & Imp. Leamington & 28 & 23 & $6 \mathrm{I}$ & 139,219 \\
\hline 1882 & Imp. Billet & 18 & 17 & 43 & 89,998 \\
\hline 1883 & Imp. Bonnie Scotland & 27 & 35 & 169 & 103,475 \\
\hline 1884 & Imp. Glenelg & 18 & 32 & 108 & 98,862 \\
\hline 1885 & Virgil & 21 & 24 & 56 & 73,235 \\
\hline 1886 & Imp. Glenelg & 20 & 34 & 136 & I $13,638^{8}$ \\
\hline 1887 & Imp. Glenelg & 21 & 33 & 120 & I 20,03I \\
\hline 1888 & Imp. Glenelg & 22 & 33 & I 34 & 130,746 \\
\hline 1889 & Imp. Rayon d'Or & 13 & 27 & IOI & 175,877 \\
\hline 1890 & Imp. St. Blaise & I0 & 27 & 105 & 189,005 \\
\hline $189 \mathrm{I}$ & Longfellow & 24 & $5^{2}$ & 143 & 189,334 \\
\hline 1892 & Iroquois & 14 & 34 & 145 & 183,026 \\
\hline 1893 & Himyar & 18 & 27 & $13^{8}$ & 249,502 \\
\hline 1894 & Imp. Sir Modred & 17 & 36 & 137 & I 34,318 \\
\hline 1895 & Hanover & II & 40 & 133 & 106,908 \\
\hline 1896 & Hanover & 12 & 42 & 157 & 86,853 \\
\hline 1897 & Hanover & 13 & 54 & 159 & I 22,374 \\
\hline 1898 & Hanover & 14 & 43 & 124 & I I $8,59^{\circ}$ \\
\hline 1899 & Imp. Albert & 17 & 19 & 64 & 95,975 \\
\hline 1900 & Kingston & 16 & 33 & 110 & I 16,368 \\
\hline I9or & Sir Dixon & 16 & 24 & 94 & 165,682 \\
\hline 1902 & Hastings & 9 & 29 & 63 & I 13,865 \\
\hline 1903 & Imp. Ben Strome & 17 & 21 & 9 I & 106,965 \\
\hline 1904 & Imp. Meddler & 14 & 21 & 55 & 227,555 \\
\hline 1905 & Hamburg & ro & 30 & 60 & 58,160 \\
\hline
\end{tabular}

Explanatory of the table, the horse Lexington in 1870 at 20 years of age had 35 sons and daughters win 82 races and a total of $\$ 120,360$. 


\section{CHAPTER IV}

\section{THE AMERICAN SADDLE HORSE}

The use of the saddle is common wherever horses are in existence, no matter what the type or character of animal. Of the various classes used, the one which has the most highly developed movement adapted to the saddle and furnishes the most grace of motion and comfort for rider is the American saddle horse. This horse does not as yet represent a fixed breed, but through the character of his breeding and action he possesses much that is interesting to the student of horses.

The history of the American saddle horse extends back into Virginia, Kentucky, Tennessee, and Missouri more intimately than elsewhere, for in these states the active work of his development has been conducted. Much of this breeding has been done in Kentucky, hence the common term "Kentucky saddle horse." Early in the history of Kentucky, when railways were unknown and poor roads common, horseback riding was universal. The early saddle horses were hard-gaited, and this resulted in the selection of the better type of Thoroughbreds, easy of gait and light of foot, some of which found their way into Kentucky from Virginia. A few easy moving mares, with an ambling or slow pacing gait, were sought for and found many years ago, and to them Thoroughbred saddle stallions of easy movement were bred. The pacing blood came in part from Canada and New England, and so involved some Morgan breeding. Thus by selection there developed a class of very easy-gaited saddlers peculiar to Kentucky and adjacent states. Through much care and selection a variety of gaits developed from this breeding, thus giving special distinction to the American saddle horse.

The influence of Thoroughbred blood on the American saddle horse is interestingly brought out by investigations made by Mr. John H. Ward. He found that the 108I horses registered in 
Volume I of the studbook contained Thoroughbred blood as follows :

Of pure Thoroughbred breeding . . . . . . . 2 horses

Containing 50 per cent Thoroughbred blood . . . 50 "

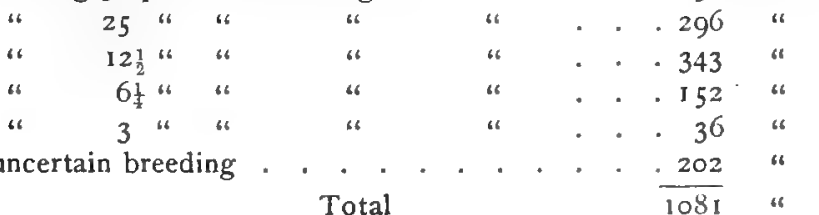

Investigation in subsequent studbooks showed no material change in the percentages above given.

The foundation stock of the American saddle horse as agreed upon by the American Saddle Horse Breeders' Association, after years of careful investigation, and as revised in 1902, consists of the ten stallions:

Denmark (Thoroughbred) by Imp. Hedgeford.

John Dillard, by Indian Chief (Canadian).

Tom Hal (imported from Canada).

Cabell's Lexington, by Gist's Black Hawk (Morgan).

Coleman's Eureka (Thoroughbred and Morgan).

Van Meter's Waxy (Thoroughbred).

Stump-The-Dealer (Thoroughbred).

Peter's Halcorn.

Davy Crockett.

Pat Cleburne, by Benton's Gray Diomed.

Denmark is the most distinguished animal in this list. His sire, Hedgeford, was foaled in England in 1825 , brought over to New York in 1832, and later taken to Kentucky, where he died in 1840 . His son, Denmark, was bred to what is known as "Stevenson's mare," from which came unusually good results in saddle-horse lines, she producing to him Gaines's Denmark, Muir's Denmark, and Rob Roy. The former proved a great breeding stallion, and from him are descended many of the best saddle horses of to-day. The Denmark horses of the earlier days, bred to the pacing stock from the North, produced excellent results. Then Thoroughbred and so-called native mares 
were used, and the blood of the descendants of the foundation stock was judiciously blended, from which has been derived the best of modern American saddle-horse character.

The two most famous saddle horses, from their importance as sires, were Black Squirrel 58, by Black Eagle 74, tracing back to Denmark, and Montrose 106, by Diamond Denmark 68. Black Squirrel sired more saddle horses of renown than any other stallion of this class, living to the ripe age of twenty-two and leaving a long list of distinguished sons and daughters. Black Eagle 74 , the sire of Black Squirrel, was also a great breeder as well as show horse. Among other celebrated saddle horses are Highland Denmark 750, by Black Squirrel; Forest Squirrel 80 I, by Black Squirrel (first prize at Columbian Exposition) ; Monte Cristo 59, by Montrose 106; Red Squirrel 53, by Black Squirrel; and Black Squirrel Jr. 2d 395, by Black Squirrel; Goodwin 1 227, by Highland Denmark (sent to Porto Rico); and Cupid I I 52, by the same sire, purchased by the Japanese government. The mares Mollie, dam of Black Squirrel 58; Amelia, by Red Eagle; Patsy McCord I600, by Black Squirrel; Highland Maid I 270, by Highland Denmark; Emily 855, by Bourbon Chief, by Harrison Chief 384I ; Rowena I362, by Chester Dare Io, by Black Squirrel 58 ; and Miss Rex 820 , by Rex Denmark.

Characteristics of the saddler. These do not materially differ from the roadster of superior conformation, with all the best quality obtainable. In height 15 hands $1 \frac{1}{2}$ inches to 15 hands $2 \frac{1}{2}$ inches is the standard, with weight ranging from 950 to 1050 . For ladies the lighter type is preferred, while for heavy weights the larger type is more desirable. The saddler shows much style in carriage of head and arch of neck and tail, while a round, wellturned, neat body is desired. The back should be very strong in order easily to sustain weight. The shoulders and pasterns must be sloping and long, the pasterns in particular being long, strong, and springy, thus favoring an easy gait.

The gaits of the saddle horse are especially distinctive. Saddlers may be divided into two classes: (I) the walk-trot-canter horse, gaits commonly found in all saddlers, and (2) those of the American saddle horse in particular, viz. the walk, trot, canter, rack, and the running walk, or fox trot, or slow pace. 
A comprehensive discussion of the gaits of the saddle horse, coming from the pen of one well qualified to present the subject, ${ }^{1}$ and long identified with saddle-horse interests, the writer thinks appropriate to introduce here.

There are different kinds of saddle horses, and they are classified in part at least by their gaits. The three natural gaits of a horse are the walk,

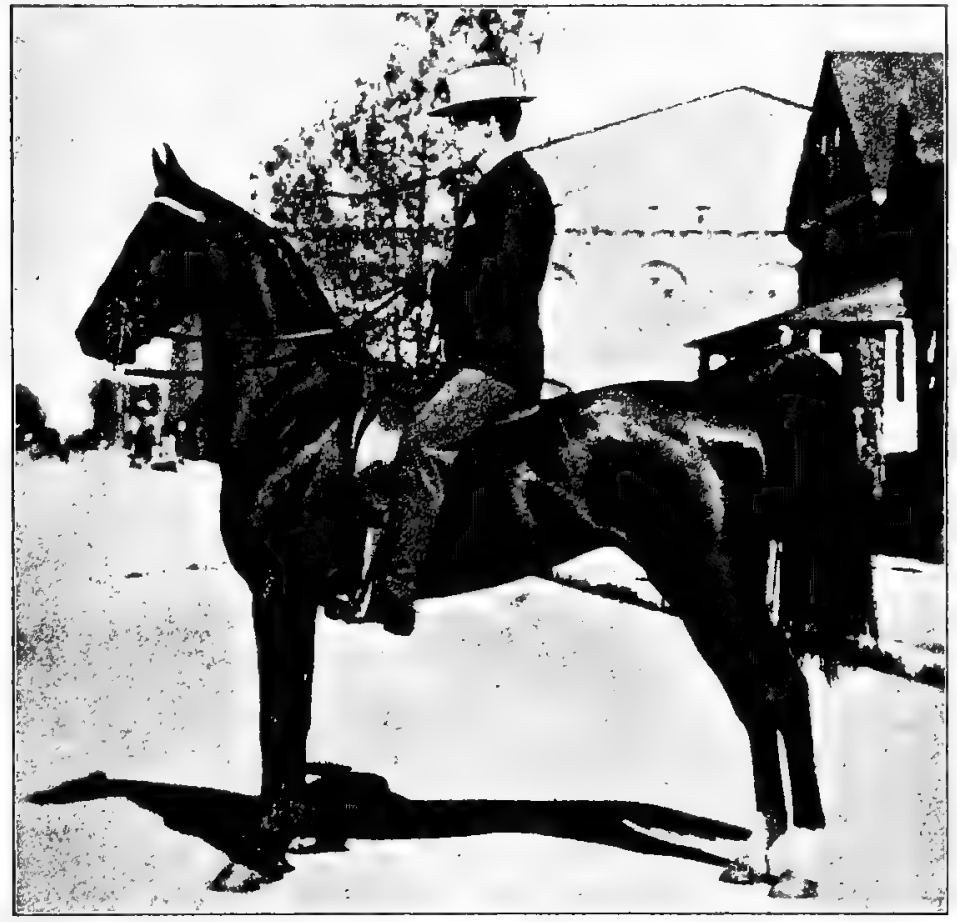

FIG. 8. Gypsy Queen. An American saddle horse, first in class of gaited sadders at Chicago Horse Show in 1903 and 1904. A very beautiful mare, and a winner at numerous shows. From photograph from Ball Bros., Versailles, Kentucky

trot, and gallop or run. Artificially, that is by education, the gallop is made into a canter, which is a gait performed by practically the same movement of the legs, but slower, more restrained, and easier to ride. We then have one kind of a saddle horse called the walk-trot-canter or plain-gaited horse. This horse suits a lot of people, primarily, because they do not know any

1 Editorial by W. R. Goodwin, Jr., Breeder's' Gazette, June 10, 1903. 
other gait; secondarily, because they are imitators of the English fashion of riding; and lastly, and leastly, because they do not like other educated and easier gaits.

These easier gaits are the running walk and the rack. The latter is also called single foot, inasmuch as in this gait each foot has a separate impact on the ground, no two of them striking it at the same time, as in the trot and pace.

The running walk is called a slow gait, and there are two other gaits allied to it, - the slow pace and the fox trot. The name "running walk" defines the gait accurately, and at once identifies it to the understanding.

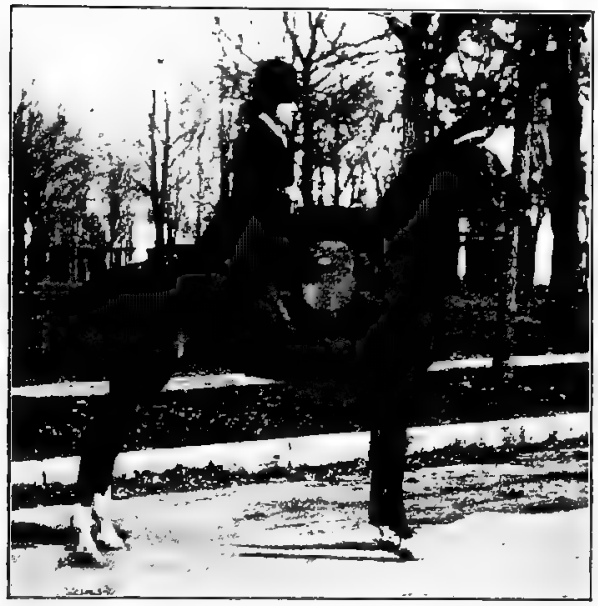

Frg. 9. Lady Bonnie. Champion three-gaited American saddle horse at Chicago Horse Show, 1904, owned by Miss Jennie Bull, Racine, Wisconsin. From photograph from Miss Bull

It is faster than a flat-foot walk, and is produced by a movement of the legs more rapid than in a walk, but in about the same rhythm; that is, each foot strikes the ground independently of the others. Most horses going the running walk bob or nod their heads, and some of them even flop their ears in rhythm with their footfalls. It is an all-day gait, easy alike to the horse and the rider, and it covers ground at an astonishing fashion for its apparent speed. It is taught by urging a horse out of the walk but restraining him from a trot.

The slow pace is a somewhat similar movement but borders more on the sidewheel gait or lateral pace, in which the two feet on one side of a horse strike the ground at the same instant. The true pace, however, is in no sense a saddle gait. It is rough and uncomfortable. A rider cannot rise to it and save himself, as in a trot, and it is positively the worst gait a saddle horse can possess. In the slow pace this side-wheel motion is slightly modified so that the impact on the ground of the two feet on a side is broken, thus avoiding the rolling motion of the true pace. The slow pace is a very comfortable gait, and is very showy, especially when a horse throws just a bit of knee action into it. It has grown common in the show ring during recent years, as saddle-horse trainers appreciate its catchy qualities and endeavor to teach their horses to go this gait. The best saddle-horse men, however, do not look on it with favor, as it is so easily corrupted into the 
abominable side-wheel pace, which ruins a saddle horse for comfortable and satisfactory work. Unless a rider is careful his mount may almost imperceptibly degenerate from a distinct and correct slow pace into a plainly defined pace, and then there is sure enough trouble.

The fox trot is a slow trot or a jog trot. It is a rather peculiar gait and not so desirable as the running walk or the slow pace. Some horses cannot acquire either of these two gaits and so their trainers pull them down into a very slow trot and seek to pass that gait off as a fox trot. It is a

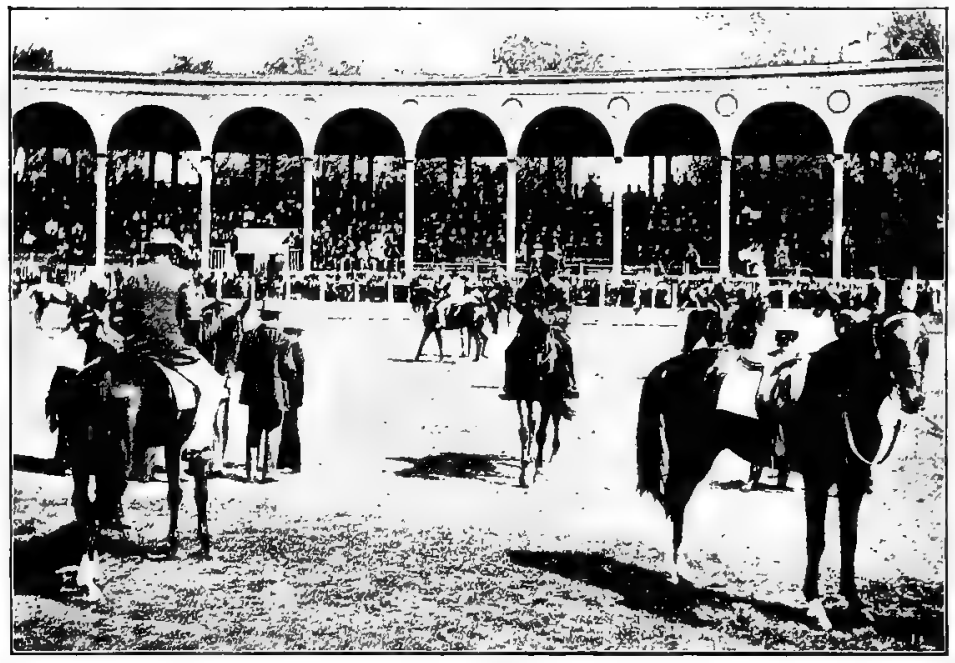

FIg. 10. Showing saddle horses. The St. Louis Fair, 1899. Photograph from National Stockman and Farmer

broken-time gait, in a measure, somewhat easier than a pure trot, and when cleanly performed it will answer as a business gait.

The trot is the diagonal gait. The off fore foot and the near hind foot strike the ground at the same instant and the horse bounds off them to hit the ground again with the near fore and the off hind. This gives a two-beat gait. The impact of the feet on the ground is one, two, one, two.

The pace is the lateral gait. The off fore and off hind foot hit the ground at the same interval, and the other pair on the near side follow. This is also a two-beat gait.

The rack is a four-beat gait. Each foot hits the ground at a separate interval in a one-two-three-four beat. The rack can be distinguished by ear as far as the footfalls of the horse may be heard; each foot rings clear its own note on the hard ground. In teaching the rack the horse is forced forward by the spur and restrained by the curb. His diagonal gait is thereby 
broken up and he flies into a four-beat gait. The rack is easy for the rider, hard for the horse. It is a showy gait and is performed at great speed sometimes. The trainer who has a fast racking horse will generally keep him on that gait when in the show ring, hoping to dazzle the judge by the flashiness of the performance. ... This gait has been officially named the rack by the American Saddle Horse Breeders' Association, and hence the name "single foot" should not be used, as it merely leads to confusion among the uninformed.

The five gaits recognized by that association are the walk, trot, canter, rack, and the running walk, or slow pace, or fox trot. Any one of these three slow gaits will answer. Some horses can go only one of them, some can show them all. When a horse can show these five gaits he is called $a$ gaited horse.

The prices paid for superior saddle horses often run into high figures, $\$ 500$ to $\$ 1000$ not being uncommon. There is but a limited supply of gaited saddlers, and these are always in demand by a class of patrons who are willing to pay a price consistent with merit. In I 906 Major David Castleman is reported to have sold the stallion, The Moor I907, by Cecil Palmer, for $\$ 7500$, to General William Palmer, of Colorado Springs. This same year General John B. Castleman, of Kentucky, sold the mares Eugenia, by Highland Denmark, out of Emily, and Magna, by Cromwell Jr, out of Maria, to J. A. Davis, of Massachusetts, for $\$ 5000$.

The American Saddle Horse Breeders' Association was organized at Louisville, Kentucky, in I89I, as the National Saddle Horse Breeders' Association. In I899 the name was changed to the American Saddle Horse Breeders' Association. Thus far five volumes of the studbook have been published. 


\section{CHAPTER V \\ THE ROADSTER TYPE}

The roadster, or light harness horse, occupies a class by itself, representing a lighter type of driver than the coach horse. Such a horse is desirable for speed, in rapidly conveying along roadways a light driving vehicle. The American trotter or pacer is the common type used for this work. Speed and endurance seem to be the principal points sought in the roadster, and less uniformity of type is found in this class than in any other. Light harness horses vary widely in height, weight, and conformation.

The best type of roadster stands from $15 \frac{1}{4}$ to $15^{\frac{3}{4}}$ hands high and weighs about a thousand pounds. In conformation this horse tends to be angular, the muscles and joints showing prominence, with the ribs more or less noticeable. There is proportionately less body and more leg, a thinner neck, with muscularity at the croup and quarters.

Discussed in some detail, the following are the more important characteristics in the roadster. The head as a whole is lean, small, refined, denoting intelligence, spirit, and vigor. The neck is inclined to be slender and long with a straight top, though ewe necks are not uncommon among mares and geldings of this class. The shoulders are quite oblique and long, and are set deep in the back, ending at the withers, which are sharper and more prominent than in any other type of horse. The long sloping shoulder, with powerful muscle attachment, accounts for the long and powerful front reach of the roadster when in motion. The arm should be large for the size of the horse, and the fore arm very muscular, being wide and thick at the top, with muscle well carried down, and from elbow to knee fully twice as long as the cannon bone. The legs show prominent and strong development, with the tendons most prominent and very free from fleshiness. The leg of the roadster is often lacking in depth at the upper part of 
the cannon, whereas it should be of good depth and the bone hard, smooth, and flat. The pasterns should stand at an angle of about 45 degrees with the floor, and be long, smooth, and springy. The feet should be of good size, round, wide at top, well developed at heel, and preferably dark of bone. The chest usually presents less breadth and more proportionate depth, the roadster thus often seeming narrow-chested. Plenty of lung capacity, with prominent breast, is essential, but these features are not inconsistent with such a form of chest. The body

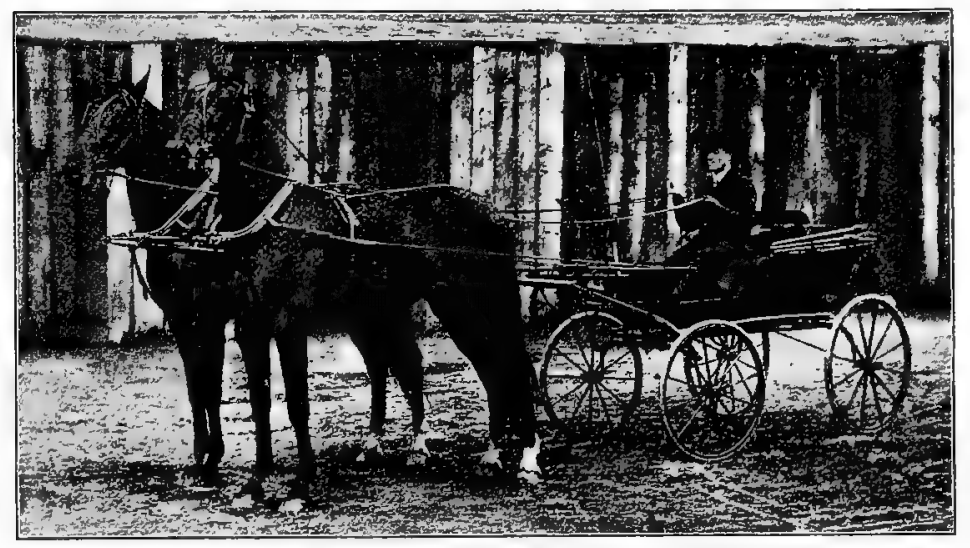

FIG. 1I. Rhea W. and Easter Belle. A great pair of prize-winning roadsters. Champions at National Horse Show, Madison Square Garden, New York, 1904. Owned by Miss K. L. Wilks, Galt, Ontario, Canada. Photograph from the owner

should be strongly ribbed, the back short, the coupling close, the loin strong and muscular, and the entire body framework indicating constitution. Muscle and not fat is what the roadster should carry, and thus his body frequently appears lacking in capacity, as is in fact the case. Some of the most famous trotters and pacers have certainly appeared to lack girth, with flanks high, and circumference around the body at hind flank distinctly less than good conformation would imply desirable. A strong but not overprominent hip is preferable. The croup is one of the most variable features of the roadster. Length, breadth, and levelness are associated with the trot, but the 
steep, short croup is responsible for many a pacing gait, for a horse with steep croup can pace more easily than trot, handling his feet with less interference than would occur in trotting. The thighs and quarters are usually long and thin, measuring a great proportionate length from hip to hock, as is also the case with the Thoroughbred. The hocks should be deep and strongly muscular, and should be placed square and true in relation to each other. If the hocks tend to come in and the hind feet toe out, the pacing gait often naturally occurs. Trueness of position of feet and legs will assure a trueness of gait if the feet are properly shod and balanced. Quality is an essential in the roadster. This is seen in the fine hair and soft skin, the refinement of head and limbs, the prominence of veins and muscles, and the harmony and symmetry of parts. Action of the most powerful kind is looked for in this type. It must be true, varying neither to right nor left; each foot must be carried along the proper line, and the movement, no matter of what kind, should be snappy and free of interference or clumsiness. Strong, long-reaching knee and hock action, with the feet picked up smartly, is most essential. Horses of this class carry the legs farther forward and back, thus having a greater stride, with less elevation of knee and hock, than the coach horse. The action of the roadster, however, should approach that of the coacher, up to the point where speed is not sacrificed for coach form. 


\section{CHAPTER VI}

\section{THE AMERICAN TROTTER}

The history of the English trotting horse goes back for several centuries. About Norfolk and Yorkshire, trotters were great favorites two centuries ago, and trotting races of an unofficial character were of frequent occurrence. Old records tell us that the Norfolk trotting mare Phenomena in 1800 trotted 17 miles in 56 minutes on the Huntingdon road, carrying a weight in saddle of about 225 pounds. In 1806 the horse Pretender trotted 16 miles within an hour, carrying 2 Io pounds. All the early racing records were made under the saddle. In connection with the early evolution of the Hackney its use as a trotter and racer became popular.

The early use of the trotter in America no doubt extends back into colonial times, though to what degree is uncertain. What were probably running horses were taken from England to Massachusetts as early as I629. Horses of this class were also bred in Virginia and the Carolinas. The recorded use of the trotter in America extends back to the first part of the nineteenth century. In 1802 a law forbidding all horse racing and trotting was enacted in New York, but this law was amended in I82I, to permit training, pacing, trotting, and running of horses upon certain regulated courses in Queen's County on Long Island. Early trotting records take us back to June, 1806 , when the horse Yankee, under saddle, trotted a mile in 2.59 on the Harlem race course, New York. On August 25, I 8 io, a horse from Boston is reported to have trotted a mile at Philadelphia in harness in $2.48 \frac{1}{2}$. Later, in 1818 , Boston Blue made an authentic mile in 3.00 at Jamaica, New York. This record compares favorably with English records in Norfolk and elsewhere.

A most important source of trotting blood in America was the importation of the stallions Messenger and Bellfounder, whose histories are worthy of special mention. 
Messenger, commonly known as Imported Messenger, was a Thoroughbred, his pedigree tracing back through his sire to Flying Childers and the Darley Arabian. He was foaled in 1780 in England and proved a successful racer, and as a five-year-old won the King's Plate. Believing that he would do valuable service in the stud, he was imported to the United States in May, I 788. Messenger, however, though a trotting sire, had no immediate descendants that proved to be noted trotters. He secured his chief fame through his son Mambrino, a Thoroughbred, that in turn was sire of Abdallah, a breeder of trotters. Messenger was a gray, I $5 \frac{3}{4}$ hands high, with strong loins and powerful hind quarters. He was in stud service for twenty years in America, - in Pennsylvania, New Jersey, and New York. He died January 28,1808 , leaving a lineage of driving horses of remarkable excellence.

Bellfounder, known as Jary's Bellfounder in England and as Imported Bellfounder in the United States, was foaled in I 815 , and was imported from Norfolk in 1822. He was a bright bay, with black mane, tail, and legs, stood 15 hands high, and was a natural trotter. At the time he was brought to America he was regarded as one of the very fleetest and most powerful trotters, and is said to have trotted 17 miles in an hour. Velocity, his dam, trotted 16 miles in an hour on the Norwich road in 1806 , while two years later she is reported to have made 18 miles in I hour and 47 seconds. Thus it can be seen how a strong line of trotting blood was brought to America. Bellfounder was taken to Orange County, New York, where he went into stud service. Here he sired the Charles Kent Mare, a most important connecting link with his American fame. Bellfounder died on Long Island in 1843 .

Trotting families of note have been developed in America during the past century, from which are descended the trotting horses of eminence to-day. The families introduced below are recognized as the most important. The judicious blending of these families has, in cases, resulted in very great success, as for example in the case of the Hambletonian and Mambrino.

The Hambletonian family. On May 15, 1849, the Charles Kent Mare gave birth to a male foal from service of Abdallah, 
the grandson of Messenger. This mare was owned by Jonas Seely of Chester, Orange County, New York, who later sold her with foal at side to William M. Rysdyk for \$125. This colt was later named Hambletonian 10 , and is frequently referred to as Rysdyk's Hambletonian. This stallion proved the founder of the most famous American family of trotters, for to him may be traced many of the most illustrious trotters of history. In 185 I Hambletonian began service in stud, which, with the exception of one year (1868), he continued until 1872. During twenty-one years of service he sired 1287 foals, the service fees for which amounted to $\$ 185,7$ I5. Hambletonian Io was a bay in color, with a star and white hind ankles, stood $15 \frac{1}{2}$ hands high, and was powerful in build. His head was large, with pleasant eyes, his neck and shoulders strong, the body round and full, legs and feet of superior character, and he stood somewhat higher behind than in front. As a three-year-old Hambletonian made a record of $2.48 \frac{1}{2}$ over the Union course. $\mathrm{He}$ died March 27, 1876, long after his value as a sire began to be appreciated. He was undoubtedly the greatest progenitor in American trotting history.

Among the famous sons and daughters of Hambletonian Io are Alexander's Abdallah, Electioneer, George Wilkes, Aberdeen, Volunteer, Happy Medium, Harold, Strathmore, Dictator, Dexter, Nettie 2.I8, Orange Girl 2.20, Gazelle 2.21, Jay Gould $2.2 \mathrm{I} \frac{1}{2}$, and Bella 2.22. The first eight of these proved very prepotent sires, and thus demonstrated the value of their remarkable sire.

The Mambrino family. This family is named from Mambrino Chief, foaled in 1844, and bred by Richard Eldridge of Dutchess County, New York. Mambrino . Chief was by Mambrino Paymaster and he by Mambrino, the Thoroughbred son of Messenger. His dam is untraced. He was a dark brown stallion about 16 hands high; by some referred to as coarse, though he proved a very superior breeder. Mambrino Chief was taken to Kentucky in 1854 , where he went into active service and passed the rest of his days. His son, Mambrino Patchen, sired scores of trotters, while his daughter, Dolly, was the dam of Onward, Director, and Thorndale, a remarkable trio. Mambrino King, by Mambrino Patchen, was regarded by many as the most beautiful 


\section{Pedigree of Hambletonian io}

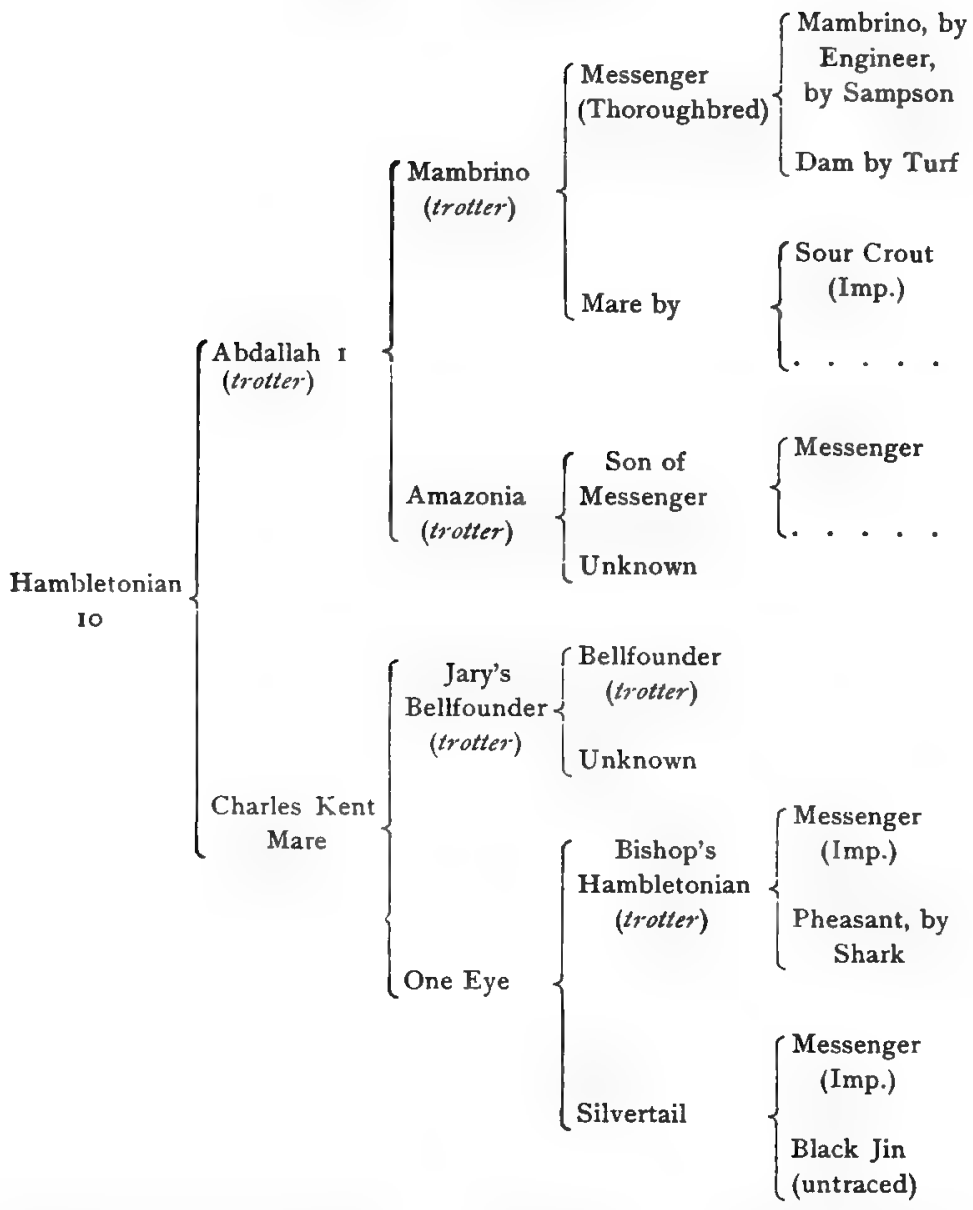

horse in America in his day. Lady Thorn, a daughter of Mambrino Chief, trotted 106 heats inside 2.30, and won national fame. The union of the descendants of Mambrino Chief and Hambletonian Io produced most efficient results.

The Morgan family. This is one of our oldest trotting families, and inherits its name from a stallion named Justin Morgan, foaled in 1793 at West Springfield, Massachusetts. From this 
place he was taken to Vermont, in which state this family of horses has gained great distinction. Justin Morgan was sired by True Briton, whose ancestry may be traced back to the Godolphin Barb; his dam is given as Diamond, she also tracing back to the Godolphin Barb. It is but fair to state here that the breeding of Justin Morgan is more or less questioned, and the above ancestry is hased on investigations of Joseph Battell of Middlebury,

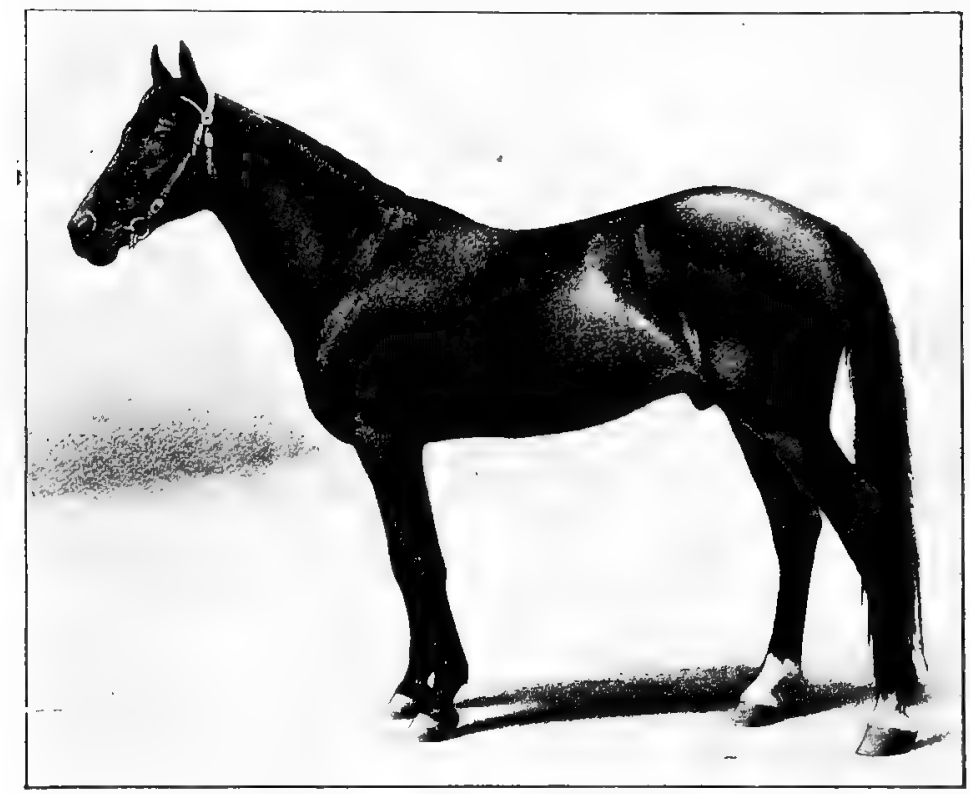

FIG. I2. Arion. The highest-priced American trotter. Purchased by J. Malcolm Forbes, Boston, Massachusetts, for $\$ 125,000$. Now owned by M. W. Savage, Minneapolis, Minnesota. Arion holds the fastest record for a threeyear-old colt of $2.10 \frac{1}{2}$. Illustration by courtesy of Mr. Savage

Vermont. This stallion is described as about I4 hands high, weight 950 pounds, dark bay with black points, and possessed of great vitality; he died in $182 \mathrm{r}$, at twenty-eight years of age. $\mathrm{He}$ was a fast walker, a good trotter, and was most intelligent, being used as a military charger or parade horse, as a short-distance runner and a farm work horse. He proved to be a wonderfully prepotent stallion, and on his blood is founded the Morgan horse 
family. There is a register for Morgan horses; already about five thousand have been recorded in the second volume, and to be eligible for registration the pedigree of every horse recorded must trace in some degree to Justin Morgan.

Justin Morgan had a long stud career, but he did not produce great breeding sons in the same degree as did Hambletonian Io. Three of his sons, Bulrush, Woodbury, and Sherman Morgan, were his greatest offspring. A son of Sherman Morgan, named Black Hawk, foaled in 1833 , was a trotter and vigorous sire, and fourteen of his sons became recognized trotters. Ethan Allen, his greatest son, was bred in New York State, and was foaled in I 849 from a dam of unknown ancestry. He became very famous and popular as a successful trotter and he proved also to be a great sire. The mare Pocahontas, by Iron's Cadmus, with a record of $2.17 \frac{1}{2}$ in 1855 , bred to Ethan Allen, became the dam of another Pocahontas, for which Robert Bonner later on paid $\$ 40,000$. Among the thirty-six producing sons and daughters of Ethan Allen no one attained such distinction as did Daniel Lambert, himself the sire of thirty-eight trotters. The sire of the dam of Daniel Lambert was Abdallah, the sire of Hambletonian 10. Later years have shown that the Hambletonian and Morgan families could be bred together to very great advantage.

At the present time the United States government is conducting special experiments with the purpose in view of developing an American breed of heavy harness horses. The Morgan family is being used to furnish much of the important blood used in this work. The stallion Carmon, a descendant of Justin Morgan, is the chief stallion in use in the stud at the Colorado Experiment Station, where the government is conducting this work. The Vermont Experiment Station is also establishing a stud of Morgans, where experimental breeding will be conducted under government direction.

The Clay family. In I 820 a stallion was imported from Tripoli, foaled in 1816 , that was regarded as of great beauty, action, and speed. He was a small iron gray, standing $141 \frac{1}{4}$ hands high. Used in the stud near Philadelphia he sired Young Bashaw out of a granddaughter of Imported Messenger. Young Bashaw sired Andrew Jackson, the fastest trotter of his day. The 
trotting mare Lady Surrey, brought from Canada and owned by George M. Patchen, was bred to Andrew Jackson, from which in 1837 she dropped a foal, named Henry Clay, the sire from which this family derives its name. Henry Clay sired Black Douglas and Cassius M. Clay, the latter celebrated in his day and the sire of George M. Patchen. The latter made a record of $2.23 \frac{1}{2}$ in 1860 and later became a distinguished sire, sixteen of his sons having standard records and thirty-five of his daughters being dams of either trotters or pacers.

The Pilot family. A black or dark brown horse by the name of Pilot first attracted attention in this family. He was foaled in 1828 in the province of Quebec. His sire is unknown and his dam was Jeanne d'Arc, by Voyager. When eighteen months old he was taken to Connecticut, and in I830 to New York. In I 83 I he was sold to go to New Orleans and in 1832 he was returned to Kentucky, where he died about 1853 on the farm of Robert Bell near Henderson. Pilot was not only a pacer but he would also trot. His greatest son was Pilot Jr., a gray horse I $5 \frac{1}{2}$ hands high, foaled in I 844 , out of Nancy Polk by Funk's Havoc. Pilot Jr. was a very successful breeder of brood mares. Bred to Sally Russell, a Thoroughbred daughter of Boston, he sired Miss Russell, one of the greatest American brood mares, the mother of the great Maud S. Another daughter, Midnight, out of a Thoroughbred daughter of Lexington, was the dam of Jay-ìye-See with a pacing record of 2.064 and a trotting record of 2.10. Waterwitch, another daughter of Pilot Jr., produced nineteen foals that lived, six of which made records of 2.30 or better. The family history of Pilot is more or less obscure. He bred both pacers and trotters, and rendered valuable service to the American racing-horse interests.

Hal family. Years ago down in Kentucky there was kept a roan saddle horse, bred in Canada, known as Tom Hal. It is said that he was much abused in his time, was ridden nearly to death over rocky roads by a drunken wretch in an elm-crotch saddle. For years he stood at a fee of $\$ 5.00$ to insure, with no pay if he did not get a good saddle horse. His ancestry is somewhat obscure, but it is claimed that he had Morgan blood in his veins. Tom $\mathrm{Hal}$ attained fame as the sire of Gibson's Tom Hal, the 


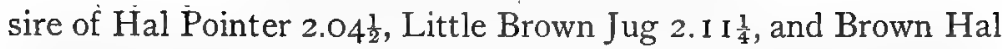
2. $12 \frac{1}{2}$. The latter became the sire of Star Pointer, a pacer of marvelous speed, character, and endurance, that reduced the pacing record to $1.59 \frac{1}{4}$. Brown $\mathrm{Hal}$ is the sire of about fifty in the list,

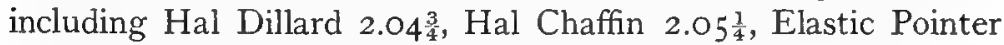

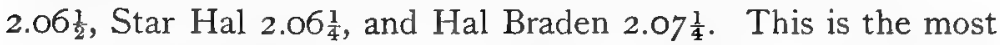
distinguished family embracing a large percentage of pacing blood.

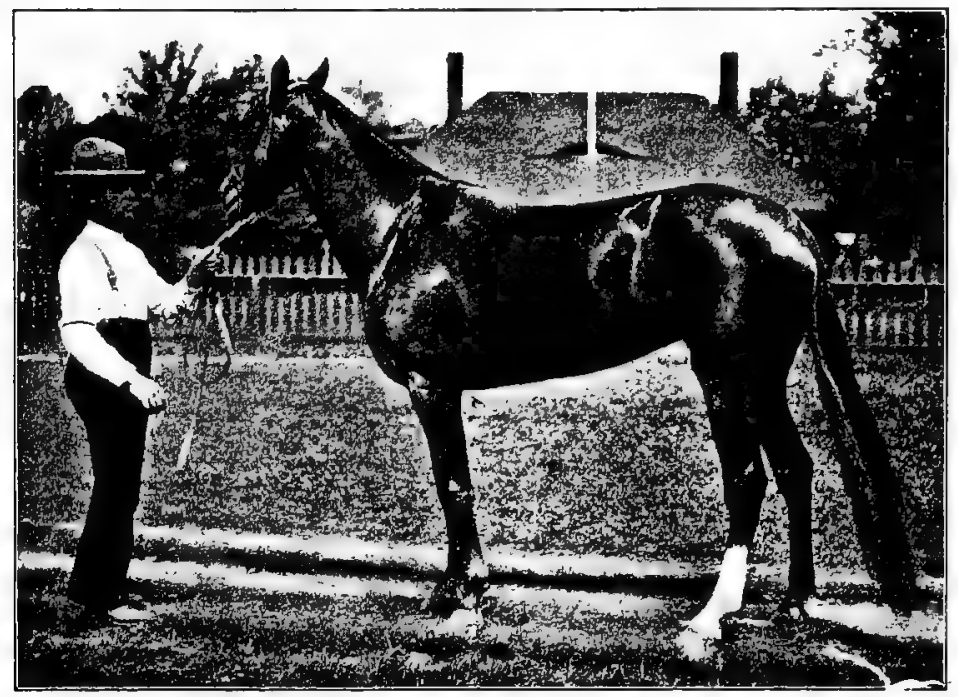

FIG. I3. Lou Dillon. Holds trotting championship of the world, at $1.58 \frac{1}{2}$. The most sensational trotter in American history. Owned by C. K. G. Billings, Chicago, Illinois. From photograph taken in 1905 , by courtesy National Stockman and Farmer

The type of the American trotter is far from being fixed. No breed of horses has been produced under more variable conditions, and no recognized breed of stock contains a greater variation in size, color, and character than does this light harness breed. In fact, there is so little breed type that many persons refuse to recognize it as a breed. In its best development this light harness horse has symmetry of form, - a lean, intelligent head ; a medium long, refined, and graceful neck; sloping, welllaid shoulders; sharp withers; fairly level, short, strong back; graceful, muscular croup, with tail well carried and set high; lean, 
muscular thigh ; round, deep body ; and legs short, clean, fine boned, and with excellent feet. This horse has a strong, long, quick stride, a clean hock action, and greater activity of motion than any other trotter known. Weights of I I 50 pounds for a stallion and 900 pounds for a mare are very acceptable; while any color will pass, although bays and browns are most numerous.

What is a standard-bred trotter? In 1882 the constitution of the National Association of Trotting Horse Breeders, an association organized in 1876 , was amended, and among the rules adopted were the following.

In order to define what constitutes a trotting-bred horse, and to establish a breed of trotters on a more intelligent basis, the following rules are adopted to control admission to the records of pedigrees. When an animal meets with the requirements of admission and is duly registered, it shall be accepted as a standard trotting-bred animal.

First. Any stallion that has, himself, a record of two minutes and thirty seconds (2.30) or better; provided any of his get has a record of 2.40 or better; or provided his sire or his dam, his grandsire or his grandam, is already a standard animal.

Second. Any mare or gelding that has a record of 2.30 or better.

Third. Any horse that is the sire of two animals with a record of 2.30 or better.

Fourth. Any horse that is the sire of one animal with a record of 2.30 or better; provided he has either of the following additional qualifications : (1) a record himself of 2.40 or better; (2) is the sire of two other animals with a zecord of 2.40 or better; (3) has a sire or dam, grandsire or grandam, that is already a standard animal.

Fifth. Any mare that has produced an animal with a record of 2.30 or better.

Sixth. The progeny of a standard horse when out of a standard mare.

Seventh. The progeny of a standard horse out of a mare by a standard horse.

Eighth. The progeny of a standard horse when out of a mare whose dam is a standard mare.

Ninth. Any mare that has a record of 2.40 or better, and whose sire or dam, grandsire or grandam, is a standard animal.

renth. A record to wagon of 2.35 or better shall be regarded as equal to a 2.30 record.

The "Trotting Register," as published by J. H. Wallace, first appeared under his name in $187 \mathrm{I}$, and horses were registered in this according to the above rules. The American Trotting Register Association succeeded the National and Mr. Wallace sold to it his Trotting Register as well as his Year Book in 
which the annual trotting records are published. The present rules for registration of the American Association are as follows :

When an animal meets these requirements and is duly registered it shall be accepted as a standard-bred trotter.

I. The progeny of a registered standard trotting horse and a registered standard trotting mare.

2. A stallion sired by a registered standard trotting horse, provided his dam and grandam were sired by registered standard trotting horses, and he

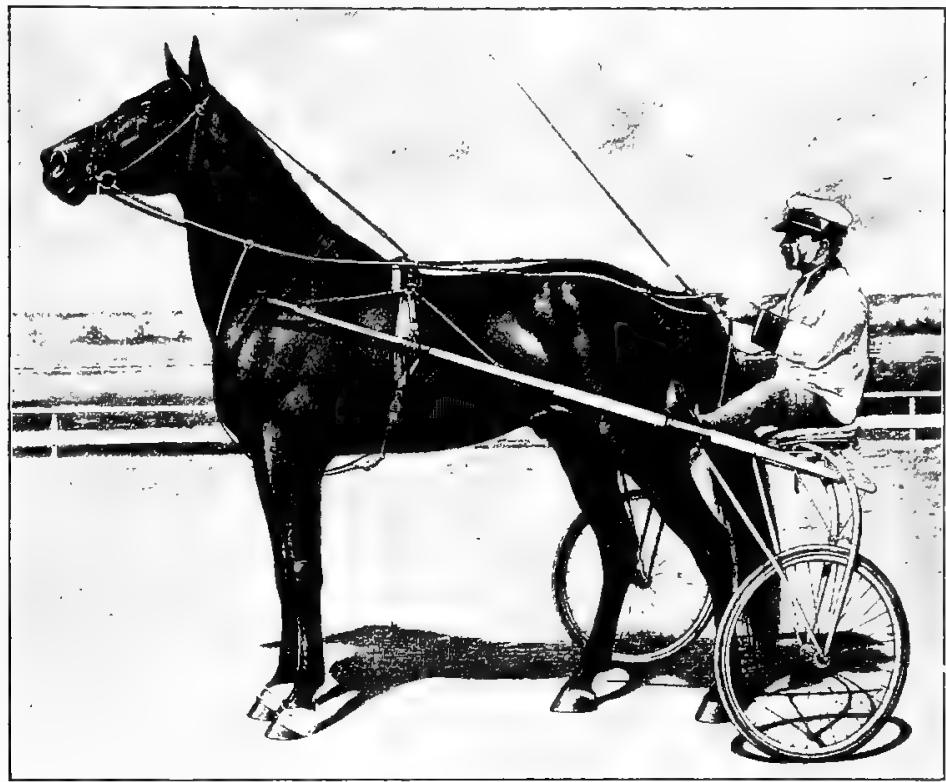

FIG. I4. Dan Patch. The fastest pacer in history. Holds world's record of r.55t. Purchased for $\$ 60,000$ by Mr. M. W. Savage, Minneapolis, Minnesota. Illustration by courtesy of Mr. Savage

himself has a trotting record of 2.30 and is the sire of three trotters with records of 2.30 from different mares.

3. A mare whose sire is a registered standard trotting horse, and whose dam and grandam were sired by registered standard trotting horses, provided she herself has a trotting record of 2.30 or is a dam of one trotter with a record of 2.30 .

4. A mare sired by a registered standard trotting horse, provided she is the dam of two trotters with records of 2.30 .

5. A mare sired by a registered standard trotting horse, provided her first, second, and third dams are each sired by a registered standard trotting horse. 
The speed of the trotter is the main factor influencing values, and the speed record of an animal, or its relationship to such, will essentially affect its selling price. As might be expected, foals occasionally change hands at large prices, based on the pedigree and speed records therein. The speed of the trotter has been constantly improved, until the end of 1904 saw records that would not have been thought possible by persons living a generation ago. All of the standard racing records have been materially changed during the nineteenth century. The following statement shows how this record has been lowered between 1810 and 1904, representing horses in harness and not under saddle.

REDUCTION OF TROTTING RECORD

\begin{tabular}{|c|c|c|c|c|c|c|c|c|}
\hline NaMe of & & orst & & & & Place of ReCord & Date & ReCORD \\
\hline Boston. & . & . & . & . & . & Philadelphia, Pa. & Aug. 25,1810 & $2.48 \frac{1}{2}$ \\
\hline Trouble . & & . & 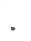 & . & & Jamaica, N.Y. & Oct. 3,1826 & $2.43 \frac{1}{2}$ \\
\hline Sally Miller . & . & . & . & . & . & Philadelphia, Pa. & Nov. 21,1834 & 2.37 \\
\hline Edwin Forrest & . & - & . & . & . & Philadelphia, Pa. & Oct. 16,1838 & $2.36 \frac{1}{2}$ \\
\hline Dutchman . & . & . & . & . & . & Hoboken, N.J. & July $\quad 18,1839$ & 2.32 \\
\hline Lady Suffolk & . & . & . & . & . & Hoboken, N.J. & Oct. I 3,1845 & $2.29 \frac{1}{2}$ \\
\hline Pelham . . & . & . & . & . & . & Jamaica, N.Y. & July $\quad 2,1849$ & 2.28 \\
\hline Highland Maid & & . & . & . & - & Jamaica, N.Y. & July 14,1853 & 2.27 \\
\hline Flora Temple & . & . & . & . & . & Jamaica, N.Y. & Sept. 2,1856 & $2.24 \frac{1}{2}$ \\
\hline Flora Temple & . & . & . & . & . & Kalamazoo, Mich. & Oct. 15,1859 & $2.19 \frac{3}{4}$ \\
\hline Dexter . . . & & . & . & . & . & Buffalo, N.Y. & Aug. 14,1867 & $2.17 \frac{1}{4}$ \\
\hline Goldsmith Mai & & . & . & . & . & Milwaukee, Wis. & Sept. $6,187 \mathrm{I}$ & 2.17 \\
\hline Goldsmith Mai & & . & - & . & . & Boston, Mass. & Sept. $\quad 2,1874$ & 2.14 \\
\hline Rarus . . . & . & . & . & . & . & Buffalo, N.Y. & Aug. $\quad 3,1878$ & $2.13 \frac{1}{4}$ \\
\hline St. Julien . & . & . & . & . & . & Oakland, Cal. & Oct. 25,1879 & $2.12 \frac{3}{4}$ \\
\hline Maud S. . & . & . & . & . & . & Chicago, Ill. & Sept. 18,1880 & 2.109 \\
\hline Jay-Eye-See . & . & . & . & . & . & Providence, R.I. & Aug. $\quad I, 1884$ & $2.10^{\circ}$ \\
\hline Maud S. . & . & . & . & . & . & Cleveland, Ohio & July 30,1885 & $3.08 \frac{3}{4}$ \\
\hline Sunol . . & ${ }^{\circ}$ & - & . & . & . & Stockton, Cal. & Oct. $20,189 \mathrm{I}$ & $2.08 \frac{1}{1}$ \\
\hline Nancy Hanks & . & . & . & . & . & Terre Haute, Ind. & Sept. 28,1892 & 2.04 \\
\hline Alix. . . & . & . & . & . & $\cdot$ & Galesburg, Ill. & Sept. 19,1894 & 2.03 \\
\hline The Abbot & . & - & . & . & . & Terre Haute, Ind. & Sept. 26,1900 & 2.031 \\
\hline Cresceus . & - & . & . & - & . & Columbus, Ohio & Aug. $\quad 2,1901$ & $2.02 \frac{1}{4}$ \\
\hline Lou Dillon & - & . & . & . & . & Readville, Mass. & Aug. 24,1903 & 2.00 \\
\hline Lou Dillon & . & . & . & . & . & Memphis, Tenn. & Oct. 24,1903 & $1.58 \frac{1}{2}-$ \\
\hline
\end{tabular}

With wind shield. 
Some of the fastest trotting records to January I, I906, are given below. There are numerous standard trotting events, such as against time, in races, double teams, three abreast, half-mile track, mile track, etc. There are many fastest records, of which these are perhaps of most interest.

\begin{tabular}{|c|c|c|c|}
\hline EYENT & NAME OF HORSB & DATE & RECORD \\
\hline Half mile. . . . . & Major Delmar, b.g., by Del Mar . . & 1904 & $.59 \frac{1}{12}$ \\
\hline One mile . . . . & Lou Dillon, ch.m., by Sidney Dillon. & 1903 & I. $58.2 *$ \\
\hline Two miles. . . . & Cresceus, ch.h., by Robert McGregor & 1902 & 4.17 \\
\hline Five miles. . . . & Zambro, br.g., by McKinney . . . & 1902 & I 2.24 \\
\hline Ten miles. . & Pascal, blk.g., by Pascarel . . . & 1893 & 26.15 \\
\hline Twenty miles . . & Capt. McGowan, rn.h., untraced . & I 865 & 58.25 \\
\hline Fifty miles . ' & Ariel, br.m., untraced & 1846 & $3.55 \cdot 40 \frac{1}{2}$ \\
\hline One hundred miles & $\begin{array}{l}\text { Conqueror, b.g., by Latourette Bell- } \\
\text { founder. . . . . . . . . . }\end{array}$ & 1853 & 8.55 .33 \\
\hline $\begin{array}{l}\text { Fastest stallion. . . } \\
\text { Fastest mare. . . . }\end{array}$ & $\begin{array}{l}\text { Cresceus, ch., by Robert McGregor. } \\
\text { Lou Dillon (see above mile record) }\end{array}$ & 1901 & $2.02 \frac{1}{4}$ \\
\hline Fastest gelding . . & Major Delmar, b.g., by Del Mar . . & 1903 & $1.599^{3 *}$ \\
\hline $\begin{array}{l}\text { Fastest yearling colt . } \\
\text { Fastest yearling filly }\end{array}$ & $\begin{array}{l}\text { Adbell, b., by Advertiser } \\
\text { Pansy McGregor, b., by Fergus }\end{array}$ & 1894 & 2.23 \\
\hline new performer, & 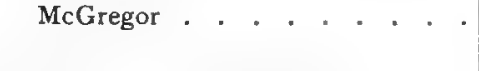 & 1893 & $2.23_{4}^{3}$ \\
\hline $\begin{array}{l}\text { stallion } \\
\text { Fastest new performer, }\end{array}$ & Kinney Lou, by McKinney . . . . & 1903 & $2.07 \frac{3}{4}$ \\
\hline mare $\cdot$ astest new performer, & Lou Dillon . . . . . . . . . & 1903 & $1.50_{2}^{1,1}$ \\
\hline $\begin{array}{l}\text { gelding } \\
\text { Trotting to wagon, one }\end{array}$ & Lord Derby, b., by Mambrino King . & 1900 & 2.07 \\
\hline mile $\cdot \cdot \cdot \cdot \cdot \cdot$ & Lou Dillon . . . . . . . . : & 1903 & 2.00 \\
\hline Double team, one mile & $\begin{array}{l}\text { The Monk, br.g., by Chimes; and } \\
\text { Equity, blk.g., by Heir-at-Law . : } \\
\text { Belle Hamlin, br.m., Globe, br.g.; and }\end{array}$ & 1904 & $2.07 \frac{3}{4}$ \\
\hline & Justina, b.m. . . . . . . . . & I 891 & 2.14 \\
\hline
\end{tabular}

Important sires of both trotters and pacers are listed in considerable numbers. There is no great trotter or pacer of breeding prepotency, with an extended list of offspring, but what has sired some animals that were natural trotters and some pacers. Most prominent among the stallions that have sired 2.15 per-

* With wind shield. 
formers up to January I, 1906, are the following, selected from a list of about two thousand: Alcantara 2.23, by George Wilkes 2.22; Baron Wilkes 2.18, by George Wilkes 2.22 ; Brown Hal $2.12 \frac{1}{2}$, by Tom Hal; Chimes 2.303, by Electioneer; Electioneer, by Hambletonian 10; George Wilkes 2.22, by Hambletonian 10;

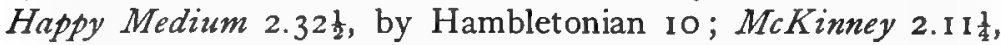
by Alcyone 2.27; Onward 2.25 Wilkes 2.40, by George Wilkes 2.22; Robert McGregor 2.17t, by Major Edsall 2.29; Simmons 2.28, by George Wilkes 2.22.

The list of famous American trotting or pacing brood mares is a very long one, there being over four thousand of more or less distinction at this time. Three of these mares well deserve to be placed at the head of this list.

Beautiful Bells, by The Moor, dam Minnehaha, was foaled in 1872 . She was bred by L. J. Rose in California, though owned at Palo Alto by Leland Stanford, where she dropped her first foal in 1880 to the service of Electioneer. She produced trotters of great merit, either by Electioneer or his sons. On her sire's side she was a Pilot, on the dam's a Mambrino.

Green Mountain Maid was foaled in I 862. She was bred by Samuel Conklin of Middletown, New York. Her sire was Harry Clay, dam Shanghai Mary. She was a brown mare with star and white hind ankles, and stood I 5 hands high. At the Stony Ford Farm of Charles Backman she spent most of the twenty-six years of her life, dying in 1888. Her greatest son was Electioneer, one of America's most prepotent sires. Green Mountain Maid was the dam of sixteen foals. In memory of this mare, a red granite monument was erected in I 889 by $\mathrm{Mr}$. Backman, "on the spot dedicated to her worth and honored by her dust."

Miss Russell, a gray mare foaled in 1865 , bred by R. A. Alexander at Woodburn, Kentucky, is the third worthy. She was sired by Pilot Jr., and out of Sally Russell by Boston, and her fifth dam was by the great imported Thoroughbred, Diomed. Miss Russell was the dam of eighteen foals. Nutwood, by Belmont, her first foal, was her greatest son, he siring 133 trotters and 35 pacers, while Maud S. by Harold, was her most famous daughter. 


\section{CHAPTER VII}

\section{THE PACER}

The ancestry of the pacer does not differ from that of the trotter. The distinguishing difference between them, if any, depends upon the gait. However, the same horse may pace on one occasion and trot on another.

The pace consists in the two legs on one side being moved forward at about the same time, thus presenting a sort of parallel movement. The horse naturally paces when his body is hardly long enough to permit of a free diagonal movement without interference of the feet. The pace provides a freer movement.

The trot consists in moving forward at much the same time front and rear opposite limbs, as, for example, the left front leg and the right hind leg. On account of the special leg movement, as exhibited by the gait, the pacer is often referred to as a "side wheeler," or "racker," while the trotter is called "diagonalgaited." The pace involves more of a swaying movement than the trot and is much less popular than the smoother moving trot.

The trot and pace are interchangeable, and numerous race horses possess each gait. The stallion Direct, with a pacing record of $2.05 \frac{1}{2}$, also had a trotting record, as a four-year-old, of 2. I 81 . Brown $\mathrm{Hal}$, a great pacing sire, also has a trotting record. John R. Gentry $2.00 \frac{1}{2}$, a standard-bred trotter, is a very fast pacer and a sire of pacers. Jay-Eye-See was first a trotter at 2.10 and later a pacer at $2.05 \frac{1}{4}$. Most horses naturally have one gait, but many of them are easily taught the other. Hamilton Busby states that he has seen the late Robert Bonner, the well-known light-horse enthusiast and student of equine form and foot ballast, take a pacing colt and in a few minutes change it to a trotter by simply changing the bearing of its heels. The pace is the faster gait of the two, being regarded as about three seconds faster than the trot. 
The conformation of the pacing horse often shows a steepness of croup and curving of hocks which appear to be more or less associated with the gait, though not necessarily so. Some of the most famous pacers in American racing history have had this peculiar conformation which, to say the least, is not beautiful.

The pacing standard, as established by the American Trotting Register Association, is the same as the existing trotting standard. Except that the word "pacer" is substituted for the word "trotter," the word "pacing" for the word "trotting," and the

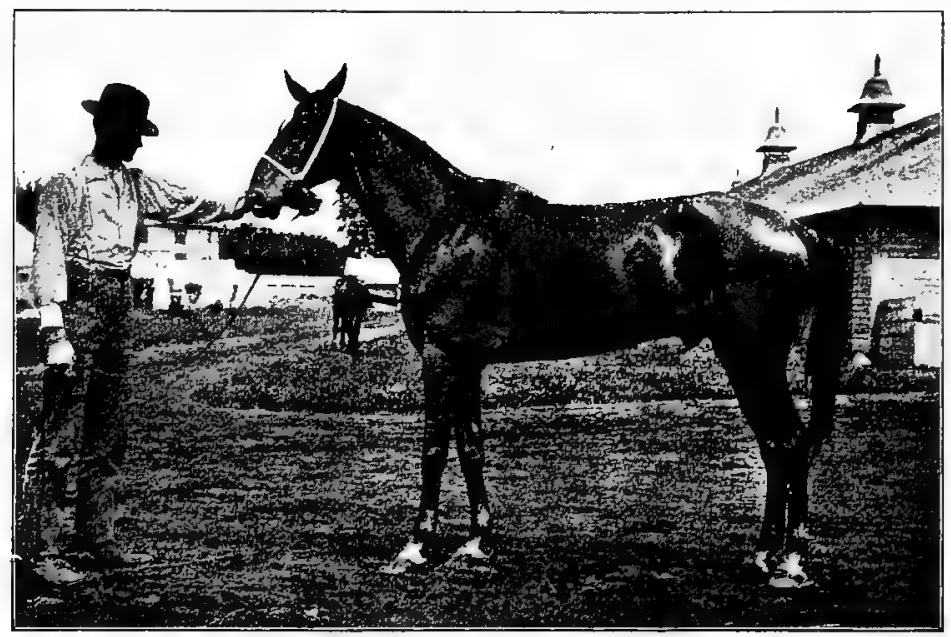

FIG. 15. Dan R. One of the fastest recent pacers, with a record of 2.018 in 1903 , and credited with the fastest heat of that year. Photograph from National Stockman and Farmer

speed standard 2.25 for 2.30 , the first five paragraphs of official trotting and pacing standards are alike. The pacing standard, however, has a sixth paragraph, which is as follows:

6. The progeny of a registered standard trotting horse out of a registered standard pacing mare, or of a registered standard pacing horse out of a registered trotting mare.

This last paragraph brings out the interesting point in an offi-cial way, that the result of the union of a pacer and trotter may create a standard-bred pacer. 
Pacing records now receive much attention from the public, although in early days the trot was the greater favorite of the two, especially prior to I 860 . The following table shows how the pacing record has been reduced since $\mathrm{i} 839$.

Reduction of Pacing Record to January i, I 906

\begin{tabular}{|c|c|c|c|c|c|c|c|c|c|c|c|}
\hline NAML & $E$ or & F & Hor & & & & & & Plack of Record & DATE & Recond \\
\hline Drover . . & . & . & • & - & * & • & - & & New Jersey & 1839 & 2.28 \\
\hline Fanny Ellsler & . & & . & . & • & . & . & & Albany, N.Y. & 1844 & $2.27 \frac{1}{2}$ \\
\hline Unknown . & - & • & - & - & - & - & - & & New Jersey & 1844 & 2.23 \\
\hline Pet. . . & . & . & . & . & . & . & - & & Long Island, N.Y. & 1852 & $2.18 \frac{1}{2}$ \\
\hline Pocahontas & - & - & . & . & . & - & - & & Long Island, N.Y. & 1855 & $2.17 \frac{1}{2}$ \\
\hline Sleepy George & . & . & . & . & - & - & - & & Rochester, N.Y. & 1879 & $2.15^{\frac{1}{2}}$ \\
\hline Sleepy Tom . & . & . & . & . & • & . & . & & Chicago, Ill. & 1879 & $2.12 \frac{1}{4}$ \\
\hline Little Brown Ju & & - & . & - & • & . & . & . & Hartford, Conn.' & $188 \mathrm{I}$ & $2.11 \frac{1}{2}$ \\
\hline Johnston . . & . & & . & . & & . & . & & Chicago, Ill. & 1884 & $2.06 \frac{1}{4}$ \\
\hline Direct . . & - & ${ }^{\circ}$ & - & 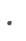 & & - & - & & Independence, Iowa & 1891 & 2.06 \\
\hline Hal Pointer . & - & . & . & . & • & - & • & & Chicago, Ill. & 1892 & $2.05 \frac{1}{4}$ \\
\hline Mascot . . & . & . & . & . & ${ }^{*}$ & - & - & & Terre Haute, Ind. & 1892 & 2.04 \\
\hline Robert J. . . & - & . & - & - & $\theta^{\circ}$ & - & - & & Terre Haute, Ind. & 1894 & $2.01 \frac{1}{2}$ \\
\hline John R. Gentry & & & . & • & ${ }^{\circ}$ & . & - & & Portland, Me. & I8g6 & $2.00 \frac{1}{2}$ \\
\hline Star Pointer. & . & - & . & 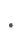 & • & . & . & & Readville, Mass. & I 897 & I. $59_{1}^{1}$ \\
\hline Prince Alert . & - & . & . & - & • & - & - & & Empire City Track, N.Y. & 1904 & $1.57^{*}$ \\
\hline Dan Patch. & . & & . & . & - & . & - & & Memphis, Tenn. & 1905 & I. $551 *$ \\
\hline
\end{tabular}

Some of the Fastest Pacing Records to January i, igo6

\begin{tabular}{|c|c|c|c|c|c|}
\hline EVENT & Name of Horse & & & DATE & RECORD \\
\hline . . . . . & Dan Patch, by Joe Patchen & & & 1903 & $.56 *$ \\
\hline One mile. . . & Dan Patch, by Joe Patchen & - & & 1905 & $1.55 \frac{1}{4} *$ \\
\hline Fastest heat, stallion & Star Pointer, by Brown Hal & . & & 1897 & $2.00 \frac{1}{2}$ \\
\hline Fastest heat, gelding & Prince Alert, by Crown Prince & 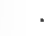 & & 1901 & $2.00 \frac{3}{4}$ \\
\hline Fastest heat, mare . & The Broncho, by Stormcliffe & . & & 1905 & $2.03 \frac{1}{4}$ \\
\hline $\begin{array}{l}\text { Fastest heat, four-year- } \\
\text { old . . . . }\end{array}$ & Searchlight, by Dark Night. & . & & 1898 & $2.04^{\frac{1}{2}}$ \\
\hline $\begin{array}{l}\text { One mile to high wheel } \\
\text { One mile with running }\end{array}$ & Dan Patch . . . . . & & & 1903 & $2.04 \frac{3}{4} *$ \\
\hline mate . . . . & Flying Jib, by Algona. . & & & I 894 & $1.58 \frac{1}{4}$ \\
\hline $\begin{array}{l}\text { Three miles to wagon } \\
\text { One mile on half-mile }\end{array}$ & Longfellow, by Red Bill . & . & 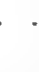 & 1868 & 7.53 \\
\hline track . & Dan Patch & - & - & 1905 & $2.01 *$ \\
\hline
\end{tabular}

* Wind shield and pace maker in front. 
Money-winning trotting or pacing families. During 1904, according to the American Horse Breeder, I 50 sires were represented by money-winning performers on the Grand Circuit. Of these, 128 , or $85 \frac{1}{3}$ per cent, trace back through the male line to Hambletonian Io; while $7 \mathrm{I}$, or 47.3 per cent, trace back to Hambletonian's greatest son, George Wilkes, he having I 4 sons, 44 grandsons, and I 3 great-grandsons among the winning sires. These descendants of George Wilkes won a total of $\$ 243,682$, or more than half of all the money won during the season. Total winnings credited to descendants of Hambletonian were $\$ 407,084$ as against a grand total of $\$ 464,847$.

The following is the summary:

\begin{tabular}{|c|c|c|c|c|c|c|c|c|}
\hline Familie & & & & & $\begin{array}{l}\text { Total } \\
\text { Sires }\end{array}$ & Per cent & $\begin{array}{c}\text { Torral } \\
\text { WINNINGS }\end{array}$ & Prk CEnt \\
\hline Hambletonian 10. & . & . & . & . & 128 & 85.33 & $\$ 407,084$ & 87.6 \\
\hline Mambrino Chief. & . & - & - & . & 9 & 6.00 & I 8,4 I 5 & 3.9 \\
\hline Tom Hal . . & . & . & . & . & 6 & 4.00 & 31,960 & 6.9 \\
\hline Pocahontas Boy & . & . & . & . & 2 & I. 33 & $\mathbf{I}, 875$ & .4 \\
\hline Miscellaneous & . & . & . & . & 5 & $3 \cdot 33$ & 5,513 & 1.2 \\
\hline Total & $\cdot$ & . & - & - & 150 & 100.00 & $\$ 464,847$ & 100.0 \\
\hline
\end{tabular}

The number of record-making horses listed among those standard-bred is very large and is constantly and rapidly increasing. At the close of the year 1904 there were 20,282 trotters in the 2.30 list, and 11,745 pacers in the 2.25 list.

The prices paid for standard-bred horses represent in some cases remarkable valuations, while a long list might be given of animals that have changed hands at $\$ 10,000$ or more each. The highest price ever paid for a trotter was \$25,000, paid by $\mathrm{Mr}$. J. Malcolm Forbes of Boston for Arion 2.07妾, by Electioneer. In I 905 , at a sale at Madison Square Garden, Mr. M. W. Savage of Minneapolis purchased Arion for $\$ 2500$. The trotting stallion Axtell 2.12, by William L., was purchased by a company at Terre Haute, Indiana, for $\$ 105,000$. Dan Patch 1.55 , the great pacing horse, was purchased for $\$ 60,000$ by Mr. M. W. Savage, who has since refused $\$ 180,000$ for him. Among other 
notable prices paid for standard-bred horses are the following: Nancy Hanks, $\$ 45,000 ;$ Sunol, \$4I,000; Maud S., \$40,000; Mascot, $\$ 26,000$.

Successful drivers of light harness horses must be men of exemplary habits, and must, in order to accomplish results, possess the keenest knowledge of the temperament and capacity of the horse. Among the famous drivers of America may be mentioned Ed. Geers, Budd Doble, John Splan, Charles Marvin,

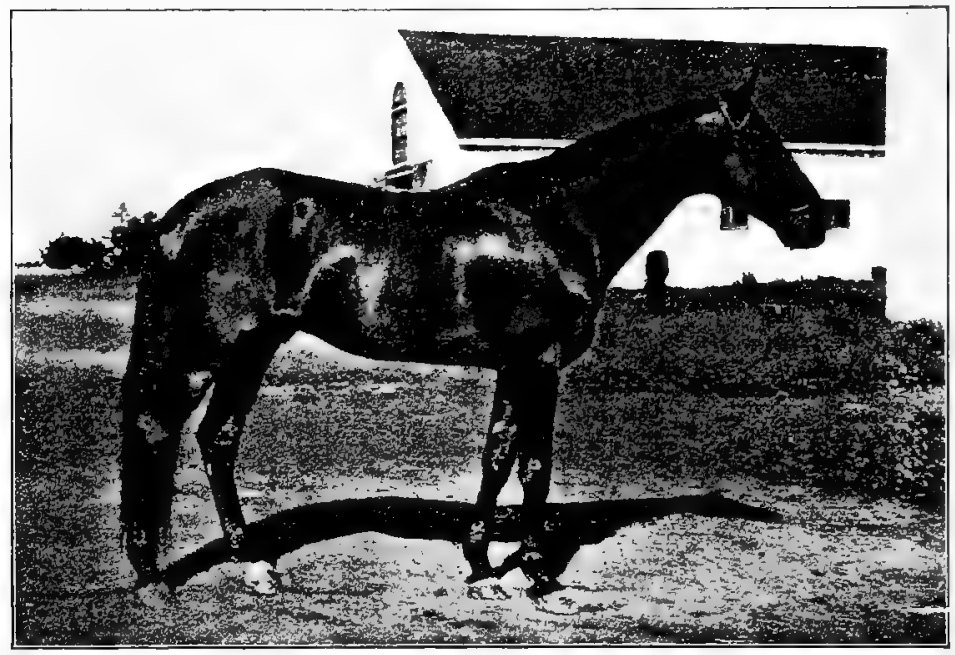

FIG. I6. Elastic Pointer, a pacer with record of $2.06 \frac{1}{2}$. A full brother of Star

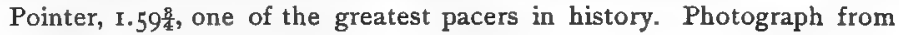
National Stockman and Farmer

Alonzo and Alta McDonald, W. J. Andrews, Al. Thomas, Chas. De Ryder, and George Spear. In 1905 the following sums were won in races by successful drivers: Ed. Geers, $\$ 32,004$; Lon McDonald, $\$ 27,160 ;$ T. Murphy, $\$ 16,920 ; A 1$. Thomas, $\$ 16$, I 48 . 


\section{CHAPTER VIII}

\section{THE ORLOFF TROTTER}

This breed is comparatively unknown in America, being of Russian origin and not much bred outside of that country.

The origin of the Orloff dates back to 1780 . Count A. G. Orloff-Tschesminsky, from whom the breed takes its name, made a journey to Constantinople in 1780 as the emissary of Cath erine II of Rússia. The Sultan of Turkey sent back to Russia a gift of the Arab stallion Smetanka, an animal of superior breeding and unusual size and strength. This Arab was bred to a Danish mare, from which came a horse foal that was named Polkan Ist. The result of this union, bred to a big Dutch mare known as a "Hartdraver," produced another male foal, which was designated Bars Ist, which is regarded as the first representative of the true Orloff breed of trotters. While in the evolution of the breed outcrosses with mares have been made, the line of descent from Bars Ist on the sire's side has been in-efully guarded.

The characteristics of the 0rloff are of a variable nature, as based on those shown in America. Mr. Jacob Heyl thus concisely describes the Orloff : 1

In the first thirty years of our century (nineteenth) the Orloff trotters showed such pronounced type that it was difficult to distinguish one from another. The average height of the Orloff horse of to-day is from $15 \frac{3}{4}$ to 16 hands. To the casual observer they hardly give the impression of great quality, - at least not such as would warrant the presumption of extraordinary performances.

The head is small and clean, the face wide between the eyes and almost invariably dished. The ears are small, the eyes large and full, though somewhat sleepy when the horse is at rest. The neck is well connected, but inclined to be a trifle thick in the throat, arched beautifully, and carried very high, rising high from the withers. Owing to the rise of the withers,

1 Breeders' Gazette, August 16, 1893. 
the back, which is short and strong, appears slightly swayed and runs into broad, full loins. The croup has a peculiar rounding and is somewhat sloping. It is supplied with clearly defined layers of muscles, from which the horse derives its great propelling power. The shoulders are quite sloping and well muscled without being heavy. Fore arm and thigh show plenty of muscle and great length, while the cannons are correspondingly short, with an abundance of bone below the knee and hock. In standing the legs are generally carried well under the body. Forelock, mane, and tail show

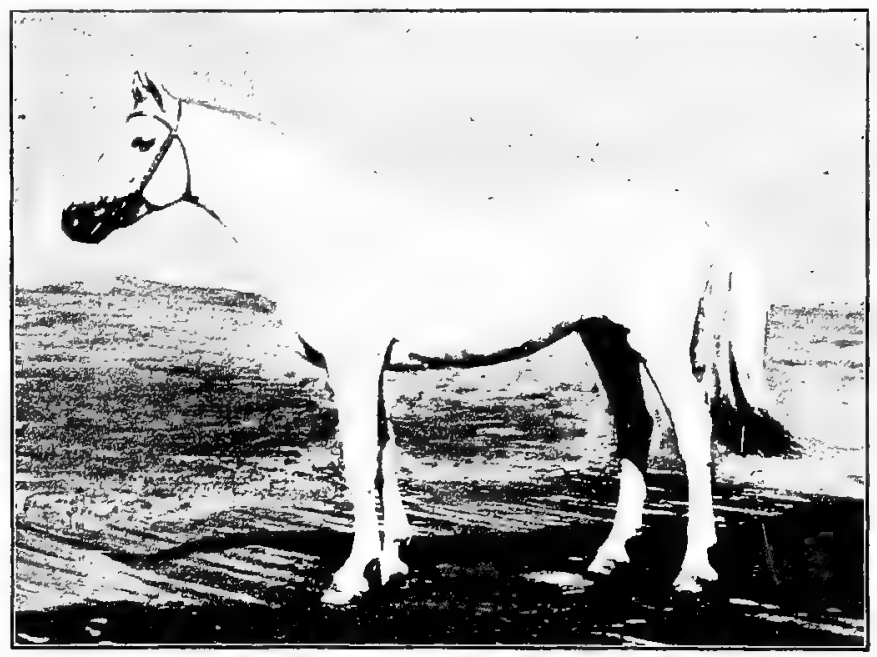

FIG. 17. Oussan. An Orloff trotter shown at Columbian Exposition, Chicago, 1893. Commended for perfect form, size, and speed. Owned by the Grand Duke Dimitri of Russia

a rich growth of medium fine hair, inclined to be wavy. A peculiarity is the growth of fine, long hair on the fetlocks, which seems to act as a protection in deep snow.

The general appearance of the Orloff when at rest is that of an animal of good size and substantial build, perhaps a trifle leggy on account of the proportionately small rump as compared with shoulders and hind quarters, and a faint suggestion of coarseness on account of the strong legs and full hoofs. The whole appearance changes wonderfully, however, the moment the horse is in motion. Going up on the bit, head carried up and well arched in the neck, ears pointed and constantly playing, nostrils dilated and eyes sparkling, he moves along with determination and the precision of a piece of mechanism. The fore legs are well bent in the knee, the feet almost touching the elbows, while the hind legs are brought forward with great power, striking the ground well in front of the imprints of the fore feet. 
At all times the horse seems to trot within himself and be in perfect balance without outward aid.

The disposition of the Orloff is perfect and his docility admirable; he is a free, fearless driver. . . . He is a horse of great endurance, trotting mile after mile without any apparent fatigue.

The above description is given by one who has not only studied the animals of this breed in Russia but who has also imported and owned them in America.

There are apparently several types of Orloffs. Mr. M. W. Dunham, who judged this breed at the Columbian Exposition in I893, reports on the heavy type of Russian trotter, weighing

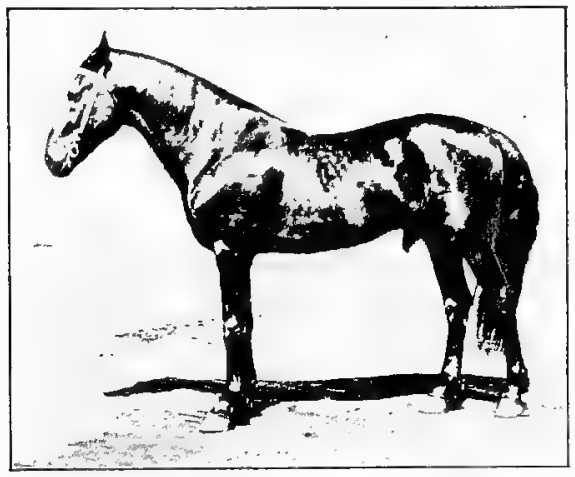

FIG. 18. Ouriadnik. First-prize Orloff trotter at Columbian Exposition, 1893, in class of six judged by Mr. M. W. Dunham. Owned by Russian State Stud from I 100 to I 300 pounds and standing from $15 \frac{3}{4}$ to I $6 \frac{1}{2}$ hands high; he also reports on a lighter, finer sort. Though credited with great power and speed, some of the fastest ones have degenerated into a coarseness of form not sought after by American buyers. The lighter type is criticised by American judges as rather too long of back and sloping of quarters, and as having a higher knee action and less speed than the American trotter. They are commended as having great beauty of head, neck, and shoulders, and as possessing much intelligence and endurance, besides considerable speed. Yet they are too much like the American trotter to be wanted here.

The color of the Orloff is quite commonly gray, white, or black, yet chestnuts and bays occur.

Importations of Orloffs have been made to America on several occasions. In the spring of 1877 four stallions and one mare were brought over and sold at auction on October I3, all being bid in by Lieutenant Ismailoff of the Russian army, at prices 
ranging from $\$ 300$ to $\$ 995$. In 1890 Jacob Heyl, of Wisconsin, imported two black stallions, and in 1892 two stallions and four mares. That same year F. G. Bourne imported five stallions and one mare, while on July 25, I 893, eighteen head were imported, for showing at the Columbian Exposition. On April IO, I902, after spirited bidding, twenty-eight Orloffs, imported by Bergh \& Company, were sold at auction in the American Horse Exchange for an average price of $\$$ I 243 . With the exception of one chestnut, all of these were blacks or grays. The highest price paid was $\$ 6400$ for a pair of matched drivers.

The speed of the Orloff is most excellent, but not the equal of the American trotter. The gray Orloff, Wzmakb, imported by Jacob Heyl, has a record for a mile in $2.27 \frac{3}{4}$. In $1893 \mathrm{Mr}$. J. H. Sanders gave the fastest Russian record of 1.40 for one verst (3500 feet) as made by the Orloff trotter Poitieshnoy, equivalent to a mile record of a trifle under 2.3 I. In short-distance races the record of the Russian trotter is inferior to the American, but on long stretches of three or more miles he is distinctly the superior.

A cross of the Orloff and the American trotter seems to have been attended with excellent results. In recent years trotters have been taken to Russia from America, and the cross-bred progeny has shown superior speed, especially where the dam was the Orloff. In fact the half-bred offspring has shown greater speed as a rule than the sire. 


\section{CHAPTER IX}

\section{THE COACH OR CARRIAGE HORSE TYPE}

The coach or carriage horse is also frequently called the heavy harness horse. This type is intended for the special purpose of drawing coaches and other vehicles, such as may be commonly seen in every city of importance. It is also of value in light work where a larger type than the American trotter is wanted. A certain size and conformation generally found in the coach breeds are associated with this type. The American trotter of the larger size may, however, furnish the essentials needed in a high-class coach horse.

The general appearance of a coach horse in good condition shows smooth, graceful body lines, with a general fullness in all the parts. The height should be about $\mathrm{I} 6$ hands and the weight from I 100 to 1250 pounds for geldings or mares. Stallions will usually range from $\mathrm{I} 250$ to 1550 , according to breed. In quality the coacher should be superior, showing the best of feet, bone, and hair. Action of the very best, high and strong at both knee and hock, is important, while graceful carriage is equally essential. In general appearance the best type of coach horse shows a long arching neck, round full body, long level croup, high carriage of tail, and what is known as a "coachy" or "trappy" action.

The head of the coach horse should be lean, graceful, broad of forehead, rather prominent and bright of eye, deep of cheek, and wide and strong in lower jaw, the muzzle fine and nostrils full and open, the ears refined, being neither large nor small, carried close and erect, and turning in slightly at the tips. The head should indicate quality in its leanness, intelligence in the broad, full forehead, and animation in brightness of eye and carriage of ear and head in general. A smooth, neat attachment of head to neck is highly essential, a fullness at the throat and about the windpipe being most undesirable. 
The neck of the coach horse in its best development may appear somewhat long, is gracefully arched, and shows a smooth, full, muscular development, yet is entirely free from thickness of draft-horse character. A ewe neck is out of place in this class. Much of the style and symmetry of the coach horse at rest is seen in the carriage and make-up of head and neck. In its attachment to the body the neck should blend smoothly.

The chest of the coach horse calls for neither the thickness of the draft horse nor the narrowness of the Thoroughbred, but for a happy medium. It should be deep, and the breast should be carried out with some prominence. Too broad a chest prevents an open, free action.

The shoulders of the coach horse are long and oblique, sloping well into the back, with withers medium prominent and refined. A steep shoulder prevents a strong, rapid gait and promotes hard action, leading to defects of feet and legs. High or free knee action is dependent on a long, well-laid, muscular shoulder. The long shoulder, the short back, and the long underline are features associated with the best development.

The body of the coach horse should be round, short on top and long below, the ribs being long and well arched and the back and loin covered smoothly with strong, thick muscle. The loin in particular calls for strength, as indicated in levelness, breadth, and thickness. Depth of body at both front and hind flanks is desirable, with not too much prominence and overshadowing of hips.

The croup of the coach horse furnishes the power at the hind end. It should be long, broad, carried high, and thickly muscled. A steep, short croup is inconsistent with a beautiful coacher. The tail should have a high attachment, and should be carried with style and elevation.

The thighs and quarters of the coach horse must be muscular and plump, furnishing fullness of outline. The muscle of the thighs at the quarters must be thick and deep, giving fullness to the hind end. The gaskin, or lower thigh, should be strongly muscled and long.

The hocks of the coach horse, viewed from one side, should be deep from front to rear; the front should be broad and the 
rear thin, the entire joint being lean and smooth, with no puffiness or coarseness. The action so essential in a coach horse can only be found in a normal, smooth, and strong hock.

The legs of the coach horse, as a whole, must show cleanness, good bone, and plenty of muscle. The arm must be short, broad, and flat, with great muscle development. The elbows should stand out showing room between the legs and chest, indicating easy moving power. If the elbow is too close to allow the easy insertion of the hand between that and the body, the legs will not

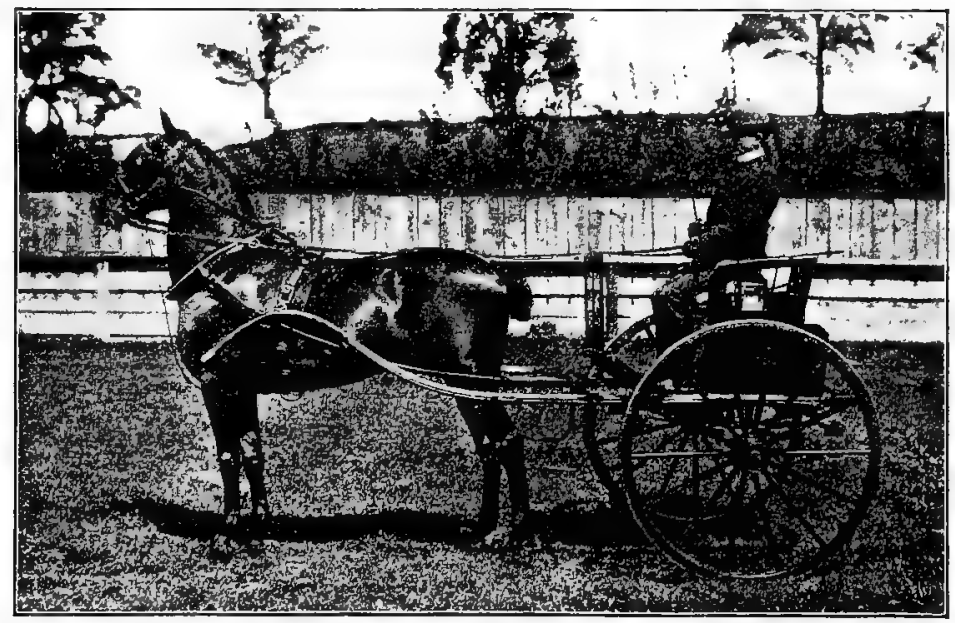

FIG. 19. Glorious Red Cloud. A nearly perfect specimen of a standard-bred American trotter in heavy harness as a coach horse. Owned by Thomas W. Lawson of Boston, Massachusetts. Photograph by Schreiber from National Stockman and Farmer

stand straight and the front toes will turn out, while if the elbow is too far from the body, the opposite result will obtain, in either case giving an awkward movement. The fore arm should be very long and strongly muscled, wide at top, and tapering gracefully downward. The knee in its strength is broad in front and narrow behind, is full and prominent, and strongly attached both above and below. Sometimes the knees come too close together, often they are crooked, and occasionally they project too far over the cannon bones. The cannons, both front and rear, should be flat, 
smooth, short, and strongly attached above and below. The tendons which pass along behind should stand out clear and strong, thus giving depth to the leg at this point. As the hand is passed down over the cannons no unnecessary roughness should be felt. Under both knee and hock the cannons should be deep, showing a strong attachment at these joints. The fetlock should be strong and placed straight and should be free from fleshiness. The pasterns should stand at an angle of about 45 degrees with the floor, and be long, smooth, and springy. As the horse stands naturally the pasterns should be well sustained, with no tendency to drop low and appear weak. If the pastern is short or straight, an easy gait cannot be assumed and the conditions promote foot and leg cliseases. A correct pastern at 45 degrees allows the proper placing of the foot, the frog striking first with the resulting jar or concussion less than it would be otherwise. The feet are most important, and a capable judge of the horse will give them almost a first consideration. These should be of suitable size, round, wide at top, well developed at heel, and preferably of dark, hard bone. Ample size is important, for a small foot in the horse presages trouble. The hind part, or heel, should be wide and of reasonable depth, a low heel and flat foot being associated with poor feet. The bottom of the foot, or sole, should be concave and well arched. In a well-formed foot the frog should be wide at the heel, be strongly developed, and just touch the ground when the horse is at rest. Passing about the frog in a continuation of the wall of the hoof from behind is the bar of the foot. This bar helps to hold the sole of the foot together, and should be strong and show character. The front feet are usually rounder than the hind, and they are also more subject to injury and are more commonly defective than the hind feet.

The proper position of the legs of the horse when at rest may be noted as follows: Front leg. A plumb line dropped from point of shoulders will bisect the knee, cannon, pastern, and foot, viewed from the front. From the side, dropped from the center of the arm at the lower part of the body, such a line should about divide the leg to the fetlock joint, and then, passing to the ground, should just touch the back part of the foot. Hind 
leg. From the rear, a plumb line dropped from point of croup or buttock will pass the center of hock, cannon, pastern, and foot. Viewed from the side, if dropped from point of croup or buttock, it should touch the point of hock and pass along close against the back edge of the cannon and parallel with it.

Action in the coach horse is an absolute requirement. People vary in the degree to which they desire this. The lover of the Hackney desires a rather high, bold knee action of a flashy sort, with a notable elevation of the foot at its highest point. The hind legs have a powerful movement, the hocks are strongly bent or flexed, and the legs are carried well up under the body. This is what is known as a "trappy gait," and such a horse is a "high stepper." The coach horse possessing such a movement is in great demand. in the horse market, and brings the highest price, other things being equal. Such a gait is not consistent with the best speed, and wise lovers of the horse prefer less high action and more reach and power. Further, with high knee action comes a greater concussion to limbs and feet, and consequently greater punishment and more rapid wearing out of the horse than would otherwise be the case. Especially is this true on the city pavement. Trueness of action is essential, whether a high stepper or not, the legs being carried forward in the same general line and the feet moved neither in nor out. The hocks should be firm and not show weakness, as springing wide apart when in action, and the feet should be held true, neither turning in nor out at the toes. When either at walk or trot the horse should pass from or come toward the judge on the same true line, without sidewise gait, dragging feet, paddling, clicking, etc. Straight and regular movement should be sought for. Ordinarily a coach horse is expected to have a speed of about eight or ten miles an hour.

Sub-classes of coach horses. On account of the requirements of city trade in particular, in relation to the size and use of various vehicles, the coach horse is divided into groups. This classification only occurs, however, in the important horse shows and in the exclusive trade of the city dealer. Pure-bred coach horses, as a rule, do not come within these sub-classes when of the smaller type, though the Hackney may furnish an exception. 


\section{CHAPTER $\mathrm{X}$}

\section{THE HACKNEY}

The word " Hackney" has long been in use in Great Britain. The Norman invaders in the eleventh century brought from France the term Haquenée or Hacquenée, which is derived from the Latin equus, horse. As early as 1303 this word is said to have come into active use. This same century Chaucer in his writings refers to the hakeney or hacknay, spelling it both ways. Prior to the eleventh century it is supposed that the word "nag" (from the Anglo-Saxon knegan, neigh) was the common term in reference to the saddle horse of light type. Since those early days the words "nag" and "Hackney" have been in common use.

The early British home of the Hackney was mainly located in eastern and northeastern England, in the counties of Suffolk, Norfolk, and York. The people in this region have for centuries greatly patronized the saddle horse or roadster. In the fifteenth century trotting horses were highly esteemed, and one of the family of Berney in Norfolk placed on one of his horses an estimate equivalent to $\$ 350$.

The original Hackney stock was subjected to variable influences. The Romans no doubt introduced horses from southern Europe, and these must have bred with the native English stock. Following them came Scandinavian intruders, and it is assumed that Norwegian ponies were used in the mixture, giving British horse stock both speed and endurance. The abundance of trotting horses in sections occupied by Danish settlers would indicate the popularity of this type. Besides the commingling of different strains of blood, some enactments on horse breeding and development took place by royal decree as far back as 1495 , when Henry VIII was on the throne. In 1558 Ralph Blundeville, of Norfolk, produced the first English book on the horse, which he designated, The Foure Chiefest Offices belonging to Horsemanship. 
The active development of Hackneys really began in the eighteenth century. In Norfolk there frequently appeared in the papers advertisements regarding horses for sale or breeding purposes, various animals being named specifically. These statements showed the use of Arabian, Barb, and Turkish stallions

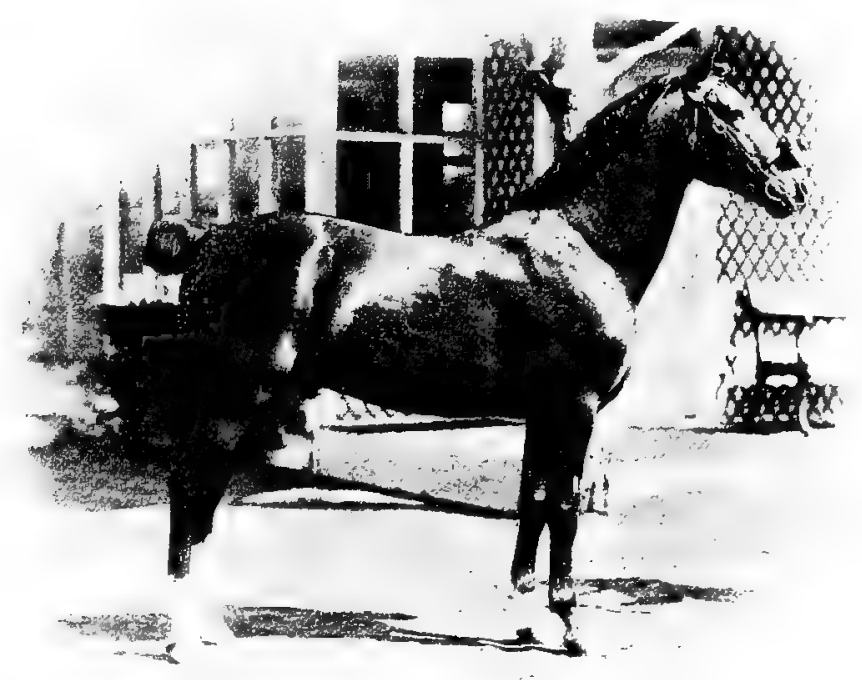

FIG. 20. Royal Danegelt (5785), by Danegelt (174). One of the most famous Hackney show horses and sires of England in recent years Owned and bred by Sir Walter Gilbey, Bart., England. Photograph from Sir Walter Gilbey

on Norfolk mares. Undoubtedly the road horses of Norfolk and Suffolk were much appreciated for speed, and any blood that would contribute to this purpose and not injure stamina was used. Thus the Thoroughbred also played a part in early Hackney development.

The important evolution of the Hackney probably began with a horse known under a variety of names, viz. Schales, Shales, The Original Shales, and Shields. This stallion was foaled in - I755 and was probably sired by Blaze, a son of Flying Childers. In the breeding of this horse, registered in the first volume of 
the Englisl Hackney Studbook as The Original Shales (699), occurs Arabian, Turk, and Barb blood. He is but four generations from the Darley Arabian. The Original Shales sired among others one son, Scot Shales (692), and he proved a great breeder, although not famous for speed. He was famous for getting "good stock out of common mares." In I 782 he was "justly esteemed the best stallion known to get good road horses." The Original Shales was also sire of Driver (187) that proved a great breeder. Coming along after these, as important factors in Hackney development and history, were the following: Fireaway (201) (Jenkinson's), foaled in I 780; Fireaway (203) (West's); Fireaway (2 I I) (Flanders); Pretender (596) (Wroot's); Fireaway

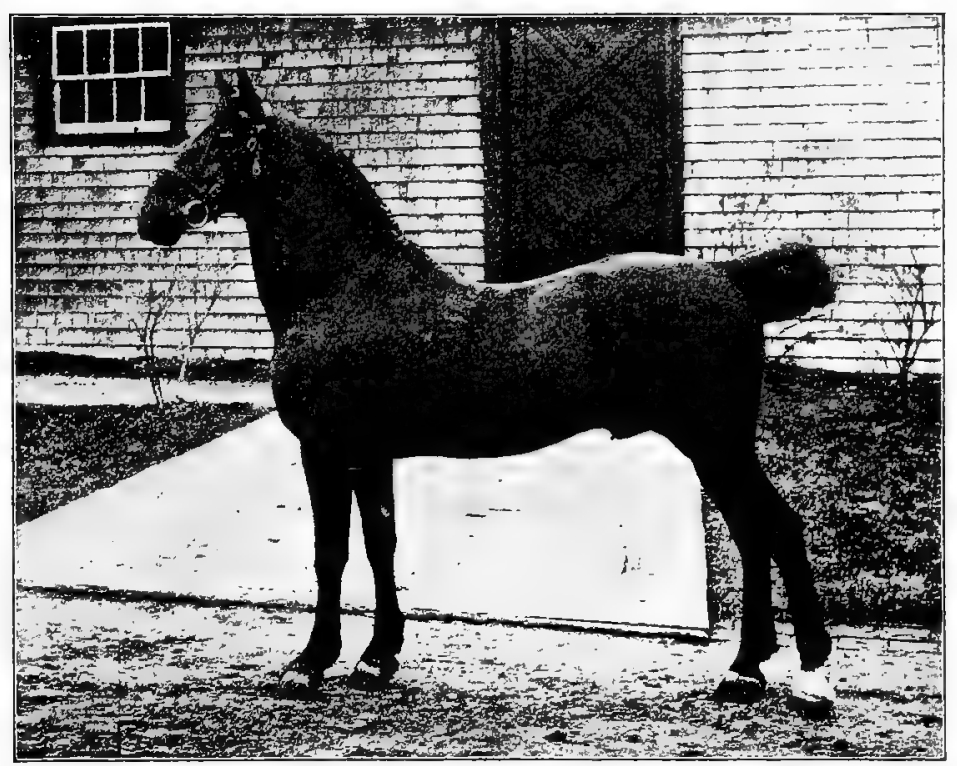

FIG. 2I. Lord Denby II, a Hackney stallion that has sired some of the choice show horses of the breed. Owned by Eben D. Jordan, Boston, Massachusetts. Photograph from Mr. Jordan

(208) (Burgess); Bellifounder (52) (Steven's); Bellfounder (55) (Jary's), imported to America in I822; Wildfire (864) (Ramsdale's); The Norfolk Cob (475); The Norfolk Phenomenon (522); Phenomenon (573) (Ramsdale's) foaled in I835; Sir Charles 
(Beal's 768), foaled in 1843; Denmark (Bourdas' 177 ), foaled in I 862 ; Danegelt ( 174 ), foaled in 1879 , and died in I 894 . During the past fifty years the blood of Denmark and Danegelt has been most potent in Hackney history. Perhaps the five sires of most importance in the last quarter of the nineteenth century were Lord Derby 2d, Bourdas' Denmark, Triffitt's Fireaway, D'Oyley's Confidence, and Danegelt.

Speed and endurance have always been important Hackney characteristics. Driver ( 187 ) is said to have trotted 17 miles in one hour, while Fireaway (20I), old advertisements state, made 2 miles on the road in 5 minutes. The Norfolk Cob is said to have trotted 24 miles in one hour. The famous mare Phenomena, in June, I 800 , at twelve years of age, trotted I 7 miles on the Huntingdon road in 56 minutes, and again in July in less than 53 minutes. In $18 \mathrm{I}$, when twenty-three years of age, she trotted 9 miles in 28 minutes 30 seconds. The Hackney in early days was ridden to the saddle and so carried loads, often of weight approximating 200 . pounds. During hot July weather, John A. Logan, Jr., drove a pair of Hackney mares, hitched to a twoseated buckboard, 94 miles in two days along the Hudson River and made the last 23 miles in I hour and 53 minutes.

The Hackney in America dates back to I 822, when James Booth, of Boston, imported from Liverpool, Bellfounder (55) (Jary's), commonly known as Imported Bellfounder. He was sired by Bellfounder ( 52 ), with Pretender (596) for grandsire, and out of a mare named Velocity. The Bellfounders proved animals of great speed and endurance, tracing back from the original Fireaways. Bellfounder was the sire of the Kent mare, the dam of Hambletonian IO. The great speed in the Hambletonian family of trotters may justly be regarded as tracing through the Bellfounder lineage.

It is believed that the Hudson Bay Company imported to Canada in 1830 an English Hackney named Fireaway, but for years no importations of this breed other than these two came to America, and they were not brought over as Hackneys. In I 88 I M. H. Cochrane of Hillhurst, Canada, brought an importation to Canada from England, having among others a fine stallion named Fordham, by Denmark I77. The first Hackney 
stud founded in the United States was established by A. J. Cassatt of Philadelphia. In the spring of 1883 he imported the stallion Little Wonder and the mares Patience and Buttercup, having previously brought over the mare Stella by Confidence I 58. Little Wonder was exhibited in I883, and later proved to be a breeder of much excellence. Other importations were as follows: Prescott Lawrence, Newport, Rhode Island, I884; J. B. Perkins, Cleveland, Ohio, 1887 ; Henry Fairfax, Aldie,

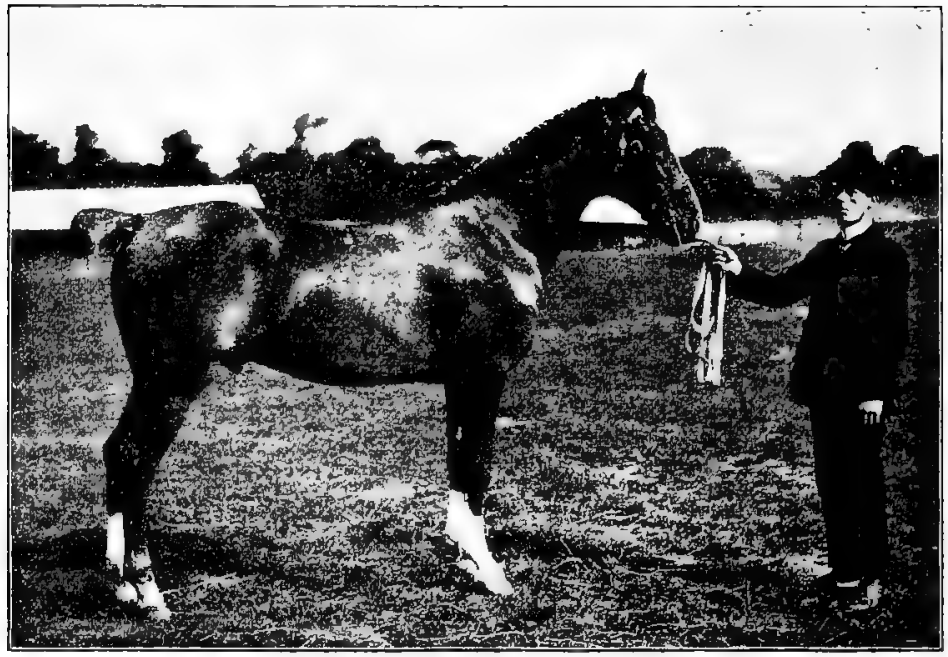

FIG. 22. Kirkburn Sensation (8533). Champion Hackney stallion at Royal Agricultural Society of England Show, I 904, and first and junior champion at London Hackney Horse Society Show, 1904. Owned by Sir Walter Gilbey, Bart. Photograph from Wm. Cooper \& Nephews, Berkhamsted, England

Virginia, I 888 ; John A. Logan, Youngstown, Ohio, ı 888 ; Galbraith Bros., Janesville, Wisconsin, J. H. Truman \& Son, Bushnell, Illinois, Powell Bros., Springboro, Pennsylvania, and some others, I889. In I 890 Dr. Seward Webb, Shelburne Farms, Vermont, made an importation of twenty-seven mares and four stallions, the most important consignment up to this time. Since then many Hackneys have been brought to the United States from England. Among more recent importers, F. C. Stevens, 
Attica, New York, Eben D. Jordan, Boston, Massachusetts, and Robert Beith, Bowmanville, Ontario, Canada, are perhaps best known.

Hackney characteristics are especially shown in conformation and gait. The type of this breed is usually associated with the horse full of breast, short of back, long, level, and broad of rump, deep of rib, short of leg, with a carriage of head and neck of the coachiest type. The Hackney may perhaps be regarded as

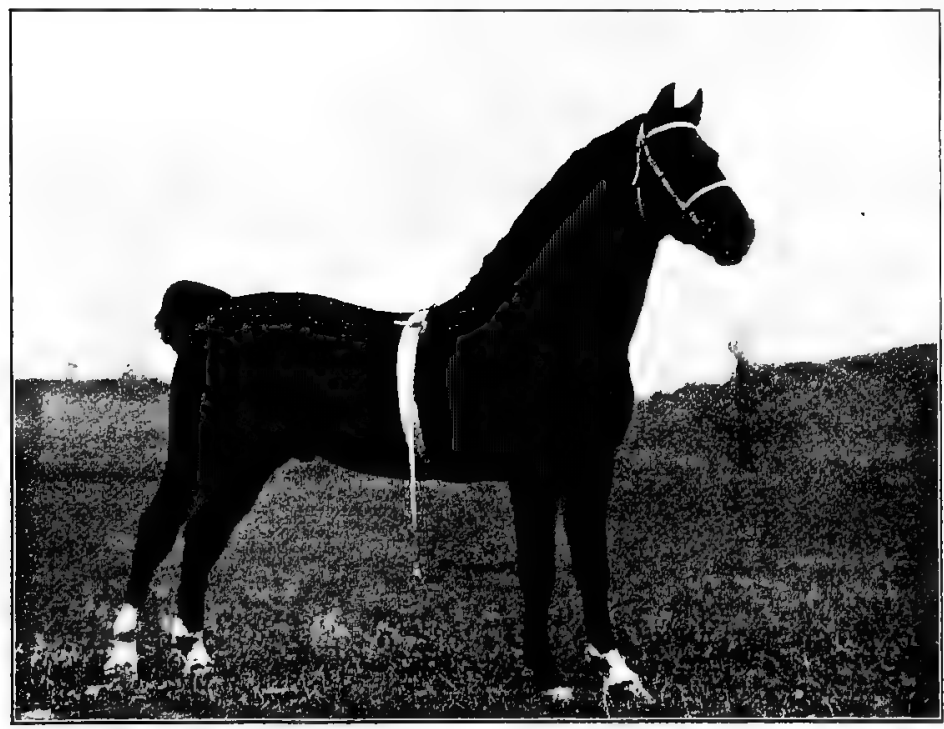

Fig. 23. Fandango 2d 373. A fine type of Hackney stallion. First at Boston Horse Show and New York Open Air Show in 1899 and a winner at other exhibitions since. Owned by F. C. Stevens, Attica, New York. Photo. graph from owner

blockier of form than other coach breeds of cob-like character. Mr. Henry F. Euren states that the general description of the Hackney which fitted both old style and new ideal is in brief this: "A powerfully built, short-legged, big, broad horse, with an intelligent head, neat neck, strong, level back, powerful loins, and as perfect shoulders as can be produced."

While Hackney breeders desire a height ranging from $15 \frac{1}{2}$ to I $5^{\frac{3}{4}}$ hands, this breed shows quite a variation in height. In I885 
the Royal Agricultural Society of England, at the request of the Hackney Studbook Society, increased the standard height for the breed to $15 \frac{1}{2}$ hands, and the class was well filled. There are Hackney ponies under I 4 hands, Hackney cobs larger than ponies, and Hackney coachers over 16 hands.

The gait of the Hackney originally had its chief value in a long, strong trot for road work. With the evolution of years the fashion of modern times called for the high stepper with extravagant action. The horse Confidence 158 (English studbook) was the sire of many horses of this type of gait, and, as some think, to the detriment of the breed, though " the get of Confidence yielded a larger total profit than any other horse of his day." While the fancy city trade desires matched pairs with very high action, this is inconsistent with the most graceful or forceful movement. The ideal Hackney has a perfect walk, and a trot associated with a powerful stride. The feet are carried clear and full from the ground and are strongly and actively raised at the knee, while the hock is carried forward under the body with much grace, strength, and action.

The soundness of this breed has been much emphasized. At the first show of Hackneys held in Agricultural Hall, London, in 1885 , it is said that over twenty stallions from four to sixteen years old were selected by the judges as absolutely sound. For some years the English Hackney Society, in its shows, has had the horses on exhibition examined for soundness, and the animals have had to undergo a veterinary examination before being submitted to the judges. The following figures show the results of examinations for five different years.

\begin{tabular}{c|c|c|c}
\hline Exhibition of & Horses Examined & Rejected & Per cent Rejected \\
\hline 1896 & 396 & 17 & 4.20 \\
1897 & 438 & 23 & 5.47 \\
1898 & 436 & 21 & 4.80 \\
1903 & 422 & 21 & 4.97 \\
1904 & 416 & 24 & 5.76 \\
\hline
\end{tabular}

The color of the Hackney varies, but chestnuts at present seem in great favor. Bays and browns always have been popular and common, while black, roan, buckskin, and sorrel occur 
occasionally. White markings also occur, as a blaze face or star, a white foot or pastern, or lower part of leg.

Half-bred or grade Hackneys have become more or less popular in both America and Great Britain, while in France Hackney stallions have had much influence. A study of pedigrees will show an important relationship of Norfolk Hackney blood in building up the French Coach, and the French have

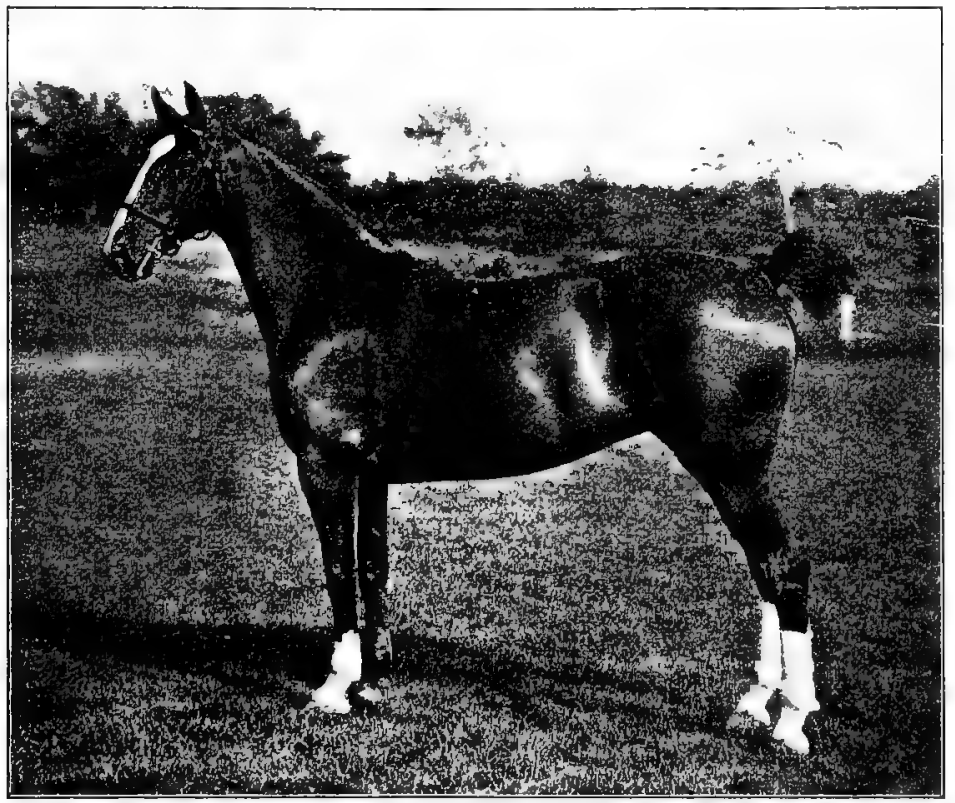

FIG. 24. Hildred, a very perfect type of a Hackney mare, imported and owned by Eben D. Jordan of Boston. This mare in recent years has been a notable prize winner and favorite in American horse shows. Photograph from Mr. Jordan

not been backward in using the Hackney for cross-breeding. In America Hackney stallions have been mainly used in the more eastern states. Mr. Henry Fairfax of Virginia has used Hackney stallions on common farm mares with much success, and grades of this breeding have been successfully exhibited. Some years ago the late John A. Logan, Jr., had an extensive Hackney stud at Youngstown, Ohio, where he had about fifty 
racing mares. He selected twenty-five as near types of their respective families as possible, including two Thoroughbreds, and bred to them a Hackney stallion, from which he obtained twentythree live foals. This Hackney stallion also was bred to about thirty other mares in the vicinity, including several grade Percherons, two Clydesdales, and the balance mainly ordinary farm work mares. From fifty-six mares fifty-two live foals were obtained, not one of which was blemished or crooked. Says Mr. Logan: "Every colt I have ever seen (and I think I have seen them all) has a wonderfully short back, round well-developed quarters, short flat legs, with a great amount of bone and substance. A stranger can pick them out from any number of others of different breeds almost at a glance." The result of this cross gave the greatest satisfaction, producing horses with substance, style, finish, and a high-class carriage gait.

The distribution of the Hackney is more widespread than that of any other coach-horse breed. It is generally found in the eastern and north central United States, Pennsylvania, New York, Massachusetts, and Illinois being breeding centers. It is also found almost all over the world. In 1903 horses were exported from England to Africa, Australia, Belgium, Argentine, Canada, Denmark, France, Germany, Holland, Italy, Japan, New Zealand, Spain, and the United States.

The English Hackney Horse Society was established in 1883 , and published the first volume of its studbook in 1884. Up to 1905 this society has published twenty-two studbooks and has registered 9076 stallions and I 7,074 mares.

The American Hackney Horse Society was organized in I891, and Volume I of the studbook appeared in I893. Since then, up to 1905, but one other volume has been issued. 


\section{CHAPTER XI}

\section{THE FRENCH COACH}

Early French horse history. The horse has been known in France since prehistoric times, and the remains of horses have been found in the eastern part of the country in large numbers. These were associated with the Stone Age. Just when the horse first became domesticated in France is unknown. He may have been used in a measure by the early people of the country, both for food and labor. Several hundred years prior to the time of Christ horses were used in Gaul for military purposes.

Horse racing in France dates back several centuries. It is said that racing was practiced in 1323 under Charles le Bel and even earlier. Systematic attempts to improve the racing horse began during the reign of Louis XIV, in the latter part of the seventeenth century. Colbert, one of the ministers of Louis XIV, founded the "Administration des Haras." During these early days more or less horse racing was engaged in, but in no persistent form. Between 1775 and 1790 French horses were taken to England and raced on the turf by French owners. The French saw the merit of the English Thoroughbred, and along in this period they began to buy and send them to France for both breeding and racing purposes. Several of the sires taken to France in and about 1776 became famous, as, for example, Comus by Otho, Glowworm by Eclipse, King Pepin by Turf, and Pyrois by Matchem. Some mares were also taken across the Channel.

Very early in the nineteenth century Napoleon the Great undertook to promote the development of the horse, though he had in view the army service as well as use on the turf.

The French Jockey Club was organized in 1833 , and with it came the first real influential development of the light horse in

1 Administration of Studs. 
France. This club was aristocratic, wealthy, and influential, and began to promote racing and breeding. Since that time the government haras, the Jockey Club, and horse-breeding societies have done much to improve the horse of France.

Origin of the French Coach horse. The term "French Coach" is an American one, there being no breed of that name in France. The type of horse that we know by this name in America is termed Demi-Sang in France, meaning half-blood. These horses when descended from English sires and mares of Normandy have been called AngloNormans and are often referred to as such.

Besides the Thoroughbred, there were introduced into France Hackneys and Nor. folk trotters from England and Arabs and other horses from the Orient. Descendants of the great Hackney stallion Phenomenon were taken to France and used in the studs with much benefit. Evidence before the Irish

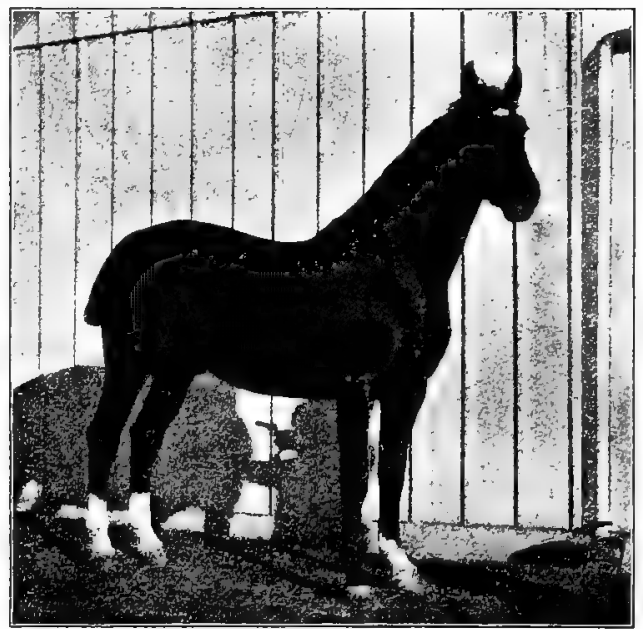

FIG. 25. Apropos 3445, a. French Coach stallion im. ported by McLaughlin Bros., Columbus, Ohio, in I903. Grand champion at American Royal at Kansas City in I904, and at International Live Stock Exposition, Chicago, in I905. Photograph by author

Commissioners of Horse Breeding showed that during the last quarter of the past century from twenty to thirty Hackney stallions a year were bought in England for the French haras, on government orders. These, however, have not as a rule gone into those sections drawn upon for carriage horses for the American trade.

The leading source of French Coach stock has been in a famous horse region in a district west of Paris, extending to the seashore, notably in the counties or departments of Calvados, Orne, and 
La Manche, in that section of France known as Normandy. Here was early felt the influence of the race course, and it was found that by using English sires to the Normandy mares a certain degree of coarseness and plainness was removed, while there was an increase in speed and quality. There was much experimental

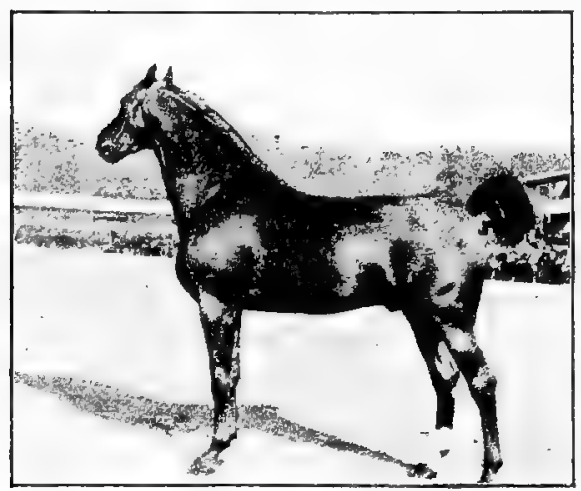

FIG. 26. Harley, a prominent French Coach sire in service in France. Photograph by James B. McLaughlin, Columbus, Ohio breeding, resulting in considerable variation in the beginning. English horses were used to a consider. able extent in the early development, but since I 840 French-bred horses have been used almost exclusively.

The coach or carriage horse of France is derived from trotter stock. 'The purpose of breeding fast horses, capable of performing hard work, was clearly in the minds of the

French people. The pedigrees of the best of French Coach horses trace back through lines of descent into the blood of English Thoroughbreds, Hackney and Norfolk trotters, Arabs, etc. For example, the stallion Niger, foaled in I 869, had Norfolk Phenomenon for sire and Miss Bell, a half-blood American mare, for dam. He was used in the national haras and became a very famous sire. The stallion Tigris is three generations removed from the English Thoroughbred, The Heir of Linne, imported to the national haras at Tarbes, in 1859 , a stallion that made a strong impression on the Demi-Sang. Another interesting phase of the influence of foreign blood is shown in the stallion Aemulus, foaled in $187 \mathrm{I}$, sired by Mambrino Pilot and out of Black Bess. He was a prize winner on the American turf between 1876 and I 880 , but was taken to France in I $88 \mathrm{I}$ and placed in the haras of Colaincourt (Aisne), where he rendered good service. Aemulus was a combination of Mambrino blood on the sire's side and Morgan on the dam's. Conquerant, foaled in 1858 , another 
famous Demi-Sang stallion that proved to be a remarkable breeder, being in service at the national haras at Le Pin from I862 to I880, had Thoroughbred blood on both sire and dam sides four generations back. The famous stallion Indre 385 , imported by the late M. W. Dunham, foaled in 1886 and still alive in 1905, was a grandson of The Heir of Linne on the sire's side and greatgrandson of Conquerant on the dam's side. The stallion Young Rattler, bred in England but in service in Normandy from 1820 to 1834 , proved to have a most important influence on the French turf. These examples suffice to show the influence of foreign horses on the mares of France in developing the Demi-Sang. In recent years it is claimed that the breeding has been restricted to French blood entirely.

Methods of the French to promote horse improvement. It is appropriate to give here in some detail the methods employed in France to improve the horse, these applying to the Percheron, discussed elsewhere, as well as to the French Coach.

Beginning with the Administration des Haras in the latter part of the seventeenth century, the French government has, in a more or less degree, continuously promoted horse improvement. In I 690 by government decree there were I600 stallions classed as either royal or approved. In I 7 I 4 Louis XV established a government stud, or haras, at Le Pin, which

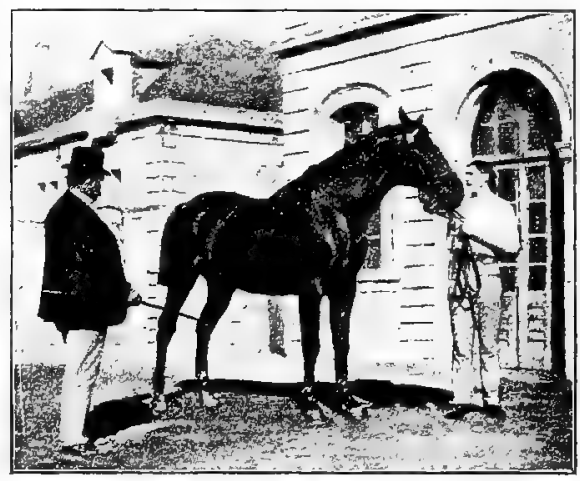

FIG. 27. Radziwill, a famous French Coach stallion, purchased by the French government for 25,000 francs; under examination by a juror at Caen. Photograph by James B. McLaughlin has since been the leading one of France, and where also an equine school has been maintained. In 1755 a stud with twelve sub-studs was established at Pompadour, this being under government control. In 1789 there were 3239 approved and government stallions in France, which served about I I 5,000 mares. 
During the first part of the nineteenth century the government purchased many stallions for the haras. From I8 I 5 to 1833 there were bought 1902 stallions, of which 223 came from Arabia and other foreign countries, 853 from the northern departments of France, and 826 were selections from the government studs. In 1833 a royal decree established a studbook for the preservation of pedigrees. This was designated The French Studbook: A Register of Demi-Sang Horses, Born and Imported into France, ${ }^{1}$ the first volume of which was published in I89I, comprising 32 I9 stallions and 1445 mares registered between 1840

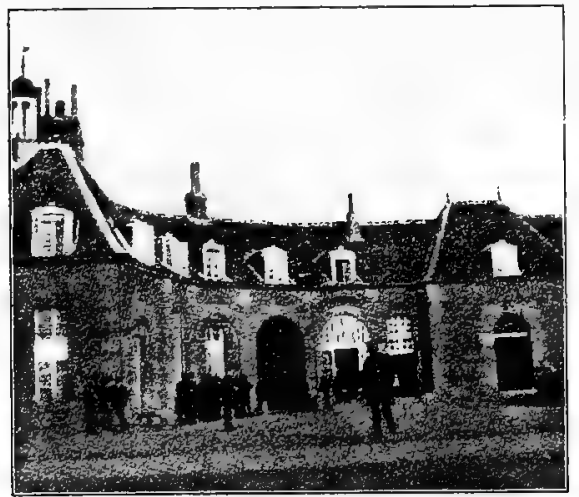

FIG. 28. A view of the Equine School at Le Pin, France. Photograph by James B. McLaughlin, Columbus, Ohio and $\mathrm{I} 890$.

On May 5, I870, the management of the government haras was given to the Department of Agriculture and Commerce. These were placed in charge of a director general, eight inspectors, twenty-six sub-directors, ten superintendents, and twenty-six veterinarians. To hold one of these offices one must be a graduate of the equine school at Le Pin.

In 1874 the government issued an order to increase the stallions in France by 200 per year until the total number should reach 2500. The Chamber of Deputies appropriated I, 500,000 francs $(\$ 300,000)$ for prizes for breeding animals, and 50,000 francs (\$IO,000) to experiment with the Arab and Anglo-Arab, using 60 superior mares at the haras of Pompadour.

Classes of breeding stallions in France. In order to promote intelligent breeding and a superior stock of horses in France, the government made three different classes of stallions, both coach and draft: 'First, stallions owned in the government haras.

I Stud-Book Français: Registre des Chevaux de Demi-Sang, Tome I, Paris, I 89 I. 
Second, approved or subsidized stallions, such as are owned by private parties. Upon inspection by government experts, those of the second class that are found of sufficient merit are given government approval. The owners of such horses are allowed from 300 to 5000 francs bonus (\$60 to \$1 $\$ 000$ ) from the Minister of Agriculture for the year for which this approval stands, during which time the horses are to be used on the mares of the community in which they are located. Third, authorized stallions. These by official inspection are pronounced of good quality and worthy of public patronage. Since 1885 the French law has prohibited from public service stallions not coming up to this standard.

According to official statement in $1903,{ }^{1}$ there were owned in France by private proprietors, 1476 approved and 265 authorized stallions. Of the approved, 522 proprietors owned one stallion each; 167 , two; 74 , three; and 29, four; while 208 owned one authorized stallion each.

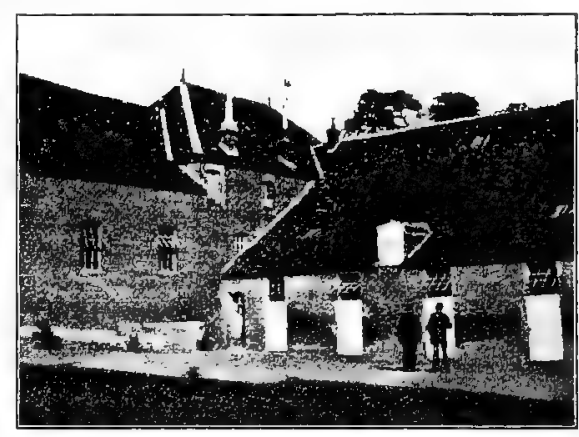

FIG. 29. A view of the stable at the Equine School, Le Pin, France. Photograph by James B. McLaughiin, Columbus, Ohio

Characteristics of the French Coach. This breed really presents some variation in type. The larger, smoother sort brought to America is what we know as the coacher. These generally average about, 16 hands high, and American trade prefers this height for stallions and geldings of maturity. Mares will stand from 15 to 16 hands. In a list of 22 stallions before the writer the average weight in sale flesh is 1396 pounds, the lightest weight being 1300 and the heaviest 1475 . For stallions in fair condition I 350 may be regarded as an acceptable weight, with mares at I 200 pounds. There is also a smaller, more cobby type of coacher, or French trotter, that is not so commonly brought to America, yet is highly valued by the French for its speed quality.

1 Rapport de l'inspecteur général directeur des haras à $M$. le ministre de l'agriculture sur la gestion de l'administration des haras en 1903 . 
There is not a great variation in color, bay, in varying shades, and brown, being most common. Of I 47 stallions and mares owned by two of the leading dealers in the United States there were 90 bays or brown bays, 29 browns, I 7 blacks, and I I chestnuts.

The French Coach is characterized by very good length of body, with a long, somewhat arching neck and a long, wide, level croup. The trot of this breed is long and powerful, rather than high and trappy like the Hackney. The French have sought strong bone and excellent feet and great speed for a heavy type of trotter.

The French race track, which is either two and one half or two miles long, is over a course of turf. The sod track causes

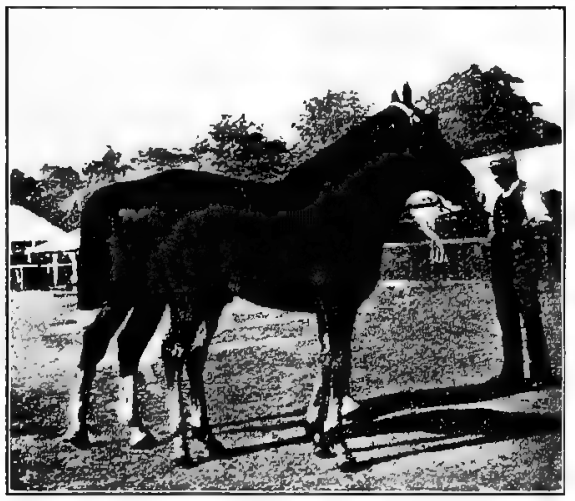

FIG. 30. A first-prize French Coach colt at a show in France. Photograph by James B. McLaughlin a high knee action and long stride as well as a strong, well-flexed hock movement.

Speed records of French Coachers. As might naturally be supposed, the use of stallions from high-class speed ancestry on French mares produced fast trotters. The horses of France, however, have never made as fast time as those of America. In I $873 \mathrm{Niger}$ trotted $2 \frac{1}{2}$ miles in 6.55 , while up to I 877 the fastest record was by Pactole, who made $2 \frac{1}{2}$ miles in 6.38 . In I 89 I there were 1399 contestants in races, 3 I 2 of which trotted races from 2 to $33^{3}$ miles at less than 3 minutes per mile, 137 under 2.50, I 12 under 2.45 , and 62 under 2.40 .

The size and strength of this horse enable him to go considerable distances at comparatively great speed. In 1875 , at Toulouse, Zethus, under saddle, trotted $12 \frac{1}{2}$ miles in 37 minutes 2 I seconds, and in another trial at Caen trotted the same distance in 37 minutes I9 seconds. In 1877 the mare Zacinthe trotted $18 \frac{3}{4}$ miles on an ordinary road in 59 minutes, defeating Zethus, then fourteen years old. 
The preceding records speak well for the speed capacity of the French Coach horse.

Distribution and adaptation. This breed has been rather extensively distributed over Europe and the United States, although it is not generally bred outside of Normandy in France. In the United States it is fairly well known east of the Mississippi and north of the Ohio. The best-known breeding and importing studs are in Ohio and Illinois. The late Mark W. Dunham of Wayne, Illinois, and Powell Bros. of Springboro, Pennsylvania, were the most important breeders and importers in

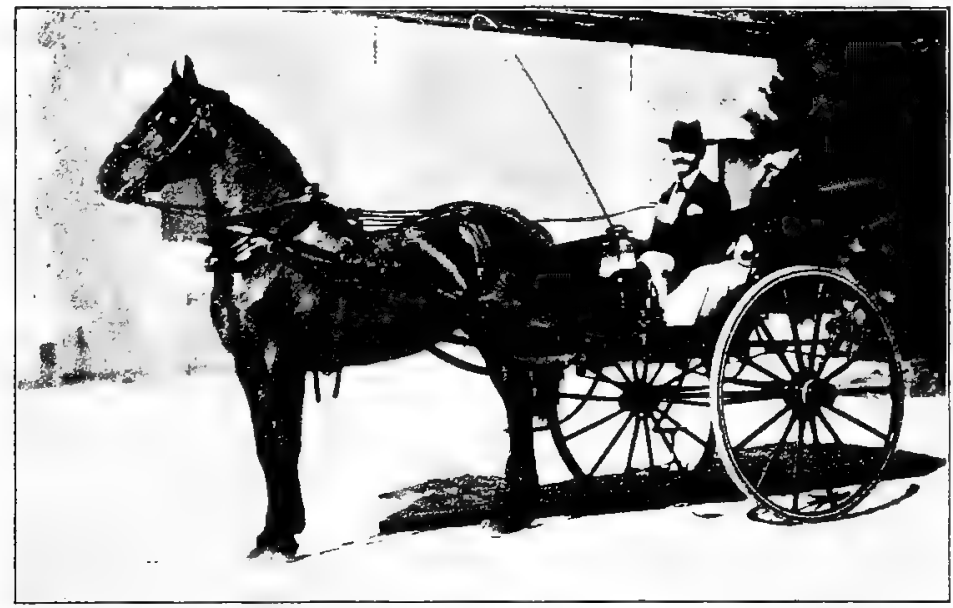

Fig. 3r. A French Coach stallion I8 years of age. A fine example of vigor and breed character. Photograph taken in France by the author

this country for years. More coach horses of this breed are being brought to the United States than of any other kind, unless the Hackney be excepted.

French Coach horses seem to thrive very well in the Atlantic seaboard states and in the upper Mississippi Valley. There are but very few breeding studs. In the main stallions are imported and are then used for breeding on the larger type of light driving mares of common stock, to produce coachers for the city market. When there is a harmonious mating with American trottingbred stock, a superior class of carriage horse is developed. 
The grade or half-bred French Coach horse, the result of purebred sires on American-bred mares, is comparatively little known. In some localities very excellent carriage horses have come from French Coach sires on mares of trotting-blood ancestry, while in other regions the cross has not been satisfactory. The Hamlins of Buffalo, New York, sent twelve trotting-bred mares from Village Farm to Oaklawn, the stud of the late M. W. Dunham, to be bred to French Coach sires. They were retained for two years at Oaklawn, and the half-bred colts met with considerable favorable comment. One of the half-bred stallions was placed in the imperial stud of Japan. Another became prominent as a saddle horse. Cogent, got by Mambrino King out of a French Coach mare, was not only a sire of some distinction, but also won numerous prizes as a heavy harness horse. Mr. J. S. Sanborn of Boston, on his Maine farm, mated French Coach stallions to trotting mares and produced some very choice harness horses. In a communication to the Breeders' Gazette, Messrs. Dunham, Fletcher \& Coleman write :

A few years ago a shipment of half and three-quarter bred French Coach mares and geldings, matched and finished for the trade, was made from Iowa to New York, where the animals were sold at highly renumerative prices, as high as $\$ 3000$ a pair being paid. Carriage horses of exactly the same and still higher breeding have been shipped continuously from the same districts in the Hawkeye state ever since, with equally or still more profitable results.

American studbook. There are two societies in the United States for French Coach horses, viz. The French Coach Horse Society with present headquarters at Chicago, Illinois, and the French Coach Registry Company with headquarters at Columbus, Ohio. The former was organized in I 885, and published its first studbook in 1906 . The French Coach Registry Company was organized in 1904, and also published Volume I of its studbook in 1906. 


\section{CHAPTER XII}

\section{THE GERMAN COACH}

The history of the German Coach horse is hardly clear to American students. Nearly all the evidence we have regarding it is found in live-stock and agricultural journals, which in the main consists of contributions from partisans of the breed. In the United States carriage or coach horses from Germany have been advertised as Hanoverian, Oldenburg, and German Coach.

The home of horse breeding in Germany has long been recognized as especially located in the northwestern section, in the rich lowlands drained by the rivers Elbe, Weser, and Ems, all of which flow into the North Sea. Here was originally found the great draft horse of northern Europe, and here to-day the coach horse is bred, especially in the states of Hanover, Oldenburg, and Schleswig-Holstein, and in the district of East Friesland.

Early records of horse breeding in Germany go back nearly five centuries. We are told that early in 1500 important annual fairs were held in Friesland near the Holland boundary, where buyers from Holland, Belgium, and Germany found superior horses. From 1628 to 1648 the stables of Count Ulrich II contained numerous stallions of high repute. A government stud was established at Ilo, which contained I 82 horses in 1648. In I658 Count Enno Ludwig sent the Emperor Leopold a number of beautiful and valuable horses. In I 708 Prince George Albrecht prepared a catalogue of his stud, which contained horses from the prominent horse countries of the world, including Turkey, Poland, Hungary, Transylvania, Denmark, England, and even Iceland. This shows the mixed character of the early German horse stock. At Harlingerland, in East Friesland, government studs were in operation and reports refer to these as far back as I 7 I 2, when I 6 stallions were used here for service on 819 mares. In I 889 , in this same region, I 5 stallions were used on 142 I mares. 
Government supervision of horse breeding in Germany has obtained for centuries. The use of stallions on the mares of East Friesland was regulated by royal edict for many years. Finally more liberality was permitted in the use of stallions, but government supervision, much as in Belgium, was the rule. It was made a law that no permits should be issued authorizing the use of stallions, unless they passed a satisfactory government inspection. At the present time both the government and agricultural societies promote intelligent horse breeding. Prizes are awarded for animals of special merit, and such animals must remain in the country for a specified term. First prizes are awarded only to mature horses and mares that have shown merit as breeders. Stallion shows have long been held at Aurich, in East Friesland, where the horses are brought annually for inspection and approval. Prizes for brood mares are also awarded by the government.

The type of German Coach horse, as seen in America, possesses some considerable variation. In I 893, at the World's Columbian Exposition at Chicago, an exhibit of over eighty German Coach horses was made, including special exhibits from Germany made by the Oldenburg Agricultural Society, the Hanoverian Agricultural Society of central Germany, and the East Friesland Head Agricultural Society. There was some considerable variation in the types shown, and following the awards by German judges came pronounced objection and dissatisfaction. This resulted in an editorial statement on the German Coach type, which appeared in the Breeders' Gazette and was authorized by the German judges. This statement is of importance to American students, and so is given here :

The visiting German horsemen make the following claims concerning the light types of horses. Four types of light-legged horses are recognized, and each now has its separate studbook. The Trakekner is the lightest of all and is a carriage and saddle horse, not a heavy coacher. The Holstein and Hanoverian horses are about the same type, but the $H$ anoverians are more used for saddle horses and the Holsteins for carriage horses. This difference in use implies somewhat of a difference in action. The Oldenburg is the heaviest type, and these horses are used for heavy coach work, such as state coaches, and as farm or all-purpose horses, and are not put under saddle. Then there are the East Friesland horses, which are practically Oldenburgs, as they are bred from Oldenburg sires. It is claimed that these distinctions are actual rather than artificial. 
The history of the German Coach horse in America is a comparatively brief one. These horses were first brought to the United States along in the eighties. Not much prior to 1890 did the breed receive recognition at American shows. A. B. Holbert, of Greeley, Iowa, was one of the earliest introducers of the breed. The Oltmann Bros, of Illinois and Crouch \& Son of Indiana

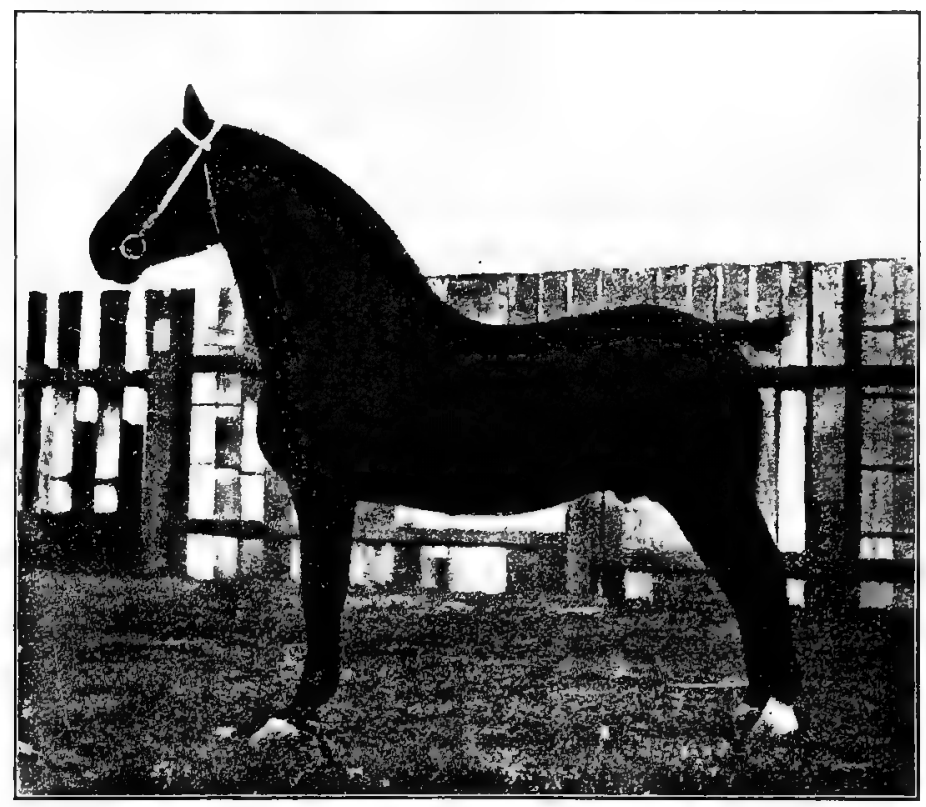

FIG. 32. Hannibal, a German Coach stallion imported by Crouch \& Son, La Fayette, Indiana. It is doubtful if a better specimen of the breed has been shown in America. A prize winner of the highest rank at many shows. Photograph by the author

have also been most actively and prominently identified with its promotion during its career in the United States. Its distribution began in Indiana, Illinois, and Iowa, was extended to California, and is now being projected over still wider fields, the South and general West being included.

The German Coach horse organization in America began in I 892 with the incorporation, under the laws of Illinois, of the German, Hanoverian, and Oldenburg Coach Horse Association. 
Very soon after the organization of this association came the Oldenburg Coach Horse Association, which was also incorporated in Illinois. Both of these organizations still exist, though just why they should is not clear. So far as the American public is aware, the various coach horses brought to America from Germany are exhibited here as the German Coach breed, whether Oldenburg, Hanoverian, or otherwise. Leading importers who advertise, designate their horses as "Oldenburg, German Coach," or "German, Hanoverian, and Oldenburg Coach." This difference of title may be accounted for in part by the variety of type. This apparent confusion of names in America, the advocates of the breed or breeds would do well to clarify in some permanent way.

Characteristics of the German Coach horse. In height the breed ranges from 16 to $16 \frac{1}{2}$ hands, and in weight from 1350 to I 450 pounds. The color does not vary greatly, being almost exclusively bay, brown, or black. The head is fairly typical of the coachers, the neck being long and arched, the shoulders well placed, and the withers prominent. The body of the German Coach is somewhat larger than that of the French Coach, and the croup is high and the tail well placed. The legs show considerable length compared with the Hackney, while the feet are excellent. On the basis of many specimens brought to this country, seen by the writer, the German Coach varies materially in size and quality. Coarseness is not uncommon, as seen in large heads and joints with more or less largeness of bone. In action there is a wide difference of merit, and, from the coach-horse point of view, frequent deficiency. A superior folding of knee and flexing of hock, with desirable activity, is not a prevailing attribute of American specimens of the breed. This contrast in style and action will be clearly brought out by visiting both German Coach and Hackney stables, and studying the movements of numerous horses of each breed.

Cross-bred or grade German Coach horses are now becoming more common than formerly in this country. Some of these, the product from American mares, are very good, while others lack quality and finish. When used on coarse mares a stallion of the breed will not be likely to produce satisfactory offspring. Used on the finer sort of mare of trotting ancestry better returns 
may be expected. One prominent importer, who is seeking to introduce the breed in the South, says in the Breeders' Gazette: "We are advising our southern friends to cross their small mares on the German Coach stallion, which weighs from I 300 to 1400 pounds, and the progeny of this cross will be a good, strong serviceable horse that will do their work in the fields, can be used on the roads, and is a marketable horse in every respect."

German Coach horses of importance are not as yet known in America in large numbers. Among the earlier imported Moltke I 3, Kaiser Wilhelm 494, Young Altona I 458, and Young Adonis 476 met with favorable comment, the latter being a successful prize winner in California in 1891 . In the central West the horses Bertus, brought out by Oltmann Bros., and Euto and Hannibal, by Crouch \& Son, have been distinguished specimens of the breed in the show ring, winning against the severest competition for years in succession.

German Coach mares have not as yet been brought to America on any scale of importance, and there has been no breeding stud that has gained prominence. A very great percentage of the offspring of the stallions must be grades, the product of native mares.

The distribution of German Coach horses is very widespread. They may be found in various European countries, in South America, South Africa, and quite widely over the United States and the Canadian Northwest. For years the most prominent importers, exhibitors, and promoters of the breed have had headquarters in Indiana and Illinois.

A German Coach horse studbook of " the German, Hanoverian, and Oldenburg Coach Horse," containing pedigrees of registered stallions and mares imported or raised in America, has been published by the association bearing this title. Two volumes have been issued up to I906. They contain the registration of about eighteen hundred animals, mostly stallions. 


\section{CHAPTER XIII \\ THE CLEVELAND BAY}

The native home of the Cleveland Bay horse is in northeastern England, in the county of York. It is also said that a similar type formerly existed in Devon in south England. The breed, as now known, has its breeding center in the counties of Durham, Northumberland, and especially York, and it is in the latter county, among the Cleveland Hills, in North and East Riding, it has been found in its greatest purity. York is a rolling or slightly hilly country, with rougher land up in Northumberland. Superior pastures cover these hills and make ideal conditions for producing coach horses of the Cleveland Bay sort.

The origin of the Cleveland Bay is very obscure. Formerly it was known as the Chapman or pack horse, the name Cleveland Bay being a modern one. Some have assumed that the breed is descended from Roman days in Britain, and comes from the union of Oriental horses and English stock. Others have attributed the breed to the use of Thoroughbreds on British carthorse mares, which no doubt is quite within the facts. This theory has been resented by some Cleveland Bay authorities who wish to show a pure ancestry. The use of Scandinavian horse blood has also been suggested, thus accounting for the black points in the Cleveland. Another eminent authority offers the theory that this breed has been gradually developed from the native horses in southern England, with possibly some help in early times from Oriental or Thoroughbred blood.

In spite of these various theories nothing definite is known on the subject. The mares of Cleveland were, no doubt, crossed more or less with Thoroughbred or other blood, and plenty of evidence exists to show that in early times, at least, the breed was not of absolute purity. This criticism however will apply to most other breeds as well. 
The early purpose of the Cleveland Bay is universally recognized as agricultural or general utility. In I823 a writer in the .Farmer's Magazine made this statement:

The original breed of the country was neither blood nor black, that is, a distinct race from the English blood horse, and equally distinct from the black or cart breed of the country. It was the basis of the breed of the old London coach horse when heavier cattle were used for these conveyances; and after it became the fashion to adopt a lighter horse for carriages, this valuable breed was allowed to become almost extinct until their excellence for agricultural purposes was noticed by some practical farmers in the north of England, who for several years have been exerting themselves to revive the breed.

The purity of the Cleveland Bay as a breed has been the subject of much controversy. For nearly a century supply and demand has affected the welfare of this horse. The preceding reference, written in 1823 , indicates that. In I 849 George Legard, in the Journal of the Royal Agricultural Society, contributed still other evidence in the same line:

Formerly a large, powerfully boned animal was required for carriage purposes. The fashion of the present day has, however, changed in this particular, and now it is necessary that the London carriage horses should be at least three parts Thoroughbred. Consequently all traces of the original pure coaching breed, or Cleveland Bay, as it was termed, are nearly obliterated.

Marshall, himself a native of Yorkshire and a famous agricultural writer of a century ago, deplored the use of the Thoroughbred as spoiling the Cleveland. The breed was of great endurance, and the mares bred to Thoroughbreds produced Hunters of superior merit and power.

When the fields of Yorkshire became more subject to tillage, and when the mines and city drayage began to require heavy horses, then the lighter Cleveland type became unpopular, and the cart horse, the Clydesdale and Shire, came into prominence. The heavy horse brought the most money, and so the Cleveland Bay fell into disfavor and was neglected.

From $185 \mathrm{I}$ to 1867 the breed was in considerable favor, after which came a decline in its popularity. In I 884 the Cleveland Bay Horse Society was organized in Yorkshire, to promote its 
purity and to put the breed in proper relation to the public. Even this, however, did not give such impetus to its development as might have been anticipated. At the 1885 show of the Royal Agricultural Society, held in the county of York right where the breed is supposed to be strongest, but one entry of a Cleveland Bay was made, a mare and foal. At the I 900 exhibit of the Royal Society, again held at York, a very good show of Clevelands was made, forty-one head being entered. Since then

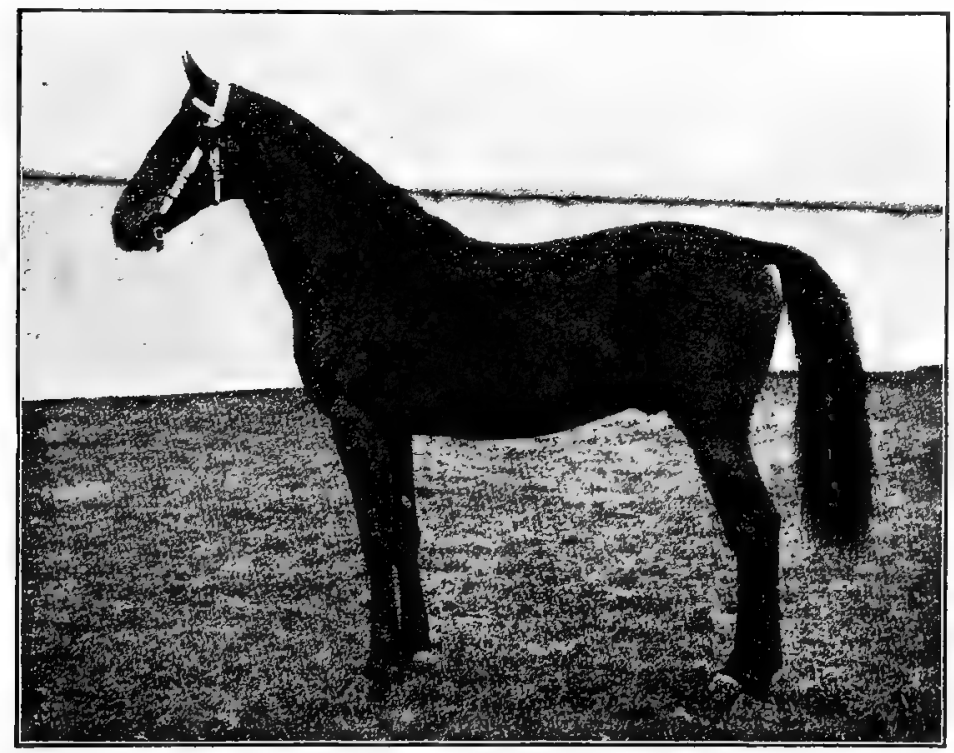

FIG. 33. Special Delight. Champion Cleveland Bay stallion at the Royal Agricultural Society Show of England, I 904. Photograph from William Cooper \& Nephews, Berkamsted, England

some quite creditable exhibits have been made at various English shows. This indicates some progress, still the breed cannot to-day be regarded as common in England.

The Cleveland Bay in America must be regarded almost in the light of a failure. Along in the eighties quite a number were imported, and in 1885 the Cleveland Bay Horse Society of America was organized at Chicago. At one time Stericker Bros., then of Springfield, Illinois, had a large stud of this 
breed and made most attractive exhibits. The people of the United States, however, have never been favorably impressed in a large way, consequently Cleveland Bay interests have mainly died out. Specimens of Cleveland Bays are now almost unknown in our horse shows. In I 900 the class for Cleveland Bays at the Illinois State Fair was discontinued, yet Illinois but a few years before had the principal stud of this breed in America. Neither is there any breeder prominently advocating the merits of the breed, and importations are rarely made.

Cleveland Bay characteristics need but a brief consideration here. The color is always bay, either light or dark, with black legs, mane, and tail. White is not permissible, except a small star in the forehead or few white hairs on the heel. More white, the breeders say, indicates foreign blood. The color may be dappled, and dark bars may occasionally be seen on the lower arm or possibly above the hock. The height ranges from $16 \frac{1}{4}$ to $16 \frac{3}{4}$ hands, and the weight from I 200 to I 550 pounds. A pure-bred mare, Jessica 2 I 4, owned by the Ohio State University, weighs about I 350 pounds in moderate flesh. The stallion Lord Derby 23 I (740), a first-prize winner at the Yorkshire show, and imported by Galbraith Brothers, weighed about 1550 pounds. The body of the Cleveland Bay is of the larger coach type with long sloping shoulder and high, broad croup. The head has been regarded as lacking in refinement, while the limbs have not as much quality as the best market demands. In action the movement is strong and powerful, but not stylish. The breed is perhaps the largest of the coach type, and lacks somewhat the quality of the prominent coach breeds. William Scarth Dixon, one of the best English authorities on the breed, writing in I902, says:

The Cleveland Bay is distinguished for his size, the peculiar quality and amount of his bone, and for his general symmetry. Color is indispensable. ... "What we want is more quality," say breeders and dealers alike. Admitted, but at the same time I must point out that quality is a very elastic term; that there is a so-called quality which is certainly of a very meretricious character, for it tends to eliminate from a breed its most valuable characteristics. And it must be urged, even to the point of tediousness, that as the quality of the Shire horse is different from the Thoroughbred, so in character does the quality of the Cleveland Bay differ from the quality of the Yorkshire Coach horse. 
A number of Cleveland Bays which the author has known have been characterized by none too gentle a disposition.

Cleveland Bays as roadsters are very capable, and in fact always have had fame in England for this quality. Cases have been known where the Cleveland Bay has traveled from sixty to seventy miles within twenty-four hours, with heavy loads, three or four times a week, besides being employed occasionally on intermediate days. Hodgson, in a Journal of the Royal Agricultural Society says:

I knew a Cleveland mare that carried a man seventy miles a day for a week together. Tommy Miles, of Harlsey, near Northallerton, rode his Cleveland mare to York for a week together, to have his name called over in court as a juryman; he was in York by nine o'clock every morning (thirty-five miles), and slept in his own bed at Harlsey (thirty-five miles) every night.

Half-bred or grade Cleveland Bays have not met with favor in America, though the writer has seen some excellent specimens of the latter in active service as general purpose horses of the lighter type. These had plenty of stamina and were of fair quality. Half-breds in England, resulting from breeding Thor. oughbreds to Cleveland mares or half-bred mares, made very superior Hunters. A medium-sized or small Thoroughbred stal. lion on short legs bred to a Cleveland mare of substance was a favorite cross many years ago in Yorkshire, producing a Hunting horse exactly suited to the needs then, as no doubt it is now.

Cleveland Bay studbooks have been published in both England and the United States. Two volumes have been issued in this country up to I905, Volume II dated I89I. These contain registrations of 762 stallions and 192 mares. The studbook directs attention to the fact that with the pure Cleveland of merit the ancestry will go back to one or more of the three families, - descendants of Dart (83), The Hob Horse (3I6), and Barley Harvest (447).

The distribution of the Cleveland Bay is rather widespread, they having been exported to various parts of the world, including Sweden, Canada, United States, South Africa, Australia, and South America. At the present time a large share of those exported go to South Africa. 
The Yorkshire Coach horse bears a peculiar relationship to the Cleveland Bay, and calls for some consideration at this point. In England there is a Yorkshire Coach Horse Socjety in addition to the Cleveland Society, and horses of each kind are registered separately. In America, however, Yorkshire Coach horses and Cleveland Bays are regarded as one breed and are registered in the Cleveland Bay Studbook of North America. The Yorkshire Coach horse is of more recent development than the Cleveland, and has been designated as an improved Cleveland. It tends to be smaller in size, is more coachy in action, and has perhaps more quality. The improved quality is due to Thoroughbred blood. In the Yorkshire Coach Horse Studbook of England, published in 1887, is the following official statement of "The Origin and Characteristics of the Yorkshire Coach Horse."

It cannot be claimed for the Yorkshire Coach horse that he is a purebred animal, but that, on the contrary, by the judicious crossing of largesized, good-colored mares with stallions altogether or nearly Thoroughbred a class of horses has been produced suited to the wants and circumstances of the times. By universal consent the color should be bay or brown, with black eyes, mane and tail abundant but not curly, the height from 16 hands to 16 hands 2 inches, with fine head, sloping shoulders, strong loins, and lengthy quarters, high-stepping action, good sound feet, flat legs, and abundance of bone and muscle. 


\section{CHAPTER XIV}

\section{THE DRAFT TYPE}

The general conformation of the draft horse involves a massive form, a compact and blocky body, and a comparative shortness and strength of limb, the whole being in harmonious proportion. Weight is a most important consideration, for a true draft horse must weigh heavy compared with the lighter type. A draft horse in fair condition at maturity may weigh anywhere from I 500 to 2000 or more pounds. Grouped into classes, the light draft horse may weigh usually from 1500 to 1600 pounds, the medium from 1600 to 1700 , and the heavy from 1700 up. The greater the weight, as a rule, the higher the price paid for the superior specimen of the type. An increase of twenty-five cents for each additional pound of weight has been given as representing this growth in value. In order to pull heavy loads the draft horse must possess plenty of weight. It becomes very evident that the heavy horse in harness brings greater power into the collar than does the light one. The height is not so material, provided there is the necessary weight. Draft horses usually stand from I6 to $17 \frac{1}{2}$ hands, though occasional exceptions occur. The light draft represents the lesser height, and as the weight increases the height may also bear a relationship to it. Quality and substance, as shown in hair, bone, and joints, should be preeminent with this horse. The hair should be fine and silky, even if long, and the bone smooth and attractive, with neatly turned joints, the lower limbs being generally free from all superfluous fleshiness. Coarse joints are usually associated with coarse and poor bone and feet, and often with a coarse and undesirable head. The long hair on the leg of the Clydesdale or Shire is indicative of quality, fine silky hair being associated with superior bone and feet.

The action of the draft horse should be true and bold. As the horse comes toward one or goes from him the line of movement 
of the limbs should be true, the feet being carried straight away, with no so-called paddling or irregularity of gait. The feet should be picked up with snap, whether at walk or trot, and carried clear of the ground, showing the sole of the foot clearly in the movement. High knee action is not essential, but a strong, full, true movement of both knee and hock, without dragging or stiffness,

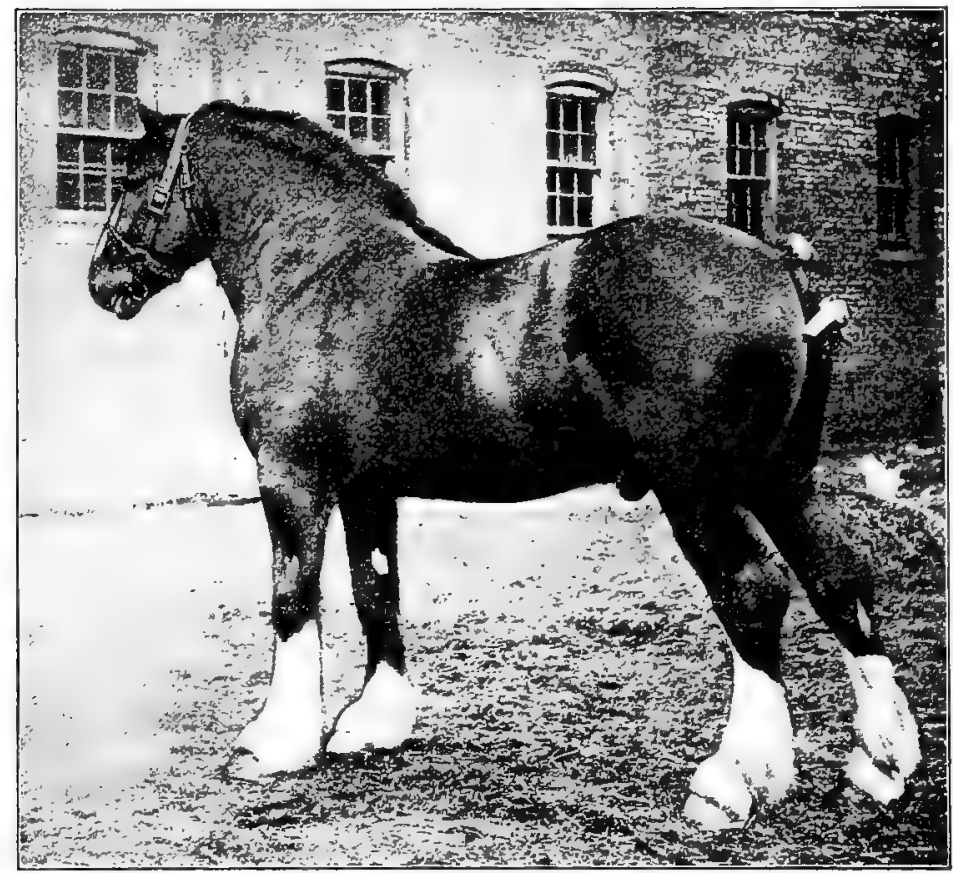

FIG. 34. A champion Clydesdale stallion owned by Galbraith \& Son, showing draft weight and conformation. Photograph from McLay Bros.

is very important. The draft horse should have an active walk, for the value of a fast walker considerably exceeds that of the sluggish type. In the sale or show ring high-class action with a draft horse adds materially to the selling or show value, no matter what the breed. A free and easy movement of knee and hock is essential to high-class action. In connection with good action the head and neck should be carried high, with style and body action. 
The head should be lean, not out of proportion with the body, have plenty of breadth between the eyes, which should be reasonably prominent and bright. The nose and muzzle should be broad yet not coarse, with nostrils of ample size for easy breathing. Nicely matched lips and strong cheeks and lower jaws help to make a strong head with character. The head should be crowned with fine ears of medium size gracefully placed and carried.

The neck of the draft horse is strong and muscular, supporting the head cleanly and gracefully, and being joined smoothly and deeply at the body. Some arch to the neck is desirable; this should appear in a very small degree with mares and geldings, yet enough to suggest power.

The shoulders should not be as long and sloping as with a light driver, but more upright, being well set into the back, a happy medium between the straight and sloping shoulder giving the best power and movement for the draft horse. Too straight a shoulder promotes excessive concussion and bone trouble of the limbs and feet. Smoothness of shoulder is essential, for roughness and prominence will be sure to involve soreness and trouble from fit of collar.

The chest should be full and deep, indicating large capacity of the vital organs. Narrowness behind the shoulders is quite common, and indicates defective constitution. Too much thickness of chest, an unusual occurrence, may cause a swaying movement in action.

The arm must be large and muscular, and placed so as to bring the legs in proper position under the body, not standing out at the corners.

The fore arm should be comparatively long, broadly and strongly muscled in its upper part, and gradually taper to the knee. A powerful fore arm on the draft horse is highly important and its value is not likely to be overestimated.

The knee must be broad, as viewed from the front, be well carried back, and be amply supported from below. This part should be neat and cleanly jointed.

The cannon bone is round, but has tendons extending down its back edge, more or less separated from the bone. As viewed from one side, the cannon and its attachment should be deep, 
amply supporting the knee; and viewed from rear or front, should be quite flat, thus representing the strongest conformation. Often the cannon is tied in beneath the knee, which indicates weakness. A long or rounded cannon shows faulty conformation. Flatness and shortness below the knee are always associated with the best development. A fair girth at the smallest point is $9 \frac{3}{4}$ inches. A large girth, however, does not always indicate proper development, as the leg may be coarse and out of proportion.

The fetlock, or, as it is often called, the pastern joint, must be smooth and deep, with no roughness.

The pastern is an important part of the leg. It should be fairly long, be perfectly smooth and free from extra flesh, and stand at an angle of about 45 degrees. At this slope concussion is received in perhaps the least degree, and with least injury to the foot and leg. There is some difference of opinion among horsemen on the length of pastern, some preferring one reasonably long and others one of medium length. The slope is more important than the length, but no doubt better feet prevail where the pastern leans toward length rather than shortness. Side. bones, ringbones, and other foot troubles are most prevalent with short, straight-pasterned draft horses. As the horse naturally places the foot in action, the pressure first comes on the frog and is then distributed over the rest of the foot. If the pastern is straight, the toe and front of the foot strike first, and thus the concussion is greatest.

The foot ought to be large, the hoof dense and preferably dark in color, the sole concave, and the frog large. There is an old saying, "No foot, no horse." Sound feet are absolutely" essential to comfort and efficiency of work. The interior of the foot contains very sensitive nerves and membranes. If the foot is too small and contracted, if the frog is too narrow and low, inflammation of the membranes will frequently follow. The ample foot, wide on top and behind, well supported at the heel, and carried true in movement, turning neither in nor out at the toe, is least likely to be troubled with disease.

The body should be short on top, long below, broad along the back, with the ribs strongly arched and of great depth. A long 
back indicates weakness of both constitution and draft power, while a short, deeply muscled back means strength. If the ribs are well sprung and deep, it shows capacity of the internal organs, indicates a good feeder, and materially adds to the weight necessary in the drafter. Usually satisfactory rib development provides a proper body conformation. Often immature horses appear to lack depth of body to some degree, but age and feeding establish the proper proportions. The horse that lacks depth of body will also lack such essentials as capacity and the power of endurance.

The loin should be broad and thickly muscled. Narrow, thin loins indicate weakness of a serious character. Often the loin is depressed directly in front of the space between the hips, a distinctly undesirable conformation. Animals with a sway back as a rule show this weakness of loin.

The croup should be broad, wide, fairly level, and heavily muscled. A steep croup is very objectionable, and affects both the beauty and power of the horse. A short, steep croup is less strongly muscled than one that is long. The Belgian and French draft breeds seem most subject to steepness of rump and low setting of tail.

The $t / i g / l$ should be strongly muscled, and the quarters should be thick and full. A horse split up high behind, with a thin, sharply tapering thigh, lacks good draft form at this place. The gaskin, or lower thigh, when properly made, is deep from front to rear and heavily covered with muscle.

The hock is a part which requires careful study. As viewed from one side, it should show considerable depth, while from the rear it should possess a certain degree of thinness, though broad in front, the entire joint being free from extra flesh. Thick hocks are very common with draft horses, due to various reasons. The joint may be fleshy, puffiness may occur from lack of exercise, or a form of spavin may exist. The hock should be smooth and its various natural curves well defined. As the horse stands in a natural position on his feet, the hocks should be straight and true as viewed from behind, showing no evidence of weakness. Where the hock holds a true position the hind feet also stand true, neither toeing in nor out. When toeing 
out the points of the hock come too close together, while if toeing in notably the points may be wide apart and the hocks appear springy and weak when in action. The hock should be supported by a wide, thin, clean-boned cannon which may be about I I inches in girth at its smallest point. A true position of the hind leg may be ascertained by the use of the plumb line which, dropped from the point of the buttock or croup, viewed from behind, should pass the center of point of hock, cannon, pastern, and foot. From one side it should pass parallel to the entire edge of the cannon, and when suspended from the point of the hip, should pass the gaskin at the center and drop to the center of the foot.

Draft-horse measurements of special interest were made by Mr. A. H. Snyder of the Ohio State University, College of Agriculture, under the direction of Professor T. F. Hunt. The following table shows the average result from this study.

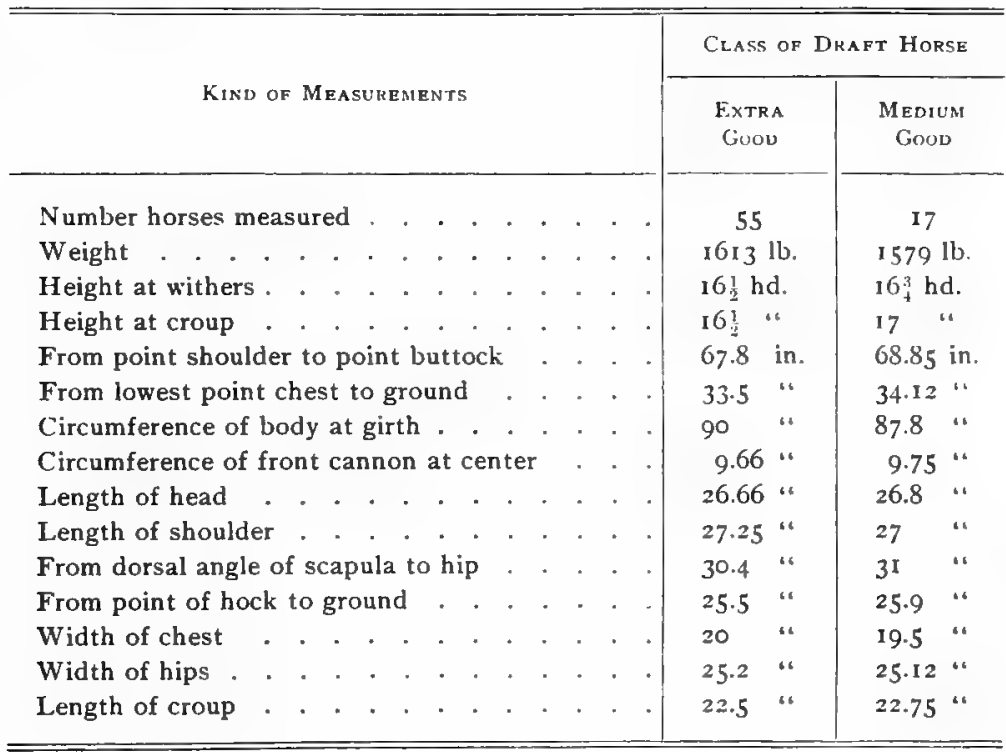




\section{CHAPTER XV}

\section{THE PERCHERON}

The original home of the Percheron horse is La Perche, France. For many centuries draft horses have been bred in France. The Percheron, however, has developed within certain limited French territory. In northwestern France, bounded on one side by the English Channel, is a district known as Normandy. It comprises nearly seven million acres, and is divided into five departments, - La Manche, Calvados, Orne, Eure et Loir, and Sarthe. In the southeastern part of Normandy, and extending beyond its borders, is what might be termed a county known as La Perche. All of this part of France referred to has from time immemorial been a famous horse-producing region, and many of the draft type of French horses and French Coachers that are imported to America come from this section. The region of $\mathrm{La}$ Perche is about fifty by sixty miles in area, and is rather broken of surface, having numerous valleys and small streams of water.

The origin of the Percheron breed is most obscure. For many centuries horses of a draft type were bred in the vicinity of $\mathrm{La}$ Perche. In early times this stock was without doubt typical of the heavy draft horse generally existing in northern Europe, and it is assumed that here existed the foundation stock from which the modern Percheron is developed. Foreign blood, however, has played an important part in the make-up of this breed.

The improvement of the early Percheron type is generally credited by French and other writers to the use of the horses of the Orient. This is accounted for by the existence of large numbers of Arab and Barb horses in France at the time of the Saracen invasion in the early part of the eighth century. These horses were brought from the East, and no doubt were more or less crossed upon the horses of La Perche. Two government studs were established in the eighteenth century, one at Le Pin, on the 
borders of La Perche, in I 7 I 4, and the other at Pompadour in 1755. These were destroyed during the revolution, but were restored by Napoleon in 1806, and have ever since remained important breeding studs, where the Percheron has been greatly improved. Abour I 775 Madame du Barry, of Paris, received a gift of a pair of

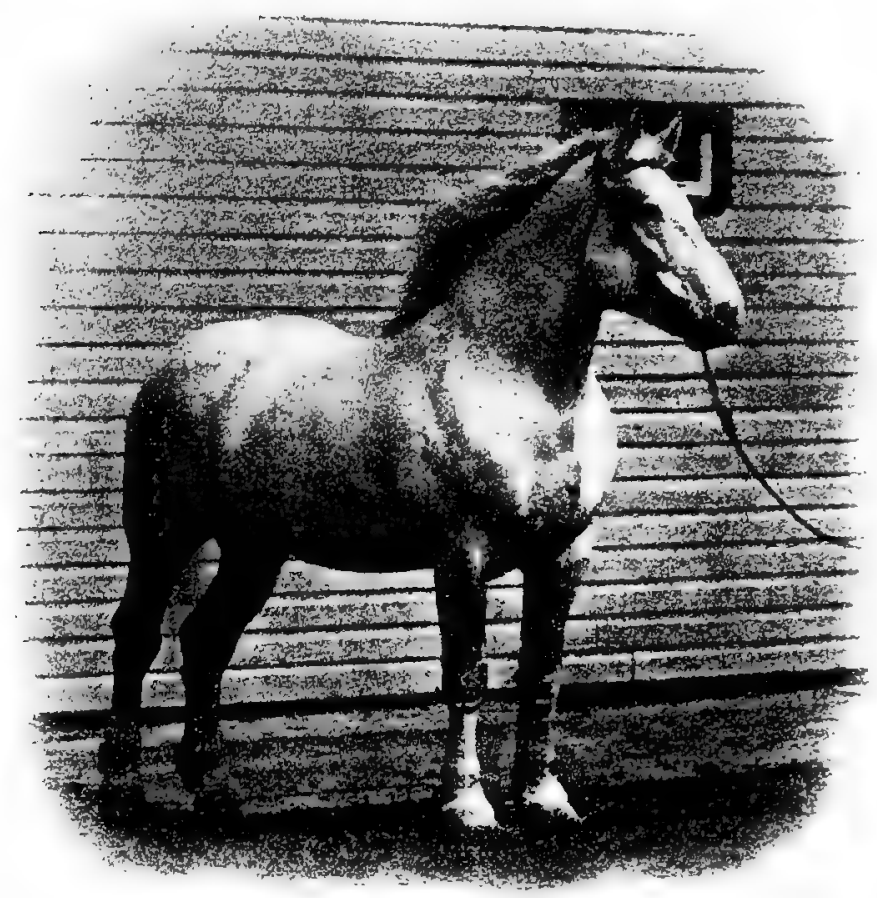

FIG. 35. A fine example of Percheron type and character. From photograph by John W. Hills

Danish horses. These became popular, and later others of the same sort were taken to Normandy. Then English stock was introduced, and horses also came in from adjoining districts and from Belgium. In 1820 two Arabian stallions, Godolphin and Gallipoli, from the government stud at Le Pin, were used on French mares. These sires were gray, and no doubt had considerable influence in developing the gray color among the horses of $\mathrm{La}$ 
Perche. The general effect of this Arabian blood on the French horse has been to impart quality, as shown in superior bone, style,

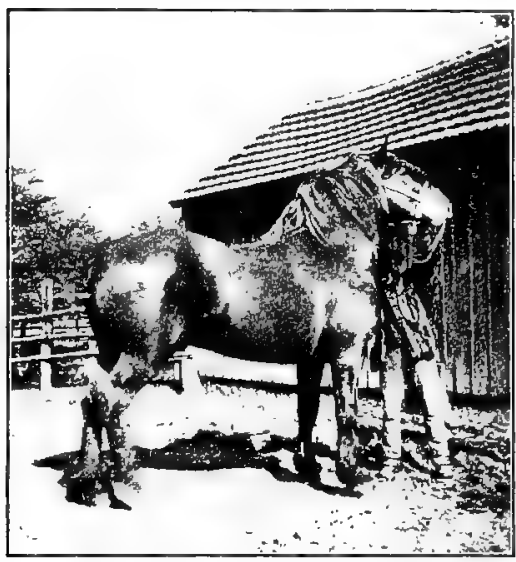

FIG. 36. Orangiste 29606. First-prize threeyear-old Percheron in France in 1902 at the annual show at Paris and at the show of the Société Hippique Percheronne at Nogent-le-Rotrou. Also first prize in class at International Live Stock Exposition, Chicago, 1902. Imported by McLaughlin Bros. Photograph taken by James B. McLaughlin in France and finish. Gallipoli, in particular, had a very beneficial influence. Jean Le Blanc (739), foaled in 1823 , a grandson of Gallipoli, is regarded as having had a remarkable influence on the breed in his day.

The early type of Percheron resulting from this amalgamation of races was not so large a horse as is known to-day. The farmer of La Perche required a horse suited to general purposes, so the early type was smaller and more active of foot than the presentday Percheron. Either under saddle or .before gig, Percherons trotted with considerable speed. Records of Percherons show that not in-. frequently they have trotted at a rate of about a mile in four minutes. Richardson gives interesting illustrations of the ability of this horse to travel long distances with considerable speed:

A gray mare six years old which took a heavy gig 56 miles over a heavy road in 4 hours and 24 minutes; and another, seven years old, drew an ordinary country gig 55 miles in 4 hours, 1 minute, 35 seconds, returning the next day over the same ground in 4 hours, I minute, 30 seconds, the last 14 miles being covered in 1 hour, and neither in going or returning was she touched with the whip.

The characteristics of this early type showed less scale, a lighter weight, with a height ranging from 15 to 16 hands. It was a superior general-purpose horse of drafty conformation, yet lacking large size and heavy weight. This type met with such great favor that buyers from various parts of France, 
Germany, and elsewhere began to draw upon La Perche for their horse stock.

Percheron deterioration came in with the improvement of the breed. Toward the close of the first third of the nineteenth century the demand for these horses in La Perche became so great that the farmers sold their best brood mares and stallions to such an extent as to require their replacement. Not enough good Percherons were available, so that other French races were introduced. Large numbers of mares similar to Percherons in size and style were introduced from Brittany, Picardy, Boulogne, Caux, and elsewhere. These often lacked bone, substance, and quality. With the improvement of highways came a demand for heavier horses, and then buyers purchased large ones to meet the increased demand. For a time quality was sacrificed for quantity, the heaviest stallion being most in demand. Many of the best brood mares of lighter type were sacrificed, thus causing serious deterioration. This condition of affairs continued for some years, until breeders recognized the absolute necessity of superior type and quality with increased size.

The type of Percheron about 1877 is thus described by Richardson, an English writer who was familiar with these horses in their native home.

The characteristics of the best horses are that they run from 15 to I6 hands in height; the head is handsome, though perhaps sometimes heavy, but more frequently as fine as an Arab's; the nostrils wide; the eye large and expressive ; the forehead broad; ears silky; neck rather short, but with a good crest; withers high ; shoulders long and sloping; chest rather flat, but broad and deep; body well ribbed; loins rather long; crupper level and muscular; the buttocks often high, leaving a depression above the junction of the tail, which is set on

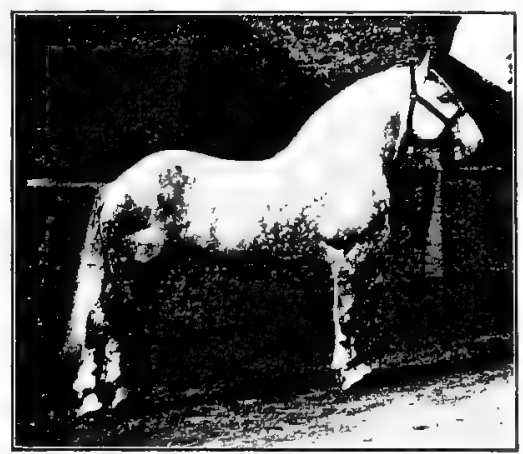

FIG. 37. Pyrrhus, a prize-winning Percheron stallion in France at Nogent-le-Rotrou and Vendôme. Photograph taken in France by James B. McLaughlin high; joints short and strong; the tendons often weak; legs clean and free from coarse hair; feet always good, though rather flat when reared upon moist pastures; the skin fine, and mane silky and abundant; the color 
is generally gray, but there are some grand black Percherons. .. . Docile, patient, honest workers, very hardy, the Percherons are unexcitable, but active and cheerful, rarely showing bad temper, and very free from natural blemish, trotting away cheerfully with heavy loads. The French call them the best draught horses in the world.

Yet even when Richardson penned this (I877) he stated that these qualities were rarely found combined in any of the Percheron horses, on account of the deteriorating influences already referred to.

The more approved type of Percheron to-day calls for all the best features in the model draft horse. In weight mature stallions usually average from 1700 to 2000 pounds, and mares from I 500 to 1800 pounds. Exceptions, however, very naturally occur. Univers 33977 P.R., the celebrated show stallion, weighed in show form about 2300 pounds, while Chichi 40072 P.R., as a two-year-old in show form, weighed 2150 pounds. A most approved weight of mature mare is 1650 pounds. The height of stallions ranges from $15 \frac{1}{2}$ to $I 7$ hands, and mares from I $5 \frac{1}{2}$ to $16 \frac{1}{2}$. Tall Percherons are not regarded with favor, a lower set form being preferable. The color is usually a gray or black, but bays and browns occasionally occur. Fashion has caused some changes in color production, there having been periods when grays were most common, while later blacks were much in favor. It is said that at the fair at Chartres, France, in February, I 877 , one dealer had eighteen blacks, for which he asked about the equivalent of $\$ 10,000$ for the lot, "and they were well worth it." Grays have been most popular in the United States and France, and dark gray may be regarded as a typical Percheron color. However, in spite of the criticism of black as a horse color, the opening years of the twentieth century have seen a great demand for black Percherons or dark iron grays, and most of the horses recently imported have been of these colors.

The body of the Percheron is characteristically compact and blocky of form, full in the chest, and broad of back. Horses of the breed, however, often have steep, rather short rumps, with the tail set too low, and even with the best specimens the type of rump tends to unnecessary slope. In depthand fullness of body there is also a lack. The legs and feet are quite distinctive of 
the breed. No more shapely and well-developed feet are found on any draft horse than on the Percheron. The bone of the leg is usually superior, but the cannons are not infrequently lacking in breadth and flatness, while the hocks may be fuller than is desirable. The clean limbs, free of long hair, account for much of the popularity of the Percheron in America. Percheron action at a walk is reasonably true and snappy. The trot, with good representatives of the breed, is carried with vim and life, the knees

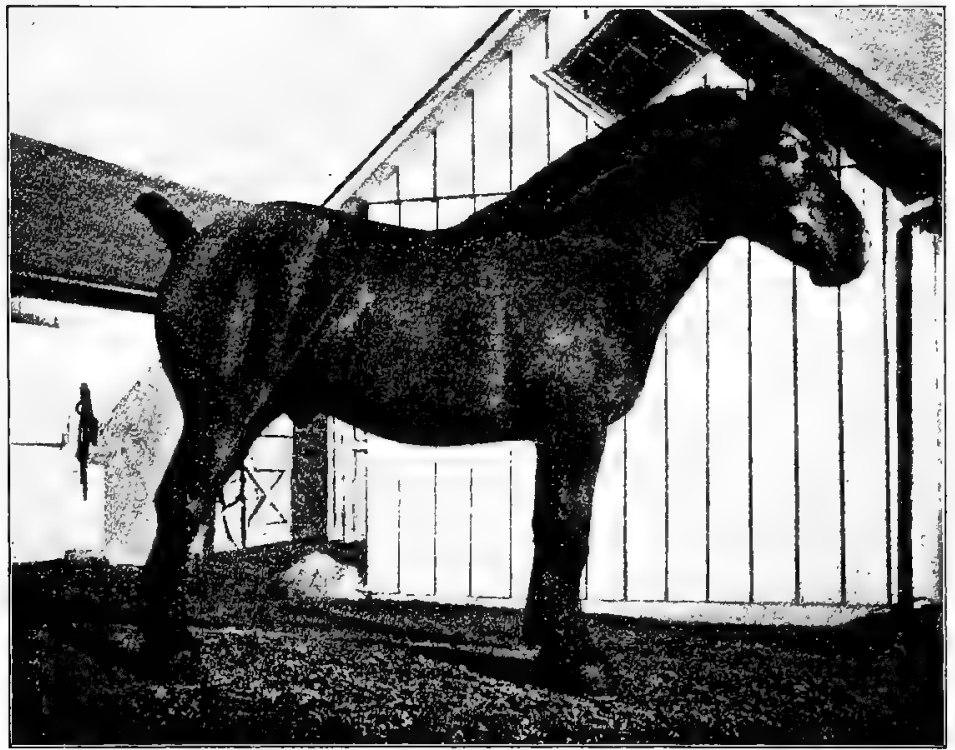

FIG. 38. Monaco II. A capital stamp of a Percheron stallion, first in a ring of 29 at the International Live Stock Exposition, Chicago, 1905. Imported by McLaughlin Bros. Photograph by the author

being moved strong and the hocks well flexed. The Percheron may be regarded as one of the very best actors among the draft breeds, being surpassed only by the Clydesdale. The Percheron head and neck are typical of the most attractive draft-horse character. The eye is usually full and prominent, the forehead broad and reasonably full, the face straight or slightly dished above the nose, the jaw strong, the ears refined and attractively set and carried with animation. The graceful neck is usually 
smoothly blended with the body and cleanly attached to the head, being crowned with profuse mane and foretop. Those things which give special distinction to the Percheron breed are the head and neck suggesting the Arabian, the blocky body and droopy tendency of rump, the short smooth legs, the characteristic color, and the superior action. As a draft beast the pure-bred or high-grade Percheron ranks in France and America at the very front, with no superior.

The improvement of the Percheron in France is due to both public and private methods. The government for over a century has maintained studs in which select animals have been kept for breeding purposes. The best horses in France have been in the past and are at present reserved by the government for home improvement. In addition to this, subsidies are paid private individuals to keep horses of merit in the stud. Animals are critically inspected by government veterinarians, and if up to a certain standard, they are designated as subsidized, and a cash bonus is paid for keeping them in the country on the farm of the owner, available to the owners of mares. This bonus ranges from 300 to 500 francs ( $\$ 60$ to $\$ 100$ ) per year, according to the breeding and excellence of the stallion. Horses of not quite so good a grade are authorised after passing inspection, and the owners are given a card which is a government recommendation of the sires to farmers. A third class, known as approved, of which there are but few, are permitted to be in service, but neither bonus nor special certificate is given for them.

Since I 885 a government decree has excluded from public service all stallions not coming within these classes.

The Percheron horse society of France (Société Hippique Percheronne) was organized in 1883 , and its purpose has been to promote the purity of the breed. In I 890 this society passed a rule that all colts must be entered for registry between the ages of three and six months. At the time of registration a veterinarian appointed by the society is required to brand its official mark on the colt's neck.

American Percheron horse associations date back to 1876. At this time, owing to the common usage of the word Norman, it was planned to organize the Norman Horse Association. French 
horses, known as Normans, had been used in the West some years, for as far back as 1854 Dillon \& Company, of Normal, Illinois, showed what they termed Normans. The word Percheron was also in use. Mr. J. H. Sanders had been made secretary of the new association, and he added the word Percheron to the title, so that it read Percheron-Norman Horse Association, and his action was approved. This was followed by some members withdrawing and organizing the National Register of Norman Horses, which was later changed to the National Register of French Draft Horses. With the organization in France of a Percheron society the word Norman was dropped from the American title, in order to correspond with that of the French association. The career of the American Percheron Horse Breeders' Association proved rather unsatisfactory to many of its members, due to too much one-man power vested in its secretary. This resulted in the organization, in 1902 , of the American Percheron Horse Breeders' and Importers' Association, with headquarters later established at Chicago, Illinois. In 1905 the name of this was changed to the Percheron Society of America. There was also organized in 1902, at Columbus, Ohio, the Percheron Registry Company. More recently, in October, 1905, another association, known as the American Breeders' and Importers' Percheron Registry, was incorporated, with headquarters at Plainfield, Ohio. Each of these associations was organized to promote the breed in America, to register animals, and to publish studbooks. The old association is now defunct, but the other three are actively promoting the breed.

Percheron studbooks are published both in France and America. Volume I of the French book (Stud-Book Percheron publié par la Société Hippique Percheronne) first appeared in 1883 , since which numerous volumes have been issued. The old Percheron-Norman Horse Association published two volumes, the first appearing in 1877 . Later, with the change of name to Percheron Horse Association of America, three more volumes were issued under the name of the Percheron Studbook of America. In 1906 this association published Volume VI. In 1905 the Percheron Registry Company published Volume I. 
The introduction of the Percheron to the United States dates back many years. French horses were brought to America as long ago as I8I6, when a stallion was taken to Quebec and later sold to go to Washington County, New York. It has been assumed that this was a Norman horse. In I 839 the first "genuine" Percheron importation to America was brought over by Edward Harris to Moorestown; New Jersey. This importation consisted of one stallion and two mares. The stallion died at sea, and the mares were unfortunate, one landing in poor health, while the other injured herself in car shipment, necessitating killing. Mr. Harris at once returned to France and

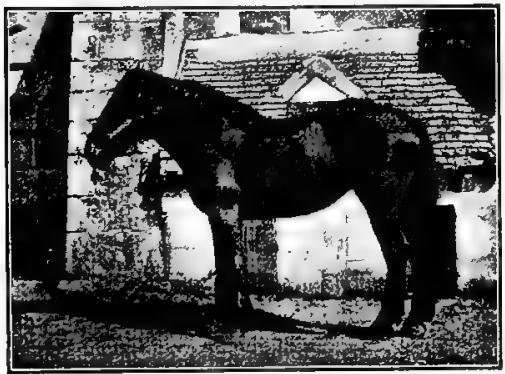

FIG. 39. Ténébreuse. A Percheron mare owned in France. Photograph by James B. McLaughlin, Columbus, Ohio imported the stallions Diligence and Bonaparte, with several mares. These wcre the smaller type of Percheron, standing about 15 hands high and weighing 1200 to I 500 pounds. Diligence, who died in 1860 , was regarded as a fine specimen of the breed.

An important half century of Percheron history in the United States began in $185 \mathrm{I}$. At this time Fullington and Martin, of Milford Center, Ohio, brought to that state the first importation to the West, the gray colt Louis Napoleon. He was $15 \frac{1}{2}$ hands high and weighed 1600 pounds. In $1856 \mathrm{~A}$. P. Cushman of Illinois purchased him. Louis Napoleon proved to be a great breeder, and was no doubt one of the very best draft horses ever brought to America. It has been estimated that over 400 of his sons were successful stallions. In I85 I another importation was also brought to Ohio by Dr. Marcus Brown of Circleville. He imported a stallion named Normandy, often referred to as "Pleasant Valley Bill," "Old Bill," or "The Valley Horse." He stood I $5 \frac{1}{2}$ hands high and weighed about 1500 pounds, and it is said that for eighteen years he averaged about sixty colts a year. Also the same year Captain Samuel Holmes, of Chester Springs, Pennsylvania, brought two stallions from France, and following 
these two, others were brought over for John J. Parker of West Chester and Edward Shippen of Meadville. In 1856 Jordan and Martin, of Woodstock, Ohio, imported a stallion named Rollin, which was not long after sold to go to Illinois.

Numerous importations followed the above. In I866 W. T. Walters, of Baltimore, Maryland, brought over several mares and stallions, he being the first person to establish an important breeding stud in America. Mr. Walters had lived in France and had studied the breed there, and so was able to buy to advantage. In I $870 \mathrm{M}$. W. Dunham, of Wayne, Illinois, and in I874 William Singmaster, of Keota, Iowa, began breeding and importing. They both became famous Percheron authorities, and the studs founded by them are still in existence. Besides these the Stubblefields of Bloomington, Ellis Dillon of Normal, and Ezra Stetson of Neponset, Illinois, and the Fullingtons of Ohio were early breeders and importers.

The distribution of the Percheron in America is widespread. Weld estimates that in 1866 there were fully five thousand Percherons in this country, but no doubt many of these were French drafts of other breeds. The leading breeders and importers have seemed to center about Illinois, Ohio, Iowa, and Michigan, with small studs scattered all over the country, but notably in the Mississippi Valley. Between I85 I and I883 nearly four thousand Percherons were imported or bred in the United States of which a more or less correct record is kept. These were widely distributed, Illinois having I834; Ohio, Indiana, and Michigan 577 ; Wisconsin, Iowa, and Minnesota 424 ; New York, Pennsylvania, and New Jersey 280; and Missouri, Kansas, and Nebraska 186. In the early eighties many were brought over, 2600 being reported as imported or homebred in $188 \mathrm{I}, 1882$, and I 883 . In 1884 more than two thousand of all ages were brought to America from France. At the present time (1906) importations are quite active, and considerable shipments of stallions are being made to states in the Northwest and on the Pacific slope. In Canada horses of this breed are in use, but not on so extensive a scale as the British draft breeds.

Cross-bred or grade Percherons are very common in America. In fact the number of pure-bred registered mares is comparatively 
small. Pure-bred stallions mated to the larger type of grade mares, of drafty conformation, furnish most of our best draft teams. Prepotent Percheron stallions mated to mares of other draft breeds also usually give satisfactory results, and this is a favorite combination in some localities where legs with feather hairs are found on mares of Clyde or Shire ancestry. The resulting offspring are usually smooth-legged and more easily satisfy the common market demands. In the South, Curtis has not reported so favorably on the mating of Percherons on native mares, finding that the "half-blood colts" were somewhat prone to bone and leg diseases. This, however, is not a general difficulty with Percherons, for if it were the popularity of the breed would long ago have suffered severely. The most prominent buyers in the Chicago horse market have testified in the highest terms to the demand for Percheron grades and crosses, and repeatedly grade geldings of show-ring form have sold for $\$ 500$ per head and over.

Famous Percheron sires. Naturally during the history of the breed there have been many sires of excellence in America. Among these the following ten stallions may be regarded as of special importance, mainly on account of their influence as breeders, although some of them were famous show horses.

Loutis Napoleon 281 : foaled, 1848 ; imported, 1851.

Normandy 35I (also known as Pleasant Valley Bill): foaled, I849; imported, $185 \mathrm{I}$.

Success 452 : foaled, 1864 ; imported, 1868.

Vidocq 483 (732): foaled, I869; imported, I874; sire, Coco II (714); dam, by Cheri.

Brilliant 1271 (755): foaled, 1876 ; imported, 1881 ; sire, Brilliant 1899 (756); dam, Ragout, by Favori I (711).

French Monarch 205 (734): foaled, March, I865; imported, 1874 ; sire, Ilderim (5302); dam, by Vieux Pierre (894).

Fenelon 2682 (38): foaled, 1880 ; imported, 1883; sire, Brilliant 1271; dam, Ernestine, by Duke of Perche 173 (740).

La Ferte 5144 (452): foaled, I 881 ; imported, 1886; sire, Philibert (760); dam, Julie (7594), by Brilliant 1899 (756).

Gilbert 5154 (461): foaled, 1882 ; imported, 1886 ; sire, Brilliant 1271 (755); dam, Sophie (7694).

Seducteur 8850 (7057): foaled, 1884 ; imported, 1888 ; sire, Fenelon 2682 $\left(3^{8}\right)$; dam, Rosalie (5688) by Brilliant 1899 (756). 
Of the above horses Louis Napoleon and Brilliant were probably most famous, each proving remarkable breeders, although all of the horses in question stand out as famous sires.

The leading Percheron shows in France are held under different conditions. Each year a great central show is held at Paris. For years the annual Percheron show of France has been held in a migratory way, coming back to the same locality every twelve years. In 1905 it was held at Rouen. The Percheron Society show is held once each year in La Perche district, at either La Ferte, Mortagne, or Nogent-le-Rotrou.

The American Percheron shows of most importance are held at the International Live Stock Exposition, Chicago, the Kansas City Horse Show, and the state fairs of Ohio, Illinois, Iowa, Missouri, Indiana, Minnesota, and Wisconsin.

Very high prices for Percherons have been paid. Mr. Dillon, of Illinois, was the first importer to pay as much as $\$$ I 600 for a stallion in France, paying this price in 1882 . The late M. W. Dunham years ago made one sale of three mares and a stallion for $\$ \mathrm{ro}, 000$. In I903 McLaughlin Bros., of

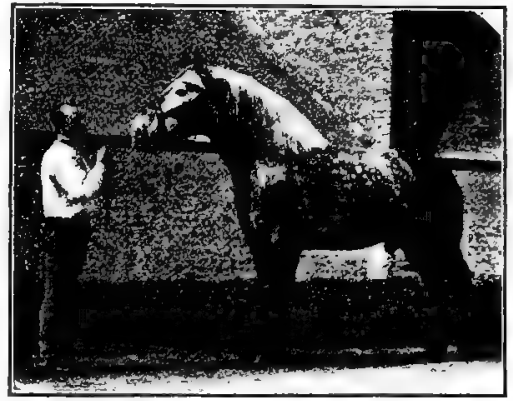

Fig. 4o. Adrian. A Percheron stallion showing excellent breed type. Photograph from James B. McLaughlin Ohio, sold the stallion Orangiste 29606 for $\$ 5500$, and a month later sold Pour-Quoi-Pas 27248 for $\$ 7000$. In December, I 905 , this same firm sold the stallion Rosenberg, grand champion Percheron at the International Live Stock Exposition, for $\$ 8000$, the highest price paid for a draft stallion in America. McLaughlin Bros. also sold Fronton 34289, the champion stallion of the breed at the Louisiana Purchase Exposition, for $\$ 6500$. These represent the highest prices associated with this breed.

Percheron geldings are great favorites in the horse market and many very high-class ones are sold. At the 1905 International Exposition the six-horse teams of geldings exhibited by Armour \& Company and Pabst Brewing Company caused universal 
admiration. George, owned by Pabst, the first-prize gelding of the 1904 exposition, weighed when shown 2140 pounds. In I905 the Pabst Brewing Company purchased a pair of geldings on the Chicago horse market, paying $\$ 1300$ for them, the highest price thus far paid for such a team.

The present popularity of the Percheron is very great. While it is true that any high-class draft horse is looked on with favor in the market and readily commands a good price this breed is an American favorite. No other draft breed is raised pure on so large a scale as this. Percheron studs, containing pure-bred mares, are becoming more common than ever before in the United States. The large number of horses of this breed seen at the shows, attests its general favor in the Mississippi Valley. In the horse market Percheron blood predominates. This popularity is largely due to docility, intelligence, activity, heavy weight, excellent feet, and reliability in heavy draft work. This prestige bids fair to remain for years to come. 


\section{CHAPTER XVI}

\section{THE FRENCH DRAFT}

A brief consideration of the French Draft horse is essential, although no recognized breed of this name exists. In America it has been customary for many years to refer to draft horses brought from France as French Draft horses. Not only this, but we now have in the United States an organization which registers draft horses from France in a French Draft studbook.

Distinct breeds of French Draft horses, however, are well known, and in France are clearly recognized. Years ago there was some confusion among importers on this point, but at the present time we have more definite knowledge on the subject. All heavy horses in France are not of the same breed, even if brought to America as French Draft. It is quite customary to name certain European breeds after the localities in which they received their chief development, and this applies to the horses of France. It is extremely doubtful if any draft horses come to this country from France that cannot be properly listed as belonging to one of the following breeds, which essentially represent the characteristic draft breeds of that country.

I. Percheron. This is the best-known and most highly developed of the French Draft breeds. For an extended consideration of the breed, see Chapter XV.

2. Boulonnais. This breed is largely found in the district of Boulogne in northern France and in adjoining Belgium, deriving its name from the former. The breed is somewhat larger and coarser than the Percheron, is coarser of neck, steeper and squarer of croup, and while not deficient in action, shows less than the Percheron. The color is variable, though frequently gray or white. It is claimed by the French that there is no interchange between the horses of Boulogne and La Perche, and that the Boulonnais has mainly been improved by selection and care, 
though it is suggested that some improvement may have come from Percheron blood. The breed has an excellent reputation in France, where a studbook kept in its interest is widely used, and the Boulonnais is regarded as second only in importance to the Percheron. Prominent importers have stated that Boulonnais horses have not been extensively brought to America, although no doubt they are well represented in the United States under the names of Norman or French Draft.

3. Breton. This breed belongs to Brittany in extreme western France, in a section opposite southwest England, from which it is separated by the English Channel. This is quite a prominent horse section, but in its past history rather miscellaneous breeding has been resorted to. English, Arabian, and cross.bred stallions have been used, and more recently Percheron. Richardson, in discussing these horses thirty years ago, says :

Though larger than the horses of the center, those in the north only run from 14 hands to 15.1 , having improved up to the latter point, which the best horses now commonly reach. They are of much the same character as the Percheron; indeed, there has been a continual interchange between the two districts, and the color is chiefly the same - gray; but the Breton horse has a heavier head, more hair about the heels, broader feet, a heavier frame, he is shorter below the knee, and the pasterns are shorter, in fact, he shows less blood.

In the past large numbers of weaned foals have been sold to go out of Brittany. "Nor," says Richardson, " are they known again as Breton horses. The grays become Percherons and the bays Normans."

Leading Percheron importers claim that none of the Bretons are brought to America, but that they are largely used for omnibus horses in Paris.

4. Nivernais. This breed is mainly found in the department of Nière in central France. It is a somewhat modern black breed, largely the result of using black Percheron stallions on the mares of the region, which are hardly as large as Percherons. This breed has not been imported to any important degree, as it does not exist in large numbers in its native home, this region being most celebrated for its cattle. 
5. Ardennais. This is a native of Ardennes on the Belgian frontier in northern France. It has been described as a small type of Belgian, and is probably not much imported.

6. Picardy. French authorities rather class this as the Flemish horse, very large and generally bay in color. It is bred in northern France and Belgium, and is in fact the Belgian breed, though M. La Motte Rouge, who was for many years employed in the government studs of France, claims that the Picardy is in fact a variety of Boulonnais.

Of the above breeds the first three are the only ones of importance as possibly affecting American trade.

The National French Draft Horse Association of America publishes a studbook in which may be registered any of the abovenamed draft horses, irrespective of breed. This association was first organized as the National Norman Horse Association in 1876 , but in 1885 its title was changed to the National French Draft Horse Association. This was entirely correct, as there is no such breed of horses in France as Norman, notwithstanding the current use of this word in America for over half a century. Thus far this association has published eight studbooks. 


\section{CHAPTER XVII}

\section{THE CLYDESDALE}

The Clydesdale is the recognized draft breed of Scotland and stands to-day in great degree as the product of Scotch breeders.

The early history of the Clydesdale is veiled in more or less obscurity. Scotch writers on the horse state that in the seventeenth and early part of the eighteenth century there was doubtless an interchange of draft-horse blood between Scotland and England. Scotch cattle dealers driving herds into England returned north with English mares which were bred to stallions in the northland. This was prior to the use of the word Clydesdale. Claims have been made that the Duke of Hamilton brought black stallions from Flanders in Belgium to Scotland about the middle of the seventeenth century, and bred them to the native Scotch mares. This, however, is traditional. Undoubtedly very mixed blood was in the early breeding.

The origin of the modern Clydesdale seems to trace back to about 1715 or 1720 . John Paterson was a tenant farmer of Lochlyoch in Carmichael parish in the county of Lanark. This county is in southern Scotland, and through its center flows the river Clyde, from which the name Clydesdale is derived. Written testimony of the family shows that at about the above-referredto period Paterson brought a Flemish stallion from England to Lochlyoch, which was bred to the mares in the region thereabouts. The result of this union created a superior strain of draft horses for that time, and they met with special favor during the latter part of the eighteenth and the early part of the nineteenth century. Breeders valued the influence of the Lochlyoch blood, and this is now regarded as essentially Clydesdale foundation stock. The mares descended from this Flemish stallion are described as "generally browns and blacks, with white faces and a little white on their legs; they had gray hairs in their 
tails, along with occasional gray hairs over their bodies, and invariably a white spot on their belly, this latter being regarded as a mark of distinct purity of blood."

The use of English blood on the Clydesdale, following the days of Paterson up to comparatively recent times, is admitted by Professor Wallace, a leading Scotch authority. Tintock, a Shire stallion, along about 1860 was used in Scotland on Clydesdale

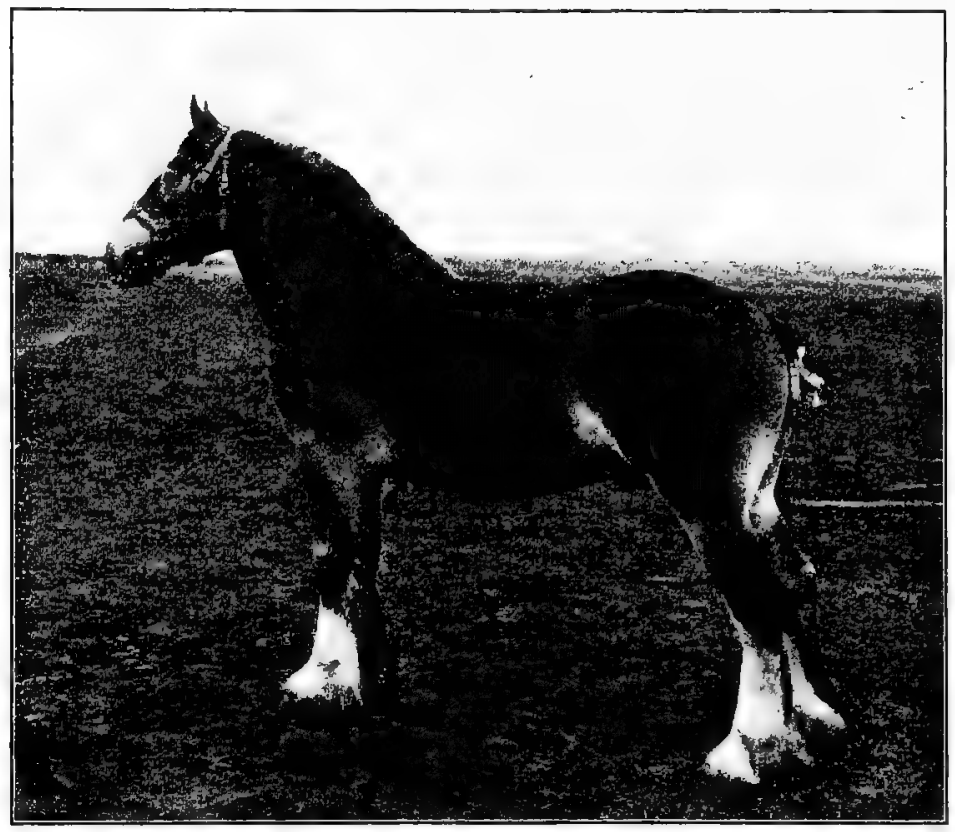

Fig. 41. His Royal Highness. Junior champion Clydesdale stallion at Louisiana Purchase Exposition, 1904. Bred and owned by McLay Bros., Janesville, Wisconsin. Photograph from owners

mares, producing very excellent breeding females. The grandams of the Prince of Wales were both Shires of English blood. In I842 Professor Low commented on the distribution of the breed, and stated that they "have been mixed in blood with all the other varieties." During recent years, however, the Clydesdale has been maintained as a pure breed.

Important Clydesdale sires, other than the Flemish stallion of Paterson, date back to early in the nineteenth century. The first 
of distinction was Glancer (335), alias Thompson's Black Horse. The Scotch studbook states that he was foaled about 1810 , but this date is questioned. The story is that Glancer was sired by a black stallion named Blaze, bought in Ayrshire about I 780 and taken to Lanark for service. He was a stallion $16 \frac{1}{4}$ hands high, perhaps had some coach blood, and possessed both style and action. Blaze in service to a mare known as the Lampits mare, on the Lampits farm in Lanark, sired Glancer. The result of this union became more than locally famous, for from him "nearly all the best animals of the present day are descended," says the American Clydesdale Studbook. Glancer's dam, which died in 1827 , was a famous brood mare, having produced other superior foals.

Broomfield Champion (95) was a notable stallion following Glancer (335). He sired Clyde alias Glancer (153), Glancer (338), Bowman's Colt ( 1078 ), and a number of great brood mares. Some of his offspring were successful in the show ring, but his chief distinction comes from being the sire of Glancer (I53). Broomfield Champion was brown with white hind pasterns and a narrow white streak on the face. His name is most frequent in early Clydesdale pedigrees.

Clyde, alias Glancer ( 153 ), was owned by William Fulton of Renfrew County, a noted breeder, and was bred by Mr. Forest of Lanark County. Though not a show animal himself, from I 844 to 1850 the leading honors of Scotch exhibitions went to the produce of Clyde. He was dark brown in color and, having been ruptured, was known as "The Ruptured Horse." Seven sons and one daughter of his are recorded in the first volume of the Scotch Clydesdale Studbook. Most of these sons proved later to be sires of great merit, and were used in various localities in improving the breed.

Prince of Wales (673), foaled in 1866 , bred by James $\mathrm{N}$. Fleming of the county of Ayr, and later owned by several different persons, was one of the two greatest Clydesdales in recent history. He was sired by General (322), whose sire was Sir Walter Scott (797), a great show horse and breeder, while his dam was Darling, a mare of unknown breeding beyond one generation. Prince of Wales was a dark brown horse with a white stripe on 
his face and more or less white on three legs. He was somewhat straight in his hocks and a bit Roman-nosed, but in general was of good form and a remarkable mover at walk or trot. He was not only a great show horse, but was regarded as one of the greatest breeders of sires that the Clydesdale breed has produced. Prince of Wales was last owned by David Riddell, of Paisley, who purchased him at auction when eighteen years old

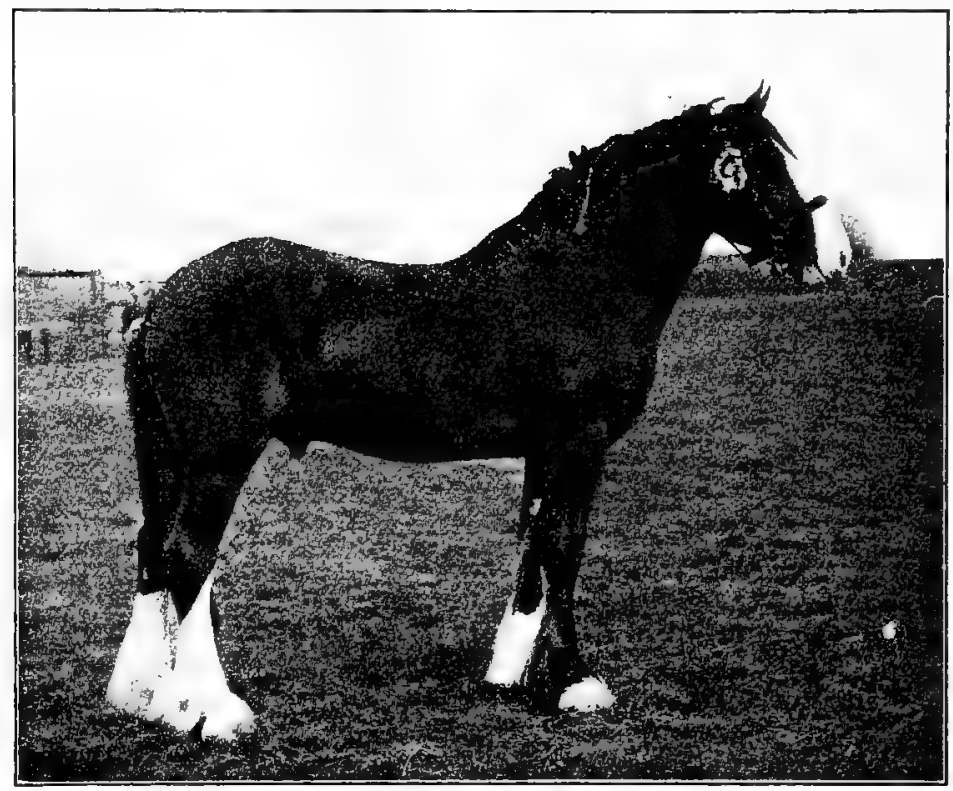

FIG. 42. Baron A lister. Clydesdale stallion, champion in I904 at the Royal Agricultural Society Show of England. Exhibited by A. \& W. Montgomery, Scotland. Photograph from William Cooper \& Nephews, Berkhamsted, England

for $\$ 4725$, and in whose possession he died in I 888. Prominent among his sons are Prince of Albion, sold for $\$ 15,000$; his full brother, Prince of Kyle, sold for $\$ 8000$; Prince Alexander, sold for $\$ 6000$ as a yearling; and Prince Robert.

Damley (222), foaled in 1872 , a bay, was bred by Sir William Sterling-Maxwell and was purchased when three years old by David Riddell, the owner of Prince of Wales. His sire was Conqueror (199); and his dam, Keir Peggy (I87), had a fine 
show-yard record, and as a dam of ten foals is regarded as one of the greatest mares of the breed. Her sons, Darnley, Pollock, and Newstead, all won first prizes at the Highland and Agricultural Society shows. She died in 1888 . Darnley himself had a most distinguished career in the show ring up to twelve years of age. If Prince of Wales was a great stallion sire, so Darnley was a famous sire of mares. The descendants of these two animals mated unusually well, and from their union has resulted much that is best in recent Clydesdale blood. Three of Darnley's best sons were MacGregor (1 487), Flashwood (3604), and Topgallant (1850). These were all great horses, but especially so was MacGregor, whose sons gained fame in the show rings of Canarla and the United States. As a breeder this animal is regarded as second only to his sire and Prince of Wales.

Baron's Pride (9122), sired by Sir Everard (5353), a son of Topgallant (1850), represents the most distinguished of recent Clydesdale sires. He proved a fine show horse, while his get have been most successful. His son Benedict (IO315) 9300 was a successful show horse in Scotland, and was imported to the United States in 1900 by Brookside Farm, Fort Wayne, Indiana, where he stood at the head of that famous Clydesdale stud till December, 1904, when he was sold to Scotch buyers and returned to Scotland.

Other Clydesdale sires that have performed an important part in the history of the breed in Scotland during the latter part of the nineteenth century make a considerable list. Those worthy of special mention are Lord Erskine (144), by Boydston Boy, foaled in 1879; Farmer (286), by Merry Tom (536), foaled in I869; Merry Tom (536), by Rob Roy (714), foaled in 1860; Lord Lyon (489), by Hercules (378), foaled in 1867 ; Old Times (579), by Lord Clyde (478), foaled in 1869; Lochfergus Champion (449), by Glancer (338), foaled in I86I; Topsman (886), by Wonderful (9I5), foaled in 1869 .

Clydesdale characteristics. This breed of draft horses possesses certain features of a distinctive kind, on which loyal Scotchmen lay great emphasis. The feet and bone and action are cardinal points with Clydesdale breeders. The feet must be large, round, and open, with an elastic frog and well-spread, clearly expressed 
heel; the coronet wide; the pasterns fairly long and rather sloping ; the cannons short, flat, hard, and cordy; and the fore arms, arms, thighs, and quarters notably muscled and strong. From the back side of the leg at the cannons should grow an abundance of long, fine hair, a striking feature in the best specimens of Clydesdales, indicative of quality. White feet, though common, are objectionable, since they lack the density and wearing power of dark feet, and there is a distinct objection to them in the Argentine and elsewhere. Emphasis is laid on the fullness of the feet, the obliqueness of the pastern, and the flatness and cleanness of bone of lower leg. The body of the Clydesdale has been most subject to criticism in the past, lacking in depth and circumference when it should have fullness as showing both feeding capacity and weight to draw loads. Good horse critics still insist that this deficiency of form is still too prevalent with this breed.

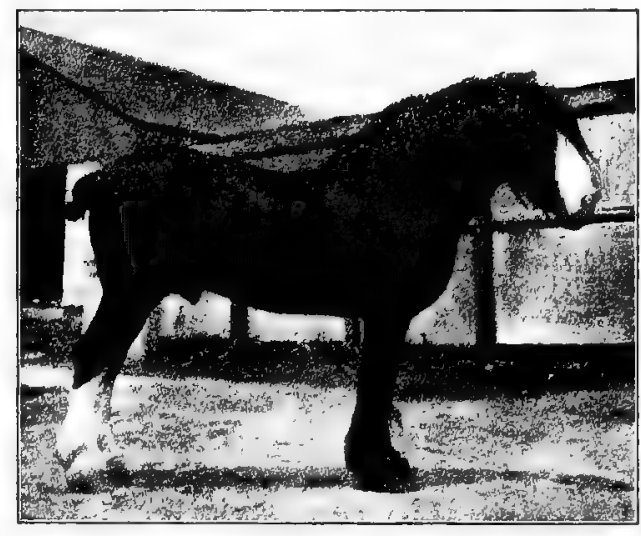

FIG. 43. Benedict 9300, a Clydesdale stallion imported to America by Brookside Farm, Ft. Wayne, Indiana. In 1904 bought by Montgomery Bros., of Scotland, and returned to that country. One of the greatest sires among modern Clydesdales. Photograph by the author

The shoulder is rather

oblique, with high withers, being superior in this respect among the draft breeds. The chest is narrower than with other drafters, a very wide chest being regarded as objectionable, giving less action and more of a paddling gait than is consistent with smooth, true movement. The action of the Clydesdale is notable, not being surpassed by any breed. Says Alexander Galbraith, an acknowledged Scotch-American authority on this breed:

Great attention has been paid by the Scottish breeders during the last twenty or thirty years to the matter of action. No other draft breed has received one half the attention that the Clydesdale has in this respect, and 
for that reason they far surpass all others in length of stride, in straightness and sprightliness of movement, in their ability to keep their hocks together, with mechanical accuracy of motion, whether walking or trotting.

The head of this breed does not differ essentially in its requirements from a correct conformation. The writer discussing the Clydesdale in Heavy Horses (1894) notes some peculiarities of the head worth recording here :

A tendency to "dish face" may be observed in some tribes, and this is generally accompanied by a small ear and what, in the main, is characterized as a "pony head." Wherever this style predominates there is probably a strain of Highland or old Galloway in the blood. On the other hand, the hard, narrow face and Roman nose are regarded as equally if not more objectionable. Such features are usually indicative of a strain of Shire blood and, indeed, they are not otherwise to be accounted for in the Clydesdale. An open, level countenance, vigorous eye, and large ear are greatly valued, and are not readily sacrificed.

The height of the fully developed stallion is about $16 \frac{1}{2}$ hands, with the mares from one to two inches less. Prince of Albion $(6178)$ and Flashwood (3604), two nearly model specimens of the breed, stood $16_{4}^{3}$ and 17 hands respectively. Weights of 2000 pounds for the stallion and 1800 for the mare represent good standards, though somewhat above the average. The standard color markings are bay or brown, with a white star or blaze on the forehead or face, and with all or part of the legs, up to the knees and hocks, white. There are also occasional blacks, grays, or chestnuts. Gray is unpopular and chestnut indicates Shire blood.

The first Clydesdales brought to America were probably taken to Canada, doubtless on account of the love of Scotch settlers there for their favorite breed. The following represent the earlier importations, the first occurring in I 842: Gray Clyde 78, importer, Archibald Ward, Markham, Ontario, 1842; Sovereign I8I, importer, R. Johnson, Scarborough, Ontario, I 845 ; Cumberland 106, importer, David Roundtree, Jr., Weston, Ontario, I850; George Buchanan 182, importer, John Wilson, Oshawa, Ontario, 1851; Bay Wallace 5, importer, William Cochrane, Claremont, Ontario, I 854.

Along in the seventies Clydesdales were brought to the United States in a small way, both through Canada and by direct 
importation. In the early eighties they were brought over in larger numbers, especially in $188 \mathrm{I}$, and between then and 1892 the trade increased greatly and several thousand stallions and mares were brought across the water and distributed over the country.

Clydesdales of merit in America date back to their early importation. Of these the following may be mentioned as of special

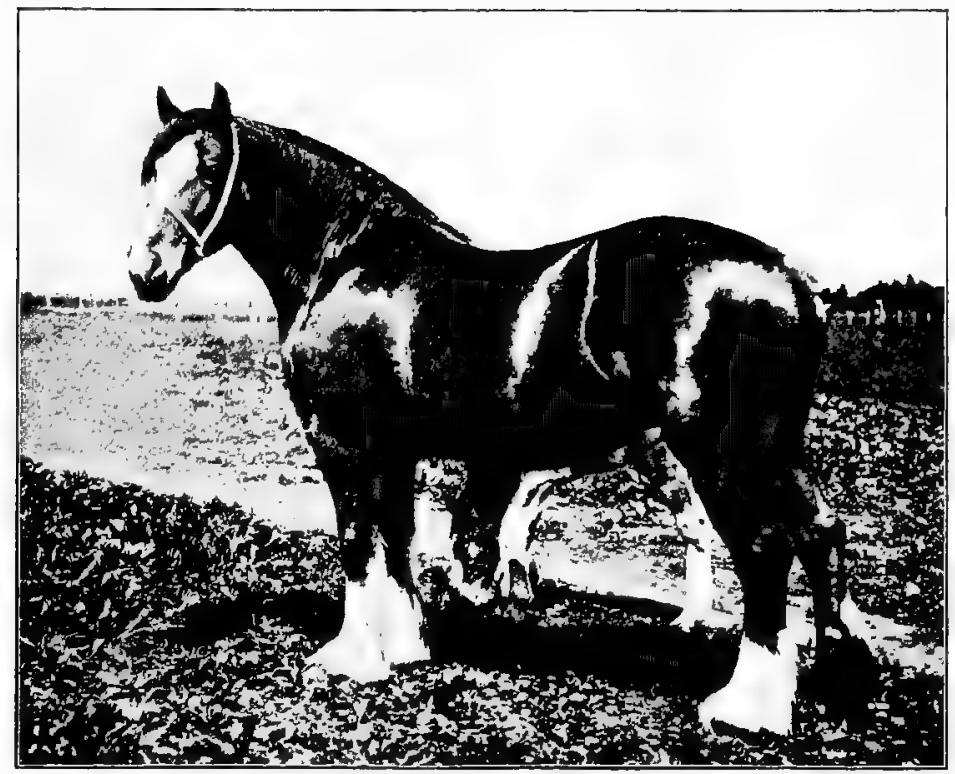

Fig. 44. Princess Handsome. One of the notable American-bred Clydesdale mares. First-prize winner at Intemational Live Stock Exposition, Chicago, in 1901, 1902, and 1903. Bred and owned by McLay Bros., Janesville, Wisconsin. Photograph from owners

distinction : Donald Dinnie 273, by Glancer (339); Johnny Cope (4I6), by Justice (420); Glencoe 158, by Prince of Wales 487 (673); MacQueen 35 I 3, by MacGregor (1487); Cedric 929 (I087), by Prince of Wales 487 (673); Lord Lyndoch 4 II3 (4530), by Lord Blantyne (2243); Lyndoch Chief 5642, by Lord Lyndoch 4I.3 (4530); Young MacQueen 8033, by MacQueen 3513 (5202); Laminated Steel 8700, by Cedric 929 (1087) ; Benedict 9300 ; $103: 5$ ), by Baron's Pride (9I22). 
Some prominent early introducers of the Clydesdale to the United States were Powell Bros., Springboro, Pennsylvania; Robert Holloway, Alexis, Illinois; Galbraith Bros., Janesville, Wisconsin ; N. P. Clarke, St. Cloud, Minnesota ; Brookside Farm, Fort Wayne, Indiana.

The American Clydesdale Horse Association was organized in I 877 , and up to January I, I905, had published twelve volumes of studbooks, covering about i 2,000 registrations.

The Scotch Clydesdale Horse Society was organized in 1878 and had published twenty-eight studbooks up to and including I905.

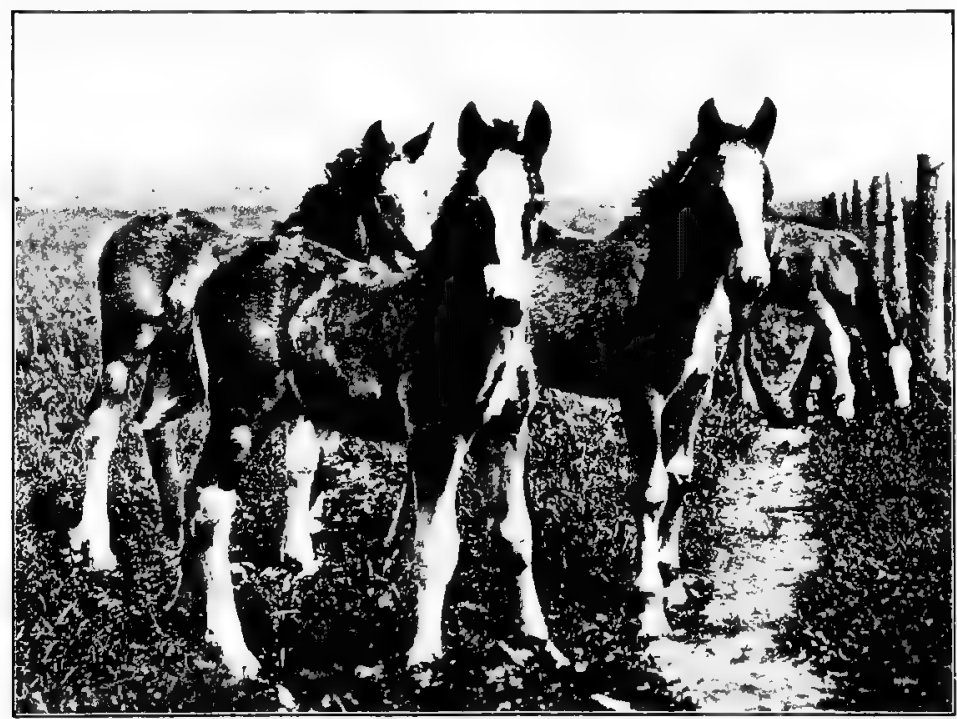

Frg. 45. Clydesdale foals bred and owned by McLay Bros., Janesville, Wisconsin. Photograph from the owners.

This society has registered within this period over I 3,000 stallions and over I 7,00o mares.

The distribution of the Clydesdale as a breed is very widespread, but it has found most favor in English-speaking countries, notably Canada, Australia, and New Zealand, though it is also used in Germany, Russia, Sweden, Cape Colony, and Argentine Republic. In the United States it has found the most favor in the upper Mississippi Valley, between Indiana and Nebraska. 
As might be supposed, this breed finds its greatest champions among the Scotch-Americans.

Half-bred or grade Clydesdales are not uncommon in some sections of the country. Pure-bred stallions on native mares of draft character produce excellent horses for farm or city work. They are usually of medium draft weight, are active on foot, and are quiet and docile of temperament. They frequently lack weight for the heaviest work, which emphasizes the necessity of using only such stallions for sires as have plenty of middle, as well as quality and bone.

High prices for Clydesdales are more common in Scotland than in America. Prince of Albion $(6178)$ is said to have sold for $£ 3000$ (\$ I 5,000), Prince of Kyle for $\$ 8000$, and Prince Alexander (8899) for $\$ 6000$. The highest price ever paid for a twoyear-old filly was 1000 guineas $(\$ 5000)$ for Montrave Rosea by Prince of Albion.

Criticisms of the Clydesdale are not uncommon among horsemen. The hairy legs are objected to by farmers who find it necessary to use them on dirt roads or under conditions in which mud or dampness are prevalent in the cooler months of the year. The Scotchman argues that the hair protects the skin of the leg, and is an evidence of superior bone. In spite of this assertion the average buyer prefers a horse with a leg free from superfluous hair. On a city pavement or on the hard macadamized roads of Europe the hair is not so objectionable.

The shortness of rib of this breed, with a tendency to ranginess of body, has also counted against it in the past. A short coupling and broad, deep body must be a part of the best draft type, to give the necessary weight for hauling heavy loads. The more recent show horses are distinctly deeper of rib and meet with a more favorable reception by horsemen generally. 


\section{CHAPTER XVIII}

\section{THE SHIRE}

The very early history of the Shire horse traces back into the days of Roman conquest and almost prehistoric times. Abundant evidence, as set forth in British history by the earliest writers, makes it clear that a heavy type of work horse existed in those days. During the period when armor was worn it was necessary that a horse be of good size and be able easily to bear heavy weight in the saddle. In the sixteenth century in England, when armor was used, according to Tower of London officials a man's armor weighed $99 \frac{1}{2}$ pounds, the horse's $8 \mathrm{I}$ pounds, and the spear 20 , a total of 200 pounds approximately. Adding to this the weight of a man, the horse had to support nearly 400 pounds.

Various early paintings show the draft type of horse in use. Albert Dürer, in I 505, made a painting of "The Great Horse," as it was termed. Vandyke, about 1620 , painted a picture showing the Duke of Arenburg on a great horse. A famous painting by Paul Potter shows the great horse about 1652 .

The special region of Shire horse breeding in England has been in the east central part, especially in the counties of Lincoln, Cambridge, Huntingdon, Northampton, Leicester, Nottingham, Derby, and Norwich. However, the breed has been extensively produced on the low-lying lands outside this area. During its past history it has been known in England as the "Great Horse," the "War Horse," the "Cart Horse," "Old English Black Horse," "Giant Lincolnshire," and the "Shire." The name "Large Black Old English Horse" was in use from the time of Oliver Cromwell to modern times.

The real origin of the Shire is fairly speculative. It is known that horses of this large draft type existed in England from very early times. We are told that a large draft type of horse existed in Flanders, Holland, and in Germany, in the valley 
of the Elbe, and that one hundred stallions were brought to England from these countries as early as the twelfth century. These were used on the English horses of large type. Referring to the great paintings of cattle and sheep made by Paul Potter, who died in Amsterdam, Holland, in 1654, Sir Walter Gilbey says: "It is only reasonable to suppose that he exercised equal care in painting horses. The strain of North German and Flanders blood was at this period so strongly represented in our English Great Horses of the best stamp that we need not inquire whether this horse was of German, Flemish, or English origin, the character of all being practically the same." Thus no doubt the early Shire was of very mixed breeding.

Robert Bakewell improved the Shire during the latter part of the eighteenth century, though it was then known as the Leicestershire Cart Horse. Bakewell was one of the earliest important improvers of the English Shire horse. He went to Holland and imported mares, using them in systematic crossing with English stallions. He pursued a careful course of selection and added to the value of the breed. It was during this century that this class of horses came into use for draft and farming purposes, the coat of armor having become obsolete. With the improvement of roads and the use of coaches the draft horse came into special demand. Gilbey, in his interesting historical work on The Great Horse, gives copies of pictures of Shire horses: one, the horse Elephant, by an unknown artist about I792; another, a gelding in use by a brewery in 1792, painted by Garrard; and a third, of two horses, Pirate and Outlaw, painted in 1810 by Zeitter. These horses are all of draft character, with hairy legs, mane, and tail.

The old-fashioned type of Shire was large, coarse, and slow. They had big heads, coarse ears, and their thick lips had long hairs on them. The shoulders were heavy, the legs hairy, and the pasterns straight. Their action was sluggish, but their temperament was mild. Excess of hair seemed a characteristic, as based on some of the pictures extant. In 1842 Low wrote :

The modern English black horse retains the general characteristics of the preëxisting race, but greatly modified. His color is usually a sooty black, with frequently a white lozenge-shaped mark on the forehead; and 
he has very generally one or more of the feet and part of the legs, and not unfrequently the muzzle, white. His body is massive, compact, and round ; his limbs are stout, his chest is enormously broad, and his neck and back are short. His mane is thick and somewhat frizzled, and his legs below the knee and hock are hairy down to the heels. His whole aspect conveys the idea of great physical power without corresponding action. The main defects of this conformation and temperament are his too great bulk of body and want of action and mettle. For a pull with a heavy weight he is admirable.

Different varieties of the Shire formerly existed in England; some have said two, others three. In the first Shire Studbook Dr. Reynolds groups the breed into three varieties, viz.:

(I) Those having the upper lipgarnished with a long, thick moustache, considered at one time a distinguishing characteristic of the Lincolnshire horse.

(2) Horses having the lips, muzzle, and eyelids destitute of the hair. The skin in these places is either entircly bald or covered with exceedingly fine down, is almost invariably flesh colored, and is sometimes marked with small dark spots and blotches. These are termed bald horses or bald faced.

(3) Those having a long tuft of hair growing from the front of each knee, and rarer examples having also a similar growth from the hind part of the hock, just below its point. This is quite different from the ordinary hair on the back of the cannons.

It is also to be noted that in the past the horses in some counties of England have differed from those of other counties. However, modern effort on the part of breeders has resulted in producing a more uniform type. Within very recent years Alexander Galbraith, an excellent authority, has said that the type that won at the London show twenty years ago would have no chance now. Greater refinement, better bone, more action, and perhaps less hair are demanded.

The modern Shire horse is an improvement over the horse of fifty years ago. The features of large size, hairy legs, and draft type have been maintained, but the modern Shire has more action and life, possesses more quality and finish, and has more uniformity of type than had his ancestors. The English breeders recognized the need of improvement of their draft horse, emphasizing quality, action, flat bone, and uniformity. In recent times this improvement has been greatly aided by the Shire Horse Society and the comparisons possible through the exhibitions of this society at Islington. Sir Walter Gilbey, a prominent breeder and horse student, has been a leader in this work. 
Important Shire stallions of breeding fame in England seem to date back to about 1755 .

Packington Blind Horse, said to have been foaled about I 760 , is recognized as a prepotent force in early days in the counties of Leicester and Derby.

Honest Tom (1062), foaled in 1806 in Lincolnshire, was a prominent sire in his day and his descendants proved his merit.

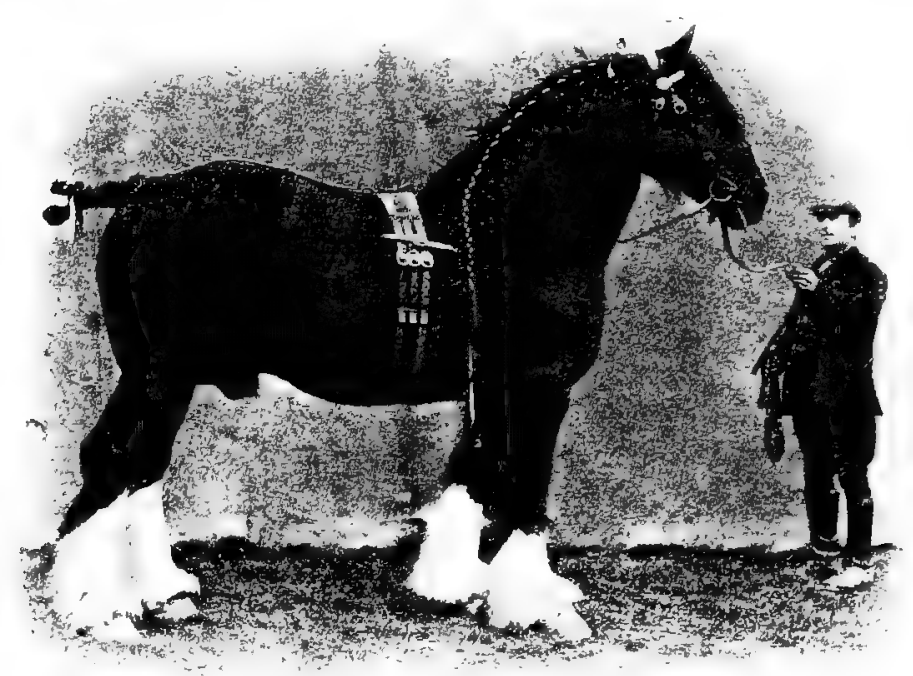

FIG. 46. Blythwood Conqueror (14997), a Shire stallion of great merit, representative of the best type. Famous in England as a sire and show horse. Owned by Sir Walter Gilbey, Bart. Photograph from the owner

This horse at five years of age scld for 300 guineas (\$ I 500). He was also known as Old Tom, alias Little David, alias Old David. John Bull ( I I69), for a time owned by gypsies, also proved a valuable sire in early days.

Lincolnshire Lad II ( 1365 ), foaled in 1872 , a gray in color, is one of the best known modern sires of show-ring winners. He stood 17 hands high, had an excess of hair, was somewhat lacking in depth of body, but had much ambition and courage and proved a great breeder. 
Honest Tom (1105), foaled in 1865, a bay, was owned for many years by Mr. T. H. Miller, of Lancashire, England. He won first prize each year from I 867 to 1872 at the Royal Agricultural Society of England shows, as well as at numerous others. Some of his progeny also proved noteworthy show animals.

William the Conqueror (2343) was foaled in I 862 in Nottingham County. He was a brown in color, a winner of some prizes in the show ring, and was the sire of Prince William (3956), Esquire (2774), and Staunton Hero (2918), all noted stallions.

Bar None (2388), a bay, foaled in 1877 , was bred by Thomas Holmes of Yorkshire. He won the Shire Society championship in 1882. He attained great success in the stud, transmitting superb quality and high-class legs.

Premier (2646), a bay, foaled in I 880, was bred by John Fisher of Lancashire. His sire, What's Wanted (2332), was a wellknown show and breeding animal. Premier proved a quite successful sire of prize-winning animals at the Shire Society Show.

Harold (3703), a brown, foaled in 1881 , bred in Derbyshire, won numerous important prizes in the show ring. He was very meritorious as a sire, transmitting to his offspring size, excellent bone, and plenty of energy. He was sired by Lincolnshire Lad II (I 36 ;), previously referred to.

Blythwood Conqueror (14997), foaled in I893, was bred by Sir James Blyth. He was sired by Hitchin Conqueror (4458) and had for dam Blythwood Bountiful (I 1607). Blythwood Conqueror is a fine representative of the modern Shire. He has attained considerable distinction as a sire of prize winners, notably in the stud of Sir Walter Gilbey.

Bury Chief Victor (I I I 05), a black with white markings, was foaled in 1889. He was a horse of very superior conformation, was a great show animal and prize winner and a superior sire. In I 89 I he was sold to Mr. Wainwright for 2500 guineas $(\$$ I 2,500$)$, the highest price for a Shire up to that time.

Prince William (3956), by William the Conqueror (2343), had for dam Lockington Beauty, by Champion (457). He was foaled in 1883 and died in 1905, aged twenty-two years. For twenty years he stood at the head of the stud of Lord Wantage. In 1894 fifty-two animals sired by him sold at an average of $\$ 600$. 
Hitchin Conqueror (4458) was foaled in 1883 , being sired by William the Conqueror (2343). His dam was Flower, by Honest Prince (1058). Hitchin Conqueror sired many fine prize winners and superior breeding animals.

Shire characteristics of distinctive importance are as follows. In size this is the largest of the British draft breeds, and is

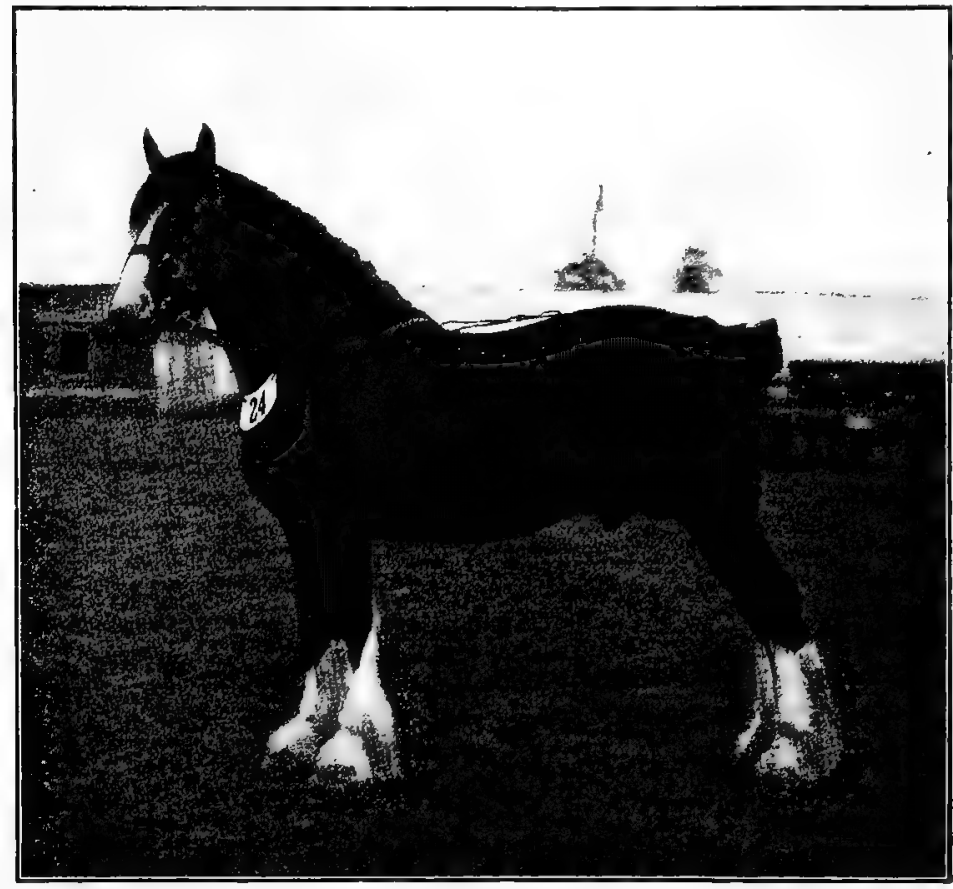

Fig. 47. Souldern Scylax. Champion Shire stallion at the Royal Agricultural Society Show of England, 1904. Photograph from National Stockman and Farmer

excelled in weight only by the Belgian. Stallions weighing from I 800 to 2000 pounds are comparatively common, massiveness having long been sought for by Shire breeders. In height the Shire stallion should stand close to $\mathrm{I} 7$ hands, although the average is about two inches less. The color of this breed is somewhat variable, though in recent years bays and browns have been most common, white markings on the face or forehead 
and on the legs below the knee or hock being characteristic. Gray, black, sorrel, chestnut, and shades of roan also prevail in a minor degree. The barrel of the Shire is larger and deeper than that of the Clydesdale, thus giving more weight. The lcgs are large and powerful and the bone fairly flat. British critics in the past have objected to frequency of round cannons, and flatter, stronger legs have become more common in recent years. The back of the cannon bones, knees, and hocks have long, flowing, fine hair in the best specimens of the breed. Excessive leg hair and heavy bone are objected to as indicating sluggishness and lack of quality, as compared with less hair and finer bone. The pasterns have been subject to criticism as being too short and not sloping enough, though modern types show improvement here. The fect are large and inclined to be flat at the heel. The hcad has a tendency to a Roman profile, while lack of breadth between the eyes is perhaps too common. The croup is long, broad, but not so level as with the Clydesdale, though the difference is not great. The action is greatly improved over early days, nevertheless the Shire is more deficient in this feature than the other draft breeds, still preserving more or less of its carly inherited sluggishness.

Critics of the Shire in America have charged the breed with lack of action, with too hairy a leg, which will probably never be popular in this country, and with too flat a foot. This accounts for the limited number of Shires imported during recent years.

Importation of Shires to America began many years ago, but just when the first of this sort came over cannot be absolutely stated. A horse named Tamworth, possibly of this breed, was brought from England to London, Ontario, Canada, in 1836. In 1847 another horse named King Alfred was imported. In I 853 a Mr. Strickland brought a stallion known as John Bull from England to Aurora, Illinois, where he became well known. Several others were imported into northern Illinois not long after. George E. Brown, long a prominent Shire breeder at Aurora, states that as far as he has been able to learn, the earliest advertisement of Shires by any importer in Western agricultural papers was in 1875 . Along in the eighties many stallions were 
brought to America from England. Since then the number has greatly decreased.

The use of the Shire in crossing on large mares is to be commended, if the stallion used presents quality of a proper sort, with a typical Shire conformation. In such crossing the chief objection will rest against the probable transmission of the hairy leg.

The distribution of the Shire is general in English-speaking countries. In England it is the really great draft breed. In America the breed has been best known in Illinois, Indiana, Ohio, and the states of the upper Mississippi Valley, especially in the so-called corn belt. Shires have been exported from England to the continent of Europe, especially Germany, ancl to the Argentine Republic in South America and to Australia.

Organizations to promote the Shire breed are not old. The English Cart Horse Society was organized in 1878 , essentially to promote this breed, but in 1884 it

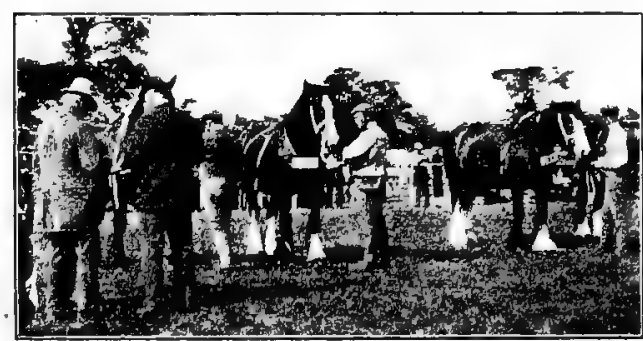

FIG. 48. Placing awards on Shires at the Royal Show, England. Photograph by author changed its title to that of the Shire Horse Society. Up to January I, I905, this society has published over twenty volumes of studbooks, has registered many thousand animals, and has a very large and influential membership. The American Shire Association was organized in 1885 and has a comparatively small membership; and up to January I, 1905, has published four volumes of studbooks.

The demand for the Shire in the city horse market is always good. The heavy weight of this breed, or of good grade progeny, makes it in active demand at all times for the heavy draft trade of cities. Very high prices have been paid for drafters of Shire breeding. In 1904 a grade Shire gelding of remarkable size and quality was sold on the Chicago horse market for $\$ 865$, up to that time the highest price on record in this market for a draft gelding. 
The Shire in the show ring has not thus far received great attention in America. The shows of the Shire Horse Society in England, however, are very notable events. The twenty-sixth annual show of that society, in 1905, was the largest ever held, seven hundred stallions and mares having been entered. No such remarkable breed exhibition of horses has ever been held in America. All the horses shown are required to undergo a careful veterinary examination.

Importers of Shires of prominence are not large in number. Alexander Galbraith of Wisconsin, George E. Brown, Burgess Brothers, and the Truman Pioneer Stud Farm of Illinois, and Bell Brothers of Ohio were prime and influential promoters of the breed years ago, and are more or less engaged in importing and breeding Shires to-day. 


\section{CHAPTER XIX}

\section{THE BELGIAN}

Belgium as a horse-breeding country has a reputation extending back to remote times. Remains of the horse have been found in the cave dwellings of the Lesse and Meuse, showing the relationship of man to this valuable animal in that country in prehistoric times. Since the days of historical record the horse of Belgium has been famous. Diodorus Siculus, a Greek historical writer of the first century B.C., mentions that the Belgians were great judges of horses, and Cæasar states that they were willing to pay high prices for a superior class of foreign horses. Tacitus, the historian and well-known writer of the first century A.D., commented on the extensive buying of horses from Belgium and the inability of the people to furnish as many as were desired. It has even been assumed that perhaps the greater part of the Roman cavalry consisted of Belgian horses. Up to about the sixteenth century horse breeding was an important industry in Belgium, but with the general introduction of gun. powder it is said that the use of the horse was largely relegated to agricultural pursuits, and Belgium lost her prestige as a horseproducing section.

Modern horse breeding in Belgium is comparatively recent in its activity. The country suffered from revolution in 1830 , and from then on for ten years the industry was seriously neglected. Government officials, however, had their attention directed to the loss to Belgian interests occasioned by this neglect, and in I 850 the government established a stud for stallions at Tervueren. Since that period much attention has been paid to the improvement of the draft horse in Belgium.

The official draft horse society of Belgium (Le Cheval de trait Belge) was founded in 1886 . The draft horse is the only race in Belgium officially promoted by the government, and this 
society was organized to (I) encourage the breeding of native horses by the organization of annual national shows; and (2) maintain a studbook of Belgian Draft horses. The studbook is published by a special commission appointed by the society. Up to 1904 there had been issued eleven volumes recording 12,630 stallions and 21,767 mares. The large numbers of mares recorded, compared with stallions, is to be noted, a condition quite the reverse with draft-horse studbook registrations in the United

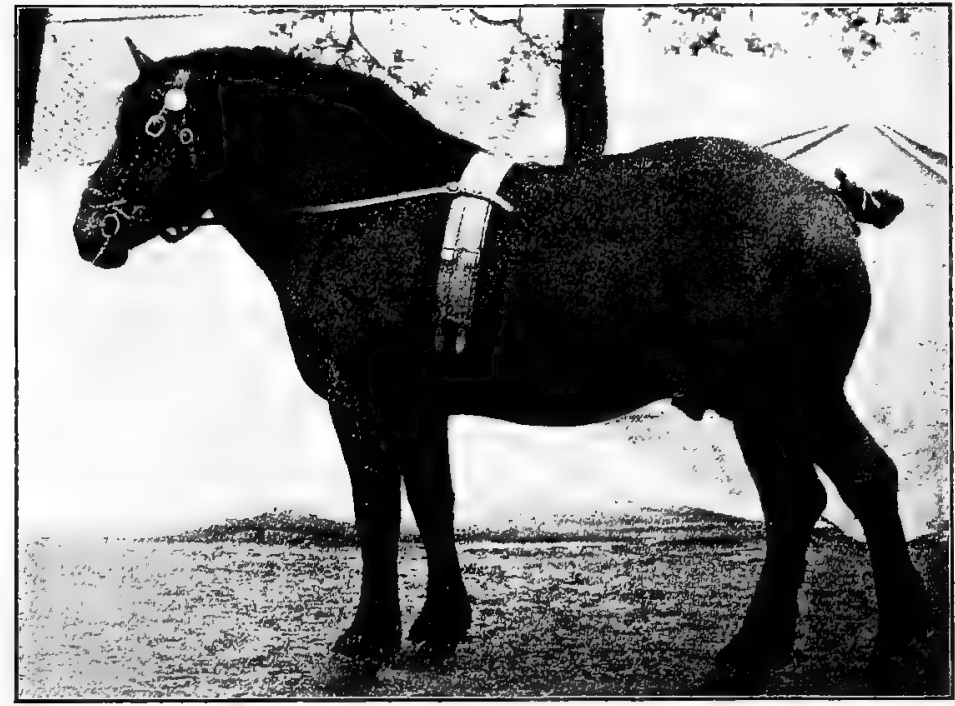

FIG. 49. A typical Belgian stallion. Photograph from A. Van Schelle, Special Commissioner of Agriculture from Belgium to the Louisiana Purchase Exposition

States. To promote the work of this society the government makes an annual grant of 30,000 francs (\$5000). Besides this, since 1890 national premiums have been offered for the best stallions. This society has some eleven hundred members.

The methods employed by the Belgian government to encourage horse breeding are of special interest. Certain state regulations concerning the breeding of draft horses are subject to constant supervision. The sum of about 350,000 francs $(\$ 70,000)$ is annually expended in behalf of this work. This money is used 
to meet the expense of shows of foals and mares, which are fixed by provincial regulations and which occur in some fortyfour different places. Stallions are also submitted for examination at this time. At each of these shows two classes of prizes are awarded : (I) a first prize of 400 francs ( $\$ 80$ ) and a second of 300 francs for the first and second prize three-year-old stallions; (2) a first prize of 550 francs (\$I IO) and a second of 400 francs for the first and second prize four-year-old or older stallions. Other smaller extra prizes may be awarded on stallions of rank subordinate to the first and second.

To promote home horse improvement the examining committee may award a maintenance bounty of 700 francs to the owner of each stallion not under four years old that has won a first prize at a previous annual show. A similar prize of 500 francs is awarded the owner of the stallion which has won for two years the second place in the class of stallions four years old or over. If the committee regards as of exceptional value a stallion that has won a maintenance prize, it may nominate him to compete for a bounty of 6000 francs $(\$ 1200)$ payable annually by fifths, so long as the horse remains approved by the committee and retains its value. At the end of five years the owner of such a stallion, if it remains approved, may continue to enjoy an annual maintenance of from 600 to 800 francs. In case a stallion that has received the 6000 francs bounty is sold to leave Belgium, the fifths already received by the owner must be returned to the treasury of the state. There is an annual competition in each province for stallions four years old or over that have won the above special prizes, at which they may compete for a first prize of 900 francs and a second of 700 francs.

The examination of stallions usually occurs the sixth year, with a show of foals, and fillies of two and three years, and brood mares, when considerable prize money is awarded. Maintenance bounties may also be awarded owners of the best mares in order to retain them in Belgium.

Draft-horse shows in Belgium are held each year at Brussels in June. These are notable events, for here is the largest show of one breed that is made in Europe. In I 904 at this show there were nearly 800 entries representing 264 stables. While the 
exhibits come from all over Belgium, the most important ones in recent years have come from Brabant and Hainaut and the provinces of Liège and Namur. Numerous agricultural associations also hold exhibitions in Belgium, at which local horses are shown.

The history of the Belgian Draft horse in America is comparatively brief. Dr. A. G. Van Hoorebeke of Monmouth, Illinois, brought horses to this country from Belgium as early as I866,

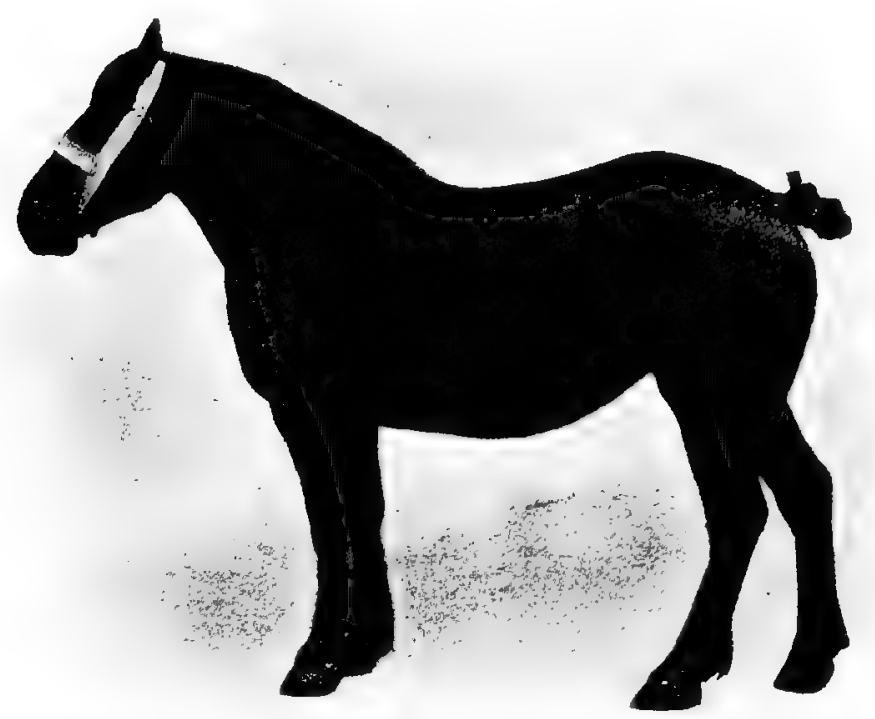

FIG. 50. Babette. A typical Belgian mare. Photograph from A. Van Schelle, Special Commissioner of Agriculture from Belgium to the Louisiana Purchase Exposition, 1904

when they were designated as Boulonnais. The incorrect use of this word, however, was recognized after a few years, when the correct title of Belgian was given. Massion \& Son of Mintonk, Illinois, were also early importers. In I858 Mr. E. Lefebure came to America from Belgium and settled in Iowa, and from I 888 till his death in 1905 he was one of the leading promoters of the breed in this country.

Exhibitions of Belgians in the United States are comparatively recent. Small exhibits have attracted attention at the Chicago 
horse show and at some of the central West fairs during the past twenty years, but it is only very lately that general interest has been taken in the breed. A small show of Belgians was made at the World's Columbian Exposition in 1893 at Chicago by A. B. Holbert, Van Volsen Bros. and Vanderschuerm, Lefebure \& Sons of Iowa, and J. Crouch \& Son of Indiana. During the past two or three years interest in the breed has greatly grown, and at the International Live Stock Exposition at Chicago in I 903 there were shown twenty aged stallions, while in 1905 a very large and creditable show was made. In all the exhibitions, however, but very few mares are found; in fact, there are but very few pure-bred Belgian mares in America.

The American Association of Importers and Breeders of Belgian Draft Horses was organized in 1877 , and works in harmony with the Belgian society. Thus far it has published but one studbook, issued in 1905 .

Characteristics of the Belgian Draft horse. The general conformation is of the most compact form, this breed having a maximum of weight within a given space. The body is very full in the breast and unusually broad and deep of back, no breed in proportion to its size showing so much body girth. Symmetry of form is not as frequent as could be wished, owing to a rather characteristic steepness and shortness of rump extremely common with Belgians, with the tail set rather low. The head shows considerable refinement, and is carried with spirit on a short, symmetrical neck. The head, neck, and rump rather suggest the French breeds in style and carriage. The legs of the Belgians are devoid of long hair and are notably short. Compared with an ordinary draft horse one is impressed by the closeness with which the body comes to the ground. While the legs may not be open to objection, frequently there is a tendency to too much lightness of bone and lack of substance to support the body weight and withstand the severest of labor. Neither do the hocks show great depth and strength as frequently as is desirable. An important criticism of the breed by Americans has been directed to the feet. These tend to be small and lack in circumference at the crown, besides being high and narrow at the heel. Probably no class of draft horses brought to America has the 
feet so severely criticised as does the Belgian. If one may judge from the specimens exhibited in America, there is reason in this objection. In action the Belgian is somewhat slow, though some remarkable actors have been seen in our shows. Omer, the champion of the International Live Stock Show of 1903, imported by McLaughlin Brothers, has a stride and style most unusual in a draft horse of any breed. In color the chestnut is the most

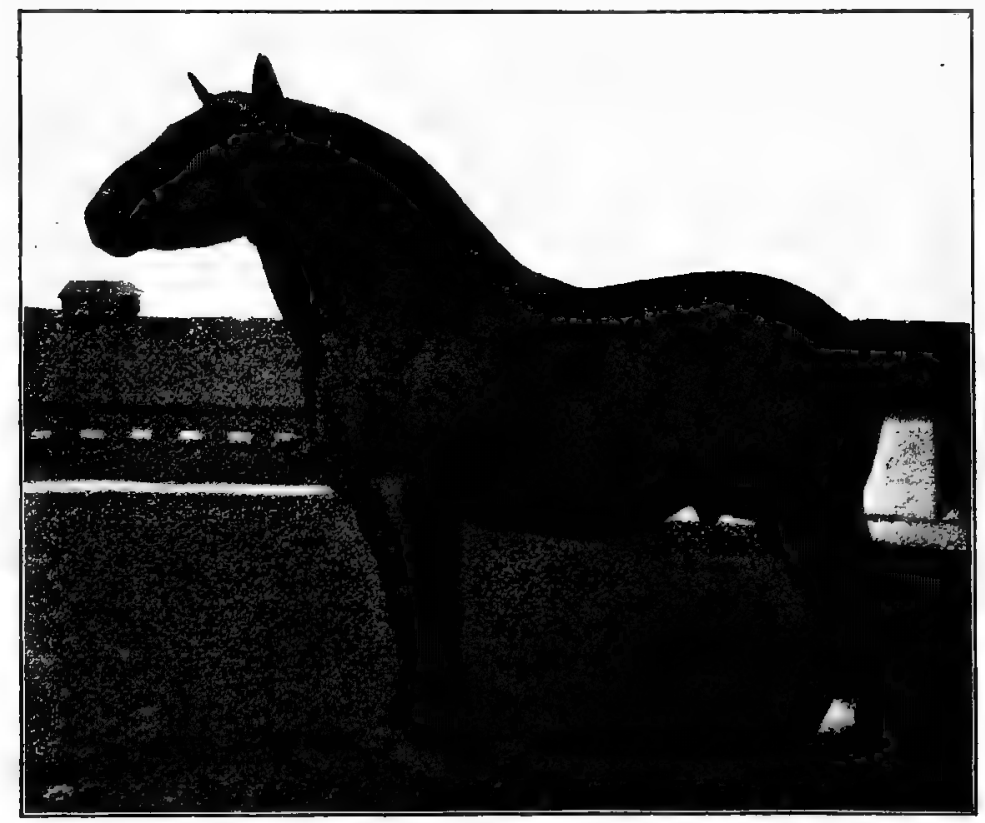

FIG. 51. Omer 1269. A prominent prize-winning Belgian stallion, imported and exhibited by McLaughlin Bros., Columbus, Ohio. First in class and grand champion of the breed in 1903 at International Live Stock Exposition. Photograph by author

popular, although bays, bay browns, and roans are more or less frequent. Grays are not in favor either at home or abroad. The height and weight vary. M. Albert Van Schelle, the special commissioner from Belgium in charge of the exhibit of Belgian Draft horses at the Louisiana Purchase Exposition at St. Louis in 1904, classes the horses of Belgium into three types according to the sections of the country to which they belong. Those 
from Flanders range in height from $16 \frac{3}{4}$ to 17 hands or more, and the stallions weigh about 2000 pounds. Those from Brabant stand $15^{\frac{3}{4}}$ to $16 \frac{3}{4}$ hands, and the stallions weigh about 1600 , while those of the Ardennais stand from 15 to $15 \frac{1}{2}$ hands in height and weigh about 1200 pounds. In temperament the Belgian draft horse stands without a superior, due no doubt to being raised in a country having small farms, and in close contact with the everyday life of the people. As the author saw these horses at work on the streets of Antwerp and on the farms of Belgium he was impressed with their docility of temper and their great draft power. Certainly the typical draft horse of Belgium possesses the weight so essential to move great loads with the least exertion.

The cross-bred Belgian has as yet been but little seen in the United States, but he has met with a favorable reception where produced. A few years ago a consignment of grade Belgian drafters, the product of pure-bred stallions on native mares, was sold at auction in Chicago market at from $\$ 200$ to $\$ 335$ per head, and received much favorable comment. The writer has seen numerous grade geldings shipped to Ohio feeders from the West, which have presented a most attractive individuality. Ohio shippers are looking with more and more favor on heavy Belgian geldings as quite satisfactory to the city trade. They seem to be reasonably sound of limb and possess the blocky form and weight so much in demand for heavy hauling.

The distribution of Belgian Draft horses is very widespread. Germany is a prominent buyer, while England, Holland, Sweden, France, Denmark, Austria, and the United States have buyers in the Belgian market. In 1903 more than three hundred were shipped to the United States At the 1904 Brussels show an official representative of the Hungarian government purchased ten stallions, including six first-prize winners. In the United States the Belgian has been longest known in Iowa, Illinois, and Indiana. Stallions and grades are, however, becoming distributed over the Mississippi Valley states north of the Ohio, wherever the heavy draft horse is needed. 


\section{CHAPTER XX}

\section{THE SUFFOLK}

The native home of the Suffolk, or Suffolk Punch horse, as it has been known, is in Suffolk County in the eastern part of England. This county is flat in character with clayey soil, is generally cultivated, borders on the seashore, and comprises about fifteen hundred square miles. The breed is also more or less raised in Essex and other eastern counties, while specimens are found in other parts of England to a slight extent.

The early career of the Suffolk horse traces clearly back to about I 7oo. While Normandy horse stock has been assumed by some as playing an early part in the formation of the breed, no positive information exists on this point. In purity of blood it is believed that the Suffolk surpasses any other breed in Great Britain. The general evidence, as given by various authorities, indicates that for several centuries this breed has been bred in Suffolk with much purity.

The pure-bred Suffolk foundation really dates back to a horse of unknown sire, foaled in 1768, known as the "Crisp horse," being owned by a Mr. Crisp of Ufford, Sussex. To this horse are traced all pedigrees of the breed that may be registered in the studbook of either England or America. This history has been clearly and fully traced, and stands accepted by breeders universally. The Crisp horse was a bright chestnut in color, stood I $5 \frac{1}{2}$ hands high, and proved a remarkable breeder. In the development of the Suffolk since his time four attempts have been made to introduce foreign blood and thus improve the stock. In no case, however, has this blood held its own, but has been completely absorbed and the breeding lost.

The foreign blood used to improve the Suffolk was as follows:

1. The Blake strain. This came from the use of a Lincolnshire trotting horse with no Suffolk blood, known as Blake's 
Farmer. This strain was in existence from 1780 to 1880 , and at one time was very popular.

2. The Wright strain. This originated from a horse from Lincolnshire known as Wright's Farmer's Glory, or the Attleboro horse. He was a chestnut, clean limbed, and may have been a half-bred Suffolk. This strain existed from I 800 to about i 880 .

3. Shadingfield strain. This came from the produce of a trotting horse, the son of a Thoroughbred, and he also was a

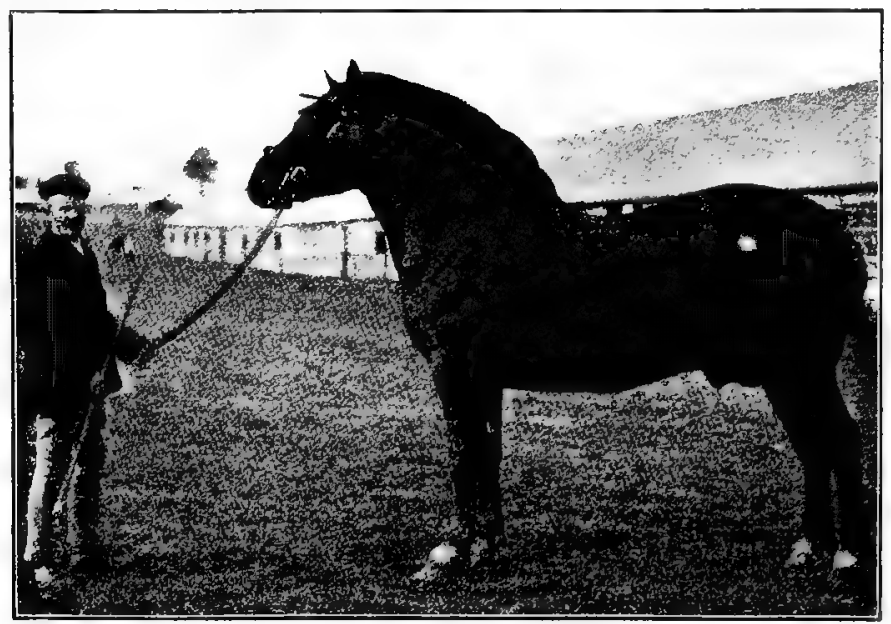

Frg. 52. A first-prize Suffolk stallion at the Royal Show, London, England, 1904. Photograph from William Cooper \& Nephews, Berkhamsted, England

chestnut. This strain existed for about half a century, the last being foaled in 1846 .

4. Martin's Boxer strain. This appeared to be a Suffolk, though he was not, being out of a "black blood mare." This strain never obtained any foothold beyond two mares of remote breeding.

These strains were all started to improve the breed, but they presented deficiencies; neither could they overcome the predominant Suffolk blood and character.

The history of the modern Suffolk horse is essentially a most compact one. It deals with the development of the breed mainly in Suffolk and vicinity by the farmers generally, and is very well connected, largely due to the far-reaching investigations of 
Herman Biddell, the editor of the first Suffolk Studbook. Among the horses of the last century that had much influence on the development of the breed are Edward's Old Briton 490, Catlin's Duke 296, Crisp's Fairhead's Boxer 405, Julian Boxer 755, Crisp's Cupbearer I 4I6, Garrett's Cupbearer the third, and Foxhall. The latter was imported to America by Galbraith Bros.

The history of the Suffolk horse in America is rather restricted, these horses being comparatively unknown in the United States in the early eighties. In 1882 the editor of the National Live Stock Journal wrote: "If some of these Suffolk horses could be imported and bred alongside of the Shire and Clydesdale, it would give an opportunity to see what would prove the best for American purposes." In 1883 this same journal states that Suffolks are finding great favor in Canada. However, Powell Brothers of Pennsylvania imported the first stallions to the United States in 1880 . In 1888 Galbraith Brothers, of Janesville, Wisconsin, made their first importation of stallions, while the same year Peter Hopley \& Company, of Lewis, Iowa, imported the first mares. At the present time Galbraith \& Son and Peter Hopley \& Son are the leading breeders and exhibitors of Suffolks in the United States. At the World's Columbian Exposition at Chicago in 1893 a few Suffolks were exhibited, mainly by Peter Hopley \& Company, although B. Ramsey of Iowa and Mossom Boyd \& Company of Canada also exhibited. In 1903 forty-one head were imported to America. A few Suffolk horses are now being imported, but the breed as yet is but little known, and does not meet with rapidly growing favor. At the I904 International Live Stock Exposition an exhibit of about a dozen Suffolk stallions and mares was made by Peter Hopley \& Son, the firm name being changed.

Characteristics of the Suffolk horse. This breed has long possessed certain distinctive features, quite marked in contrast with other breeds. The following are worthy of special consideration.

The Suffolk has a tendency to small ears, the forehead is broad, and the eyes are of medium size and only fairly prominent. The nose tends to Roman form, which has been rather characteristic of the breed. The jaws are rather strong and the cheeks deep and full. The neck has something of an arch,-in 
fact with stallions this is very pronounced, - with not too much heaviness at the crest. The neck sometimes joins the head a bit heavily, but at the shoulders, as a rule, it is well placed. The shoulder should be long but not extremely oblique. A race-horse placing of shoulder is not desired among Suffolk breeders, a straighter shoulder being better suited to draft work. The body of this breed is one of its notable features. It has long been characterized by great depth and circumference, considering the size of the horse. The ribs have an unusual spring and depth, thus giving the body a very round, full form. Formerly this was unnecessarily deep and round, giving it a paunchiness from which the term "Punch" was evolved and given as a part of the breed name. Modern breeders object to heaviness of belly. For size the body girths unusually well. A girth of about eight feet back of the shoulders is recommended. The rump is full and well carried out, the tendency to steepness being slight.

Strong quarters and hocks are a feature of the breed, but there has been some criticism of weak hocks. One family, Catlin's Boxer 299, has had this feature of bent hind legs and weak hocks, and Crisp's Conqueror 41 3 and Cupbearer 4I6, famous sires as they were, had a tendency to this trouble. The legs of the Suffolk are very free from superfluous hair, and while they have been criticised as lacking in bone, the breeders insist that this is not so. If fairly compared with the long-haired breeds, they maintain that plenty of bone will be manifest. Yet the bone is not large, but of superior texture. A girth of $10 \frac{1}{2}$ inches below the knee is given by Mr. Biddell as ample, more being thought unnecessary. The feet of this breed have been criticised much in the past. The middle of the last century it was claimed that the feet were flat and the hoofs brittle, and that side bones were common. Now for years, however, by rules of the Suffolk society, all horses shown must be submitted to a veterinarian's examination, which has resulted in a great improvement. In I $880 \mathrm{~A}$. B. Allen wrote :

The reason why they have not long since been imported and bred extensively in our country is undoubtedly owing to their possessing almost unusually too small legs for their bodies, their bad hoofs, and shelly feet. I examined this breed very attentively when I first visited England in 184I, . . . but finding them so deficient in the feet and legs, I made up my mind not to recommend their importation to this country. 
In I 893 Professor Robert Wallace, the Scotch authority, stated that "at one time they were flat-footed and liable to become lame if worked regularly on the hard road or on stone pavements, but the care bestowed upon breeding has in recent years eliminated this defect among animals of the first rank."

The quality and action of the Suffolk rank well. The breed cannot be classed as coarse, while in action it stands next to the Clydesdale among the draft breeds. Wallace states that they twist their legs and feet when moving, but this does not apply to-day as much as it may have formerly. The height ranges from 16 to 17 hands, though 16 to $16 \frac{1}{2}$ is more common. In fact this breed should be short of leg and close to the ground, though the Suffolks the author has seen in this country have shown considerable height and weight. The zeeight should not run high, I 800 to I 900 pounds being ample. Greater weights than this are obtained, but they are not most typical ; for example, Galbraith gives 1800 to 2200 pounds, but this brings him up to a horse of large size among the draft breeds, a thing never claimed by Suffolk breeders. The Suffolk should not be as large as Clydesdale or Shire, and is not bred for the heavy draft work of the city, but for farm purposes, where less weight is required. This is generally conceded by advocates of the breed. The color is a Suffolk characteristic, for it is always a chestnut, varying from a bright to a dark shade. This has always been a breed feature, no other color being allowed. Biddell allows for seven shades, a bright one being considered most desirable, with mane and tail of same color. Some have favored the dark shade, but it is not generally recognized as desirable. A light, mealy chestnut is quite condemned, as indicating weak constitution, soft legs, and slow temperament. White hairs to a slight extent in the body color may be permitted, but are not desired.

The Suffolk as a draft horse ranks high among the farmers of eastern England. It is considered capable of doing a maximum amount of labor on a less amount of feed and for longer periods than other drafters. This is the opinion of the people of Suffolk, however. Its steadiness and persistence at pull has long made the breed famous, but this same characteristic is probably equally well established with other breeds. 
The distribution of Suffolk horses is extremely widespread, in fact more so than is commonly supposed. They have been exported to the Argentine, Australia, New Zealand, Spain, France, Austria, Germany, Sweden, Russia, South Africa, and the Nile region of Africa. In Canada and the United States they have no great foothold, but are scattered over these countries in a small way. In this country up to this time they have been best known in Iowa. In I 904 a small stud of these horses was purchased of Hopley \& Son for the Mt. Hermon Boys' School in Massachusetts, and this same firm in 1905 made shipments to Washington and Oregon. They report an increasing interest in the breed.

The value of the Suffolk horse crossed on common drafty mares has hardly been tried on an extensive scale. Alexander Galbraith states that the grades from native American mares have good size and bone, while they are particularly smooth-built and are almost invariably chestnut in color. They make high-class animals for heavy farming and express-wagon work.

The fecundity and longevity of Suffolks is highly attested. Numerous cases are given to show that the breed is very prolific and tenacious of life. The dam of Webb's Rising Star I 266 was twenty-two years old when he was foaled, and the dam of Loft's Cupbearer 842 had sixteen foals in sixteen years. A mare and foal were shown at one of the early Suffolk Agricultural Association shows, the mare being thirty-seven years of age when the foal was dropped. The great stallion Julian Boxer 755 traveled at least twenty-five seasons and left a large num. ber of superior sons and daughters.

The Suffolk Studbook is published by the Suffolk Studbook Society in England. Volume I was issued in 1880. Up to January, I905, this association had published fourteen volumes. There is an American Suffolk Horse Association, but as yet no studbook has been published. 


\section{CHAPTER XXI}

\section{PONIES}

A standard height for a pony does not obtain, but the line between a true pony and a horse is drawn at $14 \frac{1}{4}$ hands, anything over this passing out of the pony class.

The polo pony is not a breed, but represents a type and size suitable to be used in playing polo. For this purpose anything possessing the necessary speed, activity, endurance, and intelligence will do. The maximum height allowed by the American Polo Association is $14 \frac{1}{2}$ hands. Small Thoroughbreds, Western

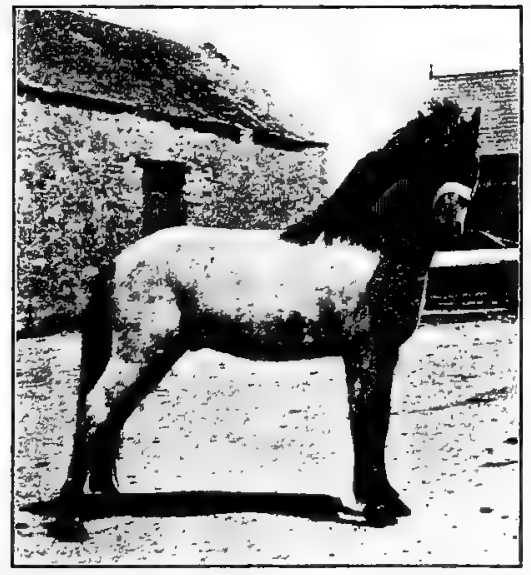

FIG. 53. A typical Welsh pony, bred by John Jones, Llandudno, Wales. From photograph by author ponies, and cross or half breds are popular.

The Welsh pony is a class that has long been bred in Wales and is now receiving more recognition than ever before. They have been somewhat improved by Arab and Thoroughbred blood in the past, and so often show the influence of superior breeding. These ponies, however, offer considerable variation, and even among the people of Wales are not altogether regarded as a breed. In Wales and western England one will see these ponies in various sizes and types. In 1897 , the writer visited one of the largest studs in Wales, where many fine ponies were shown, but where considerable difference of type was to be seen. In Wales there is a Welsh Pony and Cob Society for promoting and registering 
these smaller types of Welsh horses. This society divides these ponies or small horses into four groups as follows:

I. Welsh mountain pony. Height not to exceed $12 \frac{1}{2}$ hands. Color of any sort. In type this resembles a small Arabian, possessing much the same character and carriage of head, rump, and tail. It is found in the more hilly sections, and has great bonc and superior muscle and endurance. No doubt it was originally improved by Arab stallions.

2. Should range from i $2 \frac{1}{2}$ to $13 \frac{1}{2}$ hands, is of the cobby type, and is not as well adapted to mountain lands as the pre. ceding. In harness both classes I and 2 make a very showy appearance.

3. Should range from $13 \frac{1}{2}$ to $14 \frac{1}{2}$ hands. This comes into the cob class, a blockier sort than 1 and 2.

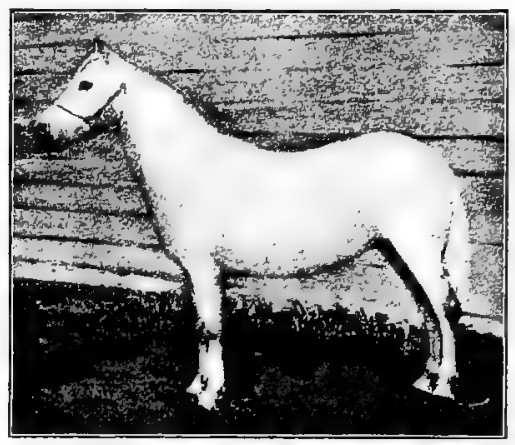

FIG. 54. Lady White, a Welsh pony mare. First at the Royal Show, Manchester, England, 1897. A winner of many prizes. Owned by John Jones. Photograph by the author

4. Should range from over $14 \frac{1}{2}$ to not more than $15 \frac{1}{2}$ hands. Those in this class are suited to mounted infantry or cavalry service. Ponies of classes $\mathrm{I}$ and 2 are freely used in Wales, where, attached to really heavy carts, they trot across country at remarkable speed.

Welsh ponies have been used in America for many years, but are now attracting more attention than ever. They possess more style, action, and size than the Shetland, and are suited to either saddle or harness. A good specimen of the breed should at least show plenty of speed and forcible knee and hock action. Owing to their general activity and endurance they find favor for polo playing.

The Exmoor pony has long been known on the moors of southwestern England in Devonshire. Here on some twenty thousand acres, these ponies have been bred more or less wild for perhaps centuries. This breed has been classed as the highest type of pony, closely resembling the Arab in 
conformation. Captain W. C. Kerr describes the breed in part as follows:

The true Exmoor pony is a strong, well-knit, 13-to-14-hand animal of the dray-horse sort in miniature type ..., sure-footed, docile, generally bay in color, and possessing an iron-clad constitution... His salient points are strength of loin, well-sprung ribs, great breadth of chest; in fact, he is what your people would term a "chunky" little fellow. . . A All are natural fencers, and the way they surmount the tremendous banks is marvelous. I ought to mention that their heads are very neat and bloodlike, in some cases very Arab-like; they carry their tails gayly, have a little silky hair about the heels, but, like all our ponies, are often faulty about the shoulders.

Exmoor ponies have been considerably improved by Arab and Thoroughbred blood. The improved form meets with favor for polo playing, for use with children in saddle, and as a harness pony for cart, phaëton, or other light vehicle. There are but few Exmoor ponies in America.

New Forest and Dartmoor ponies have been known for centuries in south England. Dartmoor is an extensive tract of land in Cornwall, embracing about three hundred and twenty-five square miles. Here ponies have been bred and have run wild for many generations. The New Forest embraces about one hundred and forty-five square miles of fields and forest in south-central England, where ponies also have run wild for centuries. These ponies belong to the same class as the Exmoor, and have been more or less improved by Arab and Thoroughbred blood. A New Forest Pony Association has existed in England for some years.

The Arab pony is simply an Arab under $14 \frac{1}{4}$ hands high, and is discussed elsewhere as a separate breed.

Indian ponies, mustangs, or bronchos are descendants of the horses brought to America by the early Spanish conquerors. They often possess much beauty of form and high-class heads and limbs. They have remarkable endurance and are capable of the severest work under the saddle. They vary somewhat in type, those owned by northern Indians not being the equal in quality and conformation of those of the south. Those of the Apache Indians are said to greatly resemble Exmoor ponies. Indian ponies are of all colors, usually solid, though piebalds 
occur. They tend to be ewe-necked, are often deficient in quarter, and have a remarkable spirit, which is frequently far from amiable. Many of these ponies, with all their other good qualities, are most uncertain of temper and may prove very irritating when least expected. Curtis makes the mustang and Indian pony of different breeding, though they range the same in height

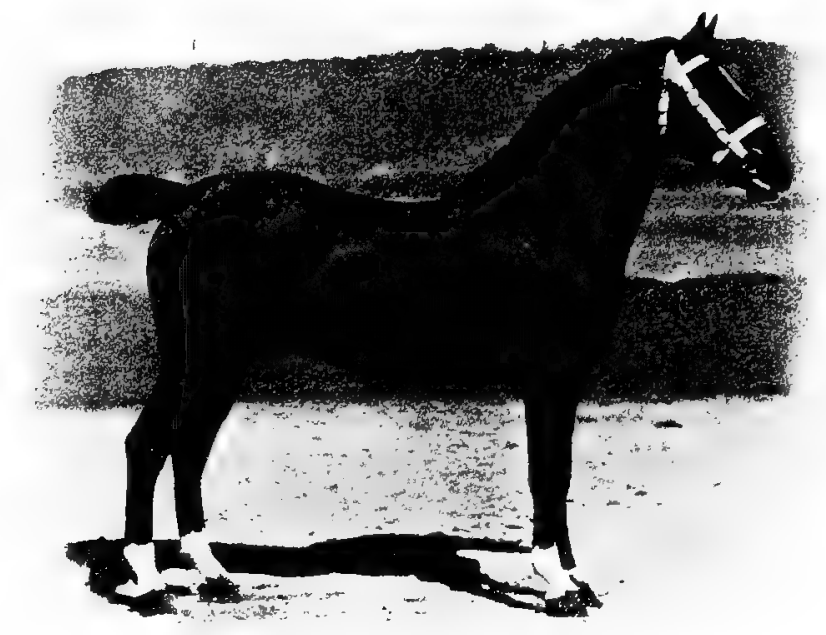

FIG. 55. Dilham Prime Minister (5174). The most famous Hackney pony in America, noted as a prize winner and a sire. Imported and owned by Eben D. Jordan, Boston, Massachusetts. From photograph from-Mr. Jordan

(I 2 to I 4 hands), weigh much the same (600 to 850 pounds), and have much the same color. The Indian pony is given as more blocky than the mustang, the cannons are wider and the pasterns more upright.

Hackney ponies are Hackneys $14 \frac{1}{4}$ or less hands high, with the general characteristics of the Hackney horse. 


\section{CHAPTER XXII}

\section{SHETLAND PONY}

The native home of the Shetland pony is on a group of rocky islands about 200 miles north of Scotland. These lie between $59^{\circ}$ and $61^{\circ}$ north latitude, slightly to the east of north, and comprise a total of about 120 islands, with a total area of some 500 square miles. Only about fifteen of these islands are inhabited. The principal island is Mainland on which is located Lerwick, the largest town and port with about 3700 inhabitants. Other important islands are Fetlar, Bressay, Fair Isle, Yell, and Unst. These islands are rough and barren as a rule, and are situated in a turbulent sea, under unfavorable climatic conditions, where a comparatively low temperature prevails for much of the year. No trees or brush of significance grow on the islands, and what land is cultivated lies in the valleys. On the islands the ponies are fed grass and hay, not often receiving any grain, and it is said that sometimes they are even obliged to eat seaweed on account of shortage of hay.

The ancestry of the Shetland pony is of course uncertain. The drawings of the prehistoric horse in the caves of France show considerable resemblance to the Shetland type, and it is supposed that they are descendants of this prehistoric form. How long they have been bred on the islands is not a matter of record, but they have been bred there for centuries. In their early history they are doubtless more or less related to the ponies of Iceland and Scandinavia, and perhaps Wales and Ireland.

The type of the Shetland pony is really that of a small draft horse, although many are seen that are fine of bone and slender of body, more after the trotting-horse type. However, the ponies on some of the Shetland Islands are of a different type from those on others. In fact, it is claimed that a different type is found on each of the following islands: South Mainland, Unst, Fetlar, 
Fair Isle, and Bressay. For example, on Fetlar, Lady Nicholson, a Scotch breeder, has used Arab pony stallions on Shetland mares, producing a pony of considerable refinement about 46 to 48 inches high. These are known in the trade as Fetlar or Lady Nicholson ponies. On Bressay, Iceland ponies have been crossed on Shetlands. Visitors to the islands have there seen work horses weighing from I 200 to I 500 pounds, some of which have been bred to Shetland stallions.

Characteristics of the Shetland pony. The height ranges from 36 to 44 inches in choice specimens, but with variations outside

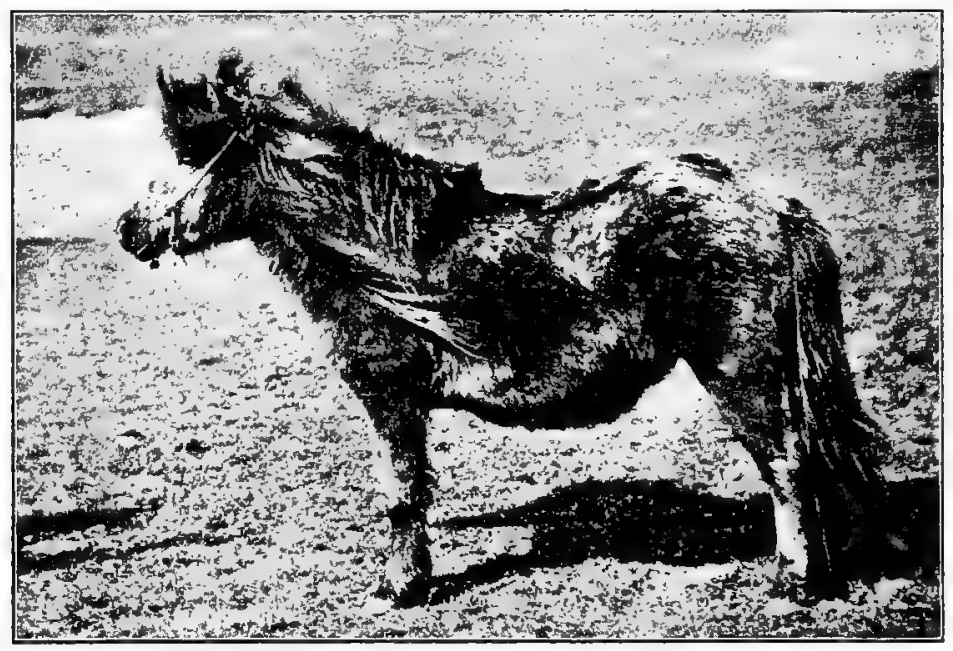

FIG. 56. A pony mare in winter coat on one of the Shetland Islands.

Photograph from John Anderson \& Sons, Lerwick, Shetland

of this. Eli Elliott of Iowa, who has bred and imported many from the islands, says: "I never saw in any country what I believed to be a 'right Shetland' that was as much as 46 inches high. As a rule they are 40 to 43 , and some as small as 36 to 38 inches, and the smaller the better." The smallest pony ever seen by Mr. Elliott was 34 inches high, weighing under 200 pounds. Feeding and care, however, will affect the height and weight. On the prairies of the American corn belt the pony tends to increase in size from generation to generation. In the American 
Shetland Pony Studbook quite a number of ponies ranging from 30 to 36 inches have been registered. The American Shetland Pony Club in its standard gives twenty-five out of a hundred points to height. Ponies over four years old should be 42 inches and under, and two points are deducted for every inch over this up to 46 , above which height they are disqualified. Catherine Sinclair, in Shetland and its Inhabitants, says that when well fed the ponies will reach the size of a donkey, and in contrast notes that a Mr. Hayes raised a perfectly formed pony only 20 inches high. As the Shetland is used to a considerable extent in coal mines in England for hauling coal cars, a small pony is preferable to a large one. The weight of a good specimen of the breed may be about 350 pounds for one 40 inches high.

The head of the Shetland should not be too fine, the eye should be prominent, the neck incline to be short and strong with some crest in stallions, the shoulders should be strong and drafty, the breast prominent and full, the body short in coupling, wide on the back, with considerable spring and depth of rib, the croup broad, fairly level, and wide, with the tail set high, the quarters full and strong, the legs short and of superior bone, though perhaps appearing heavy, and the feet round, dark, and of excellent bone. A long heavy coat of hair occurs on the body in cold weather, while at all times a long, heavy foretop, mane, and tail are characteristic. No breed of horses carries so much hair naturally as does the Shetland. If the pony is leggy and lacks in body, this will be due to Icelandic or other blood. Narrow chests and cow hocks are far too common with specimens of the breed seen in America. The color is quite variable, black, bay, and brown being common, but there are gray, roan, and chestnut, with combinations of white with all these colors. In fact piebald or spotted ponies are quite common.

The improvement of the Shetland pony was begun in 1873 by the Marquis of Londonderry of England, who owns extensive coal mines. He purchased the island of Noss and part of Bressay, and maintained studs there and at Seaham Harbor on the northeast coast of England. The work of the Marquis of Londonderry resulted in greatly improving the uniformity of type and color, reducing size, but increasing bone without detriment to quality. 
The use of the Shetland in America is nearly exclusively for children, they not being generally regarded as beasts of burden. However, about Columbus, Ohio, where large numbers of these ponies are common, they are frequently seen in pony carts, phaëtons, or small surreys, hauling two or four persons over the pavements with comparative ease. Ponies for this heavier work approximate forty-five inches or more in height. No breed equals the Shetland for children. The very universal gentleness of these ponies makes them safe

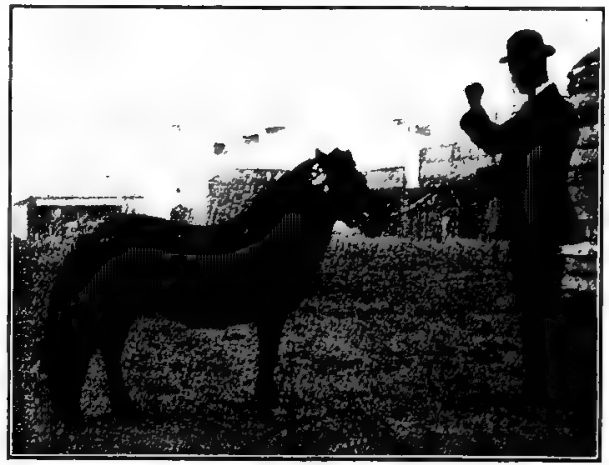

FIG. 57. Oman (33). First-prize Shetland pony stallion at the Highland Show, Scotland, in 1896 and 1897 , and at the Royal Show in 1897 . Also won the President's Medal for being the best specimen of the breed at the Highland Show. Bred by the Marquis of Londonderry. Photograph by the author for small children to use with the greatest freedom in any way. Even when but two years old Shetlands may be used in a moder-

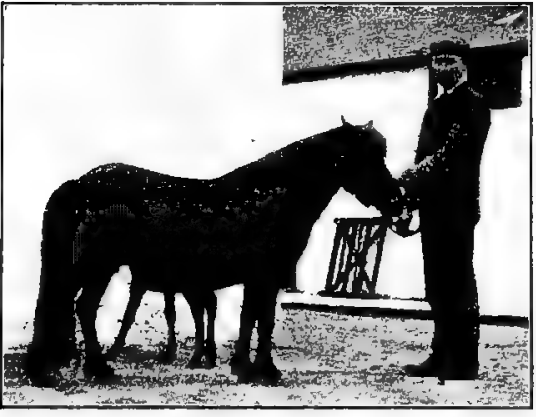

FIG. 58. Bretta. A Shetland pony mare with foal, owned by the Marquis of Londonderry, England. Photograph by the author ate way in the saddle by little children. Recently the demand for Shetlands has greatly increased. In 1905 the largest importation ever made to America occurred in the bringing over from England of $20 \mathrm{r}$ head.

The price paid for Shetland ponies is naturally variable, but ranges from $\$ 75$ upward. Choice stallions have sold at from $\$ 500$ to $\$ 1000$ each. Mr. C. E.

Bunn states in his catalogue that he refused $\$ 1500$ for his champion stallion Chestnut 3572 . The price is in some degree 
affected by size, other things being equal, the smaller ones fetching the most money.

Shetland ponies of special interest in America in recent years are Prince of Wales I 190, Chestnut 3572, Trinket IOI, Trinket Jr. I I 87, and Bunn's Trinket 2598. From I 893 to I 90 I Prince of Wales was the greatest show stallion of the breed in America, while he also proved a great breeder, siring Chestnut 3572 , also a great show and breeding horse. The Trinket family is spotted and numbers many fine specimens of the breed.

Shetland pony organization in the United States is promoted by the American Shetland Pony Club, organized in I888. Six studbooks had been published up to January, 1906, including the registration of 5700 animals. 


\section{CHAPTER XXIII}

\section{THE ASS}

The ancestry of the ass may be traced to the wild ass of Africa and Asia. The males are usually termed jacks and the females jennets. The following are the important species of the wild ass.

The African wild ass (Equus asinus). This species is found wild in Abyssinia, Nubia, and northeastern Africa between the Nile and the Red Sea. It is very similar to the domestic ass in color and markings, but has a distinct shoulder stripe extending from the withers to the arm of the fore leg.

The Asiatic wild ass (Equus hemionus). It occurs in Asia on extensive plains, from Syria through Persia, Afghanistan, the Punjab, and Tibet to the Chinese frontier. The general color is reddish gray, varying to fawn or pale chestnut. A dark brown stripe, sometimes with a white edge, extends along the spine from the back of the head to the tail. The ears are large, the tail is covered with short hair which increases in length to form a black brush, and the mane is erect. There are callosities on the fore legs but none on the hind. The height varies from I I to 12 hands. This ass is remarkable for speed and endurance. The voice is a shrieking bray.

From the wild ass various breeds of the domestic ass have descended, ranging in size from those no larger than a Newfoundland $\operatorname{dog}$ to the size of a draft horse. There are several breeds of importance, from which we in America secure the jackass, or jack, for mating to mares, and these will be discussed after first briefly referring to the domestic type.

The characteristics of the domestic ass include several features not possessed by the horse. The female is pregnant fully twelve months, the horse eleven. The fore legs have callosities (chestnuts) while the hind legs have none. The ears are very large and long, the foretop and mane is usually very scanty, and the 
tail has no long hair excepting at its lower part, which has a brush of hair. The body is often covered with long hair, in some cases showing remarkable length, while in other cases it is fairly short. The body is very compact, the quarters lacking deep muscling, while the legs are very strong of bone, often heavy of joint, with small, narrow feet. The ass makes a peculiar noise called a bray. The standard color in America is black, with a light creamy or mealy shade about the muzzle and along the belly. Gray occurs in this country, but does not meet with favor,

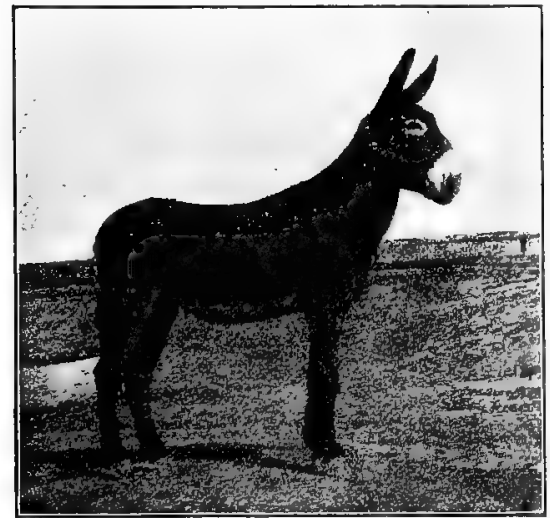

FIG. 59. Antar Jr. 2I7. First-prize two-year. old jack at the World's Columbian Exposition, Chicago, in 1893 , also first in class in 1897 at Illinois State Fair. Photograph by the author and is not approved by the American Breeders' Association of Jacks and Jennets. The Andalusian jack is native to Andalusia in southern Spain, where it is an ancient breed. The color is gray, with rare cases of black. This breed has considerable size and stands I $4 \frac{1}{2}$ to $15 \frac{1}{2}$ hands high. The bone is excellent and the breed possesses much substance. Sessions refers to one $15 \frac{1}{4}$ hands high having a girth of 67 inches with the bone below the knee measuring $8 \frac{3}{4}$ inches around. The head and neck are said to be very good. This breed and color have never been popular in America, although well scattered over the country.

The Maltese jack comes from the island of Malta in the Mediterranean Sea. This breed is either black or brown in color, and is of the smaller type, rarely exceeding $14 \frac{1}{2}$ hands. The

- head is of excellent form, with sharp, upright ears. The Maltese possesses much life and vigor, but is objected to on account of too fine a bone and too much refinement, with not enough substance. A larger type is in demand in the American trade, which restricts the importation of this breed. 
The Catalonian jack is a Spanish breed from Catalonia in extreme northeastern Spain, bordering on France. This is a black or brown breed with light points, black largely prevailing. The coat of hair tends to be thick and short. This breed stands from $14 \frac{1}{2}$ to 15 and occasionally I 6 hands high. From the standpoint of critics of this class of animals the Catalonian possesses

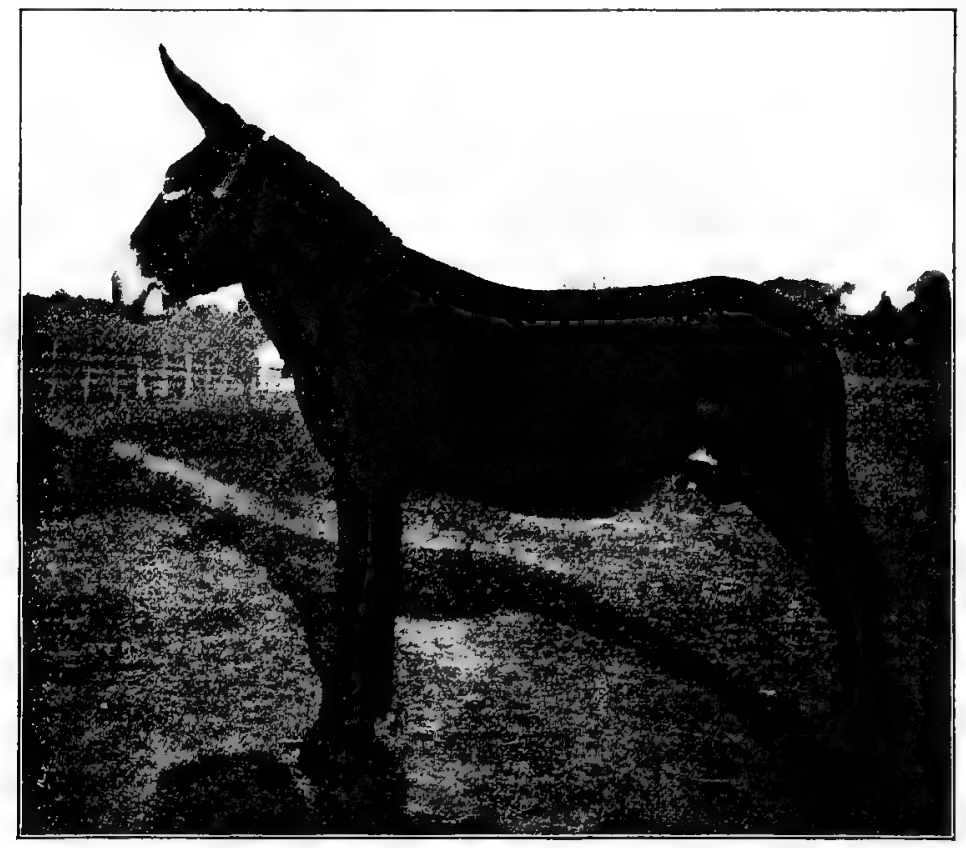

FIG. 60. Dr. Hartman. The leading prize-winning jack at the principal fairs in the blue grass region of Kentucky, and first in yearling class at Louisiana Purchase Exposition, St. Louis, 1904. Owned by J. F. Cook \& Co., Lexington, Kentucky. Photograph from owners

unusual style, beauty, and action. The head shows considerable character, and the ears are rarely droopy. While the bone is not so large as the Andalusian or Poitou, it is very superior in texture and free of flesh, so that it is not objectionable. The Catalonian is also a wiry, tough type that matures early. This breed has been largely used as foundation stock for producing mules in Tennessee, Kentucky, and Missouri, where it is 
yet in great favor. H.W. Session states that the produce of these jacks from 16 to 17 hands high, as seen in Missouri, Kansas, and the eastern United States, have much weight and substance and make the best mules in the world. They are quick, active, and good sellers, and mature early.

The Majorca jack is a breed of more recent introduction to America from Majorca, one of the Balearic islands in the Mediterranean Sea off the coast of Spain. This is a large sort of drafty type with heavy bone, averaging $15 \frac{1}{2}$ hands high, standing perhaps a hand higher than the Catalonian. The head and ears are said to be conspicuously large, the latter being longer than those of any other breed and poorly carried. There is a lack of style and action with the Majorca, the tendency being to sluggishness. The breed has not attained popularity in America, and but few have been brought here. It has, however, met with considerable favor in Spain for producing artillery mules, and many of the jacks have been exported to South America. In its native home it has long been bred with much purity.

The Poitou jack is a native of France, where for many centuries he has been bred, especially in the province of Poitou, bordering on the Bay of Biscay. Here, in the departments of Vendée and Deux-Sèvres, the Poitou ass is bred in his greatest perfection. This is the most powerful of the several breeds of asses. In general, they may be described as having an unusually big head, with large, long ears; small mouth and nostrils; thick, short neck; broad chest ; good-sized, long body; quarters rather spare; fore arm long but not thick, but knees and joints large; hocks as big as those of a heavy draft horse ; bone large, many measuring nine inches around below the knee, but legs very short and superior; feet large. The prevailing color is black with light points. Grays occur occasionally, but are not regarded with favor and are not eligible to registry in the French jack studbook. Much is said about the hairy development of the Poitou jack. $\mathrm{He}$ is covered with a profuse growth of long, silky hair, which adorns the ears, neck, and legs. The tail, which is rather short, is quite devoid of hair excepting at its lower part. In his native home, when in service, the Poitou jack is said to be a very unattractive beast, for he is never groomed or trimmed. In Poitou 
these jacks are bred to a very large, drafty, powerful type of mare, native to that region, from which are produced big mules of the most valuable kind. As yet jacks of this breed have not been brought to America to much of an extent, but they are generally regarded with favor wherever introduced.

The desirable height for a jack depends upon the use. If to be mated to a mare, about I 5 hands meets approval, while if for jennet service, a larger type is sought, ranging nearer I6 hands. In an examination of heights of jacks in the American jack studbook Ioo individuals averaged 15.2 hands high, practically $15 \frac{1}{4}$ hands. Of the first roo registered whose height was given the lowest was I4 and the highest $16 \frac{1}{2}$ hands, but nine per cent coming within the 16 hands measure. Twentyfive Catalonian jacks had an average height of I5, and seven Majorca 15.2 hands. Fifty jennets showed an average height of 14.48 or

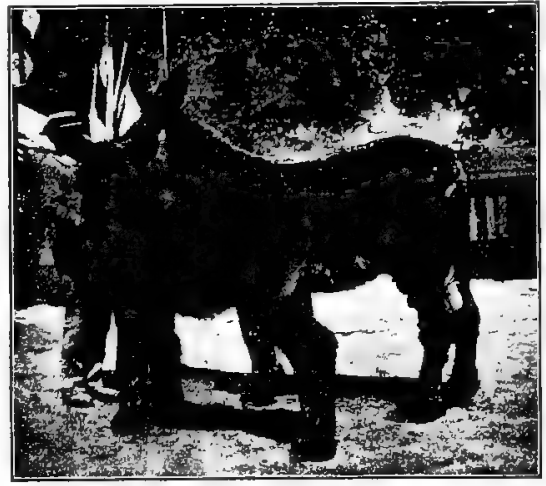

Fig. 61. Lisa and foal. The first-prize Poitou jennet at Nantes, France, 1901. Notice the long, rough coat of hair. Photograph from James B. McLaughlin

I $4 \frac{1}{2}$ hands. Tegetmeier and Sutherland give the height of the Poitou jack as $13 \frac{1}{2}$ to 15 , and of the jennets as I 3 to I 4 hands. In 1877 Richardson described the Poitou ass as standing from I $3^{\frac{3}{4}}$ to $14 \frac{3}{4}$ hands, while Sessions says they rarely exceed $14 \frac{1}{2}$ hands. The large jack of 16 hands or more is not desired, for he frequently breeds a leggy mule that does not weigh as well as those sired by a shorter-legged type of jack. The rules of the American Breeders' Association of Jacks and Jennets on the subject of height are as follows :

2. Up to January $I, 1892$, all jacks $14 \frac{1}{2}$ and all jennets 14 hands high, standard measure, shall be eligible to registration, if black with light points.

3. After January I, I 892 , jacks and jennets of unrecorded sire or dam shall be eligible to registration only when black with light points, and of the following height, standard measure : 
Imported jacks and jennets, the produce of unrecorded sire or dam, I 5 hands.

Native jacks, the produce of unrecorded sire or dam, $15 \frac{1}{2}$ hands.

The introduction of the ass to America is said to date back to colonial times, when, soon after the Revolutionary War, the King of Spain sent as a gift to General George Washington, a Spanish jack and jennet. In Washington's time some early interest was shown in breeding mules, as a result of this gift. Henry Clay is said to have imported some very fine Spanish jacks to Kentucky. From the Clay stock Kentucky obtained the start which has resulted in such fame for that state in mule breeding. One of the first imported jacks taken to Tennessee was imported about I 840, and was taken to Maury County by a Mr. Thomas. About I 867 or I 868 Messrs. A. C. Franklin and Tul Craig of Sumner County, Tennessee, imported some Catalonian jacks. About I $882 \mathrm{Mr}$. Lyle of Kentucky imported some Andalusians from near Seville, and the same year Leonard Brothers of Missouri made a similar importation. Many importations from Spain, France, and the Balearic and Malta islands have been brought to America since 1884 .

High prices for jacks prevail to an extent not generally supposed. In France the Poitou ass brings a large figure, common ones selling close up to $\$ 1000$ and the better class from $\$ 500$ to $\$ 2000$. At a recent Paris exposition one is reported selling at $\$ 3200$. Paragon 63 , imported from Catalonia in 1886 , was sold for $\$ 2000$. This same year an importation of Catalonian jacks was made to Tennessee, from which Jumbo sold for $\$ 2000$, Peacock for $\$$ I 500 , Boyd's Monarch for $\$$ I 500 , and the Douglas jack for \$I I 50. From another importation the jack King James sold for $\$ 2000$.

The American Breeders' Association of Jacks and Jennets was organized as a stock company at Springfield, Illinois, in I888. Five volumes of studbooks have been issued to 1906. The headquarters of the association are in Tennessee. In France an association for registering jacks and jennets also exists. 


\section{CHAPTER XXIV}

\section{THE MULE}

The mule is not a true breed, as ordinarily considered, but is a hybrid. Its importance is so great, however, in certain sections of America that it is worthy of consideration as an important draft animal.

The mule is a hybrid, having for sire a jackass, commonly termed a jack, and a mare for dam. If, however, a stallion be bred to a female ass, the result is a hybrid, known as a hinny. This last union produces an offspring inferior to the mule in size, and in those qualities desired in a draft animal. The mule is sterile and will not breed, although several cases are on record of mare mules getting in foal and producing to a stallion.

The mule in history has been known many centuries. No doubt it has been used more or less in Europe since the days before Christ. In the days of ancient Rome and Greece mules served various purposes. Varro, who wrote in the first century B.C., refers to mules in Roman agriculture, as does also Columella.

The geographical distribution of the mule is widespread. $\mathrm{He}$ is especially bred in great perfection in Spain, France, Portugal, Italy, and certain sections of the United States and South America. Great Britain has never looked with favor on the mule. Sessions has recently written in The Live Stock Journal:

The mule line extends north from the equator, and includes Africa and Europe up to 45 degrees of latitude and Asia and North America as far as the 35 degrees. On the south side of the equator we can include most of Africa, the northern half of Australia, and South America as far south as the 35 degrees. Within this vast radius hundreds of thousands of mules are bred each year. Many of the mules are big, heavy animals, with great power and bone and stand 16 and 17 hands high.

Mule raising in the United States began in colonial times. About 1787 George Washington was presented by the King of 
Spain with a jack, which was used in stud at Mount Vernon and sired mules that sold for upwards of $\$ 200$ each. The value of the mule as a draft animal was soon recognized by intelligent Southerners. Henry Clay in 1832 imported a jack from Spain to Kentucky for use on mares, and others followed his example. To-day, Kentucky, Tennessee, Missouri, and Texas are the most important producers of mules, Missouri leading, with St. Louis the most prominent mule market in the world.

The characteristics of the mule partake of both sire and dam. There is the long ear, slender body, tufted or slightly haired tail,

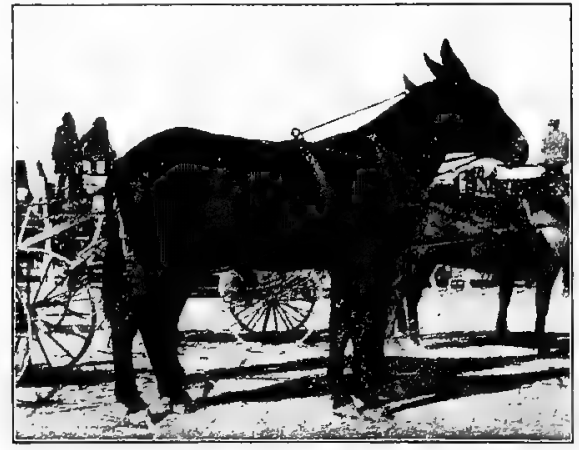

Frg. 62, An unusually choice pair of show mules of Plantation or Sugar class, first-prize winners at Illinois State Fair, I897. Photograph by the author and small, slender foot, and braying voice of the ass. These features seem to attach a peculiar character to this non-breeding farm animal. Mules vary greatly in size and quality, naturally due to their parentage. Other things being equal, a large mule brings a higher price in the market than does a small one. Mules are sorted and classed for various purposes. The larger, heavier mules are used in city drayage and heavy draft work, or in lum. ber camps. A medium size is used on farms and in military service, while the smaller grades find places in mines and elsewhere.

The market classification of mules usually includes five groups, which are as follows.

I. Plantation mules. These are of two classes, viz. sugar mules and cotton mules. In general, plantation mules represent the larger, heavier, better type. In the Chicago market a sugar mule stands from I 6 to $I 6 \frac{1}{2}$ hands high and weighs from I 100 to 1400 pounds. On the Kansas City market the height is given at I 5 to 16 hands. Sugar mules are by some placed in the highest class as regards quality and value. They must be smooth of finish, show refinement of head and neck, and have superior 
bone. Sugar mules bring the highest prices. Cotton mules on the Chicago market range from 14 to $15 \frac{1}{2}$ hands high and weigh from 900 to 1000 pounds. John Grant of the Kansas City yards is credited with stating that they range from I 3 to $I 6$ hands and that they are at the best age when from four to seven years old. In the Southwest cotton mules are very common. They are not of so uniformly high quality as sugar mules, but must be smooth in finish. In bone they range from light to medium.

2. Lumber mules stand from $15 \frac{1}{2}$ to 17 hands high and are the largest, heaviest-boned, and most rugged sort. Capacity for hard work is regarded as more important than quality, and weight is essential in its application to hard pulling of logs. Very high prices are paid for lumber mules.

3. Railroad mules range from $15 \frac{1}{2}$ to $16 \frac{1}{2}$ hands, and weigh from 1200 to 1500 pounds, as graded on the Chicago market. They must be of excellent quality and weigh somewhat less than lumber mules. They are used in grading and general hauling in railroad construction.

4. Mine mules - of two kinds, known as pitters and surface mules - vary from I I to I $5 \frac{1}{2}$ hands high, and must be chunky and hardy, with heavy bone. Prices vary according to height, quality, and weight. In commenting on this class, Mr. John Grant further says :

The miners are the hardest class to supply. They must be either dark bay or black in color. White and sorrel mules are never used. When the mines have long shafts, as in the Pennsylvania coal regions especially, they say a white mule resembles a ghost and frightens the other mules beyond control. The pitters must be long in body, heavy-boned, and have good weight. They range from 12 to $15 \frac{1}{2}$ hands and bring from $\$ 135$ to $\$ 200$, while for any other trade they would bring $\$ 50$ less. Surface mules are used on the long hauls on top of ground. They are heavy but taller, and have not such large bones.

5. Levee mules are about the same as railroad mules, though of somewhat better quality. They are used near steamboats and docks for heavy work, especially in the South. They must be of a rugged sort, perfectly sound, and capable of hard work.

The above classes vary somewhat in detail, according to the local markets, - St. Louis, Chicago, Kansas City, Louisville, or 
New Orleans, - each having more or less variation from any proposed general classification.

The best type of mule must show the general excellent conformation of the horse in symmetry of form. The body tends to be more cylindrical and smaller than in the horse, but a capacious body is desirable rather than otherwise, though paunchiness is objectionable. The nearer the general body conformation approaches that of the superior draft horse, the more completely will the mule suit the demands of the critical trade. In the show ring those mules which meet with greatest favor possess the horse form in greatest degree. Legs of superior quality are fine and hard, the bone very smooth and dense, the tendons prominent, and the muscles well develcijed. The feet of the mule are smaller and longer than those of the horse, and the arch of the foot is greater. In general, the mule is distinguished for superior feet and legs.

The temperament of the mule is quiet and patient, while for steadiness under the collar and hard pulling he has no equal in the equine world. However, the mule should show an active temperament, with sprightly carriage and style. It has been common to regard the mule as given to kicking, but this is not based on fact, for mules are no worse than horses in this respect. Horses are more nervous and uncertain in temperament than mules, and are more subject to fright and consequent runaway.

The color of the mule is variable, though brown and bay are the most common colors. Besides these, various shades of gray, white, black, sorrel or chestnut, and buckskin-yellow occur more or less.

The endurance of the mule is remarkable. It is worked under the severest conditions, and shows great power of resistance to fatigue. Tegetmeier quotes from a Texas correspondent:

Six mules, the leaders no larger than ponies, will take 6000 to 7000 pounds anywhere, making fifteen to thirty miles a day according to the state of the roads, and I have known a team in summer driven fifty miles, with 1000 pounds a head of load, to reach water, and not appear to suffer.

Mules usually live to a greater age than horses, and perform their work with regularity and on less feed, a most important point in 
their favor. Cases are recorded of mules living to seventy years of age, and Mr. J. L. Jones refers to one in Tennessee that at thirty years of age was doing effective service attached to a reaper.

The resistance of the mule to disease has been a frequent subject of discussion. It is commonly claimed that the mule is not so generally subject to disease as the horse. Pomeroy in an essay on the mule credits this animal with freedom from any kind of disorder or complaint. In an investigation of "blind staggers" among horses in Virginia and North Carolina, conducted under the direction of United States Secretary of Agriculture Coleman, mules were found quite exempt from this disease, although they are credited with other maladies. In regions in the lower Mississippi Valley infested with buffalo gnats, Professor F. M. Webster reports the mule as the animal most subject to fatality from attacks of this insect. Southern-bred mules, however, are far less susceptible to the bites of the gnats than those imported from more northern localities. While the mule is not so subject to leg and foot diseases as is the horse, cases of spavin, ringbone, sidebone, and other troubles do occur. Corns are rarely found on the feet of the mule. Even when affected with foot or leg disease, this animal, as a rule, without doubt, is less disabled from work than is the horse. The resistance of the mule to disease, its activity, sureness of foot, docility, and easiness of keep, have resulted in its finding much favor in the army service.

The mule as a carriage or saddle animal is important in certain sections. In the Southern states he is thus used very commonly by negroes and the poorer classes of whites. In the central West, in states bordering the Ohio river, one occasionally sees gentlemen driving mules, either singly or in pairs, in harness, attached to carriages, the animals trotting with commendable speed.

The Poitou mule is a famous French mule, the result of using the Poitou ass on a large type of French mares. There are two types of these mules bred in the Poitou region, a large and a small, but the larger type is in greater demand. The finest and largest cart mares are used for this production, the French farmers making a business of producing this grade of mule. Besides size, Poitou mules are celebrated for the shortness and stoutness of 
their legs, with their superior bone and unusually large and finely formed feet.

The sex of the mule has a bearing on its salability. Mare mules are preferred by buyers, feeders, and dealers generally, and sell more easily than horse mules. The females assume a matured form at an earlier age, and fatten best for the market. The horse or male mules have a more angular and leggy form, and cannot be fattened so early as the mares. One dealer in mules tells the author that horse mules in pasture with other stock will worry them, when the mares would not. The sexual organs of the mule are supposed to be incomplete, but several cases are on record where mare mules have become impregnated and produced young. Such cases, however, are remarkable and are not accepted as authentic by most scientists.

The prices paid for mules vary, naturally, with the quality and character of the animals offered. However, the average farm price for mules is greater than for horses. On January I, 1905, the average farm price for horses in the United States was $\$ 70.37$, while for mules it was $\$ 87.18$. In those markets where mules are important, very high prices rule, and a pair of heavy, matched mules of superior quality and conformation sell easily for $\$ 500$ and upwards. The Poitou mule in France, rated the best in Europe, sells at $\$ 200$ to $\$ 300$ a head, and sometimes fetches $\$ 400$. Large numbers of mules change hands at from $\$ 100$ to $\$ 50$ per head. In I905 The National Stockman and Farmer noted the sale in Kentucky of one pair weighing 3100 pounds at $\$ 550$ and of another pair of 2600 pounds weight at $\$ 450$. 


\section{A FEW REFERENCE BOOKS ON THE HORSE}

Those marked with a $*$ are especially recommended.

*E. L. Anderson and Price Collier, Riding and Driving. New York, I905.

* Robert Black, Horse Racing in France. London, 1886.

*W. C. A. BLEW and others, Light Horses: Breeds and Management, London, 1894 .

*Hamilton Busby, The Trotting and Pacing Horse in America. New York, 1904.

Louis Henry Curzon, A Mirror of the Turf. London, I892.

Richard Darvill, A Treatise on the Care, Treatment and Training of the English Race Horse. 2 vols. London, 1846.

E. Daumas, The Horses of the Sahara. London, 1863 .

William DAY, The Horse. London, 1890 .

William Day, The Race Horse in Training. London, 1892.

John Dimon, American Horses and Horse Breeding. Hartford, 1895 .

William S. Dixon (The Druid), Post and Paddock. London, 1856.

William S. Dixon (The Druid), Silk and Scarlet. London, I859.

*Theodore A. Dodge, The Riders of Many Lands. New York, 1894 .

* Charles Du Huys, The Percheron Horse. New York, 1868.

William Henry Flower, The Horse. London, I89I.

* Sir Walter Gilbey, Ponies Past and Present. London, 1900.

* Sir Walter Gilbey, Riding and Driving Horses. London, igor.

* Sir Walter Gilbey, The Great Horse: The Shire. London, 1899.

* Sir Walter Gilbey, The Hamess Horse. London, I898.

* Sir Walter Gilbey, The Old English War Horse. London, 1888.

*M. Horace Hayes, Points of the Horse. London, 1897 .

*Heavy Horses: Breeds and Management. London, 1895.

*H. T. Helm, American Roadsters and Trotting Horses. Chicago, 1878 .

*H. W. Herbert, Frank Forester's Horse and Horsemanship of the United States. 2 vols. New York, 1871.

*J. P. HORE, The History of Newmarket. 3 vols. London, 1886.

F. H. Huth, Works on Horses and Equitation: A Bibliographical Record of Hippology. London, 1887.

*D. C. Linsley, Morgan Horses. New York, I857.

*C. Bruce Lowe, Breeding Race Horses by the Figure System. New York, 1898.

- Charles Marvin, Training the Trotting Horse. New York, r8gz.

Pirrre Megnin, Le Cheval et ses Races. Vincennes, 1895.

*H. C. MERwin, Road, Track and Stable. Boston, 1893.

Joseph Osborne, The Horse Breeders' Handbook. London, N.D. 
J. H. Reeves, The Orange County Stud Book. New York, I880.

*William RIDGEWAy, Origin and Influence of the Thoroughbred Horse. Cambridge, 1905 -

IsaAc Phillips Roberts, The Horse. New York, igo5.

J. H. Sanders, Horse Breeding. Chicago, 1893 .

*S. Sidney, The Book of the Horse. London and New York, N.D.

C. H. Smirh, Horses: The Equidæ or Genus Equus. Naturalists' Library, Vol. XII. Edinburgh, I 84 I.

John Gilmer Speed, The Horse in America. New York, rgo5.

John Splan, Life with the Trotters. Chicago, I889.

* Charles Trevathan, The American Thoroughbred. New York, I905.

J. H. Walsh (Stonehenge), The Horse in the Stable and the Field. London, 1871 .

James C. White, The History of the British Turf. 2 vols. London, 1840.

* Hiram Woodruff, The Trotting Horse of America. Philadelphia, 1868.

*William Youatt, The Horse. London, 1846 , and Philadelphia, 1848.

The Ass and Mule

* Harvey Riley, The Mule. New York, i867.

*W. B. Tegetmeier and C. L. Sutherland, Horses, Asses, Zebras, Mules and Mule Breeding. London, 1895. 


\section{PART II - CATTLE}

\section{CHAPTER XXV \\ BEEF TYPE OF CATTLE}

The general appearance of the beef animal, when of correct type, shows a distinctly meat-producing form. The animal is compact and broad of back from shoulder points to hips; has a wide, deep body; short and somewhat thick neck; wide, deep, full bosom; rather broad, thick, fleshy hind quarters; and a generally deep, wide body. Viewed from one side the top and bottom lines of body run rather parallel, with the back quite level. From front or rear the outline should be rather full and broad. Cattle of this type are commonly referred to as "blocky," indicating compactness and squareness of form. If the body is inclined to be long it may be termed "rangy," while animals long of leg, showing too little depth and fullness of body, may be termed "leggy."

The head should have a broad, strong muzzle, indicating superior grazing and feeding capacity. The nostrils, when somewhat prominent and large, with a wide nose, show ample nasal capacity to supply the lungs with air. A Roman nose sometimes occurs with cattle, but it is neither attractive nor desirable. The distance from the muzzle to a point immediately between the eyes is preferably short, with some curve, or "dish," as it is termed, just below the eyes, which should be wide apart, large, and indicate a gentle temperament. A quiet eye means an easy feeder, while a nervous, restless eye shows an animal unsatisfactory to handle and care for. The forehead, as indicating mental capacity, should be broad and reasonably full. The face and cheeks in a superior head are full and deep, connected with a rather broad, strong lower jaw. If of the horned type, the horns should 
not be coarse at the head, but should show plenty of fine texture and quality, and be graceful and of harmonious proportions. An abundance of rather long hair should crown the poll, or top of the head. It is most desirable that the ear should be neatly attached to the head, without coarseness, and that it should be of superior quality, and neatly pointed and covered with silky hair, with long hair at edges and tips.

The neck of the beef animal tends to be short, thick, and muscular, of medium depth, and should be neatly attached to the head and smoothly blended with the shoulders. The bull at maturity shows a neck of more length, with heavier muscles, some arch, and a heavy coat of hair. The female will have a shorter, lighter neck, with less thickness and less depth. The steer should have a shorter, thicker, fuller, smoother fleshed neck than the cow. When in perfect pose, with head up, the top line of the neck should be but slightly raised above the height of the withers.

The shouldors should extend well into the back, lying smoothly covered with flesh, blending neatly with the body. A high type of shoulder is uniformly covered with flesh from shoulder point to top of withers. Rough, angular shoulders, unevenly covered, are among the most common defects of cattle. A prominent shoulder also emphasizes the development behind it.

The breast and chest are most important. The former should be carried well forward and be broad and full in the bosom. As one stands and views a beef bull in show form a great breadth of breast and strength of brisket meets the eye. Sometimes the breast and chest have great depth, and the brisket comes within fifteen inches of the level of the foot. Viewed from one side it may curve forward like the prow of a ship. With the cow considerable bosom may show, but not in so great a degree, and with less breadth and more feminine outline. The chest, which lies between the shoulders and just back of them, should be full at the crops, showing much spring of rib, and also well filled out in the front flanks. The most beautiful front an the beef animal, no matter whether bull, cow, or steer, is a smoothly laid, wellfleshed shoulder, with a strong arch of rib behind, leaving little or no depression. Much depression behind the shoulders, or a narrow, contracted lower chest, indicates lack of constitution. 
The front legs should have a wide muscular attachment of arm at the shoulder, with plenty of room from armpit to armpit below the chest. Short, well-placed legs, coming straight down, viewed from front or side, are essential. The toes should point straight forward, this indicating a proper position. Closeness of knees indicates a narrow chest. Fine bone and smooth joints point to superior quality. The front shank bone of a mature animal of the beef class should show refinement at its narrowest point.

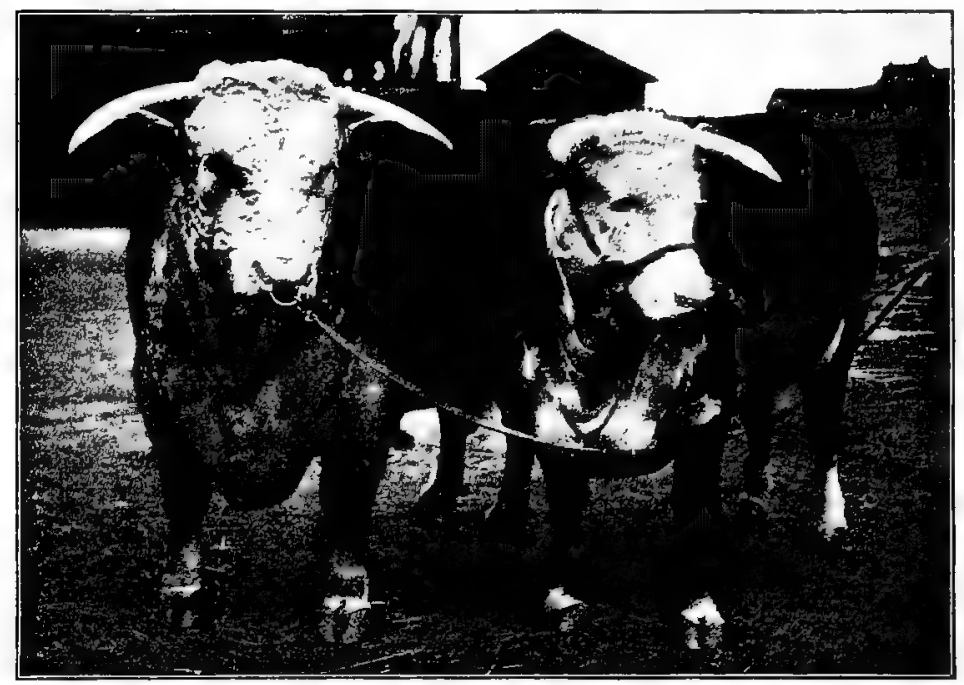

FIG. 63. The Hereford bull March On VI and the heifer Bouquet. These show beef form in a pronounced degree, especially as viewed in front. Photograph from the National Stockman and Farmer

The back of beef cattle carries an immense weight, supported at fore and hind quarters. It should thus be very strong and level to sustain this burden. As the highest-priced meats on the carcass are found on the back, it is important that the ribs be well arched, that a broad back be provided, to carry as much meat as possible, thus adding to the value of the animal. Great width is desirable from the point of the shoulders to the hips, and as viewed from front or rear along the back there should be much breadth, covered uniformly with mellow flesh. Dimples 
or tucks in the back, rough spots, and uneven patches of fat detract from the value of this part.

The ribs should not only be well sprung but be long and carried down to help make a capacious body. This goes with the strong feeder, and is also most essential with the breeding female. With bulls and steers a very close coupling between the hips and last ribs, or all the ribs in fact, is desired, but with cows for breeding purposes some greater length is approved of. The depth at front and hind flank, with a thick, full feel at the latter, are associated with superior form.

The hips should be well placed, snugly laid, and with steers well covered with flesh. A wicle hip in the bull is undesirable, for such a feature may be transmitted and be a source of danger to the cow on birth of wide-hipped offspring. A greater width and more prominence of hip is allowable among the cows, although too frequently one sees the hip too prominent.

The rump of a beef animal, no matter what the kind, should be long from hip to point of body, be of great width, and comparatively level. This not only promotes a maximum of flesh production, but it gives a more beautiful form and offers a conformation better suited to the breeding female thandoes any other. A droopy, peaked rump is a defective conformation, obstructs easy calving, may reduce flesh capacity, and certainly detracts from beauty of form. With beef cattle the rumps are sometimes rough about the tail head or at the ends of the rump on each side of the tail. Smoothness and fullness here indicate better fleshing qualities.

The hind quarter, viewed from behind, should be quite thick, coming down perpendicularly on the outside to where the thigh naturally narrows. On the inside a thick, broad edge, with much depth from tail head to a full, well-turned twist should be apparent. From one side the hind quarter will appear long and broad, with considerable depth of flesh to the rear. The whole will appear thick, and smoothly covered with flesh.

The hocks and legs indicate the capacity for fleshing at the hind end. If the hocks are strong, muscular, clean, and well placed, with no special tendency to come together, they will be generally associated with thicker-fleshed quarters than otherwise. 
The hocks should stand squarely under the animal, so that a plumb line dropped from the pin bones will bisect them and the shank bone of the leg below. Crooked hocks are bad, showing weak conformation and ugly form. When the hocks tend to come together at the points - a very common thing - the toes point out. Only very rarely do the toes point in. The necessity for a graceful and straight position of the hind leg, smoothness of joint, shortness of leg, and fineness of bone is apparent.

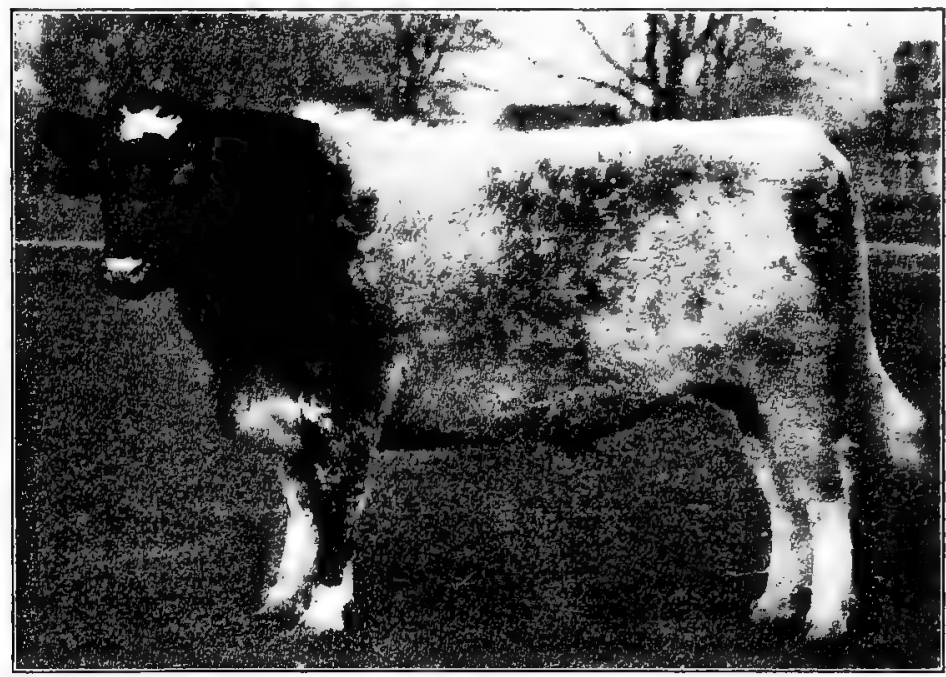

Fig. 64. The grade Shorthorn steer Flashlight, shown at the 1904 International Live Stock Exposition by Purdue University. Winner of first honors in grade and cross-bred classes. This picture shows a fine example of beef form as viewed from one side. Photograph from Professor J. H. Skinner

The udder of the beef cow is too frequently ignored. It should be of good size and shape, extending well up behind and in front along under the body, with four well-placed teats. Every beef cow should be able to furnish ample milk for her calf for the first eight months of lactation. It is not creditable to a beef cow to have an ill-shaped udder or to produce but little milk.

The quality of the beef animal is shown in bone, skin, hair, ears, and horn. A coarse bone, with large rough joints, long legs, and heavy horns, indicates lack of quality. If the ears are large and 
coarse, with heavy attachment, there is also lack of quality. The most signal indication of quality is in the hide, which should always be mellow and pliable, and in the hair, which should be silky and fine. In winter there are thick, fine hairs lying in great profusion next to the skin, with longer ones projecting beyond, thus providing great protection from rough weather. As one views an animal with very distinct evidence of quality in the skin, there will be a glisten and finish to the coat and a roll to the hide which only goes with good quality. Taken in the hands, along over the ribs, the skin seems mellow and pliable to the touch, being easily grasped and stretched. A very thin hide is undesirable, the better sort having a moderate thickness, exceeding that of a dairy animal.

The fleshing of beef cattle is very important. There should be uniformity of flesh all over the body, even though it be not a fattened animal. On highly fed ones, especially steers, the flesh should increase in thickness, but not lose its uniform distribution over the frame. The palm of the hand pressed along the back, shoulder, or side should find no evidence of irregular covering, with bare spots in one place and heavy fleshing near by. Such fleshing indicates an undesirable type for feeding and killing. 


\section{CHAPTER XXVI}

\section{THE SHORTHORN}

The original home of the Shorthorn breed of cattle is in northeastern England, in the counties of York, Durham, and Northumberland. The North Sea borders this section on the east, with the Cheviot Hills of Scotland the boundary on the north. Winding its way through a beautiful grazing country, the river Tees forms the dividing line between Durham on the north and York, the largest county in England, on the south. Here in the valley of the Tees the Shorthorn received its early development and improvement, from which it spread out over the rest of Great Britain and the civilized world. This valley country has beautiful long stretches of rolling grass lands and fields of grain and roots, but farther north in Northumberland and south in York the land becomes rougher and more hilly.

The origin of the Shorthorn is naturally veiled in obscurity. No doubt the early invaders of England - the Romans, Normans, and others - brought over cattle which crossed with the native English stock. It has been assumed that even prior to 1600 cattle of Shorthorn type were bred on the estates of the earls and dukes of Northumberland in Yorkshire. ${ }^{1}$ Black, horned cattle prevailed more or less in Yorkshire, while farther south, in Lincoln and vicinity, white, red, and other colors prevailed. Early in the eighteenth century the Teeswater cattle represented one popular type, while in southeastern Yorkshire another sort, known as the Holderness, was developed. About the middle of this same century Michael Dobinson and Sir William St. Quintin brought over bulls from Holland, and used these in their herds, owned in Durham and Yorkshire respectively. In I789 George Culley wrote :

1 The word "shire" in Great Britain signifies county, and is often used as a part of the county name, as "Yorkshire," for example. 
I remember a gentleman of the county of Durham (a Mr. Michael Dobinson), who went in the early part of his life into Holland, in order to buy bulls; and those he brought over, I have been told, did much service in improving the breed; and this Mr. Dobinson, and neighbors even in my day, were noted for having the best breeds of Shorthorned cattle.

Following these importations of Dobinson and St. Quintin, came others of more inferior stock, such as really injured the beef cattle of the country. By Culley's time, however, much of this evil effect, he writes, was overcome. Other improvers of the early Shorthorn were Sir James Pennyman, the Aislabies of Studley Royal, the Blacketts of Newby, Millbank of Barningham, James Brown, Stephenson, Wetherell, Maynard, Snowdon, Waistell, and Richard and William Barker.

The more distinguished improvers of the Shorthorn really date from about I780, and include Charles and Robert Colling, Thomas Bates, Thomas Booth and his sons John and Richard, and, Amos Cruickshank. There were many other prominent and

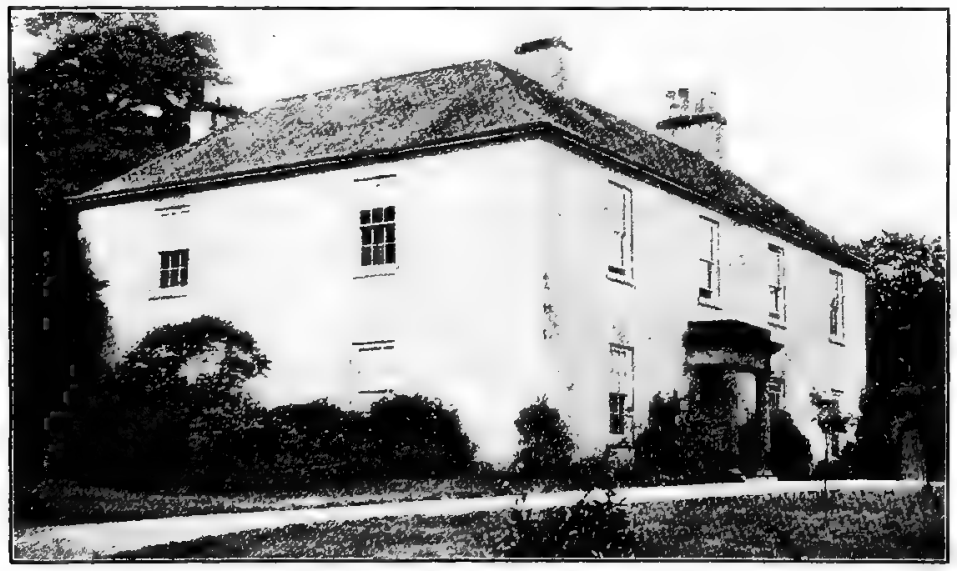

Fig.65. Ketton Hall, the home of Charles Colling, near Darlington, England. Photograph by the author

successful breeders, but these men distinguished themselves as epoch makers, about whose careers clusters much of the best in Shorthorn history.

The Colling brothers. These were Charles and Robert. Charles was born in 1750 and lived at Ketton, just north of Darlington 
in Durham, while Robert, born in 1749 , lived at Barmpton, not far from Charles. They sought to make better feeders, have their cattle mature early, dress out with less offal, and have more constitution than the old sort. They gathered about them two very famous herds, which had a great influence in uplifting the breed.

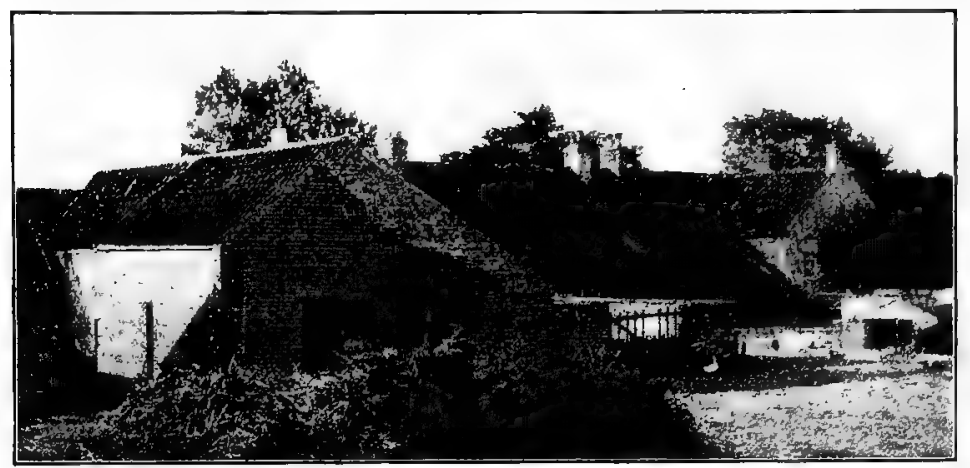

Frg. 66. A rear view of the house and part of the stable at Kirklevington, near Yarm, England, the residence of Thomas Bates. Photograph by the author

The herd of Charles, comprising 47 animals, was sold at auction in 18 Io for an average of about $\$ 750$ a head. The herd of Robert was sold in two parts, 61 animals in 1818 averaging about $\$ 650$, and 46 animals in 1820 averaging about $\$ 250$ each. So great a work did the Colling brothers do that they have often been referred to as the founders of the Shorthorn breed. Robert died a bachelor, in $\mathbf{1 8 2 0}$, and Charles died in 1836 , leaving a widow but no children. The Colling brothers founded the Phoenix, Wildair, Princess, Red Rose, Bright Eyes, Daisy, and some other tribes.

Thomas Bates was born in Northumberland in 1775 and died at his Kirklevington estate, near Yarm, in Yorkshire, in I849. $\mathrm{He}$ early became acquainted with the prominent breeders of his time, notably the Colling brothers, and began the systematic development of a class of cattle having superior dairy as well as beef qualities. He was a very careful investigator, keeping detailed records of the relationship of food consumed to beef and milk production. His cattle had much quality, were rather large for the breed, possessed great dairy capacity, but were somewhat 
criticised for lack of constitution and breeding capacity. He developed the Duchess, Oxford, Waterloo, Cambridge Rose, Wild Eyes, Foggathorpe, and other tribes. Bates died a bachelor, and with his death in 1850 came the dispersal of his herd of 68 animals at an average price of about $\$ 335$ per head.

The Booth family became prominent in Shorthorn history with the establishment of a herd by Thomas Booth, at Killerby in north Yorkshire, prior to I790. His herd was established with good Teeswater cattle and animals purchased from the Colling

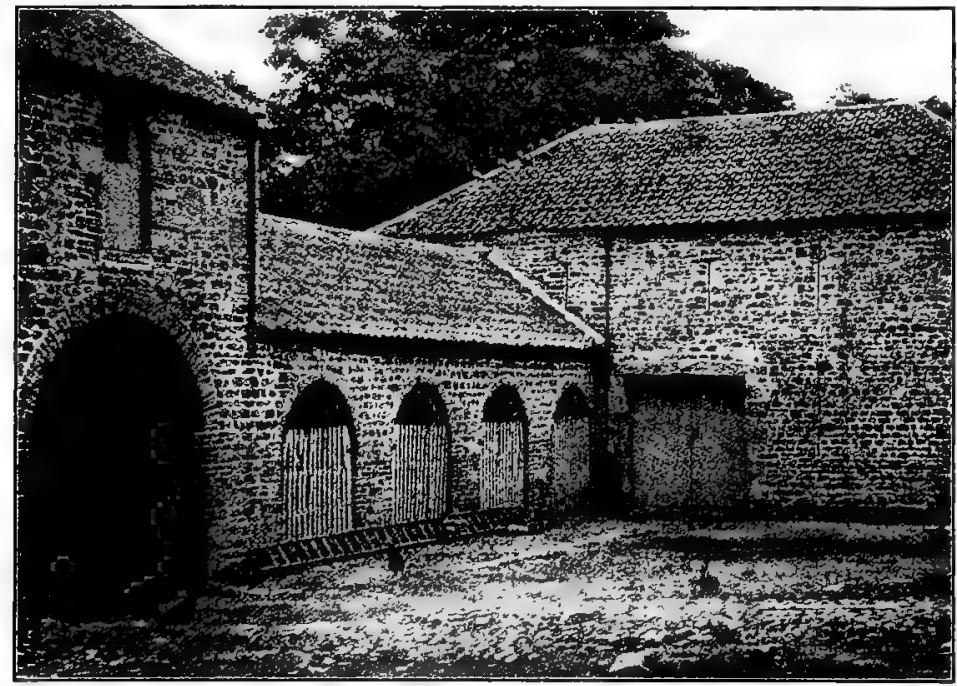

FIG. 67. One corner of the stable at Killerby, the home of Thomas Booth in Yorkshire. Photograph by the author

brothers. He also owned an estate named "Warlaby," on which he lived during the latter years of his life. Thomas had two sons, John and Richard, who took up the work where the father left off John lived at Killerby and died in I 857 , aged seventy years, while Richard lived at Studley adjoining Killerby, and later at Warlaby, where he died in I864, aged seventy-six. These two men had a very great influence on Shorthorn history, and really developed the breed along lines adopted by the Colling brothers. The herd of John Booth was sold at auction in 1852 , while that of Richard was inherited by his nephew, Thomas C. Booth, who died 
in 1878 . A son of the latter, in the prime of life, now maintains the Booth reputation by breeding Shorthorns at Warlaby. Thus Shorthorns have been bred by the Booth family, along systematic lines, for over a century. The beef type was emphasized, easyfeeding, thick-fleshed animals with plenty of quality and strong heart girth being sought. Booth cattle were rougher and more robust appearing than Bates cattle and met with much favor. In Ireland in particular they have a strong hold. Important among the Booth tribes are the Anna, Isabella, Medora, Halnaby or White Strawberry, Bracelet, Moss Rose, Mantalini, Blossom or Fairholme, and Cherry Blossom.

Amos Cruickshank was born in Aberdeen, in northeastern Scotland, in I 808 , and died in 1895 at Sittyton, Aberdeen. In partnership with his brother Anthony, who was a merchant in the city of Aberdeen, Amos in I 837 took possession of a somewhat rolling farm, where roots, the small grains, and grass were produced. Here he began to select and buy Shorthorns from various sources, choosing animals that possessed plenty of vigor and rapid flesh-

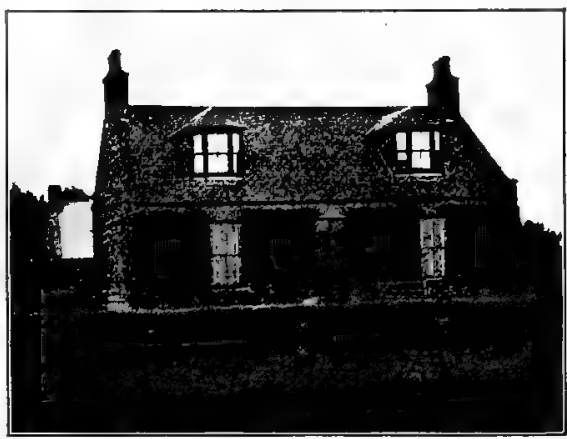

FIG. 68. The farmhouse of William Duthie at Collynie, Tarves, Scotland. Photograph by the author producing qualities. Gradually he developed a type of Shorthorn known as Scotch, which is essentially broad and thick of back, deep and compact of body, short of leg, heavy in fleshproducing quality, and early maturing, - an easy-keeping sort of much vigor and superior killing quality. Cruickshank met with much success, and to-day Scotch cattle, tracing back in an important degree to his breeding, are meeting with great favor all over the world. Among the important tribes established by him are the Violet, Venus, Mimulus, Picotee, Broadhooks, Lady, Nonpareil, Orange Blossom, Brawith Bud, Lancaster, Victoria, Secret, Lavender, Spicy, and Lovely. 
Other important Shorthorn breeders who assisted in establishing the breed were Christopher Mason of Chilton; Jonas Whittaker of Otley near Leeds; Wetherell of Aldborough ; Sir Charles Knightley of Fawsley Park, Daventry, and William Torr of Riby and Aylesby, all of England; these men, and more recently J. Deane Willis of Bapton Manor, Codford, had an important influence during the past century. In Scotland, besides Cruickshank, Robertson of Ladykirk, the first Scotch breeder of Shorthorns; John Rennie of Phantassie, Haddington; Captain Barclay of Ury, Stonehaven; John Hutcheson of Monyruy, Peterhead; Grant Duff of Eden, Aberdeen; William Hay of Shethin, Tarves; Sylvester Campbell of Kinellar; W. S. Marr of Uppermill; and William Duthie of Collynie, Tarves, materially added to the fame of the Shorthorn breed.

Individual foundation Shorthorns of interest date back early into the eighteenth century. In the establishment of the many families or tribes of Shorthorns during much over a century it is but natural that very many animals of great merit and influence on the breed should have existed. Only a few of these can be referred to here, and these of very early days. The Studley Bull (626), dropped in 1737 , is known as one of the very first important Shorthorn breeding bulls. James Brown's Red Bull (97), a descendant of the Studley Bull, met with much success as a breeder of foundation stock. The bull Hubback (319) is regarded by some as the founder of the Shorthorn breed. $\mathrm{He}$ was calved in 1777 and was a yellowish red with some white. He was sired by Snowdon's Bull $(6 \mathrm{I} 2)$ and was a direct descendant of the Studley Bull (626). His dam was a cow of Stephenson's breeding of an old tribe. Hubback was owned by various persons, but his fame is chiefly due to his services when owned by Robert Colling and later by Charles, who paid about $\$ 40$ for him. Charles Colling used him two years and then sold him in 1785 to a Mr. Hubback in Northumberland, from whom he got his name. Hubback sired some very fine heifers at Ketton, one of which, Haughton, bred to Richard Barker's Bull (52), produced the bull calf Foljambe (263) which became a great breeder. A son of his, Bolingbroke (86), and a daughter, Phœnix, mated, produced the bull Favorite (262), one of the most famous 
Shorthorn bulls of early history. Favorite was dropped in 1793 and died in 1809 . He was mated to his nearest relations in the herd by Charles Colling, and bred to his dam sired the heifer Young Phœnix, which he was in turn bred to, resulting in the bull Comet. This last bull was very beautiful, and reached such great public favor that at the dispersion sale of Charles Colling in 1810 he brought one thousand guineas $(\$ 5000)$, which was the highest price paid up to that time.

Of Booth breeding, some of the most famous founders were White Strawberry, Anna, Isabella, Moss Rose, and Countess. The latter was grandam of the twins Necklace and Bracelet, two of the most famous show heifers of history; Bracelet became a remarkable breeder and founder of a tribe. Isabella as a show cow was "matchless," yet she also was a great breeder. The bulls Young Albion (I 5), Pilot (496), Julius Cæsar (I 143), Buckingham (3239), Crown

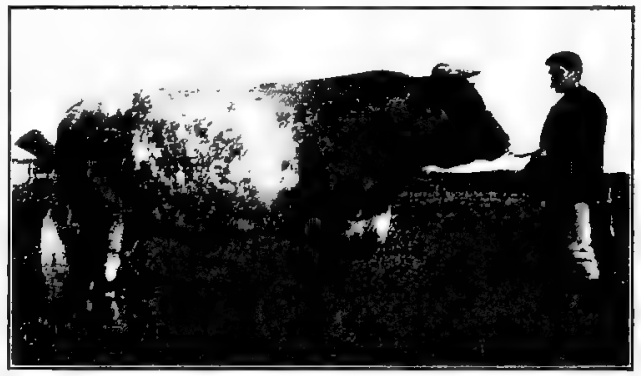

FIG. 69. Pride of Morning (120551), by Star of Morning (I2 I243). Main stock bull in the herd of William Duthie, Scotland. Photograph by the author

Prince (I0087), and Windsor (I40I3) were leading Booth sires.

In the herd of Thomas Bates foundation stock of eminence began with Daisy Bull (I86), obtained from Charles Colling. In I 804 Bates bought the cow Duchess by the above bull, from which in 1805 he secured the bull calf Ketton (709), sired by Favorite. A granddaughter of Duchess, named Young Duchess, sired by Comet, was the ancestress of the Duchess tribe of Bates, his favorite family. The Matchem cow from which the Oxford tribe descends, the Princess cow by Favorite, and a cow known as Acklam Red Rose (Red Rose Ist) from which descends the Cambridge Roses and American Rose of Sharons, were most important foundation dams in the Bates herd. Of the bulls which brought fame to Bates, the more conspicuous were 2d Hubback (1423) by The Earl (646), Belvedere (1706) by. 
Waterloo (28I6), Short Tail (262I) by Belvedere, and Duke of Northumberland (1940) by Belvedere. The Duke bull, out of the famous show cow Duchess 34th, Bates regarded as the greatest result of his breeding career.

Up in Scotland the Cruickshanks used with much success in their herd as early dams Moss Rose, Venus, Sunflower, Phantassie, Premium, Fancy by Billy (3 I 5 I), Clipper (also by Billy), Victoria rgth by Lord John (I 73I), Pure Gold, Butterfly's

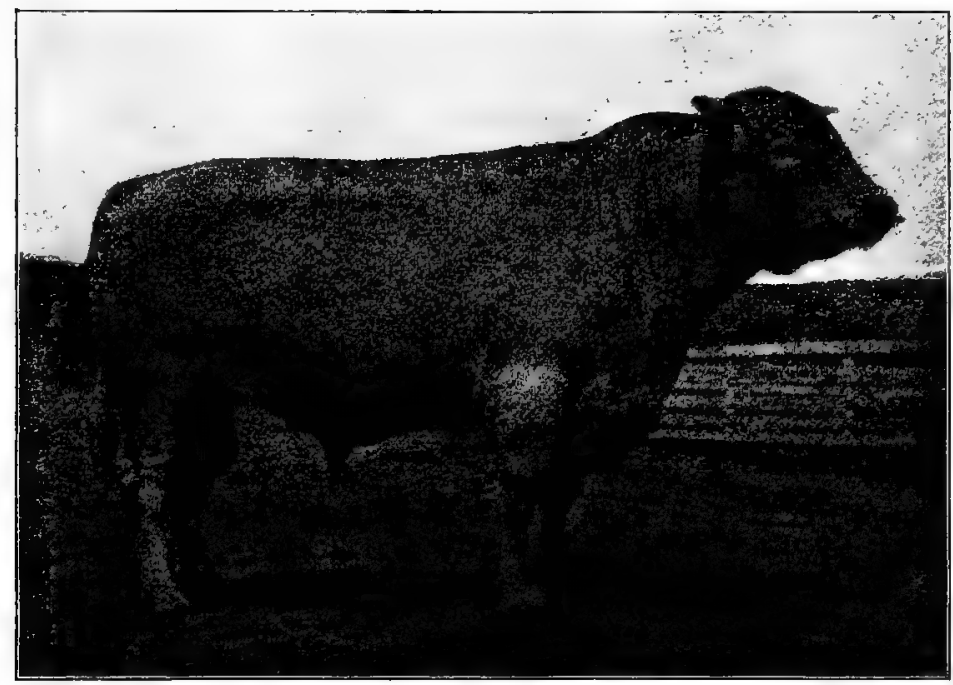

FIG. 70. White Hall Sultan I63573, a prominent Shorthorn show bull in I 904 and 1905, winning the highest honors at the International Live Stock Exposition and elsewhere. In 1903 chief stock bull of E. S. Kelly, Yellow Springs, Ohio; later purchased by F. W. Harding, Waukesha, Wisconsin. Photograph by the author

Pride by Royal Butterfly (16862), Spicy by Marmaduke (I4897), and Lancaster I6th. Among the sires which contributed most to the success of the Cruickshanks were Fairfax Royal (6987), bought in I 845, Matadore (I 1800 ), Lord Raglan (13244), Lancaster Comet (II633), Champion of England (I7526), Royal Duke of Gloster (29864), and Roan Gauntlet (35284).

There were other important foundation animals in the minor herds already referred to, which in a more extended consideration would receive proper notice. 
The first Shorthorns imported to America were brought to Virginia in 1783 by Gough and Miller, and though not called Shorthorns the evidence shows them to have been of this breed. These men also imported again about 1792 . It is said that in $179 \mathrm{I}$ and also in I $796 \mathrm{a} \mathrm{Mr}$. Heaton brought Shorthorns to New York State. A Mr. Cox also brought a bull and two cows to Rensselaer County, New York, after the close of the War of 18 I2. In I8I7 the first pedigreed bulis, Marquis (408) and Moscow (94I3), were brought to America, S. M. Hopkins importing them into the Genesee Valley in New York. What are known as "The Seventeens" were imported in I 8 I 7 by Colonel Lewis Sanders of Kentucky, including four bulls and four heifers. One of these heifers died before reaching Kentucky, but the others, Mrs. Motte, the Durham Cow, and the Teeswater Cow, were the first to be imported west of the Alleghanies, and their descendants are known as "The. Seven-

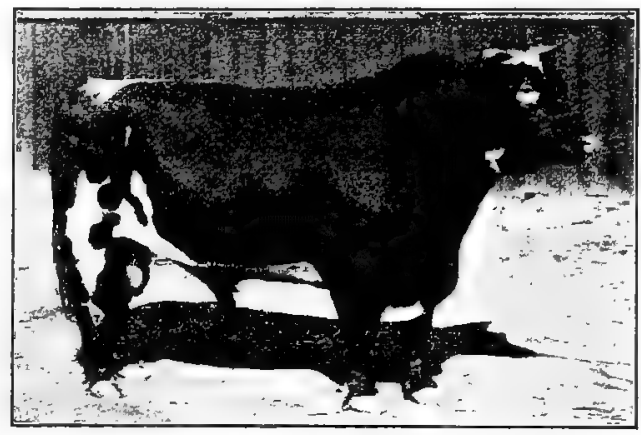

FIG. 7I. The Lad for Me 140618, a well-known Shorthorn show bull and sire, bred and owned by J. G. Robbins \& Sons, Horace, Indiana. Photograph by the author

teens." In 1817 and I 818 importations were made to Massachusetts; in $182 \mathrm{I}, \mathrm{I} 822$, and $\mathrm{I} 823$ importations were brought to New York State, and from then on, into various sections of the eastern states.

The Ohio Importing Company, organized at Chillicothe, Ohio, in I833, with about fifty stockholders, became the most important factor in introducing Shorthorns to America up to this time. In I 834 Felix and Josiah Renick and E. J. Harness went to England, where they visited Bates, the Booths, Maynard, Clark, and other famous breeders, and purchased nineteen head and brought them to Ohio. In this shipment were the heifers Rose of Sharon by Belvedere, bred by Thomas Bates, and Young Mary 
by Jupiter, bred by J. Clark. The history of these cows is inseparably associated with Shorthorn fame in America. Importations were also made in 1835 and 1836 , and on October 29, 1836, occurred the most important Shorthorn auction sale held in America, when this importation was sold off and the herd closed up. Forty-three animals sold for $\$ 34,540$, an average of $\$ 803.25$. The formation of the Ohio Company was one of the notable steps in American Shorthorn history, although later numerous other companies were organized for the importation of the breed.

Shorthorn characteristics. Having traced briefly the influences surrounding the development of the Shorthorn, a consideration of the characteristics of the breed is here appropriate. In geneval conformation the Shorthorn adheres closely to the beef type, though certain tribes, notably Bates bred, tend strongly enough to milk production to be known as general purpose cattle. In size mature cows usually weigh about 1400 pounds, though they frequently exceed that and in rare cases reach 2000 pounds. The mature bull will easily attain I 800 to 2000 pounds; many weigh from 2000 to 2200 , and weights upward to 2500 pounds occur, though the latter is infrequent. This may be regarded as our largest breed of cattle, although the Hereford is a close second, and may be considered by many as its equal in weight and size. The following points especially apply to the cow. The horn is variable, but is always comparatively small and short, and preferably curves forward, with the tips bending inward or upward. In color a waxy yellowish tint is preferred, though blackish tips are not debarred. The head should be lean and shapely, and short from between the eyes to the muzzle, which should be flesh color and broad, with large nostrils. A dark or blackish muzzle is distinctly objected to by most breeders. The neck should be short, and be neatly attached to the head, and blend smoothly into the shoulders. Shorthorn shoulders tend to be a bit prominent and bare. They should be well laid in and smoothly covered with flesh. Back of the shoulders the crops and fore flanks are often deficient, and lack of heart girth is a frequent criticism of the breed. Superior animals show a body that is very broad of back, strong of loin, and so prominent of rib as to give a large girth and digestive capacity of the first order. The flanks before 
and behind are also low and full. A thick, deep body is usually associated with a low, full chest and prominent breast, - essentials with a proper constitutional development. The brisket should be broad and deep and carried forward as a part of a smooth, full, and attractive breast. The hind quarter of the Shorthorn is usually typica! of the breed, - superior in its general development to that of any other beef breed. Regarding the hips, William Housman writes of the Shorthorn: "In fat or lean animals the

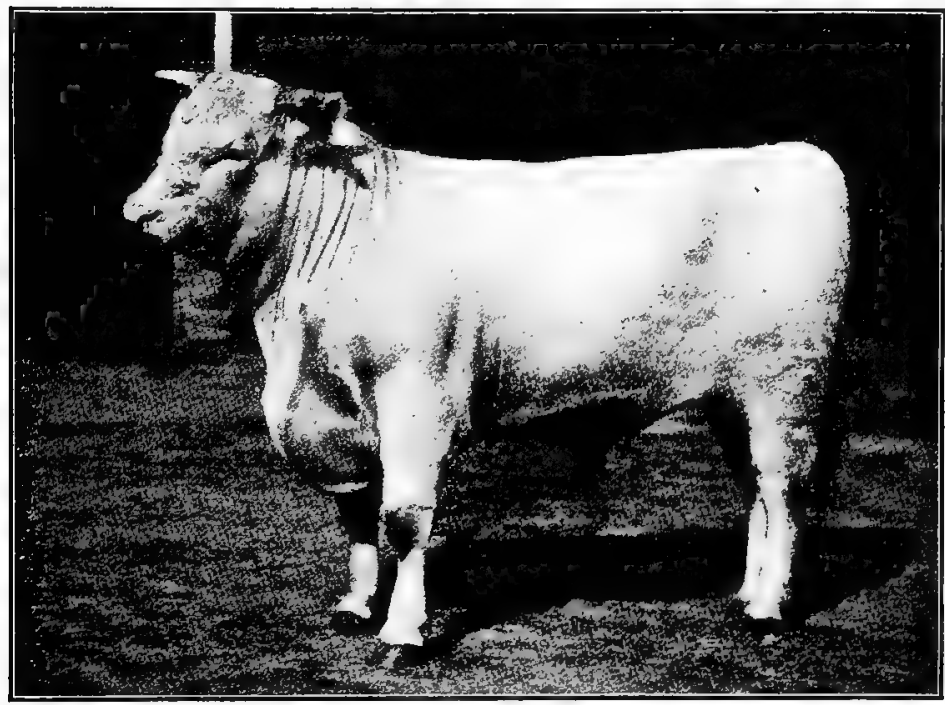

FIG. 73. Missie's Diamond 221080, the junior champion Shorthorn bull at the Louisiana Purchase Exposition, St. Louis, 1904. Bred and owned by D. R. Hanna, Ravenna, Ohio. This picture shows the bull as a short yearling. Photograph from D. Y. Robertson

hip bone must be liberally covered, not bare, hard, or sharp; each hip 'cleft,' and the hollow filled with elastic flesh. This is an important test of the quality of the animal, especially in the lean state." The rump is usually long, level, and broad, and well covered with meat, while the thighs and quarters are long, thick, and deep from front to rear, showing a maximum amount of meat for this quarter. Animals of naturally heavy fleshing qualities frequently get "patchy" about the root of the tail at the rump, and also roll some on the sides, thus detracting from the 
smoothness of finish; but these are characteristics of easily fattened animals only. The udder of the Shorthorn averages decidedly greater capacity than does that of the other beef breeds, and is a noteworthy feature. No beef breed is better able to nourish the calf than the Shorthorn. It is due to emphasizing the importance of milk production on the part of some of the best breeders in history that has resulted in the American farmer regarding the Shorthorn as better suited to general farm purposes than any other breed. In limb animals of this breed should show shortness of leg, small, clean bone, and strong yet not coarse joints. A criticism often made of Shorthorns, and not without some justice, is that they have a tendency to be too long of leg. This has been especially said in the past of cattle of Bates's breeding, and this criticism has been materially weakened by the influence of Scotch blood.

The Shorthorn bull should possess in the main the desirable features of the female, without her feminine qualities. His head, horns, and neck naturally should be stronger and larger, the latter being thick and arched, the whole front showing character and breeding power. The horns of the bull are less bent than those of the cow, and should be prominent yet not coarse. Over the forehead and neck should be a covering of thick, fine, and moderately long hair. In general form the bull should also be broad in front, with full deep bosom, broad powerful arms, a comparatively shorter and more blocky body than that possessed by the cow and with greater relative size.

The color of the Shorthorn is in part distinctive of the breed. This may be pure red, red and white, pure white, or roan, the latter being a commingling of red and white hairs without forming solid color. The shades vary, the red ranging from light to dark and the roan from light or white roan to dark or red roan. No other breed claims the roan color. Black is not a Shorthorn color, and should not occur in pure-bred animals. The importance of the color varies in the estimation of different persons, but color has never indicated the best animals, and wise breeders select on the basis of intrinsic merit rather than color.

The relative prevalence of the different Shorthorn colors has been brought out by the author through researches made in the 
American Shorthorn herdbooks. The colors of I0,000 head registered between 1859 and 1903 , distributed over the entire period, shows the following distribution: red, 4943, red and white, 2748; roan, 2034 ; and white, 275. This record involved 7000 bulls and 3000 cows. During the period of forty-four years the percentage of red increased, while the other colors relatively decreased. In the past some sections have been considered as favoring certain colors, as for example, Kentucky the red. In the stock yards the roan has been long regarded with favor as a prime feeder and killer.

In quality the Shorthorn ranks very high. The mellowness and elasticity of skin and fineness of hair and bone are characteristics indelibly stamped on the breed.

The Shorthorn as a butcher's beast ranks in the first class. All of the really great British breeders had in mind the importance of the Shorthorn as a beef producer, and Cruickshank gave this feature special distinction. In the leading fat stock

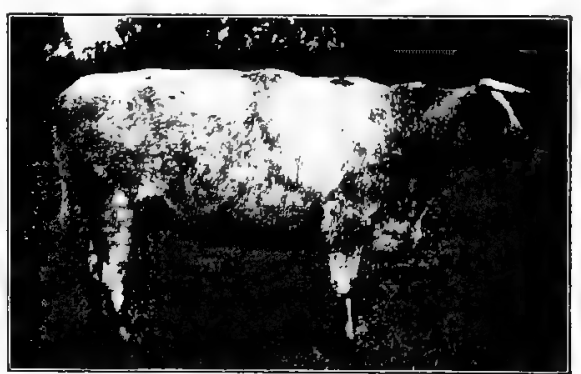

FIG. 73. A Shorthorn cow in the herd of Queen Victoria at Windsor in I900. Photograph by the author

shows of Great Britain and America, Shorthorn steers far outnumber any other breed, while in the stock yards Shorthorn grades largely predominate. The Shorthorn produces a highclass beef, and has the strong loin and hind-quarter development associated with profitable production. If compared with the Aberdeen Angus, the Shorthorn will not dress out quite as high a percentage of meat to offal, though the difference is not large ; also the dressed carcass of the Shorthorn will show somewhat more tallow and external patches of fat than will the Angus. In the records of feeding experiments with different breeds given by Professor W. A. Henry, twenty-six Shorthorns fed at five different experiment stations averaged I 5 IO pounds at IO I days, gained a daily average of I.50 pounds from birth, and showed an average dressed weight of 64.4 per cent. At the I905 International Live 
Stock Exposition the best record of a Shorthorn in the two-year carcass test was to dress out 62 per cent. In the car lots the best record was 64.2 per cent.

The Shorthorn steer in the show ring has not in recent years been maintaining his reputation as a grand champion, the purebred or grade Aberdeen Angus or Hereford surpassing him repeatedly. The following are the Shorthorn grand champions at the American Fat Stock Show at Chicago from I 878 to 1892 :

\begin{tabular}{|c|c|c|c|}
\hline YEAR & Name of StemR & WeIGHT & OWNER AND LOCATION \\
\hline 1878 & John Sherman & $2 \mathbf{I} 95 \mathrm{lb}$. & J. D. Gillett, Illinois \\
\hline 1879 & Nichols & 2060 " & J. H. Graves, Kentucky \\
\hline 1880 & Nichols & 2465 “ & J. H. Graves, Kentucky \\
\hline 188 1 & McMullen & 2095 “" & J. D. Gillett, Illinois \\
\hline 1882 & McMullen & 2565 “ & J. D. Gillett, Illinois \\
\hline I 884 & Clarence Kirklevington & 2400 " & Bow Park Farm, Canada \\
\hline 1887 & Doctor Glick & 1855 & D. M. Moninger, Iowa \\
\hline 1889 & Rigdon & $1950 "$ " & Elbert \& Fall, Iowa \\
\hline I 890 & Nonesuch & $2090 " 4$ & W. H. Renick, Kentucky \\
\hline
\end{tabular}

Shorthorn steers at the International Live Stock Exposition have not yet won a grand championship since the establishment of that show in I900. The following are the breed champion pure-bred Shorthorn steers at this show:

1900 Cumberland Chunk, shown by T. J. Ryan \& Son, Iowa.

1901 Prince of Quality, shown by Iowa Agricultural College.

1902 Prince of Quality, shown by Iowa Agricultural College.

1903 Silver Crown, shown by Iowa Agricultural College.

1904 Auditor, shown by Abram Renick, Kentucky.

1905 Trout Creek Wanderer, shown by Purdue University, Indiana.

Among grades and crosses the Shorthorns have only rarely held a prominent place in the six last shows, as may be seen :

1900 Got no nearer than fifth place in any class.

190I Right Sort secured third place. Shown by Wm. Smiley, Iowa.

1902 In the entire list of five classes, of the first five in each class, or twentyfive in all, were only three Shorthorn grades, each being third in class. 
1903 In five classes, of five highest-ranking animals in each, only five were Shorthorn grades or crosses, three being in junior calf class.

1904 Flashlight, shown by Purdue University, Indiana, was champion of all grades and crosses.

I 905 In five classes third place was highest, this being secured in twoyear-old, junior yearling, and senior calves.

The importance of the Shorthorn in grading or crossing, in spite of what is brought out in the show-ring steer test, is most important. No breed thus far has done so much to improve

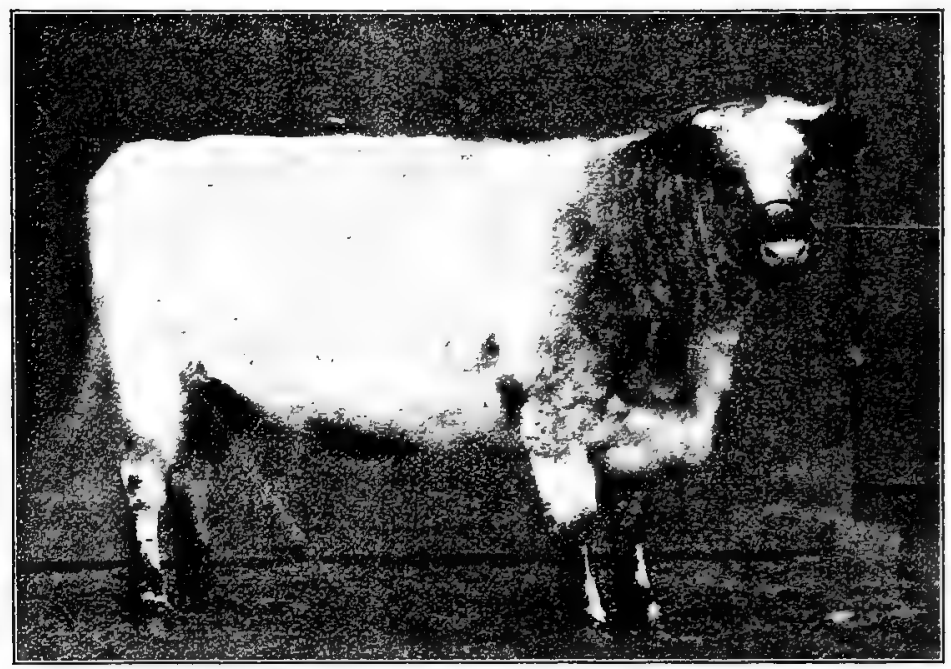

FIG. 74. Golden Thistle (imp.) by Roan Gauntlet (35284). A very beautiful example of the Scotch type in the former herd of Colonel W. A. Harris, Linwood, Kansas. Photograph from Colonel Harris

beef stock as this. Shorthorn bulls mated to grade cows have revolutionized the character of the meat stock of the world. All over America to-day herds of excellence may be found, - animals graded up by Shorthorn bulls. In the principal stock yards of America the blood of this breed predominates, and well-finished, high-grade Shorthorn steers are always at a premium with the butcher. In Scotland and England white Shorthorn bulls bred on Galloway or Angus cows produce what is termed "blue grays," which as steers meet with the highest market favor, being steel gray in color and showing much quality and superior 
killing value. Animals of this breeding shown at the International Exposition by the Iowa Agricultural College have met with much favorable comment. Along with the Hereford and Aberdeen Angus the Shorthorn has been a power in improving the blood of the cattle on the ranges of the far West. The disappearance of the old Texas type of steer is largely due to the influence of Shorthorn bulls on the range.

The Shorthorn from the dairy point of view ranks high. In England a great percentage of the dairy herds are of Shorthorn

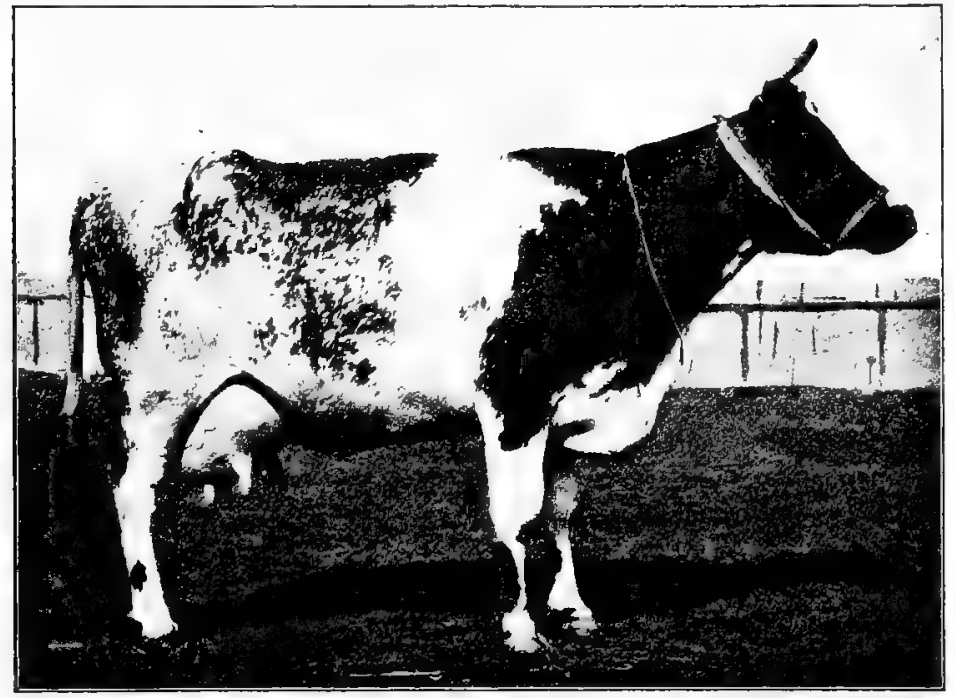

FIG. 75. A choice example of a dairy Shorthorn. A grade cow, first in Dairy Cow class at the Royal Agricultural Society of England Show at York in 1900. In 1899 this cow was shown thirteen times, winning first place in each case. Photograph by the author

blood. As one crosses the midland and southern counties he may see large numbers of Shorthorns with udders indicating great milking capacity. Much of the milk shipped into London comes from Shorthorn herds. The author visited one farm in Berkshire where some five hundred cows of this breed were milked daily and the product shipped to London. In the United States many farmers, notably in the central West, rely upon Shorthorn cows for their milk supply. 
As has been already indicated, as a result of hereditary transmission, and the early breeding of Bates and others, the Shorthorn produces an abundance of milk. No beef breed equals it. Shorthorns generally may be in a measure grouped into two classes, the beefy type and the general purpose sort. As a rule, it is true, the latter class will not fatten as easily and does not present the beef conformation in as high a degree as does the former. Even then the beefy class of Shorthorn surpasses the Hereford, Aberdeen Angus, and Galloway in furnishing milk for its offspring.

Shorthorn dairy records have been repeatedly made in public and private tests. The most important public dairy record of the breed made in America up to this time occurred in 1893 at the World's Columbian Exposition at Chicago, when cattle of this breed competed against herds of Jersey and Guernsey. In the cheese-making test of I 4 days, the Shorthorn ranked third, producing I 2, I 86.9 pounds of milk, from which was made I077.6 pounds of cheese. The Shorthorn cow Nora stood second to a Jersey, producing 60.56 pounds cheese at a net profit of $\$ 6.27$. In the butter-making test for 90 days, in which gain in live weight was credited, the following results were secured:

\begin{tabular}{|c|c|c|c|c|c|c|}
\hline BREED & & $\begin{array}{c}\text { Number } \\
\text { Cows }\end{array}$ & $\begin{array}{l}\text { MrLK } \\
\text { lb. }\end{array}$ & $\begin{array}{c}\text { BuTTER } \\
\text { lb. }\end{array}$ & $\begin{array}{l}\text { GAIN Live } \\
\text { WEIGHT }\end{array}$ & Net Profit \\
\hline Jersey . & • & 25 & $73,478.8$ & 4573.95 & 776 & $\$ 1323.81$ \\
\hline Shorthorn . & . . & 23 & $66,263.2$ & 2890.86 & 2826 & 9I I.I 3 \\
\hline Guernsey . & . & 25 & $6 I, 781.7$ & 3360.43 & 466 & 997.63 \\
\hline
\end{tabular}

This was a very creditable showing, especially in view of the fact that the Shorthorns were not selected with the great pains and expense that the Jerseys were, and did not represent as many high-class dairy specimens as did the other breeds. Professor Jas. Long of England, who inspected the cows, reported on his return home that in England they would not rank high as dairy Shorthorns. In this test the cow Nora made 3679.8 pounds of milk, yielding I 60.57 pounds butter, and gained I I 5 pounds; while the Jersey cow Brown Bessie, which led this breed, made 3634 
pounds milk, yielding 216.66 pounds butter, and gained $8 \mathrm{I}$ pounds live weight. In a 30 days' butter test at the Columbian 24 Shorthorns made 15,6 I 8.3 pounds milk, yielding 662.66 pounds butter, at a net profit of $\$$ II9. I 3. Both Jersey and Guernsey made less milk but more butter and a greater net profit. In this test the best Shorthorn cow was Kitty Clay 4th. She produced I 592.8 pounds milk, yielding 62.24 pounds butter, showing a net profit of $\$$ I9.57. In a fourth test of one week six Shorthorn heifers under three years old competed with six Jersey heifers, the Shorthorns producing $258 \mathrm{I}$ pounds milk, yielding $\mathrm{I} 22.36$ pounds butter, at a net profit of $\$ 47.42$; the Jerseys gave 3356.6 pounds

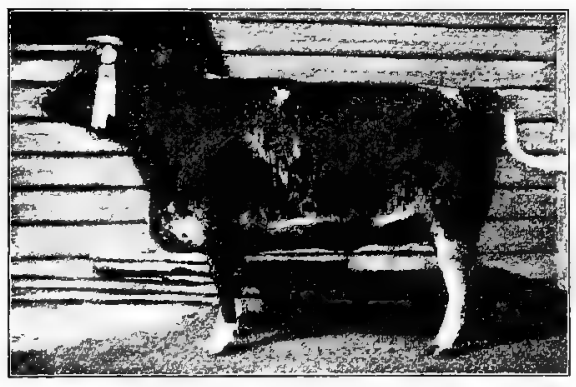

FIG. 76. Fair Queen, the champion Shorthom cow at the Louisiana Purchase Exposition in 1904. Owned by E. W. Bowen, Delphi, Indiana. Photograph by the author milk, yielding 194.22 pounds butter and a net profit of $\$ 56.27$.

The dairy test of Shorthorns at the Louisiana Purchase Exposition in I904 yielded more satisfactory returns than has any previous public test of the breed. In a test of I 20 days, in which 20 Shorthorns were carried entirely through, the cows made an average of 4421.6 pounds milk, 165.3 pounds butter fat, 382.7 pounds solids not fat, and an average gain in weight during I 14 days of 105.3 pounds.

Numerous public dairy tests of Shorthorns have demonstrated the ample capacity of the breed at the pail. In I9OI, at the Pan-American Exposition, between May I and October 3I, five Shorthorn cows produced a total of 1307.55 pounds churned butter, yielding a net profit of 164.77 . At the London Dairy Show in 1904 a fine showing of Shorthorns was made, one cow producing 58 pounds milk in a day, and 14 averaging 46.6 pounds milk per day. Many state-fair records show the Shorthorn to yield a liberal milk flow. An interesting record of a grade is the cow Rose, that at the Wisconsin Experiment Station in 326 days produced 10,163 pounds milk, containing 433.82 
pounds butter fat, equivalent to 506.12 pounds butter. Deducting cost of feed, there was a net profit from Rose of $\$ 79.86$. One of the very best private dairy records for an entire herd of grade Shorthorns comes from John Kingsbury of South Dakota, who in 1898 reports 16 cows averaging 6000 pounds milk, from which was made an average of 301 pounds 5 ounces butter, while in 1899 the same number of cows yielded an average of 6342 pounds milk and 317 pounds 5 ounces butter.

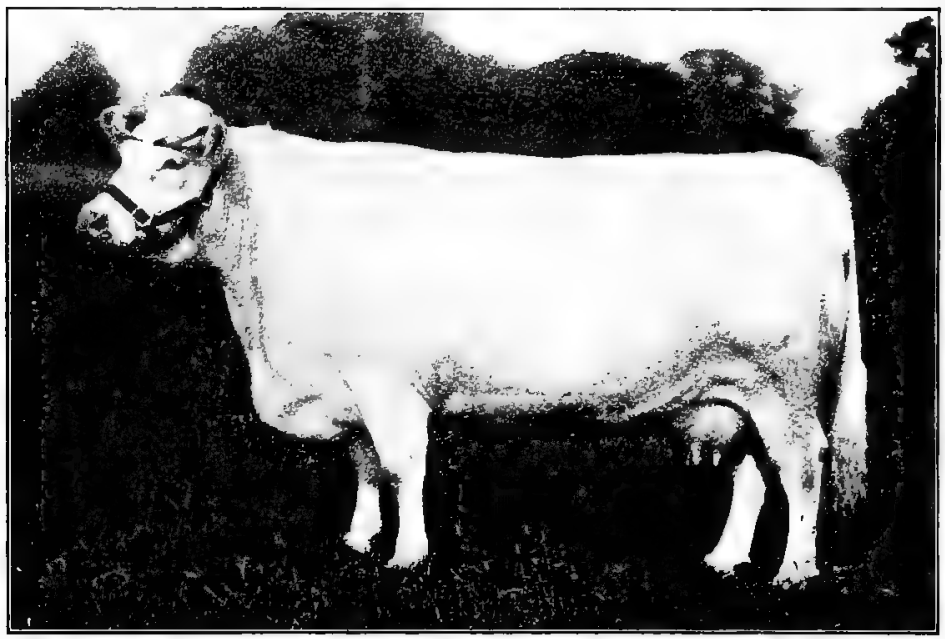

Fig. 77. White Heather, first-prize and champion Shorthorn cow at the Royal Agricultural Society of England Show of 1904. One of the most beautiful specimens of the breed seen in England in recent years. Bred by J. Deane Willis. Photograph from William Cooper \& Nephews, Berkhamsted, England

The prices received for Shorthorns range up to higher figures than for any other breed of cattle. For over a century high prices have been obtained at both private and public sales. Many bulls have changed hands at $\$ 5000$ each since the time of Charles Colling's sale in 18 ro when Comet was the first to bring this figure. The sale of Walcott and Campbell, held September 10, 1873, at New York Mills, New York, is the recordbreaking Shorthorn sale of history. At this time 109 animals sold for $\$ 381,990$, an average of $\$ 3504$. The cow Eighth Duchess of Geneva brought $\$ 40,600$, the highest price ever 
paid for either cow or bull, while I 8 other animals ranged from $\$ 5000$ up to $\$ 35,000$ each, the latter being the price paid for Tenth Duchess of Geneva. The bull Second Duke of Oneida brought \$2,000. In 1869 Daniel McMillan sold at Xenia, Ohio, at auction 7 I head which averaged \$864.6 I each, while in 1874 Colonel W. S. King of Minnesota sold in Chicago 79 head at an average of $\$ 1628$ each, the bull Second Duke of Hillhurst selling at $\$ 14,000$. Between 1870 and 1880 there were sold 26,15 I Shorthorns at auction in the United States at an average price of $\$ 294$ per head. Between I89I and I900 inclusive the Kansas Board of Agriculture reports 15,74I head sold at auction at an average price of $\$ 138.4 \mathrm{I}$. One of the most important high-priced sales of recent years was the dispersal sale of the Uppermill Herd of W. S. Marr in Scotland in 1904, when I I 3 animals brought about $\$ 780$ each, the bull Bapton Favorite heading the list at $\mathcal{E} \mathrm{I} 200$, or $\$ 6000$. At this same time William Duthie of Collynie, Tarves, near by, sold i 8 bull calves at an average of about $\$$ I I 30 each.

The geographical distribution of the Shorthorn is most widespread, no other breed equaling it in this respect. It is so well suited to a wide range of conditions, and has been so extensively distributed, that it has been termed "the universal intruder." It is generally found in North America; in South America, more particularly in Argentina; in Europe, being the most prominent breed on the British Isles, although bred to some extent on the Continent ; in Australasia, where it has long met with favor; and to some extent in South Africa and Asia. In the United States the Shorthorn is the most popular breed of cattle, as attendance at the great shows, especially in the states of the Mississippi Valley north of the Ohio, will demonstrate. The evidence of its wide distribution speaks for the adaptability of the breed. However, on the western range, under severe winter conditions, and where "roughing it" is required, the Shorthorn will not thrive quite equal to the Hereford or Galloway.

Organizations for the promotion of Shorthorn cattle precede all other breeding associations. The first live-stock registry was the Shorthorn herdbook, published by George Coates of Yorkshire, England, in $\mathbf{1} 822$. This forms the foundation of the English 
Shorthorn Herdbook, known as Coates's Herdbook, which in I904 attained its fiftieth volume. Mr. Coates edited the first five volumes when, owing to his death in I 846 , he was succeeded by Mr. H. Strafford, who served as editor of the next fifteen volumes. The Shorthorn Society of the United Kingdom of Great Britain and Ireland in 1876 assumed control of the publication of the herdbook, and through its editing committee has ever since maintained supervision of the records of the Society. The first volume of the American Shorthorn Herdbook appeared in $\mathrm{r} 846$, being published by Lewis F. Allen of New York. In I 869 the American Shorthorn Record first appeared, being published by A. J. Alexander of Kentucky, and ten volumes were issued. In 1878 the Ohio Shorthorn Breeders' Association published a record and followed it with two others. In 1882 the American Shorthorn Breeders' Association absorbed these and continued the publication of the old herdbook established by Allen. The Canadian Shorthorn Herdbook first appeared in I867, the British American Shorthorn Herdbook appeared in I 88 I, and the Dominion Shorthorn Herdbook in 1887, the latter absorbing the other two. The American Shorthorn Herdbook now numbers sixty-five volumes, and new volumes are appearing yearly. Already over 600,000 Shorthorns have been registered in the United States, and many thousands in Canada. This breed is also promoted by several state Shorthorn breeders' associations.

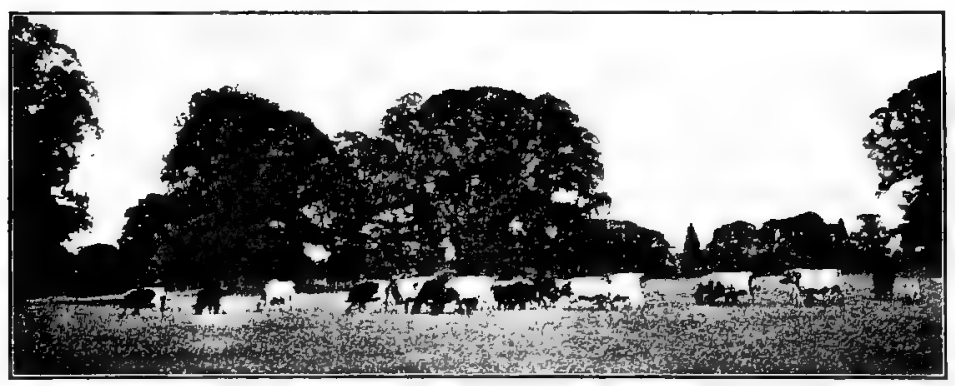

FIG. 78. Shorthorns of the Royal House on the pasture at Windsor, England. Photograph by the author 
Men who have done much to promote the Shorthorn in America since early days are many. In the United States the breeders number thousands. Among those who rendered signal service in promoting the breed during the latter part of the last century are the following : Lewis F. Allen, J. O. Sheldon, and Samuel Thorne of New York; R. A. Alexander, B. F. and A. Van Meter, B. B. Groom \& Son, the Renicks, T. S. Moberly, and William Warfield of Kentucky ; A. C. Stevenson, General Solomon Meredith, Thomas Wilhoit, S. F. Lockridge, and Robbins \& Sons of Indiana ; J. H. Potts, J. H. Pickrell, and C. B. Dustin of Illinois ; Luther Adams, Robert Miller, John Myers, and C. C. Norton of Iowa; W. A. Harris of Kansas; George Harding of Wisconsin ; and T. C. Jones, Daniel McMillan, and C. L. Gerlaugh of Ohio. In Canada M. H. Cochrane and George Brown had very famous herds. In connection with this subject Mr. A. H. Sanders, managing editor of the Breeders' Gazette, should be mentioned as one who with his able pen has done more to promote the interests of the Shorthorn than any other author of recent years. 


\section{CHAPTER XXVII}

\section{THE POLLED DURHAM}

The origin of the Polled Durham. In consideration of the fact that Polled Durham cattle are either pure-bred Shorthorns or nearly so, the author does not regard it as necessary to devote much space to them other than historical, for otherwise what applies to the Shorthorn applies to the Polled Durham, excepting in the head variation. This so-called breed is divided into two groups, and the origin of each may be discussed separately.

The " single standard" Polled Durham was the first type of hornless Shorthorn to attract attention in America. This is the result of uniting native mulley cows with pure-bred Shorthorn bulls. Cattle of such blood lines are quite commonly designated as "single standard," because of being eligible to registration only in the Polled Durham Herdbook. When the movement for dehorning got well started nearly twenty years ago, men here and there began to seek combinations by which the horns might be bred off. Some men who were breeders of Shorthorns, or who believed in the Shorthorn type, sought to breed hornless cattle. Among the pioneers in this work were W. S. Miller, Dr. W. W. Crane, R. Clawson, and Peter Shafer of Ohio, J. F. Burleigh of Illinois, J. H. Miller of Indiana, and T. Dunham of Iowa. These men used pure Shorthorn bulls on mulley cows of Shorthorn type, and so finally developed what they termed the Polled Durham breed. Cattle of this breeding were quite like Shorthorns, tending toward the dual-purpose type, were inclined to be leggy, and hardly met the demands of the Shorthorn critics for thickness of flesh. Those that had true polled heads were used for breeding, and thus gradually was developed, mainly in western Ohio, herds of Polled Durham cattle.

The "double standard" Polled Durham represents the demand of Shorthorn breeders and others for a pure hornless class of 
Shorthorn cattle. These are often termed "double standard" because of being eligible to registration in both the American Shorthorn Herdbook and the Polled Durham Herdbook. Very naturally, with the development of the "single standard" class, breeders began to watch for pure-bred Shorthorns free of horns. This branch has its origin in several Shorthorn families, notably the White Rose, Young Phyllis, and Gwynne.

The cow Oakwood Gwynne 4th, registered in Volume XV of the American Shorthorn Herdbook, was bred by W. S. King

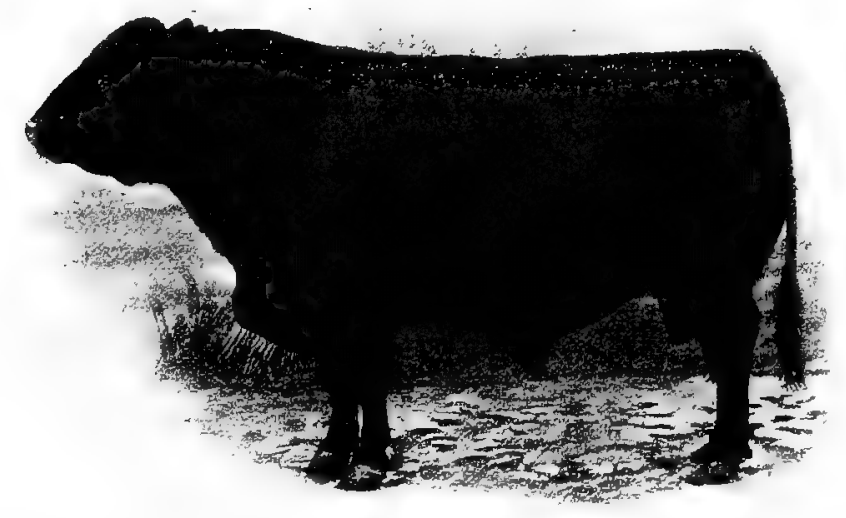

FIG. 79. Golden Hero 2847-I 50363, the leading Polled Durham bull on the show circuit in 1903 and 1904. Grand champion male of the breed at the Louisiana Purchase Exposition, 1904. Owned and exhibited by A. C. Woods \& Sons, Pendleton, Indiana. Photograph from owners

of Minneapolis, Minnesota, and was calved May 12, 1873. She had but very slight horns, or scurs, being almost polled. Bred to Seventh Duke of Hillhurst 3422I, she produced twin female calves, Mollie Gwynne and Nellie Gwynne (Vol. XXIII, p. 728), that developed true polled heads. When later bred to Bright Eyes Duke 31894, she produced as a result a red bull calf that was a true polled animal, which is recorded as King of Kine 874 I 2. In I 888 W. S. Miller of Elmore, Ohio, purchased these three offspring of Oakwood Gwynne 4 th, and with them developed a herd of pure polled Shorthorns. King of Kine was used in the herd three years and proved a very prepotent breeder, 
some 90 per cent of his calves from horned cows being polled. He was used on cows of the Rose of Sharon, Young Mary, and Phyllis tribes with much success. Then a son of his, Ottawa Duke I09292, out of Nellie Gwynne, was used in the herd, and all his offspring proved hornless. Later he came into the possession of Dr. W. W. Crane, in whose herd he rendered valuable service. Ottawa Duke sired Miami Boy I I65 I 7, and Tippecanoe $4^{\text {th }}$ I 2 I 365, well-known sires in the Crane herd. Mr. J. H.

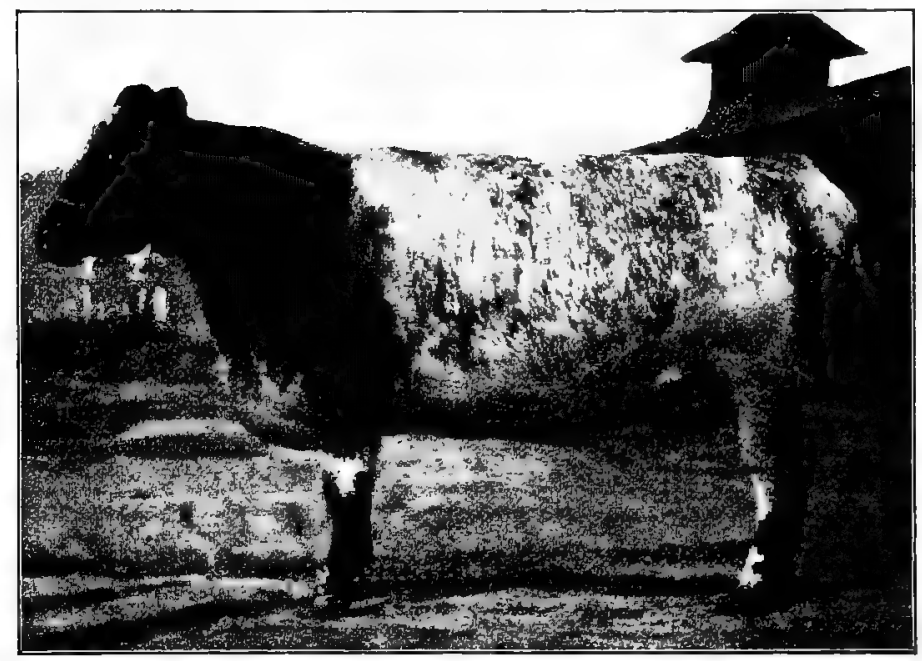

FIG. 8o. Ruby of Buttonwood, grand champion Polled Durham cow at the Louisiana Purchase Exposition, I904. Owned by Fletcher S. Hines, Indianapolis, Indiana. Photograph by the author

Miller of Indiana early became a celebrated breeder of Polled Durhams, and in I893, with some others, made at the World's Columbian Exposition the-first notable exhibit of this breed. Mr. Miller's bull Young Hamilton I I4I69, a pure Shorthorn, and the Columbian Exposition Polled Durham Sweepstakes male, rendered valuable pioneer service in his herd.

The important requirements for registering Polled Durham cattle, as originally adopted by the American Polled Durham Association, were as follows: (I) they must have true polled heads; (2) the cattle must have the color and characteristic 
markings of the Shorthorn; (3) they must have not less than $87 \frac{1}{2}$ per cent of Shorthorn blood in 1893 , at least $93^{3}$ per cent after 1896 , and fully $96 \frac{7}{8}$ per cent after 1899 . Volume III of the American Polled Durham Herdbook, published in 1905, contains the by-laws of the American Polled Durham Association as adopted April 29, I902. Section X, which qualifies registration and covers the old rule, is as follows :

Animals to be eligible to entry in the American Polled Durham Herdbook must be at least six months old; must be naturally hornless; must have both parents recorded therein or have one parent recorded in the book and the other parent recorded in the American Shorthorn Herdbook or other generally accepted shorthorn herdbook; and further, must have an ancestry, that are eligible, recorded in the American Polled Durham Herdbook.

The promotion of Polled Durham interests is officially supervised by the American Polled Durham Breeders' Association, organized at Chicago in I889. Three volumes of the herdbook have since been published up to 1906 . It is to be noted in this connection that breeders are seeking to produce mainly Polled Durhams eligible to registration in the American Shorthorn Herdbook. The greater the percentage of "double standard" Polled Durhams produced the less the necessity of maintaining an independent herdbook for the polled cattle of the breed.

The distribution of Polled Durhams is fairly widespread in the United States, but Ohio, Indiana, Illinois, Michigan, and other Mississippi Valley states lead in their development. In I $894 \mathrm{Mr}$. J. H. Miller of Indiana exported several head to the Argentine in South America, and since then has from time to time made other shipments to the same country.

The popularity of the Polled Durham is undoubtedly growing, and good specimens of this type are to-day essentially equal in merit with other Shorthorns, either as beef producers or as dualpurpose cattle.

The prepotency of the Polled Durham is well established, the polled bulls used in Shorthorn herds, as a rule, siring offspring free from horns. 


\section{CHAPTER XXVIII}

\section{THE HEREFORD}

The native home of the Hereford breed of cattle is the county of Hereford, located in the upper part of the lower third of England, with Wales for its western boundary. The county is gently rolling in places, while in other sections it is quite hilly, and superior grazing generally prevails. In this county Herefords are extensively bred, almost to the exclusion of all other kinds of cattle.

The origin of the Hereford, like that of other English breeds, is clouded in obscurity. Some have regarded this breed as descended from the aboriginal cattle. This opinion has been expressed by Youatt and by T. Duckham, the latter once prominent as editor of the Hereford Herdbook. In I 788 William Marshall, a well-known English judge of cattle, gave it as his belief that the Hereford might be regarded as the first breed on the island. This was written when the Longhorn and Devon were popular and the Shorthorn was coming into favor rapidly. Some have accounted for Hereford color and type as due to the importation into Hereford by Lord Scudamore, prior to I67I, of some white-faced cattle from Holland or Flanders. Some emphasis has been laid on the fact that an ancestor of Tully, a Hereford breeder, used a white-faced bull in his herd that had come from Yorkshire. Perhaps the wisest argument is the influence of the white cattle of Wales whose blood naturally must have mingled with the darker-colored animals of the adjoining region. Hereford color, however, has varied during the history of the breed. Marshall in I 788 wrote that the prevailing color was red with a bald face. In time a wider range of color crept in, so that in 1846, when Eyton published the first herdbook, he grouped Herefords into four classes, viz. mottled-faced, light gray, dark gray, and red with white face. Twenty-five years later, however, all of the colors but the last were practically extinct. 
Early Hereford breeders date back well into the eighteenth century. Among the earliest of prominence were the Messrs. Haywood of Clifton-on-Teme, William Galliers of Wigmore Grange and his sons William and John, Richard Tomkins of New House, King's Pyon, and his son "Benjamin the Elder," and the latter's son "Benjamin the Younger." Besides these the Tullys of Huntington, Haywood, and Clyro, and the Skyrmes of Stretton and Dewsall, were prominently identified with early Hereford improvement.

The Tomkins family has the greatest fame among early Hereford improvers. Richard Tomkins, of whose history little is known, who died in 1723 , left to his son Benjamin of Court House, Canon Pyon, some cattle above the average, including the cow Silver and her calf. This son, Benjamin the Elder, was born in 1714 and died in 1789 at Wellington Court, where he had lived since 1758 . He was a most successful breeder and possessed a noted herd of cattle. A son of his, also named Benjamin, and designated "the Younger," was born in I745 and died in 18 I5. He farmed at Blackhall, King's Pyon, and later at Wellington Court and Brook House, King's Pyon. This latter member of the family was the great improver. He bred closely in-and-in, using only bulls of his own breeding, one of which, Silver Bull (4I), was a famous sire and perhaps his best, being a noted improver of stock. The bull Wellington (4) was also an almost equally famous sire. Through Tomkins's efforts Herefords gradually matured earlier, produced less offal, became shorter of leg and more refined, and better covered over the back. $\mathrm{He}$ also gave the breed more character. His cattle presented some range of Hereford color. In I 8 I 9 his herd of fifty-two animals was sold at auction, 28 head of breeding stock bring-

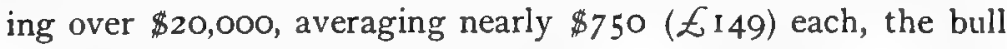
Phœenix (55) bringing \$2800.

William Galliers of Wigmore Grange, was born in 1713 and died in 1779 . He was intimate with Benjamin Tomkins the Elder and they used much of the same blood in developing their herds. His cattle passed into the hands of his son, John Galliers of Frogdon, who was born in 1755 and died in 1828. Another son, William, $\mathrm{Jr}$, a celebrated breeder, was born in 1744 and died in 1832 . 
Early nineteenth-century Hereford breeders of note are John Price, John Hewer, and Thomas Jeffries.

John Price of Ryall was born in 1776 and died in $1843 . \mathrm{He}$ was a close friend and disciple of Tomkins the Younger, from whom he obtained some of his best stock. He practiced in-andin breeding and developed a famous herd. One of his cows, Toby Pigeon by Toby (5), was a remarkable cow, dropping him 19 calves. Nearly his entire herd, sold in $184 \mathrm{I}$, descended from her. This cow herself, when 22 years old, brought $\$ 70$. Price much

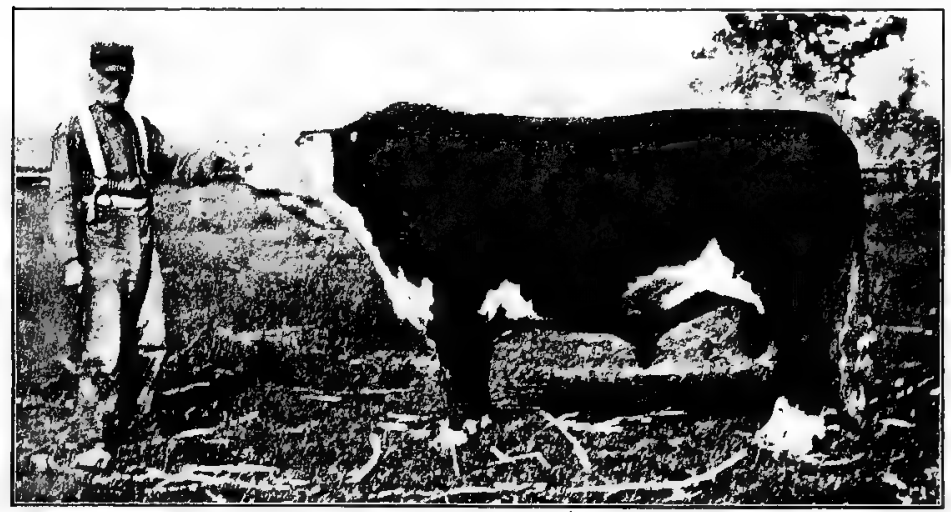

Fig. 8I. Earl of Shadeland 22d 27147, by Garfield 7015. The champion Hereford bull of I888, known as "The Record Breaker." This bull, one of the famous ones of his day, is held by Mr. John Lewis, long the successful manager of the great Shadeland herd at La Fayette, Indiana, now dispersed. Photograph by the author

improved the breed, securing great scale and constitution. He had auction sales in I8 I 3, I 8 I 6 , and I $84 \mathrm{I}$, realizing over $\$ 83,000$ total proceeds.

John Hewer (I787-1873) was a son of William Hewer, also in his day a Hereford breeder of eminence. He did much to improve the breed and laid great emphasis on scale and quality and uniformity of color. He had four favorite strains, Countess, Lofty, Red Rose, and Fanny, from which his cattle mainly descend. He let out bulls to service for large sums, and bred and owned many of the most eminent Herefords of the century. The following bulls bred by him are among the notable ones in the history of this breed: Sovereign (404), Lottery (410), Byron 
(440), Hope (4I I), Chance (355), Defiance (416), Prince Dangerous (362), Lot (364), Lottery 2d (408), Young Favorite (4I3), Wonder (420), Fitzfavorite (44I), Hamlet (5 I2), Original Ist (455), Young Waxy (45 I), Purslow (446) and Conqueror (4I2). There is scarcely a line of Hereford breeding to-day that is not traceable to the Hewer stock.

Thomas Jeffries, of The Grove, Pembridge, and other estates, was born in 1796 and died in 1843. He was a son of Thomas Jeffries, and came from a family of well-known Hereford breeders. He first began with the Hereford stock developed by the family, but later infused the blood of cattle bred by John Hewer, hiring from him Sovereign, Lottery, Byron, and Fitzfavorite. This blending of blood brought about remarkable success, and Jeffries produced numerous famous animals. Cotmore (376), by Sovereign, which he bred, has been classed as one of the finest Hereford bulls of history.

Foundation Herefords of importance are the following: Silver Cow of Richard Tomkins; Pigeon and Mottle of Benjamin Tom-

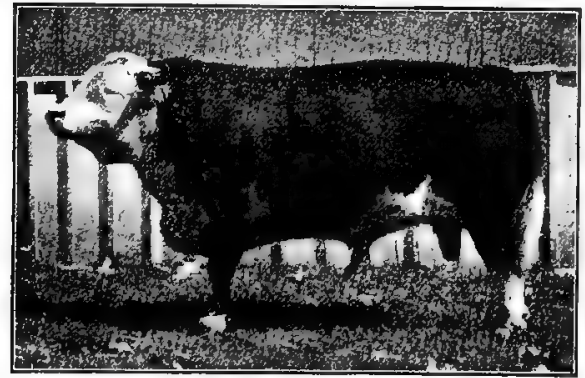

Fig. 82. Dale 6648ז, by Columbus 51875. One of the greatest Hereford bulls in the history of the breed, both as sire and show bull. Bred by Clem Graves, Bunker Hill, Indiana. Photograph by the author kins the Elder; Wellington (4), Silver Bull (4I), Slit Teat Cow, Storrell, Old Rose, and Old Lovely of Benjamin Tomkins the Younger; Toby Pigeon, by Toby (5), of John Price. These were really fundamental stock in the early establishment of the breed. Among other very important Hereford males that had a great influence on the breed in England in the last century may be mentioned Sovereign (404), Old Wellington (507), Old Silver (540), Waxy: (403), Cotmore (376), Lottery (4IO), Chance (348), Sir David (349), Walford (87I), Sir Benjamin (1387), Sir Thomas (2228), Horace (3877), Winter De Cote (4253), and Lord Wilton (4740). These bulls are inseparably associated with the development of the breed in England. 
The introduction of the Hereford to America first occurred, so far as records show, in 1817 , when Henry Clay brought four head to his home at Lexington, Kentucky, one bull dying in transit. About I 825 Admiral Coffin of the British navy sent the bull Sir Isaac and a cow as a gift to the Massachusetts Society

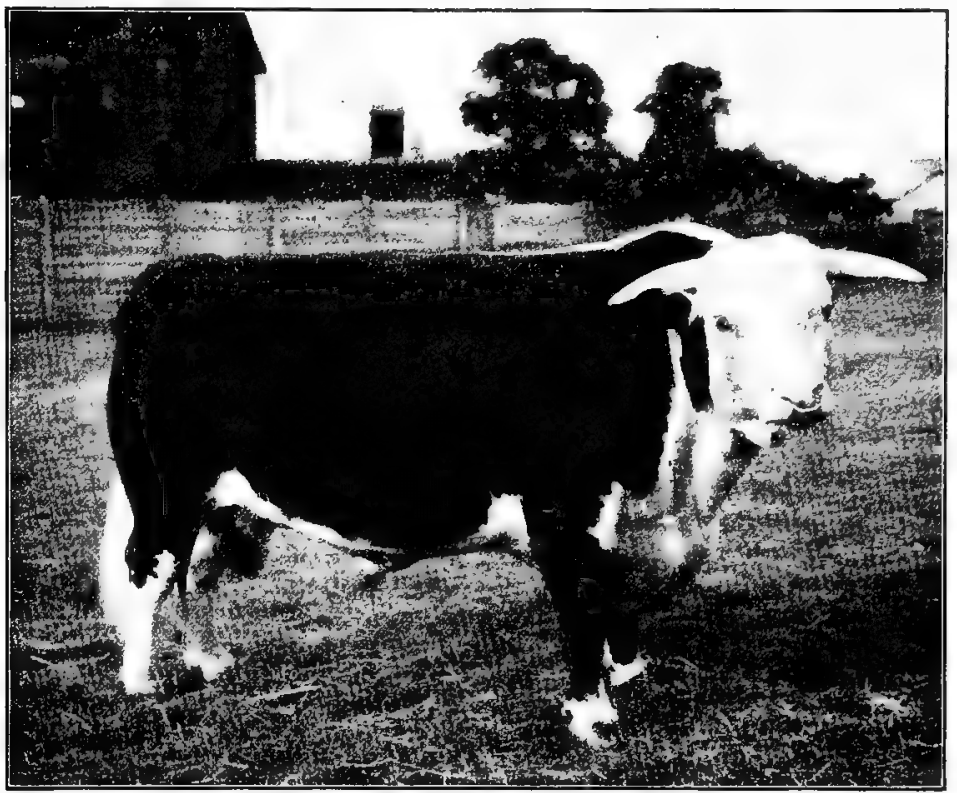

FJG. 83. Fire King (22135), first-prize and champion Hereford bull at the Royal Agricultural Society of England Show, 1904. Exhibited by King" Edward. Photograph from the National Stockman and Farmer

for Promoting Agriculture. Later other importations followed in a small way. In $\mathrm{I} 840 \mathrm{~W}$. H. Sotham, a native of Herefordshire, England, who had previously emigrated to America, imported to Albany, New York, in partnership with Erastus Corning, Jr., twenty-one cows and heifers and a two-year-old bull. This importation was followed by others in $1840,1843,1852-1853$, and I 86 I-I 862. Sotham worked hard to promote the breed, but neither the Kentucky, Massachusetts, nor New York importations awoke enthusiasm. Burleigh and Bodwell of Maine also imported some about 1840 , and in $185 \mathrm{I}$ John Humphries and Thomas Aston of Ohio did the same. In 1860 F. W. Stone of Guelph, 
Ontario, Canada, began importing, and became a most important factor in promoting the breed in that country. Later, about i 875 , T. L. Miller of Beecher, Illinois, became interested. He was a man of wealth and ability and did much to introduce Herefords into the West, and insist on the public recognizing the merits of the breed for the range country. Miller exhibited at fairs, and in 1877 his cattle attracted the attention of C.M.Culbertson of Illinois and Adams Earl, Moses Fowler, and W. S. Van Natta of Indiana, all of whom became noted breeders and importers. Culbertson, in I 879 , imported thirteen head, and in I 880 over one hundred of the choicest quality and breeding. Besides the above breeders, high place in the development of the Hereford in America must be accorded Thomas Clark, George W. Henry, George F. Morgan, and George Leigh of Illinois ; T. F. B. Sotham, son of William H., Gudgell \& Simpson, O. Harris, and J. A. Funkhouser of Missouri; C. A. Stannard of Kansas ; John Hooker of Ohio; C. B. Stuart, F. A. Nave, and Clem Graves, of Indiana; W. H. Curtice and Giltner Brothers of Kentucky; and H. C. Burleigh of Maine, who was the leading breeder in New England.

Hereford cattle of note in America date back in an important sense only to the time of T. L. Miller. From about I 880 many animals of much merit were imported. Among these history accords high place to Success 2, Sir Richard 2d 970a, The Grove 3d 2490, Sir Bartle Frere 64 19, Garfield 70 I 5 , Anxiety 2238, and Tregehan 6203. Among American-bred Herefords the following in particular are of distinction: Fowler I 2899 by Tregehan, Anxiety 4th 9904 by Anxiety, Corrector 48975 by Harold 2 I I4I, Peerless Wilton I 2774 by Garfield, Dale 6648 I by Columbus 51875, Earl of Shadeland 22d 27147, and Earl of Shadeland 4 Ist 33478, both by Garfield, and Beau Donald 58996. Dale and Earl of Shadeland $22 \mathrm{~d}$ were without doubt two of the finest show specimens of the breed ever produced in this country, and each gave eminently satisfactory service in the herd.

Hereford characteristics. This breed has undergone more of an evolution and made more improvement than any other beef breed in America, unless it be the Galloway. In 1788 Marshall gave the following description of the breed, which sixty years later Youatt stated was tolerably correct. 
The countenance pleasant, cheerful, open ; the forehead broad; eye full and lively; horns bright, taper, and spreading; head small; chap lean; neck long and tapering; chest deep; bosom broad and projecting forward; shoulder bone thin, flat, no way protuberant in bone (?), but full and mellow in flesh; chest full; loin broad; hips standing wide and level with the chine ; quarters long and wide at the neck; rump even with the level of the back and not drooping nor standing high and sharp above the quarters; tail slender and neatly haired; barrel round and roomy; the carcass throughout deep and well spread ; ribs broad, standing flat and close on the outer surface, forming a small even barrel, the hindmost large and full of length; round bone small, snug, and not prominent ; thigh clean and regularly tapering; legs upright and short; bone below the knee and hock small; feet

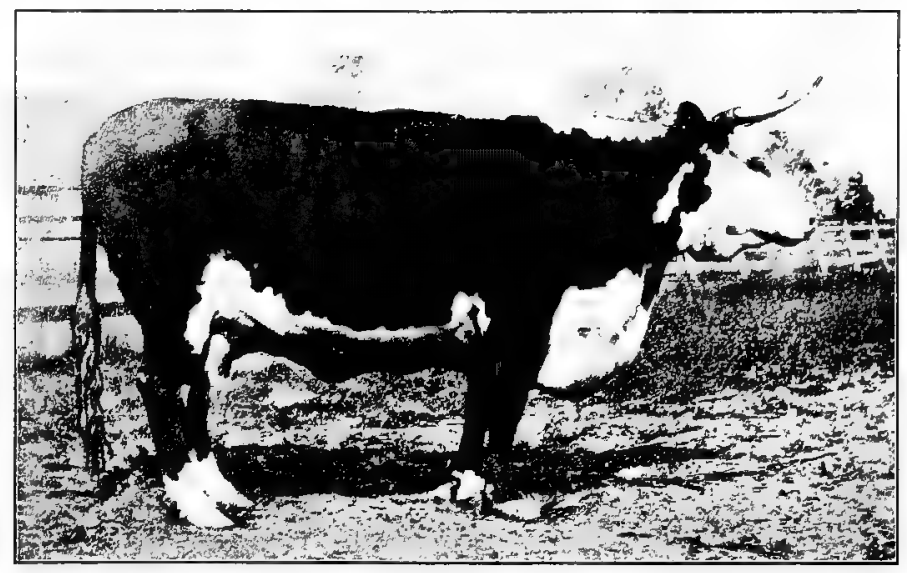

Fig. 84. Shadeland Cora 36693, by Earl of Shadeland 22d 27147. A very high-class Hereford cow in field condition in pasture at Shadeland Stock Farm, La Fayette, Indiana. Photograph by the author

of middle size; flank large; flesh everywhere mellow, soft, and yielding pleasantly to the touch, especially on the chine, the shoulder, and the ribs ; hide mellow, supple, of a middle thickness, and loose on the neck and huckle ; coat neatly haired, bright, and silky; color a middle red with a bald face, characteristic of the true Herefordshire breed.

While this description has an important application to the Hereford of to-day, in certain respects the breed has been materially improved over what it was twenty-five years ago. Two features which have subjected the breed to much criticism have been excess of throatiness and dewlap, and lack of development of rump and hind quarter. The rump has lacked in levelness and 
fullness, while the thighs have been thin and pared off, being deficient in thickness and depth. These deficiencies, however, have been materially bred out in many herds, so that the criticisms do not have the weight they formerly did. The color markings have also become more uniform, and the white face, breast, top of neck, and legs from knee and hock down, and perhaps belly, with the balance of body red, are characteristics today that are well established. The shade of red varies, but that of a medium hue is most prevalent. The shoulder is most beautifully laid and covered with flesh, this being a Hereford characteristic scarcely equaled by any other breed. The spring and depth of rib and consequent expansion of body is striking, and a wide, long loin and thickness and depth of chest clearly account for the vigor and constitution so universally acknowledged for this breed. The head of the bull is different in type from that of other breeds, being rather short and broad both in forehead and muzzle, and often slightly dished of face, crowned with white or waxy yellow horns which spring forward and down with graceful curve. The neck is usually very smoothly blended into the shoulder, furnishing a most attractive front. In fact, even to-day the fore part of the Hereford usually delights the critics, while the hind part often meets with unfavorable comment. In meat production high rank is accorded, with a general distribution of thick well-marbled flesh over the body and especially the back. The coat of hair in winter is usually thicker and more curly than that of any breed excepting the Galloway and West Highland, furnishing an abundant protection. In constitutional vigor Herefords are of the first rank. As milk producers the cows average below medium and are specially open to criticism in this particu. lar. No class of breeders carry so many nurse cows on the show circuit as do the Hereford men. In size this is one of the largest breeds, the males often weighing 2200 and the females I 500 or more. From very early times great scale was sought, and it is said that in 1815 the bull Wellington weighed 2912 pounds and in 1820 the cow Silk 2000 pounds. The Hewers emphasized size and quality, and their bull The General (I $25 \mathrm{I}$ ) is reported to have weighed 3640 pounds when six years old. It may also be said that Herefords weigh heavy for their size. In quality the 
breed is usually distinctly superior, showing fine hair, a mellow, elastic skin of medium thickness, and fine bone. In temperament Herefords are less docile than Shorthorns under similar conditions, and do not so readily accustom themselves to the confinement of limited quarters where grazing is not abundant.

The Herefords as meat producers have always ranked high. For many years their meat held the highest place at the Smithfield market in London. At the first fifty-two annual meetings of the Smithfield Club, with various breeds in competition, 185 prizes

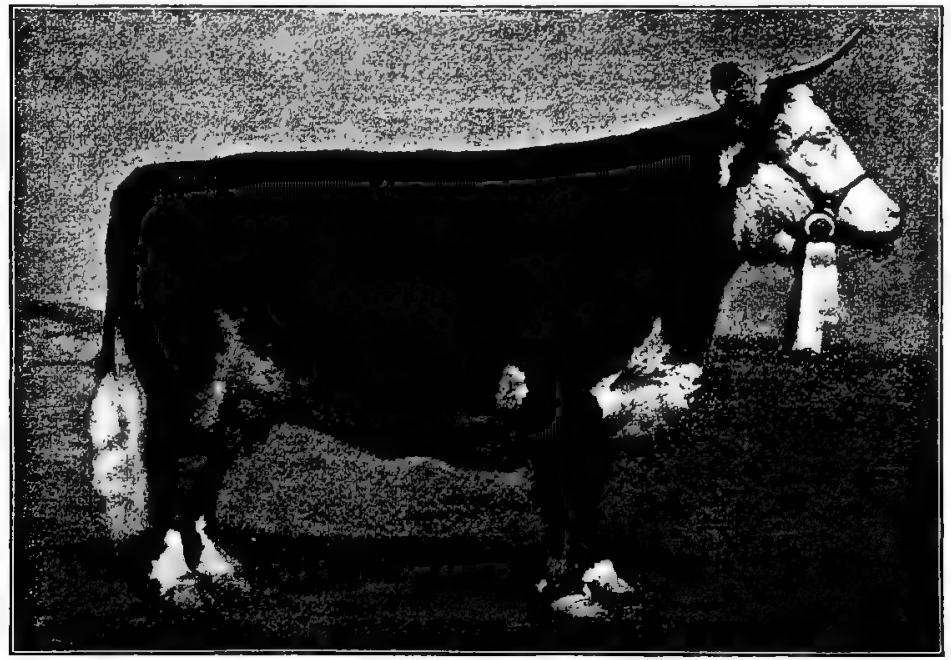

FIG. 85. Lorna Doone 94479, by Christopher 69072. Grand champion Hereford cow at the Louisiana Purchase Exposition, 1904, and at various other leading exhibitions, and noted as a great specimen of the breed. Bred and owned by W. S. Van Natta \& Son. Photograph by the author

went to Hereford steers or oxen and only igo to all other breeds or crosses combined. In recent years the Hereford has not been so uniformly successful, owing to the influence of Aberdeen Angus and Shorthorn, but even to-day it may be classed in the first rank. At the 1905 International Live Stock Exposition at Chicago a car load of grade Hereford steers exhibited by D. W. Black of Ohio, champions in their class, dressed out 65. I per cent, the record of yearling steers. In early maturity no breed excels the Hereford, and for producing "baby beef" it is of the best. 
Hereford steers in American fat stock shows have done exceedingly well. At the Chicago Fat Stock Show the following Hereford grand championships were awarded between I8 78 and I 892 : in 1883 Roan Boy, a grade sired by a Hereford bull out of a Shorthorn cow ; I885, the grade Regulus; I886, Rudolph J., a pure-bred; I89I, Hickory Nut, a pure-bred. At the International Live Stock Exposition but one grand championship has been secured by a pure-bred Hereford, this by The Woods Principal in 1902. In 1903 the grand champion was Challenger, a grade sired by a Hereford and shown by Nebraska University. In the pure-bred and grade classes large shows of Herefords are made each year at the Kansas City Fat Stock Show and at the International. In car-load exhibits Mr. D. W. Black of Ohio has attained a national reputation for showing high-grade Herefords, winning the grand championship at the Louisiana Purchase Exposition Show in 1904 and at the International Live Stock Exposition on two occasions. In 1903 W. J. Herrin of Illinois won the grand championship on car-load lot at the International. It may be said that, in the killing, Herefords dress out a high percentage of carcass compared with other breeds.

The geographical distribution of the Hereford is very wide. In Great Britain it is chiefly bred in Herefordshire and vicinity, though herds are kept with success in Scotland, Ireland, and Wales. The Hereford, however, is best adapted to a grazing region of a fair degree of level surface, and its introduction to the plains of Australia, New Zealand, Argentine Republic, Canada, and the United States has met with very great success. No breed equals the Hereford for withstanding the vicissitudes of the great ranges, where winter's cold and scarcity of feed frequently obtain. The thick coat of hair, the robust constitution, and easy keeping quality of the breed make it unusually suited to such conditions. Hereford bulls have accomplished remarkably fine results on the native cattle on the western range in the United States, and many herds, particularly in the Southwest, are graded up to very superior character. For the restricted surroundings of the eastern farm, where grazing is not so abundant, the Hereford is not so well suited. Yet in New England, and especially in Maine, Herefords have long been popular. The 
oxen of this breed have for many years met with favor in the hills of New England. In the United States, however, the Hereford is chiefly found west of the Mississippi, though herds are found in all the northern states.

Prices for Herefords have never passed through such extreme variations as have the Shorthorns, though some very high ones have been paid. Lord Wilton (4740) was sold at auction in I 884

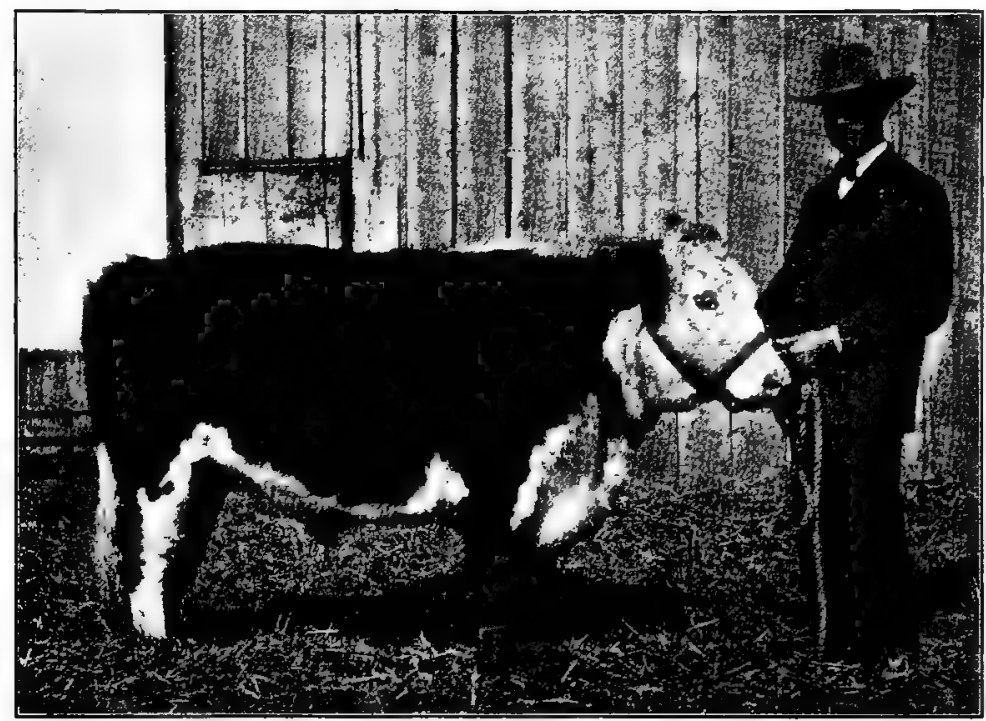

FIG. 86. Black's Ohio Champion. A grade yearling Hereford range steer, held by the noted feeder, D. W. Black, Lyndon, Ohio. Bred by Swenson Bros. of Texas. One of the grand champion car lot of feeder calves at the I904 show of the International Live Stock Exposition. Also one of the firstprize car lot of yearlings fed by Mr. Black for the 1905 show. Purchased by the Ohio State University. Photograph by the author

for $\$ 19,000$, but the buyer could not cash his bid, so the bull was later sold to William Tudge and Thomas Fenn for $\$ 5000$. The highest price paid for a Hereford in America was for Crusader 86596, at the sale of Clem Graves of Indiana, on September I6, I902, which brought $\$ 10,000$, and the cow Dolly 2d 6I799 which brought $\$ 7000$, both being purchased by Edward Hawkins of Indiana. The bull Perfection 9289I, by Dale, on January 7, 1902, was purchased at the sale of Thomas Clark in 
Chicago by G. H. Hoxie of Illinois for $\$ 9000$. Among some of the other high-priced Herefords may be mentioned the imported bulls The Grove 3d 2490, purchased by Adams Earl for $\$ 7000$; Sir Bartle Frere 6419, by the same, for $\$ 3500$; and Protector, by F. A. Nave, for $\$ 6000$. A summary of sales of 5647 head as sold at auction from I 89 I to I 900 inclusive, published by the Kansas Board of Agriculture, shows an average price of $\$ 236.92$.

The organization of Hereford cattle interests is well established in England and the United States. The Hereford Herdbook was first published in 1846 by T. C. Eyton, and in 1884 the Hereford Cattle Breeders' Association of England was organized, and took over the publication of the herdbook, of which about thirty volumes have been published. T. L. Miller of Illinois published in I88I the first American Hereford Herdbook, and the same year the American Hereford Breeders' Association was organized. Up to January I, I906, there had been published twenty-seven volumes, showing a registration of 205,000 animals.

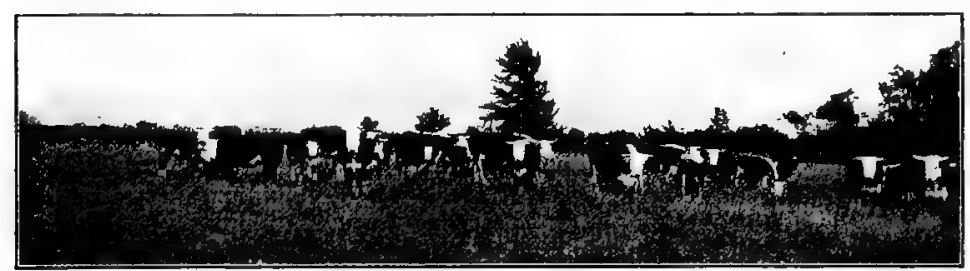

Fig. 87. A pasture view in Herefordshire. Photograph by the author 


\section{CHAPTER XXIX}

\section{THE ABERDEEN ANGUS}

The native home of the Aberdeen Angus breed of cattle is in northeastern Scotland, especially in the counties of Aberdeen, Kincardine, and Forfar. In southern Aberdeen, in the Buchan district, the breed was long known as "Buchan humlies," while in the section of Forfar known as Angus these cattle were called "Angus Doddies." The words "humle" and "dodded" are the Scotch terms for polled or hornless. This section of Scotland is north of $56^{\circ}$ and lies about a thousand miles north of the latitude of Chicago. The climate is rather damp and cold much of the time. The land is hilly or mountainous in the main, much of it being better suited to grazing than anything else, though roots, oats, and hay are quite extensively produced.

The origin of the Aberdeen Angus is purely speculative. Among the wild white cattle of Britain were polled animals, and the Aberdeen Angus may have descended from these. Some of the Scotch writers incline to the belief that this breed is a sport from a black breed with horns, which formerly existed in Scotland. Hornless cattle have been known in Scotland for long over a century. In an account book kept by a Mr. Graham record is made June 9, 1752 , of purchasing a two-year-old heifer "doded." The first printed reference to hornless cattle in Angus is dated 1797 in the Old Statistical Account of the parish of Bendochy, where it is said of 1229 cattle in the parish " many of them are dodded, wanting horns." Youatt, about I 835 , wrote "that there have always been polled cattle in Angus," and states that attention was first directed to them by enterprising farmers about I 775 . Mr. William Forbes of Aberdeenshire, writing Macdonald and Sinclair over thirty years ago, mentions two sorts of polled cattle common in Buchan about the beginning of the last century. One of these was a rather small, puny type, thin-fleshed, such as the 
crofters (small farm renters) kept ; the other a larger kind, some black, some brindled, which more readily submitted to Shorthorn blood than did the former, and lacked its power of reproduction of polled character.

The earliest improvers of Aberdeen Angus cattle include the Watson family, William McCombie, Lord Panmure, Lord Southesk, William Fullerton, Mr. Bowie at Mains of Kelly, Sir George Macpherson Grant, and Mr. Robert Walker. Numerous other breeders materially assisted in the improvement during the first third of the nineteenth century, though none of these accomplished as much as the first two named.

Hugh Watson of Keillor, Meigle, Forfar, was the first really great Aberdeen Angus improver, the Colling of this breed. He was born in 1789 , became a tenant at Keillor in 1808 , and remained there 56 years, dying in 1865 . His father and grandfather were lovers of good cattle, and when Hugh went to Keillor he took six cows and a bull, all black, with him. He also bought the same year at Brechin ten of the best heifers of various colors that he could find, and a black bull named Tarnty Jock. Most writers assume that Watson began his work of improvement on settling at Keillor, but his daughter states that this did not begin until about 1815 or 1816 , his ambition being aroused by a visit to the English Shorthorn country. Watson in-and-in bred and produced a more early-maturing, heavier-fleshed, blockier type that dressed out better than ever before. He also emphasized family lines and bred each family rather within itself. His bull Old Jock (I), calved in 1842, a great-grandson of Tarnty Jock, was his most valuable sire, possessing remarkable quality and constitution, and was a famous show animal. Watson's most famous cow, Old Grannie (1), was one of the wonders of the bovine race. She lived to be 36 years old and had 25 calves, the last, a bull of merit, Hugh (130), being dropped in her twentyninth year. Watson won hundreds of prizes at the shows and did much to improve and popularize the breed.

William McCombie was born at Tillyfour, Aberdeen, in 1805 and died in 1880 , a few months before the dispersal of his herd. In 1830 he began a polled herd and purchased from the best breeders of his county. He was a great believer in the importance 
of individual merit coupled with superior pedigree, and emphasized the value of the sire. At William Fullerton's sale he bought Queen Mother (348) from which he developed the famous Queen tribe. McCombie bred Pride of Aberdeen (58i), the founder of the Pride family and one of the most famous show cows of the breed. McCombie improved on the work of Watson and became his worthy successor. His success in the show ring was marvelous. He not only exhibited at the leading Scotch

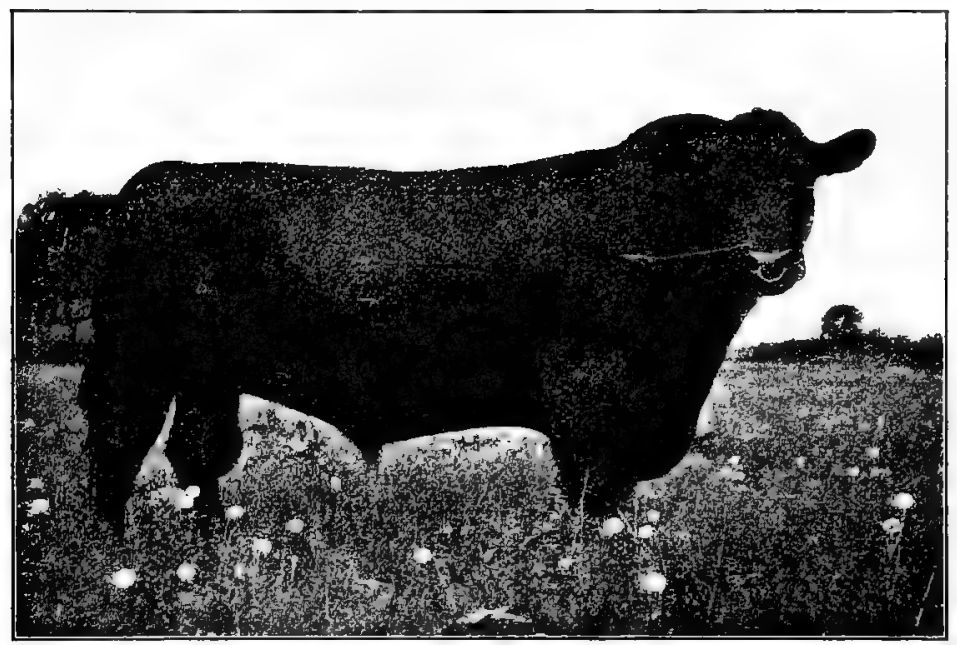

FIg. 88. Lucy's Prince 46183, by Ringmaster. Grand champion Aberdeen Angus bull at the International Live Stock Exposition in 1903 and 1904. A well-known prize winner at leading shows elsewhere. Owned by D. Bradfute \& Son, Xenia, Ohio. Photograph by the author

shows but also in France on four different occasions, always with eminent success. In 1878 his herd at the Paris International Exposition won the grand championship against all breeds and attracted international attention. Many regard McCombie as the most distinguished improver and promoter of the breed.

Sir George Macpherson Grant of Ballindalloch is considered the most important of modern Aberdeen Angus breeders. Cattle of this kind had been bred on his estate for very many years and were long of high repute, but since the dispersal of the McCombie herd in 1880 , the Ballindalloch herd has been regarded as the 
premier one of Scotland. Here some of the best bulls of the breed produced in the past twenty-five years have been bred, including Juryman (42 I), Ermine Bearer I 749, King of Trumps 2690, Bushranger (732), Justice 854, Judge 473, Prince Ito (50006), Bion 36986, Emulus 20417, Eblito 50098, and Equestrian 34216. The cows Erica 184, Jilt.422, and Coquette 2538 are among the famous founders of families at Ballindalloch.

William Fullerton founded a herd at Ardovie in 1834 and added much to the prestige of the breed through the use of the bull Panmure (5 I), bought at Lord Panmure's sale in $184 \mathrm{I}$. Fullerton bred Queen Mother by Panmure, the cow McCombie later purchased, the founder of the Queen tribe.

The Aberdeen Angus tribes in special favor to-day are the following: Queen descended from Queen Mother (4I), Erica from Erica 184, Pride from Pride of Aberdeen 38, Blackbird from Lady Ida 686, Heather Bloom from Heather Blossom 306, Nosegay from Nosegay $225 \mathrm{I}$, and Coquette from Coquette 2538. Of these the Blackbird at present is in most favor. There are numerous other families of merit in addition to the above, but these are most popular.

The introduction of Aberdeen Angus cattle to America was comparatively recent. In 1873 George Grant of Victoria, Kansas, brought the first to America, the importation being three bulls, two of which were shown at the Kansas State Fair. These bulls were imported to use on western range cows. In 1876 the Ontario Agricultural College at Guelph brought to Canada two bulls and a cow. In 1878 Anderson \& Findlay of Lake Forest, Illinois, imported five cows and a bull, this being the first firm to exhibit prominently in the Central West. In 1879 F. B. Redfield of Batavia, New York, and in 1880 George Whitfield of Rougemont, Quebec, made importations. In I88I and I 882 a number of importations were made, including a very superior lot by Gudgell \& Simpson of Missouri. In I $882 \mathrm{Mr}$. T. W. Harvey established at Turlington, Nebraska, in charge of William Watson, a son of the famous Hugh, a herd of Aberdeen Angus that for ten years, until its dispersion, was a wonderful factor in advertising the breed, containing as it did some of the most noted cattle of the time. Others who have been most important contributors to 
the success of the breed in the United States are J. S. Goodwin, L. McWhorter, Evans \& Son, Palmer \& Palmer, J. J. Rodgers, and B. R. Pierce \& Son of Illinois; Leslie \& Burwell of Wisconsin ; W. A. McHenry and A. C. Binnie of Iowa; M. A. Judy of Indiana; Wallace Estill and Hugh Elliott of Missouri; J. J. Hill of Minnesota ; D. Bradfute \& Son and J.S. Hine of Ohio, and Dr. Craik, Mossom Boyd \& Co., and M. H. Cochrane of Canada.

Characteristics of the Aberdeen Angus. In general conformation this breed differs somewhat from the Shorthorn and Hereford, the head being polled and the body more cylindrical in

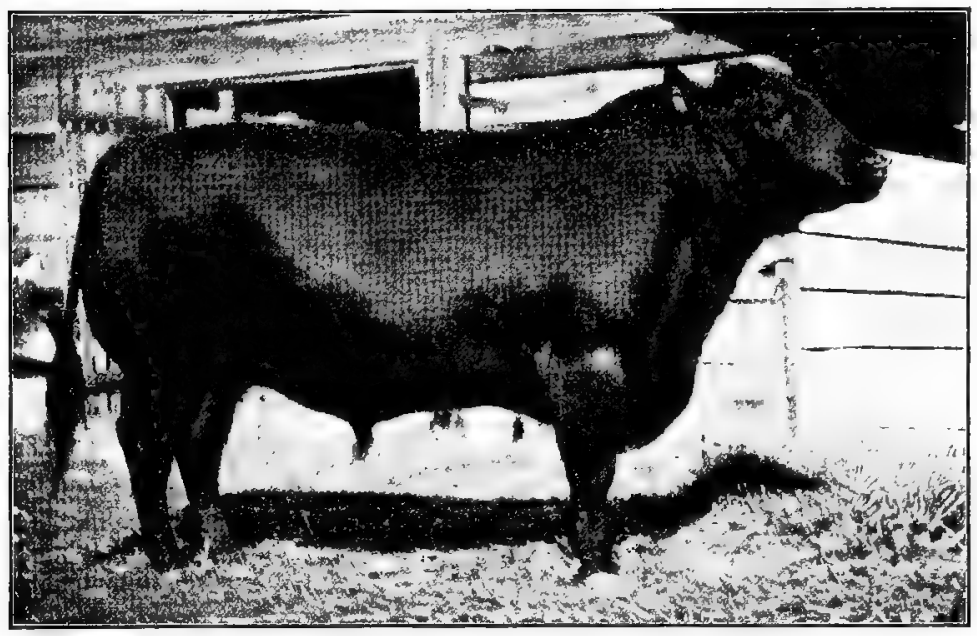

Fig. 89. Juba of Morlich 62233 (imp.), by Rover of Craibstone 550r4. A prominent Aberdeen Angus prize-winning bull. Sold in 1904 by C. H. Gardner of Illinois, in public sale for $\$ 1200$. Photograph by the author

form, while compactness is a strong feature. The head tapers at the poll and is somewhat prominent in the forehead, while the distance between the prominent eyes is considerable and the length of nose only medium. The head as a whole impresses one as belonging to a good feeder type, showing a strong, full muzzle and nostril. The neck is usually smoothly attached to head and shoulder, showing excellent finish, but the shoulder sometimes tends to be a bit prominent instead of nicely laid. The typical body has a rounded rather than square turn of rib, thus not 
showing the broad flat loin so common with Shorthorn or Hereford though heavily and thickly fleshed. The ribs show consider. able depth, and are usually very smoothly fleshed over. The back tends to dip some at the withers, though with the best specimens this is not so. The body has a great relative depth,

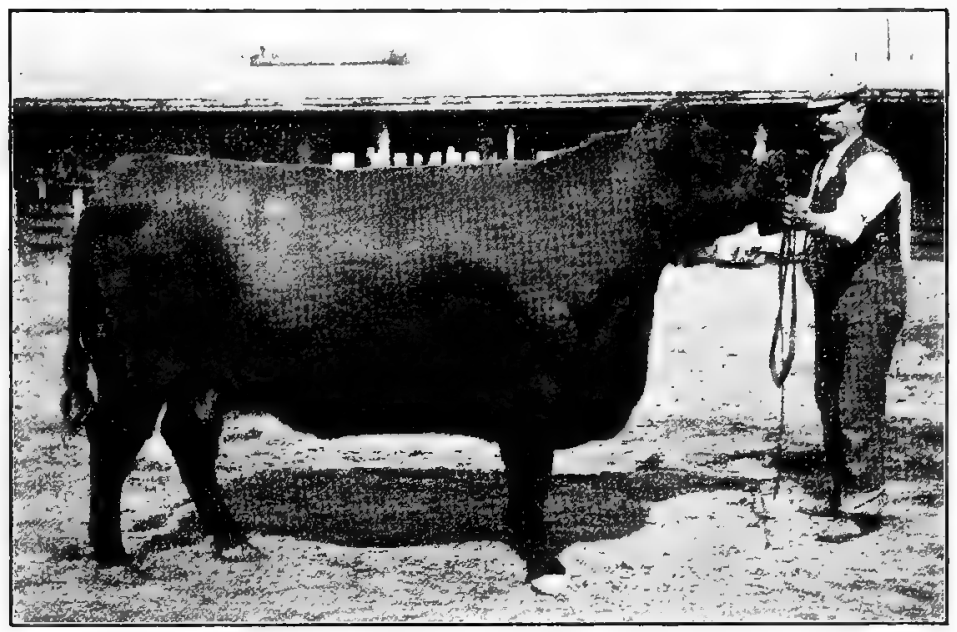

FIG. 90. Lady of Meadowbrook 2 I 466, by Zaire 5th 13067. A noted Aberdeen Angus show cow, winning the highest awards in 1898,1899 , and 1900 at the leading fairs. Owned by D. Bradfute \& Son, Xenia, Ohio. Photograph from the National Stockman and Farmer

with a corresponding shortness of leg. The hips of the Aberdeen Angus are usually nicely covered and well laid in. The rump frequently slopes considerably to each side of the tail head, which may set level or be a bit high, but is usually long and heavily fleshed. The thigh and twist carry as great a relative proportion of meat to bone as any breed of beef cattle, though it often lacks the squareness of the Shorthorn at the back thigh, being rounder in outline and very deep in the twist. The leg is usually rather short and fine in quality of bone and joint. The almost universal color is black, though red occurs at rare intervals. Originally brindles, browns, striped, and reds were common, but these colors are in great disfavor and all but black are practically of interest only historically. According to the by-laws of the American Aberdeen Angus Association, "Males red in color, or with a 
noticeable amount of pure white above the underline, or on leg or legs, or with scurs, shall not be eligible to entry for breeding purposes." A black cod is preferred in the bull, but white udders with cows, with some white between navel and udder on females, are not objectionable. Red cows may be registered, however, and also black ones with small white spots on head, body, or legs.

In quality this breed is of the first rank, as shown by the mellow, elastic, medium thick skin, the fine coat of hair, and moderate joints and small bone. Compared with the Galloway, the Aberdeen Angus has a smoother, shorter coat of hair, and generally a shorter, blockier type of body, with more spring and depth of rib. The temperament in general is somewhat more

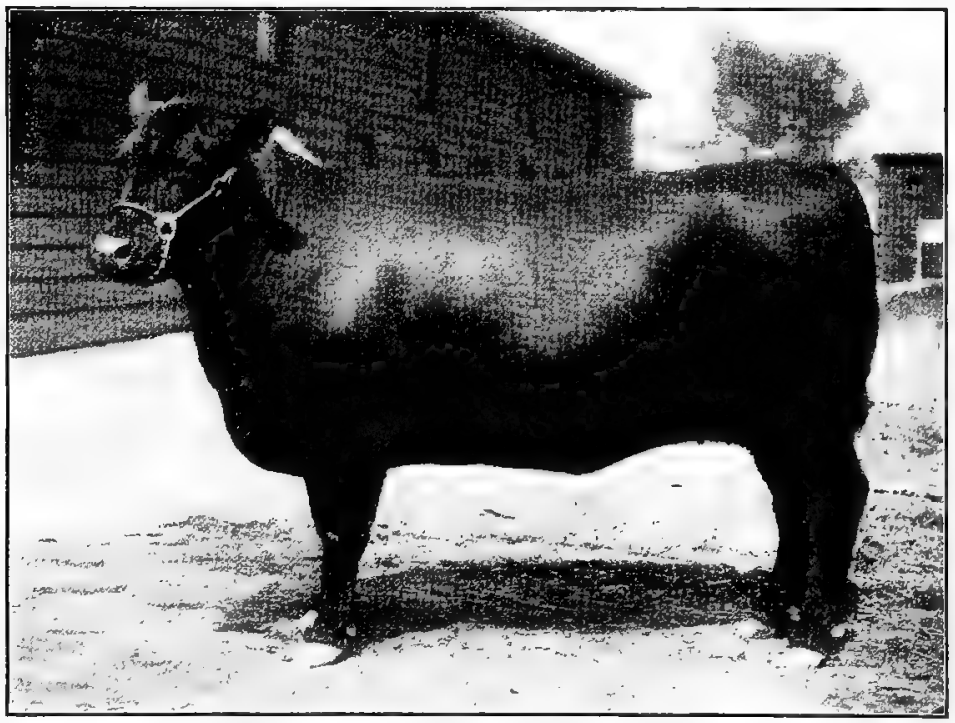

FIG. 9I. Blackbird 26th 54457, by Black Monarch of Emerson 3033I. Grand champion Aberdeen Angus female at the Louisiana Purchase Exposition, 1904. Owned by W. J. Martin, Churdon, Iowa. Photograph by the author

nervous than that of the Shorthorn. In weight this breed ranks high, and is most deceptive in this respect, bulls easily attaining 2200 pounds and cows 1400 . Some very large specimens of the breed are recorded, the famous bull Judge weighing as much as 2800 pounds and his brother Justice in full flesh exceeding 3000 
pounds. Probably no breed weighs heavier for its size than this, though as a whole it may perhaps be ranked second in weight to Shorthorn and Hereford. The quality of its flesh is unsurpassed, the grain of the meat being fine, dressing out a large per cent of carcass, often up to 65 per cent.

The Aberdeen Angus in crossing or grading ranks as unsurpassed. Bulls of this breed on common cows produce superior market cattle. In Scotland a favorite cross is using white Shorthorn bulls on black polled cattle, thus producing blue-gray cattle

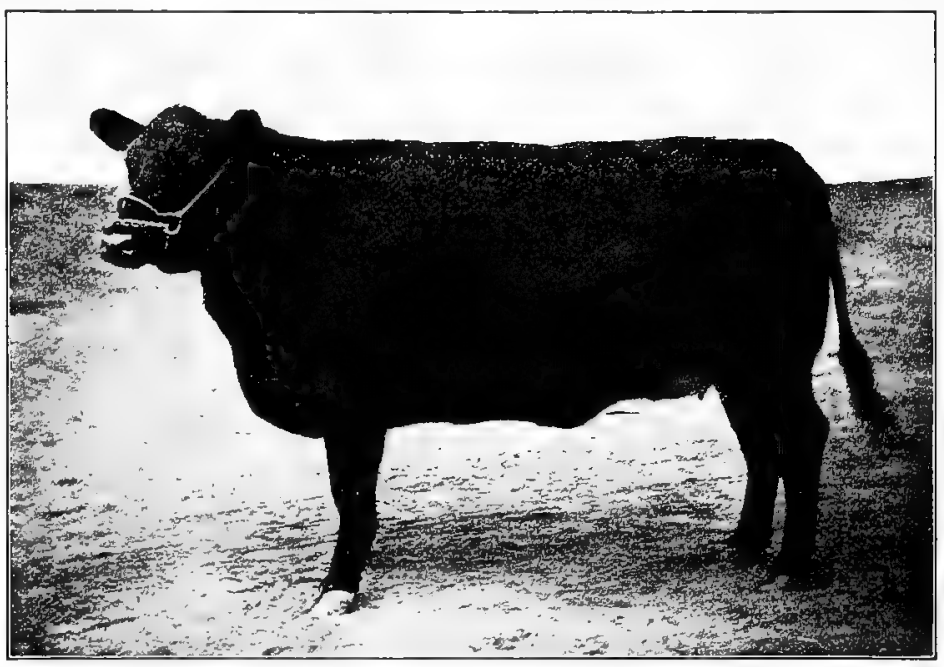

Fig. 92. Vala 37888, by Emulus of Keillor Park 26280. The leading firstprize and champion Aberdeen Angus cow of 1902 and 1903. Sold by C. H. Gardner of Illinois, at auction in 1904 , for $\$ 750$. Photograph from the National Stockman and Farmer

that meet the most discriminating market requirement. On the western range the Aberdeen Angus has not secured so strong a foothold as the Hereford, but his grade progeny is thick fleshed, short of leg, fast maturing, a good feeder, and kills the equal of anything in the market. It will be fortunate for our beef-cattle interests when more Aberdeen Angus males are used to grade up common herds.

The Aberdeen Angus as a dairy cow ranks very fair, though not high. Many excellent milkers exist among them, but the breed 
is not the equal of the Shorthorn in this respect. The higher class beef type tends away from dairy production in any breed.

The Aberdeen Angus steer in the show ring has made a remarkable record, for almost since the day of Hugh Watson this breed has been at the front as a meat producer. In 1829 Watson showed a pair of oxen that attracted much notice, one of which was slaughtered and its carcass said to be of rare quality. McCombie showed a steer, Black Prince, which at four years of age, in 1867 , won the highest honors at Birmingham and

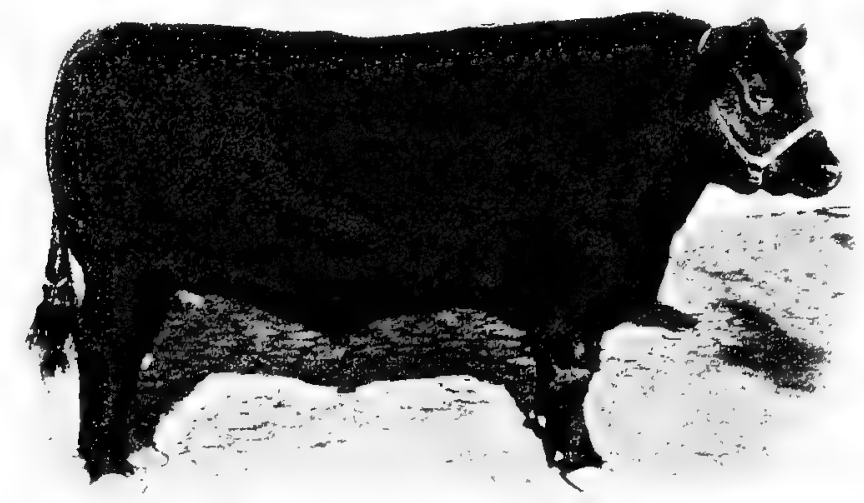

FIG. 93. Clear Lake Jute 2d. A pure-bred Aberdeen Angus steer. Grand champion at the International Live Stock Exposition, Chicago, Igo4. Fed and shown by the University of Minnesota School of Agriculture. Photograph from the National Stockman and Farmer

Smithfield. This steer was sent to Windsor for inspection by Queen Victoria, at her request, so great was his fame, and later he sold for $\$ 600$ for slaughter. For years either pure-bred or grade Aberdeen Angus steers have held the highest places of honor at the leading English fat stock shows, at the Chicago and Kansas City fat stock shows, and at the International Live Stock Exposition. The following are some of the more important prizes won by Aberdeen Angus pure-bred or grade steers in American show rings. The first pure steer of the breed shown was Black Prince, imported by Geary Brothers of Canada in 1883 , and exhibited 
that year at the Kansas City and American fat stock shows, weighing 2300 pounds as a three-year-old. He was not made grand champion, but at Chicago was awarded sweepstakes as the best three-year-old beast passed on by butchers. In 1885 the steer Sandy, shown by Gudgell \& Simpson, won the yearling championship of the Kansas City and Chicago shows, and also the medal offered by the Polled Cattle Society of Scotland. In I 886 Sandy was champion steer of the Kansas City show, winning numerous prizes for being the best steer shown. At 939 days he weighed I 885 pounds. In I 887 , at the same show, Black Prince of Turlington, a famous bullock exhibited by T. W. Harvey, won the sweepstakes over the steer Dot shown by Messrs. Estill of Missouri, though the next year at the American Fat Stock Show at Chicago Dot was grand champion over all breeds. For some years on, the exhibit of Angus steers did not attract much attention, the cattle market being very quiet.

The Aberdeen Angus steer at the International Live Stock Exposition secured premier place from the first. The first International was held in 1900, and since then the steer show there has been large and the competition keen. The show in classes has been notable, but the breed record in grand championship has been equally so, it being as follows :

\begin{tabular}{|c|c|c|c|}
\hline Name of Steer & OWNar & $\begin{array}{c}\text { YEAR } \\
\text { CHAMPION }\end{array}$ & $\begin{array}{l}\text { Price Sold } \\
\text { Per Pound }\end{array}$ \\
\hline Advance (pure-bred) . & B. R. Pierce, Illinois . . & 1900 & $\$ 1.50$ \\
\hline Shamrock (grade). . & Iowa Agricultural College. & 1902 & .56 \\
\hline Clear Lake Jute $2 \mathrm{~d}$ (pure- & Minnesota Agricultural & & \\
\hline bred). . . . . . . & College . . . . . . & 1904 & .36 \\
\hline Black Rock (grade) & Iowa Agricultural College & 1905 & .25 \\
\hline
\end{tabular}

No other breed has made so fine a record in winning this high honor. In car-load lots the Aberdeen Angus also won championship at Chicago as follows: 1900 , by L. H. Kerrick of Illinois ; 1902, Charles Escher, Iowa; I904, Claus Krambeck of Iowa; 1905, Claus Krambeck.

The prices brought by Aberdeen Angus cattle have not ranged as high as those brought by Shorthorn or Hereford, but have made 
a very good showing. Figures compiled by the Kansas Board of Agriculture of sales from 1892 to I 90 I inclusive, including 3269 head, give an average price realized per head of $\$ 2 \mathrm{I} 3.24$, the bulls averaging $\$ 190.09$ and the cows $\$ 232.07$. The highest prices of interest are as follows: Prince Ito 50006, by Eltham (91 20), sold by M. A. Judy, February 4, 1902, at Chicago to B. R. Pierce \& Son for $\$ 9100$, the record price to date for a bull of the breed. The female, Blackcap Judy 40226, by Black Monarch of Emerson $3033 \mathrm{I}$, at the same sale, offered by Mr. Judy, brought $\$ 6300$ from C. H. Gardner of Illinois, the record price for a cow of the breed. Other animals that have brought high prices are Gay Lad 19538 (bull), $\$ 3050$; Black Knight of Estill 9th (bull), $\$ 2100$; Blackbird Wellington 2d (bull), \$3010; Lucia Estill (cow), $\$ 2800$; Waterside Blackcap I 55 I (cow), $\$ 2050$; Blackbird of Corskie 2d I 235 (cow), \$205O. Many cattle of this breed have sold for from $\$$ I 000 to $\$ 2000$ per head.

The prices brought by Aberdeen Angus steers represent the highest of the market. Advance, the grand champion of the International of 1900 , sold at auction the week of the show for $\$ 1.50$ a pound. He weighed I 430 pounds, bringing $\$ 2$ I 45 , the highest price per pound for a steer on record. Mr. W. C. McGavock has shown that from I 889 to 1902 inclusive Aberdeen Angus cattle have topped the Christmas beef market, the prices per hundred ranging from $\$ 5.50$ to $\$ 21.50$ in 1901 , the latter being for the Escher champion car load of steers.

Famous Aberdeen Angus cattle in America number many animals, but the following may be appropriately ramed. Bulls : Ermine Bearer 1749, Black Knight 475 I, Heather Lad 2d 7965, Moon Eclipser 8635, Abbotsford 2702, Black Monarch of Emerson 3033 I, Prince Ito 50006, Gay Lad 19538, Zaire 5th I 3067 , Black Abbot I0423, Knight of St. Patrick 354, Bushranger 732 and Heather Lad of Emerson 2d I9049; cows: Blackbird of Corskie 685, Blackbird of Corskie 4th 7931, Rosa Bonheur of Turlington 47 8, Lady of Meadowbrook 2 1466, Lucia Windsor 2775, Heather Blossom 306, Blackcap 1552, Blackcap Judy 40226, Barbara P. 3d 19801, Progress of Turlington 7116, Heather Bloom of Turlington 7 I I 7, Abbess of Turlington 9327, Zarilda 2d 7057, and Rose of Emerson 3d 22463. 
Aberdeen Angus organizations are represented by the Polled Cattle Society of Scotland, organized in 1879 , and the American Aberdeen Angus Breeders' Association, organized in 1883. The first Polled Cattle Herdbook was issued in Scotland in I862, and Galloways were registered in the first four volumes of the Scotch society. The first volume of the American association was published in I886. Up to January I, I905, the Scotch society had published twenty-nine volumes and the American fourteen. About 76,000 Aberdeen Angus cattle had been registered in the American herdbooks up to this time.

The geographical distribution of the Aberdeen Angus is very widespread. It is generally found in northern Scotland, in various parts of England, Ireland, France, Denmark, Germany, South America, New Zealand, Sandwich Islands, Canada, and the United States. In America the breed has met with the most favor in Ohio, Indiana, Illinois, Iowa, and Missouri, and on the ranges westward of the Mississippi, both north and south. The Aberdeen Angus, according to some, is hardly the equal of the Hereford on the range, although it holds high rank and is in favor there. 


\section{CHAPTER XXX}

THE GALLOWAY

The native home of Galloway cattle is in southwestern Scotland adjacent to the sea. Here exists a district, comprising the counties of Wigton and Kirkcudbright and parts of Ayr and Dumfries, that formed the ancient province or kingdom of Galloway, and from this the breed takes its name. This region is generally rough, excepting near the seashore, and the soil is thin and gravelly. In the southern part the land is better suited for cultivation; in the north, in Dumfries and parts of Ayr, it is mountainous. Here the climate is frequently damp and cloudy and often cold and inclement.

The origin of the Galloway, like that of the Aberdeen Angus, is quite obscure. Youatt states that about 1750 the greater part of the cattle of Galloway were horned, but some of them were polled, a feature of this breed. In 1789 George Culley wrote of "polled or humbled" cattle, and stated that "for the original of these we must look in Galloway." Culley also notes that graziers and drovers took them in prodigious numbers to the fairs in Norfolk and Suffolk, England. Possibly the breed is descended from polled wild cattle. Various British authorities indicate that the Galloway is essentially a Kyloe or West Highland breed devoid of horns, and may be a sport from this. Some authorities insist that Galloways have always been a true polled breed.

The improvement of the Galloway dates back into the eighteenth century. Culley states that the breeders of Galloway complain that the old breed has become much worn out. He then says that there is little doubt of its not only "being recovered, but still more improved, when such a leading nobleman as Lord Selkirk is among the breeders. Mr. Murray of Broughton and Mr. Herring of Corrough-tree have been long very eminent in the breeding of Galloway cattle. Mr. Craik, Mr. Dalyell, and several others 
have tried a cross from Mr. Bakewell's bulls." This then was a Longhorn cross on the Galloway, but Culley says that with what success he has not been able to learn, though breeders were generally against crossing this on Longhorns or any other breed. The Galloway was also crossed on the cattle of Westmoreland and

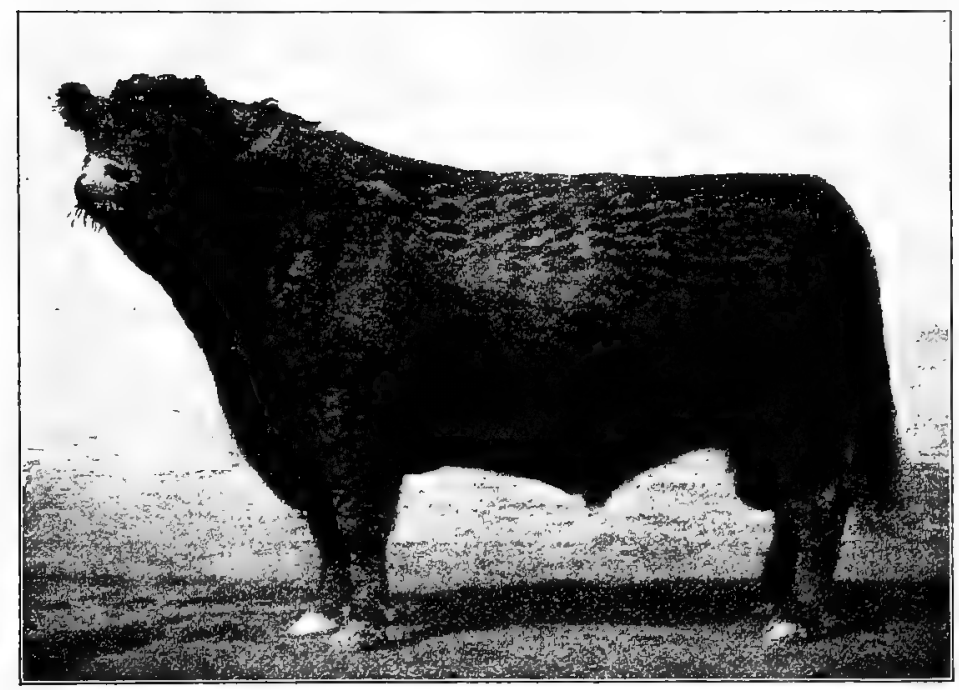

FIG. 94. Worthy 3d (imp.) 21 228. A great prize-winning Galloway bull in Scotch shows, grand champion male of the breed at the Louisiana Purchase Exposition in 1904, and champion at numerous other leading American shows. Imported by C. E. Clark, St. Cloud, Minnesota. Photograph by the author

Cumberland, England. Besides the above breeders, Youatt, about I 835 , mentions as early improvers the Gordons of Greenlaw, the Maxwells of Munches, and the Maitlands of Kirkcudbright ; and in Wigton the Earl of Galloway, the Maxwells of Mouneith, the McDowals of Logan, the Cathcarts of Genoch, the Hathorns of Castle-Wig, and the Stewarts of Phygell. It has been assumed that in-and-in breeding has not been practiced by Galloway improvers, but that the development of the breed has been largely due to careful selection, the breeders of Scotland generally uniting in this work. About 1840 dairying became popular in Galloway district, notably Ayr and Dumfries, and as the polled 
cattle were not essentially good dairy producers, the people neglected them and turned to dairy stock, especially Ayrshires. In general Galloways suffered severely from neglect, and the number sensibly diminished all over the district. A few men, however, clung to the breed in its purity and worked for its improvement, notably the Duke of Buccleuch, James Graham of Meikle Culloch, and the Messrs. Shennan of Balig. In I85 I a step forward was taken by establishing an annual Galloway bull sale at Lockerbie, and soon after another was established at Castle Douglas. In 1862 the Herdbook Society was organized, but it is said that active interest in the breed was not renewed until about 1877 .

The introduction of the Galloway to America occurred long ago, though just when is uncertain. Polled cattle came to this country in some of the early importations. L. F. Allen states that in I 837 he saw a very fine black polled Galloway cow at the General Hospital in Philadelphia, but he did not ascertain how she came there. In I 853 Graham Brothers of Vaughan, Ontario, made the first importation to Canada, though L. F. Allen thinks they were brought to the vicinity of Toronto about I850. In 1857 Allen saw upwards of forty of the breed at a show at Brantford, and later saw them elsewhere in Canada. In 186 I Thomas McCrae of Guelph, Ontario, made his first importation, and did much to promote the breed, being a leader in the work. Galloways were slow of introduction into the United States, coming to Michigan in 1870 and spreading from there into

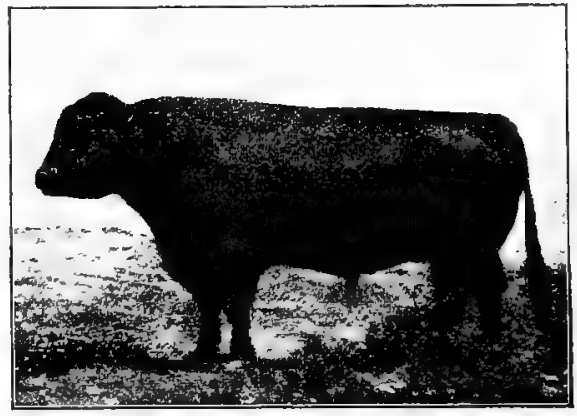

FIG. 95. Scottish Standard (imp.) I5221, a Galloway bull owned by Brookside Farm, Ft. Wayne, Indiana; famous as a sire. Photograph by the author

Ohio, Indiana, Illinois, Iowa, Wisconsin, and Missouri. Even then the breed was very slightly known. In I $885 \mathrm{Mr}$. M. R. Platt of Kansas City exhibited some Galloways at the Cotton States Exposition at New Orleans. 
Associations for the promotion of Galloways were first organized in 1862 in Scotland, although Aberdeen Angus were registered with the Galloways in the first four volumes of the herdbook. Then came a breed separation, and later, in 1877 , followed the organization of the Galloway Cattle Society, with the first Galloway herdbook appearing in 1878. The American Galloway Cattle Breeders' Association was formed at Chicago on November 23, I 882, although ten years previous to this the Ontario Galloway Stock Register of Pure Bred Galloways had been established by the Agricultural and Arts Association of Ontario. The first American herdbook, known as the North American Galloway Herdbook, was published in 1883 , since which, up to 1905 , there have been published fifteen volumes, showing 27,000 registrations.

The characteristics of the Galloway. This breed in general appearance is short of leg and close to the ground, is polled, black of color, has very thick long hair, especially in winter, and is somewhat longer of body and flatter of rib than the Aberdeen Angus. Without going into general details, certain features of the breed demand special consideration. The head in a good type should be polled and absolutely free from scurs or abortive horns, the poll being less peaked than in the Aberdeen Angus. There should be strong breadth between the eyes, with shortness from eyes to end of muzzle, which should be large with ample nostrils. The ear, Wallace, the Scotch author, states, is set rather farther back than in most breeds and should point upward and forward. A fine, broad, pointed ear covered with long hair is characteristic. The body of the Galloway is somewhat cylindrical and has considerable length. The rump is long and the hind quarter is usually well developed, especially in the lower thigh. In quality the breed is superior, for the bone is reasonably fine, the skin mellow, and the hair very fine, silky, curly, and long. The color is generally black, though a brownish or reddish tint frequently occurs in the black, and is regarded by some as an indication of purity. White or other color is a disqualification. Formerly the breed varied in color, when there were brindles, dun-colored, or drab, and some with white spots. About 1835 Youatt wrote that dark colors were uniformly preferred from the belief that they indicate hardiness of constitution. 
Criticisms of the Galloway have long been made by American stockmen, more especially for lack of spring and fullness of rib, slackness of back, prominence of tail head, and slow response to generous feeding. Some of these criticisms are justified, but the breed has been greatly improved over its form of twenty-five years ago, and is now less subject to unfavorable comment.

The modern type of Galloway represents an animal that is free from some of the deficiencies referred to. Through the efforts of the more prominent breeders of Scotland and America the

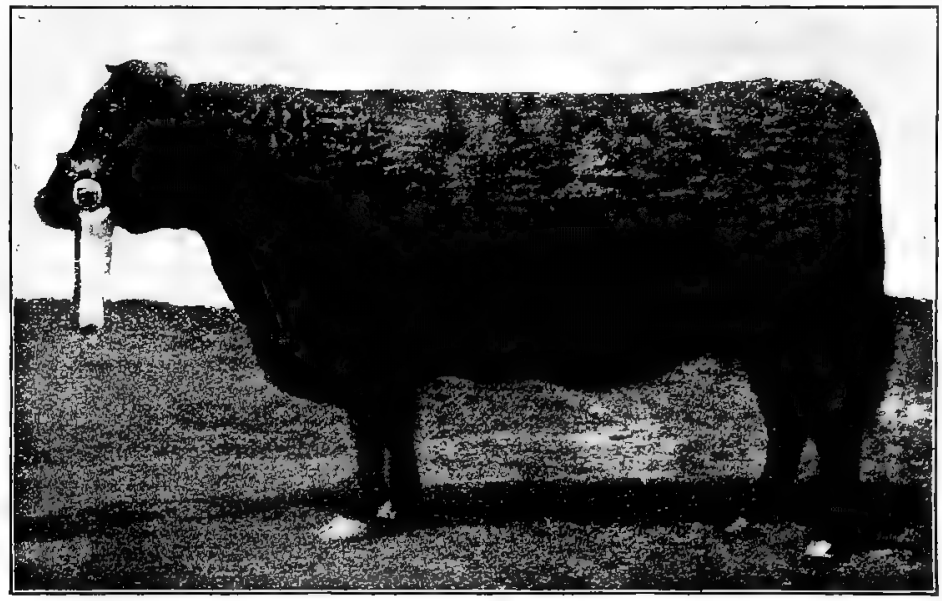

FIG. 96. Evaline 2d of Avondale 2or 24, grand champion Galloway female at the Louisiana Purchase Exposition, I904, and at numerous other prominent shows. Bred by O. H. Swigart, Champaign, Illinois. Photograph by the author

last dozen years have seen a great improvement in the breed. A wider-backed, blockier, better-fleshed, easier-feeding sort has resulted from a more careful selection and a more discriminating use of bulls on superior cows. Even yet, however, the Galloway does not as a rule mature as early or fatten as rapidly as the Shorthorn, Hereford, or Aberdeen Angus, although Galloway cattle produce a very high-class meat, fine in grain and flavor, with the fat internal rather than external, and command a superior price on the market. 
The hardiness of the Galloway is one of its inherited characteristics, and it seems eminently suited to a place on the western range where food may be scarce and where the rigors of winter are great. The thick, long coat of hair gives it better protection from cold than is provided any other recognized beef breed in America. It is for this reason and for its rustling ability that the Galloway is attaining more and more popularity on the western and northwestern range.

The hide of the Galloway, with its thick and long fall or winter coat, has a distinct value in itself. Properly tanned it furnishes a lap robe, overcoat, or floor rug, surpassing in beauty the pelt of the buffalo, now so highly prized. Good Galloway floor rugs or lap robes easily sell for twenty-five dollars, and overcoats of this fur have changed hands at high prices. In the northwestern United States and Canada coats of this fur are very common in winter.

The Galloway as a meat producer, as has been indicated, has always ranked high. For many years large droves of Galloways, said to exceed twenty thousand a year, were driven from Scotland into England and fattened and sold for beef, where they met with much favor. Galloway cattle have never been raised in large numbers excepting in the Galloway district, and so have not usually been important factors in the show ring, at least outside of Scotland. Until recently the steers have not attracted attention in America, and as yet have not attained the highest honors of the American shows in open competition. They feed uniformly and smoothly, patches and rolls being uncommon.

The cross-bred Galloway has a distinct place in the meat market of England, for the mating of white Shorthorn bulls on Galloway cows has produced a famous class of blue-gray feeders which kill out surpassingly well, often reaching 65 per cent. The Iowa Agricultural College has experimented some with this breeding, and has shown a few choice blue grays at the International Live Stock Exposition at Chicago. From time to time "prime Scots" are quoted in the English markets, and in this case these are often blue grays. In 1892 the champion steer at the Smithfield show, England, was a cross between a Galloway cow and Shorthorn bull, which at 1250 days weighed 2276 pounds, an average daily gain of 1.82 pounds from birth. 
Mr. O. H. Swigart, in writing on the Galloway, reports on two loads of range calves exhibited by a Colorado man, the offspring of common grade cows, many of them Holsteins and Jerseys, but all sired by registered Galloway bulls. These calves won first and third prizes in their class, and one load won championship in class over other breeds by ages, and grand championship over all breeds and all ages as feeders. They were purchased by an Indiana feeder and returned to market July 9, 1902. They had an average weight of I I 77 pounds, and brought $\$ 8.45$ per

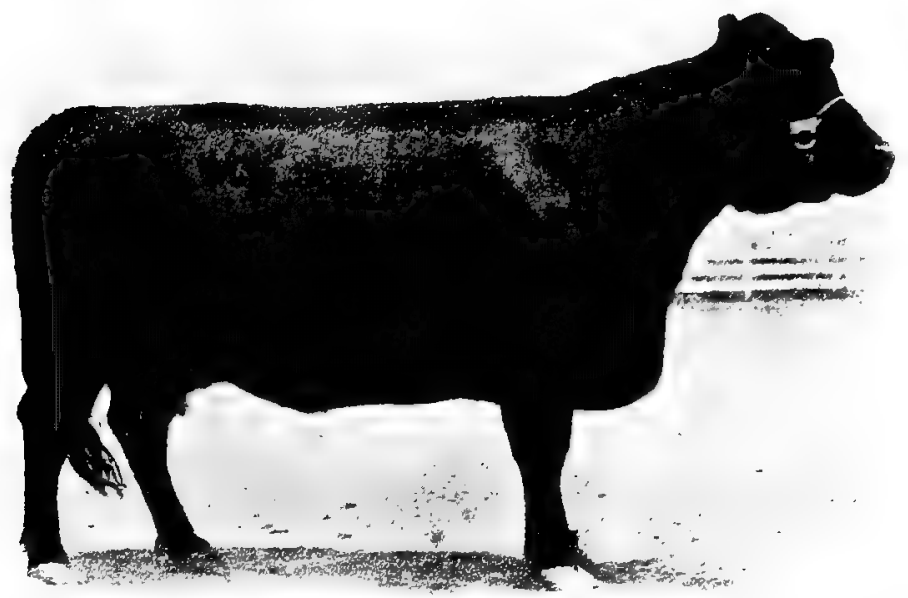

FIG. 97. Adela of Flamboro 12783, a high-class Galloway cow owned by Brookside Farm, Ft. Wayne, Indiana. This picture shows the summer coat of hair, the author having taken the photograph on July 4. Fig. 96 shows the long, curly winter coat, with some fancy grooming

hundred, within five cents of the highest price ever paid on this market for range-bred cattle of any breed, show-yard animals alone excepted.

The prepotency of the Galloway is of the first rank. Within the breed there exists much uniformity of transmission of character. In crossing or grading, where Galloway sires are used, the offspring almost always inherits the color and features of the sire. James Biggar, one of the most noted recent Scotch breeders, states in regard to the power of transmission, that 
"when a Galloway bull is crossed with any horned breed nearly 90 per cent of the produce will be black and 95 to roo per cent without horns." Mr. A. M. Thompson of Missouri reports using a Galloway bull on a herd of Shorthorn cows with very great success, 98 per cent of the calves being black and all natural polls. Galloways also cross very successfully with Herefords, producing beef of the finest quality. The progeny of Galloway bulls on other breeds, says Robert Wallace, the Scotch authority, "are on the average distinctly inferior."

The Galloway as a milk producer has no special record and very little is said on this point by writers on the breed, excepting

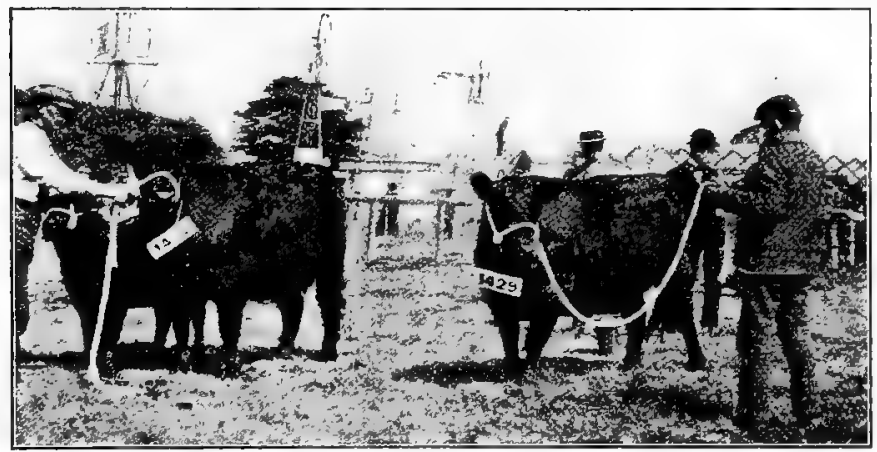

FIG. 98. A pair of Galloway cows in the ring at the Royal Show, Manchester, England, 1897. No. 1429 is Dora of Durhamhill (I3550) and 1430 is Maggie Lauder of Durhamhill (13994). The judges disagreed on these two for first place. Photograph by the author

that the cows are amply able to raise their calves. In fact this is distinctly a beef breed, and no attempt has been made to show the dairy qualities of the cows. Here and there note is made of a milk producer, as, for example, the cow Rosy 4th of Mr. R. B. Carus, of Michigan, reported by him to have been an extra milker, making as high as $42 \frac{1}{2}$ pounds of milk in a day, testing 7.25 per cent fat by Babcock machine. The quality of the milk is regarded as superior.

The size of the Galloway hardly equals that of the Shorthorn, Hereford, or Aberdeen Angus, and it may be rated as a bit smaller than these, at the same age. Mr. A. M. Thompson states that 
as yearlings past they can be made to weigh from 1000 to I 200 pounds; at two, I 200 to 1400 ; at three, from 1400 to 1600. Typical bulls will weigh about 1800 to 1900 pounds, and cows I 200 to I 300 pounds.

The distribution of the Galloway is mainly in Scotland and America. The breed is found in small herds as a rule, east of the Mississippi, though some of the best-known herds are in Indiana and Illinois. Galloways are found on the ranges and farms all over the far West, and especially in the Canadian Northwest. Important herds are also found in Missouri, Iowa, and Minnesota.

American improvers of the Galloway of special note are Brookside Farm, Indiana; O. H. Swigart and Marion Parr, Illinois; Wavertree Farm and N. P. Clarke, Minnesota; C. N. Moody, Missouri; E. H. White, Iowa; and John and David McCrae, Canada. These firms have brought the breed most prominently before the public and have bred or imported some of the best specimens of Galloways to be found in Scotland.

Galloway bulls of distinction that have materially helped to give fame to the breed in more recent times are Camp Follower (5042), Pathfinder 3d (599I), Scottish Standard (6488) I 522 I, Kekionga (2894) 2894, Druid of Castlemilk (6159) 1 7054, King Hensol 9967, Camp Follower of Stepford (7476), and Worthy 3d (7762) 21228.

The prices derived for Galloways do not average high, yet, in view of the lack of knowledge of the breed, they make a fair showing. A summary of 740 animals sold at auction from 1892 to I90I inclusive, published by the Kansas Board of Agriculture, shows an average of $\$$ I 26.75 per head for both sexes, or $\$ 141.43$ for 233 bulls and $\$$ I IO.5I for 3 I 8 cows. 


\section{CHAPTER XXXI}

\section{THE SUSSEX}

The native home of Sussex cattle is in the county of Sussex, bordering the English Channel in south England, though they are also bred in the adjoining counties of Kent, Surrey, and Hampshire. The land is tenacious and clayey and more or less rolling, the famous Southdown hills passing through the southern part. The climate is mild and the grazing superior.

The origin of Sussex cattle is associated with that of the Devon and Hereford, dating back several centuries. These cattle were formerly bred for draft purposes and were largely used to cultivate the soil on the farms of Sussex and Kent. In early days the Sussex much resembled the larger cattle of north Devon.

The introduction of Sussex cattle to America first took place in 1884 , when $\mathrm{Mr}$. Overton Lea imported a considerable herd, which he has since maintained near Nashville, Tennessee. In I 89 I several head were imported to Canada for the Agricultural College at Guelph, though perhaps others preceded them into that region.

The characteristics of Sussex cattle. The color is a solid red, a moderately deep shade being preferred. The horns incline to be large and long, curving around in front, of ten inclining downward slightly. The nose is of flesh color. The form is essentially blocky, the ribs being well sprung and long, and the body capacious. The rump is long, level, and broad, and the thighs of a distinctly thick, beefy sort. The skin is mellow and thick and is often covered with a thick coat of hair which in winter is frequently curly. Compared with Devons they present more size and general beefiness, do not tend to the dual-purpose type, give less milk, have heavier horns, thicker necks, deeper shoulders, and are coarser appearing. 
The size of Sussex cattle is large, comparable with the Hereford, which they somewhat resemble, excepting for color. Some Sussex have attained very heavy weights. Cows frequently weigh about I 400 pounds and bulls 2000 pounds.

The beef properties of Sussex cattle are superior and may be fairly compared with the Shorthorn for merit. From early days in the last century the breed has made an excellent record in the fat stock show contests of England. In Feeds and Feeding Professor Henry gives the following record of Sussex cattle shown at the Smithfield show between I888 and 1895:

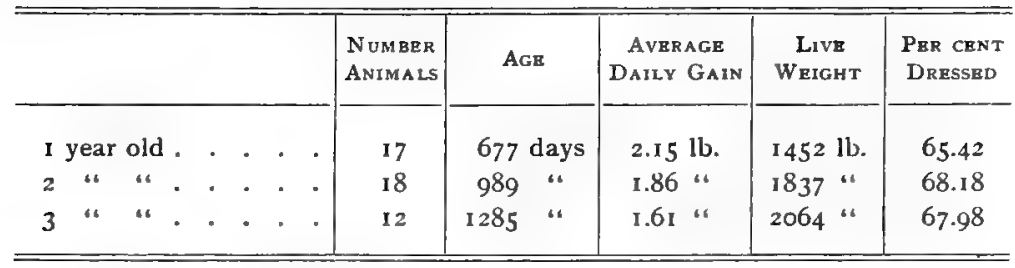

Mr. W. W. Chapman, in the Live Stock Journal Almanac for 1903, also publishes a table of Sussex weights and gains based on Smithfield Club shows. In this I 3 steers, averaging about $68 \mathrm{I}$ days old, weighed an average of $1433 \frac{1}{2}$ pounds; six, with an average of 1043 days, weighed I 829 pounds; and ten heifers, averaging 979 days, weighed $1588 \mathrm{t}$ pounds. In I902 the first-prize Sussex two-year-old steer at the Smithfield show dressed 68.02 per cent. In 1885 at the American Fat Stock Show a yearling Sussex steer received the class prize on the butcher's block and came within one vote of winning sweepstakes. Housman states that the averages for Sussex steers between three and four years old exhibited at the Smithfield Club Show during 1882, I 883, I884, and I885 showed a general average weight of about $18 \frac{1}{2}$ hundredweight (2072 pounds).

The milk-giving qualities of Sussex cattle are such as might be expected with a breed tending strongly to beef production, being somewhat inferior. The breed in recent years has not met with favor in this respect. The milk, however, is superior in quality if not in quantity. 
Cross-bred and grade Sussex cattle do well for beef production, making good grazers well suited to the Mississippi Valley, where feed is abundant. Sussex sires on native or grade cows should result in a class of cattle that will dress a high per cent.

The early maturing and grazing value of the Sussex is highly testified to by various breeders. As grazers Mr. Lea rates the breed as equal to the Hereford, but it is doubtful if they will mature as early.

The distribution of Sussex cattle is rather limited. There are numerous herds in southeastern and southern England. In the

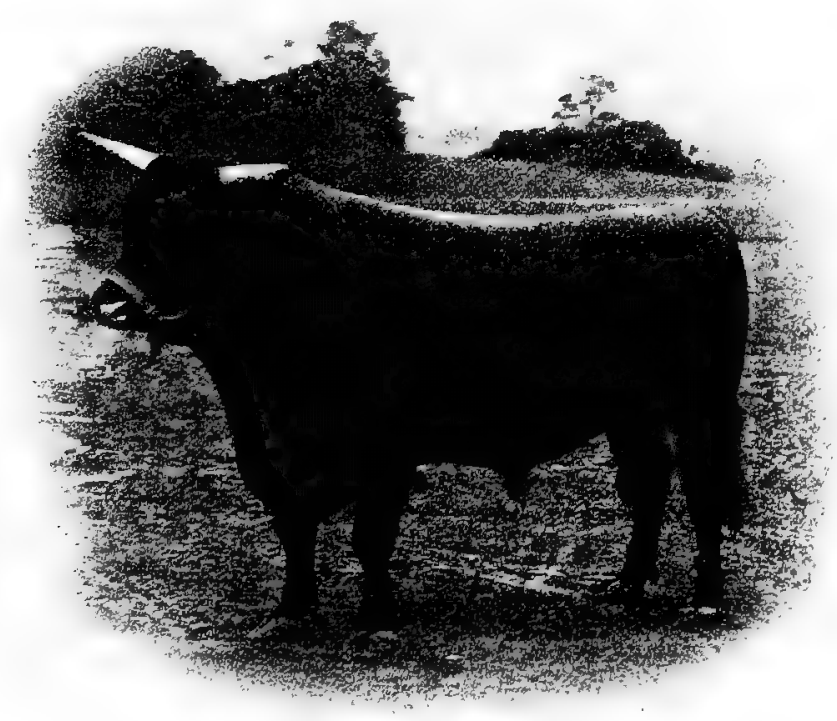

FIG. 99. General Roberts (500) a Sussex bull imported by Mr. Overton Lea, Nashville, Tennessee, in 1884 . Won first prize in class at the Royal Agricultural Society of England Show. Photograph from Mr. Lea

United States two large herds have been maintained, that of $\mathrm{Mr}$. Lea in Tennessee and one in Maine. There are a few small herds in Canada, Illinois, Indiana, and in some of the transMississippi states. Sussex have also been imported to South 
Africa, Egypt, Antigua, and perhaps to other British colonies. Whether the breed will become more popular time only can tell. It has not yet been much tried outside of its native home, but it seems to have succeeded there and at the same time to have made a good showing for itself in public competition.

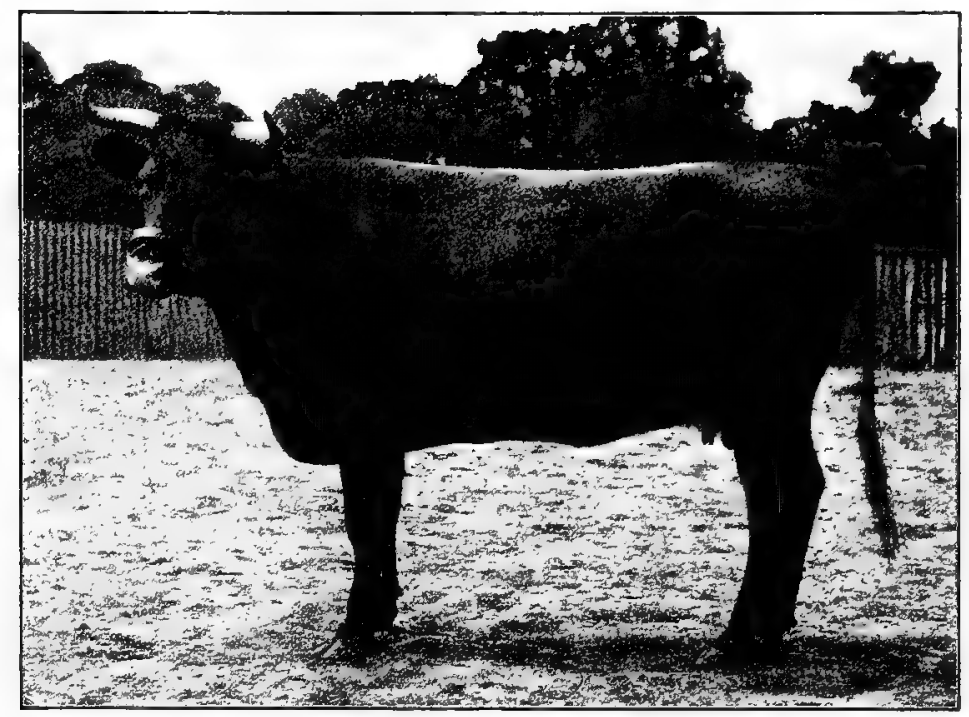

Frg. roo. The Sussex cow Milkmaid. Photograph from Mr. Overton Lea, Nashville, Tennessee

The promotion of the Sussex breed first took place in England. Mr. Alfred Heasman of Little Hampton, Sussex, published the first three volumes of a Sussex herdbook, Vol. I commencing with pedigrees from I855. In I 888 the Sussex Herdbook Society acquired the records. From that time up to 1905 this society has published twenty herdbooks. The American Sussex Cattle Association was organized in 1888 , and Vol. I of the herd register is to be issued in I906. 


\section{CHAPTER XXXII}

\section{THE WEST HIGHLAND}

The native home of West Highland cattle is in the elevated uplands of western Scotland. This particularly applies to that section known as the Highlands in Argyll, Inverness, and Perth counties, and the Hebrides Islands off the west coast.

The origin of the West Highland breed, which has also been called the "Kyloe" by some, is generally conceded to be derived from the aboriginal cattle of Britain, of which the present wild white cattle are descendants. This breed has been known for centuries, but has been kept on a comparatively small scale. During the first half of the last century two of the herds that improved the breed were those of Mr. Malcolm of Poltalloch in Argyll and the Marquis of Breadalbane of Perth.

The introduction of the West Highland cattle to America is of only passing moment. In 1879 Lewis F. Allen, one of the best-informed cattle authorities in America in the nineteenth century, stated that he knew of none in the United States, but was of the impression that a few were imported into Upper Canada some years before. About i 883 some West Highlanders were imported, among which was the cow Maid of Castle Grant, which was shown at a number of fairs in 1888 and 1889 by Judge J. S. Goodwin of Kansas. In I 89 I several West Highland cattle were exhibited at the American Fat Stock Show at Chicago. In I902 Mr. W. M. Van Norden of Westchester County, New York, imported a small herd and made an exhibit at the Louisiana Purchase Exposition in 1904. Other cattle of this breed were imported by several persons in 1906 .

Characteristics of West Highland cattle. This breed is very picturesque and distinct in character. The color is variable, being yellow, red, black, brindle, and a mixture of red and black, the former color predominating. Broken colors are not liked. In one 
herd or in the Scotch shows one may see all these colors. The hair is very long and shaggy, often reaching six inches in length. The head is very hairy and is surmounted by very long, large horns which curve forward and upward with the points wide apart. The horns are white with light colors, or white with dark tips with dark colors. The color of the muzzle varies from buff or flesh shade to dark, in harmony with depth of color of hair.

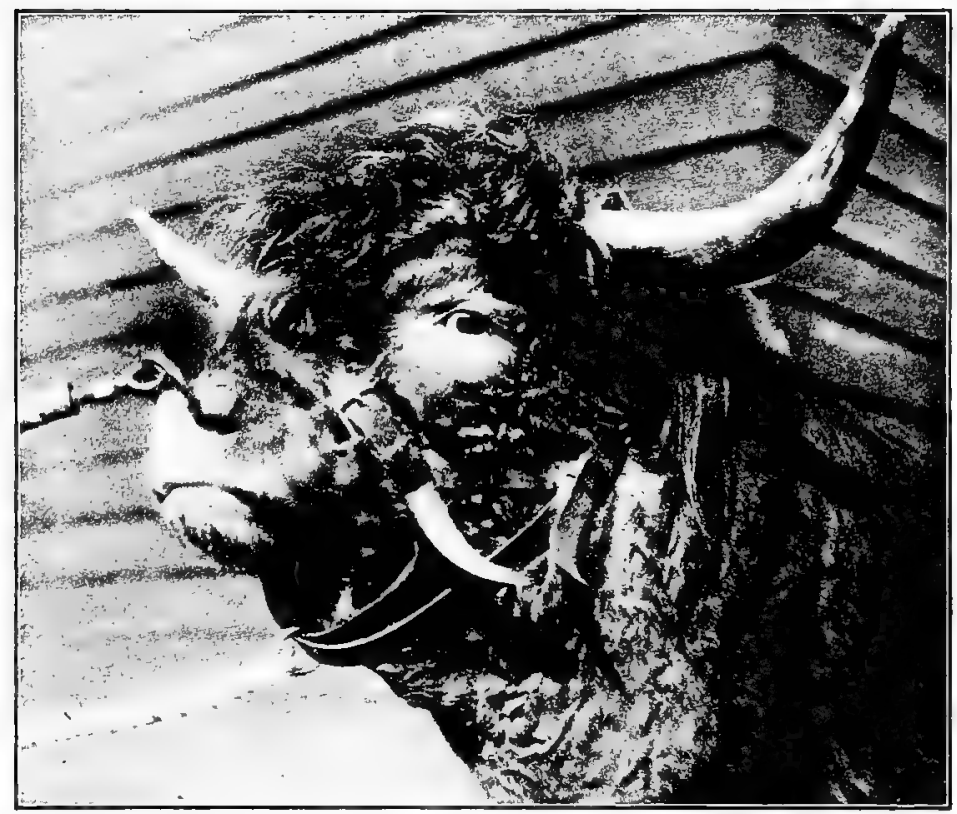

Fig. IOI. Head of the Highland bull Sir Andrew (1742), champion of the breed at the Louisiana Purchase Exposition, 1904, and one of the few males of the breed in America. Owned by W. M. Van Norden, Rye, New York

The neck is short and thick with a mane on top and heavy dewlap below. "In form," says John Robertson of Blair Athol, "it possesses all the characteristics so much and so justly prized in the Shorthorn - the straight back, the short legs, the broad chest, the breadth of loin and depth of rib, and, in short, the 'squareness' and solidity of form which always imply weight, whether in man or beast; while the noble branching horns, the fine, full, and fearless eye, the short, broad, well-bred muzzle, the 
shaggy coat of richest black or red or dun or brindle color, impart a picturesqueness which is still further enhanced by that grace and deliberation of movement so distinctive of all animals reared in per. fect freedom." The temperament is wild and bold, due to a condition of natural lack of restraint unknown among other breeds.

The size of the West Highland cattle is comparatively small, cows perhaps averaging 900 pounds and males 1200 , although one sees some larger on the hills and at the shows in Scotland.

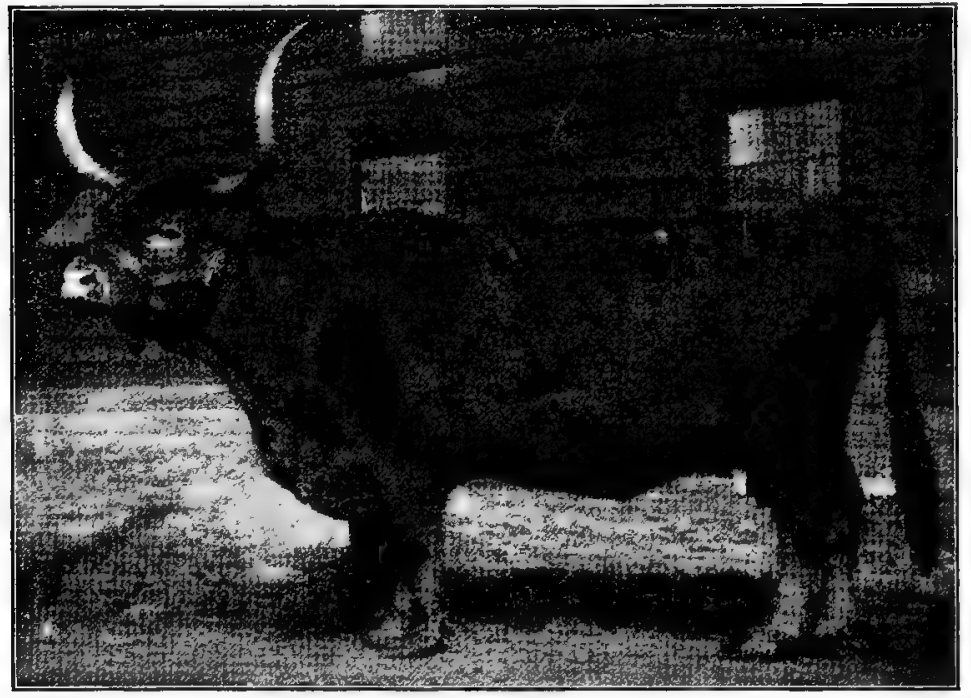

FIG. I02. Mora Oroughty, champion Highland cow at the Louisiana Purchase Exposition, 1904. A very typical specimen. Exhibited by W. M. Van Norden, Rye, New York. Photograph by the author

The West Highland breed as a beef producer is superlative so far as quality is concerned. The meat is fine of grain, the fat is well distributed among the lean, the flavor is unsurpassed, and the carcasses dress out well. In the British market beef of this breed ranks at the top. Yet these cattle feed very slowly and mature late, and seem best adapted to feeding under Scotch mountain environment.

The hardiness of West Highland cattle is remarkable. Used to a free life on the Scotch hills, where summer and winter they 
graze on grass and heather, they seem capable of enduring the roughest climate. In a letter on this breed the Earl of Dunmore wrote in 1887 , bearing on their suitability to the more exposed northwestern American range :

My average yearly loss has not been three per cent, which in a large fold of some four or five hundred head of cattle is very small. January, February, and March are pretty hard months for them, as they get no food beyond what they pick up on the hills where they are wintered. I have often seen them scraping away the snow to get at the grass ; but notwithstanding their being out all winter, they produce in April and May as strong and lusty-looking calves as a man could wish to see, with lots of bone and tremendous thick coats. That, to my mind, is the coming breed for the great northwestern ranges.

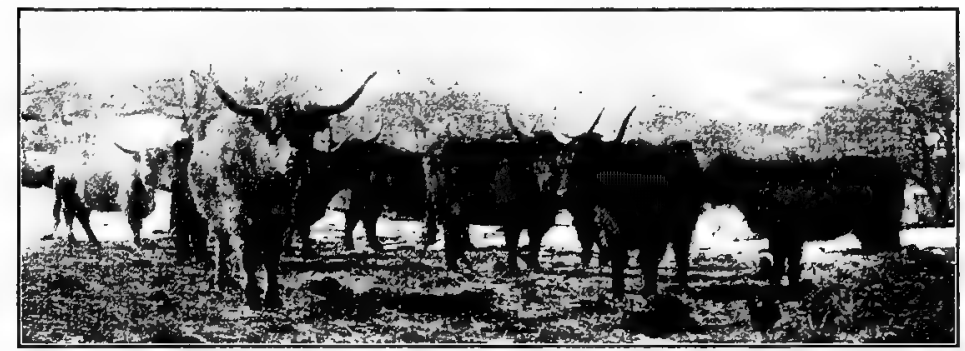

Fig. I03. A group of Highland cattle. Photograph from G. M. Rommel, United States Department of Agriculture, Washington, D. C.

The milking qualities of the West Highland are not important, for the cows are milked usually by the calves only. The milk, however, is considered rich in quality.

The breeding qualities of West Highland cattle rank high, though the heifers are not bred the first time until three years of age. Earl Dunmore states that he could quote from his private herdbook several cases of cows, after having their first calves at four years, continuing to produce yearly thereafter up to fourteen years of age one living calf and sometimes twins, all of them being born on the mountain side.

Cross-bred or grade Highland cattle are best suited to conditions where food is scarce and winters rough. Highland bulls on native western-range cows would furnish hardy stock, but it is not likely that it would meet with a favorable reception from buyers, compared with the present very acceptable Hereford, 
Angus, or Galloway grades. The claim is made by excellent Scotch authorities that West Highland cows cross well with bulls of most of the British beef breeds. Where food is abundant and the climate not too severe, such a cross may be advisable. On the more elevated Scotch hills, however, where winter exposure is great, the cross-bred progeny will not do so well as the pure-bred. Such cross-breds could not be expected to have the hardiness of the pure stock.

An organization of West Highland cattle breeders was formed by Earl Dunmore in 1884 , and a herdbook published that year, some nine volumes having appeared up to 1905 .

The distribution of the West Highland breed is mainly in Scotland, in the regions previously indicated, although herds are 'kept in England, where steers are also fed to a small extent. Although many owners of large estates maintain this breed for its picturesque character and easy keep, yet it is not common, excepting in western Scotland. In view of the fact that this is strictly a mountain breed, one might assume that it would do well on the better pastures of the Alleghany Mountains. Grazing of an excellent character is found on the mountains of Virginia, North Carolina, and Tennessee. The winters in that region lack the severity of the North, thus permitting living on the range the entire year. 


\section{CHAPTER XXXIII}

\section{DAIRY TYPE OF CATTLE}

The general appearance of dairy cattle is notably different from that of beef stock. They have less thickness of body, less breadth of back, narrower thighs, slenderer neck, and a more muscular character generally. The males are notably narrower at the withers and more divided between the hind quarters, while the females are rather sharp over the withers and full and heavy behind, with udder of ample proportions. A rather long, deepribbed, muscular, not fleshy body, and shortness of leg is notable in the high-class male. A triple-wedge form is associated with the dairy cow. Viewed from one side she shows less depth of body in front than behind. Secondly, she gradually widens from the breast to the points of the hips and hind quarters. Thirdly, as one looks down on the back at the withers the form widens out like a wedge towards the middle of the body. Many superior dairy cows show this wedge form in a striking degree, but exceptions occur, where the heavy milk production is not associated with an ideal dairy shape. Fleshiness with either sex is distinctly objectionable, unless with young animals not yet in lactation.

The head of the dairy animal should be lean, broad of muzzle, large of nostril, moderately short and broad of nose, with some dish to the face. Prominent, clear, calm eyes, wide apart, beneath a broad full forehead, are essential. The cheeks should be deep and the lower jaw strong. The fine, medium-sized, thin, pointed ears must be neatly placed and be covered with fine hair on the outside, with longer hair at tip and edges. If there be horns, they should exhibit quality, not being coarse or shelly. The top of the head, or poll, should be covered with a thick layer of fine long hair, especially in cold weather. A yellow color of the inner skin of ear and a yellowish waxy color to horn, especially at the base, are regarded as indicating that a cow will yield milk rich in fat. 
The neck tends to be long and muscular. With the bulls it is especially strong and heavily muscled, usually possessing a prominent arch, while the neck of the cow is thin and long. The lower part of the neck usually has more or less dewlap, this being a thin edge of skin extending from the brisket upwards. A very deep neck with much dewlap, fullness at the throat, or a short, thick neck on dairy cattle are objectionable, showing lack of quality and type. While the neck should have a neat attachment at head and shoulders, it does not blend in so smoothly as with beef cattle, owing to lack of flesh.

The shoulders should incline at a good angle well into the back, lying fairly close together and forming with the back line rather refined, narrow, or sharp withers. With the males greater breadth of withers is looked for. The shoulders are usually somewhat prominent, but heaviness or meatiness is distinctly objectionable.

The breast of dairy cattle does not show so great width as the beef type, and the brisket is narrower and sharper, and not carried quite so far forward.

The chest, like the breast, which is a part of it, does not show great thickness, but ample depth and reasonable spring of rib is desired. The crops, at the top of the chest behind the shoulders, are usually somewhat deficient in dairy cattle. At this place the ribs should have a fair arch from the back, showing ample chest room below. The front flanks also should be well filled out, showing a good constitution in the ample chest capacity.

The front legs should be straight from side or front, coming down without marked crookedness at knee or wide turning in or out of toes. A common feature of dairy cattle of both sexes is to have the knees come quite close together when in a natural position, thus indicating a narrow chest and poor constitution.

The back of the dairy type frequently shows some droop from shoulder to hip line. Some persons regard a sway back as necessarily associated with dairy type. A strong back, well sustained, with but little depression, if at all, is much to be preferred. Arguments have been advanced by some that a large backbone, with the vertebræ somewhat separated, offers important evidence of such a nervous temperament as should be associated with the 
dairy type. Through the backbone the spinal cord passes, connecting with the brain and the entire nervous system. A large backbone may indicate a large spinal cord and strong nervous temperament, a characteristic of the dairy type. Further there should be a strong, level, broad loin and also fair width of back throughout ${ }_{2}$ although not equal to that of the beef type.

The ribs should be sufficiently long and arched to provide a capacious body, a feature most important with animals of this

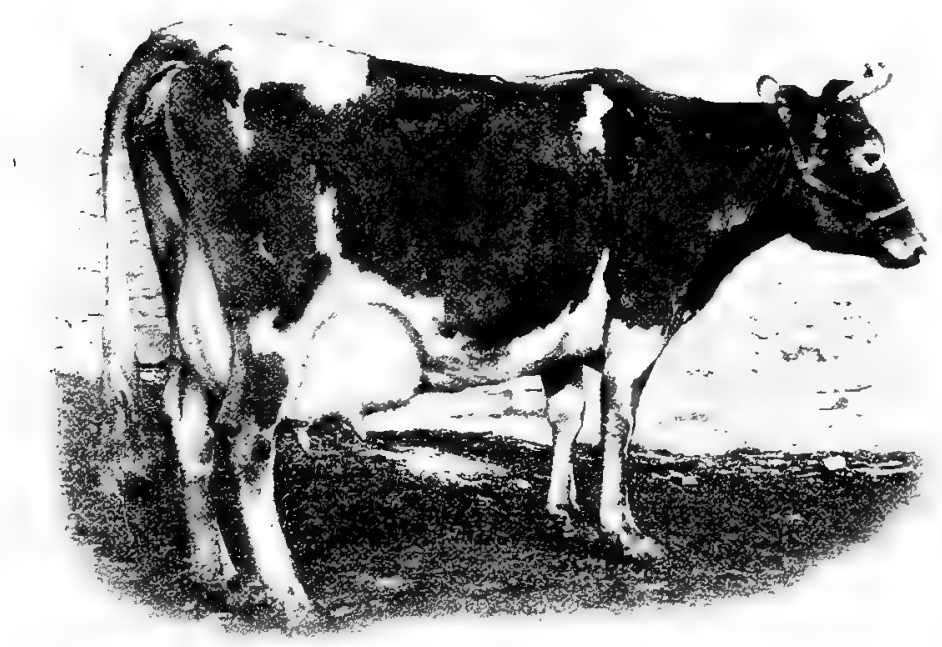

FIG. 104. This Guernsey cow, Count Topsey, owned by J. H. Beirne, Oakfield, Wisconsin, shows a remarkably high-class dairy type. As her hind quarters are nearer the camera than the fore quarters, it shows the wedge form in an abnormal degree. The udder from the side view appears nearly perfect. Photograph from Mr. Beirne

class. Flat and short ribs go with poor feeders and defective constitutions. The body of the dairy type being moderately long or rangy, the ribs do not lie quite so close together, perhaps, as with the beef type, neither is the coupling between the last rib and point of hip as close as with other cattle.

The hips tend to be somewhat prominent with both males and females. The hip points of the male should be neat and moderately close, not wide, while those of the female may be more 
widespread and prominent. This allows plenty of room for the breeding organs of the female.

The rump of the dairy type calls for ample length, breadth, and levelness. This offers more room for the reproductive operation, the peaked, droopy rump frequently causing trouble in calving, due to lack of room for the easy exit of the calf. The backbone should be prominent along the middle of the rump, in keeping with the rest of the back. The backbone from the hips to the tail head over the pelvis, on account of its prominence, shows a rise which is often termed the "pelvic arch." A fat rump is objectionable, a feature found usually in inferior milkers and animals of the beefy type.

The thighs of dairy cattle should be muscular rather than fat. A heavy, thick type of hind quarter is not desirable. The thigh should be long, should have a rather thin back edge, and should curve on the inside so as to permit ample room between the hind legs. A thick thigh and deep twist is unfavorable to large udder development.

The hocks, to secure the necessary room for the udder, must be muscular, clean, and thin, and should point directly back, with ample space between.

The legs from hock down should stand square, as viewed from side or rear, the toes pointing directly forward or nearly so. If the toes turn out, the animal hocks in and has a faulty conformation. Rarely the toes turn in and the hocks bend outward, giving a weak and poor position to the legs. The shank bones should be smooth and short, showing refinement of bone and quality.

The tail is important, mainly as a medium for protection from flies. Consequently length and a heavy brush of hair are essential. The fleshy part should extend to the point of the hock, and the brush clear the level of the feet by two or three inches. The root of the tail, or tail head, should carry on a line with the back, showing no coarseness or special prominence, fitting neatly to the end of the body. The tail as a whole is an indicator of quality, and should be refined rather than large and coarse.

The udder of the dairy cow is a most important part. In form it should be moderately thick, filling up well between the thighs, should extend by graceful curve high up behind, and should be 
extended well along the belly. The bottom of the udder in its best form has four teats some three or four inches long, hanging on the same level and placed far enough apart to be comfortably grasped in the hands. When the milk is removed from the udder that organ should be soft and pliable, showing much shrinkage. The hind part, located between wide-spreading thighs, should show much elasticity, with folds of skin apparent in the empty udder, especially with mature cows. Over the entire udder a mellow, soft skin and fine coat of hair should be found. Common defects of the udder are small, poor fronts, with the teats on this part elevated much above or close to the hind ones; small teats, especially with some breeds; meaty udders, which reduce but little with milking and yield a comparatively small flow, and last, but not least, small udders entirely lacking in profitproducing capacity. Large cows should have larger udders than small cows, but an animal of from 900 to Iooo pounds weight, at six years old, should have an udder of comparatively large size in full flow of milk, such as will yield at least 40 pounds a day. However, this standard does not apply to the larger, heavier milking breeds, which should do even better than this.

The milk veins which convey blood through the udder are usually regarded as indications of a cow's general capacity to produce milk. Young heifers have small veins, and with maturity they increase in prominence. On old cows they may be very tortuous, extending from the udder forward with numerous turns along the belly until they enter the wall of the belly through holes known as "milk wells." These latter should show comparatively large size on the application of the end of the finger at the orifice. Many cows have three milk veins, two long ones on the outer part of the belly and a short one between. In rare cases the veins branch into numerous small ones along the belly just in front of the udder. Small veins also occur on the udders of some cows. The length of vein varies, usually extending about halfway to the fore legs, although cases occur of their extending to the leg itself, disappearing behind the arm. The size of the vein varies much, the larger ones having a diameter of about three fourths of an inch. Small veins are found on the belly of the males, while miniature teats, known as "rudimentaries," 
are found along in front of and on each side of the scrotum, or purse, two usually occurring a short distance apart on a side. The length and size of rudimentaries varies greatly, ranging from small buttons to teats an inch long. We have no definite knowledge regarding the significance of these, some persons thinking that the larger they are the better the evidence that the male will transmit large milkers. Others have speculated that the position of the rudimentaries indicated the placing of the teats and form of fore udder on the offspring of the sire.

The escutcheon, also known as the "milk mirror," is found along the back of the thighs or between them, and has attracted special attention on dairy cattle only. This is shown by a line of hair turning to one side or upward, in contrast to the usual downward position of the hair. This line of reversed hair was investigated by a Frenchman named Guenon, who argued that the escutcheon indicated the capacity of a cow to produce milk. In view of the fact that the extent and position of the reversed hair varies alongside or above the udder, Guenon classified its occurrence, giving different names according to the prominence and character shown. Modern dairy-cattle authorities attach no special significance to the escutcheon, Guenon's theories not having been borne out in fact.

The quality of the dairy type is shown in the character of skin and hair, size of horn, ear, and bone, and general proportions. Under the ordinary conditions of keep for cattle of this class the skin should be very mellow and pliable, thinner than with beef cattle, with a shorter length of hair. No class of cattle show quality so clearly as do some of the dairy type, as indicated by handling, there being a rich, mellow, oily feel commonly associated with the skin of high-class animals. The skin also will often show a yellow oily secretion, conspicuous at the ears, between the thighs, and about the udder and scrotum. 


\section{CHAPTER XXXIV}

\section{THE JERSEY}

The native home of the Jersey is on the island of that name in the English Channel, about fourteen miles from the coast of France. This is one of the group known as the Channel Islands; they belong to Great Britain, and comprise mainly Jersey, the largest, Guernsey, Alderney, and Sark. Jersey is about eleven miles long and six wide and contains 39,580 acres. The north shore of the island is precipitous, the land gently sloping southward. The principal crops are potatoes and other vegetables, fruits and flowers, Jersey cattle and their products. The climate is most balmy, out-ofdoor life being pleasant all the year. So healthful are the conditions that tuberculosis among the cattle is almost unknown. The soil is very rich and most productive. The island has a population of about 60,000 . There are twelve parishes, and the farms are

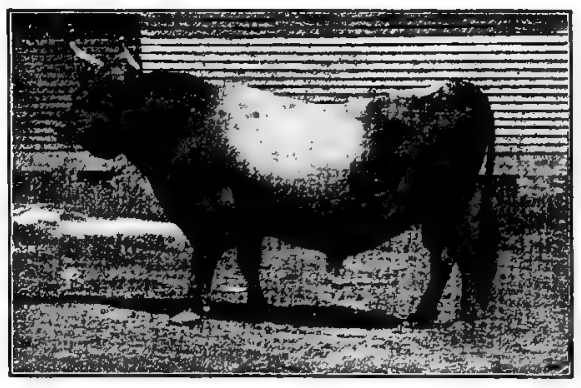

FIG. 105. Pedro $3^{187}$ at 18 years of age. Grand champion Jersey male at the World's Columbian Exposition, 1893, and one of the most noted of American-bred Jersey bulls, long at the head of the herd of Mr. T. S. Cooper, Coopersburg, Pennsylvania. Photograph from Mr. Cooper small, ranging from five to twenty acres each. Notwithstanding its small size there are about 12,000 cattle kept on Jersey, according to late reports, and the herds are well maintained.

The origin of the Jersey is unknown. The most probable theory is that it is descended from stock on the neighboring section of France, notably Brittany and Normandy. While the cattle 
of those regions to-day do not closely resemble the Jersey, they have some things in common. The fawn or white color has been attributed to certain cattle of Normandy, while the blacker color has been ascribed to the Brittany cattle, it being assumed that the Jersey has resulted from the fusing of these French types. Historically the first description regarding the Jersey that the author has secured, showing its resemblance to the breed of to-day, was by Culley in 1789 , who comments on the introduction into England of French or Alderney cattle, to ornament the grounds of the nobility and gentry and to provide rich milk. The term "Alderney" thus used applied to any of the Channel Island cattle, and the use of this word in America for many years was no doubt due to the English inheritance.

The protection of the purity of cattle on Jersey dates back into early colonial times. The value of preserving the character of the breed was recognized as early as $176_{3}$, when laws were passed by the legislature of Jersey prohibiting the importing of cattle from France to the island. In I 789 an act was passed making it a severe crime, heavily punishable, to bring any cattle to Jersey from France, excepting for immediate slaughter. Gradually other restrictions were added to prevent cattle coming to Jersey from any other country, excepting for slaughter within twenty-four hours.

The improvement of the old Jersey type really began in a general mpvement on the part of the islanders. In 1833 the Royal Jersey Agricultural Society was organized, with the view among other things of improving the cattle. In I 834 the society originated a score card for Jerseys, amounting to twenty-five points for the bull and twenty-seven for the cow. This card was used at the first show of cattle on the island, which also was held in I 834. Comments by the judges were that the cattle were poor of shape, had bad udders, some females had short, bull necks, were heavy in shoulder, etc. The application of the score card, which was revised in $1838,1849,185 \mathrm{I}$, and 1858 , was enforced, and the cattle of the island gradually and rapidly improved. This work was due to the joint efforts of the members of the agricultural society, though Colonel Le Couteur was a leader in this movement on the island. The practice of selection was followed 
with much care, and the breeders constantly sacrificed to the butcher animals of inferior quality and value.

The improvement of the Jersey in England had some bearing on the general development of the breed. Many herds had been formed in England, that of Lord Braybrooke in Essex county, dating back to $18 \mathrm{I}$, being still in existence in $\mathrm{I} 880$ when the first volume of the English herdbook appeared. About I82 I Philip Dauncey of Horwood, Buckingham county, purchased his first

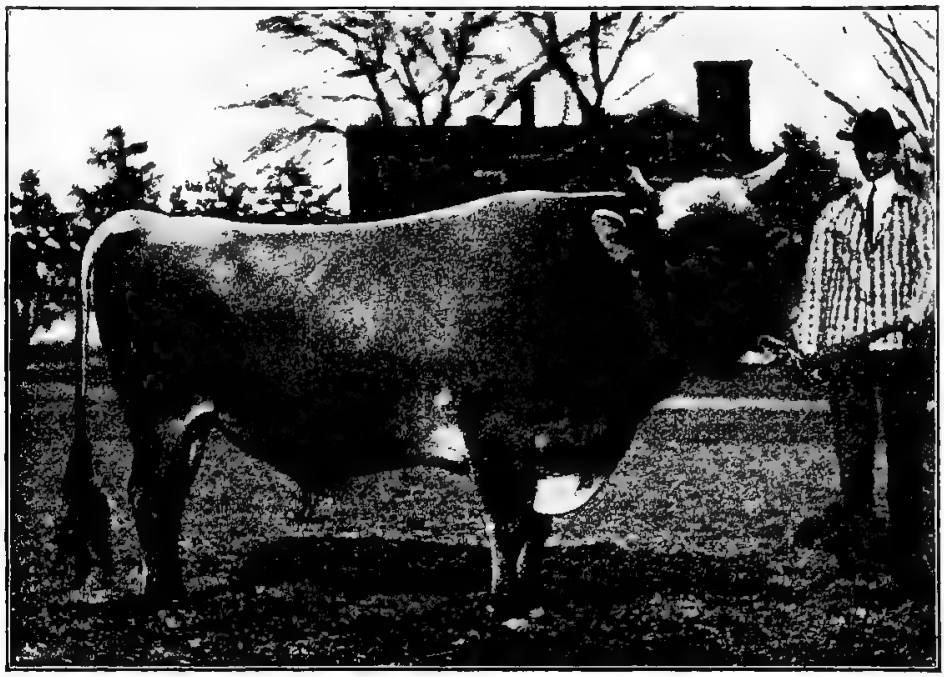

FIG, 106. King of St. Lambert's King 30752, long the leading sire in the herd of F. M. Hart, Cleveland, Ohio. Among American-bred. Jerseys this is a notable sire, having up to 1906 some forty-five daughters, each with a reported test of fourteen or more pounds of butter in seven days. Photograph by the author. - The camera being somewhat nearer the head than hind quarters shows the front slightly out of proportion to the hind part

Jersey, and later became England's most celebrated breeder. He developed a remarkable herd and it is stated that he eventually maintained a dairy of 50 Jersey cows which netted him an annual profit of \$100 each from sales of butter. His cows produced large yields of butter and greatly advertised the merits of the breed. The herd was dispersed in 1867 when 90 head averaged something over $\$ 200$ each. "Cattle from this herd were sold to go to different parts of England, Germany, Australia, and 
Tasmania. Dauncey bred with three objects in view : first, a large average butter record ; second, constitution ; third, uniform color, free from white. In 1826 he bought the bull Pope 652 on the island, which greatly improved his herd. Dauncey bred the bull Rioter 746 E, whose grandson Stoke Pogis 1269 became progenitor in America of the St. Lambert family.

The importation of Jerseys to America dates back well into the nineteenth century. As far back as 1818 Reuben Haines of Germantown, Pennsylvania, imported a pair of cattle from the island of Alderney, but no definite importation from the island of Jersey seems recorded prior to I850, when Messrs. Taintor, Buck, Norton, and other gentlemen near Hartford, Connecticut, brought over in the ship Splendid the first from the island to be registered in the American herdbook. The bull Splendens 16 is probably the first registered Island-bred bull brought to this country. In I 85 I and 1855 other importations were taken to Connecticut, including some animals that later became famous, notably the bulls Splendid 2, St. Helier 45, Rob Roy 1 7, and Pierrot 636; and the cows Dot 7, Pansy 8, Jessie 28, and the Ives cow. In I85 I Thomas Motley imported for the Massachusetts Society for Promoting Agriculture, bringing over among other cows Flora I I 3 and Countess I I4. From I 850 importations became frequent. The dates of the introduction of the Jersey into some other localities are as follows: Maryland, 1851; New York and Pennsylvania, I 855 ; Ohio, I 865 ; Canada, I 868. Many importations have been made in the last half century, yet none of these have been so extensive or important as the annual importations of Mr. T. S. Cooper of Pennsylvania, beginning in 1900 . In recent years F. S. Peer of New York has also brought over many valuable cattle from the island of Jersey.

Characteristics of the Jersey. The color is generally termed fawnlike, but is quite variable in its shade, being yellowish, reddish, grayish, brownish, or silvery fawn. Some are described as orange or lemon fawn, and others as squirrel gray or mulberry black. White as a whole does not occur, but white marks are quite common, although solid fawn color over the entire body is generally preferred. Brindle is a rare color and is objected to, but does occur. The hair about the muzzle and eyes is usually 
of a light creamy or grayish shade. In registering Jerseys it is necessary to specify whether the tongue is white or black, or the switch white or black, these being identification marks. Where color is made a point of importance in the breeding of a herd, a dark fawn, shading to light along the backbone and the lower limbs, meets with much favor, though solid colors of light fawn also are very popular. The most experienced and able breeders do not place primary emphasis on color, always making it secondary

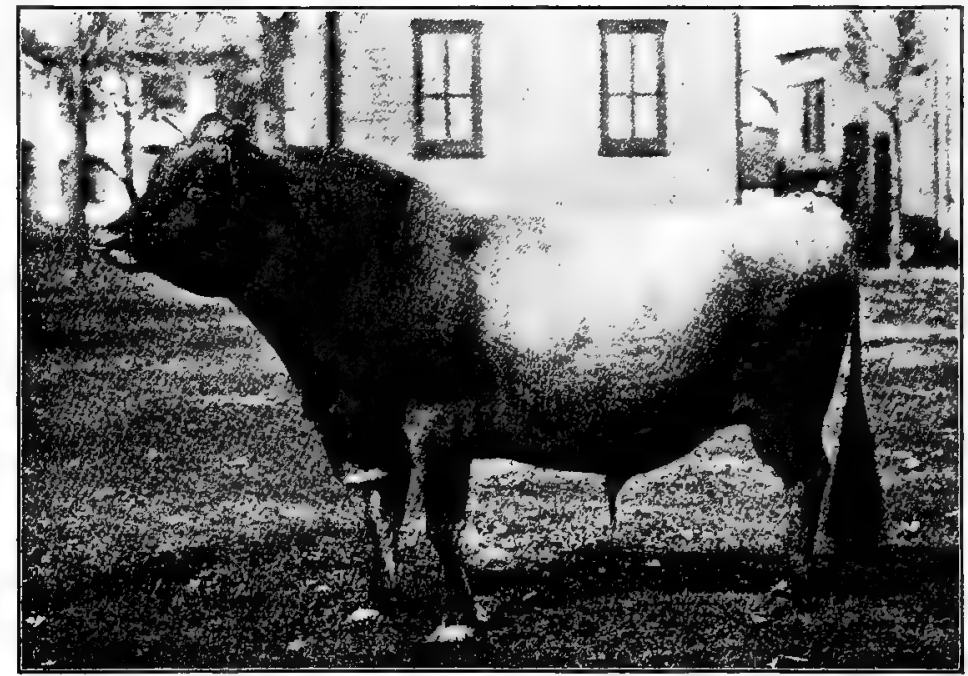

Fig. 107. Eminent 69631, imported by T. S. Cooper \& Sons from the island of Jersey. Sold at the Cooper auction in 1905 for $\$ 10,000$, to George E. Peer of New York, who soon after sold him to A. M. Bowman of Virginia for the reported price of $\$ 12,000$. This bull is noted as a sire and show animal. Photograph from Mr. Cooper

to the more important features, color being a fancy point and of no intrinsic value. In conformation the Jersey is lean and muscular, the general outline representing the dairy type. The head is lean, should be fairly short, broad between the eyes and muzzle, with some dish of face, and with deep, strong lower jaw. The horns vary in style, but those of the bull should be short and strong, curving around forward and upward and slightly inward, while those of the cow should be smaller and perhaps longer, with more curve. A white or amber-colored horn with 
blackish tip is the most approved sort. The more yellow the horn the greater the indication, some think, of rich milk production. The skin secretions are usually quite yellow, and, as seen in the ear, at tip of tail, and about the udder, indicate something of the richness of the milk. The skin itself with the Jersey should be thin, very elastic, and mellow, with a fine thick coat of hair. The chest should be deep and of moderate thickness. Too many cattle of this breed are thin-chested and lack spring of front

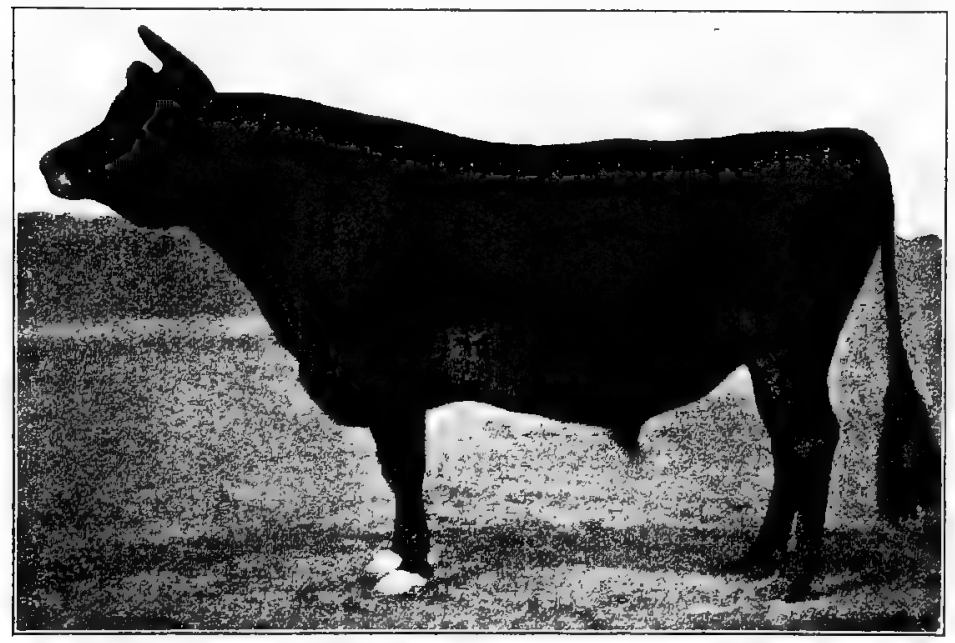

FIG. 108. Merry Maiden's 3d Son 60516. Sired by Brown Bessie's Son $3455^{\circ}$ and out of Merry Maiden 64949. Grand champion Jersey male at the Louisiana Purchase Exposition, 1904. Bred by Hood Farm, Lowell, Massachusetts, and owned by H. C. Taylor, Orfordville, Wisconsin. Photograph by the author

rib, a common criticism. The back should be strong and well supported with little if any droop, the ribs well sprung and long, the whole body showing large comparative size and digestive capacity. The hips should be fairly broad in the cow, but not in the bull, the rump long, broad, and level, the thighs thin and muscular and set wide apart, the hocks and hind feet carried straight and with ample room to allow a large udder between. The Jersey udder is usually very mellow and milks out well, but is frequently criticised for its small size as well as small teats. 
There are many beautiful udders of great capacity in this breed, but the abbreviated, elevated fore udder is far too common in many herds. The milk veins no doubt attain as great relative size and prominence with this breed as any, often being very tortuous or winding in form, large, long, and passing into large wells.

The size of the Jersey may be classed as small to medium. Cows in herds range from 650 pounds upward, 850 probably being a fair average. The cow Nabritza 5820 even attained a weight of 1650 pounds. From correspondence with a score of the leading American breeders the author has secured many weights of individual males and females. The average weight of $18 \mathrm{ma}$ ture cows in the herd of F. H. Scribner of Wisconsin was 1006 pounds, ranging from 900 to 1125 . Of 105 cows in eight herds but one weighed under 700 pounds, I I weighed between 700 and 799,35 between 800 and 899,34 from 900 to 999 , and $x 9$ from rooo pounds up.

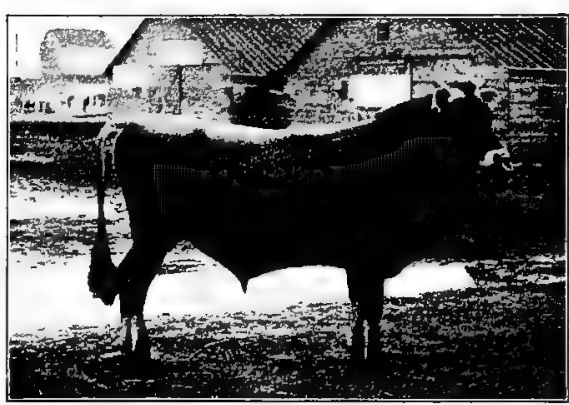

FIG. Iog. Venture's Lad 52300, a beautiful and noted Jersey bull of the 1898 and I 899 fairs. Bred and shown by J. E. Robbins of Indiana. Photograph by the author

Eighteen bulls, heads of herds, ranged in weight from 1040 to I790 pounds, the average being I4I 5 pounds. In general, a weight of 1300 pounds is desirable in the mature Jersey male. As a rule those of the St. Lambert family represent a larger type than those of other families. The average weight of 24 Jersey cows at the Columbian Exposition in I 893 was $922 \frac{1}{3}$ pounds.

The Jersey as a milk-fat producer is justly famous. An important feature in connection with Jersey milk is that the fat globules are comparatively large and the cream rises or separates easily. The value of Jersey milk for producing superior butter was recognized over a century ago in England, and first attracted Dauncey to the breed. Many fine records have been made in England and on the island of Jersey, but America has led in the testing of this breed. In I 853 the first Jersey butter test was 
made in this country, Thomas Motley of Massachusetts testing the cow Flora I I 3, when, as a three-year-old, I 4 pounds 8 ounces of butter was made in seven days from her milk. The same year the cow Rose 240 yielded 17 pounds in seven days. From this time thousands of seven-day tests have been made of Jersey cows, showing records ranging from I4 pounds of churned, salted, and worked butter up to that of Princess $2 \mathrm{~d} 8046$, reported to have made an official test of 46 pounds $12 \frac{1}{2}$ ounces in one week in 1885 . The testing of Jerseys for butter production became so extensive that Major Campbell Brown of Tennessee and others collated and published two volumes of such tests, and later in I 890 the American Jersey Cattle Club took up this work officially. Several thousand records have been published by the club in book form. Many of these records were so high as to cause suspicion of the integrity of the testing, which finally resulted in the club providing for butter-fat tests as well as churn tests, to be supervised by experiment station or agricultural college officials. The following are some of the noteworthy private records:

Notable Private Jersey Butrer Records

\begin{tabular}{|c|c|c|c|c|c|c|}
\hline Name of Cow & & & RECOKD & & Duration & $\begin{array}{c}\text { YEAR OF } \\
\text { TEST }\end{array}$ \\
\hline Oxford Kate 1 3646 & . . & . & $39 \mathrm{lb} .120$ & $0 z$. & 7 days & 1885 \\
\hline Mary Anne of St. Lambert & 9770 & & $36 " 12 \frac{1}{2} "$ & $" ،$ & $7 ،$ & 1884 \\
\hline Little Goldie 36671 & . . & - . & $34^{\prime \prime} 12 \frac{1}{2}$ " & “ & $7 "$ & 1892 \\
\hline Oonan of Riverside 69773 & .. & - . & $34^{\prime \prime} 3$ " & "6 & "6 & 1895 \\
\hline Exile's Belle 40524 . . & . . & . & 32 " 7 " & " & “6 & 1891 \\
\hline Ethleel 2d 32291 . . . & . . & - . & $30 " 15 "$ & “" & " & 1885 \\
\hline Massey Polo 67010. . . & . . & . & 30 " 61 " & $"$ " & 7 & 1894 \\
\hline Ida of St. Lambert 24990 & . . & . & $30 "$ " & "، & 7 & 1884 \\
\hline Signal's Lily Flagg 31035 & . . & . & $1047 " 6$ & “" & 365 & $1891-1892$ \\
\hline Bisson's Belle 3 II 44 . . & . . & . . & 1028 " 15 " & " & 365 & $1888-1889$ \\
\hline Eurotissima 29668 . . . & . . & . & 945 “ 9 “ & “ & $3^{65}$ & $1886-1887$ \\
\hline Landseer's Fancy 2876 . & . . & . . & 936 “' $14 \frac{3}{4}$ ' & “ & 365 " & $1885-1886$ \\
\hline Mary Anne of St. Lambert & t 9770 & o . & 867 “ 143 & “ & 365 " & $1883-1884$ \\
\hline Eurotas 2454 . . . . & . . & . . & 778 “ 1 & “ & 365 “ & $1879-1880$ \\
\hline
\end{tabular}

Since 1893, when the Jersey breed took official part in the dairy-breed competition at the World's Columbian Exposition, 
when disinterested persons supervised the tests, such large private tests have not been reported. Unquestionably many Jersey cows will yield from 14 to I7 pounds of butter in a week, while a few may pass 20 pounds. The best record made in a week at the Columbian was by the cow Brown Bessie 74997 , of 20.163 pounds; in 30 consecutive days her yield was 77.3 I9 pounds. In the Columbian Exposition tests the

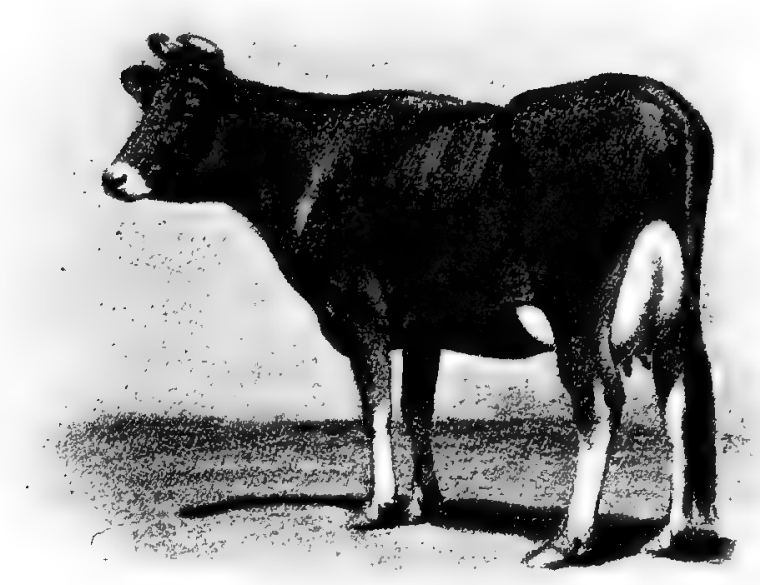

FIG. I 10. Mary Anne of St. Lambert 9770, classed as one of the most beautiful Jersey cows of her time. The property of Valancey E. Fuller, then of Canada, she had a private record of 867 pounds $14 \frac{3}{4}$ ounces butter in 365 days. Photograph by Schreiber

Jerseys excelled both Guernsey and Shorthorn in butter-fat production. In the Pan-American Exposition in I90 I the Jerseys stood second among ten breeds in profitable fat production, the Guernseys leading. In the Louisiana Purchase Exposition the Jerseys surpassed the Holstein-Friesian and Brown Swiss in butter and cost of production, the average cost per pound being IO $\frac{1}{2}$ cents for the Jersey, I $3 \frac{1}{2}$ for the Holstein, and $14 \frac{2}{3}$ for the Brown Swiss. In 90 days in this test the Jersey cow Loretta D. I4I708 produced 280 . I6 pounds butter fat at a net profit of 
$\$ 50.52$. A fair grade of Jersey milk will contain at least 4.5 per cent fat and commonly averages more.

The Jersey as a producer of quantity of milk, as a rule does not stand high. However, many records show the ability of cows of the breed to produce large quantities. It is not unusual for a Jersey to produce 5000 pounds of milk a year. In the 90-day test at the Columbian Exposition the 25 Jersey cows in the trial, including sick ones, averaged 33 pounds of milk daily, while in the Louisiana Purchase Exposition test the same number of cows for the same period of time averaged $4 \mathrm{I} \frac{1}{2}$ pounds milk per day. The latter is really a remarkable showing.

Some notable milk records of Jerseys have been published, among which are the following:

Notable Private Jersey Milk Records

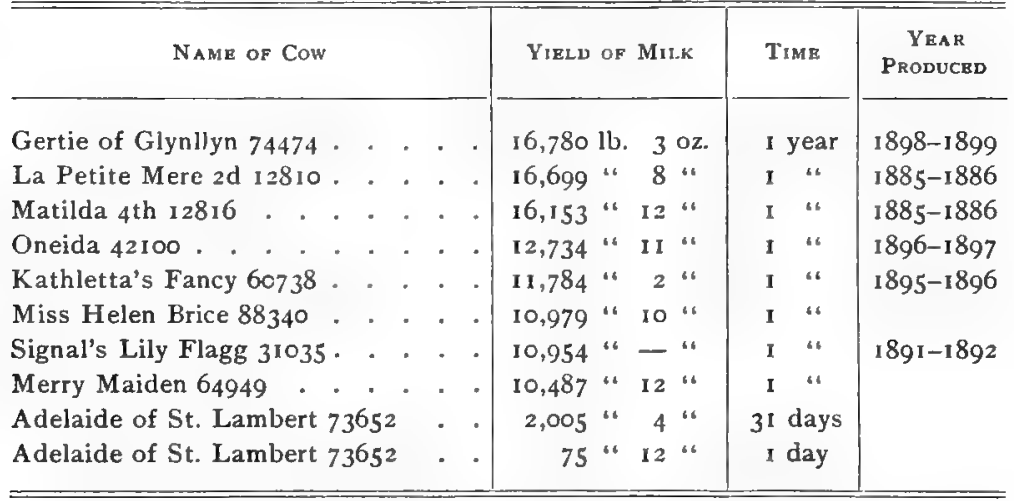

Jersey milk for cheese making ranks very high. The demonstration at the World's Columbian Exposition made clear that milk rich in butter fat made more valuable and better cheese than milk inferior in butter fat. In the Exposition cheese test the following records were secured in a 15 days' test :

\begin{tabular}{|c|c|c|c|c|c|c|c|}
\hline & & & $\begin{array}{l}\text { Amount } \\
\text { Chrese }\end{array}$ & VALUE & $\operatorname{Cos} \mathrm{T}$ & $\begin{array}{l}\text { Value } \\
\text { Pound }\end{array}$ & $\begin{array}{c}\text { Amount Milk } \\
\text { PRR Pound } \\
\text { ChaEsr }\end{array}$ \\
\hline Jersey . & - & - . & $1451.76 \mathrm{lb}$. & $\$ 193.98$ & $\$ 98.14$ & $\$ 0.13 \frac{1}{3}$ & $9.16 \mathrm{lb}$. \\
\hline Guernsey & . . & - . & II 30.626 & 135.22 & 76.25 & .12 & 9.67 “ \\
\hline Shorthorn & . & - . & $1077.60 " 6$ & 140.14 & 99.36 & .13 & 11.31 " \\
\hline
\end{tabular}


This record clearly shows that Jersey milk holds a high place in cheese production. This breed, however, finds its most important use in butter making or in the retail milk trade, and comparatively little of this milk is made into cheese.

The Jersey in crossing or grading may be used to great advantage, at least in the latter way. There are many high-grade Jersey herds in the country that are very profitable producers of butter and milk. If bulls of proper breeding and individual merit are used on native cows, very superior dairy herds should result.

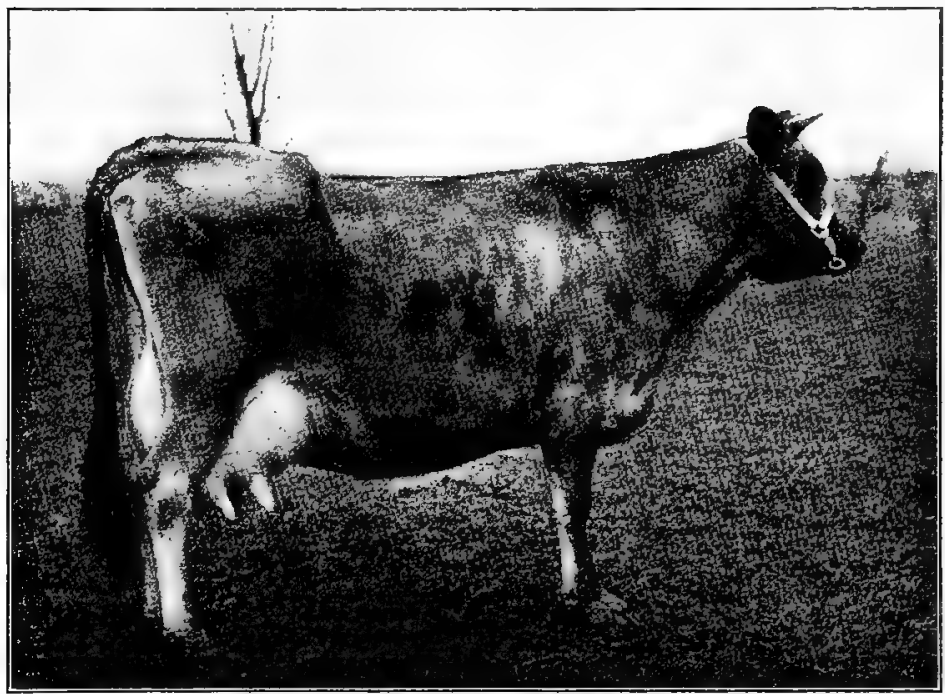

FIG. III. Silver Sheen 262 Io, a noted prize-winning Jersey cow of 1893 and 1894, shown by the late A. T. Dempsey, Columbus, Ohio. Silver Sheen was the dam of Silverine Coomassie 55600, prominent as a sire and show bull in the herd of J. E. Robbins of Indiana. Photograph from Colonel Dempsey

The Jersey as a beef producer is not worthy of serious consideration. The meat is rich in quality and fine of grain, but is too yellow in fat coloring to suit butchers. Jersey steers will lay on flesh fairly well, but do not dress out well in slaughtering, having more offal and internal fat than the distinctive beef breeds. In a breed-feeding experiment for beef at the Michigan Agricultural College the Jersey steer Roscoe at II6I days weighed I490 pounds, showing a daily gain of I.28 pound and 
dressed out 59.4 per cent, compared with a Shorthorn which dressed out 66.8 per cent. Of six breeds tested the Jersey made the poorest showing. Three Jersey steers fed by two experiment stations reported on by Henry in Feeds and Feeding, showed an average daily gain for I0 58 days of 1.36 pound per day, ranking ninth among eleven breeds in daily gain, but standing last in per cent of dressed weight. In a steer-feeding experiment conducted by the Iowa station with nine breeds, the valuation placed

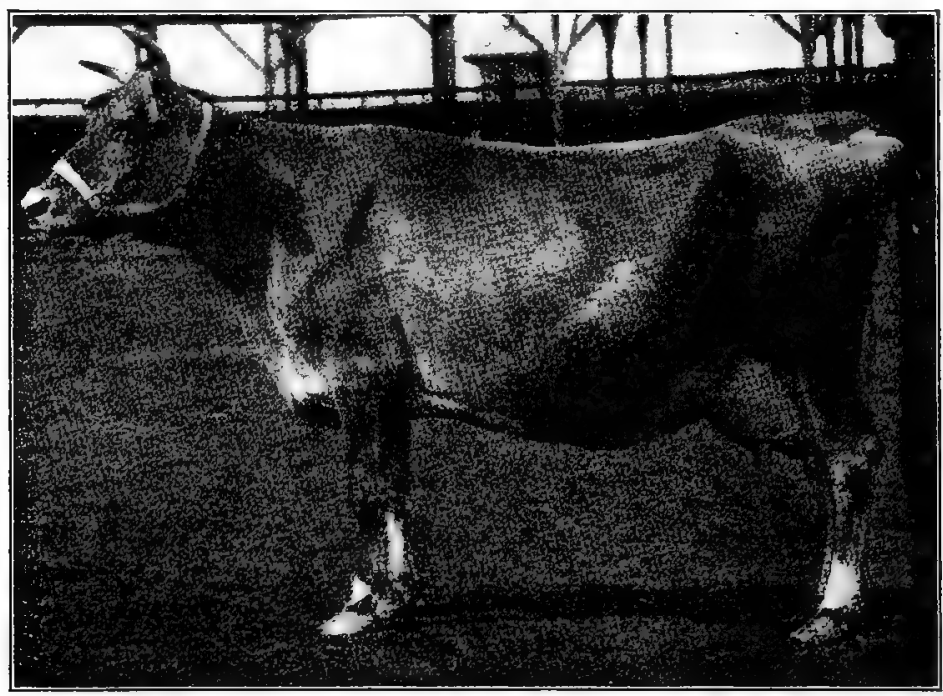

Fig. 112. Figgis 76106. This remarkable Jersey cow, at 13 years of age, won the grand championship of the breed at the Louisiana Purchase Exposition, I 1904, in very strong competition; shown by Hood Farm, Lowell, Mass. Figgis has a day's record of 50 pounds 7 ounces of milk, and of 19 pounds 15 ounces butter in seven days. Photograph by the author

on the Jersey carcass by Chicago experts was $\$ 4.50$ a hundred, the lowest of the nine, compared with $\$ 6.62 \frac{1}{2}$ for the Hereford. Jersey families of distinction in America date back now almost fifty years. Among these families the following ten may be regarded as leading ones. Signal, descended from Pansy 8; Coomassie, descended from Coomassie I I 874 ; Eurotas, descended from Eurotas 2454 ; Tormentor, descended from Angela F. I607 J.H.B.; St. Lambert, descended from Stoke Pogis i259 out of 
Essay ; Golden Lad, descended from Sultana, P. 7. H.C. ; Combination, descended from Lady Mel 429; Fontaine, descended from Fontaine, F. 2058 C.; Oxford, descended from Oxford Daisy, F. 68I6 H.C. ; and Landseer, descended from Landseer's Fancy 2876. There are also others of equal note.

Jersey bulls siring tested daughters number a long list. Among those who have been the most prolific sires may be mentioned the following ten: Exile of St. Lambert 1 3657 , St. Lambert Boy I 7408, King of St. Lambert's King 30752, Ida's Rioter of St. Lambert I 3656, King of St. Lambert I 5 I 75, Pedro 3187 , Diploma r62 I9, Tormentor 3533 (imp.), Fancy's Harry 9777 , and Stoke Pogis 3d 2238. Each of these bulls is reported to

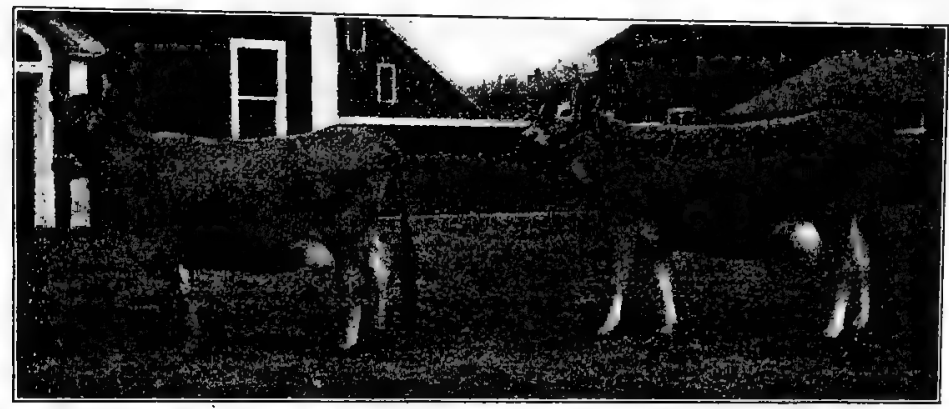

FIG. II3. Exile's Sappho I I 4262, on the left, butter test 25 pounds 6 ounces in seven days, and Exile's Pomona I I I 106 on the right, butter test I 7 pounds in seven days. These two cows, owned by F. M. Hart, Cleveland, Ohio, were sired by Exile of St. Lambert 13657. Photograph by the author

have sired over 25 daughters that have made 14 or more pounds of butter in seven days, Exile of St. Lambert being credited with over 90 .

Prices for Jersey cattle range from such as might be expected for common stock of any breed to those of very high character. Mr. T. S. Cooper of Pennsylvania paid $\$ 10,000$ for Pedro 3187 at private sale. Eminent 6963 I was sold at the auction sale of T. S. Cooper \& Sons, May 30, I905, for $\$ 10,000$ to G. E. Peer of New York, and soon after changed hands at private sale at an advance over this, going to A. M. Bowman of Virginia. In 1902, at the Cooper sale, Champion Flying Fox 6I44I was purchased by T. W. Lawson of Massachusetts for $\$ 7500$. The 
cow Imported Blue Belle 180234, in May, I904, sold at the Cooper sale at fourteen years of age at $\$ 3600$ to Gedney Farm. At the 1905 sale of Cooper \& Sons 103 head of imported Jerseys brought $\$ 63,120$, an average of $\$ 621.55$ each, the highest record in a score of years. These represent the highest Jersey prices, though many range above $\$ 1000$.

Early maturity of the Jersey is more marked than with any other common breed of cattle. Repeated cases are on record of Jersey females, through accident, having the first calf before 365 days old. Both males and females develop rapidly and are often in service too early for the good of the herd or breed. Occasionally one will find a herd of Jerseys, where the owner has bred the heifers to come fresh at eighteen to twenty months old. In these herds one is impressed by the small size and runty appearance of the cows. The wiser and more thoughtful breeders of to-day plan to have their heifers come fresh about thirty months old, depending somewhat upon the vigor and size of the animals to be bred. A greater vitality and producing capacity is thus secured.

The ability of Jerseys to reproduce ranks high, as is the case with all dairy breeds. Many males have lived to a ripe old age and been in constant herd service. The bull Pedro was in active service until nearly twenty years old, St. Lambert Boy was used until he was fourteen, and King of St. Lambert's King at fifteen is yet in active service, while numerous other similar instances could be cited. There are also many vigorous old cows of the breed, and these may be frequently seen in Jersey herds. Figgis, the champion cow at the Louisiana Purchase Exposition, was thirteen years of age, and Marjoram 2d, at sixteen years of age, was sixth in the aged cow class at the World's Columbian Exposition. Merry Maiden, Brown Bessie, and Miss Helen Brice, all famous cows, lived long, useful lives. Many Jersey cows are in their greatest usefulness at ten to twelve years old.

The distribution of the Jersey is world-wide. Prominent herds are found in various parts of England, France, Canada, all over the United States, in Australia, and elsewhere. The breed seems adaptable to a wide range of conditions, and famous herds have been developed in Canada and the New England states, where 
the winters are severe, in the milder Mississippi Valley, and in the warm south and southwest. The Jersey is the most popular and common of the dairy breeds in America.

Organizations for promoting Jersey cattle have long existed in America and on Jersey Island. The Royal Jersey Agricultural Society, founded in 1833, assumed supervision of the breed on the island, and in 1866 published the first island herdbook, since which fifteen volumes have been issued to 1905. The American Jersey Herdbook, published under the direction of the Association of Breeders of Thoroughbred Neat Stock, with headquarters in Massachusetts, was the first organization to promote Jersey interests in America, and published six herdbooks, the last appearing in 1878 . The English Jersey Cattle Society was organized in the seventies, and up to I905 had published sixteen volumes. The Maine State Pure Blood Jersey Cattle Association, chartered in 1875 , published its first herdbook in 1876 and Vol. VIII in 1898 . The American Jersey Cattle Club was organized in 1868 , and in $187 \mathrm{I}$ published its first volume, since which time, up to January, I906, some sixty volumes have been issued, registering nearly 200,000 head. In 1903 the New Zealand Jersey Cattle Breeders' Association published their first herdbook. 


\section{CHAPTER XXXV}

\section{THE HOLSTEIN-FRIESIAN}

The native home of Holstein-Friesian cattle is Holland. While the breed as we know it in America seems abundant all over Holland, it is most common in north Holland in the provinces of Friesland and Drenthe. There are several recognized breeds of Dutch cattle, but the large black and white one is the leading dairy breed, and meets with favor in northwestern Germany and Belgium, where it is extensively kept. Holland is a country mainly reclaimed from the sea, and much of the land lies below sea level, the water being held back by dikes. The soil is very fertile in some places and very poor in others. Much of the land is in meadows, separated into farms and pastures by canals. The climate is cold in winter, but the nearness to the sea breaks its intensity and furnishes satisfactory conditions for cattle the year round.

The origin of Holstein-Friesian cattle is obscure. It has been claimed that for over a thousand years the people of Holland have kept them and have been famous for the production of milk, butter, and cheese. It has been assumed that these cattle are descended from the prehistoric Giant Ox (Bos primigenus). Early writings refer to Dutch cattle as being large, more or less white in color, and great milk producers. Undoubtedly the present type of black and white dairy cattle of Holland has long existed there.

The origin of the name Holstein-Friesian becomes pertinent at this point. A quarter of a century ago cattle were brought to this country under the names of Holstein and Dutch Friesian, being sold as different breeds and championed by different breeding associations. The name Holstein has no application in Holland, but refers to a small province in Germany, between the Baltic and North seas, about a hundred miles east of the Holland 
boundary, where black and white Dutch cattle are found. The word Friesian is derived from Friesland province, Holland, and this is the name the breed should go by in America, as it does in Holland, for no such breed name as Holstein-Friesian is used in the latter country. In view of the fact that all the cattle imported to America from Holland are essentially the same, the breeders and importers finally came together and united their interests and agreed to call the breed Holstein-Friesian. If the word Holstein could by agreement be discarded, it would give a more appropriate and simpler name.

The introduction of the Holstein-Friesian to America is unquestionably associated with the early Dutch settlers of New York.

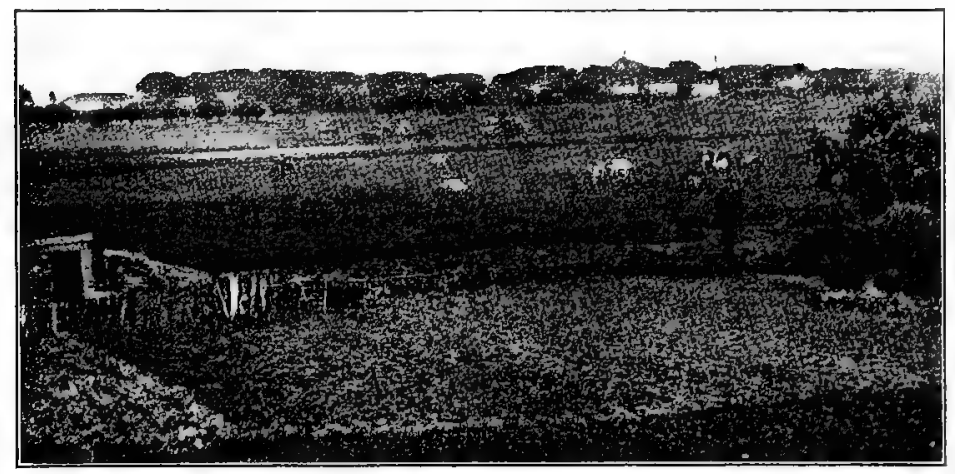

FIG. II4. A view on the meadows of Holland near Rotterdam Photograph by the author

Black or black and white cattle for two centuries have been owned in New England and the east, where they have been known as Dutch cattle. Late in the seventeenth century, when the Mohawk Valley of New York was settled by the Dutch, they probably brought cattle with them from Holland. In I 795 the Holland Land Company sent two bulls and six cows to John Lincklaen of Cazenovia, New York, who was an agent in charge of lands of the company there. Descriptions would indicate these to be much of the type of to-day. In I 8 Io a bull and two cows were imported by Consul William Jarvis and taken to his farm at Weathersfield, Vermont. About I 825 Herman Le Roy made an importation, part being taken to the Genesee Valley, New York, and the rest kept 
near New York City. A later importation was made to Delaware. Honorable W. W. Chenery of Belmont, Massachusetts, imported one cow in $185 \mathrm{I}$, and in 1857 and 1859 two more, which were destroyed by the government, owing to pleuro-pneumonia; but

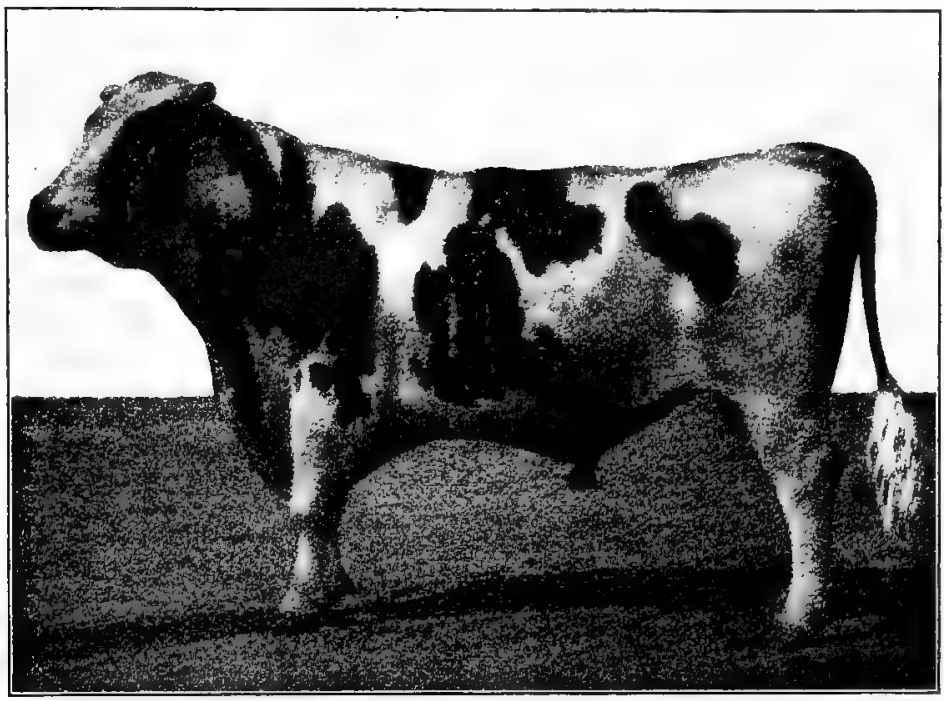

FIG. II 5- Sarcastic Lad 2397\%, grand-champion Holstein-Friesian bull at the Louisiana Purchase Exposition, I904, and sire of a number of daughters in the Holstein-Friesian advanced registry. Owned by Illinois University. Photograph by the author

in 1861 he made another importation which became a permanent herd. In 1867 Gerrit S. Miller of Peterboro, New York, secured cattle from Holland. Beginning with the early seventies, cattle were imported in considerable numbers from Holland until near the close of the nineteenth century, when the trade materially declined.

The characteristics of the Holstein-Friesian are distinct and peculiar to the breed. In general appearance animals of the breed are large, often have great udders and milk veins, are black and white in color, and show remarkable milk-producing capacity. The head is usually lean, tends to be somewhat long with straight nose and dark mottled or flesh-colored muzzle, is wide between the eyes, and carries a white horn usually black tipped. The 
horns should be short, gradually taper, and curve out, forward and inward and slightly upward. A coarse horn is not common. The neck of the male is usually rather large with a distinct arch, while that of the female is moderately slender. The shoulder is frequently heavy and prominent, laying back in well, with withers of moderate thickness, being neither fine nor thick. The body is large with long, well-sprung ribs, showing great feeding capacity. The hips are often prominent, the rump long and level, the thighs inclined to be somewhat thick with more quarter than obtains with other dairy breeds. The udder is frequently very large, and with maturity shows a pendant form after the shape of a letter $U$, with the teats placed at the corners on the same. With this form the fore udder lacks extension. The milk veins

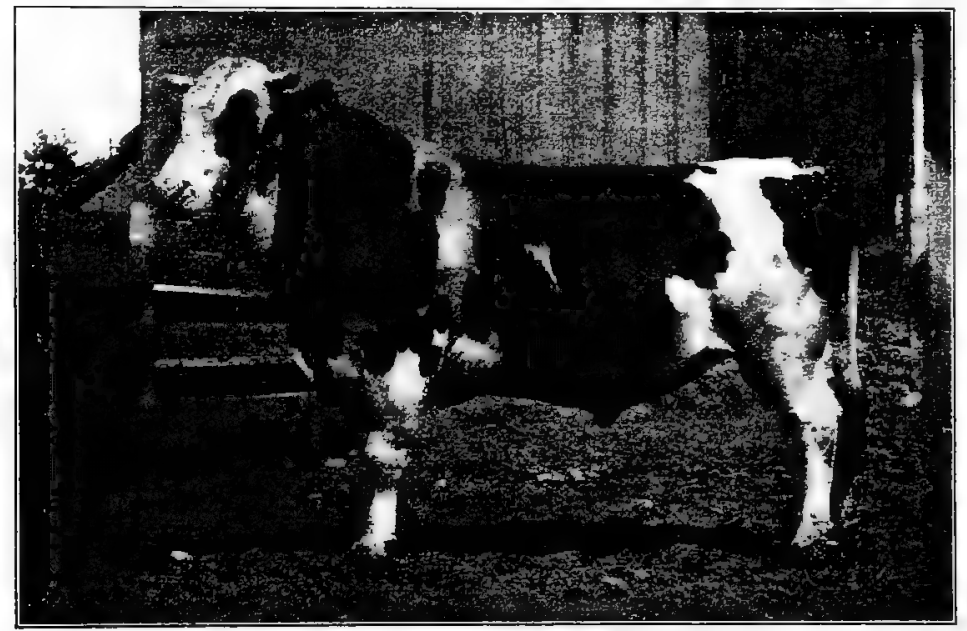

FIG. 116. Sir Soldene Wayne De Kol 27I7I, Holstein-Friesian bull. Owned by the Ohio State University. Second prize in class at the Pan-American Exposition, 1901, and frequently first prize and champion on the 1902 fair circuit. Photograph by the author

average large, but are not longer or more crooked than in other breeds. The color in America is almost always black and white in patches, white with some animals prevailing, while black prevails more with others. In Holland red and white animals of the breed exist, and several pure-bred herds of the color are 
maintained, to the exclusion of black and white. In quality the Holstein-Friesian is too frequently deficient, as exhibited in coarse hair, large joints, and thick skin lacking in mellowness. In temperament this compares favorably with other dairy breeds.

The size of the Holstein-Friesian places it among the largest breeds of cattle. The writer for many years has recorded the birth weights of calves, including six breeds. Of these the Holstein-Friesian has produced the largest, one weighing 125 pounds the day calved. Mature bulls often weigh very heavy. Kate Spray's Paul De Kol, when owned by the Ohio State University, attained a weight of 2600 pounds and never was fat. The bull Constantyn 2040 H.H.B., when six years old, weighed 27I5 pounds. Netherland Prince 7 I6 H.H.B., the most famous bull imported twenty-five years ago, at eight years weighed 2050 pounds. A reasonable and moderate weight for the aged bull ranges from 1900 to 2000 pounds. Like the males, the females of the breed sometimes attain great size. The cow Rosa Bonheur $5^{\text {th }}$ I 1227 weighed as high as 1850 pounds while owned by the Michigan Agricultural College, while Belle Sarcastic 23039, owned by the same college, weighed 1900 pounds when fat. These cows, however, are extreme cases. Among noted cows of the breed at maturity Pietertje 2 d 3273 H.H.B. weighed 1365 pounds; De Kol 2d 734 H.H.B., I 240; Pauline Paul 2 I 99 H.H.B., I450; Aaggie 90 I H.H.B., I 375 ; Echo I 2 I H.H.B., I920; and Princess of Wayne 954 H.H.B., 1370. For mature cows a weight of 1250 to 400 is acceptable, some families tending to weigh heavier than others. The average weight of the cows five years old or over recorded in the fourth volume of the advanced register is given as 1262 pounds.

Some measurements of Holstein-Friesian cows of interest are published by the association promoting the breed. The average measurements of cows in Vol. IV advanced registry are as follows :

Height, perpendicular, at shoulders . . . . . 51.8 in.

Height, perpendicular, at hips . . . . . . . . 53.0 "

Length of body, extreme point shoulder to point rump 64.9 "

Length of rump, front hips to extreme point rump . 21.4 "

Width of hips . . . . . . . . . . . . . 21.9 "

Girth of heart at smallest chest circumference . . 75.6 " 
The Holstein-Friesian cow as a producer of milk, in quantity leads all other breeds and occupies a class by herself. Wonderful records have been reported during the past twenty-five years in America, credited to Holstein-Friesian cows. A few of the leading private tests are as follows:

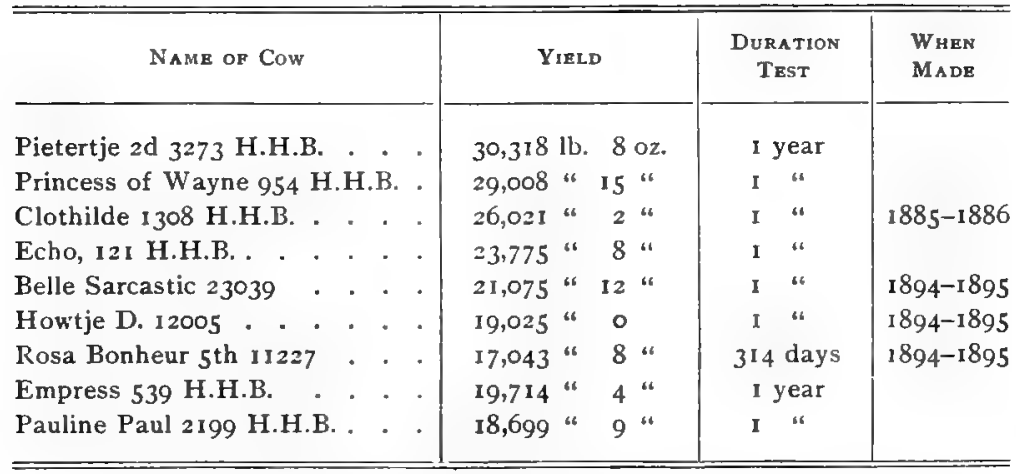

In I90 I a circular issued by the Holstein-Friesian Association stated that 77 cows had been received to advanced registry that had produced from I 5,000 to 30,000 pounds of milk in periods of ten months to one year. A fair cow of the breed, when five years old or over, should produce from 7000 to 9000 pounds of milk a year with proper feed and care.

Daily milk yields of Holstein-Friesian cows have been reported up to $122 \frac{1}{2}$ pounds in one day, this being the largest yield reported, credited in private test to Shadeland Boon 2d 8892 H.H.B., owned by Powell Brothers of Pennsylvania. Many cows have produced 60 pounds in a day. In the Louisiana Purchase Exposition breed test the 15 Holstein-Friesians for 120 days averaged 53.4 pounds of milk each daily, compared with 4I.5 for the Jerseys and 44.2 for the Brown Swiss.

The Holstein-Friesian as a butter producer takes high rank on account of the large yield of milk. The milk is not rich in butter fat, possessing an average range of from three to four per cent. Some families tend to produce a milk poor in fat, while others show a greater amount. The fat globules in this milk rank in the smaller class, and do not cream by gravity so rapidly as 
Jersey or Guernsey milk. In total butter-fat or butter production, however, large records have been made. The largest annual butter record reported in any breed is that of Pauline Paul 2 I99 H.H.B., said to have produced in private test in one year I I 53

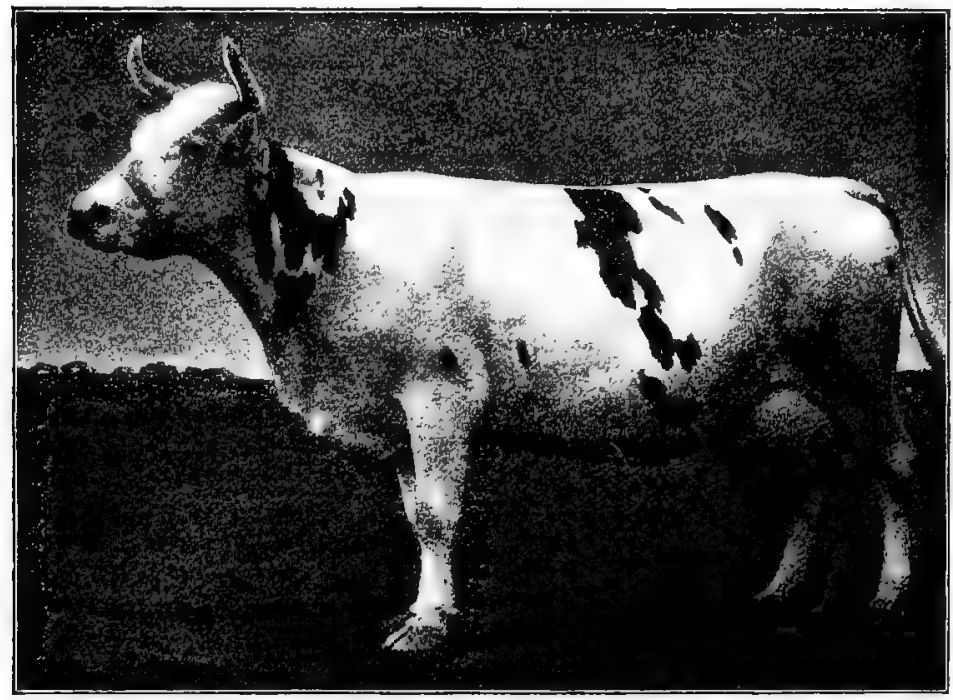

FIG. I I7. Jolie Johanna 36779 , grand-champion Holstein-Friesian cow at the Louisiana Purchase Exposition, 1904. In the working dairy at the exposition, in 120 days, this cow produced 6630.6 pounds milk, yielding 221.6 pounds butter fat. Photograph by the author

pounds $15 \frac{3}{4}$ ounces of churned and salted butter. Aaggie Cornucopia Pauline 48426 holds the largest weekly Holstein-Friesian butter record, that of 34 pounds 5.2 ounces in this time. She also has a one-day record of 6 pounds $6 \frac{1}{2}$ ounces of butter.

The immense yields of milk and butter reported in private test are open to the same objections as have been raised against those made by other breeds.

The official testing of Holstein-Friesians by agricultural experiment stations or college supervisors has resulted in establishing a large number of official records worthy of credence, which show something of the ability of animals of the breed. Among the official weekly records based on butter-fat tests, estimated to 80 per cent butter fat, the following are of interest : 
Aaggie Cornucopia Pauline 48426. Yield $34 \mathrm{lb} . \quad 5.2$ oz. butter

Mercedes Julips" Pietertje 2166. . " 29 " 5.7 " "

Beryl Wayne II77 . . . . . . " " 27 " 14.0 "

Alta Posch r 882 . . . . . . " " 627 " 27 I.2 "

Netherland Hengerveld II33 . . " " 26 "

De Kol 2d 412 . . . . . . . " " 26 " 9.2 " 96

Lilith Pauline De Kol 1415 . . . " " 26 " 96.6 "

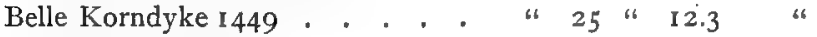

Mutual Friend 2d 96I . . . . . " " 25 " 12.2 "

Susie De Kol 1325" . . . . . " " 25 " 429 " 4

Canary's Mercedes II 09 . . . . " " 25 " 2.6 "

The largest record for a two-year-old is 27 pounds 0.7 ounces, estimated 80 per cent butter, from the heifer Alta Posch 1882.

In the Louisiana Purchase Exposition dairy test the average per cent of fat in the Holstein-Friesian milk in the I20 days' butter test was 3.4 per cent. In this test the cows of the Dutch

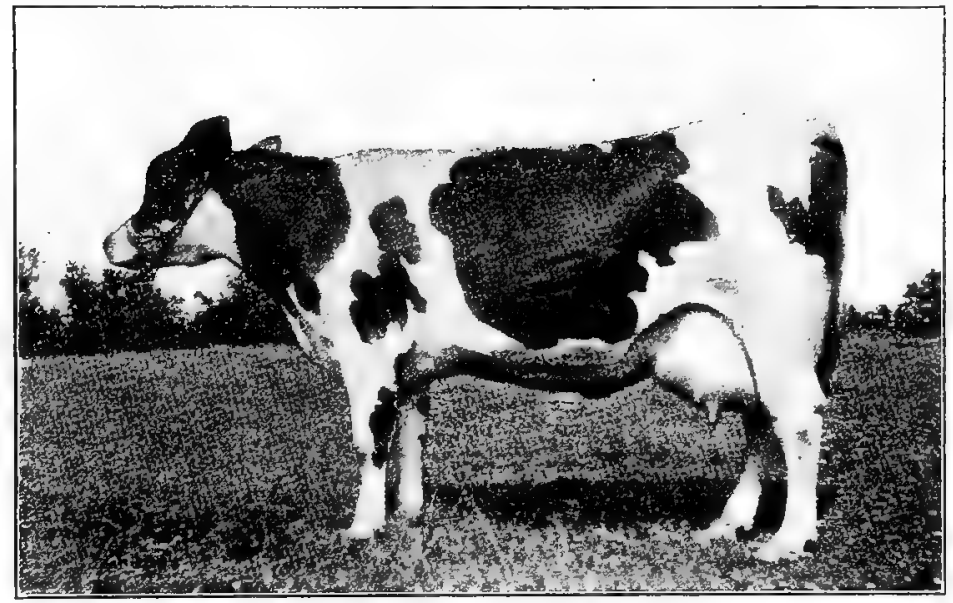

Fig. I I8. Colantha 4th's Johanna 48577, a Holstein-Friesian cow, owned by W. J. Gillett \& Son, Rosendale, Wisconsin. In I90I, in three-year age this cow produced $12,887.7$ pounds milk, testing 444 pounds butter fat. Photograph by the author

breed made an average of $\mathrm{r} .832$ pound fat per day, or 2 . I 2 pounds estimated butter. The Holstein-Friesian cow Shadybrook Gerben 43753 in the 120 days produced 8 IOI.7 pounds milk, containing 282.6 pounds butter fat, the largest record made by any cow of any breed, showing a net profit of $\$ 46.02$ over cost of production. 
Holstein-Friesian milk for cheese is very extensively used in Holland, where large quantities of Edam, Gouda, and other cheeses are made and shipped all over the world. This milk contains a large percentage of solids not fat, and so makes a very nutritious cheese, though its food value would be increased by a greater percentage of fat in the milk.

Holstein-Friesians as beef producers do not rank well in America, any more than do the other dairy breeds. There is too much waste in killing, with too much bone and intestinal fat. Young

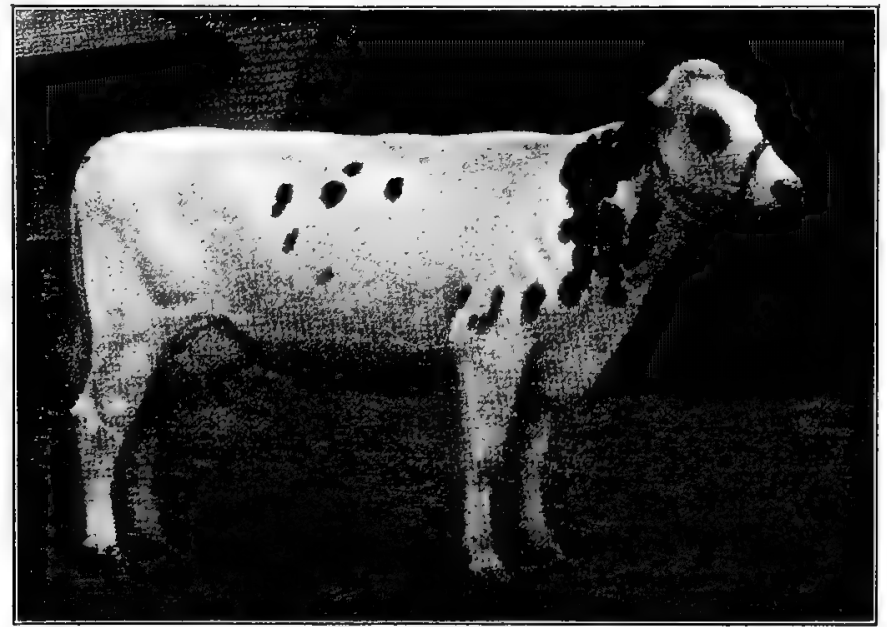

FIG. I 19. Kate Spray $5^{\text {th }} 67832$, first-prize Holstein-Friesian heifer at Ohio State Fair in 1905 . Owned by W. B. Smith \& Son, Columbus, Ohio. Photograph by the author

Holsteins, however, make excellent veal, and the author has rarely eaten veal in America equal to that commonly served in hotels in Holland. In valuations placed on Holstein beef fed by the Iowa Agricultural College, experts rated it eighth among nine breeds, the Jersey coming last. Holstein-Friesians will gain in weight but will not produce the desired quality of beef to suit the buyers.

The grade or cross-bred Holstein-Friesian may be an improvement over the dam, if a pure-bred bull be used. The wisdom of this breeding, however, depends on the purpose. If for milk production, by means of pure-bred bulls a high-grade, very 
profitable herd may be produced. In the vicinity of large cities are to be found herds of high grades that produce large yields of milk for the retail trade. By selecting sires coming from families yielding milk superior in quality as well as quantity, more favorable results may be expected than if no care in

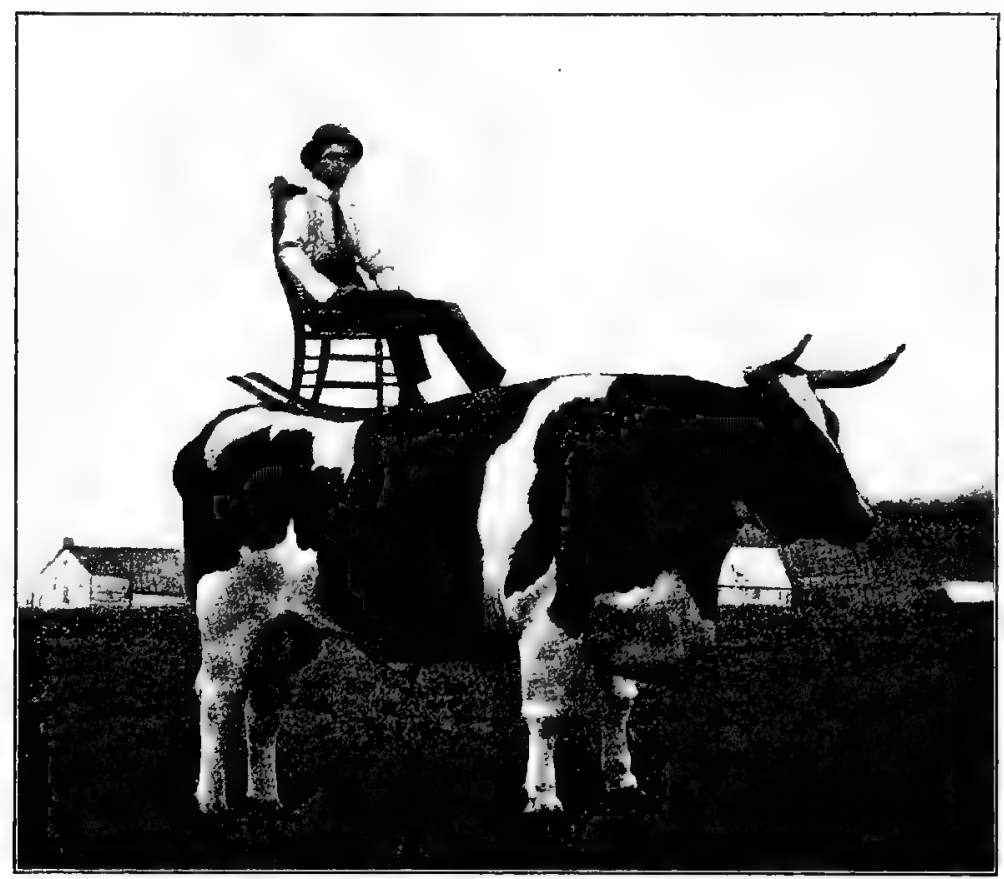

FIG. I 20. The pure-bred Holstein-Friesian ox Jerry, owned by J. D. Avery, Buckland, Massachusetts. This ox is reported to measure $17 \frac{1}{2}$ hands high, to girth $10 \frac{1}{4}$ feet, and to weigh 4365 pounds. On a good road he will easily walk a mile in 30 minutes. Photograph from Mr. Avery

selection is practiced. Owing to their size, the bulls should not be mated to animals of smaller breed type.

Holstein-Friesian oxen are in favor in some localities where cattle are employed in draft work. Mr. James D. Avery of Massachusetts, who has long used them, testifies highly to the worth of the breed for this purpose. A pure-bred ox of his, named Jerry, at nine years old weighed 4365 pounds, stood $17 \frac{1}{2}$ hands high, was ro feet 3 inches in girth and I 5 feet I I inches long. 
The breeding power of the Holstein-Friesian and maturing qualities are about average. The calves do not mature as rapidly as most of the dairy breeds, but stand well in ability to reproduce and give extended service in breeding. The heifers usually come into milk at about 26 to 30 months old, though some prefer earlier.

Among the great breeding Holstein-Friesian bulls special mention should be made of the following as leading sires having numerous officially tested daughters recorded in the advanced registry: Aaltje Salo 3ds Tritomia Netherland 19856, De Kol 2 ds Paul De Kol 20735, Paul De Kol 14634, Paul Beets De Kol 22235, Aaggie Beauty 2d's Statesman I8I69 and Hengerveld De Kol 23102.

Each of these bulls has sired a large number of cows that have made tests, ranging from 50 with the first listed to I I with the last.

Holstein-Friesian families of prominence may be mentioned as follows, though there are others of equal note: Aaggie, descended from Aaggie 901 ; Netherland, from Lady Netherland 1263 ; Clothilde, from Clothilde I 308 ; Johanna, from Johanna I42I; Wayne, from Queen of Wayne 955 H.H.B.; Pauline Paul, from Pauline Paul 2 I 99 H.H.B.; De Kol, from De Kol 2d 734; Schuiling, from Schuiling 3350; and Pietertje, from Pietertje 2d 3273. Each of these families has many distinguished representatives.

Organizations for the promotion of Holstein-Friesian cattle first developed in America. About 1872 a number of men in the eastern United States, led by W. W. Chenery of Massachusetts, organized the Association of Breeders of Thoroughbred Holstein Cattle. In 1872 the first volume of the Holstein herdbook was published. Nine volumes in all were issued, the last appearing in I 885. In 1879 a number of men who had been importing and breeding Dutch cattle, who disapproved of the word Holstein as being illogical and out of place, organized the Dutch Friesian Cattle Breeders' Association and in I 880 published Volume I of the Dutch Friesian Herdbook, of which four volumes were issued, the last in 1885 . After more or less friction, in view of the fact that each organization was bringing over the same class of cattle, a conference was held in 1885 and the two associations amalgamated under the name of the Holstein-Friesian Association of North America. Since I 885, up to January, I905, twentytwo herdbooks have been issued by the combined association. In 
I 875 an association was organized in Holland under the name of the North Holland Herdbook Association. In I 885 an American branch of this was organized, and Volume I of the American Branch of the North Holland Herdbook was published in I888. There is also an organization in Canada, - the Holstein-Friesian Association of Canada, founded in I89I, which has published seven herdbooks to 1905. Besides the above the HolsteinFriesian Association of North America publishes an advanced registry, established in $\mathrm{I} 885$, of cows that have made official butter tests under expert, impartial supervision. This registry also contains lists of sires of tested cows. The first volume was published in $\mathrm{I} 887$, followed by three other separate volumes, after which the advanced registry was for a time incorporated in the regular issue of the herdbook. In Volume I 3 I bulls and 300 cows were registered. Recently the Holstein-Friesian records have been published in an annual yearbook.

The distribution of Holstein-Friesian cattle outside of Holland is mainly in Belgium, northern Germany, and parts of Russia, while the breed is widely distributed over North America. For years important breeding herds have been kept in New York State, a recognized Holstein-Friesian center. Large herds are also kept in Ohio, Pennsylvania, Wisconsin, Illinois, Missouri, Michigan, New Jersey, and Massachusetts. In extensive dairy districts and near large cities herds of this breed are most common. While not so well suited to hot, dry climates, and to rough, poor lands, Holstein-Friesians seem to thrive over a wide range, for herds are successfully kept from California to Maine and from Canada to Mexico. Naturally abundance of food is essential for this large type of cattle.

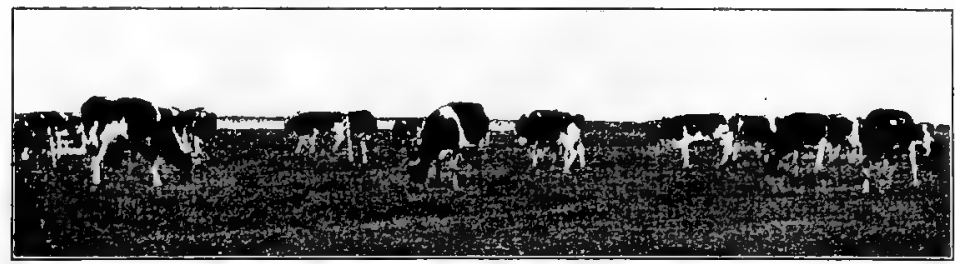

FIG. I21. A pasture view of the Holstein-Friesian herd of K. N. Kuperus in Holland, one of the best-known Dutch breeders. Photograph by the author 


\section{CHAPTER XXXVI}

\section{THE GUERNSEY}

The native home of Guernsey cattle is on the islands of Guernsey and Alderney, in the Channel Islands group, off the coast of France in the English Channel. The island of Guernsey, on which they are mainly bred, is triangular in form and is about nine and one half miles long from southeast to northwest, and six across in the widest part. The south coast is a long cliff, reaching a height of 270 feet, the land roughly sloping northward to a low beach. There is a population of about 35,000 on the island, St. Peter Port is the main town, and the people beside producing cattle, make a specialty of crops under glass, such as grapes, tomatoes, melons, flowers, etc., for the London market. Guernsey is second in size to Jersey, contains, with one or two little islands, 12,600 acres, and maintains some 5000 head of cattle. The climate is most balmy the year round, the island being a famous health resort. The cattle are kept in small herds, each animal being tethered when in pasture, grazing systematically and making careful use of all food.

The origin of the Guernsey, like that of the Jersey, is quite obscure, but is supposed by many to have been derived from the same French ancestry of Brittany and Normandy cattle. It is assumed that the red color and size of the breed are derived from the use of bulls from Normandy taken to the island in very early times. Like the Jersey, the Guernsey for many years has been protected at home by the exclusion of all other breeds. Any live cattle brought to the island, excepting from Alderney, must be slaughtered within twenty-four hours. By a long-continued process of selection a larger type of cattle than Jerseys has been produced, yet these have much in common with that breed.

The systematic improvement of the Guernsey was materially promoted by the organization of the Royal Guernsey Agricultural 
and Horticultural Society, which sought to establish the breed on a uniform and high basis. Annual exhibitions are held, the cattle on the island compete, and the best individuals are carefully inspected and given proper distinction and prizes according to merit.

The introduction of the Guernsey to America dates back early in the last century. In I824 Reuben Haines of Germantown, Pennsylvania, wrote in the Memoirs of the Pennsylvania Agricultural Society that he "procured a pair of cattle of the Island

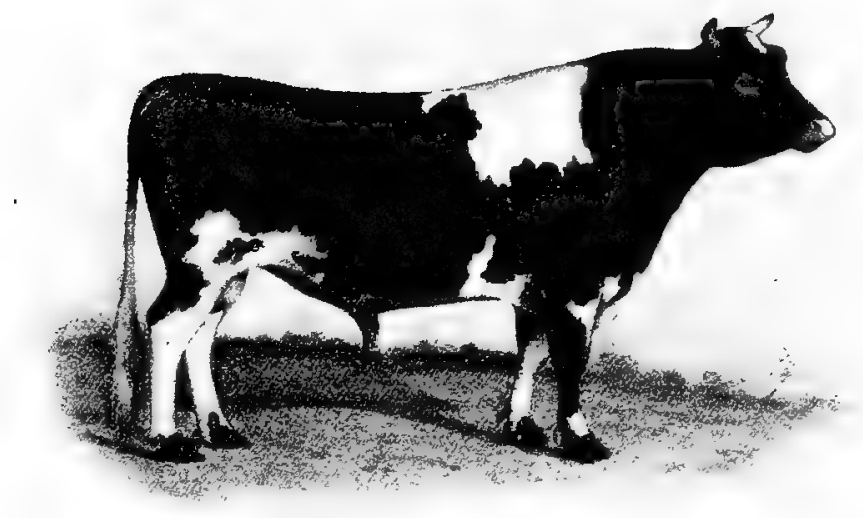

FIG. I 22. Sheet Anchor 2934, a famous Guemsey sire and show bull. Owned

by H. McKay Twombly, Madison, New Jersey. Photograph by Schreiber

of Alderney" and soon satisfied himself that no breed in the country would bear a comparison with them. These were imported in I8I8, and may be regarded as Guernseys in fact, inasmuch as cattle on the Alderney Island are to-day registered in the island of Guernsey herdbook. According to publications of the American Guernsey Cattle Club, cattle were brought to America from Guernsey about 1830 , but concerning these no special record was made. About i 850 a few were brought to the vicinity of Philadelphia, and after I 865 more began to be imported to the seaboard states. About I865 E. P. P. Fowler 
and P. H. Fowler began importing. Soon after J. M. Codman of Boston, E. F. Bowditch of South Framingham, Massachusetts, and T. M. Harvey of Chester County, Pennsylvania, began to import. In 1877 a few energetic breeders came together in New York City and organized the American Guernsey Breeders' Association. At the annual meeting in December, 1877 , it was reported that 193 Guernseys were registered by the secretary, I I 4 of which were imported. Then for years the interests of the breed met with but slow growth, until about I893, when public interest was much excited by the record made by Guernseys in the dairy cattle tests at the World's Columbian Exposition at Chicago.

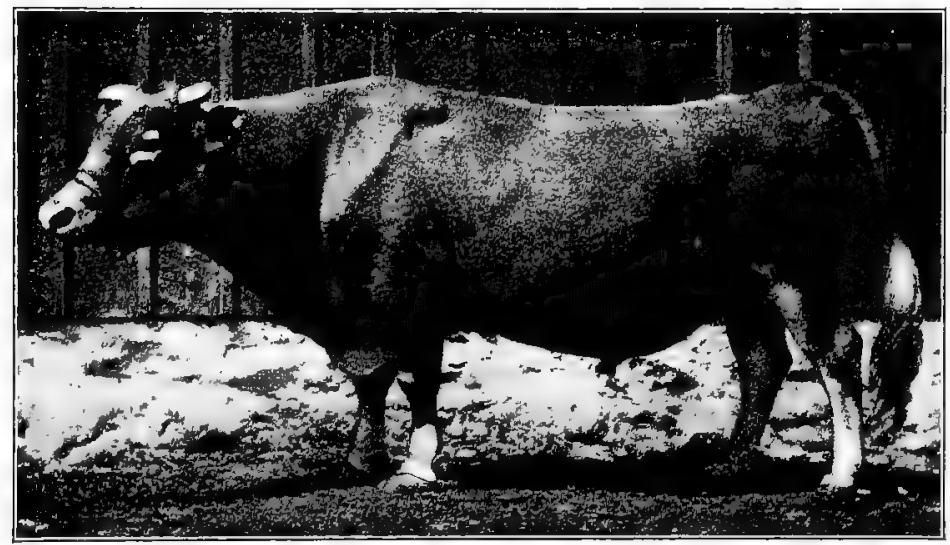

FrG. I23. Coralette's Son 3987, second-prize aged Guernsey bull at the Louisiana Purchase Exposition, 1904. Bred and exhibited by G. C. Hill \& Son, Rosendale, Wisconsin. Photograph by the author

Characteristics of Guernseys. In general appearance the cattle of this breed are larger than Jerseys, are coarser of style, show more constitution, and have a different shade of fawn color. The color is either yellowish, brownish, or reddish fawn, the latter prevailing, frequently with white markings or with white on the limbs or under part of the body. The muzzle is buff or flesh colored and is surrounded by a whitish or yellowish circle of hair. The eyes also are usually encircled by a similar marking. The horns should be white or amber colored, and are often tinted a deep yellow, curving gracefully around inward and slightly 
upward with the cows, though the bull's horns are shorter, stronger, and less curved. The hoofs should also be of amber color. A rich yellow secretion is most characteristic of the Guernsey, breeders laying much emphasis on it in the scale of points. The color of skin, as shown generally, and especially in the ears, about the udder or scrotum, and at the end of tail, is a very deep yellow. The udder of the Guernsey is larger and shows more fore-udder development and larger teats than does the Jersey, though not materially differing in quality. In general quality cattle of this breed show very mellow, thin, elastic skins, moderately fine hair, frequently heavy shoulders and have somewhat larger and coarser limbs than the Jersey. The temperament is superior, the males perhaps being hardly as nervous and irritable as are Jersey bulls, although the dairy temperament is characteristic with each sex.

The size of the Guernsey most acceptable to the American Guernsey Cattle Club is about 1500 pounds for a bull four years old or over, and ro5o pounds for a cow of the same age class, these being the score-card standards.

The quantity of milk produced by the Guernsey may be very considerable. The cows are retentive milkers and produce rather freely. In general, a yield of 5000 pounds a year should be easily averaged in a herd. Some rather large individual records have been produced in recent years, among which the following are noteworthy:

\begin{tabular}{|c|c|c|c|c|c|c|c|c|}
\hline Name of Cow & & & & & & $\begin{array}{c}\text { Agr During } \\
\text { Period }\end{array}$ & YIELD MILK & TiмE \\
\hline Yeksa Sunbeam I5439 & - & . & . & - & . & 9 & $14,920.80 \mathrm{lb}$ & I year \\
\hline Lily Alexandre 1059 & . & . & & - & & & $12,856.00 "$ & I " \\
\hline Lilyita $724 \mathrm{I}$... & . & . & - & . & . & 5 & $12,812.73$ & “ \\
\hline Miss Bobolink 2157 . & - & . & . & . & - & 13 & $12,437.00$ & “ \\
\hline Lily Ella 7240 . . . & . & . & - & . & . & 5 & $12,282.62 "$ & 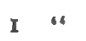 \\
\hline Gypsy of Racine 9639 & . & - & - & . & • & 8 & $12,247.50 "$ & “ \\
\hline Glenwood Girl 6th 9II3 & & . & . & . & • & 5 & $12,184 \cdot 30 " 6$ & $" 1$ \\
\hline
\end{tabular}

About 20 cows of this breed are reported as producing 10,000 or more pounds of milk a year. For average yearly herd records 
Major Alvord reports one herd of 104 animals of all ages making 53 I 7 pounds of milk; another herd of I 5 cows, 6626 pounds; and a third herd of Io averaging 6347 pounds. Yields are also given of from 48 to 52 pounds per day.

The Guernsey as a butter producer is entitled to special distinction. In numerous tests at experiment stations, on farms under official supervision, and in public competition the breed has attained very high honors. Guernsey milk is usually of a higher natural yellow color than that of any other breed equally common, due to its butter-fat content. The fat globules are large and have a deeper yellow than even the Jersey. In fact

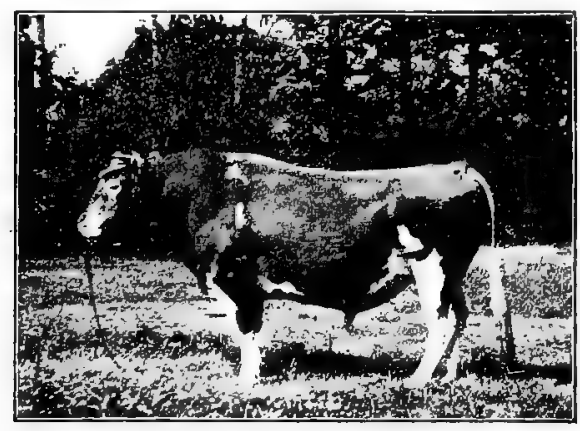

FIG. I 24. Island Champion 62623. Before importation this bull, who had won the highest honors on the island, was known as Masher II. Photographed on the island of Guernsey by the author
Guernsey breeders seek the rich yellow as a characteristic, arguing that with this breed it is not necessary to color the butter, as its natural yellow meets the market demands. In the PanAmerican dairy breed competition, in which the Guernseys secured first honors, the average per cent of fat in the milk was 4.68 , compared with 4.82 for the Jersey and 4.75 for the Polled Jersey. However, the Guernsey butter scored an average of 96.34 total points, compared with 95.80 for the Jersey; while in color that of the Guernsey had an average grade of 14.97 out of a possible $I 5$ points, the best record of any of the ten breeds. The five Guernsey cows in the Pan-American test for the six months produced I 429.43 pounds of churned butter, valued at $\$ 357.36$, yielding a net profit of $\$ 220.37$, the best record of any breed in profit, and almost the first record in amount of butter produced, the Holstein-Friesian leading in this regard by only three fourths of a pound. In this test of 50 cows of ten breeds the Guernsey cow Mary Marshall 5604, aged Io years, led the list, 
producing in six months 56 I I pounds of milk, testing 5.36 per cent and yielding 30 I.I 3 pounds butter fat and 354.26 pounds churned butter, giving a total profit of $\$ 59.43$.

Yearly butter herd records of Guernseys furnish important testimony. In 1896,83 cows and heifers of L. P. Morton of New York averaged 3 I 3 pounds of butter, and 35 cows in 1898 averaged 5 I 4 pounds. The entire herd of Ezra Michener of Pennsylvania, for ten years has averaged 325 pounds per head. Twelve head of Hill \& Son of Wisconsin, in 1893, averaged 382.2 pounds; I9 head of Sydney Fisher of Canada, 300 pounds ; 16 head of N. I. Bowditch of Massachusetts, 397. I pounds; and 28 cows of $\mathrm{H}$. McKay Twombly, 376.6 pounds. It may be safely estimated that a fair Guernsey herd will average at least 300 pounds of butter per head per year, and should do better.

While this breed has not been tested as much as either Jersey or Holstein-Friesian, it has made some large butter records, from which the following are selected as notable.

Notable Guernsey Yearly Butter Records

\begin{tabular}{|c|c|c|c|c|c|c|c|c|}
\hline \multicolumn{4}{|l|}{ Name of Cow } & \multirow{2}{*}{$\begin{array}{c}\text { AGE } \\
9\end{array}$} & \multicolumn{2}{|c|}{$\begin{array}{c}\text { AVERAGie } \\
\text { FAT IN MILK }\end{array}$} & \multirow{2}{*}{$\begin{array}{c}\begin{array}{c}\text { Total } \\
\text { FAt }\end{array} \\
857.1\end{array}$} & \multirow{2}{*}{$\begin{array}{c}\begin{array}{c}\text { ESTIMA TED } \\
\text { BUTTER }\end{array} \\
\text { I0OO.0 } \mathrm{lb} .\end{array}$} \\
\hline Yeksa Sunbeam 15439 & & . & & & 5.74 & r cent & & \\
\hline Lily Ella 7240 . . . & & . & & 5 & $6.4^{2}$ & “ & 782.2 & $912.5 ،$ \\
\hline Lilyita $724 \mathrm{I}$. . . . & • & . & & 5 & 5.69 & 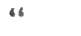 & 710.5 & 828.9 \\
\hline Charmante of the Grove & I4 & 442 & & & & & 676.5 & 789.2 “ \\
\hline Gypsy of Racine 9639 & & . & • & 8 & 5.45 & “ & 611.4 & $713.3 “$ \\
\hline Bretonne 3660 . . . & & $\bullet$ & & 9 & & & 602.9 & 703.4 “ \\
\hline Buda 7178 & • & . & • & 6 & 6.96 & “ & 602.7 & $703.0 \cdots$ \\
\hline Portia of Maplehurst 100 & & & " & 4 & & & 602.4 & $702.8 ،$ \\
\hline Miss Bobolink 2157 & - & - & - & 13 & 4.80 & 4 & 596.9 & 696.5 “" \\
\hline Glenwood Girl 6th 9113 & - & . & - & 5 & 4.78 & “ & 572.2 & 667.5 “ \\
\hline Quibble 6017 . . . & . & . & . & 6 & 5.17 & “ & $545 \cdot 3$ & 636.0 \\
\hline
\end{tabular}

The record of Yeksa Sunbeam, being officially supervised by the Wisconsin Experiment Station, is famous as being the largest official test of butter-fat production recorded for one year. This cow is owned by Mr. Fred Rietbrock of Milwaukee, Wisconsin. 
The most important butter record of a two-year-old Guernsey for one year, is that of the heifer Dolly Bloom I 2770 , which, from March 26, 1902, in 365 days produced 8841.58 pounds of milk, which tested 453.86 pounds butter fat, an average of 5.13 per cent.

Seven days' butter records of Guernseys have been made to quite an extent, and many animals listed as having made official tests of 14 or more pounds of butter in this time. Following are some of the more prominent ones:

\begin{tabular}{|c|c|c|c|c|c|c|c|c|c|c|c|c|c|c|c|c|c|c|}
\hline \multicolumn{16}{|c|}{ Name of Cow } & \multicolumn{3}{|c|}{$\begin{array}{l}\text { ButTER } \\
\text { RECORD }\end{array}$} \\
\hline Royalette 3299 . . & . & . & . & . & . & . & . & . & . & . & - & . & . & . & . & & 1b. 12 & oz. \\
\hline Nubia's Vesta 5986 & . & . & . & . & . & . & . & . & . & . & . & . & . & . & . & 25 & ; 8 & “ \\
\hline Gully 5 th 1590 . & . & . & . & . & . & . & . & . & . & . & - & - & . & - & . & 24 & $4 " 12$ & “، \\
\hline Lily Ella $724^{\circ}$. & . . & . & . & . & . & . & . & . & . & . & . & . & . & . & . & 23 & 3 “ $11 \frac{3}{4}$ & “ \\
\hline Bessie de la Pailloteri & & 409 & . & . & . & . & - & . & . & . & . & - & . & . & . & 23 & 3 " 8 & “ \\
\hline Fantine $2 \mathrm{~d} 373^{\circ}$ & . & . . & . & . & . & . & . & . & . & . & . & . & . & . & . & 23 & 36 & “ \\
\hline Fernwood Lily I 468 & - & - & . & . & . & . & . & - & . & . & . & . & . & . & . & 22 & 2" $11 \frac{1}{2}$ & " \\
\hline Select 2205 . . . & . & - & . & . & . & . & . & . & . & . & . & . & . & . & . & 22 & " 8 & “ \\
\hline
\end{tabular}

The cheese value of Guernsey milk ranks very well, although not largely used for this purpose, being mainly turned to butter production or retail milk trade. The milk stands well in total solids, that of whole herds often averaging 14 to I 5 per cent, thus furnishing a satisfactory grade of cheese. The only official test on a large scale, showing the value of Guernsey milk in cheese making, was in I 893 at the World's Columbian Exposition. In this trial, covering I 5 days, participated in by Guernseys, Jerseys, and Shorthorns, the following results of interest were secured :

\begin{tabular}{|c|c|c|c|c|c|c|}
\hline & & $\begin{array}{c}\text { Total Yieid } \\
\text { Chrese }\end{array}$ & $\begin{array}{l}\text { LB. Milk to } \\
\text { I LB. Chegse }\end{array}$ & $\begin{array}{c}\text { Total Value } \\
\text { Cheme }\end{array}$ & $\begin{array}{c}\text { Nat Profit } \\
\text { of Test }\end{array}$ & $\begin{array}{c}\text { Scork of } \\
\text { CheEse }\end{array}$ \\
\hline Guernsey & - & $1130.62 \mathrm{lb}$ & 9.67 & $\$ 135.22$ & $\$ 88.30$ & 87.2 \\
\hline Jersey . . & . . & $1451.76 "$ & 9.16 & I93.98 & 119.82 & 90.7 \\
\hline Shorthorn & . . & $1077.60 ،$ & I 1.3I & 140.14 & $81 \cdot 36$ & 90.5 \\
\hline
\end{tabular}

This record places the Jersey first and the Guernsey second, excepting in grade of cheese, where it ranked third. 
The Guernsey in beef production can have but a subordinate place. A larger and perhaps fatter carcass may be made than with the Jersey, but this presents the same objection as other dairy breeds, - too much offal, a low percentage of high-priced cuts, and, in this case, too yellow fat. In flavor and quality Guernsey beef or veal will rank high.

The cross-bred or grade Guernsey has its distinctive place on the dairy farm. Crossing of breeds is not advisable, but using

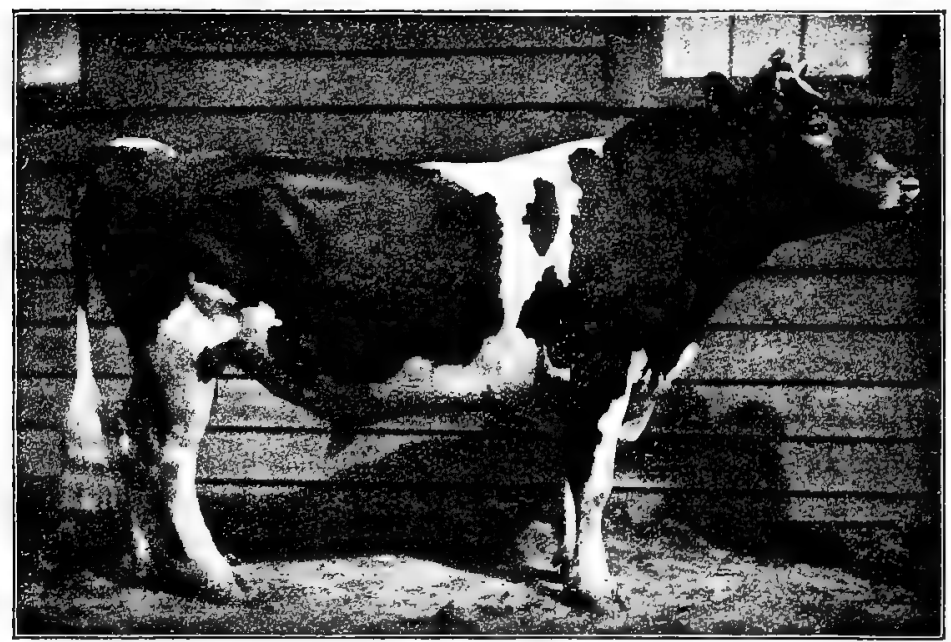

FIG. 125. Guernsey Champion 8218, by Island Champion 6263, grandchampion Guernsey bull at the Louisiana Purchase Exposition, I904. Owned and exhibited by H. McKay Twombly, Madison, New Jersey. Photograph by the author

Guernsey sires on grade cows will give excellent results if intelligently followed, yielding very rich milk eminently suited to butter making or city cream or milk trade. If a sire with strong constitution is selected for use on grade Jerseys, the constitution, size, and productivity of the herd may be improved; if used on grade Holstein-Friesian cows, a herd producing richer milk, though not so much, may be expected.

The early maturing character of the Guernsey is not marked. The young bulls show masculine traits more slowly than the Jersey, and reach maturity somewhat later. 
Guernsey bulls of special distinction in America are not in large number, due to the fact that until recently the breed has not been prominently before the public, and comparatively few

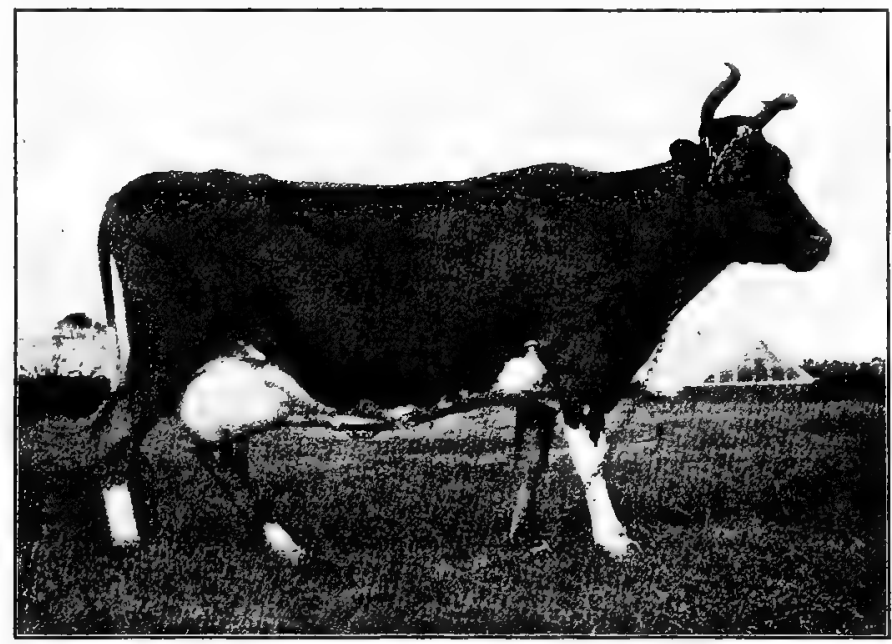

FIg. I26. Princess May I 479 F.S., a choice specimen of a Guernsey cow, and dam of the imported bull Deputy 29I7, at head of the PanAmerican Exposition Guernsey herd. From a photograph taken by the author on the island of Guernsey

elaborate tests of females have been made. The following bulls have attained eminence both as sires and as show animals in the most important exhibitions :

Lord Stranford 2187 (imported) by Chronicler 41 8 P.S.

Benjamin 193I by Jeweler 1274 .

Sheet Anchor 2934 by Lord Stranford 2187.

Mainstay 3789 by Sheet Anchor 2934 .

Lily Ella's Jeweler 5417 by Springunde 4302.

Island Champion 6263 (imported) by Masher 705 P.S.

Prince Rosendale 429I by Viscount 2177.

The distribution of the Guernsey breed is mainly restricted to Guernsey Island, England, the United States, and Canada. For many years large and superior herds have been maintained in England, especially in the midland and southern counties. In the United States the breed is best represented in New England 
and New York, Pennsylvania, New Jersey, and Wisconsin, but is also found occasionally in other states, notably in the East and middle West. Why the Guernsey has not attracted more attention in the United States has never been clear to the author. It is a dairy breed of the highest merit, as repeated tests have shown, yet it is quite limited in development, and does not seem to get much foothold in some of our greatest dairy states, especially in the Mississippi Valley.

Organizations for the promotion of Guernsey interests exist on Guernsey and in England and the United States. The Royal Guernsey Agricultural and Horticultural Society has for many years supervised the registration and promotion of Guernseys on the island. Two herdbooks are maintained, one for

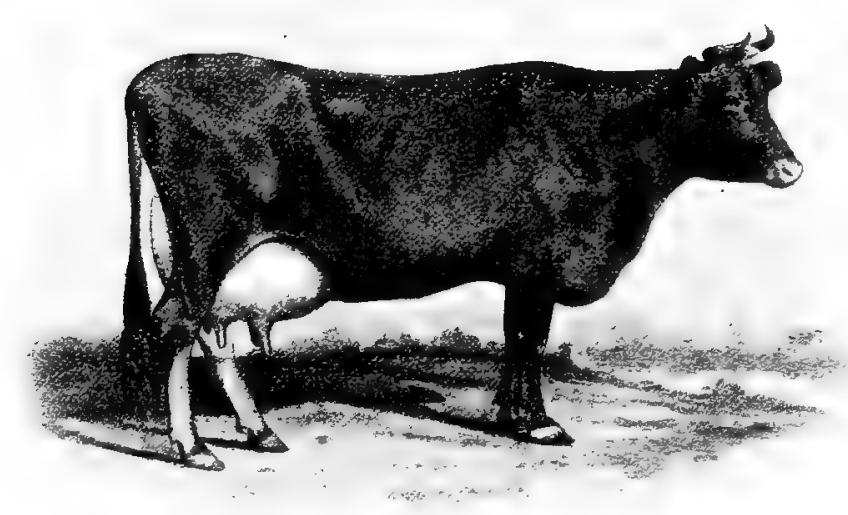

FIG. I27. Rutila's Daughter 6670, a very beautiful Guernsey cow with a record of 8988 pounds milk in one year, testing 489.8 pounds butter fat. Owned by H. McKay Twombly, Madison, New Jersey. Photograph by Schreiber

general registration, the other for advanced registry. The English Guernsey Cattle Society was organized in I 885 and has published twenty herdbooks to 1904 . The American Guernsey Cattle Club was organized in 1877 in New York City, and has published to 1905 about fifteen herd registers, these being issued in 
quarterly parts, since I895, as the American Guernsey Herd Register and Breeders' Jourmal. The American club also maintains an advanced register. Bulls are admitted in two classes: (a) after scaling 80 points and having two daughters in the register ; and $(b)$ without scaling, after two daughters are registered. Cows are placed in two classes : $(a)$ for milk or butter-fat records and scaling over 75 points; and $(b)$ for milk or fat records

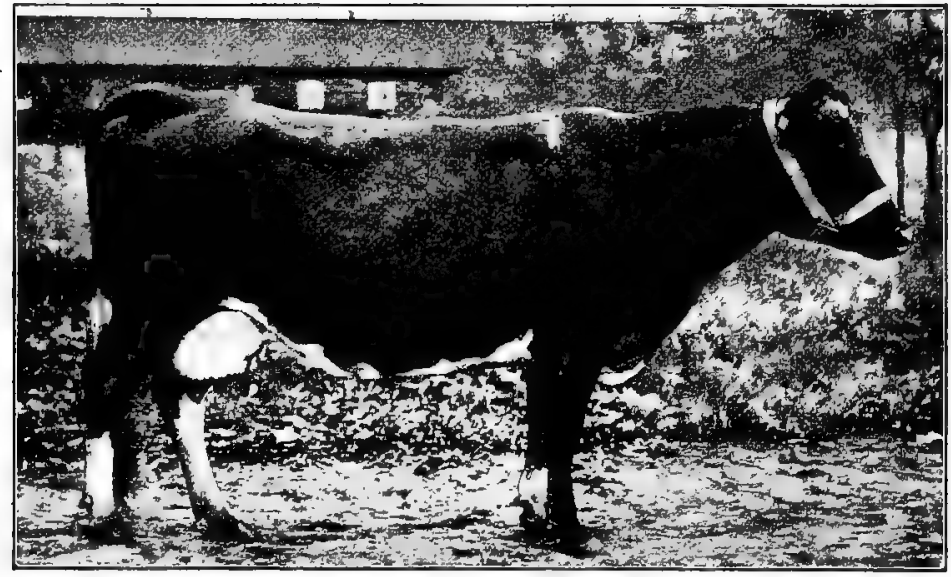

FIG. I 28. Yeksa Sunbeam I 5439, the Guernsey cow holding the world's record for the largest official butter-fat test in one year. During 12 months ending in 1905 she produced $14,920.8$ pounds milk which tested 857.15 pounds fat, equivalent to 1000 pounds butter. Owned by Fred Rietbrock, Milwaukee, Wisconsin. Photograph from the owner

without scaling. The cows must produce from the first day of two years of age, or before, at least 6000 pounds of milk, and this is scaled up to a minimum of I0,0oo pounds for cows five years old or over. So the year's butter-fat record must have a minimum of 250.5 pounds at two years, and 360 for over five. Seven-day fat tests are also provided for. The tests for advanced registry are supervised by agricultural college or experiment station experts. 


\section{CHAPTER XXXVII}

THE AYRSHIRE

The native home of the Ayrshire is in southwestern Scotland in the county of Ayr, from which the breed derives its name. Ayr is triangularly crescent in its shape, its southern tip just touching latitude $55^{\circ}$ north, its western boundary somewhat indented and bordering the Irish Sea and river Clyde, its other sides skirted by the counties of Renfrew, Lanark, Dumfries, Kirkcudbright, and Wigtown. There is an extreme length of about 80 miles, with an area of about I I 50 square miles. Rather poor and sandy land occurs in the southern part toward the sea, while much beautiful rolling pasture land of fair soil is found more inland, and some rougher land on the eastern borders. On the better lands, which are clayey, grass, oats, and wheat are largely grown and there is abundance of summer grazing. The climate is very moist, but the bitterness of a northern winter is somewhat tempered by the sea.

The origin of the Ayrshire has been in the main a complex one. Aiton, the first and almost only early authority on the breed, wrote $A$ Survey of Ayrshive about I8I I. He regarded it as the native breed of Ayr, improved by certain other stock. Some time about I770 Teeswater cattle, Shorthorn, or similar stock were introduced into Ayrshire. John Dunlop of Dunlop is credited with importing cows of large size, of either Teeswater, Dutch, or Lincoln breeds, and in 1805 Dunlop stock is referred to by Forsythe as having been established in the parish of that name for over a century. Other writers claim that the cattle of the Channel Islands crossed with Shorthorns were early used in Ayrshire. About 1818 West Highland cattle were used by Mr. Parton near Dalry, Ayr, on a superior herd of Ayrshires. Devon and Hereford blood are also said to have been used by other breeders. The earliest accounts of the cattle of Ayrshire show 
them to have been black and white. About 1780 red and white became fashionable, while from $\mathrm{r} 785$ to 1805 brown and white mottled cattle were much preferred, and later, in $18 \mathrm{IO}$, red and white was a common color. These latter colors of brown, red, and white have been carried down to the present time. Thus it is apparent that the Ayrshire as a breed is evolved from a variety of blood, mainly from types associated with larger milking capacity.

The early improvers of the Ayrshire were not notably distinguished over the general run of breeders who seek to improve

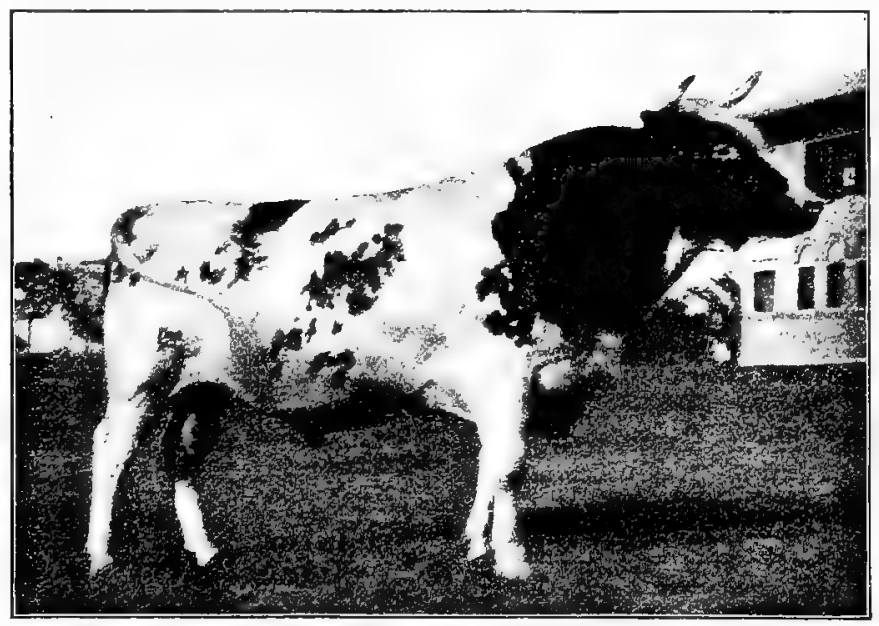

Fig. 129. Dunraven of Ste. Annes 7662, an Ayrshire bull owned by Howard Cook, Beloit, Ohio. This animal has been a prominent first-prize winner and champion at leading shows in 1905 and 1906. Photograph by the author

local cattle. It was early evident that the people laid importance on milk production. Forsythe, a Scotchman, writes in 1805 of cows yielding from 24 to 30 quarts of milk daily; and in I 829 William Harley states that he had cows that occasionally gave 25 to 30 quarts daily, and one day even produced 40 quarts. In 1836 the Highland and Agricultural Society of Scotland offered a large premium to be competed for by the breed. By 1850 Ayrshires were the prevailing stock in Ayr and also in Renfrew and Lanark counties. In 1853 the first systematic effort at improvement came in a scale of points adopted by the Ayrshire 
Agricultural Association. In I 866, in a prize essay on county Ayr, Archibald Sturrock writes that "a capacious and well-set udder is certainly the chief point of excellence in the Ayrshire cow."

The introduction of the Ayrshire to America probably first occurred early in the last century, when Scotch settlers moved to Canada. In the Memoirs of the Pennsylvania Agricultural Society for 1824 considerable discussion is devoted to breeds of cattle, yet the name Ayrshire is not used. John Hare Powell, the secretary, who had studied the breeds in Europe, says, "I have traced every importation of which I have heard," and makes special reference to eight different states and various breeds, but does not mention the Ayrshire. Sturtevant states that the first importation into the United States is thought to have been made in 1822 by $\mathrm{H}$. W. Hills to Windsor, Connecticut. In 1837 the Massachusetts Society for Promoting Agriculture imported one cow, which is reported to have yielded sixteen pounds of butter a week for several weeks. Lewis F. Allen of New York writes that in 1837 he visited the Ayrshire herd of John P. Cushing near Boston, Massachusetts, who had imported from Ayrshire regardless of price. In I $848 \mathrm{E}$. A. Brown introduced Ayrshires to Ohio, these being the first of this dairy breed to enter the state.

Characteristics of Ayrshires. Mature cattle of this breed impress one as of medium dairy size, as large milk producers, and yet with more of a beefy tendency than some other dairy breeds. The color includes red, brown, and white. In I 875 Sturtevant quoted as follows from a letter from Robert Wilson, a breeder in Scotland:

Colors of Ayrshires are much the same since I can remember; different breeders have their particular color. Light yellow, though common with some breeders, is not the most common color. Red and white flecked, though it should incline a little to yellowish or brown, is more a prevailing color of the breed. ... White, if there be not roan mixed with it, I do not consider a proof of the presence of Shorthorn blood. Our favorite colors are white flecked or red bodies and white legs. Dark reds and black muzzles are favorites also.

In 1875 Sturtevant published statistics of a color classification of 2852 Ayrshires in the United States, of which 2014, or 70.61 per cent, were red and white ; 222 , or 7.78 per cent, red or mostly 
red; $24 \mathrm{I}$, or 8.45 per cent, brown and white; and 194 , or 6.80 per cent, white and red, the balance being split into various colors. Secretary Winslow of the Ayrshire association in the I902 yearbook reports that the color that seems to please the majority is dark red and pure white, about one third white in splashes. In Canada and Scotland a strong admixture of white is popular. The horns are white with black tips, curve outward and upward, and often, especially with cows, turn back at the tips. They frequently appear both long and rather large. Winslow states that

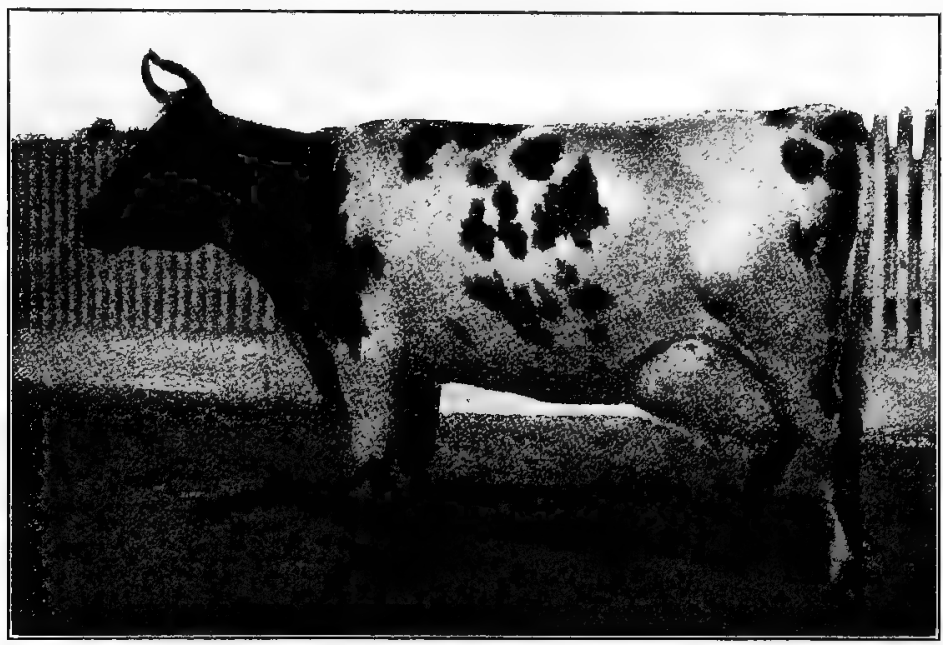

FIG. 130. Gladys Drummond I 1800, an Ayrshire cow, successfully shown by

J. F. Converse \& Co., Woodville, New York. Photograph by the author

the size is a matter of local taste, either fine or coarse, the Scotch or Canadians preferring a larger horn than do the people in the States. The body of the Ayrshire is capacious, the ribs being long and well sprung, the rump usually high, broad, long, and level, while the thighs and the hind quarter partake somewhat of fleshiness. The depth of body often appears great, with a relative shortness of leg. The udder development of the modern Ayrshire presents a higher average perfection of form, in the writer's opinion, than does any other breed. The type is not pendent, but the rear part is carried well up behind, while the fore udder has unusual extension. A row of aged Ayrshire cows 
in a show ring alongside other breeds is conspicuous for the uniform and superior type of udder. In quality Ayrshires are only medium, though thick heavy skins are far too abundant. The temperament is of a nervous character, this being especially true of the bulls, the cows having a reasonably mild clisposition.

The size of the Ayrshire is fairly uniform in the mature type. The American standard calls for the mature bull to weigh about I 500 and the cow rooo pounds. The Scotch standard favors a cow weighing about I050 pounds. Sturtevant gives the weights of nine pure-bred aged cows in his herd, which varied from 985 to 1200 pounds. The cows in Mr. Winslow's herd from I 88 I to I 887 showed an average yearly weight of from IO2O to I IO2 pounds per head.

The Ayrshire as a milk producer has ranked high since she first became known as a breed. In I8I I Aiton wrote that probably I 200 Scotch pints (2 I 48 quarts) of milk from each cow in the course of a year would be a fair average. In 1829

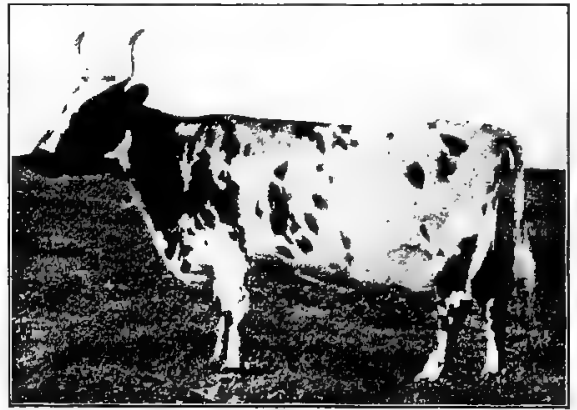

FIG. I3I. Knockdon Maggie, a prize-winning Ayrshire cow in Scotland, owned by Alexander Cross, Kilmarnock. Photograph by the author Harley, a famous dairyman, placed the average of his herd at 12 quarts a day. One of his cows for a considerable time gave 40 quarts per day. Ayrshire milk is only average in quality, usually testing between 3.5 and 4 per cent butter fat and I 2.5 per cent total solids.

Ayrshire herd milk records of interest have been available for many years, a number of eastern breeders having long kept such statistics. In the Sturtevant herd in Massachusetts in 1873I 874 an average of 5475 pounds was secured from I4 cows. Mr. J. D. W. French of Massachusetts reports average herd records between $I 874$ and $I 890$ ranging from 5222 pounds to 6934 pounds per head. Between I 880 and 1889 the herd of Mr. C. M. Winslow of Vermont averaged from 5782 pounds to 
7025 pounds a year per head. During four years the herd of Mr. L. S. Drew of Vermont averaged 6010, 5849, 6020, and 6182 pounds per head annually.

Notable individual records of Ayrshire cows compare favorably in amount with those of any breed except the Holstein-Friesian. The following official tests are recorded in the Ayrshire Yearbook:

\begin{tabular}{|c|c|c|c|c|c|c|c|c|c|c|c|c|c|}
\hline & & $N_{A}$ & & & & & & & & & & YIELD MiLK & TIME \\
\hline Alice Douglas 4398 & - & - & - & $\cdot$ & - & . & • & - & . & - & & $12,617 \mathrm{lb}$ & one year \\
\hline Rena Myrtle $953^{\circ}$ & . & . & . & • & . & . & . & . & . & . & & 12,172 & “ $،$ \\
\hline Myra 2955 . . & * & • & - & - & • & • & • & - & . & . & & I I ,908 " & $"$ " \\
\hline Queen Mary 6578. & . & . & . & . & . & . & . & - & . & . & ${ }^{\circ}$ & I I,I 54 “ & $"$ \\
\hline Ruth 4816 . . . & . & • & . & - & . & . & . & - & . & . & . & $10,219 \frac{1}{2} "$ & “ \\
\hline Miss Ollie I 2039 . & . & . & - & . & . & - & . & . & $\cdot$ & & & I,649 " & month \\
\hline Durwood 12680 . & . & - & - & - & - & . & . & - & - & & - & $\mathrm{I}, 477$ " & “ \\
\hline Hornell Girl I 3993 & - & . & - & . & . & $\cdot$ & - & $\cdot$ & - & & - & $I, 45^{8}$ & "6 \\
\hline
\end{tabular}

One of the famous Ayrshire cows to attract attention was Duchess of Smithfield 4256, which in a seven days' test in 1885 produced $463^{\frac{3}{4}}$ pounds of milk yielding 19 pounds 6 ounces of butter.

The Ayrshire as a butter cow is secondary to some of the other breeds. In official yearly tests of individual cows, milk from Rena Myrtle 9530 produced 546 pounds of butter; Atalanta 10777, 429 pounds; Nancy B. 9581,416 pounds; and Acme 5th 10342, 386 pounds. Some fifty records of private tests for a year range from 400 pounds of butter up to 624 pounds credited to Lady Fox 9669. Many Ayrshire cows have official records of fifty or more pounds of butter a month, the highest being 96.66 pounds credited to Cad's Beauty 13606. Lukolela 12357 in seven days produced 18.98 pounds of butter; Miss Ollie I2039, I7.85 pounds ; and Miss Olga 13984, I6.70 pounds.

Ayrshires in public tests have stood well. In the Pan-American dairy breed test in I90 I the five Ayrshires for I 20 days ranked second in milk production, yielding 32,998.2 pounds milk, compared with 39,260.2 for the Holstein-Friesian ; fourth in estimated butter, 1434.7 pounds; and second in net profit, \$242.24. It is but fair to state in this connection that the Pan-American 
specimens of Ayrshires in the test were fine examples of the breed, which did not obtain with some of the other breeds. The best Ayrshire in the test, Betsy ist, produced 704I.5 pounds milk, which tested 3.59 per cent fat and yielded in estimated butter 298.57 pounds. She was eighth in rank among the fifty cows, giving a net profit of $\$ 46.07$, compared with the Guernsey, Mary Marshall, first, with a net profit of $\$ 59.40$. In comparisons made at various experiment stations and at fairs the Ayrshire has usually stood second to the Holstein-Friesian in milk production, but below this in butter fat.

Ayrshire milk for cheese making has long been a standard for making Cheddar cheese in Scotland, where it is made on a large scale in the Ayrshire district. Containing as it does about the

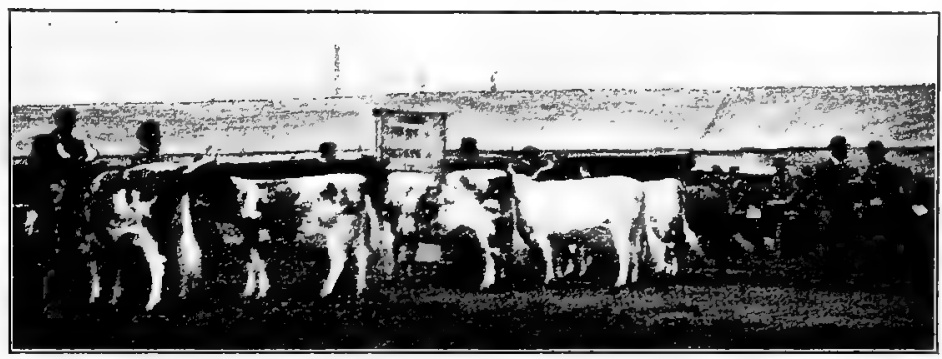

FIG. 132. In the Ayrshire ring at the Highland and Agricultural Society of Scotland Show, at Glasgow, I897. Photograph by the author

standard amount of fat and solids for cheese making, this milk is regarded with favor for this purpose. In cheese tests at the Ontario Experimental Farm Ioo pounds of Ayrshire milk produced I2.9 pounds of curd, compared with an average of I2.8 for all breeds and grades. Professor Robert Wallace, the well-known Scotch authority, states that the Ayrshire is essentially a cheese dairy cow on account of the comparatively small-sized butter-fat globules of the milk and the abundance of the curd-making material it contains.

The Ayrshire as a producer of beef ranks among the first of the dairy breeds. It is natural for animals of this breed to carry somewhat more flesh than the more refined dairy type. Ayrshire steers feed to make a very salable carcass, with a killing quality 
more acceptable to the butcher than the other dairy breeds, lacking the high fat color of the Jersey and Guernsey and the offal of the Holstein-Friesian. One Ayrshire steer 1095 days old is reported by Henry to have weighed 1320 pounds, gained 1.2 pounds daily, and dressed out 63.3 per cent, the poorest daily gain made by any of eleven breeds, but dressing out better than Sussex, Holstein-Friesian, Jersey, or native. Other evidence also indicates that Ayrshires mature and feed slowly.

The cross-bred or grade Ayrshire is better suited to milk production than anything else. Consequently Ayrshire bulls on grade cows will improve the herd to greater milk-producing power, and may add to their selling value to the butcher, if used on Jersey grades.

The distribution of the Ayrshire is almost world-wide. Considerable numbers have been exported from Scotland to Sweden, Norway, Finland, Russia, South Africa, Australia, New Zealand, China, Japan, Canada, and the United States. Quite a trade has sprung up between Scotland and Sweden and Norway. In America the breed is best represented in Canada, notably in Ontario and Quebec, while in the United States it is chiefly found in the New England and eastern states. In the Mississippi Valley west of New York the Ayrshire has never succeeded in securing but a frail foothold, in spite of its evident merit. The breed seems to have adapted itself unusually well to the cooler and more hilly sections, being a good grazer and thriving under not the best of conditions. In fact the Ayrshire in Britain has been termed the poor man's cow, being better able to thrive on inferior land and feed than any other breed excepting the Kerry. This, however, should not affect its prospering in the great dairyproducing states of America west of New York.

Organizations to promote Ayrshire interests exist in Scotland, Canada, and the United States. In 1863 a few men organized in Massachusetts and that year published Volume I of the Herd Record of the Association of Breeders of Thoroughbred Stock, Ayrshire. In I 868 a second volume was published, and in I87 I Volume III appeared with the title The American and Canadian Ayrshive Herd Record. In January, 1875, the American Ayrshire Breeders' Association was formed, which continued this record, 
publishing Volume IV that year. In I876 Volume V, old series, or Volume I, new series, of the Ayrshire Record came out, since which a total of sixteen volumes (new series) has been published up to 1905. In 1874 E. L. and Joseph Sturtevant started a herdbook, publishing Volume I in 1875 as the North American Ayrshire Register, this being for cattle tracing to importation. They published four volumes, the last in 1880. The Ayrshire Importers' and Breeders' Association of Canada was organized in 1870 and the Dominion Ayrshire Breeders' Association in 1889 ; in 1898 the former merged with the latter. In 1884 the province of Ontario published Volume I of the Dominion Ayrshive Herdbook. In 1886 Volume I of the Montreal Ayrshire Herdbook was published, and four volumes in all issued as the Canadian Ayrshire Record, after which it was merged with the Dominion book into the Canadian Ayrshire Record, Volume IX being published in 1899 . The American Ayrshire Breeders' Association also provides for an advanced registry for both bulls and cows. The minimum year record for a cow five years old or over is 8500 pounds of milk and 375 pounds of butter. The Scotch Ayrshire Cattle and Herdbook Society was founded in 1877 , the first volume of the herdbook appearing in 1878 , since when twentyeight volumes have been published up to 1905 inclusive. 


\section{CHAPTER XXXVIII}

\section{THE DUTCH BELTED}

The native home of Dutch Belted cattle is Holland, where they are known as Lakenfeld cattle, the word "Laken" meaning blanket, or sheet, about the body.

The origin of Dutch Belted cattle dates back beyond the seventeenth century. This type is said to have been established by scientific breeding and especially promoted and guarded by the

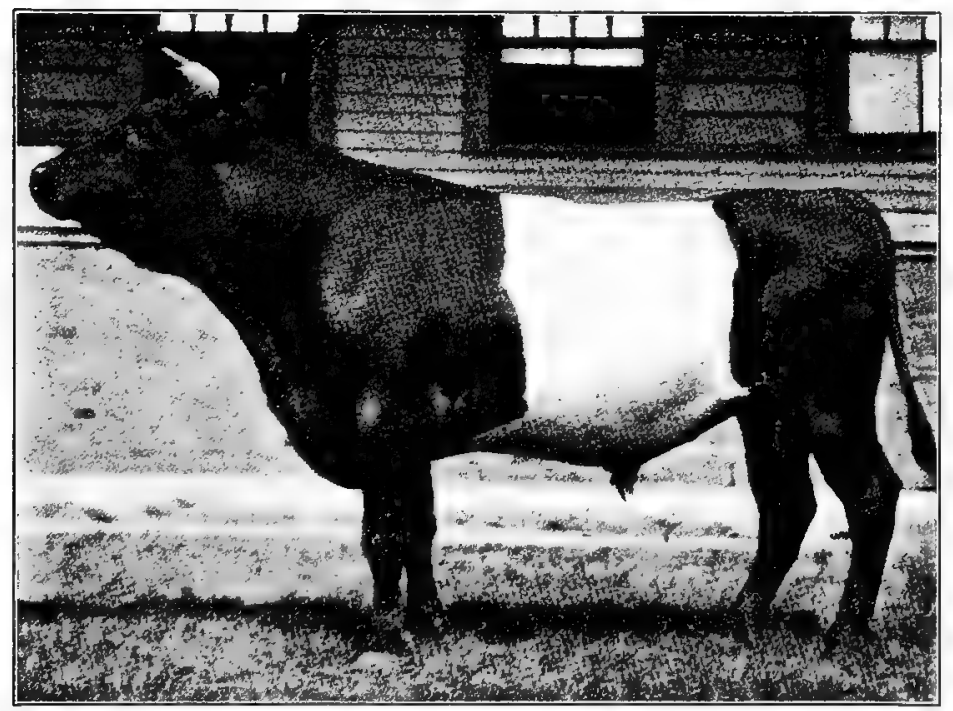

FIG. 133. Sutton 379, a Dutch Belted bull owned by F. R. Sanders, Laconia, New Hampshire. Photograph by the author

nobility of the Netherlands. The Dutch Belted Herdbook states that at one time belted cattle having black rings about one inch wide around the eyes existed in Holland, especially in the seventeenth century. Only the most obscure information is available 
regarding the origin and development of this breed, it being almost unmentioned in extensive literature on the breeds of cattle.

The introduction of Dutch Belted cattle to America dates back to I 838 , when D. H. Haight of Goshen, New York, made the first importation, followed by a second in I848. P. T. Barnum,

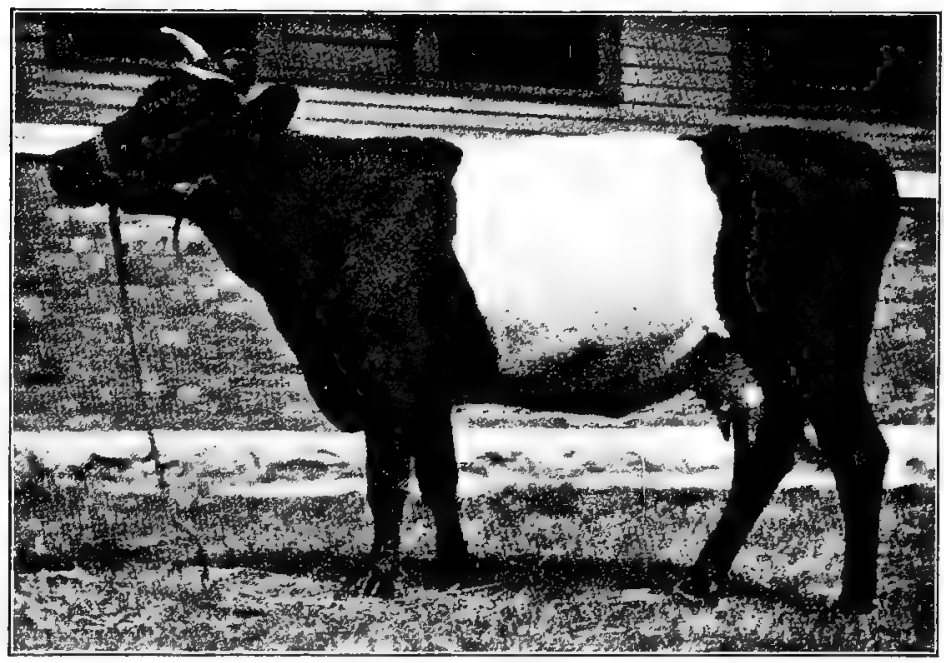

Fig. I34. A Dutch Belted cow owned by F. R. Sanders, Laconia, New Hampshire. Photograph by the author

the famous showman, and R. W. Coleman also made importations. The early development of this breed was largely in southern New York in Orange County. No Dutch Belted cattle have been brought to this country for at least fifty years.

Characteristics of Dutch Belted cattle. In size they are somewhat smaller than the Holstein-Friesian, being more comparable with the Ayrshire. Mr. G. G. Gibbs, a New Jersey breeder, states that the cows weigh from 900 to 1250 pounds, while a number of bulls have exceeded a ton in weight. The bull Duke of Ralph 255 when three years old weighed 1200 pounds; Edward the Great I, 2000 pounds ; and Duke of Goshen 27, also 2000 pounds. A weight of 1500 pounds or so should prevail with the bulls. The cow Lady Aldine I24, a well-known prize winner, weighed I 200 pounds. In color the cattle are invariably black, with a 
white band of varying width about the body, in front of the hips, rarely reaching the shoulders. Sometimes this band narrows to even a foot in width or less, and again other specimens have it as a wide blanket. The fore part of the udder of the cow is also often white. In udder conformation and development these cows are rather inferior, the size being comparatively small, the fore udder abbreviated, and the teats placed too closely together.

The dairy importance of Dutch Belted cattle is its principal value, aside from the ornamental. There is but little on record concerning the merits of the breed as a whole, although external indications would not justify high praise. Alvord states that the cow Lady Aldine I 24 produced as high as 32 quarts of milk a day on grass alone. Lady Baird 82 was credited with a similar private record in 1893 at the World's Columbian Exposition. J. A. Holbert of New York reports a herd of from 25 to 30 cows and heifers averaging per year from 8305 to 9018 pounds of milk for the herd. The only test of this breed which has been reported to the public was in the Pan-American Model Dairy test in I90 I, in which ten breeds participated. In this trial the five Dutch Belted cows made the following record in 120 days :

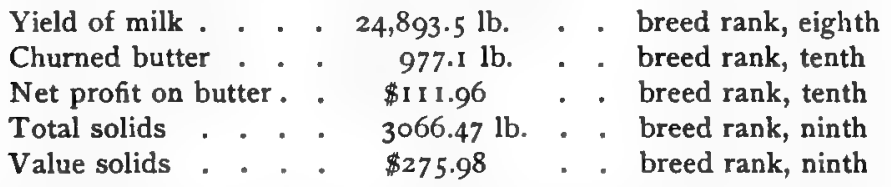

This record is not especially complimentary to the breed.

The Dutch Belted as beef producers can hardly be regarded as superior to the dairy breeds, and no doubt will not compare favorably with the Holstein-Friesian. They lack the size of the latter and do not show the tendency to produce flesh so characteristic of some Holstein-Friesians. Owing to the comparative scarcity of the Dutch Belted, one finds almost no steers of the breed on the market.

The general adaptability of the Dutch Belted is quite comparable with the Dutch type, bred to thrive on abundant food under rather favorable conditions. One of the best-known herds in America is kept in New Hampshire, in a rough, mountainous section where the winters are severe and long. The fertile 
meadows of the Mississippi Valley, however, will provide more favorable conditions for the best development of the breed.

Dutch Belted cross-breds or grades inherit the striking characteristics of the pure-bred sire. Says one breeder :

Crossed on cattle of any solid color they almost invariably produce the belt, though if the dam be a Devon the calf may be red at the ends; or if the dam is a Shorthorn, the calf may be red or roan. But the belt of the pure white is there, nevertheless.

An interesting example of this intensity of Dutch Belted prepotency took place in the herd of the Ohio State University. A cow of this breed, to the service of a pure-bred Jersey bull, dropped a cross-bred calf, with a white blanket about the body, quite similar to that of the dam, excepting for one small black spot on the white covering.

The distribution of Dutch Belted cattle is very restricted. They occur in only a small way in Holland and in the United States, Canada, and Mexico. The largest herds are found in New York, New Hampshire, Massachusetts, Pennsylvania, Ohio, and Mississippi, but there are other herds even as far as California.

The promotion of the Dutch Belted breed is supervised by the Dutch Belted Cattle Association of America, organized February 4, 1886, in New York City. Volume I of the herdbook was published the same year, containing the registration of 46 males and 177 females, mainly owned in New York, with others scattered throughout New Jersey, Pennsylvania, New Hampshire, Illinois, and South Carolina. The last volume of the herdbook, numbered VII, was published in 1903. 


\section{CHAPTER XXXIX \\ THE FRENCH CANADIAN}

The native home of French Canadian cattle is in the province of Quebec, Canada. The country is somewhat undulating and rough, though not mountainous, and excellent crops of grass, oats, barley, potatoes, and roots are grown. The winters are rather long and cold, with much snow, the summers short and cool.

The origin of the French Canadian breed is claimed to be from stock brought from France to Quebec by the early settlers, prior to 1665 . No definite information is on record as to just where these cattle came from in France, but it is presumed that they came from Brittany and perhaps Normandy. For two hundred years or more their descendants have been bred in Quebec without essential admixture of other blood.

Characteristics of French Canadian cattle. In type there is considerable resemblance to the Channel Island breeds, especially the Jersey. The color is solid black, or black with a yellow fawn stripe along the back and around the muzzle, brown brindle, or brown with black points. The black type of males is preferred. The horns are generally curved outward and then in, with the tips turned toward each other. The color of horn is white with black tip. In size the mature female weighs from 700 to 800 pounds, and the bull about 1000. They often, however, weigh less than this. In general conformation one is impressed with a certain roughness and angularity of form, after the more angular Jersey type. In quality they show a mellow hide, and a rich yellow skin, notable for its high orange-yellow color within the ear and about the udder. A fine silky coat of hair is an important indication of quality. "The chief points of these cattle," says C. N. Lepter of Quebec, "from a dairyman's point of view, are that they have large udders and teats placed far apart and pointing in front." 
The milk-producing quality of the French Canadian is its special recommendation. The only notable public test in which the breed has taken a part was that of the Pan-American Model Dairy. In this case the competition gave the breed a medium record among the ten tried. In production of milk during six months the five cows produced $24,656.4$ pounds, which yielded I I 79.65 pounds of churned butter valued at $\$ 294.9$ I, giving a net profit of $\$ 18 \mathrm{I} .8 \mathrm{I}$. In cost of butter per pound the French Canadian ranked third at 9.76 cents, the Guernseys being first at $9.3 \mathrm{I}$, and the Jerseys second at 9.48 cents. The best net profit made by a cow of this breed in the fat test, among the fifty cows of all breeds, was $\$ 40.63$ for Denise Championne, twentyfirst in the test. Rouen, another cow of the breed, ranked next to Denise Championne, the difference between these two being very nominal. Mr. J. A. Couture of Quebec, writing regarding the dairy capacity of this breed, states that the cow Pruniere I 7 I 2, the property of the Hospital du Sacré-Cour, Quebec, during 3 I 8 days produced I I, 3 IO pounds of milk, a daily average of over 35 pounds. This cow weighed about 675 pounds. The cow Azilza de Levis 956 is said to have produced 8000 pounds a year. An average yield of 5000 pounds is regarded as a standard. The quality of French Canadian milk in butter fat is good, but not equal to that of the Jersey or Guernsey. In the PanAmerican trials the milk of this breed averaged 4.04 per cent fat, the same as the Red Polled, compared with 4.68 for the Guernsey, 4.75 for the Polled Jersey, and 4.82 for the horned Jersey.

The hardy character of the French Canadian cattle is one of their strong features. They have vigorous constitutions, well adapted to the rigors of a Canadian winter, and capable of making good return at the pail with a most economical expenditure of food, thriving, it is said, where other cattle would starve. The claim has been made by Canadian breeders that cattle of this breed are not affected with tuberculosis as commonly as other cattle. They should be suited to the more northern section of the United States.

The grazing qualities of French Canadians rank very high, and the cows are said to yield large returns of milk on pasture alone. On poor pastures or hill farms they are better suited to thrive than the larger breeds. 
The breeding qualities of French Canadians also rank well. This would naturally be the case, due to the hardy, exposed lives they so often lead.

The early maturing qualities of the French Canadian are secondary. This is largely due to the limited food and rigorous conditions of keeping. More abundant food and better care would improve the breed in this respect.

The distribution of French Canadian cattle is mainly restricted to Quebec, where it is the principal breed in some twenty-five counties. Registered cattle are most bred in the counties of Berthier, Joliette, Drummond, Kamouraska, and L'Islet. They are also found in a small way in the United States, in northern New York State.

The promotion of pure French Canadian cattle has been assisted by the legislature of Quebec and a breeding association. About I 886 the legislature adopted rules for the registration of foundation animals, and until I895 a herdbook was maintained. Animals of correct form and acceptably pure descent were eligible to registration. In I 895 the French Canadian Cattle Breeders' Association was organized, and in September of that year assumed the control of all herdbook records. 


\section{CHAPTER XL}

THE KERRY

The native home of Kerry cattle is in western Ireland among the Kerry mountains. The country is rough and the soil poor. The climate is moist and fairly temperate.

The origin of the Kerry is as uncertain as that of other British breeds. From time immemorial it has been bred in Ireland, where it is known as the "poor man's cow." The opinion of British students is that this is a descendant from the smaller type of aboriginal cattle of that country, of the same character as the dark-colored cattle of Britain. Nothing more is known. The development of the breed has mainly rested with the Irish farmers or tenants, who keep but small herds.

Characteristics of the Kerry. There are two types of Kerry cattle, - the "true Kerry," which is usually black, and a smaller type known as the "Dexter-Kerry."

The true Kerry is a small breed of dairy cattle. The color is black, though red sometimes occurs. White may occur about the udder or scrotum, but is not desirable. The lean head carries upstanding slender white horns with black tips. With cows the neck is slender and long, the body of moderate proportions, the legs fine and long, and the udder large with medium-sized teats. In size this is one of the small breeds; the cows often weigh from 500 to 600 pounds, and frequently do not exceed 40 inches high. The bulls are larger, weighing 800 to 1000 pounds.

The Dexter-Kerry is of unknown cross. Some authorities think that a Mr. Dexter nearly a century ago developed the breed by crossing Kerries on other stock. Some others regard it as a result of selection. This type is more blocky, shorter legged, heavier of head and neck, and more beefy in type than the true Kerry, and, as seen by the author, much smaller. The color also is variable, being black, red, or roan. There are wider 
variations among the Dexter-Kerry branch than in the true Kerry. In each case the udder is unusually well developed, showing large capacity in proportion to size of body.

The size of the Kerry is small, the Dexter being the smallest of any British breed. The following are given as measurements of a celebrated Kerry bull, Busaco, shown as a two-year-old at the Paris Exposition in 1878 : height at withers, 34 inches; length from withers to tail end, 38 inches; heart girth, 50 inches. In 1900 the Dexter-Kerry bull La Mancha Union Jack was shown at the Royal Agricultural Society Show of England at York. He was a two-year-old, red in color, stood

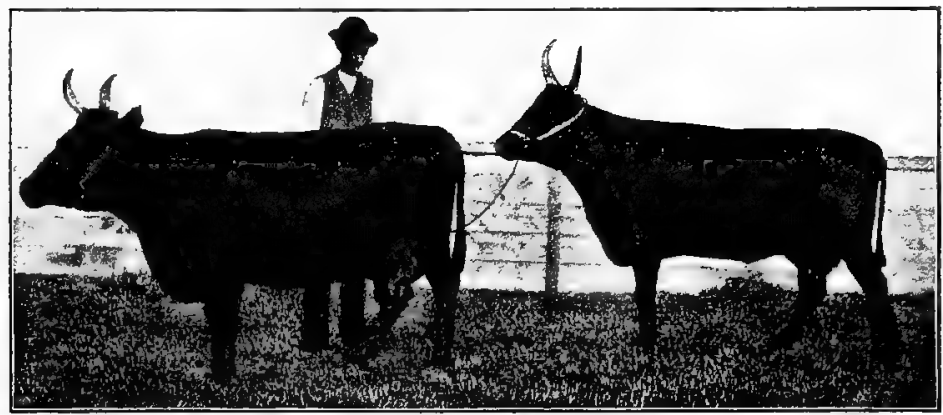

FIG. I35. A pair of Kerry cows shown at the Royal Agricultural Society Show at Manchester, England, in 1897. Photograph by the author

about 36 inches high, and weighed about 400 pounds as estimated by the author. As champion of the breed and a famous prize winner he attracted much attention, a special inspection being made by the Prince of Wales, now Edward VII. The celebrated Dexter-Kerry show cow Red Rose weighed 762 pounds.

The Kerry as a milk producer ranks high. The cow Red Rose, already referred to, yielded in one year nearly 10,000 pounds of milk. Messrs. William and James Macdonald, in reporting on the Kerry cattle shown at the 1878 Paris Exposition, state that twelve quarts of milk daily during the season, and from six to seven pounds of butter a week are the estimated yields of a Kerry cow, and that cows have been known to give sixteen quarts every day for some time after calving. The quality of the milk is also superior, being rich in fat. 
The Kerry as a beef producer may rank high as to quality, but low as to quantity. The general evidence in behalf of the breed, notably the Dexter, is that the beef is of superior quality, and that the steers dress out remarkably well. The true Kerry, however, being of the dairy type, produces a class of beef of minor importance at best. A few steers of the breed are usually shown at the Smithfield Club Show in London each year, coming in a special class for small cross-breds. At the I90 I Birmingham Fat Stock Show the first-

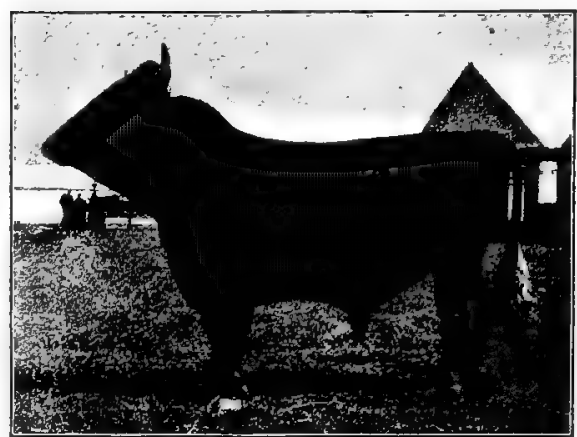

FIG. I36. La Mancha Union Jack 37, a noted Dexter-Kerry bull, two years old, standing about 36 inches high, that was champion at the Royal Agricultural Society Show at York, England, in 1900. Photograph by the author prize Kerry weighed 840 pounds at eighteen months old.

The grazing value of the Kerry is very high. This breed has been developed under adverse food conditions, and thrives on com-

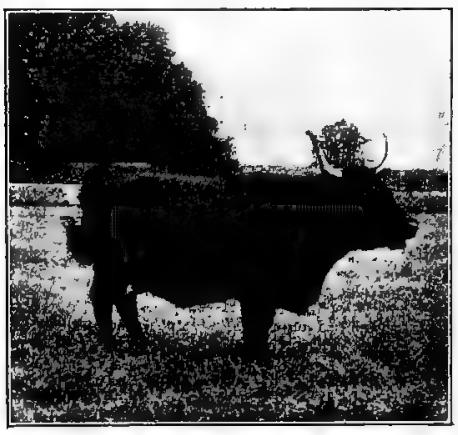

FIG. 137. A Dexter-Kerry cow at the Royal Agricultural College, Cirencester, England. Photograph by the author paratively poor rations. It well serves the purpose of furnishing the poor Irish laborer a maximum of return for a minimum of expenditure.

The hardy character of the Kerry is famous wherever the breed is known. During the entire year it is necessary for the Irish cotter's cow to adapt herself to conditions of privation, including the inclemency of winter.

The maturing characteristics of the Kerry are of an inferior order. As bred in Ireland Kerries

grow slowly, the cows producing the first calf considerably later than with other breeds. Dr. Miles states that in Ireland heifers 
do not breed until six or seven years old, due to a scanty supply of coarse food and slow growth, while in Massachusetts, under more favorable conditions, they breed in three years.

The Kerry in cross-breeding has attracted considerable attention. Shorthorn bulls have been extensively used on Kerries in Ireland, to the material welfare of the country. James Macdonald, editor of the Farmers Gazette, Dublin, writing in the Joumal of the Royal Agricultural Society, says:

A good many Kerries are brought in, and from these and Shorthorn bulls stock of wonderful size and quality are bred. Indeed, I have seen steers at Carton, crosses between small Kerry cows and Shorthorn bulls, which in shape and size showed but little inferiority to highly graded Shorthorns.

According to British authors Aberdeen Angus and Hereford bulls on Kerry cows have also produced very excellent steers. The Kerry male cannot be used to so good advantage in crossing on the beef breeds.

The distribution of the Kerry is not general. Even in Ireland, where it is commonly bred, the Shorthorn is the leading breed. It has been taken up as a fad by the English nobility, and small herds are found in various parts of England, kept rather for fancy purposes. A few Kerries have been exported to Australia, South Africa, Canada, and the United States. A small herd is kept by Mr. G. M. Carnochan of New York City, who imported and exhibited a bull and four females at the Louisiana Purchase Exposition at St. Louis in 1904. The Honorable Whitelaw Reid of New York for some years has also kept a small herd of Kerries. Years ago a few were taken to New England. A few cattle of the breed are also kept in Illinois.

A Kerry cattle organization has been in existence for several years in Ireland. In 1887 a register was started by the owners of the Farmers Gazette in Dublin, which soon after was turned over to the Royal Dublin Society, which issued the first volume of the Kerry and Dexter Herdbook in I890. In 1892 a Kerry and Dexter-Kerry Cattle Society was formed, which now attends to registration and herdbook publication. 


\section{CHAPTER XLI}

\section{DUAL-PURPOSE TYPE OF CATTLE}

Dual-purpose and general-purpose type of cattle mean the same thing. This comes in between the beef and dairy type, combining in one animal the valuable qualities of meat and dairy types. This class has been under special discussion for some years, and strong arguments have been advanced in its behalf. It is not proposed to go into a detailed discussion of this type, - it is not necessary, — but rather to emphasize the essential features.

The dual-purpose and the beef type compared show certain marked differences. The dual-purpose animal lacks the width and smoothness of the beef type, carries less flesh, shows more neck, narrower withers, and more length of leg. There is more general length of body. With the cows the udder is most essential in true specimens of the dual-purpose type, milk production being important.

The dual-purpose and dairy type compared show the former to be fuller in the bosom, more massive, broader backed, thicker at withers, smoother of shoulder, thicker and heavier at hind quarter and twist, and tending to shortness of leg. The form is generally smoother and much less angular, and carries more flesh. When in high milk flow dual-purpose cows often lose flesh and incline to the dairy conformation, but on drying off they flesh up to a notable degree.

Two classes of dual-purpose cattle are common, one rather beefy in character, with small udders, the other with strong dairy-type indications. Every large show of dual-purpose breeds contains good representatives of these two classes. For example, the Devon, a dual-purpose breed, contains the two classes in a marked degree. The dairy sort is more popular in the eastern states, the beef in the West. The same applies to a certain extent also to the Red Polled breed, though perhaps not to so 
great a degree as with the Devon. In the Shorthorn breed we have the most approved beef type of cattle, while a dual-purpose type of this breed, with strong dairy tendencies, is very common in England and not rare in America. By combining beef and milk in a really noteworthy degree the dual purpose is secured. Minus the one or the other, the animal logically must be classed with the beef or dairy type.

The demand for dual-purpose cattle is extremely widespread in this country. Many farmers greatly prefer a type of cow that will produce a liberal supply of milk, that will fatten easily to meet the demands of the butcher, and will also produce calves that will feed into superior veals or steers. In regions where dairying is not a specialty the dual-purpose type is quite commonly seen in the Shorthorn of milking strain. Notwithstanding the frequency with which cattle of this type are seen, there are comparatively few animals of the dual-purpose breeds to be found in America. Our farmers do not seem to want to pay the price necessary to obtain the pure-breds of merit.

The relationship of size to dual-purpose type is a minor consideration. It has been stated that dual-purpose cattle average larger than dairy cattle. This is not necessarily so. The DexterKerry breed belongs to the dual-purpose type, and is one of the smallest breeds known. One Dexter-Kerry cow photographed by the writer probably did not stand much over forty-four inches high. She was smooth all over, distinctly beefy, with a very large udder. 


\section{CHAPTER XLII}

\section{THE RED POLLED}

The native home of Red Polled cattle is in England, in the counties of Norfolk and Suffolk, which border the North Sea and comprise the most easterly part of England. The country is rolling, with some marshlands, and furnishes good grazing and live-stock conditions, although parts of Norfolk have poor, thin land. The climate is fairly temperate and moist, characteristic of England.

The origin of Red Polled cattle is differently interpreted by live-stock writers. Culley thought them descended from the Galloway type, and was the first to suggest this source, although the two breeds materially differ. Others have attributed the ancestry to the wild white polled sort. Mr. Euren, the organizer of Red Polled interests abroad, has suggested that the breed was derived from the polled cattle of southern Europe, as, for example, Hungary or central Russia where cattle possessed the soft satiny skin of the Red Polled, rather than from the Galloway with its heavy, long coat and thicker hide. The fact is, the breed has developed, like other British breeds, from material which passes beyond historical record. We do know, however, that the present-day Red Polled breed consists of an amalgamation of the following two types or varieties.

1. Suffolk Red Polled. The county of Suffolk lies just south of Norfolk. The northeast part of this, sometimes designated as East Anglia, was settled in the fifth century by Scandinavians, and it is stated that they brought with them cattle. In this section of Suffolk, only twelve by twenty miles, and later in the entire county as well as in Norfolk, developed a polled breed that became famous for milk production. In I734 John Kirby, in the Suffolk Traveller, wrote of the butter produced in this district as "the best and pleasantest in England." These 
cattle were small, naturally thin of flesh, and were either red, brindled, or dun colored and always polled. Arthur Young in 1794, in a general survey of the agriculture of Suffolk, describes the breed at some length. He stated that for two or three months a whole herd would average five gallons of milk a day per head, and single animals have produced eight gallons in a day. From 1778 on, numerous advertisements of auction sales of this dairy stock were published in the Norwich (Norfolk) Mercury. In I 802 a herd of "twenty-one beautiful polled cows and a bull" was advertised.

2. Norfolk Red Polled. In Norfolk County early writers referred to a type of cattle, blood-red in color, with a white or mottled face, having horns, small of bone, "fattening as freely and finishing as highly at three years old as cattle do generally at four or five," says Marshall, who regarded the Norfolk Red Polled as a miniature Hereford in appearance. These possessed poor dairy qualities, so Jonas Reeve of Wigton and Richard England of Binham began to improve and secure a type combining the good qualities of the Suffolk as well as the Norfolk. A Mr. George also took part in this improvement. They bred to produce a solid red color, perhaps using the Devon, which existed in the county, bred off the horns, no doubt with the help of Suffolk bulls, and so developed a dual-purpose type which attained considerable fame. In 18 I 8 the name Norfolk Polled began to come into use.

The amalgamation of Suffolk and Norfolk Red Polled cattle was the result of gradually developing the two breeds into a common type. Each was improved with the view of securing an easy-keeping, hornless, red-colored, dual-purpose animal. The types of each county were shown for a time at the local fairs, but they gradually came to be of the same general character. The year I 846, according to Mr. Euren, the secretary of the Red Polled Cattle Association in England, may be taken as the date from which the Norfolk and Suffolk varieties merged into each other, so as to be spoken of as one and the same breed. Finally, in I 862, an international exposition was held at Battersea, when a large exhibit was made in one class from both Norfolk and Suffolk. It was then that the improved form in each county was 
recognized as of the same kind, and given the name Norfolk and Suffolk Red Polled. About i 882 this was shortened to Red Polled, by which name the breed is now recognized.

Groups and tribes of Red Polled cattle gradually developed from the various lines of breeding. The first volume of the herdbook classes the united breed into twenty-five groups of foundation stock, each indicated by a letter of the alphabet, as $\mathrm{A}, \mathrm{B}, \mathrm{C}$, etc., and these including numerous tribes or families.

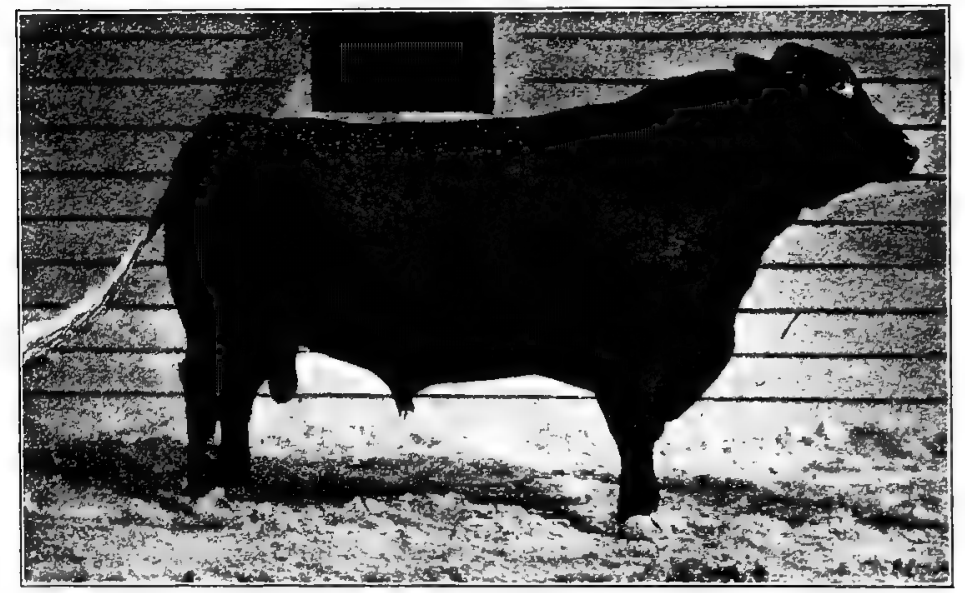

FIG. I 38. Demon 542 I (A I), one of the greatest Red Polled bulls in A merican show-yard history. Bred by J. W. Martin of Wisconsin, he was shown by Andrew Bros. of Ohio from 1898 to 1904 at the leading shows of the country. Twice champion of the breed at the International Live Stock Exposition, Chicago, and repeatedly grand champion Red Polled bull at leading state fairs. Owned by the Ohio State University. Photograph by the author

The first volume gave 233 tribes, and later these increased to 385 , but at present only about 200 tribes are represented in the registration. While the group will remain the same in letter the tribes naturally vary in number. The method has an advantage in studying pedigrees, for with it the group and tribe relationship is shown. The groups made up certain foundation herds. For example, the A group comprises the cows in theElmham herd, or owned by tenants of the estate of that name; the B group, the cows in the Biddell herds and others in the 
vicinity, etc. Thus $A_{I}$ refers to a foundation cow in the Elmham herd named Primrose; Bio to a cow in the Manfred Biddell herd named Bury, etc. Differing from other cattle associations, the registration number of the cow precedes the name, as 42 I Primrose Ar, while the number of the bull follows his name in the customary manner. None of the above groups trace far back of the first volume of the herdbook, some being comparatively recent.

The introduction of Red Polled cattle to America no doubt first occurred in colonial times in English settlements, as, for example, in Virginia. Mulley or polled cattle of a red or red and white color, similar to Red Polled, have been known in the eastern United States for over a centüry. In I 847 a Suffolk polled heifer was presented to the captain of the vessel Jamestown, that took provisions to Ireland to relieve famine, and she was brought to Massachusetts. From her descended a line of stock, termed Jamestown cattle in Massachusetts, that produced polled animals of superior character. In 1873 G. F. Taber of Patterson, New York, made the first importation of breeding Red Polled cattle to this country, consisting of a bull and three heifers, and later in 1875 four more cows, and again in 1882 three bulls and twenty-three heifers. Also in $1882 \mathrm{Mead} \& \mathrm{Kimball}$ of Vermont brought over a bull and eleven females, and in I 883 G. P. Squires of New York and Geldard \& Busk, an English firm, made importations. In I $886 \mathrm{~J}$. McLain Smith of Ohio made his first importation, and until his death in 1905 he was a prominent advocate of the breed. Captain V. T. Hills, also of Ohio, a leading American authority on the breed, imported in 1887 .

Red Polled characteristics. Animals of this breed present the dual-purpose type in its truest form, for good specimens yield milk liberally and fatten satisfactorily on drying off, producing a good grade of beef. The head is lean in type, and presents the characteristic poll. The neck of both bull and cow lacks the fullness of the beef breeds, the cows being notably thinner in this respect. The withers are only moderately broad, and the shoulders resemble those of the Shorthorn rather than the Hereford. The body is usually very well ribbed and the back strong, but is not fleshed over in a prominent degree. The hips 
or hooks lack prominence and so smooth over easily in fattening. The hind quarter presents the thinner beef form, as shown in the leaner rump, thinner thigh, and shallower twist. The udder tends to be of the pendent sort, the fore part being frequently deficient, while large teats are common; in fact, the writer has seen larger teats with Red Polled cattle than with any other breed. The udders do not often show a meaty character, but are mellow and elastic in quality. Fair milk veins and wells

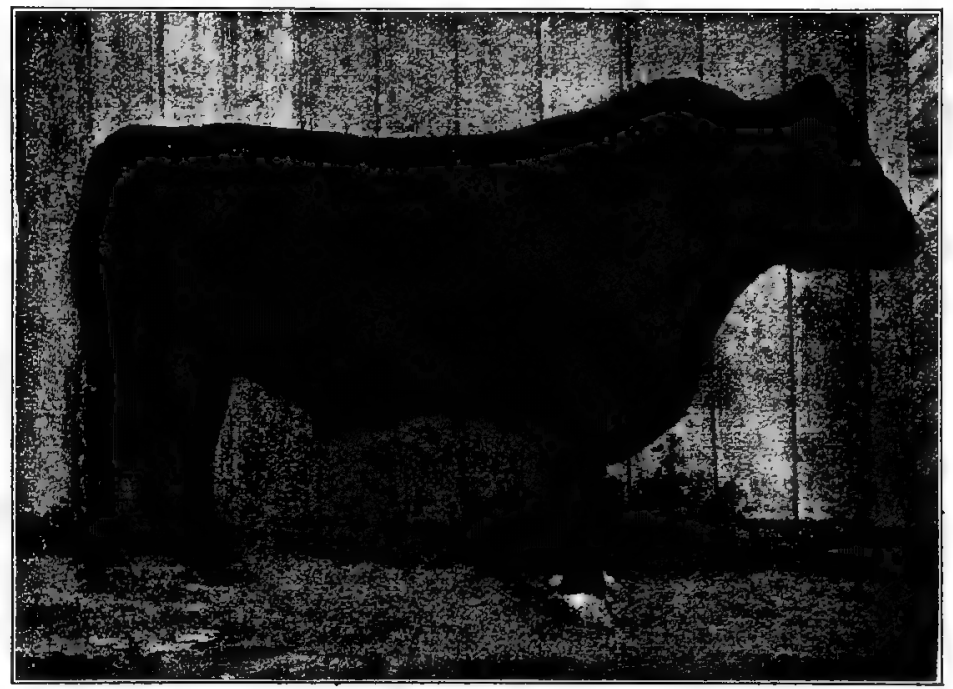

FIG. I39. Patriarch 6482, a Red Polled bull, bred by Captain V. T. Hills, Delaware, Ohio. At three years of age this bull weighed 2460 pounds. Photograph by the author

obtain ; in fact, Arthur Young commented, over a century ago, on the large size of the Suffolk cow's milk veins, and some of this inheritance still exists. The quality of the breed may be classed as fair, not generally surpassing other breeds. The color varies from light to dark red, a medium shade being most common. A little white on the udder or belly, with white brush of tail, is permissible, but solid red is and long has been preferred. In size this breed is about medium, although large specimens naturally occur, and some breeders prefer as large a type as they can produce. In temperament Red Polled cattle are more 
nervous than Shorthorns, but are not enough so to offer any important objection to the breed.

The weight of Red Polled cattle is medium, not equaling the heavy beef breeds, although heavy specimens occur. For example, the bull Patriarch $6482 \mathrm{U}_{43}$ weighed at full maturity as high as 2600 pounds. The show bull Demon 542 I A I, owned by the Ohio State University, weighed 2100 pounds in his best form. Pando I 254, I I 3, the well-known bull imported by Captain V. T. Hills of Ohio, weighed, when five years old, 2270 pounds. Wild Roy I I05, VI, also imported by Captain Hills, at five years weighed 2480 pounds. A range of from 1800 to 2200 pounds will apply to typical mature, males of the breed. Cows weigh from I 100 to 1600 pounds, or even more, I 250 to I 300 being a fair average.

Red Polled cattle as beef producers hold very good rank. While as a rule they do not win the highest honors in open competition in the great beef show rings, they feed to a point of profitable production for the stockman, and make a very good class of beef for the consumer. This beef is not usually so fat as that produced by some breeds, the outside of the frame not being so heavily covered. Red Polled steers also tend to be somewhat long of leg. Numerous cases may be cited to show that the steers gain rapidly and show well. At the I889 Smithfield Club Show two Red Polled two-year-old steers showed the largest daily gain of anything on exhibition of that class, viz. 2.18 and 2.29 pounds each. One of these afterwards was made champion as the best steer on exhibition at the Norfolk Fat Stock Show. At the Smithfield show in I 890 a Red Polled steer dressed 73.72 per cent, the highest per cent dressed out at the show. In I 899 the London and Norwich Red Polled breed cup winner at 32 months weighed I 708 pounds, showing a gain for the year of 452 pounds, or 35.98 per cent. The reserve for the breed cup was a heifer that at 863 days had a live weight of 1436 pounds. In 1900 the cup winner at both of the above shows was a heifer weighing $I 578$ pounds at $33 \frac{1}{4}$ months. At the International Live Stock Exposition at Chicago in 1904 the Red Polled steer Pompy, in the two-year-old class, weighed I 680 pounds alive, and showed a dressed weight 
in the slaughter test of 1005 pounds, dressing 64.0 per cent. Red Polled steers in good flesh on the open market are quite sure to make a creditable showing and bring a fair price.

Red Polled cattle as milk producers have long held high rank, and a large number of records might be cited to show the value of the breed in the dairy. In public tests the breed has stood well. At the Pan-American dairy test in Igor five Red Polled cows took fifth rank among ten breeds, showing a net profit of $\$ 201.6$ I for six months. Among the 50 cows tested, the cow

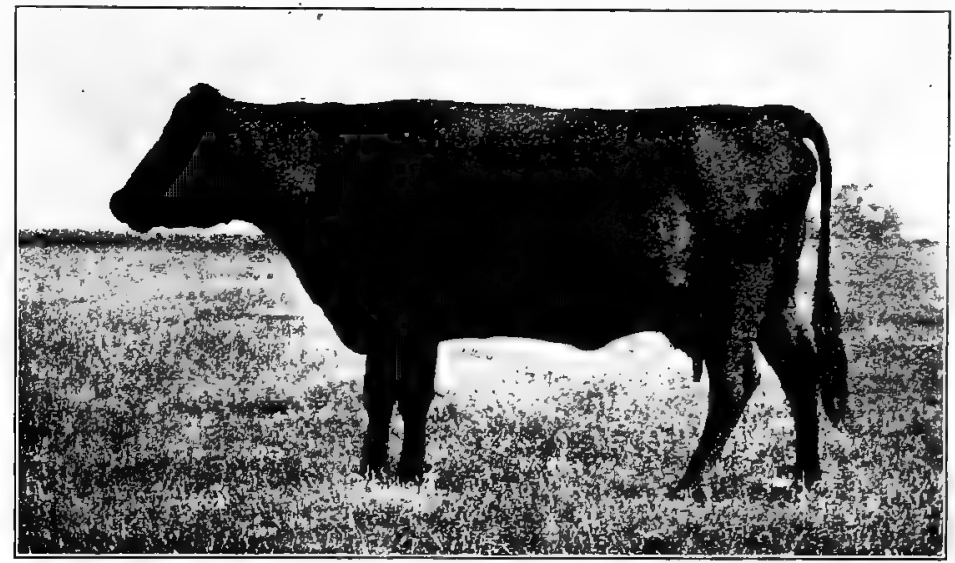

FIG. I 40. I0097 Chloe ( $\mathrm{T}_{1}$ ), second-prize Red Polled cow in general class and in farmer's cow class at the International Live Stock Exposition, 1903. Official test for 330 days 7924 pounds milk and $33^{6} .5^{8}$ pounds butter fat. Owned by the late J. McLain Smith, Dayton, Ohio. Photograph by the author

8025 Mayflower 2d, A I2, stood second, producing 6I6I pounds milk and 323 pounds estimated butter, showing a net profit in the fat test of $\$ 52$. IO. Many cows of the breed will produce 5000 pounds of milk a year. The following table shows the yearly average yields of the herd of Lord Rothschild at Tring Park, England, as giving an example of what a superior herd can accomplish.

\begin{tabular}{c|c|c|c}
\hline Year & Number W Weks & Number Cows & Average Yteld Milk \\
\cline { 2 - 3 } & 53 & 36 & $7033.45 \mathrm{lb}$. \\
I898-1899 & 52 & 34 & $6520.00 \mathrm{6}$ \\
I899-1900 & 52 & 43 & $6895.76 \mathrm{G}$ \\
I900-190I & & \\
\hline \hline
\end{tabular}


In 1903 fifteen herds contributed records of their daily milk yield to the English Red Polled Society Herdbook. Of 267 cows which had produced in the year, having had their second calf or more, 194 gave a total yield for the year of 5000 pounds and over. Thirteen of these gave 9000 pounds and over, the best record being I0,392 pounds. The cow 2965 Mayflower, AI2, in the herd of V.T. Hills of Ohio, produced from July 18 , I892, to July IO, I 893, a total of I I,008 pounds of milk; while for four years, from August I, I 890, to July 3 I, I 894. she produced 43 , I $8 \frac{1}{4}$ pounds of milk, or a daily average of about 25 pounds. The London Live Stock Journal in I 898 published the milk record of a Red Polled cow of I 3,126 pounds in 347 days, an average of 37.82 pounds daily. This same journal also reports on the Red Polled cow Hester that from October, I 890 , to October, 1904, produced the remarkable yield of 84,177 pounds of milk, an average yield for fourteen years of 601 2 pounds per year. This was also a very successful show cow in England.

Red Polled cattle as butter producers stand very well. Their milk tests about 3.8 per cent fat, although many cases show even better. The average of Mayflower for four years by Babcock test is 4.35 per cent butter fat. At the Pan-American Exposition the five Red Polled cows produced in six months 1319.45 pounds churned butter valued at $\$ 329.86$, with Mayflower 2d second in the butter-fat test. In this test the average butter-fat content was 3.98 per cent. Professor Curtiss of the Iowa Agricultural College has stated that a number of Red Polled cows in the college herd were producing from 300 to 400 pounds of butter per year. In I 904 a cow in the herd of the Ohio State University was milked 348 days and produced 8777 pounds of milk, which by Babcock test showed 379 pounds butter fat, equal to about 440 pounds commercial butter.

The use of the Red Polled cattle in crossing or grading may be beneficial from either the beef or dairy point of view. Red Polled bulls used on the beef type should increase the milk-producing character of the descendants, but may lower the meat standard somewhat. Used on the dairy breeds, the beef character should be improved in the offspring, but whether the dairy qualities will be benefited will depend on the kind of dam used, better results 
coming where a small milker is mated rather than a large producer. Red Polled cattle are very prepotent, and will transmit their red color and polled heads with much uniformity when used on other breeds or grades.

The deficiencies of the Red Polled cattle are not serious, but they exist. The udder, with all its capacity, is too irregular in type, often being deficient in front, and with abnormally large

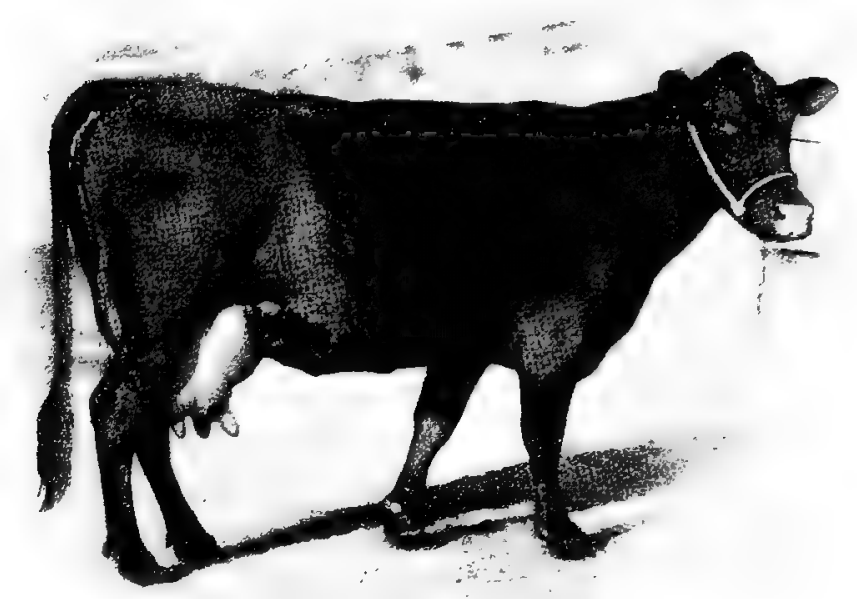

FIG. 141. 2965. Mayflower (AI2), a Red Polled cow of dairy type, noted as the founder of the Mayflower family. This cow gave I I,008 pounds of milk from July 18,1892 , to July 10,1893 , and $43,118 \frac{1}{4}$ pounds of milk in four years from July I, I890, to July 3I, I 894 . Owned by Captain V. T. Hills, Delaware, Ohio. Photograph from Captain Hills

teats, too large to be comfortably grasped in the hands. Comparison of the form of udder on cows of this breed with that of the Ayrshire shows it to be distinctly inferior. The Red Polled breed also lacks uniformity of type, some persons selecting along beef lines and others along dairy lines. This is a general difficulty existing, however, among dual-purpose breeds, and is rather due to the variations in the standards of the breeders. There is a constant tendency to produce either for beef or for dairy purposes. 
The distribution of Red Polled cattle is widespread, yet the breed cannot be regarded as common. In Britain it is mainly bred in Norfolk and Suffolk counties, although large herds exist elsewhere, and considerable milk is shipped to London from Red Polled herds. Specimens of the breed have been exported from England to Russia, South Africa, Australia, New Zealand, Canada, and the United States. In the United States it is pretty well distributed, mainly in the Mississippi Valley and as far south as Texas. The more prominent herds are found in Ohio, Wisconsin, Illinois, and Iowa. The breed is fairly well adapted to a wide range of climate, comparable perhaps with temperate latitudes.

Organizations to promote Red Polled cattle interests exist in England and the United States. Through the efforts of Mr. Henry F. Euren, a herdbook was published in England in I874, and this work he continued until I888 when the Red Polled Society of England was organized. The American Red Polled Cattle Club was organized in 1883 at Chicago. In 1887 the first American herdbook appeared. This contained also the registrations in the first six volumes of the English society. Since that period, up to I.9oI inclusive, the American herdbook has also contained the registrations of the English book, thus including all Red Polled registrations in England and America. At present only American-owned animals are recorded in the American herdbook, which up to 1905 included 16 volumes and 22,238 animals registered 


\section{CHAPTER XLIII}

\section{THE DEVON}

The native home of the Devon breed of cattle is in southwestern England in the counties of Devon and Somerset. Devon is washed by the sea on its north and south borders, while Somerset also borders the Bristol Channel on the north. The section contains much rough and hilly land, reaching a height of even $2000 \mathrm{feet}$, and is better suited to grazing than tillage, though the soil is fertile. In the southern part the climate is mild and balmy, being well suited to outdoor life for cattle the year round.

The origin of the Devon is prehistoric. It has been assumed that the breed is descended from Bos longifrons, the smaller type of aboriginal cattle in Britain. The earliest English records show the prevalence of cattle in Devon of a color and type indicative of the modern breed. The early British writers on live stock testify to its ancient character.

The early improvers of the Devon were Francis Quartly and his brothers William and Henry, and John Tanner Davy and his brother William. Besides these J. T. Davy, above referred to, credits much to Merson and Michael Thorn of North Molton, Tapp and Buckingham of Twitchen, Mogridge and Halses of Molland, and others, who maintained the high character of their herds when breeders generally, on account of high prices, were selling their best stock for slaughter and keeping poor cattle in reserve.

Francis Quartly is generally conceded to have accomplished for the Devon what the Collings did for the Shorthorn. He lived at Champson-in-Molland near South Molton, where his father in I776 began to breed Devons. The father died in 1793 and Francis at once began active work as a breeder on his own responsibility. The cattle of Devon were deteriorating for the reason already given. He recognized this, and not only refused to sell but sought out and purchased the choicest individuals 
possible, thus developing the best herd of his time. From his herd, which was sold on his retirement in 1836 , has descended the most distinguished Devon blood. William Quartly also had a herd until 1816 , when he sold it to his eldest brother Henry, who continued breeding until his death in 1840 . Neither Francis nor William were ever married, but Henry was, and left two sons, James and John, who succeeded him. They also became great breeders, as did John's son, Henry, later on. The Quartly family lived in North Devon, not far from Somerset County.

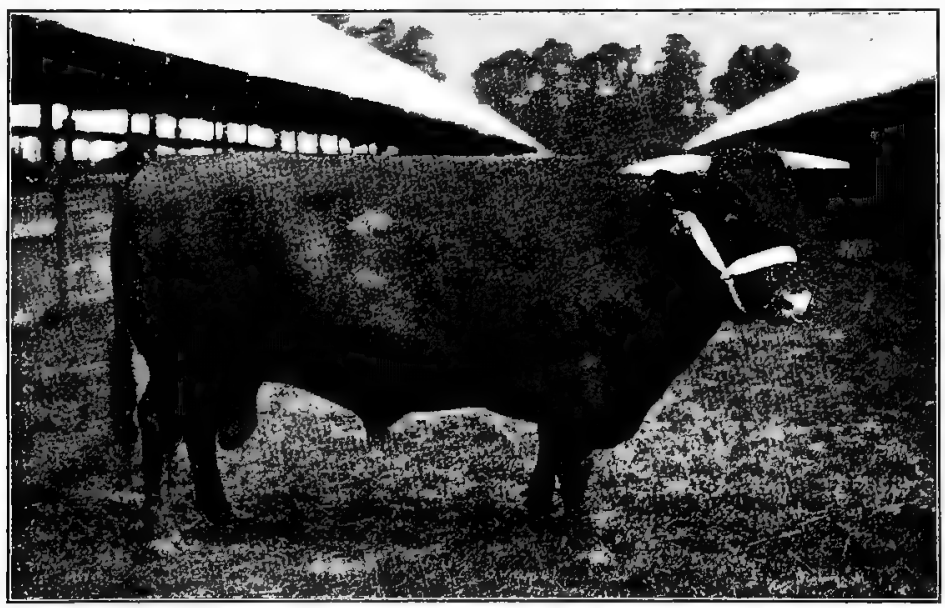

FIG. 142. The Devon bull Joker, a noted prize winner in England.

Photograph from L. P. Sisson

John Tanner Davy was a son of John Davy, a Devon breeder, who was born about I 706 and died at Rose Ash, South Molton, North Devon, in I790, leaving a choice herd to two sons, John T. and William. John produced a celebrated herd and won many prizes. Numerous celebrated Devons descend from his herd. He died in 1852 and was succeeded by his son, Colonel Davy, the founder of the Devon herdbook. This son, who died in I887, aged fifty-nine, was during his prime the most distinguished student and promoter of Devons in England. He not only founded the herdbook but contributed much to Devon literature.

The introduction of the Devon to America doubtless dates back to colonial times, and perhaps these were the first real 
pure-bred cattle to reach our shores. The port of Plymouth, from which the early colonists and the Mayflower sailed, is on the south shore of Devon, and the vessel Charity which sailed in I623 is thought to have had Devon cattle on board. Devons were imported in 1800 to Massachusetts, and in I805 General Eaton took some to Otsego County, New York. In 1817 the first purebred registered Devons brought to the United States came over in the brig Margaretta and were landed at Baltimore. These were

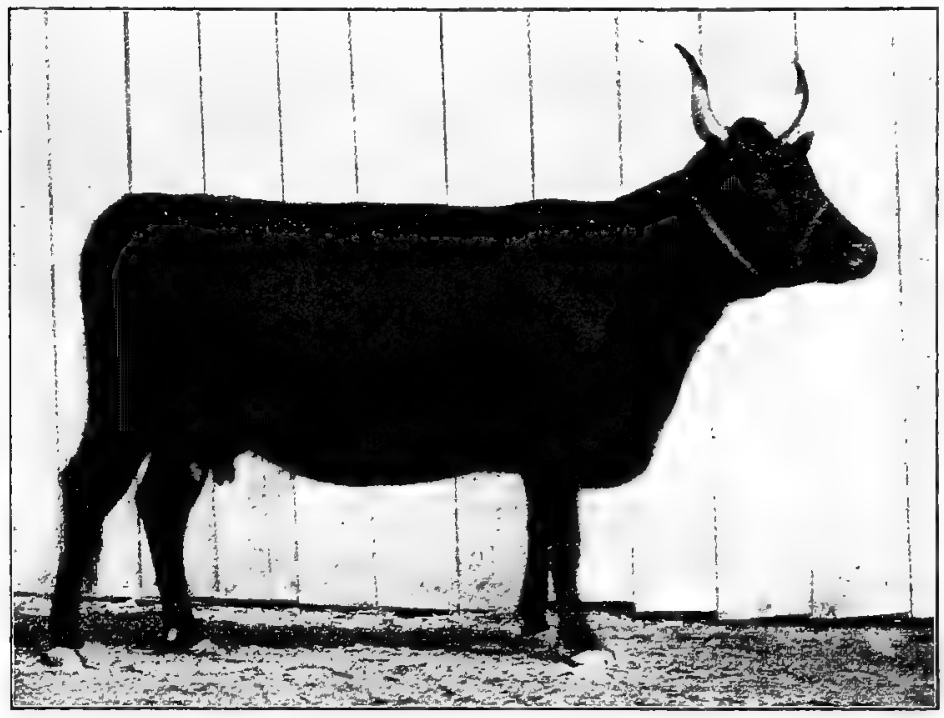

FIG. 143. Nettle Top I 2989, grand champion Devon cow at the Lewis and Clark Exposition, Portland, Oregon, 1905. Exhibited by L.V. Mc Whorter \& Son, North Yakima, Washington. Photograph by the author

a present from Mr. Coke (later Earl of Leicester), of Holkham, England, to Robert Patterson of Baltimore, and consisted of six two-year-old heifers and a bull. These became foundation animals in the American Devon Record. Other importations were later made by the Patterson family, and most of the early American Devons are descended from the stock of this family. From 1825 to 1850 and later many Devons were imported into the Atlantic coast states and into Canada, and the breed became very well known. 
Characteristics of the Devon. The Devon is not easily confounded with other breeds, owing to its individuality. The color is usually a bright red, for which they have been nicknamed "Rubies." The shade varies from light to dark. White is not admissible, excepting about the udder of the cow, or in front of the scrotum of the male, and not beyond the navel with either, nor outside of the flanks or elsewhere on the body. The hair about the eyes and muzzle should be of a creamy tint and the muzzle be flesh-colored. In addition to color as an identifying mark, the head, horns, and neck have distinctive breed attributes. The head is lean and cleanly made, and, with the female, is crowned by a pair of slender horns that are "long, spreading and gracefully turned up, of a waxy color, tipped with a darker shade." The bull's horns grow at right angles from the head or are slightly elevated, are stout and waxy at the base, and are tipped with a darker shade. The neck shows a considerable refinement, with neat head and body attachment. The body of the Devon is medium in size, is blocky of form, and usually carries a wellsprung and deep rib with strong heart girth. The legs are small and show more refinement than is the case with some other breeds. In fact typical Devons have often been referred to as deerlike in character, owing to the natural refinement of the breed.

Two types of Devons essentially exist. Those in north Devon have always been of the smaller form, and beef production has been emphasized with them. In south Devon, where the breed is known also as the South Devon or South Hams, the cattle average larger, are lighter colored, tend to be coarser, and are more productive of milk, due, it is said, to the blood of Guernsey cattle. These two types have been more or less intermingled, but the best breeders of to-day advocate adherence to type. Professor Robert Wallace in his work on the Farm Live Stock of Great Britain gives a third, a special Somerset type, found in north Devon. These cattle are larger, have a more droopy horn, and are coarser than the north Devon type, due to the better soil and climate of Somerset. As exhibited in America, the breed shows at a distinct disadvantage, for in the same show ring the beefy type may and does compete with the dual-purpose type. Western breeders appear to favor the north Devon style, while 
eastern breeders lay emphasis on the dairy value of the breed, as does, in fact, the Devon cattle association.

The size of the Devon accordingly shows considerable variation. Naturally Devons are of the smaller class as seen in beef-cattle classes in America, and this is one objection that has been raised against the breed in this country, together with the fact that the steers will not fatten as rapidly as some of the other kinds. Mature cows, according to Sinclair, weigh from I 300 to 1500 pounds and bulls from 1500 to 2100 .

The Devon as a butcher's beast does not attain the high weights of the common beef breeds, nor does it fatten as rapidly as some, but kills out extremely well, with small bone and moderate offal, producing the best of beef, fine of grain and of superior quality. Devons in the past have made a good record at the British fat stock shows, often winning high honors. This applies in particular to the beef type of north Devon. The modern breeders of that section agree that to increase the size will injure the quality, and therefore refuse to do so. Sinclair notes one English Devon breeder, whose specialty is steer breeding, who reckons that the weight of a fat Devon steer a little under three years old should be about 800 pounds. In I 89 I the first-prize Devon steer at the Smithfield Club Show, London, "not exceeding two years old," was 558 days old and had a live weight of 964 pounds.

Devons as milk producers rank very well. Many New England farmers keep Devon grades or pure-breds, from which they often secure fair yields. The milk is rich in fat, comparing favorably with that of the Jerseys. The breed is essentially unknown in competitive dairy tests in this country. In the American Devon Record are numerous examples showing that many cows of the breed are ample dairy producers. E. C. Bliss states that his fullgrown cows yield an average of 300 pounds of butter a year. J. W. Collins writes: "I have one cow, Lucky 3784, that has produced $2 \frac{1}{2}$ pounds of butter per day for weeks, and I have frequently had others that have made $2 \frac{1}{4}$ to $2 \frac{1}{2}$ pounds per day." Wallace states that as a breed for milk production "it has been and still is inferior. The cows give but a small quantity of milk and tend to go dry early." Alvord, who knew the breed well, states that some families bred and selected for dairy 
purposes have made fair milk records, single animals producing 40 and even 50 pounds a day.

The Devon in crossing or grading has seen much service in the eastern United States. Owing to its long pure inheritance the breed characteristics are usually strongly transmitted. Devon bulls on grade cows will produce a superior class of beef and rich milk.

The Devon as a grazing beast has always ranked high. In its native home many steers are grass fed and receive but little grain.

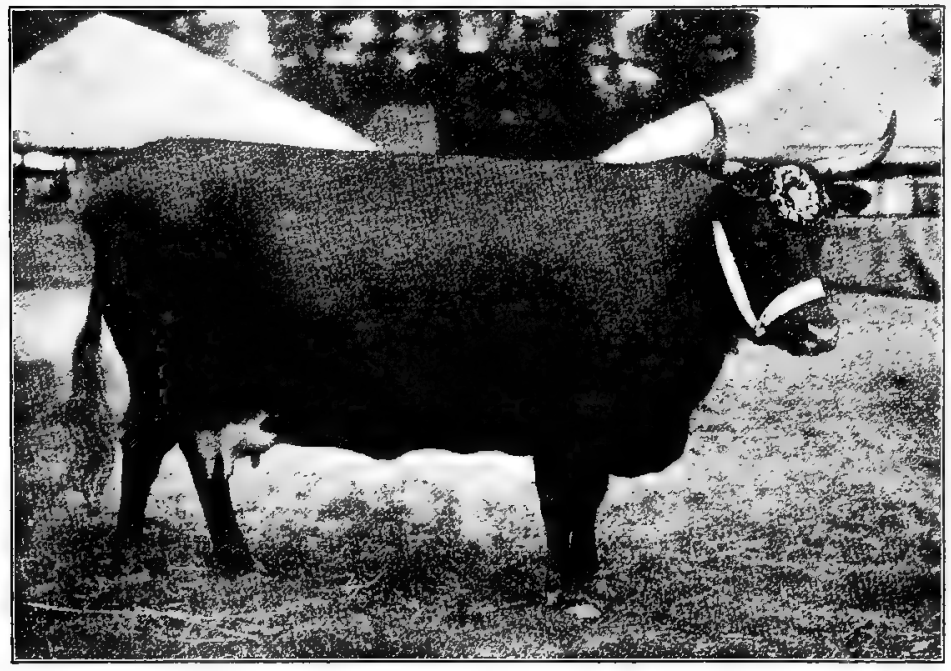

FIG. 144. Fern of Halsden, champion Devon cow at the Royal Agricultura] Society of England Show, in I904. This shows the beefy type of Devon. Photograph from William Cooper \& Nephews, Berkhamsted, England

Devon oxen have long ranked very high. In New England and the eastern United States, when oxen were more extensively used than to-day, the Devon was a favorite sort. Years ago in New England one might have seen many fine yokes of grade Devon oxen, that were highly valued for intelligent and active draft service on the hill farms. No cattle are more light and active of foot for this purpose.

The distribution of Devons is almost world-wide, although the breed is not nearly as popular to-day as it has been. There are some herds in England outside of the Devon district, mainly in 
the south section, in Ireland, the United States, Canada, New South Wales, Tasmania, New Zealand, Queensland, Mexico, the West Indies, and South Africa. Devons in a general way have been distributed all over the United States, but are not in large numbers in any state. Ohio, Pennsylvania, New York, and New England are the foremost sections in Devon breeding in America. The breed seems quite adaptable either to the rougher, grazing regions, or to the more fertile, low-lying countries.

Organizations to promote Devon interests exist in England and America. The first Devon herdbook was published by Colonel Davy in $185 \mathrm{I}$, who subsequently published seven more volumes, the last in $188 \mathrm{I}$. About I 880 the Devon Cattle Breeders' Society was organized in England, and the herdbook publication was transferred to it about $\mathrm{I} 884$ by Messrs. Hawkes and Risdon, who had purchased the rights from Colonel Davy in 1883 . Some twenty-eight volumes of the Devon herdbook have been published since I $85 \mathrm{I}$, registering over 5000 bulls and 20,000 cows. About 1890 the South Devon Herdbook Society was organized, publishing its first herdbook soon after in I89I, since which time eight volumes have been published up to 1905 . In the United States an American Devon Herdbook was first published in 1863 , four other volumes following, the last in 1879 . The American Devon Record was first published in I88 I by James Buckingham of Zanesville, Ohio. Later this record became the official register of the American Devon Cattle Breeders' Association, and up to 1905 seven volumes were published, showing nearly I 3,000 animals recorcled.

The popularity of the Devon in America at the present time is very low. For a breed with such an old and creditable history it is a remarkable thing that it should have come to such a subordinate place among well-known breeds in America. But few Devons are seen at the fairs outside of New England, while at the large shows they are often unrepresented. At the Louisiana Purchase Exposition at St.. Louis in 1904, the greatest American cattle show in history, the Devon exhibit was represented by two small herds, such as hardly produced a comment by the live-stock press. At the International Live Stock Exposition at Chicago the same year not one Devon was shown. 


\section{CHAPTER XLIV}

\section{THE BROWN SWISS}

Two distinct races of Swiss cattle are found in Switzerland, one known as the Brown Schwyzer, and the other the Simmenthal or spotted breed. The former comprises about two fifths of the cattle of that country, while the latter represents three fifths of the total. The former are bred and imported to the United States, while the latter are not exported unless in so small a way as to be inconspicuous.

The native home of the Brown Swiss is Switzerland, where in winter they dwell in barns in the lowlands and valleys, while in summer they pasture, even to the upper grazing line of the Alps. They are distinctly a hardy mountain breed, and in general subsist on pasture or hay exclusively, grain being but very little used. These cattle are bred in their greatest purity in the central part of Switzerland in the cantons of Schwyz, Uri, and Zug, though the breed is generally found over the northern and eastern parts of the country.

The origin of Brown Swiss cattle is probably prehistoric. Horns, skulls, and other bones have been found in the Swiss lake dwellings, which date back to the Bronze Age, that closely resemble those of the Brown Swiss of to-day. It is generally conceded that the breed is very ancient, and that it has long been bred with much purity and care by Swiss farmers.

The introduction of Brown Swiss to the United States first occurred in 1869 , when H. M. Clark of Belmont, Massachusetts, purchased of Colonel G. Bürgi of Arth, canton of Schwyz, seven heifers and one bull, which soon after their arrival were resold to D. G. Aldrich of Worcester, Massachusetts, and David Hall of Providence, Rhode Island. In 1882 Scott \& Harris of Massachusetts imported nine two-year-old heifers and a bull, and in I883 ten heifers. In I883 William Thoch of New York and 
Ridge and Eldredge of the same state made importations. The most important recent importation was that made in 1904 by McLaury Brothers of New York, who brought over a number of show cattle which they exhibited at various state fairs and at the Louisiana Purchase Exposition at St. Louis. The breed has never secured an important position in America since its introduction.

The characteristics of the Brown Swiss. This is essentially a dual-purpose breed of very uniform and distinct breed characteristics. The color is a light or dark brown, that most esteemed

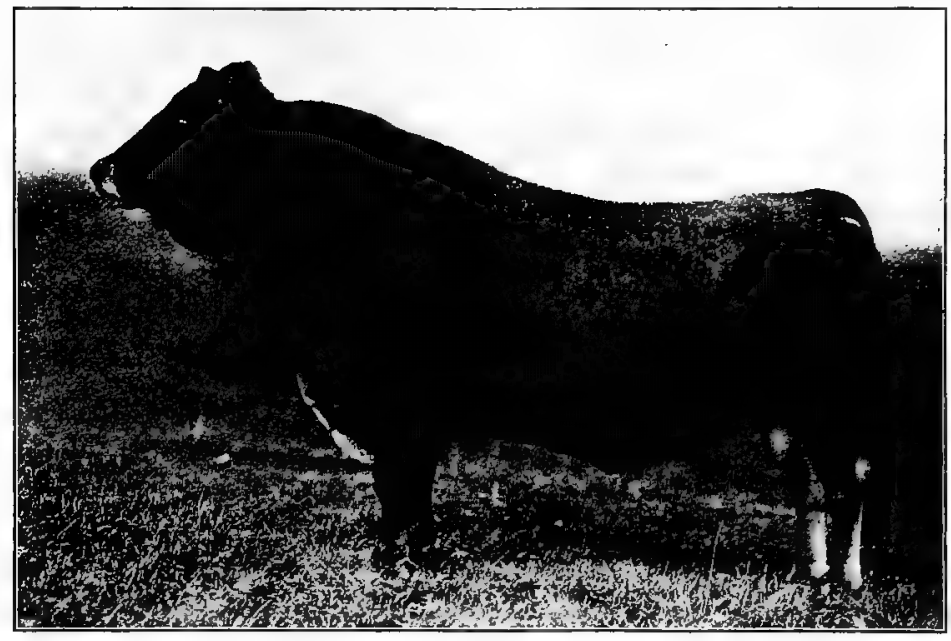

FIG. 145. Upland Hobby 1488, grand-champion Brown Swiss bull at the Louisiana Purchase Exposition, 1904, and one of the most noted prize winners of the breed. Owned and exhibited by F. R. Hazard, Syracuse, New York. Photograph from the owner

being a dark brown or mouse color, fading to gray along the backbone to the tail head, and sometimes also about the belly. There is also a mealy or creamy ring about the muzzle. The udder is usually white, the hoofs black, and the horns white in the lower part and very dark at the tips. The tongue and nose are very dark colored, approaching black. The general form of Brown Swiss cattle is distinctly blocky, much more so in fact than other dual-purpose breeds, the points being full from breast to hind quarter, showing thickness and depth. The head is 
rather heavy, and combining as it does a sizable horn and a fullness of the neck quite unknown with British breeds, impresses one as somewhat coarse. The neck is large and heavy in both sexes at all ages, the skin about the throatlatch and along the dewlap being strikingly abundant. The breast is broad and deep, and the shoulders rather heavy and prominent, not being set in deep. The body shows a great deal of feeding capacity with plenty of depth, but the back is frequently slack in front, and the fore ribs have scarcely enough spring for best conformation. The hind quarter is long, level, and broad at the rump, the thighs and twist incline to be distinctly beefy, and the legs are short and strong. The cows have large udders, frequently long, wide, and deep, with well-placed teats of convenient size. The milk veins and wells average medium in size, comparing fairly with dairy breeds. The quality, from the standpoint of an American, averages rather below medium, as is very commonly seen in the thick, none too elastic, deep yellow skin, rather coarse hair, large joints, and heavy head, neck, and fore quarters. In temperament cattle of this breed are very superior, being quiet and docile to the most satisfactory degree.

The size of Brown Swiss cattle is somewhat variable, according to American consuls in Switzerland, being smaller in the high Alpine districts than in the lower regions. A standard weight of cow, however, is given at from I 300 to 1400 pounds at maturity. The males may weigh over 2000 pounds, although I 500 to 1800 pounds represent standard weights. It is thought by some that the males more nearly approach the females in weight than in most breeds.

The dairy qualities of the Brown Swiss appeal particularly to the people of Switzerland, for this is the leading milk-producing breed of the country. Numerous records of Swiss dairies show large capacity on the part of the Brown Swiss cow. Mr. F. H. Mason, as United States consul in Switzerland, reports that at Cham the 6000 cows supplying the Anglo-Swiss Condensed Milk Company yielded 5315 pounds each. These cows were milked for an average of about nine months, and were fed only grass and hay. Consul Beauchamp of St. Galle reports visiting one of the largest herds of pure-breds in Switzerland, that of 
Mr. Kühn of Degersheim, where 40 superior cows averaged I 7 to 20 quarts of milk per day. In the Pan-American dairy test in 1901 the five Brown Swiss cows stood third in total milk solids produced, eighth in net profit in fat, and fourth in pounds of milk produced, being surpassed in milk yield by the Holstein-Friesian, Ayrshire, and Shorthorn respectively. In net profit in the six months' test the highest rank attained by a Brown Swiss among fifty head of ten breeds was nineteenth, the cow Bell $\mathrm{T}$. showing a net profit of $\$ 41.23$, compared with

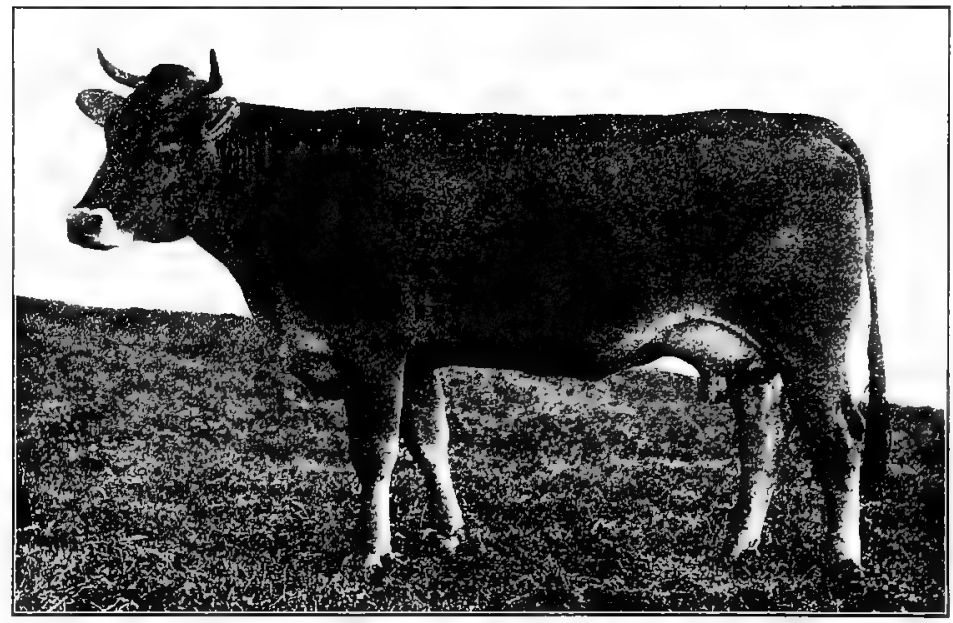

Fig. 146. An excellent type of Brown Swiss heifer as seen in Switzerland. Photograph from McLaury \& Son, Portlandville, New York

$\$ 59.2$ I for the cow in first place, a Guernsey, Mary Marshall. The late Major H. E. Alvord reports a Brown Swiss cow in Massachusetts to have produced by accurately recorded weights 86,304 pounds of milk before twelve years of age, making from 500 to 6 Io pounds of butter per year for four years. The milk is merely fair in per cent of fat, the average in tests of several thousand head being 3.30 per cent. In Switzerland, where much cheese is made from this milk, about twenty pounds are required for one pound of cheese.

The dairy test of the cow Brienz I 68 is of special interest in connection with this breed. In November, I89 I, this cow, aged 
twelve, weighing 1400 pounds, in a public test at Chicago under the auspices of the Illinois State Board of Agriculture, averaged $8 \mathrm{I} .7$ pounds of milk per day for three days, the total milk yielding 9.32 pounds butter fat, which stands as the largest public milk and butter-fat test yet made by any breed. Brienz was a Brown Swiss, owned by Mr. Abe Bourquin of Illinois.

The Brown Swiss as beef producers rank well in Switzerland, the Germans especially seeking the fattened cattle, which are said to produce a desirable class of meat. In America there is little evidence on this point. The cattle, however, keep in good flesh easily and fatten rapidly. Weights of 400 to 600 pounds at

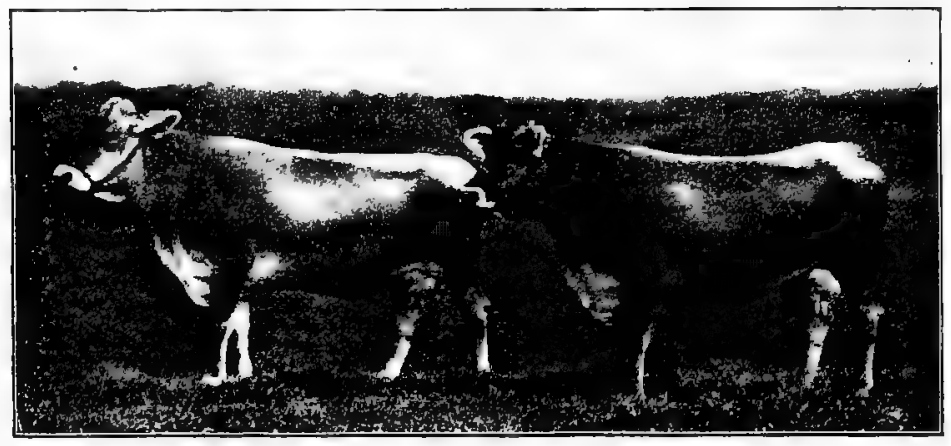

FIG. 147. A pair of Brown Swiss cows, Upland Laura 200 and Upland Augusta 2266. Owned by F. R. Hazard, Syracuse, New York. Photograph from the owner

four to six months old are given as common, and the steers attain a large size and dress out 55 to 60 per cent. It is not likely, however, that cattle of this type will ever become popular in the beef-cattle market in America.

The distribution of Brown Swiss cattle is mainly over continental Europe, they thriving there, it is said, very generally, excepting in Spain. In the United States there are but comparatively few herds, the better-known ones to-day being in New York, Ohio, Illinois, Missouri, Wisconsin, Minnesota, and Colorado.

The adaptability of the Brown Swiss to a wide range of conditions seems apparent. Their native home is in the mountains, 
where they thrive on rations that would not be regarded as satisfactory in America, and where they are distinctly hardy. The herds kept in the more sterile sections of the eastern United States seem to thrive equally well with those in the corn belt of the West. No doubt they have a special place in dairy sections, notably in the more elevated regions where a rugged breed is desirable. From the profit point of view it is doubtful if they can compete satisfactorily with some of our other breeds in the fertile West.

The Brown Swiss in crossing or grading will do very well where mated with stock lacking in vigor, for this breed is of superior vigor and hardiness. No doubt many grade dairy herds of Jersey or Guernsey character would have increased vigor restored by a Brown Swiss cross, with a higher value from the butcher's point of view.

The American Brown Swiss Breeders' Association champions the cause of the breed in this country. This association was organized in 1880 , and up to 1905 had published three small herd records, showing a registration of II 57 bulls and I7I4 cows. A very creditable and comparatively large exhibition of Brown Swiss cattle was made in 1904 at the Louisiana Purchase Exposition, New York, Missouri, and Illinois being represented. This was the largest show of the breed thus far held in America. 


\section{A FEW REFERENCE BOOKS ON CATTLE}

Lewis F. Allen, American Cattle. New York, 1890.

* Lewis F. Allen, History of the Shorthorn Cattle. Buffalo, 1872.

A BerdeEn Angus, The Breed that Beats the Record. Detroit, I 886.

George Armatage, Cattle: Their Varieties and Management. London, N.D.

Robert W. Ashburner, The Shorthom Herds of England. Warwick, N.D.

*C. J. BATES, Thomas Bates and the Kirklevington Shorthorns. London, I 897 .

* Rev. W. Holt Beaver, An Arithmetical Arrangement of the Leading Shorthom Tribes. London, N.D.

* Thomas BeLl, History of Improved Shorthorn-Durham Cattle. Newcastle-onTyne, 1871 .

J. Coleman, Editor, The Cattle of Great Britain. London, 1875 .

William S. Dixon (The Druid), Saddle and Sirloin. London, 1870.

Charles L. Flint, Milch Cows and Dairy Farming. Boston, I889.

Thomas J. Hand, Guenon on Milch Cows. New York, 1883.

Willis P. Hazard, The Jersey, Alderney, and Guemsey Cow. Philadelphia, 1872 .

*Frederick L. Houghton, Holstein-Friesian Cattle. Brattleboro, 1897.

*William Housman, Cattle: Breeds and Management. London, 1897.

* William Housman, The Improved Shorthom. London, i 876.

* John S. I Insley, Jersey Cattle in America. New York, I 885.

IV Illiam McCombie, Cattle and Cattle Breeders. Edinburgh, 1875 .

*James Macdonald and James Sinclair, The History of Hereford Cattle. London, 1886.

* Macdonald and Sinclair, History of Polled Aberdeen or Angus Cattle. Edinburgh, I882.

T. L. Miller and T. F. B. Sotham, History of Hereford Cattle. Chillicothe, 1902.

*Charles S. Plumb, Litle Sketches of Famous Beef Cattle. Columbus, Ohio, 1904 .

Dr. G. Pusch, Die Beurteilungslehr des Kindes. Berlin, 1896 .

* Consular Reports, Cattle and Dairy Farming. Washington, i 887.

*Alvin H. Sanders, Shorthom Cattle. Chicago, 1900.

* James Sinclair, History of the Devon Breed of Cattle. London, I893.

* Rev. John Sturer, The Wild White Cattle of Great Britain. I

*E. Lewis Sturtevant, The Dairy Cow (A monograph of the Ayrshire breed of cattle). Boston, 1875 .

EMILe THIFRe, Les Vaches Laitières. Paris, I 895 .

Grorge VASEY, A Monograph of the Genus Bos. I.ondon, 1857 .

* William Yuuatr, Cattle: Their Breeds, Management, and Diseases. London, 1835 . 


\section{PART III - SHEEP}

\section{CHAPTER XLV \\ THE MERINO OR FINE-WOOL TYPE OF SHEEP}

The Merino involves several families, and all sheep of this group are known as fine wools, producing the finest of fiber used in the woolen trade.

The Merino in general conformation may be compared to the dairy cow. The body lacks fullness of bosom, breadth of back, and general thickness all through; the leg of mutton is not thick and full, and the neck and legs tend to be long. A muscular development of the entire body prevails, rather than smoothness and heavy fleshing. The wool is somewhat short of staple, is very thick over the entire body, and is remarkably fine in quality. An oily secretion, commonly known as yolk or grease, found on all sheep, exudes from glands at the base of the wool fiber, and gradually passes up the wool to the tip. Some sheep possess much more yolk than others, notably Merinos of the Spanish-American type with heavy folds. This yolk accumulates dust and dirt on the exterior of the fleece, forming a dark, dirty covering. There are exceptions, however, with the smoothbodied Merinos, some showing but little external yolk.

Three classes of Merino sheep are recognized to-day by many of our leading breeders. Owing to the difference in type, as shown by the folds or wrinkles on the neck and body, in I 893 the World's Columbian Exposition at Chicago grouped these sheep into two classes. This same classification has been accepted and used elsewhere, including the Louisiana Purchase Exposition in 1904 at St. Louis. The classes are as follows:

Class A Merino represents the distinctiy Spanish or American type, with heavy folds at the neck and over the body and hind 
quarters, with a very high percentage of wool and yolk to carcass. At a public shearing at Middlebury, Vermont, in 1882 a bunch of 54 ewes and rams of this class averaged 23.3 per cent unwashed fleece to live weight, and cases are on record where 36 per cent of the original weight of sheep was fleece.

Class $B$ Merino carries the Spanish or American blood lines also, but has a smoother body, with less folds and less yolk in the staple. Sheep in this class usually have some folds about

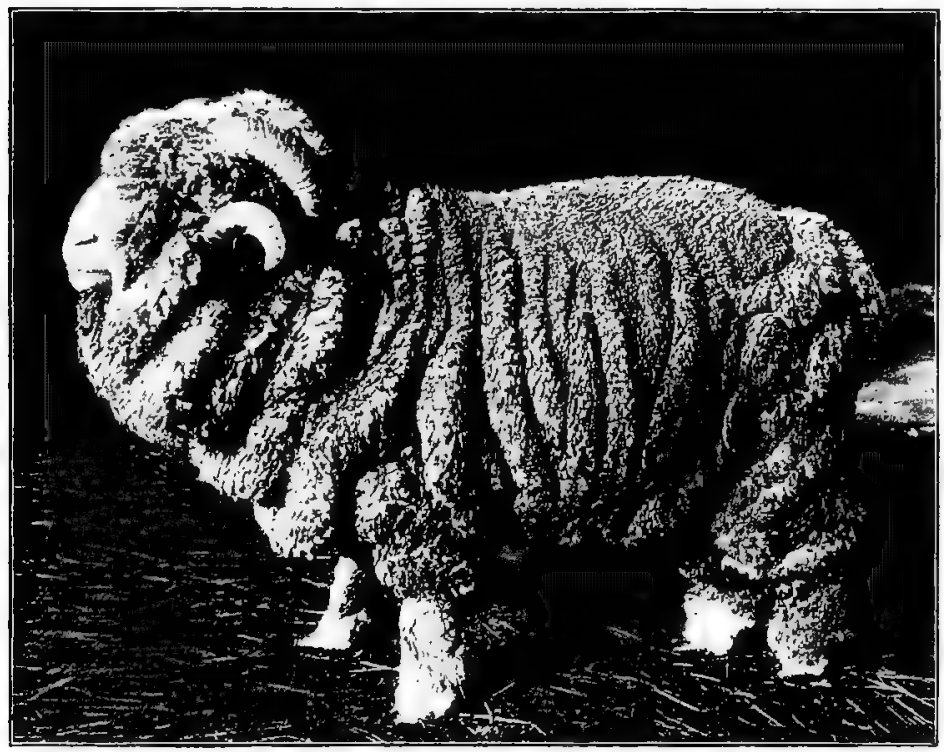

FIG. 148. A fine example of a "Vermont Merino," well illustrating the Class A type. Photograph from the National Stockman and Farmer

the neck and breast, and perhaps in a slight way at the thighs. They usually have somewhat more scale and carry more natural flesh and some less wool and yolk though with a longer staple than those belonging to Class $\mathrm{A}$.

In order to more sharply draw the line between Merino sheep of different types, many breeders, notably in Ohio, have a third class, known as Class C Merino.

Class $C$ Merino has a very smooth body, with no folds at all, unless to a very slight extent in the neck or breast. The 
Delaines and Rambouillets represent this type. These have a fleece with less yolk and weight although an increased length of staple, with a still larger, smoother body, approaching nearer the mutton type of carcass, while the fleece retains its typical fine-wool character.

The use of the three classes of Merinos may be found in the very best American flocks, one man keeping sheep of each class. As sheep of Class C lack weight and quality of fleece to some

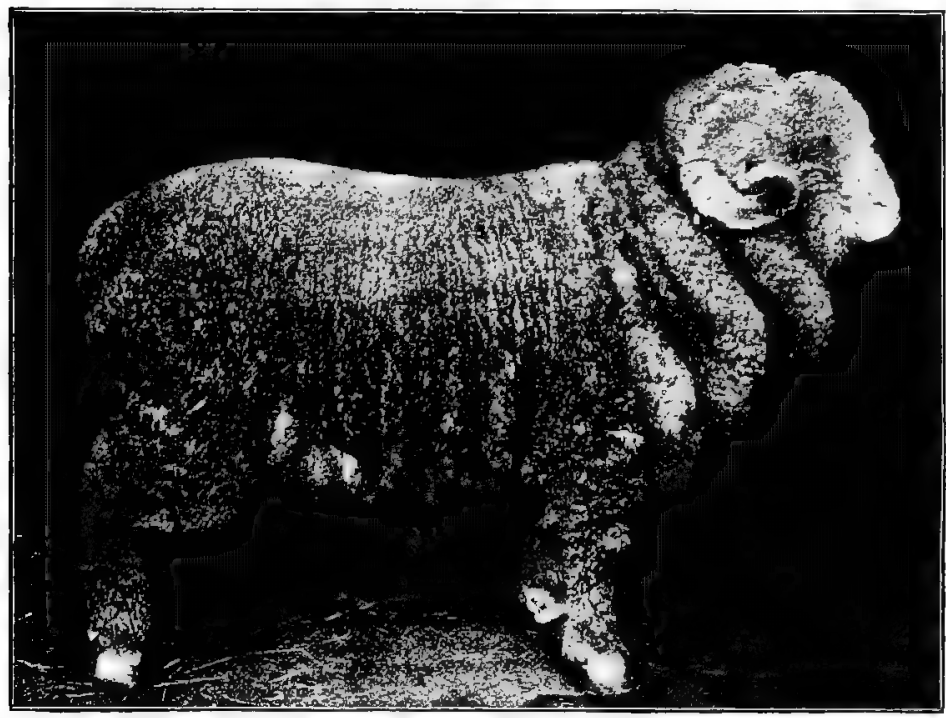

FIG. I 49. The Sweepstakes Merino ram of the Class B type at the Illinois State Fair and the St. Louis Exposition and Fair. Exhibited by C. H. Bell of Ohio. Photograph from the American Sheep Breeder

extent, careful matings of rams of Class $A$ are made upon ewes of $\mathrm{C}$, resulting in the more desirable $\mathrm{B}$ sort, shearing much more easily than those of $\mathrm{A}$, giving a reasonably heavy fleece, and producing an improvement over $\mathrm{A}$ for mutton. By variously mating these three classes the breeder may secure a type of Merino to suit his special needs. Thus some of our best breeders are able to supply calls for sheep of any or all of the three types.

The head of the Merino sheep should be short, broad at the muzzle, with large nostrils. A nose short and inclined to be 
wrinkled, and somewhat thick or Roman with the rams, is preferred. There should also be ample width between large, clear, mild eyes, with a prominent forehead. The ears should be fine and short, be actively carried, and have a covering of silky hair. The horns, which occur on the males, as a rule interfere with a natural action and movement of ear. The horns on mature rams are large, are rather angular at the base, and have a spiral turn backward, then downward, around forward, and up, forming a more or less corkscrew shape. The horn when fully developed usually shows one and one-half turns, and with some the tip of horn turns upward and with others down. The head of the male, as a whole, should show sex character in a strong degree.

The neck of the Merino should be of moderate length, neither thin nor thick and heavy, but should be moderately muscled and blended smoothly to head and shoulders. The neck of the male should be more heavily muscled, showing distinct masculinity, with some indications of throatiness or depth of covering.

The shoulders should be smooth and incline well into the back, and not be too prominent. A prominence of shoulder is a too common feature with this type. The withers are frequently sharp and high, although a neat, close, nicely rounded, smooth top at this point is desirable especially with the ewes. More prominence of withers is desired with rams, and some of the greatest sires have been very strong in this respect.

The breast and chest should exhibit considerable depth, with a reasonable thickness in proportion. A common feature of the Merino is to have too peaked a breast, lacking thickness at the chest. The crops and fore flank, which show material deficiency in many cases, should be reasonably well filled out.

The front legs of the Merino are characteristically crooked at the knees. As one looks at them from in front the knees fairly touch together, while the toes spread out. Sometimes the wool on the legs causes deception in this respect, but as a rule the legs are too crooked at the knees, due primarily to a narrow chest. The same rule will apply to sheep as to other animals in regard to position of leg, quality of bone, and length of parts. The pasterns should be springy, of medium length, and should be strong and support the sheep in proper form. 
The back of the Merino varies according to the class. Those of Class A usually are narrower and flatter of rib. In any class a strongly supported, fairly wide back, with level, wide loin is essential.

The body should have a rather strongly rounded out form, the ribs showing a fair arch and consiclerable length, thus furnishing ample feeding and breeding capacity. A blocky, short body is not so typical as one with more roundness and of moderate length. The hind flanks should show ample depth.

The lips must be sniooth, not especially prominent, and should be neatly covered.

The rump of the Merino, in correct form, is long, level, and wide, but a common defect of specimens of this breed, no matter what the class, is a peaked, droopy rump.

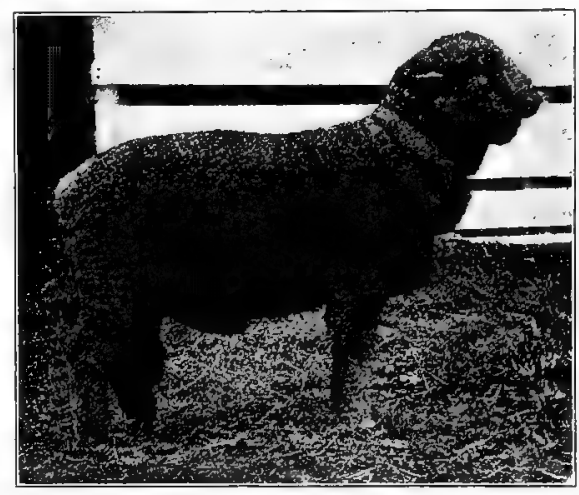

FIG. I50. An example of the Class C type of Merino. Photograph by the author

The leg of mutton varies with the class. The nearer one approaches Class $C$ the more filled out in all its parts the hind quarter becomes. Nevertheless, even in Class A, the thigh should be strong and reasonably full, though not so thick or full in twist as with Classes B and C. Considering that Class C emphasizes mutton value, the leg of mutton here should be strong of development.

The hind legs should be muscular and straight, whether viewed from either rear or one side, the shank bones fine and short, the pasterns strong and well carried, and the toes neatly placed. Instead of that, the hind legs in all classes of Merinos strongly tend to crooked hocks, the points nearly if not quite touching, and the toes turning out. Often the legs below the hocks are carried too much under the body, the shanks being too slanting. Owing to lack of attention, the toes often grow too long, and thus the foot becomes thrown out of proper placing 
and the entire leg is affected. Careful trimming of the toes will easily remedy this. Sheep of the A class tend to have bad feet and should be carefully selected and mated with the view of avoiding this trouble as much as possible.

The skin of the Merino should be firm and of a bright pink color and free of all scurfiness. No class of sheep, as a rule, shows such excellent, high-class color of skin as generally prevails with this breed. The smoothness of skin varies, that of Class A having notable folds, as has been explained on page 333 , Class $B$ having less, and Class $C$ hardly any at all. The skin of Class A sheep is also thicker, mellower, and more porous than that of Class $\mathrm{C}$ which is thin and more delicate than the other.

The fleshing of the Merino of Class A type is limited in degree, zing really a very muscular body with almost no fat. A smoother, better-fleshed body occurs with Class B, while Class $\mathrm{C}$ in ideal form is well rounded out, smooth in all the parts, neatly covered with flesh without superfluous fat.

The wool of the Merino, as has been stated, represents the finest grade produced on the sheep. This varies in diameter and length, according to the breed or breeding, and is discussed to some extent under Merino families proper. In all cases, however, the fleece should cover the body densely, and the fibers be very fine, uniform in diameter, and carry considerable crimp. The oil or yolk should be sufficiently abundant to keep the fleece in superior condition at all times, indicating a healthy condition of skin and body. This oil exposed to the sun turns darker in color than when shaded in the fleece and so adds to the dirty external appearance. A white oil is said to turn darker than the more yellow sort. A fleece colored moderately yellow by the oil, being neither white nor egg-yellow, is preferred. A very heavy exudation of oil is objected to as not only causing unnecessary shrinkage of fleece in washing but also as being something of a drain on the animal's vitality. To some extent it is probable that the amount of oil may be affected by the food. Professor J. A. Craig states that lambs fed grain from birth invariably sheared heavier fleeces than those that only had grain during the latter three months of feeding. The wool should be naturally bright and lustrous, with a clean white color. 


\section{CHAPTER XLVI \\ THE AMERICAN MERINO ${ }^{1}$}

The Spanish Merino as the parent of the American Merino should receive a brief consideration introductory to this breed.

The native home of the Merino is in Spain, in southern Europe. The country is quite variable in character, the interior consisting of plains as well as long ranges of mountains, some of which are many thousand feet high. There are numerous rivers and deep valleys. The climate is generally dry and mild in the lowlands, and oranges, citrons, olives, and grapes are commonly produced; while on the plains and mountain sides are extensive pastures, where in times past large flocks have grazed. On the lower, richer lands the sheep are larger than on the dryer, poorer soils or more elevated mountains.

Sheep husbandry in Spain was for centuries an important industry. Historians at the beginning of the Christian era directed attention to the superior fleece of the sheep of Spain, especially Columella, a famous Latin writer on agriculture, who wrote during the first century. As early as the eighth century, when the Saracens took possession of Spain, they established many mechanical arts, among which was the woolen industry, and the Spanish sheep furnished the fiber. The statement has been made that in Seville no less than sixteen thousand looms existed in the thirteenth century. Some of the Spanish cloths were highly esteemed for their quality. By the fifteenth century, however, the Moors had been largely driven from Spain and the woolen industry fell into decay and finally became unimportant. Later an attempt was made to revive the manufacture of fine fabrics from wool, but without success.

1 The word "Merino" is Spanish, signifying governor of a small province, and likewise one who has care of the pastures or cattle in general. He receives his appointment from the king, is a person of rank, and is termed Merino Mayor. 
Two great groups of Spanish sheep existed in times past. One, known as Estantes or stationary, consisted of flocks of the coarser wooled types, and these remained permanently on many of the hill farms. The other group, termed Transhumantes or migratory, consisted of flocks that were driven during the spring season, under the care of competent shepherds, across country and into the mountains over a grazing region, to be returned in the fall to the original home. The Transhumantes were divided into two

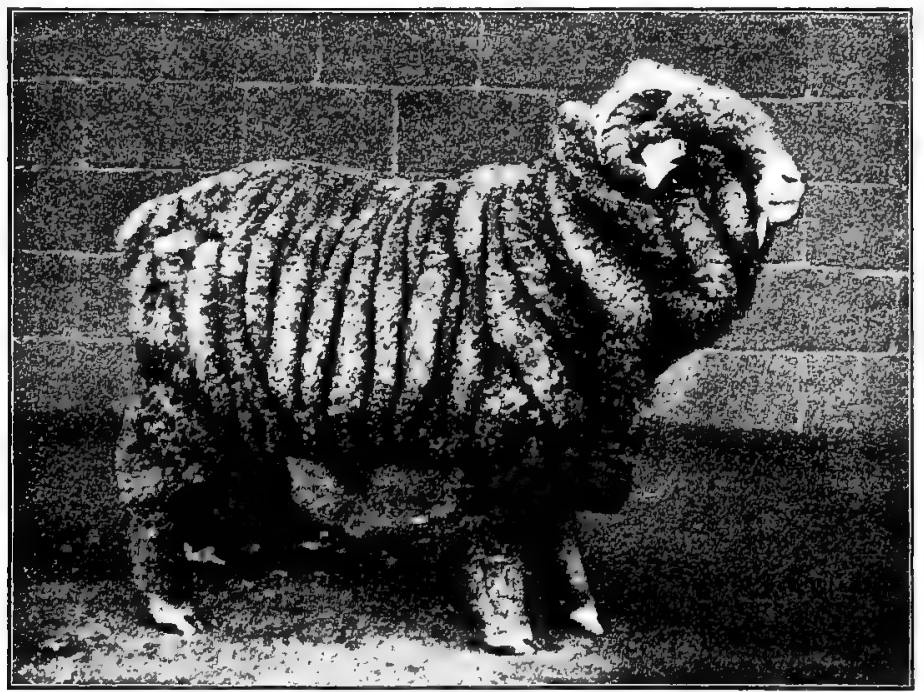

FIG. I51. An American Merino ram, shown at the Pan-American Exposition in Igor by H. D. Jackson of Bridport, Vermont. This ram was first-prize yearling and the champion ram of the Class A type. Photograph from the National Stockman and Farmer

classes, the Leonese and Sorian. The former was the more numerous and was the highest esteemed. Most of the sheep brought to America from Spain belonged to the Transhumantes group.

The annual Merino drives in Spain were most important affairs. Youatt writes as follows :

The Leonese after having been cantoned during the winter on the north bank of the Guadiana, in Estremadura, begin their march about the fifteenth of April in divisions of two or three thousand. They pass the Tagus 
at Almares, and direct their course towards Trecasas, Alfaro, and L'Epinar, where they are shorn. This operation having been performed, they recommence their travels towards the kingdom of Leon. Some halt on the Sierra (ridge of the mountains) which separates Old from New Castile, but others pursue their route to the pastures of Cervera, near Aquilar del Campo. Here they graze until the end of September, when they commence their return to Estremadura. The Sorian sheep, having passed the winter on the confines of Estremadura, Andalusia, and New Castile, begin their route about the same time. They pass the Tagus at Talavera and approach Madrid ; thence they proceed to Soria, where a portion of them are distributed over the neighboring mountains, while the others cross the Ebro in order to proceed to Navarre and the Pyrenees.

It is said that these periodical journeys can be traced back to the middle of the fourteenth century, when a tribunal was established for their regulation. The number of these migratory sheep seventy-five years ago was placed at ten millions, and they were divided into flocks, each in care of a Mayoral or chief shepherd.

The important provincial flocks of Spain, from which the best Merino blood was exported, were represented on about a half dozen estates, there being mainly, according to Livingston, about 30,000 on each estate. These flocks have been described by various early writers, notably Consul William Jarvis, who was familiar with the flocks in Spain a century ago, he being United States consul at Lisbon, Portugal, from which port thousands of Merinos were shipped. The information concerning the early Spanish flocks is more or less obscure, often indefinite, and sometimes conflicting. The following is such evidence as can be presented of the groups or classes from which American importations were mainly drawn. In Spain these classes were more or less interbred, and the same applies to American flocks.

Paular Merinos. This type which produced the largest and best fleeces was originally owned by the Carthusian friars of Paular, on the borders of Andalusia, an agricultural class of monks that paid great attention to horses and sheep. This was probably one of the handsomest flocks of Spain, having close, compact, soft, and silky wool, with less surface yolk than most types. The Paulars were credited with enlargement behind the ears, with considerable throatiness, and their lambs had a coarse hairy appearance at birth. 
Aguirre Merinos. This type had more wool about the face and legs than did the other types. The wool was more crimped than that of the Paulars and less so than that of the Negrettes, and was thick and soft. The Aguirres had short legs, round and broad bodies, and much loose skin or folds.

Negrette Merinos. These were the largest and strongest of the Transhumantes sheep of Spain. The wool was some shorter and more open than that of the Paular, and "inclined to double." Many Negrettes were wooled on the face, and on the legs to the hoofs. All the loose-skinned sheep had heavy dewlaps. The rams possessed large horns.

Guadalupe Merinos were heavier of bone than the Negrettes, and were of much the same size, but were not so handsome,

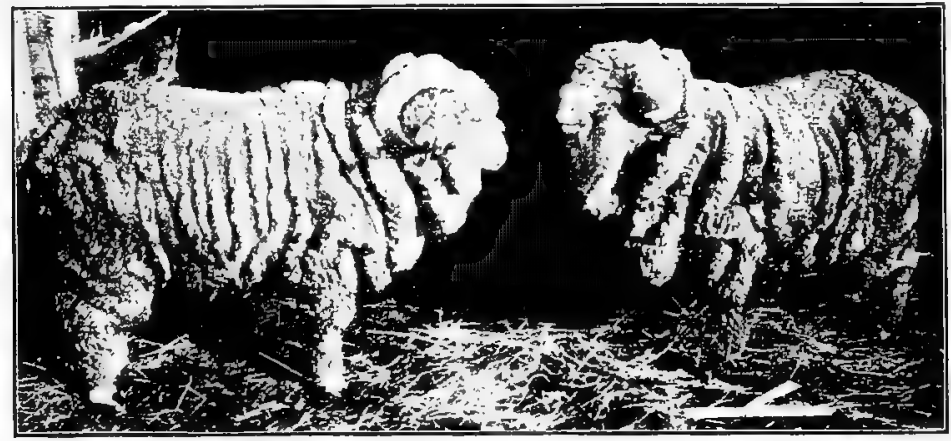

FIG. 152. Wooly Nose and White Nose, two American Merino rams owned by J. J. Deeds of Ohio. Photograph from the American Sheep Breeder

according to Jarvis, although Lasteyrie credits them with the most perfect form, and says they are celebrated also for the quantity and quality of their wool. These sheep had numerous folds, and the wool was thick and crimped and more oily than the Negrette.

The Escurial Merinos were about as high as the Paulars, but were slighter of frame. Their wool was crimped and not so thick as the Paular wool, and they had less wool on the legs and faces, nor were their skins so loose as the Negrette and Aguirre families. Montarco Merinos closely resembled the Escurials.

Infantado Merinos were mainly bred by the Duke of Infantado. They were very superior sheep and many of them were brought 
to America, notably by Colonel Humphreys. The horns on the rams came nearer to the sides of the head than did those on the Paulars and Negrettes. The Infantados of Atwood were mated with Paulars and gave a great improvement, and from this commingling of blood resulted the Atwood family of Merinos, long celebrated for superiority of fleece.

The origin of Merino sheep is merely speculative. It has been assumed that the parent stock existed in Spain prior to the Christian era, and that this was improved by the introduction of Tarentine sheep from Tarento, southern Italy. Lucius Columella is said to have introduced these A.D. 4I, and he also imported African rams. The people of Carthage and Phoenicia in northern Africa brought fine-wooled sheep to Spain, as did probably other invaders also. The sheep of Spain in those days were of various colors, - white, black, red, or tawny, the red fiber being of the finest quality. Undoubtedly these early sheep were much inferior to those we know to-day in America, but they without question produced finer wool than did other European sheep. The modern i mprovement of the Merino was essentially accomplished out of Spain. The Spanish government opposed most of the first exportations, and many sheep were smuggled from the country.

The exportation of Merinos from Spain to European countries and America was of great importance, for with this the improvement of the Merino began.

Swedish Merinos. It is believed that the first of these sheep exported from Spain were taken to Sweden in 1723 by $\mathbf{M}$. Alstroemer.

The Saxon Merino. In I 765 the Elector of Saxony imported from Spain 92 rams and I 28 ewes, these coming from the flocks of Count Negrette. Part of these were placed on a farm near Dresden, and were later distributed to various farms, where they were carefully bred, and where they did remarkably well. Youatt states that the wool of the Saxon Merino became finer and more serrated than its Spanish progenitor, and so had an increased value. It nas been claimed that the Saxon is the least hardy of the modern Merinos. The modern type of Saxon is essentially free of folds.

German or Silesian Merinos. The first attempt toward the establishment of this family was in 1768 by Mr. von Vinke, 
near Halle, who introduced some Saxon Merinos. Ten years later he secured pure Merinos from Spain and crossed them on the sheep in that section of Germany. In 1776 Frederick the Great became interested and imported 300 pure Merinos from Spain, but through disease and mismanagement these came to an unfortunate end. Later von Vinke purchased a thousand pure Merinos under government commission, agricultural schools were established for the instruction of shepherds, and sheep husbandry was specially promoted. This resulted in establishing the German or Silesian family.

French Merinos or Ramboullets. These were imported from Spain to France in $\mathbf{I} 786$ by government commission. This type is discussed by itself further on.

English Merinos. About I 787 , during the reign of George III, the "farmer king," a small flock of mixed Merinos was smuggled from Spain through Portugal and taken to England. These were inferior, so in I79I, at the request of the king, a select lot of Negrette sheep, consisting of four rams and thirty-six ewes, were collected by one of the Spanish nobility and presented to the king. These arrived in England in good shape, but did poorly at first. Not being suited to the moist climate and rich pastures they suffered much from disease and especially foot rot. They gradually became acclimated and thrived fairly well. A society was organized in I8I I to promote them, but the small size of this sheep and its inferior mutton quality caused British farmers to gradually give them up. To-day Merinos are almost unknown in England.

The Australian Merino. Late in the eighteenth century a few Merinos had been taken to Cape of Good Hope, South Africa, from England. Later, in 1797, these were taken to Sydney, New South Wales. Since that period Australia has become the greatest Merino sheep country in the world. There these sheep thrive and produce a very superior grade of wool.

The introduction of the Merino to the United States probably occurred in I793. Mr. William Foster of Boston, Massachusetts, smuggled from Spain one ram and two ewes. These he presented to a friend, who, not realizing their value, used them for meat, though he later purchased a ram for $\$ 1000$ at auction. 
In I80 I Seth Adams, then of Dorchester, Massachusetts, imported a pair of Spanish Merinos, which were conveyed through France to the seaboard. Later, in I 807 , Adams moved to Ohio, taking the first Merino sheep west of the Alleghany Mountains. In I80 I M. Dupont de Nemours had four ram lambs shipped to America, three of which died at sea. The other, Don Carlos, was taken to Dupont's farm along the Hudson River in New York,

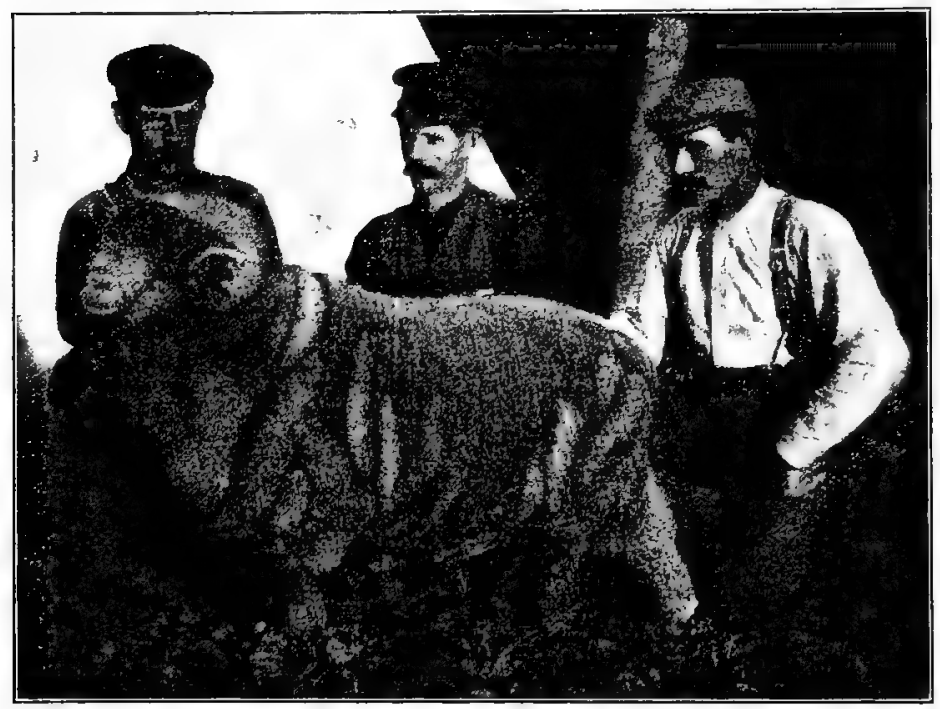

FIG. I53. Don Dudley's Pet I493, an American Merino ram noted as a sire and prize winner. Owned and shown by R. D. Williamson of Xenia, Ohio. Sold in 1906 at six years of age for $\$ 300$, to go to South Africa. The men in the picture are three of the most prominent Merino breeders of Ohio and the United States. Mr. Williamson is on the left, Mr. A. T. Gamber in the center, and George $\mathrm{H}$. Helser on the right. Photograph by the author

where for nearly four years he was used on the flocks of that region. Later he was taken to Wilmington, Delaware, and the influence of his blood became felt extensively in New York, Delaware, Maryland, Pennsylvania, and Virginia. In I 802 Colonel David Humphreys imported from Spain twenty-one rams and seventy ewes to his home in Derby, Connecticut. Robert Livingston, Minister to France, sent four head to New York the same 
year. In I 805 Livingston returned to America and began breeding pure and grade Merinos. He was very successful in his breeding, and his sheep attracted wide attention and brought high prices. He had great social influence and was a famous politician, so that he induced many to take up sheep husbandry. In 1809 he wrote an Essay on Sheep, which was ordered printed by the New York legislature. Through his influence the legislature also passed an act in 1808 to encourage raising and breeding Merinos. In I809-18 10 William Jarvis of Vermont, United States Consul at Lisbon, Portugal, shipped at different times a total of about 4000 Spanish Merinos, of which I 500 came to New York, I000 to Boston and Newburyport, and the remainder to Philadelphia, Baltimore, Alexandria, Richmond, Norfolk, etc. "Indeed," says Mr. Jarvis in his correspondence, "I was disposed to distribute these valuable animals to every state which would be likely to profit by their acquisition." All of these were sheep of superior breeding. They included Paulars, Aguirres, Escurials, Negrettes, and Montarcos. Jarvis placed 400 head on his farm in Vermont, in the care of Paular shepherds, and he writes that "I bred the respective flocks separately till 1816 or 1817 , when I mixed them together, and have so bred my Merinos ever since." The importations of Humphreys and Jarvis distributed Spanish Merinos widely over the northeastern states, and from these our American Merinos received their im. portant early start. Each of these men bred most successfully, greatly improving their flocks.

A mania for Merino sheep began to develop, and in 18 io both Livingston and Humphreys sold rams at $\$ 1000$ each, while the latter sold two ewes and two rams for \$1500 each. Then came a great craze for fine-wool sheep, and it is stated that in 1810 over I0,000 were shipped to America; Cochran Johnston, Goold Brothers, and Charles O'Neil importing from Lisbon, and R. W. Meade and others from Cadiz. It is estimated that from April I, I810, to August 3I, I8II, there were brought to the United States 19,65 I Merino sheep.

The early improvers of the Merino began with Adams and Humphreys, but during the middle of the century a few men rendered very great service in the improvement of this sheep. 
Notable among these were Stephen Atwood, Woodbury, Connecticut, whose flock was commenced in 1813 , and who was a breeder until his death in 1867 ; Edwin Hammond, Middlebury, Vermont, I 844-1870; William Jarvis, Weathersfield, Vermont, I 8 I I-I 859; Tyler Stickney, Shoreham, Vermont, I834-I 882 ; Andrew Cock, Flushing, Long Island, New York, a breeder from I8 I I to I823; Charles Rich of Shoreham, Vermont, who

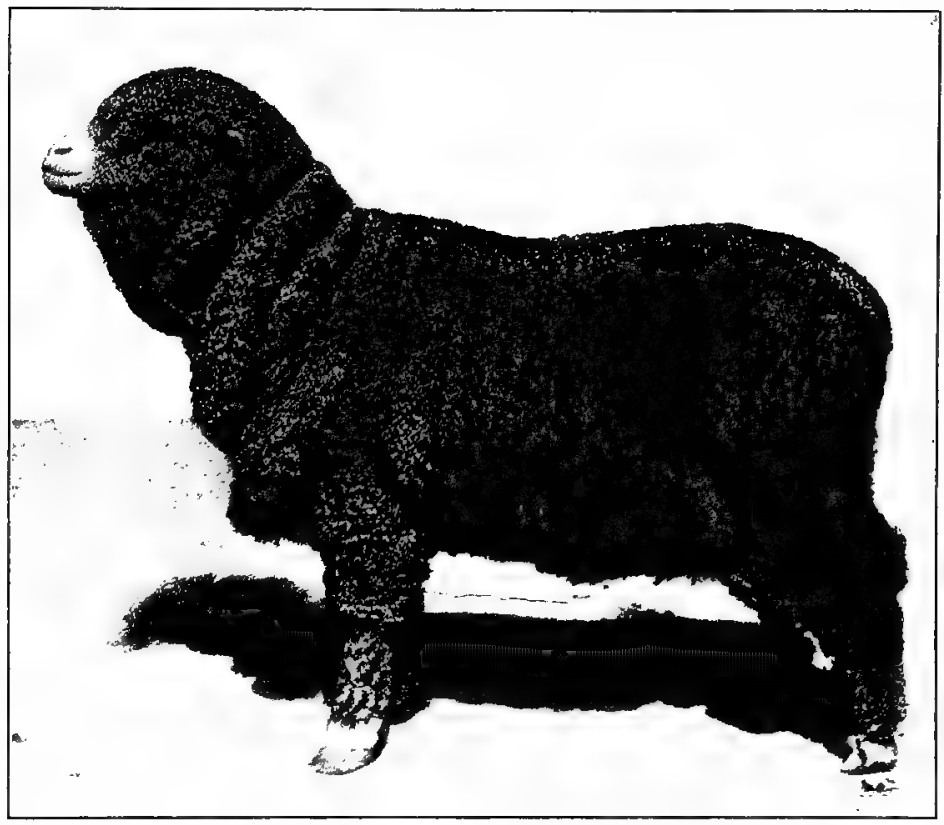

FIG. I 54. An A merican Merino ewe of the Class B type, first in class at three state fairs. Owned and exhibited by R. D. Williamson. Photograph from the National Stockman and Farmer

began his flock in 1823 , his sons, John $\mathrm{T}$. and Charles, continuing the work, this also descending to a third generation in his grandsons, J. T. and Virtulan, sons of John T.; William R. Dickinson of Steubenville, Ohio, who bred from about 1809 to I830; and Bezaleel Wells, also of Steubenville, who maintained a flock over much the same period. These men were among the really great pioneer breeders of America; they did much to 
improve the Merino, notably in character and quantity of fleece, and from their flocks descends the best blood of to-day.

Characteristics of the American Merino. This Merino is simply an improved form of the Spanish, characterized by heavy folds on the body, excepting over the back. The head is small, being comparatively broad and short, the rams carrying heavy, spirally twisted horns, and the ewes being hornless. The lips and nostrils are white and fine silky white hairs surround the muzzle and extend part way up the nose. The ears are small and are covered with fine white hairs. Reddish or tan-colored hair is occasionally seen on the ears and nose of the Merino, which suggests a reversion to the same color of earlier days. Some Merino breeders have valued this color variation, while others have endeavored to breed it out. The neck is thin and tends to be long below and short above, the shoulders are very sloping, the chest narrow but deep, the withers thin, the back moderately narrow, the rump frequently steep, the thighs thin, the legs small and fine. The skin is of the most attractive bright pink color, and in good specimens is in folds along the bridge of the nose and neck, about the breast, shoulders, lower part of the sides, and about the rump and thigh. There are usually no folds over the hack and perhaps upper third of sides, unless in a small degree. In 1892 an eminent breeder is thus quoted by Ezra Carman :

The prevailing fashion is to have from three to five heavy folds on the neck, not large on the upper side, but large on the under side; two or three short folds on and immediately back of each elbow or arm; fine, thick wrinkles running down the sides, but not extending over the back. Wrinkles across the hips, sometimes from the tail in the direction of the stifle, and sometimes at right angles with them, folds also around the tail to give it a wide appearance, and also folds across the thigh with a deep flank.

The fleece covers the entire body and legs, excepting on the nose, on the lower half of the head, and on the ears. The eyes are often hidden by the fleece covering the head. The outside of the fleece is of a dirty black color, caused by the accumulation of dust in the yellow oil or yolk which exudes to the end of the fiber, adding greatly to the unwashed weight. A considerable amount of oil is desirable in the fleece and especially 
is it important in the rams. A dry, white fleece is an inferior wool, and rams with such fleeces are not usually the best breeders. This grease, oil, or yolk may be scoured off, to show a shrinkage in weight of 65 per cent. American Merino wool is the finest produced, and the more folds on the body, and the more crimped the fiber, the finer the staple. The one-yearold fleece of a mature sheep will show a length of about two and one-half inches. The temperament of the Merino is very lively, yet not necessarily inconsistent with docility.

The size of the American Merino naturally varies. Weights of I 30 pounds or upward for the rams and about 100 pounds for the ewes are acceptable to breeders. The finer specimens of rams often weigh 150 to 200 pounds, but many excellent ewes weigh less than Ioo pounds.

The American Merino as a wool producer is famous. No class of sheep shears so strong, fine, and heavy a fleece. Many mature females shear from 12 to 15 pounds and rams easily attain 20 pounds. The Vermont Merino Register gives thirty-six rams, three years old or over, whose fleeces averaged 3 I pounds I ounce each, one weighing 37 pounds 8 ounces. A two-year-old ram, at the annual shearing of the Vermont Sheep Shearing Association, sheared 44 pounds 3 ounces, the heaviest on record. Records are given by the Vermont Register of fifty-four ewes, two years old and over, which sheared 1064 pounds, 9 ounces, an average of I 9 pounds I I ounces, the heaviest fleece weighing 25 pounds. In 1887 forty-six ewes averaged 2 I pounds 5 ounces.

The relationship of weight of Merino fleece to body is regarded as showing the true wool-producing capacity of the sheep. The thirty-six rams above referred to sheared 25.2 per cent wool to weight of carcass. Quoting from Vermont reports, in 1812 the best rams produced but about 6 per cent wool to weight of body. In 1844 the wool had increased to I 5 per cent, from 1844 to 1865 to 2 I per cent, and from then to I 880 up to 36 per cent, showing a remarkable improvement in wool production. In 1878 Vermont exhibited seventy-eight fleeces at the Paris Exposition, which showed 22 per cent wool to live weight, thirty of the best ones showing 25.2 per cent, the six best 30.I, and one up to 36.6 per cent. At a public shearing at Middlebury, Vermont, 
in 1882 , fifty-four rams and ewes averaged 23.3 per cent wool to live weight.

The fineness of Merino fiber has greatly improved since the introduction of this sheep to America. A set of measurements of twenty-four sheep given by Dr. Cutting showed an average diameter of fiber for rams and ewes of $\mathrm{Ir} g \mathrm{~g}$ inch, the rams averaging $I_{0} \frac{1}{5}$ and the ewes ${ }_{1 \frac{1}{3}}$, the finest ewe fiber being $\frac{1}{y_{1} I}$ inch. Dr. William McMurtrie, who conducted extensive investigations on wools for the United States Department of Agriculture, gives this table of the comparative diameter of wools of different breeds:

\begin{tabular}{|c|c|c|c|c|c|c|c|c|c|c|c|c|c|}
\hline & & & & & & & & & & & & \multicolumn{2}{|c|}{ Average Diameter Figer } \\
\hline \multicolumn{12}{|c|}{ BREHD } & Centi- & Fraction of \\
\hline Merino . & . & . & . & . & . & . & . & - & . & . & - & 2.127 & तर \\
\hline Southdown . & $\cdot$ & . & - & - & - & . & - & - & * & - & - & 2.936 & $\frac{1}{86} 5$ \\
\hline Hampshire Do & own & . & - & . & - & - & . & . & . & - & • & 3.298 & $\frac{1}{7} \overline{9}$ \\
\hline Lincoln . . & - & - & . & . & - & - & . & - & . & - & - & 3.707 & $\frac{1}{6} 5$ \\
\hline Leicester. . & . & - & - & - & - & - & - & - & . & . & • & 3.879 & $\frac{1}{5} 4$ \\
\hline Cotswold . . & . & . & . & . & - & . & . & - & . & - & • & $4 \cdot 196$ & $\frac{1}{65}$ \\
\hline Oxford Down & . & . . & . & . & - & - & . & - & . & . & - & $4 \cdot 365$ & $5^{\frac{1}{8}} \mathrm{I}$ \\
\hline
\end{tabular}

The mutton qualities of the American Merino are inferior. These sheep are muscular in type and carry but little fat, and when pure-bred are of but secondary importance as mutton.

The cross-bred or grade American Merino is not improved for wool production, but by mating with middle wool blood a better mutton sheep is produced, though shearing less wool and being less hardy. Sheep of the Delaine type are more or less bred to the American type, thus reducing the folds but not seriously affecting the wool-producing value. In Australia the American type is preferred to the smooth-bodied Merino, while in the United States the reverse is the case. In order, however, to maintain high-shearing qualities, studs of American Merinos must be maintained to thicken up the fleece of the smoother sort and keep up the weight. In New Zealand the Romney 
Marsh and Merino are crossed extensively, the cross-bred withstanding, says Mr. George A. Brown, the bleak climate of southern New Zealand better than any other combination. Mr. Brown says that in Australia the most successful flocks of cross-bred sheep he has seen were from crossing long-wool rams on Merino ewes. The half-bred ewes are culled as though pure-bred, and those selected for breeding are drafted into two lots, one of long wool and the other of Merino type. Merino rams are then used on long-wool type ewes, and long-wool rams on Merino type ewes. Every year this selection is followed out, and a very even type of sheep obtained. On large estates famous for cross-breds, studs of Merino and long-wool rams are kept for this kind of mating, which produces a class of sheep in favor with the butcher, and the wool of which sells well. The French have developed an important sort in France, known as the Dishley Merino, the result of using Leicester rams on Merino ewes.

The adaptability of the American Merino is great. On the rough mountain pastures of New England and on the ranges of the far West it seems equally at home, though a better fleece is produced in the northeast than the southwest, the dryer climate being more unfavorable. On the richer soils of the middle West the Merino attains more size than in the far West. The American Merino is extremely hardy and thrives on scanty pasture and in cold weather. Grazing in large flocks on the plains, it is specially adapted to the care of the shepherd. Larger flocks of Merinos may be kept together more successfully than is possible with the other breeds. Merinos are very active and rustle for themselves under unfavorable conditions.

The breeding qualities of the American Merino are rather inferior. The lambs of the heavy-fleeced sort are often weak when dropped; the ewes are not very prolific and are not superior milkers. In I903 Mr. C. S. Chapman, one of Ohio's bestknown breeders, wrote:

For many years previous to I 880 my father and I were breeders of the heavy-folded Merinos, having ewes shearing 18 to 20 pounds each, and using rams shearing 30 to 36 pounds each, from the flocks of the best breeders in Vermont. We had our sheep bred so strongly to the production of wool that we could not raise over 50 to 60 per cent of the 
lamb crop. They (the lambs) would be so feeble when dropped that in a majority of cases you could not tell for twenty-four hours whether they had vitality enough to live.

They, however, breed far longer than the average sheep and raise a fair percentage of lambs.

The early maturing qualities of the American Merino are of secondary character, the lambs developing more slowly than the mutton breeds.

The distribution of the Merino has been general all over the civilized world where sheep husbandry is followed at all. Australia, New Zealand, Germany, and the United States are the leading countries breeding sheep of the American Merino type. These sheep have been bred in all parts of the United States, but are not so popular as they were a half century ago, now that mutton is more in demand and wool has depreciated in value. Further, sheep of the American type, with numerous folds, are objected to, on account of the difficulty in shearing, so that smooth-bodied Merinos are more popular than the American. At the present time Ohio, Vermont, New York, Michigan, Wisconsin, and Missouri are the states containing the principal flocks of this class. Many Merinos have been exported from Vermont and Ohio to South Africa, Australia, New Zealand, Tasmania, and South America.

Organizations to promote Merino sheep are numerous. The Vermont Merino Sheep Breeders' Association, organized in 1879, has published four volumes of flock books and registered over 300,000 sheep, mainly as flocks. The United States Merino Sheep Register was organized in Ohio in 1876 , and published a volume of its flock book the same year. In I882 the Ohio Spanish Merino Sheep Breeders' Association was organized at Columbus, and published its first volume in I885. The National Record of the American Merino Sheep Register was organized in $188 \mathrm{I}$ in Wisconsin, the first volume of the flock book being published in I882. The New York Merino Sheep Breeders' Association was organized in 1879 and the Michigan Merino Association in 1880. In other states associations for recording Merino sheep also organized, but these have never become very active factors in the Merino industry. In January, 1906, a conference of Merino 
breeders, representing different registry associations, was held at Columbus, Ohio, for the purpose of consolidating into one strong organization. This resulted in the incorporation of the American and Delaine-Merino Record Association. By official action the Standard Delaine, the International Delaine, and the Improved Spanish Delaine associations merged into the new organization. This, it is hoped, is the beginning of a movement of consolidation

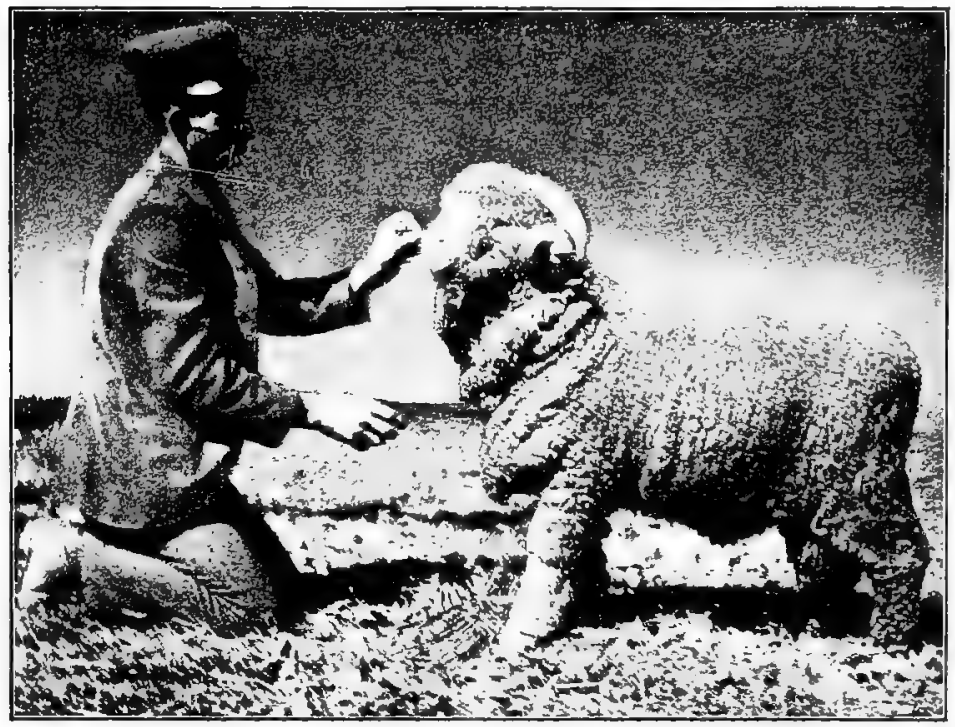

FIG. 155. Ringleader 553, a Delaine Merino ram, bred by and shown by A. T. Gamber, Wakeman, Ohio. This ram has never been defeated in the show ring. In I 903 , as a yearling, he was first at the state fairs of Ohio, Indiana, Illinois, Kentucky, and Michigan. Also shown with equal success in 1904. Photograph by the author

which will result in greatly unifying and strengthening Merino interests. In I904 about nineteen Merino associations of different kinds, organized to register sheep, were in existence. Many of these are now very weak organizations, transacting but little business.

Some famous Merino rams are worthy of note on account of their influence in improving the breed. Among these are the following : Bolivar, born in I 820 , died in 1834 , owned by W. R. 
Dickinson and others in Ohio; Consul, bred about 1838 by William Jarvis; Stickncy's Consul, bred by Jarvis in 1835; California, bred in 1858 by Victor Wright; Comet, bred in I $86 \mathrm{I}$ by W. R. Sanford of Vermont, and later taken to Ohio; Eureka by Comet, and Kilpatrick by Comet, both bred by Sanford; Wooster, bred in $\mathrm{I} 849$ by Edwin Hammond, sired Young Matchless and Old Greasy; Gold Drop, bred in I 86 I by Edwin Hammond, who was several times offered $\$ 10,000$ for him, and who valued him at $\$ 25,000$; Stowell's Sweepstakes, bred in 1860 by Edwin Hammond; Golden Fleece by Stowell's Sweepstakes, bred in 1862, said to have earned his owner over $\$ 20,000 ;$ General Fremont, bred in 1865 by Tyler Stickney; Bismarck, owned by H. C. Burwell of Vermont, that was sweepstakes Merino in I 876 at the Centennial Exposition; Banker, bred in 1875 by V. Rich of Vermont; Ravis, bred in 1874 by Geo. Hammond, winner in 1880 of first prize as a sire at the International Sheep Show at Philadelphia; Don Dudley, bred in I 891 by J. P. Ray of New York; and More Quality, bred in I 898 by R. D. Williamson of Ohio, was sire of many of the prize winners at the Louisiana I'urchase Exposition in I904.

High prices for Merinos have been paid. In 1808 James Wadsworth paid Humphreys $\$ 1000$ for a ram, and in March, I 810 , Colonel Humphreys sold two rams and two ewes for $\$ 6000$ to go to Kentucky. This year, I 8 I o, there was a Merino mania on, and many sheep changed hands at phenomenal prices. On September 22, I8 IO, an auction of 2 I 5 Paular Merinos at the country home of F. B. Winthrop, Horne's Neck, New York, brought $\$ 57,000$, averaging $\$ 265$ each. Many thousand Merinos were imported in $18 \mathrm{IO}$ and $\mathrm{I} 8 \mathrm{II}$, and were largely sold at auction, bringing abnormally high prices. Then came a collapse, and Merinos were sold for a song. Again in the early sixties high prices prevailed, and many sheep sold at thousands of dollars each. The people of Australia have long paid high prices for Merino rams. The ram President sold for 1600 guineas $(\$ 8000)$ to go to Tasmania, and several of his sons sold for I000 guineas each. The following rams also sold in Australia for the prices affixed: Sir Thomas, 680 guineas; Sir Thomas 2d, 404 guineas; Golden Horn, 560 guineas; Golden Horn 2d, 630 
guineas; Golden Tom, 500 guineas. Many sheep have been shipped from Vermont and Ohio to Australia at prices from $\$ 500$ upward per head, several sales being made in 1906 .

A notable American Merino show-ring victory, worthy of record here, occurred in I863, when George Campbell of Vermont exhibited twelve Vermont-bred Merinos at the International Exposition at Hamburg, Germany. There were I77 I sheep entered in competition, 913 being Merinos from every part of

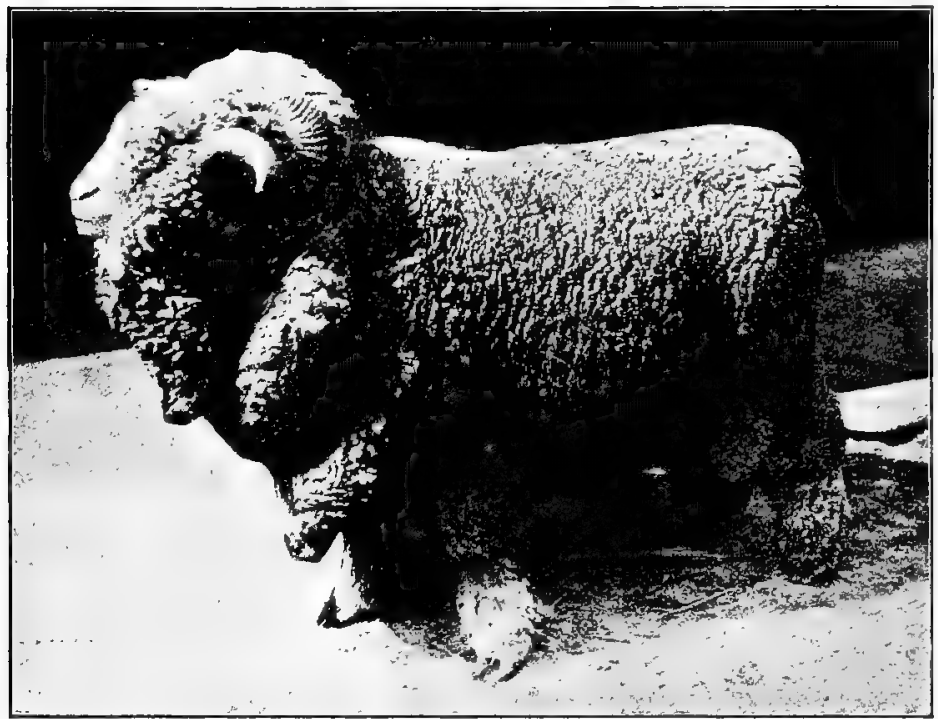

FIG. I56. Stickney, a Delaine Merino ram at the head of the flock of G. B. Quinn of Ohio. This ram sheared 25 pounds. Photograph from the National Stockman and Farmer

Europe, - France, Italy, Austria, Russia, and Germany being represented. The twelve sheep shown by Mr. Campbell were the only ones from the United States, and these took three premiums, two firsts and one second, one first being for length of staple and one for weight of fleece. These prize sheep were later sold to Count Shen Thors of Silesia for $\$ 5000$. This was a great testimonial to the superiority of American Merinos.

Important subtypes or families of the Merino exist to-day. Among these are the Delaine and the Rambouillet, which are 
discussed separately further on. There are also several other families, which are now of less importance than formerly, notably the Atwood and Paular. The former was established by Stephen Atwood and later was especially promoted by Edwin Hammond. It was a type having many folds and was very popular from I 845 to 1895 . The Paular comes from Spanish stock imported by Andrew Cocks and later improved in the hands of Jehiel Biedle, Tyler Stickney, Erastus Robinson, and the Rich family of Vermont. This also possessed many folds and a large amount of oil in the fleece. Both the Atwood and Paular families are important strains of the American Merino stock. The Saxon Merino at one time had some popularity in America, especially in New York, Pennsylvania, and Ohio, but this family has now but very few pure-bred representatives and these mainly in Pennsylvania. It deteriorated so in weight of fleece and constitution as to be generally discarded. 


\section{CHAPTER XLVII}

\section{THE DELAINE MERINO}

The word "Delaine" is derived from two French words, de, signifying of or from, and laine, meaning wool or woolen. The word in the woolen trade indicates a class of wool used to make fine untwilled worsted dress goods. A combing process takes place, in which the fibers of wool are drawn parallel with each other and spun at full length in the yarn, thus securing the full strength of the fiber and making the strongest and most durable of woolen dress goods. This was due to an invention of $\mathrm{E}$. R. Mudge of Boston. Previous to this time only coarse wools were combed, fine wools being carded, a process inferior to combing.

Delaine Merino types exist under several names, these being of American Merino ancestry, bred mainly by selection into a variety quite or nearly free from folds, of the smoothbodied sort. These types

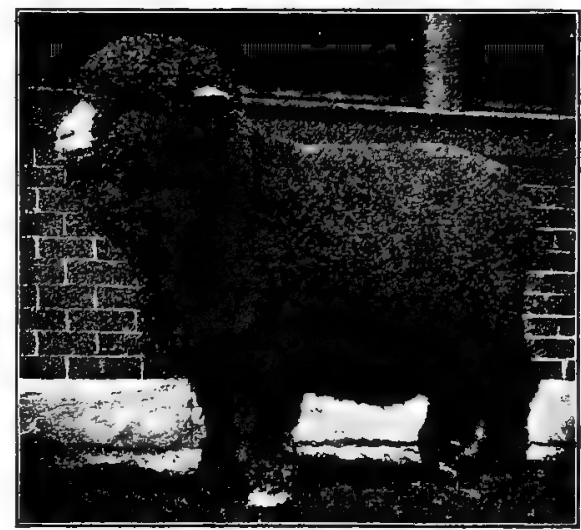

FIG. I 57. Gamber's Model, a very choice specimen of Delaine Merino ewe, bred and exhibited by A. T. Gamber. This ewe was first in class at the Ohio State Fair in 1905. Photograph by the author differ in a limited degree, being really very much alike.

The origin of the Delaine Merino traces back to the Humphreys importation of 1802 and that of $R$. W. Meade about $I 820$. From these flocks certain selections were made and types gradually evolved from them, breeders generally keeping in mind both mutton and wool production. 
The Dickinson Delaine was named after William R. Dickinson who lived for years at Steubenville, Ohio, where he was an extensive breeder of sheep. About 1807 or 1808 Thomas Rotch, a Quaker, moved from Connecticut to Stark County, Ohio, bringing with him a small flock of sheep, some of which were from the Humphreys importation. In 1809 Mr. Dickinson

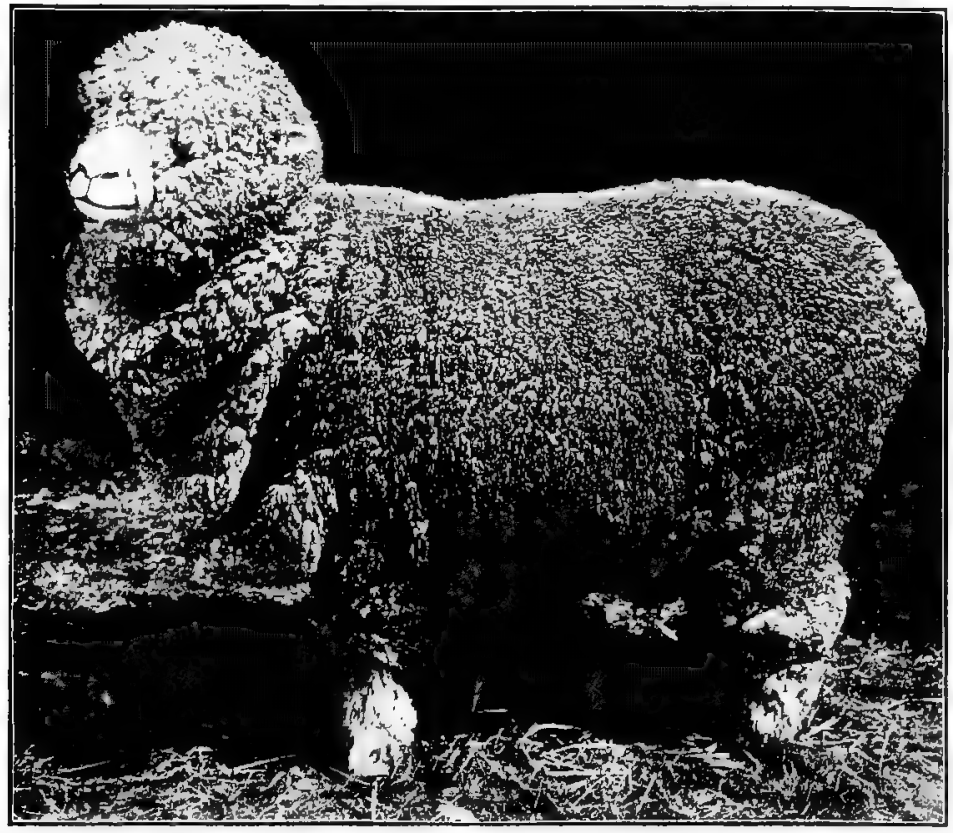

FIG. 158. A Delaine Merino ewe of very superior character, successfully exhibited by C. H. Bell of Ohio. Photograph from the National Stockman and Farmer

became the owner of some of these imported sheep of Mr. Rotch, which he kept by themselves and carefully bred. In I 820 Adam Hildebrand became superintendent of Mr. Dickinson's farm, thus getting acquainted with Mr. Dickinson's sheep and his methods. In his flock was a smooth-bodied ram named Bolivar, that became a great prize winner for his individual merit. In I830 the Dickinson flock was sold, and Hildebrand obtained some of the best sheep. In $1823 \mathrm{Mr}$. James McDowell became an employee of 
Mr. Dickinson, and later went into the service of Mr. Hildebrand. A part of his remuneration was to be "a selection of the best two ewe lambs and the second-best ram lamb of the last crop of lambs bred by Mr. Dickinson, descended from the select Humphreys flock and sired by Bolivar." These lambs, according to Mr. McDowell, were the foundation stock of the Dickinson Merinos, and the McDowell family of Stark County, Ohio, notably H. G. McDowell, has been the leading improver of this variety.

Characteristics of Dickinson Delaines. The standard of excellence of the Dickinson Merino Association specifies that this sheep shall have a deep, round, wide, and long body, showing mutton capacity, carrying heavy, thick flesh, the top and under lines being straight, and the skin smooth, pink, and well filled out, being free of folds. The head may have small horns, but a polled head is preferred; the nose is covered with fine white hairs, and the ears are small and also covered with silky hairs. The fleece extends over the body excepting the lower part of the nose, the legs also being wooled to the toes. The fleece should be from three to five inches long, of a quality graded as XX or XXX fine Delaine combing. Rams should shear 15 to 25 pounds and ewes 10 to 15 pounds unwashed wool. The fleece is not so oily as that of some of the Merinos, but carries enough oil for good quality. The size of the Dickinson Delaine runs large, the standard for mature rams being 200 pounds, and for ewes 150 pounds. The mutton qualities of this family have been especially looked to by the breeders, so that they rank well in this respect. Wonderful, one of the best-known Dickinșon rams, bred by H. G. McDowell, weighed 200 pounds when two years old and his second fleece weighed 26 pounds.

The National Delaine. About I820 Mr. R. W. Meade, at one time Minister to Spain, imported some Merinos to this country. Most of these sheep were taken to the farm of Alexander Wilson near Philadelphia, Pennsylvania. In I82 I or thereabouts Alexander Reed of Washington County, Pennsylvania, purchased these Meade sheep as well as other Merinos and placed them on his farm. From this Meade importation the Delaine type was first developed, tracing back to Reed stock; but the family was mainly established through the careful breeding operations of 
John McNary, W. H. McNary, J. S. McNary, Ebenezer McClelland, George Craighead, George Murray, and William Brownlee. In connection with the development of this family R. H. Russell of Pennsylvania and C. H. Beall of West Virginia played an important part. In 1862 a ram of Spanish and Black Top blood purchased from Beall was used in the flock descended from McClelland, then in the hands of his sons. In $1877 \mathrm{R}$. H. Russell, who began his flock in 1852 with fifty Black Top Merinos from William Davis, with J. C. McNary purchased a Spanish ram named Victor, bred by J. M. Miller, which was used in their

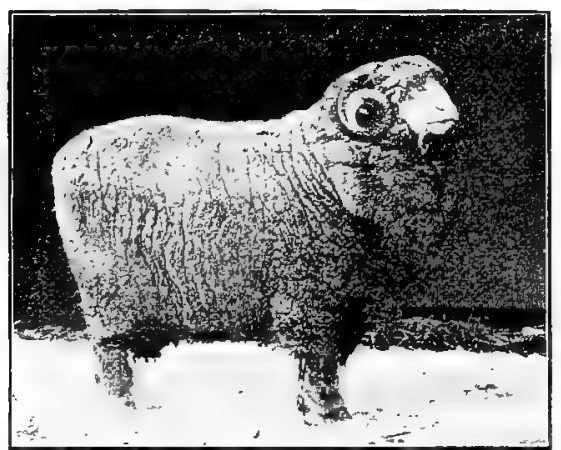

FIG. 159. Wonderful 700, a Lickinson Delaine Merino ram bred by $\mathrm{H}$. G. Mc Dowell, Canton, Ohio. Grand-champion Delaine ram at the World's Columbian Exposition, Chicago, I893. Photograph from the owner flocks. Both of these rams were very prepotent and unusually fine individuals. The descendants of these two rams nicked to great advantage, resulting in high-class Delaines that were long known as VictorBeall Delaine Merinos. It can thus be seen that the Delaine strain was developed by a combination of Black Top and Spanish blood, or a combination of smooth-bodied with wrinkled Merino.

Characteristics of National, Standard, or Victor-Beall Delaines. These are essentially much like the Dickinson family. The body is smooth, excepting for slight folds at the neck, and perhaps at the breast in the form of an apron. The rams may or may not have horns. According to Mr. S. M. Cleaver, Secretary of the Standard Delaine Association, writing in 1890 :

The demand of the times calls for a plain body growing a Delaine staple. Long experience teaches us that it is almost impossible to keep up density and weight of fleece to give the best results when wrinkles are entirely done away with; for this reason it is important to stay in the blood of wrinkly sheep in selecting the sires, yet striving to keep the body clear of wrinkles and the neck nearly so. It is proposed to pay more attention to a good broad back and deep, round quarters, making a type easily kept in order. 
While the fleece will not be as heavy as in the wrinkly type, it should weigh from seven to nine pounds, and sell without any reduction. This will equal an oily fleece of twelve to fourteen pounds, with a third taken off by the wool buyer. Plain sheep, as a rule, are better milkers, more careful mothers, have better feet, and are the easier to prepare for the butcher's block.

Sheep of this variety should have a staple three inches long for twelve months' growth. Rams at maturity should weigh at least I 50 pounds and ewes not less than IOO pounds.

The Black Top Spanish Merino. The foundation of this variety extends back to the 1802 importation of Colonel Humphreys. Mr. W. R. Dickinson of Ohio, about I 809, purchased of Thomas Rotch some sheep of Humphreys's importation. In Dickinson's

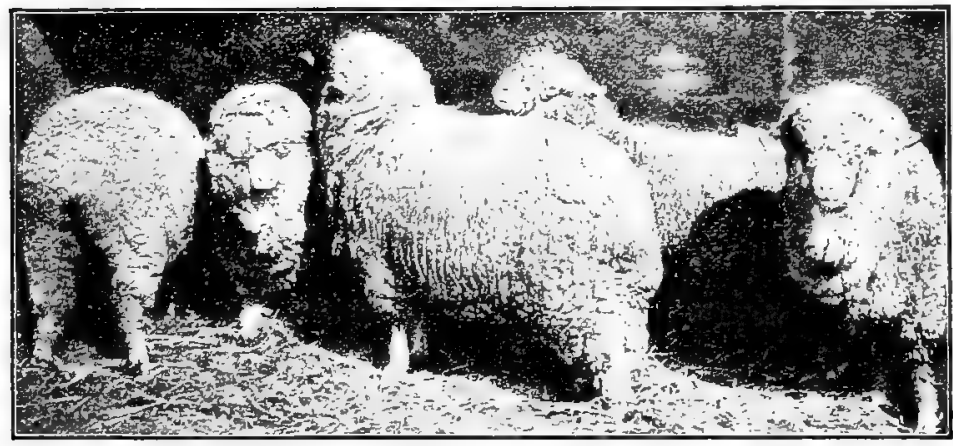

FIG. I60. A group of Dickinson Delaine Merino ewes bred by Mr. H. G. McDowell and very typical of this family. Photograph from the owner

hands these sheep were bred with some care for about twenty years. In I 82 I William Berry of Washington County, Pennsylvania, purchased from $\mathrm{Mr}$. Dickinson a few ewes and a choice ram of Spanish breeding. These sheep Mr. Berry bred with care, developing a large flock. Mr. Berry bred his flock in family lines at first, and then crossed the families, endeavoring to produce a large, heavy-shearing, fine-wool sheep with smooth body of mutton value. In his breeding he decided that those sheep with the darkest outer covering of wool or most oil had the hardiest constitutions and most vigor, and were less affected by change of climate than those with fleeces of lighter color. Thus he selected the darker sort and termed these Black Tops. In I 847 his flock numbered about 500 head, when he divided equally between 
his sons, Matthew and William, they taking choice alternately. Matthew Berry maintained his flock in pure Black Top lines, while William bred likewise until I 856 , when he introduced Vermont Merino blood, with inferior results, which finally caused him to dispose of his flock. The flocks of William Berry and his sons, notably Matthew, are the foundation of this family.

The Improved Black Top Merino is a family that has its foundation in ten ewes purchased in I 844 of George Craighead by Robert Johnston of Washington County, Pennsylvania. These ewes were bred to Craighead rams until I 847, after which, till I 853, rams bred by Alexander McConnell were used, the latter obtaining his foundation stock from W. R. Dickinson. From I 853 to I $867 \mathrm{Mr}$. Johnston used only pure Black Top rams in his flock, and from I 867 to I 884 used rams bought from Matthew Berry. In I 850 George Black of Washington County, Pennsylvania, purchased twenty-five Black Top ewes running back to Dickinson stock, and by use of Berry and Johnston and other rams, established a Black Top flock that is foundation stock in this family. This Black Top family has been assumed by its promoters to be more carefully selected and of higher standard than the Black Top Spanish.

Characteristics of the Black Top Merino. It is difficult to distinguish this from the Delaine, of which it is really a variety. The size is a trifle larger perhaps, and the fleece weighs a little heavier. The Improved Black Top standard requires a weight for mature rams of at least I 80 pounds and I 30 pounds for ewes. The Black Top also has a somewhat darker fleece on the outside, and is not quite so heavily wooled over the head as is the Delaine. The fleece should be from three to four inches long, and the rams should shear thirteen to fourteen pounds and the ewes seven to twelve pounds of brook-washed wool. The rams have horns while the ewes are hornless. Emphasis is placed on the mutton character of this family, which has long been bred with that feature in view. The Black Top has been likened to the Southdown in size and form, with the fleece of a Merino. The back is of good breadth, and is thickly fleshed, while the hind quarters are heavy and of mutton type.

The maintenance of Delaine type in these varieties is by selection or by introducing new blood. For example, one may visit the 
flocks of prominent Merino breeders, in which both American and Delaine sheep are found. The former are mated with the latter, according to circumstances, in order to regulate type and wool production. If a Delaine ewe of excellent mutton type has too open and light a fleece, she will be bred to an American ram of high wool-producing qualities, with the expectation of obtaining a Delaine with a better fleece. More folds may exist at the neck

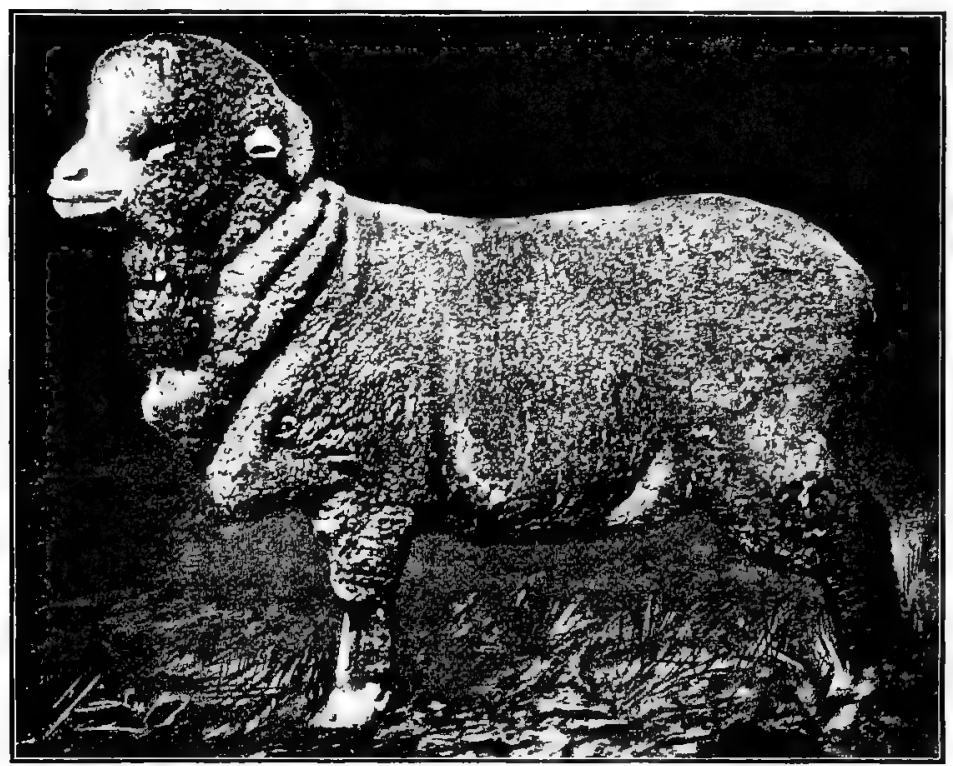

FIg. I6r. A Black Top Merino ewe, first prize at the Ohio State Fair, I905. Exhibited by R. D. McGonigle \& Sons of Ohio. Photograph from the American Sheep Breeder

and breast, but not enough to furnish serious objection on the part of the Delaine breeder. The important thing is to keep up the size and mutton form without reducing the amount and character of the wool below a satisfactory grade. This calls for a fleece to grade XX or better and have a staple of superior length, diameter, strength, and crimp. There should also be plenty of freeflowing oil, essential for a high-grade fleece.

The mutton value of the Delaine has long been emphasized, and is an important argument advanced by breeders in its behalf. 
The wethers mature fairly early and sell at a comparatively satisfactory price in the market, being in demand on account of usually being not over fat. They will not dress out quite so well as the true mutton type, but show a fair per cent of carcass to offal. In I882 McClelland Brothers of Pennsylvania sheared roo threeyear-old wethers that averaged eleven pounds washed Delaine wool, after which the sheep on the market weighed i $10 \frac{1}{2}$ pounds each. In 1884, in Pittsburg market, James McClelland sold a car load of three-year-old wethers that averaged $114 \frac{1}{2}$ pounds and brought seven cents per pound on the hoof.

The breeding quality of the Delaine is distinctly superior to the American Merino. Breeders have sought to produce better breeding stock, - more prolific, larger milkers, and better mothers. This will apply generally to the Delaine type. The lambs also are more robust at birth and more readily raised.

The cross-bred or grade Delaine is valued on the range. Purebred rams used on range ewes give a better mutton sheep and are better suited to the range trade than where American Merino rams are used. Many Delaine rams have been shipped West for this purpose.

The Delaine as a feeder ranks at the head of the Merino group, though not equal to the mutton breeds. The lambs at $t$ welve months may be turned on the market, weighing eighty pounds or so.

The adaptability of the Delaine is not equal to that of the American Merino, for it lacks the rustling qualities to some extent. Delaines will do well in mountainous districts where grass is abundant; in fact they have had their greatest development in the hills of Pennsylvania and Ohio. They also do well on rolling lands where food is abundant.

The distribution of the Delaine is widespread in the United States, and is constantly growing. Ohio, Pennsylvania, Michigan, New York, and Iowa have many flocks, notably the two former states. The Black Top is found more especially in Pennsylvania and the Dickinson in Ohio. The distribution of the smoothbodied Merino is sure to grow in favor, on account of the ease of shearing and the objection to the American Merino on this point.

Organizations to promote the Delaine Merino began in $\mathbf{1 8 8 2}$ with the Victor-Beall Delaine Merino Sheep Breeders' Association 
established in Pennsylvania. In I 887 this name was changed to the National Delaine Merino Sheep Breeders' Association. In I 890 the Standard Delaine Spanish Merino Sheep Breeders' Association was organized in Pennsylvania, and the same year the Improved Delaine Merino Sheep Breeders' Association was incorporated in Ohio. In I 882 the Ohio Spanish Delaine Merino Sheep Breeders' Association was also organized. In 1883 the Black Top Spanish Merino Sheep Breeders organized in Washington County, Pennsylvania, and in 1885 the Improved Black Top Merino Association organized in the same state. In 1884 the Dickinson Delaine Merino Sheep Breeders' Association was organized in Ohio. These several Delaine associations have published a few flock books and have registered several thousand sheep. In January, 1906, a conference of Delaine Merino breeders, members of different registry associations, met at Columbus, Ohio, and engaged in extended discussion of the wisdom of a consolidation of Merino sheep registry associations. As a result of this meeting, directly following the conference, the Improved Delaine, Standard Delaine, and International Delaine Sheep Associations consolidated into the American DelaineMerino Record Association. The object of the new association is to promote the purity of breeding, registering, and preserving the American Merino sheep, in accordance with the types A, B, and $C$. The new association secures a combined membership from the three old ones of several hundred persons. It is anticipated that still other associations will unite with the new one and thus reduce the number in the field and so simplify the business of registration. 


\section{CHAPTER XLVIII}

\section{THE RAMBOUILLET}

The native home of the Rambouillet is in France, in the northern part, not far from Paris. The country is gently rolling, the soil is generally of a calcareous nature, and the climate is quite temperate, being warm in summer and not severe in winter. Grasses, wheat and oats, and a variety of crops grow in this region.

The ancestry of the Rambouillet is Spanish, this being a member of the great Merino family. The people of Spain in early days produced more wool than their factories could consume, so the surplus was exported, France buying heavily. The French

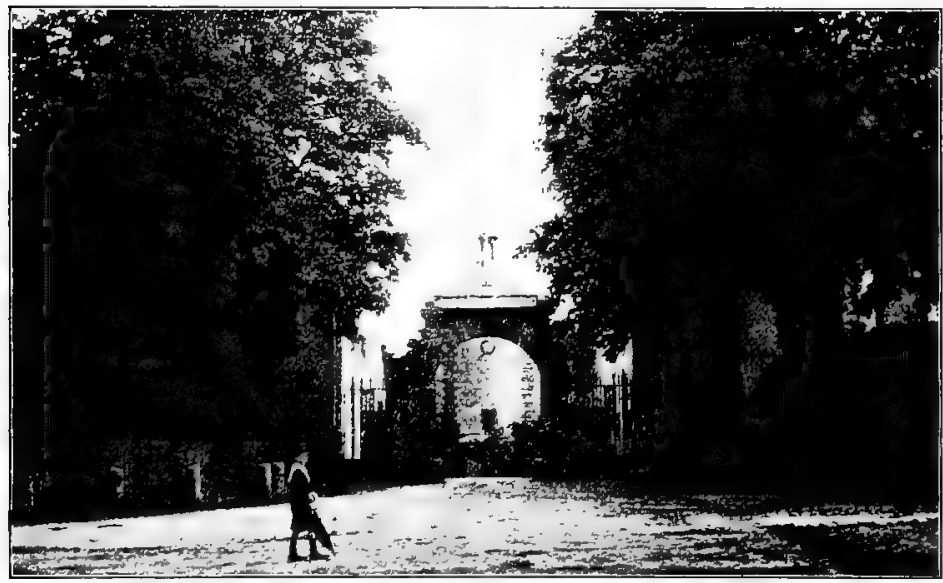

FIG. 162. A dignified gateway on the government farm at Rambouillet, France. Photograph by the author

government anticipated an increase of factories in Spain and consequent restriction on exports of wool from that country. This led the French to try to improve their flocks and produce enough fine wool at home to meet domestic demands. In 1783 Louis XVI 
of France bought a large estate at the village of Rambouillet, some forty miles west of Paris, and here he established a farm. In I 786 M. Gilbert was sent to Spain and selected a flock of Spanish Merinos representing several different families, landing 366 at Rambouillet, 3 I 8 being ewes. In I799 Gilbert again went to

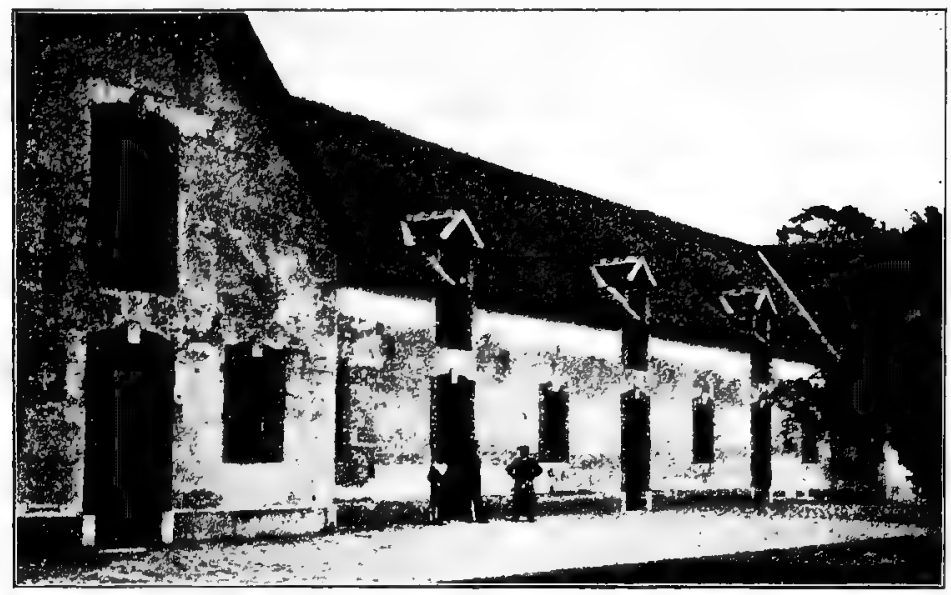

FIG. 163. One of the sheep barns on the government farm at Rambouillet, France. Photograph by the author

Spain, where after much difficulty another collection was secured, of which 237 reached Rambouillet in May, 1801. According to Gilbert, who collected these sheep, and died in Spain while doing the work, the second lot was not the equal of the first.

The improvement of the Rambouillet in the hands of the French government dates back over a century, resulting in a smooth-bodied sheep of large size. Much of this development of over a hundred years has undoubtedly been accomplished by selection. During the time France has bred these sheep many careful records have been made of weights of the sheep and fleece, of length and diameter of wool, of fecundity, mutton development, etc. Probably no other such extensive records regarding a breed are extant. The results of the work were a gradual increase in size, in weight and quality of fleece, in a better mutton form, and in more hardiness than had their Spanish ancestors. While the claim has been made that the stock at Rambouillet has 
been kept pure, in 1900 the author saw rams in the government flock, heavy with folds, quite Spanish in character, and quite different from the proper French type. The Rambouillet Merino was also developed by private parties in France and Germany. In I 800, M. Victor Gilbert of Wideville, France, started a flock from one ram and eight ewes bought of the government, and this flock was maintained in the same family by his son and grandson, Victor, for a century. In northern Germany the breed was later introduced and was much developed, notably in the region south of the Baltic Sea and north and northeast of Berlin. Baron F. Von Homeyer of Ranzin, Pomerania, became the greatest German improver and increased the size, and weight and quality of fleece. Mr. W. G. Markham of New York State in 1880, when on a visit to wool-producing countries, inspected the Von Homeyer flock and looked on it with much favor. In I 882 he received a gift of a ram and two ewes from Von Homeyer, and these were the first of this German breeding to be brought to America. In I 885 Markham received seven rams from the same source, two of which were shipped to Michigan where they produced material improvement in the flocks where used. In I 89 I some Michigan breeders imported seven rams and sixteen ewes from the Von Homeyer flock, and these were distributed among the Rambouillet men of Michigan. In I893 Mr. Markham supervised an exhibit of Von Homeyer sheep at the World's Columbian Exposition at Chicago which attracted widespread attention from their great size and superior merit. This family of Merinos is now extensively bred in Germany.

The introduction of the Rambouillet to the United States first occurred in 1840, under the name of French Merino, by which title it was generally known until about I889. The first importation appears to have been made in 1840 by D. C. Collins of Hartford, Connecticut, consisting of two rams and twenty ewes from the government flock of France. The head ram, named Grandee, sheared fourteen pounds and was regarded as a very fine specimen. In 1846 this flock with its increase was sold to parties in Vermont. In May, 1846, John A. Taintor of Connecticut imported two rams and seven ewes which he purchased of Victor Gilbert. Following this, Taintor made several other 
importations. In I848 John D. Patterson of Westfield, New York, on the western border of that state, made an importation including many superior sheep, his ewes weighing from I 20 to I 50 pounds and some of his rams up to 300 pounds. In I $85 \mathrm{I}$ F. M. Rotch of New York is said to have made an importation with Taintor of Connecticut. That same year S. W. Jewett of Middlebury, Vermont, imported eighteen rams and eighty-two ewes from Victor Gilbert, and George Campbell of Westminster, Vermont,

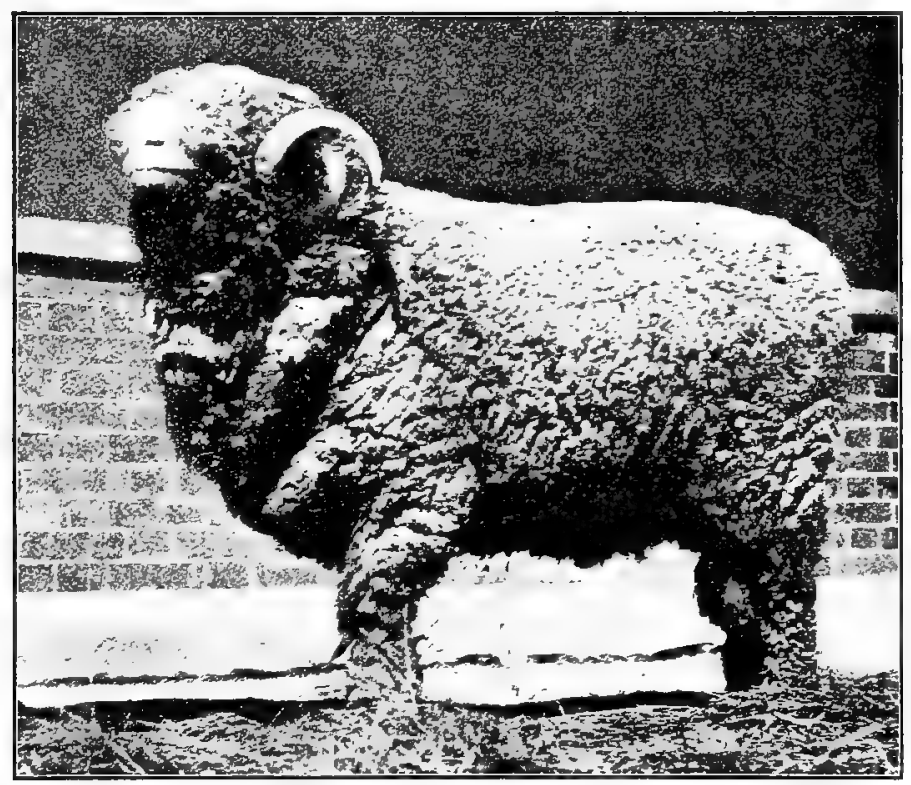

FIG. I64. A Rambouillet ram, second in class at the Ohio State Fair, I905. Bred and exhibited by Max Chapman, Marysvilie, Ohio. Photograph by the author

also made an importation. This same year a company of Ohio breeders imported about 50 head selected from private flocks in France by A. P. Howard. Some of the present Ohio flocks trace back to this importation as well as to a later one of I88I. In I 85 I Mr. R. C. Moulton of Ohio, now over eighty years old, established his flock of French Merinos, which has been maintained by him ever since, this probably being the oldest flock under one management in the country. In I $855 \mathrm{~A}$. R. Seymour of Fayette 
County, Ohio, bought two rams and twenty-five ewes of Jewett. Along about i 855 a Mr. Downs of Calhoun County, Michigan, bought a few of the Patterson sheep. The claim has been made that a Mr. Stanton of Michigan purchased from Mr. Patterson, from which stock has descended the flocks of some of the prominent Michigan breeders, but a letter before the writer, written by Mr. Patterson in 1893 , does not corroborate this claim. Between I 856 and 1860 most of the sheep owned by the latter gentleman were sold to parties in California, from which stock the French Merino sheep of the Pacific slope states descend. The BlacoGlide flock of California is said to trace back to this Patterson

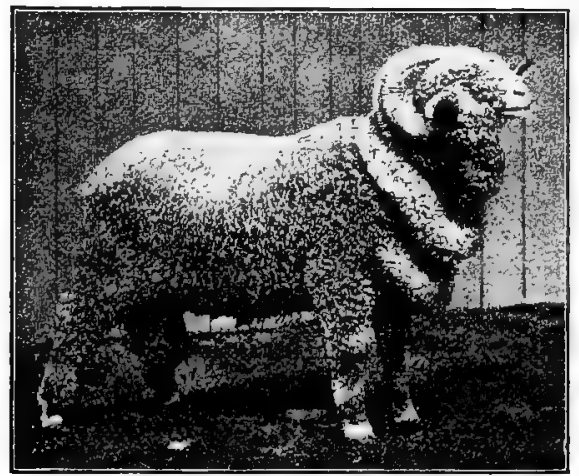

FIG. 165. A Rambouillet ram, imported by Dwight Lincoln, Milford Center, Ohio. Photograph by the author blood. What are now known as Franco-Merinos trace back into early Michigan flocks of years ago. These early French Merinos were not the success anticipated, not being hardy nor suited to American conditions, and the interest declined along in the sixties, to be revived about thirty years later. Many large importations have been made during the past ten years and notably about 1900 .

Characteristics of the Rambouillet. This variety or family of Merino does not differ so essentially in appearance from the Delaine, except in size and breeding. The head is large, the nose covered with white silky hair, and the ears are inclined to be large and are covered with fine white hair or short fine wool. The rams usually have large, spirally turned horns, but there are also hornless males and the females are hornless. The wool is fairly compact and long, averaging about three inches, and covers the entire body, extending over the face below the eyes and down the legs to the toes in good specimens. The exterior appearance is of a sheep of good size, covered with a fine, rather white fleece, 
and freer from oil or dark coloring than is the Delaine, while folds occur on the neck and breast but rarely on the body or hind quarters. One is impressed at times with a tendency to coarseness of bone and length of leg.

The size of the Rambouillet averages larger than any of the other Merinos; in fact years ago they were nicknamed "Elephant Merinos." The rams will average about 185 pounds at maturity and the ewes 150 to 160 . Some rams are said to have weighed over 300 pounds, and cases are known of ewes weighing about 250 pounds. The ram Matchless, imported by George Campbell in $185 \mathrm{I}$ from the Gilbert flock, weighed $26 \mathrm{I}$ pounds. Mr. Max

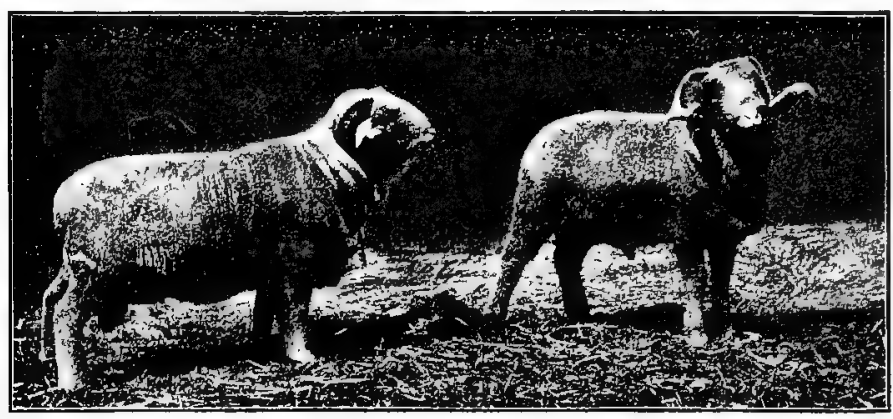

FIG. 166. A pair of Rambouillet rams, the property of Henri Gilbert, Wideville, France. These sheep had been shorn but a few weeks previous to the time the author took the photograph

Chapman of Ohio bred the ram Sampson, which weighed 280 pounds at twenty months old, and the ewe Bernice, which at three years weighed 244 pounds.

The Rambouillet as a mutton producer ranks very well, though inferior to the mutton breeds. It will mature fairly rapidly and will produce a class of mutton which will sell well, though it is not of the highest quality. This is the only class of Merinos offered a place for exhibition at the International Live Stock Exposition, a testimonial to the mutton value of the wethers. In the Iowa experiments on fattening wether lambs, in the one trial reported, the Rambouillet made an average daily gain of .37 pound, requiring 1029 pounds dry matter for I0O pounds gain. In the carcass test the Rambouillet dressed out the poorest 
of ten breeds, 49.57 per cent, compared with 55.26 for the Southdown, and was priced at $\$ 5.00$ per hundred live weight, compared with $\$ 5.75$ for the Southdown.

The Rambouillet as a wool producer ranks well. In 1838 , on the farm at Rambouillet, 40 rams yielded an average fleece of Io pounds 4 ounces, and $20 \mathrm{I}$ ewes and 85 lambs an average of 7 pounds. The years 1847, 1869, and 1877 saw a gradual improvement in weight and quality of fleece, the latter year 15 adult rams averaging 16 pounds 9.3 ounces weight of fleece, and $52 \mathrm{I}$ ewes of various ages 10 pounds 3 . I ounces. At the present time it is doubtful if the average ram will shear over I 5 pounds and the average ewe over Io pounds, but this, of course, does not apply to flocks as carefully bred as that at Rambouillet. Mr. Max Chapman of Ohio reports that the ewe Hiawatha bred by him produced one year 29 pounds of unwashed wool. The fleece of this breed is not quite so fine as that of the other Merinos and also shows somewhat less of oil and crimp.

Cross-bred or grade Rambouillet sheep are best known on the western range, where for some years large numbers of pure-bred rams have been shipped from Ohio and Michigan for use on native stock. This gives a larger, better mutton type, with a strong constitution, and at the same time increases the fleece value. Not only this, but the smooth-bodied grade is more in favor with the shearer on the range than the smaller, more wrinkled sort. Vermont breeders in the past have used Rambouillet rams on American ewes to produce large, vigorous rams suited to the southwestern trade.

The breeding qualities of the Rambouillet rank well. For twelve years preceding I88 I Bernardin, then in charge of the government flock in France, reports that 4005 ewes were reserved for breeders, of which 83 .I per cent were productive, the 83. I ewes dropping 92 lambs, including twins. In the author's experience with the Rambouillet, covering ten years, the ewes were prolific breeders, frequently dropping twins, and were unusually good mothers, having large udders and producing much milk. One objection to some of the ewes was too large a teat. The udders averaged larger than with any other breed of sheep 
in the personal acquaintance of the author. Owing to their natural vigor the ewes breed to a ripe old age.

The hardy quality of the Rambouillet is worthy of note. Formerly, when the French Merino was introduced, many found it unsuited to American conditions. The last quarter of a century, however, has shown that the Rambouillet has excellent wearing qualities, certainly surpassing the mutton breeds. In winter the writer has found them comparatively free from catarrh, while in summer on the same pasture with sheep badly suffering with stomach worms the Rambouillet seemed comparatively free from the serious effects of the parasite.

The early maturity of the Rambouillet from the standpoint of Merino development is distinctly in its favor. The lambs come on rapidly. and compare favorably with the mutton breeds.

The distribution of the Rambouillet is very widespread. It is extensively bred in France, Germany, Russia, and other countries of continental Europe

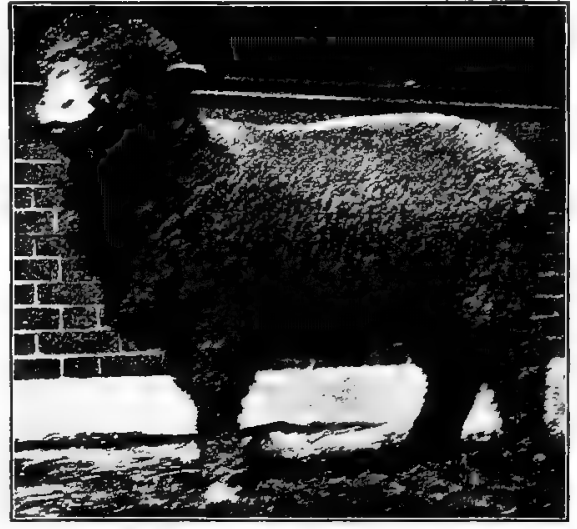

FIG. 167. A Rambouillet ewe, second in class at the Ohio State Fair, rgo5. Bred and exhibited by Max Chapman. Photograph by the author and has been exported heavily to Australia, Argentine Republic, and the United States. In South America there are large flocks of choice breeding. In the United States this Merino is extensively distributed from the Atlantic to the Pacific, but is found in pure-bred flocks to a notable degree in Ohio, Michigan, Oregon, Washington, California, and Utah, though excellent flocks occur in other states.

Organizations to promote Rambouillet sheep were first established when the American Rambouillet Sheep Breeders' Association was organized in 1889 at Pontiac, Michigan. Volume I of the flock book was published in I89I, and up to I905 seven 
volumes have been issued. In I90 I the Von Homeyer Association of Rambouillet Sheep was organized, this registering only sheep of breeding tracing to the Von Homeyer flock. This association has issued one small flock book. There is also a Franco-American Merino Association, organized in 1900 , in which blood lines combine the Rambouillet and American Merino.

Prices of interest for Rambouillet sheep date back for over half a century. In 1853 John D. Patterson of New York purchased a ram in France for $\$ 600$, from the flock of M. Cugnot. He also paid Victor Gilbert $\$ 400$ each for two rams. In the late fifties, when Mr. Patterson sold his sheep to California buyers, it is reported that he received $\$ 1500$ each for three rams, $\$ 1000$ for one, $\$ 800$ apiece for two, and for eighteen others, prices ranging from $\$ 300$ to $\$ 700$. Fourteen ewes also brought $\$ 4500$, or an average of $\$ 32$ I per head. These probably represent the highest prices brought by individuals of this breed, either in America or Europe. A. L. Bingham of Vermont, between 1847 and 1853 , paid John A. Taintor $\$ 37,500$ for I6I French Merinos, or about $\$ 232$ a head. The more modern Rambouillet has never brought such high prices, although some rams in recent years have sold for as much as $\$ 300$ each. 


\section{CHAPTER XLIX}

\section{THE MUTTON TYPE OF SHEEP}

The mutton breeds of sheep comprise two groups known as the middle or medium wool and the long wool. While the breeds within these groups materially differ in character, what is known as the mutton type or form is essentially the same with each of these groups.

The general mutton conformation embodies the feature of the best beef type, involving the compact, blocky form, the short head and neck, broad, level back, full, heavy leg of mutton, deep body, and short legs.

The head is short, the mouth of ample size, nostrils large, nose short and strong and often Roman with males, the eyes bright and prominent, the forehead broad, the poll neat, and the ears refined, short, and actively carried, indicating quality. Horns do not as a rule prevail in this type and are not a necessary consideration.

The neck should be full and smoothly muscled, of fair depth, level and short on top, and should blend in neatly at head and merge nicely at the shoulder and neck vein.

The shoulder is valuable for mutton, and should be neatly placed with the blades not prominent at the top, this entire part being smoothly covered with flesh.

The breast on a superior mutton sheep is thick in front, and the brisket is prominent and well rounded out, this showing a vigorous constitution and strong fleshing qualities. The whole front of the bosom should show a fullness and smoothness in all the lines.

The chest is most important, containing as it does the vital organs, so that both thickness and depth are essential and in keeping with the properly developed breast. The withers on top must have width and be smoothly covered, and then further down 
well-rounded crops and full front flanks are to be looked for. Sunken crops and high front flanks indicate lack of constitution and poor feeding character.

The front legs should be wide and heavily muscled of arm, the shank bones fine and short, the joints and pasterns strong. The entire leg viewed from front or side must show good form and strength, the knees not coming close together, and the feet properly pointing straight ahead. Weak pasterns frequently occur with mutton sheep, a feature to be avoided in selecting breeding rams.

The back and loin contain the valuable cuts, so that strength, width, and thickness are highly essential at all times. Breadth and levelness of back are emphasized, with some closeness of coupling.

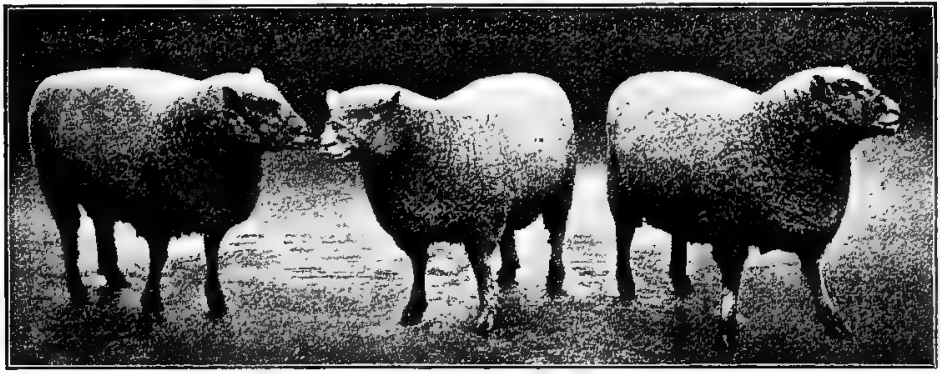

FIG. 168. First-prize pen of Southdown yearling wethers at Koyal Agricultural Society of England Show, I903. Bred and exhibited by C. Adeane, Cambridge. This picture shows the mutton form in its highest perfection. Photograph from F. N. Webb, Agent, Cambridge, England

The body to have ample capacity requires a strong arch and depth of rib, thus giving depth and thickness, invariably associated with the best type. A short body, at least with the male or feeder, is much preferred to a long one.

The hips should be inconspicuous, though not narrow, and should be smoothly covered.

The rump requires length, breadth, and levelness, with a full covering of flesh. Instead of this we too frequently find the peaked, narrow, droopy rump with low-set tail, an ill form either for meat production or in relation to the proper conformation in connection with the reproductive function.

The thighs should be thick from behind, very full and low in between at the twist, and, as viewed from one side, very wide and 
carried strongly back. The entire upper thigh should be heavily covered with flesh. The lower thigh, above the hock, must show strength and neatness.

The hocks should be straight and strong with ample space between. If the hocks take a correct position, then the legs will probably do likewise. Crooked hocks, however, are a common and weak formation and are to be guarded against in breeding stock. The legs below the hocks should be straight, short, and strong.

The skin is a quite variable feature on mutton sheep. A bright pink is the ideal color, with the skin mellow and yet firm, this showing the most healthy condition. Instead of this the skin is frequently of a bluish-white cast or appears too white. A somewhat mottled or bluish-white color also occurs with some individuals or breeds. There are differences of views as to the significance of skin color. No doubt the bluish tint of the Shropshire or Oxford skin is one of inheritance and does not necessarily signify poor condition. The clear pink skin, however, is preferable.

The fleshing of the mutton type calls for a smooth, uniformly covered, deep layer of high-class mutton without wads of fat or patchiness on sides or rump. Such a sheep with the fleece removed would be beautiful in the general symmetry of outline, whether in moderate flesh or fed for slaughter.

The wool of the mutton type ranges in length from that of the Merino to some ten or possibly more inches for a year's growth. The fleece does not cover the body so compactly as with the fine wool, but in this respect, that of the medium class greatly excels the long wool which is the most open of all. The fibers range in character from those which are fine and have considerable crimp to those which are long and wavy, with little or no real crimp. A bright fiber with brilliant luster is sought for. Uniformity of covering is important in length, fineness, and diameter of staple. The entire body, including the belly and armpits, should be covered with a compact fleece. The covering on head or legs varies with the breed. Hair (kemp) or abnormal color of wool fiber are distinctly objectionable. The oil or yolk should be of moderate abundance, keeping the wool in a healthy condition. 


\section{CHAPTER L}

\section{THE SOUTHDOWN}

The native home of the Southdown breed is in southeastern England in the county of Sussex, which is bordered on the south by the English Channel. Extending east and west through this region is a range of low chalky hills about sixty miles long and from one to six or eight miles wide, known as the South Downs. These hills, which also occur in Kent, Hampshire, and Dorset, grow a short, fine herbage, while wheat is a leading cereal crop, though roots do well under suitable conditions on the lower-lying lands. The climate is mild and balmy, being tempered by the sea.

The original stock from which the Southdown sprung, the native Sussex sheep, was somewhat small, had dark face and legs, occasionally small horns, was long and thin in the neck, light in the fore quarter with narrow, droopy back, the body lacking rib, and the hind quarter having a thick leg of mutton with the bone generally too coarse. The wool also was short and the fleece thin.

The important early improvers of the Southdown were John Ellman and Jonas Webb. Other men assisted in the improvement of the breed, but these two stand out in bold relief among the great improvers of sheep.

John Ellman lived at Glynde near Lewes, Sussex County, England. He was the first improver of Southdown sheep. He began his work about 1775 , and resided on the same farm and bred Southdowns continuously for over fifty years. Ellman saw the necessity of improving the native Sussex sheep, to secure a stronger constitution, a better mutton form, and ease of fattening, with a smaller per cent of offal in killing. He sought the best sheep wherever obtainable and made rapid improvement of the breed. A son of Mr. Ellman, also a prominent breeder in his day, especially credited his father with improvements made in 
the Southdown neck and fore quarters. Ellman very generally improved the sheep, creating a superior mutton beast, and also greatly adding to the thickness and quality of the fleece. $\mathrm{He}$ demonstrated that the breed could be heavily stocked on the land. In I788 Arthur Young wrote, "Mr. Ellman, on 500 acres, has 700 ewes, lambs, and wethers in winter, and I450 of all sorts in summer, besides I 40 head of cattle." Ellman is universally regarded as the greatest of early sheep improvers,

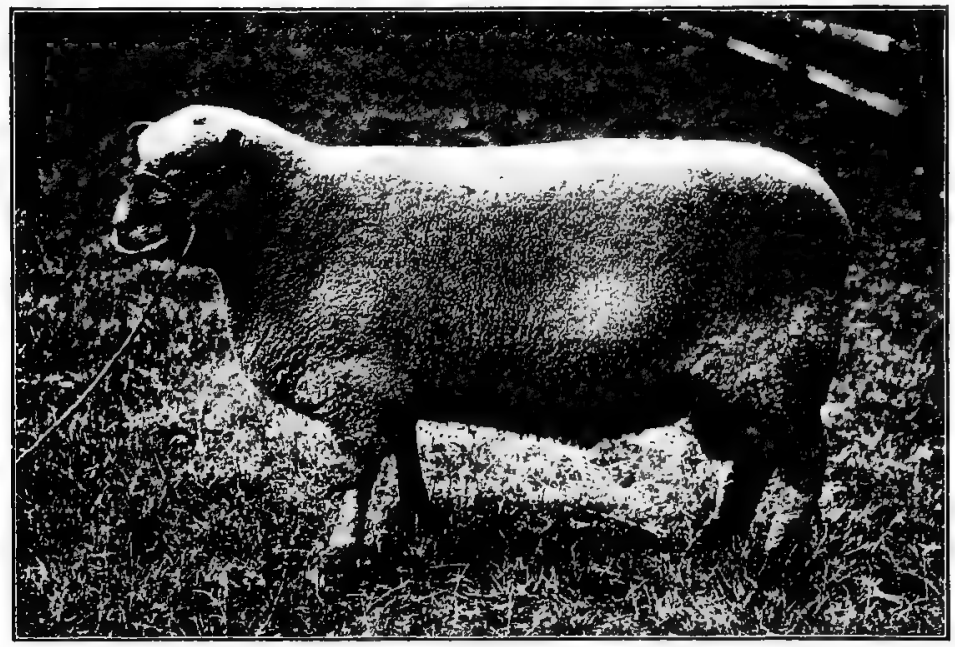

Fig. I69. Babraham Champion, first-prize and reserve-champion Southdown ram at the Royal Agricultural Society of England Show in Igor. Also won the Blythwood Challenge Bowl for the best Southdown of either sex at the Oxfordshire Show. Bred and owned by C. Adeane, Babraham, Cambridge, England, and used in the famous Babraham flock in Igor and 1902. Photograph from F. N. Webb, Agent, Cambridge, England

unless we except Bakewell. In 1829 he retired and dispersed his flock of about 1400 head, of which 24 I were wether lambs. Mr. Ellman died in 1832 .

Jonas Webb of Babraham, Cambridge, England, built on the Southdown model of Ellman. He began breeding about I82 I and purchased the best sheep he could buy, regardless of price. These he mated with much wisdom, improving the Southdown into the very best-known type of mutton sheep, — symmetrical, 
an easy feeder, and unsurpassed in quality of flesh and dressing out at killing. Southdowns of his breeding possessed more size than did those of Ellman. He began letting out rams in 1823 , and about I 846 was placing out 200 annually. For years his ram sales and letting out sales were important events. He was a most successful exhibitor, and in 1856 won a special gold medal for his Southdown exhibit at the International Exposition at Paris, France. The Webb flock was dispersed in 1862, but Mr. C. Adeane, who now occupies Babraham, is one of England's bestknown breeders and exhibitors of Southdowns.

The breeding of the Southdown by the English nobility has long been noteworthy. In the time of Ellman, George the Third

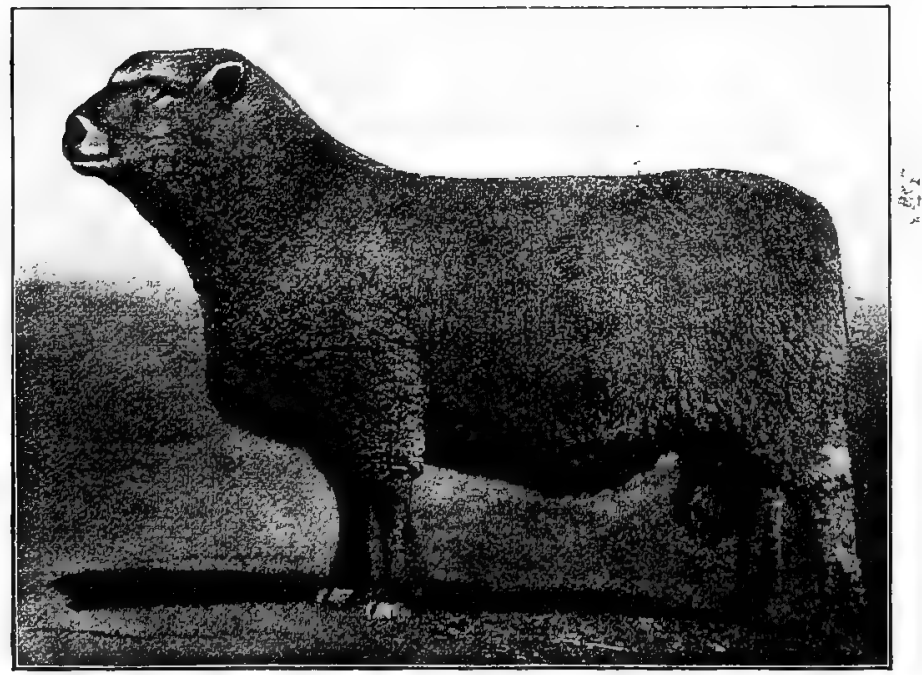

FIG. 170. Chichester King 65, 17434, first-prize and champion Southdown ram in 1904 at the Louisiana Purchase Exposition and at various state fairs. Owned and exhibited by George McKerrow of Wisconsin. Photograph by the author

became interested in this breed, which ever since has been maintained on the royal estates. The present king, Edward VII, has for years had a fine flock. Lord Walsingham has long been a prominent breeder, while the estate of the Duke of Richmond has for over a century bred Southdowns; so also 
have the Duke of Hamilton, Duke of Marlborough, Viscount Hampden, and numerous others.

The introduction of the Southdown to America without doubt dates back to colonial days, and it has been assumed that the best sheep of Rhode Island and eastern Connecticut were of this breed. In I803 a Dr. Rose of Fayette, Seneca County, New York, is said to have commenced with a small flock of Southdowns which did remarkably well. Ir I 8 I 3 these were crossed with Spanish Merinos. In 1823 Sidney Hawes of New York imported some Southdowns, and sold thirty-six ewes, two rams, and ten wethers to C. N. Bement of Albany, who kept up his flock many years. In I834 Francis Rotch of Otsego County, New York, imported six ewes and a ram from the flock of T. Ellman, the son of John. Following this

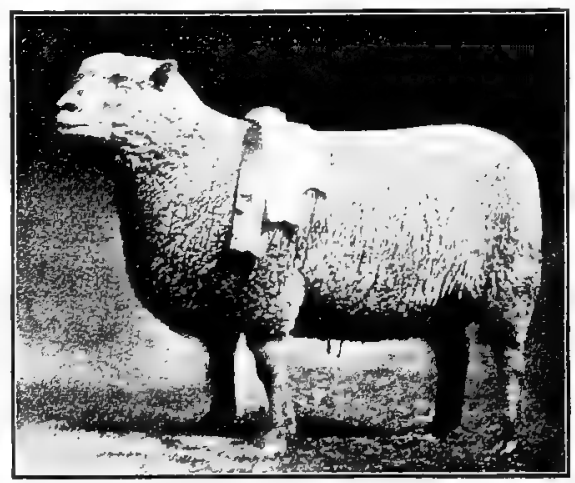

FIG. 171. Culford Ewe 18530, grand-champion Southdown ewe at the Louisana Purchase Exposition, 1904. Owned and exhibited by W. A. McKerrow, Wisconsin. Photograph by the author he made several other importations from the most noted English flocks. In I 834 Isaac Maynard of Coshocton County brought some Southdowns to Ohio, while in $1844 \mathrm{~J}$. F. King of Warren began breeding from Jonas Webb stock, imported by J. M. Hesless of Trumbull County, Ohio. With the depreciation in Merino interests Southdowns grew in favor east of the Mississippi, and many flocks were established along in the middle of the last century.

The characteristics of the Southdown as described by Ellman merit reproduction here on account of their source and their considerable application to the breed to-day.

The head small and hornless; the face speckled or gray, and neither too long nor too short; the lips thin, and the space between the nose and eyes narrow; the under jaw or chap fine and thin; the ears tolerably wide and well covered with wool, and the forehead also, and the whole space between 
the ears well protected by it, as a defense against the fly. The eye full and bright but not prominent; the orbit of the eye, the eye cap or bone, not too projecting, that it may not form a fatal obstacle in lambing.

The neck of a medium length, thin toward the head, but enlarging toward the shoulders, where it should be broad and high, and straight in its whole course above and below. The breast should be wide, deep, and projecting forward between the fore legs, indicating a good constitution and a disposition to thrive. Corresponding with this, the shoulders should be on a level with the back and not too wide above; they should bow outward from the top to the breast, indicating a springing rib beneath, and leaving room for it. The ribs coming out horizontally from the spine and extending backward, and the last rib projecting more than others, the back flat from the shoulders to the setting on of the tail; the loin broad and fiat; the rump broad and the tail set on high and nearly on a level with the spine. The hips wide, the space between them and the last rib on either side as narrow as possible, and the ribs generally presenting a circular form like a barrel. The belly as straight as the back.

The legs neither too long nor too short; the fore legs straight from the breast to the foot, not bending inward at the knee, and standing far apart both before and behind; the hock having a direction rather outward, and the twist, or the meeting of the thighs behind, being particularly full, the bones fine, yet having no appearance of weakness, and of a speckled or dark color.

The belly well defended with wool and the wool coming down before and behind to the knee and hock; the wool short, close, curled, and fine, and free from spiry projecting fibers.

All of the above essentially applies to the modern Southdown type excepting color. This is to-day of a rather grayish brown or reddish brown as shown on face, ear, and leg - of a much lighter shade than the Shropshire. The fleece has also undoubtedly been improved in its density, length, and quality ore what it was in Ellman's time. The breed is noted for its quier, docile temperament.

The size of the Southdown is inferior, ranking as essentially the smallest of the middle-wool class. Yet the compactness of the breed is so distinct that the individuals weigh very heavy for their size. The mature rams will average about 175 pounds and the ewes 135 . George McKerrow of Wisconsin, a leading Southdown breeder and importer, reports the following average weights of specimens of the breed, weighed about September I, 1889: Two two-year-old rams, 206 pounds each ; three yearling rams, I $53 \frac{1}{2}$ pounds each ; two aged ewes, I 50 pounds each ; four 
yearling ewes, I $34^{\frac{1}{2}}$ pounds each ; March lambs, IO I $\frac{1}{8}$ pounds each. The heaviest yearling weighed $I 6 I$ pounds and the heaviest lamb I Io pounds. These weights however are much above the usual.

The Southdown for mutton, since its early improvement, has held premier place in the best markets. There is no excessive fat on the average fed carcass, the flesh is of the finest flavor and grain, the offal is comparatively small, and the bone is fine.

The Southdown as a feeder is superior, maturing rapidly and making a large gain for food consumed. In feeding experiments at the Iowa experiment station Southdown wether lambs in one

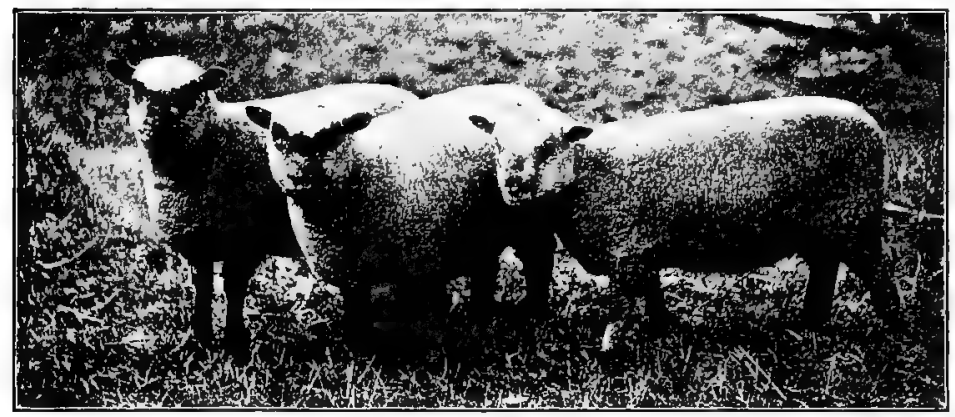

FIG. 172. A pen of three Southdown ewe lambs, first prize in class at the Royal Agricultural Society of England Show, Igor. Bred and exhibited by C. Adeane, Babraham, Cambridge, England. Photograph from F. N. Webb, Agent, Cambridge

trial gained a daily average of .45 pound, and in a second .35 pound, it requiring 738 pounds dry matter for Ioo pounds gain in the first trial and 989 pounds in the second. In percentage of dressed carcass the lambs in the first trial dressed 55.4 per cent, and in the second 55.26 per cent, averaging higher than any other of Io breeds, while the carcass also brought in each trial the highest price per Ioo pounds. At the Ontario Agricultural College the average weight of the best fat shorn Southdown grade wethers at 445 days was 185 pounds, the mean weight of all the Southdown wethers 167 pounds, while the daily gain per head was .33 pound. Wallace reports that fat wethers rising two years old, belonging to the Earl of Bathurst and sold in 
Cirencester market in the first week in December, I 884, dressed I 38 pounds per carcass, or 34.5 pounds per quarter dead weight, and yielded 65.83 per cent dressed weight. In I899, at the Smithfield Club Show, the heaviest pen of Southdown wether lambs averaged 161 pounds each.

The Southdown cross-bred or grade has long met with great favor in the mutton market. In fact the Southdown has played a leading part in forming several breeds, notably the Shropshire, Hampshire, and Oxford, though it has been used more or less on other breeds to improve the fleshing and maturing qualities. Grade lambs, the result of Southdown rams on common ewes of the Merino type or of middle-wool form, will always be in comparatively high demand by butchers.

The adaptability of the Southdown to a variety of conditions is very fair. On rolling land, and even on hilly land producing plenty of pasture, they do well. On the slightly rolling, welldrained lands of the central West they seem to thrive, while in the South this has been one of the best-known breeds. They graze well and are equally hardy with most middle-wool sheep.

The breeding qualities of the Southdown are about average. In I 856 Professor Wilson of Scotland wrote, "The ewes are very prolific and are excellent mothers, commonly rearing I 20 or I 30 lambs to the 100 ewes." In recent years, as compared with the Shropshire, the breed cannot be regarded as superior in fecundity. The ewes, however, make good mothers and have a fair flow of milk.

The Southdown as a wool sheep occupies a subordinate place. The fleece is short, averaging perhaps two and one half inches long, and, although the finest of the native British breeds, weighs light, an average yield for a flock being less than for any other common breed. Wallace gives the weight of fleece of a ewe from three to four pounds, and Shaw from five to seven. In I89 I General C. M. Clay, who bred Southdowns on a large scale in Kentucky for over fifty consecutive years, wrote that he had "raised wool from three and one half pounds to seven on an average." While the fleece is usually very fine, its short length, freedom from yolk, and small size of sheep combine to produce a fleece not weighing much over five or six pounds. 
The principal criticism of the Southdown on the part of the American farmer is the lack of wool production as well as insufficient size, though the size is not a serious objection. Wallace, a leading Scotch authority of to-day, says, "They are not good rent payers, except in their native district, being too small and also liable to foot rot." Notwithstanding the intrinsic merit and value of this breed, until it presents more scale and fleece it will not succeed in meeting equal favor in America with the Shropshire, Oxford, or Hampshire.

The distribution of the Southdown is world-wide. It has been exported from England into almost every country of Europe,

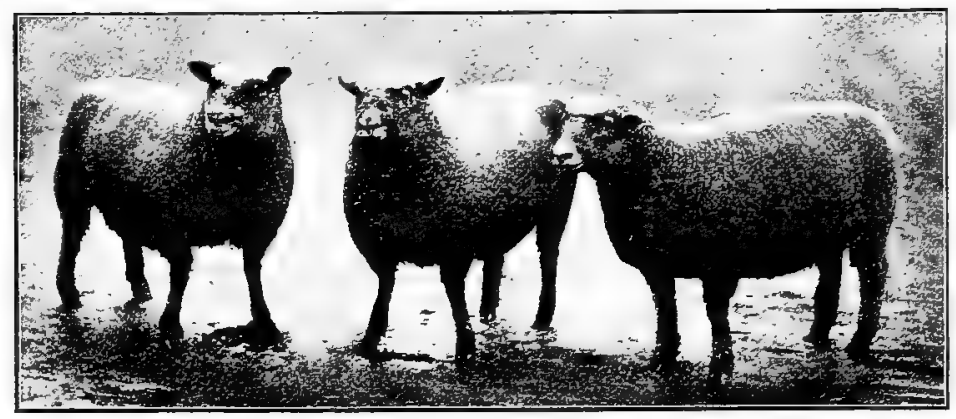

FIG. 173. A pen of three Southdown welher lambs, winners of first prize at the Smithfield Show, London, I 903 . At 10 months of age these lambs averaged I $54_{3}^{2}$ pounds each. Bred and exhibited by C. Adeane, Babraham, Cambridge, England. Photograph from F. N. Webb, Agent, Cambridge

Africa, Australia, and America where civilization and sheep husbandry at all prevail. Even as late as 1903 exports were made to the United States, France, Russia, Australia, Argentine Republic, Chile, and Japan. Perhaps no breed of sheep during its career has had an equally wide distribution. In the United States Southdowns are recorded as bred in nearly fifty states, important flocks being kept in Ohio, New York, Pennsylvania, Illinois, Wisconsin, Vermont, and Kentucky. The breed is also well represented in Canada, notably in Ontario.

Organizations to promote Southdown sheep exist in England and America. The Southdown Sheep Society, with headquarters in London, England, published its first flock book in I893, and 
up to 1905 has issued fourteen volumes. The American Southdown Breeders' Association, organized in 1882, has published nine flock books and registered some 15 ,000 sheep.

Notable prices for Southdown sheep have been paid since the days of Ellman, though the figures are not as large as those derived from Lincoln or Merino sales. In I 787 the first Southdown ram to bring ten guineas $(\$ 50)$ was sold by Ellman to Lord Waldergrave. In 1794 the Earl of Egremont gave Ellman about \$1 e each for 50 ewes. In I796 this same breeder sold a ram for 50 guineas, or $\$ 250$. Later the Emperor of Russia and the Duke of Bedford each took two of Mr. Ellman's rams at I50

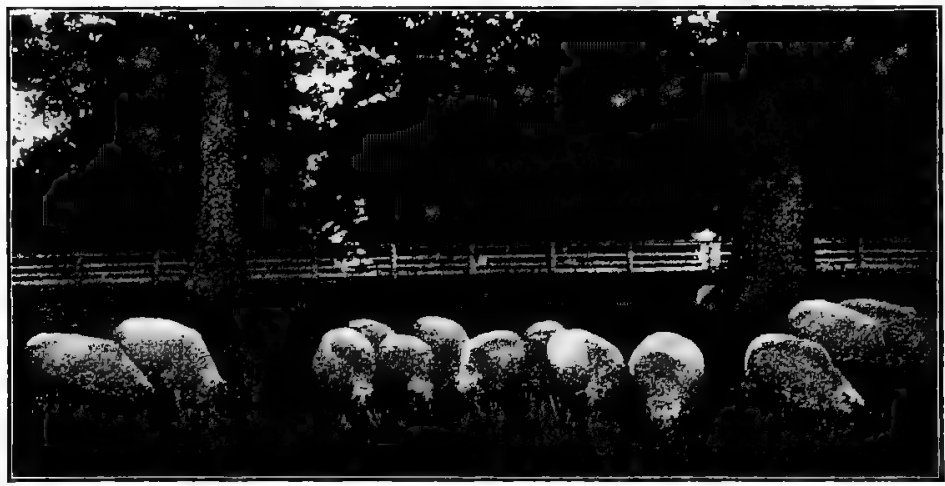

Fig. 174. A group of Southdown ewes in pasture, owned by C. J. Stuckey, Mechanicsburg, Ohio. Photograph by the author

guineas $(\$ 750$ ) per head. In 1829 , when the Ellman flock was dispersed, 36 rams averaged about $\$$ I 25 each. At the dispersal sales of Jonas Webb in I86I and I862 there were sold I404 sheep at an average of $\mathcal{E}_{\mathrm{I}}$ I I $7 s$. $3 d$., almost $\$ 58$ each, the highest price being for a ram, 260 guineas, or $\$$ I 300 . At the sales of Henry Webb in Cambridgeshire in 1889 and I 900,745 rams and ewes averaged about $\$ 60$ each, the top price being 210 guineas. In earlier days higher prices ruled for Southdowns in America than now. In 1856, at the sale of L. J. Morris, at Fordham, New York, the ewes averaged $\$ 150$, and one imported ram brought $\$ 400$. The ram Archbishop, bred by Jonas Webb, was imported by G. H. Brown and cost \$1 250 . 


\section{CHAPTER LI}

\section{THE SHROPSHIRE}

The native home of Shropshire sheep was in the counties of Shropshire and Stafford, England. The former is in centra?western England, being bounded on the west by Wales, while Stafford lies just to the east of Shropshire. The country is pleasantly rolling, with some hilly features also, but furnishes excellent grass and pasture. The climate is moderate, is fairly free from heavy snow in winter, and is well suited to sheep.

The origin of the Shropshire sheep is from several types of native sheep, on which Southdown, Leicester, and Cotswold blood was used. In 1803 Plymley, writing on the agriculture of Shropshire, wrote of a breed on the Longmynd with horns and black faces, that seemed indigenous and hardy. A century ago in southern

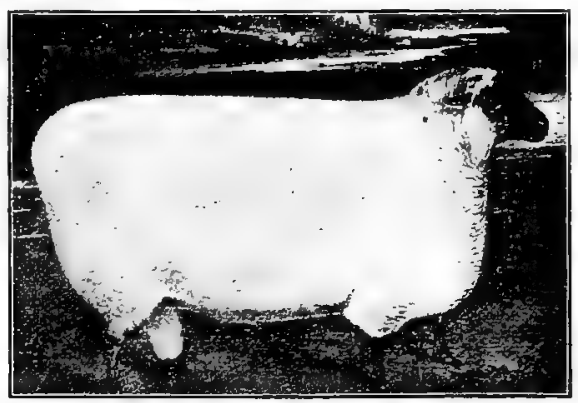

FIG. I75. A type of Shropshire ram of years ago. This illustration is reproduced from a photograph of a painting owned in England Shropshire, near Bridgnorth, on Morfe Common, as many as 10,000 sheep were pastured in summer. It was a native breed, black faced, brown, or spotted faced, with horns, the ewes dressed weighing from nine to ten pounds per quarter, and wethers eleven to fourteen pounds after feeding, and clipping a fleece of about two pounds. On Cannock Chase in Staffordshire was found a similar but somewhat larger, slow-maturing sheep, from which are descended some of the best Shropshire flocks of to-day. On Whittington Heath in Shropshire a type similar to that of Cannock Chase also existed and became 
amalgamated in the general improvement. The Southdown was used on these to secure quality, while the Leicester and Cotswold blood were used to obtain size and fleece, and from this combination came the modern Shropshire, after a considerable process of selection. The breed is comparatively recent in its present character, though Alfred Mansell says the best characteristics of the breed were present when the work of improvement was begun. As late as 1858 Professor Tanner wrote:

Only a few years since any mention of the Shropshire Down sheep raised an inquiry, even among intellectual agriculturists, as to their character, and few, comparatively speaking, knew anything of them.

Two early prominent improvers of the Shropshire are said to have been Samuel Meire of Berrington and later of Harley, near Shrewsbury, and George Adney, of Harley. Meire sought to remove the Shropshire coarseness and horns, and to improve the levelness of back and spring of rib, the obliqueness of shoulder, and breadth and fullness of rump. He purchased or hired Southdown rams from John Ellman of Glynde and used them in his flock. He also used Leicester blood with the purpose of getting better feeders and animals of shorter body. After securing his type he practiced the selection necessary to bring important improvement. Adney did not cross extensively, but a ram named Buckskin, used in his flock, with Southdown blood in his veins, produced superior sheep, one of which, the ewe Old Patentee, was a famous dam and prize winner whose blood is prominent in the best early Shropshire pedigrees. Many of the best flocks of to-day trace to those of Meire and Adney. Other prominent breeders and improvers were G. M. Kettle of Dallicott, Henry Smith of Shifnal, Green of Marlow, Horton of Shrewsbury, and Farmer of Bridgnorth.

Shropshires were first exhibited at the Royal Show in England in 1853, and in a few years it was the most prominent breed shown, 875 head being exhibited at the Shrewsbury Royal in 1884 , compared with 420 representing all other breeds.

The introduction of the Shropshire to America is comparatively recent. In 1860 Samuel Sutton of Relay House, Maryland, imported 20 ewes and a ram, which the American Farmer for 
August, I 86I, states was the first flock of Shropshires imported to America. A. B. Conger of Haverstraw, New York, had a flock about the same time, and sold the first of the breed to go into New Hampshire, to P. W. Jones of Amherst, in I864. Shropshires were exhibited at the New York State Fair at Elmira in I 86I, including the ram Gratitude that had been shown the year previous at the Royal Agricultura] Society Show at Canterbury, England. In 1862 P. Lorillard of Fordham, New York, also had a flock, and in I868 L. C. Fish of Otego, New York, began breeding them. About I875 the first Shropshires were brought from Canada to Michigan by Mrs. Ann Newton of Pontiac. In 1880 this breed was advertised by J. A. Brown \&

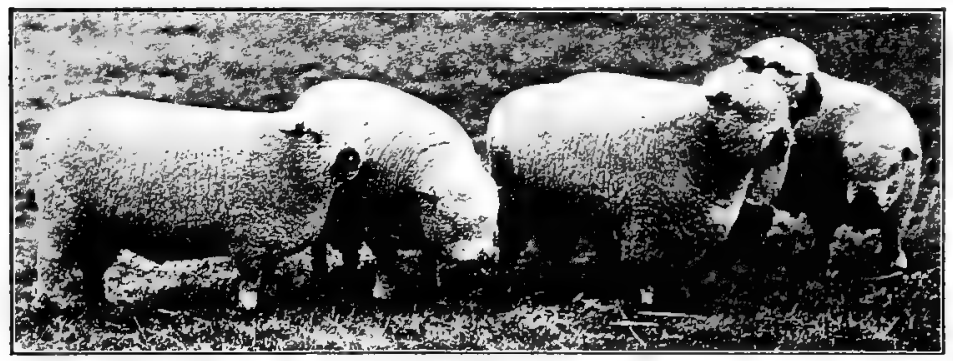

FIG. I76. First-prize pen of Shropshire yearling rams at the Koyal Agricultural Society of England Show, I904. Bred and exhibited by Sir R. P. Cooper, Bart., Shenstone, England. Photograph from William Cooper \& Nephews, Berkhamsted, England

Son of Decatur, Illinois. Along in the eighties numerous importations were made into Indiana, Illinois, and Michigan, and the breed became well distributed.

Characteristics of the Shropshire. This breed is of the mediumwool class and is somewhat heavier and larger than the Southdown. The face, ears, and legs are usually a dark brown or blackish brown, although fifteen years ago they were often grayish brown of face. The head is hornless and is slightly larger than the Southdown, and in the best specimens is covered with a striking cap of wool even to the nostrils, covering all but a small part of the nose. The ears should be small, short, and moderately broad, and should be well covered with short, fine wool. While the Shropshire is an excellent backed breed, it also 
carries such a depth of body as to usually appear fairly short of leg. A prominent feature of good specimens is a full bosom and strong brisket. The rump sometimes lacks levelness and fullness, though the thigh and twist may be excellent. The fleece covers the entire body admirably, being compact and fairly long and of superior quality. In temperament Shropshires are of the first class, being easily handled. The skin of representatives of this breed is very commonly bluish pink and lacks the superior quality and color of either the Merino or Cheviot.

The size of the Shropshire makes it about an average among the middle-wool breeds. A standard weight for mature rams is

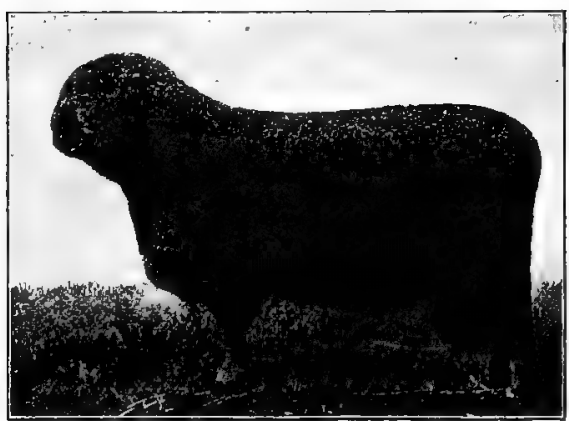

FIG. 177. Champion Shropshire ram at the Kentucky State Fair, 1903. Exhibited by the Niagara Stock Farm, Lewiston, New York. Photograph by the author 225 pounds, with 150 to I 60 for ewes. A few years ago one large importer and breeder advertised that his rams would average 250 pounds and his ewes 175 pounds. There has been a tendency in this country to develop a large type among some breeders and a smaller type among others, the latter arguing in behalf of quality rather than quantity.

The Shropshire as a mutton sheep is of a superior order, ranking next to the Southdown, and when well fed often equaling it. In the Iowa station breed test Shropshire fattening wethers of an average age of 37 I days, in the first trial, made an average daily gain of .48 pound, and in the second trial, covering 279 days, gained an average of .36 pound daily. In one trial it required 718 pounds dry matter for 100 pounds gain, and in the other 1026 for I 00 pounds gain. The valuation per Ioo pounds live weight ranked second to the Southdowns, viz., $\$ 4.63$ and $\$ 5.60$ for each trial. In feeding experiments on Shropshire lambs, conducted by Professor Brown at the Ontario College, grades of this breed made the best record among five tested. In a general way feeding experiments with Shropshires have shown excellent returns. 
Cross-bred or grade Shropshires are to-day one of the most common types of mutton sheep found on the market. Shropshire rams used on native ewes furnish lambs of a much-desired class, fattening easily, not too large, and profitable killers. In the Mississippi Valley states Shropshire grades are the common sheep outside of Merino communities. A Shropshire ram-Merino ewe cross is also a very beneficial one from a mutton point of view. Used on the long-wool grade ewes, a smaller, better mutton sheep results, with a more profitable fleece. Alex. Bruce, chief live-stock inspector for New South Wales, in 1894 wrote, "For the production of prime fat lambs there is no better ram (if

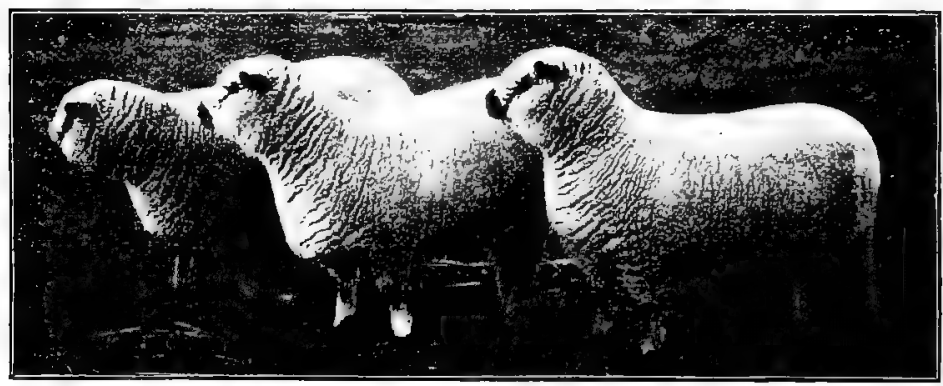

FIG. 178. The first-prize pen of Shropshire yearling ewes at the Royal Agricultural Society of England Show, 1904. Bred and exhibited by Sir R. P. Cooper, Bart., Shenstone, England. Photograph from William Cooper \& Nephews, Berkhamsted, England

there be as good) than the Shropshire, and the result is equally favorable where that ram is put to cross-bred ewes."

The fecundity of Shropshire sheep is notable. The ewes of this breed have long been noted for the number of lambs they will produce. A ewe owned by a Mr. Pochin at Leicester, England, dropped five lambs in 1882 , four in 1883 , and four in 1884. A writer in the English Agricultural Gazette in 1879 reports that in 1877 he had 125 ewes suckle 194 lambs, in 1878 he had I 20 suckle I76, and in 1879 he had I24 suckle I9I. Mr. Alfred Mansell, secretary of the English Shropshire Society, states that I 50 to 175 lambs per IOO is the usual average, that I I 666 ewes in 1896 reared I 68 lambs per Ioo ewes. In a study of 23,037 Shropshires recorded in the American Shropshire 
Flock Book the author found 13,659 , or 59.2 per cent, of single birth; 9053 , or 39.2 per cent, registered as twins; and 3 I 5, or I. 3 per cent, as triplets, this record covering the years I 890 to I 899 .

The Shropshire as a grazing sheep ranks but fair. It is especially adapted to regions where the pastures are superior, but it is not so well adapted to hilly land nor to sparse pasturage as the Merino, Southdown, or Cheviot. It is distinctly suited to the corn belt of America, where it is most abundant. It is also well suited to the better Canadian pastures, and in New England satisfactory results have been secured.

The early maturing qualities of the Shropshire are pronounced, ranking in the first class. Lambs at four months old will easily weigh 40 pounds and at twelve months old weigh over Ioo pounds.

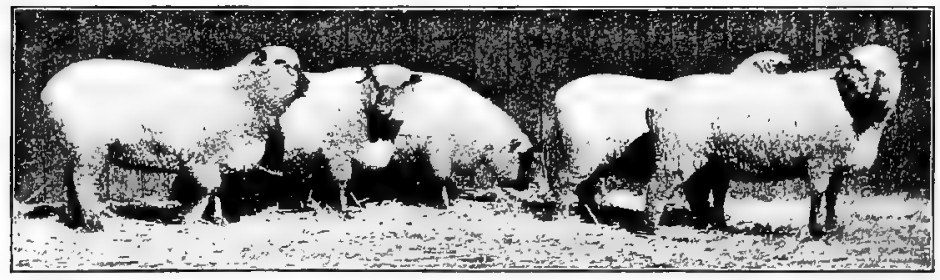

FIG. 179. The champion pen of Shropshire yearling ewes at the Koyal Agricultural Society of England Show, 1897. Bred and exhibited by T. BowenJones, Shrewsbury, England. Photograph by the author

Wallace gives 20 to 22 pounds per quarter the dead weight at twelve months old. The early-maturing, easy-fattening character of the breed or its cross or grade is what makes it so popular among feeders. Further, for years dark-faced mutton has been more popular in the market than the white-faced.

The Shropshire as a wool producer ranks very well. The average fleece of unwashed wool will probably not much exceed eight pounds. Wallace places 7 or 8 pounds a good average weight for the fleece of an ordinary ewe flock, while Professor Thomas Shaw gives 9 to Io pounds for the ewes and I 2 to 15 pounds for the rams as the average of a "good flock." The staple of the Shropshire is rather compact, of better than medium quality, in good specimens is of superior fineness and crimp and is about three and one half inches long, distinctly longer 
than the Southdown but shorter than Oxford or Hampshire. When the fleece is opened it frequently shows considerable oil for a medium wool, and has a most attractive fiber. A good specimen of Shropshire should be well covered with wool about the belly and down the legs to below knee and hock.

The Shropshire's rank as a general-purpose sheep is high, which accounts for its popularity. The combination of the better-class mutton and wool, with ample size and above average fecundity, has met the demands of the modern farmer.

The vigor of the Shropshire is criticised by some as not being as great as it should be, if compared with the Merino, being more subject to colds in winter, and showing less resistance to the twisted stoma ch worm (Strongylus) in summer than is desirable.

The distribution of the Shropshire is to-day worldwide, it being found in most of the counties of England, in Scotland, Ireland, Russia, France, Germany, South Africa, South America, Australia, New Zealand, Tasmania, Jamaica, the Falkland

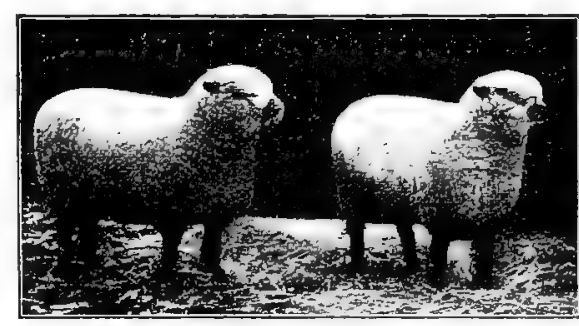

FIG. 180. A pair of prize-winning Shropshire ewes at the Pan-American Exposition, 19or. Owned and exhibited by G. H. Davison, Millbrook, New York. Photograph from the National Stockman and Farmer

Islands, the United States, and Canada. There are very successful flocks in certain mountain districts, as in Scotland and New England, but it is essentially a sheep suited to gently rolling lands, preferably north rather than in the dry south. In America fine flocks exist in Canada, and the breed is well represented in the states generally, but especially in New York, Indiana, Michigan, Wisconsin, and Iowa.

Organizations to promote Shropshire sheep are among the earlier ones of the kind. In I 882 the English Shropshire Sheep Society was established and the first volume of the flock book published in I 884 , since which twenty-three volumes have been issued to 1905. The American Shropshire Sheep Association was organized at La Fayette, Indiana, in February, 1884, and is 
to-day the strongest individual sheep association in the world. Its first flock book was published in I 889 , since which it has published eighteen, and about I 90,000 sheep have been registered to 1905. There is also a National Shropshire Association in the United States, which has published one flock book. Australia and Tasmania also have Shropshire flock book associations.

High prices for Shropshires have been paid. In I88 I Mr. A. B. Allen wrote:

I notice from late sales reported in the English papers the choicest are bringing high prices, Io to roo guineas (\$50 to \$500) each, and one ram has been sold for the extraordinary sum of 200 guineas $(\$ 1000)$.

Mr. Alfred Mansell, long a prominent auctioneer of Shropshires abroad, has published quite a record of Shropshire sale prices. A list of 464 rams ranged in average selling price at auction from slightly above $\$$ IOO per head to over $\$ 200$, while I 700 ewes sold at prices ranging from $\$ 20$ to over $\$ 50$ per head. A list of 53 rams is also given, by name, which have either sold or been hired for from $\$ 305$ up to $\$ 1250$ each, nine of which came within the $\$ 1000$ list. In $1896 \mathrm{Mr}$. Mansell wrote:

Foreign and colonial flock masters have been good customers, and at high prices, running up. to 200 guineas for rams, 30 guineas for ram lambs, 40 pounds for ewes, and 15 guineas for ewe lambs.

In the United States Shropshire rams have sold for as high as $\$ 500$. 


\section{CHAPTER LII}

\section{THE OXFORD DOWN}

The native home of the Oxford Down sheep is Oxford County, England, in the region adjacent to the early home of the Cotswold. The soil is quite variable, being clayey in some places and light and poor in others. The climate is fairly temperate and suited to sheep husbandry. Good grazing abounds in Oxford, and roots and small grains do well on the better-class lands.

The origin of the Oxford Down sheep is comparatively recent. About I 833 Mr. Samuel Druce of Eynsham and Messrs. William Gillett of Southleigh, Blake of Stanton Harcourt, all in Oxfordshire, and Mr. Twynham in Hampshire, began to develop a new breed, though Mr. Druce was the leader in the movement. In I 859 Mr. Druce wrote to Mr. Pusey :

The foundation of this class of sheep was begun about the year 1833 , by using a well-made and neat Cotswold ram with Hampshire down ewes. At the same period several breeders of sheep in this neighborhood also tried the experiment ; consequently there has always been an opportunity of getting fresh blood by selecting sheep which suited different flocks, and thereby maintaining the uniform character which is now established.

Druce and Gillett also used Southdowns to some extent in the early days of their cross-breeding. In establishing this cross Mr. Druce wrote in 1853 that he found no difficulty in keeping the form and size of the animal as it should be, and the wool of a valuable quality and not deficient in quantity. He also maintained that the good qualities could be better secured by using cross-bred animals on both sides than by using the first cross. Crossing was undoubtedly continued for many years, with the view of securing a sheep better suited to light farm land and producing superior mutton and a heavier fleece than that yielded by the pure-bred. "Mr. C. S. Read," says Wrightson, "tells us that the (flock) owner formerly divided his flock into three parts, 
putting a half-bred ram to the ewes that were about right - a Cotswold to the small ones and a Down to the coarser sheep." In I 862 the then fairly well established type was given a special place at the Royal Agricultural Society Show at Battersea, under the name of Oxfordshire Down.

The introduction of the Oxford Down to America began over a half century ago. In I 846 "New Oxford or Cotswold crossbred sheep " were first imported to the United States by Clayton

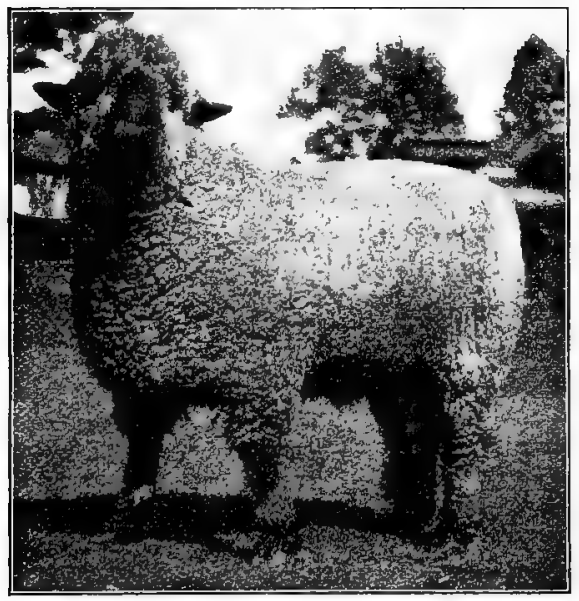

FIG. 181. Bryan's No. 9, 31747, grand-champion Oxford ram at the Louisiana Purchase Exposition, Ig04. Owned and exhibited by R. J. Stone of Illinois. Photograph by the author Reybold of Delaware. In I $853 \mathrm{~W}$. C. Rives, then in England, sent to his home in Virginia one ram and five ewes. In September, I853, R. S. Fay of Lynn, Massachusetts, imported a small flock. Soon after J. T. Andrew of West Cornwall, Connecticut, established a flock which became very famous. In 1857 Andrew sold the Messrs. Smith of Middlefield, Massachusetts, 27 head, and in September the same year sold a flock to C. L. Whiting of Granville, Ohio, the first Oxfords to enter that state. This breed seems to have attracted considerable attention, and even as early as I 859 a flock was owned in Texas by Colonel C. G. Forshay, who had purchased from J. T. Andrew. The Civil War caused a break in Oxford Down interests, and not until years afterward did this breed again come into prominence. Fifteen to twenty years ago W. A. Shafor of Ohio, R. J. Stone of Illinois, George McKerrow of Wisconsin, and Robert Miller of Ontario, Canada, imported many superior Oxfords, including prize winners at the leading English shows.

Characteristics of Oxford Down Sheep. This breed, at a superficial glance, closely resembles the Shropshire. It is hornless, has 
a dark brown face and legs, is wooled over the forehead, and is a typical mutton sheep. However, under average conditions, the Oxford Down is lighter brown than the Shropshire, is not so heavily wooled over the head, though with longer, looser forelock, has a larger frame and more scale, with a longer, more open fleece. In early days the Oxford face was speckled or mottled brown and white or gray, and the fleece was rather long

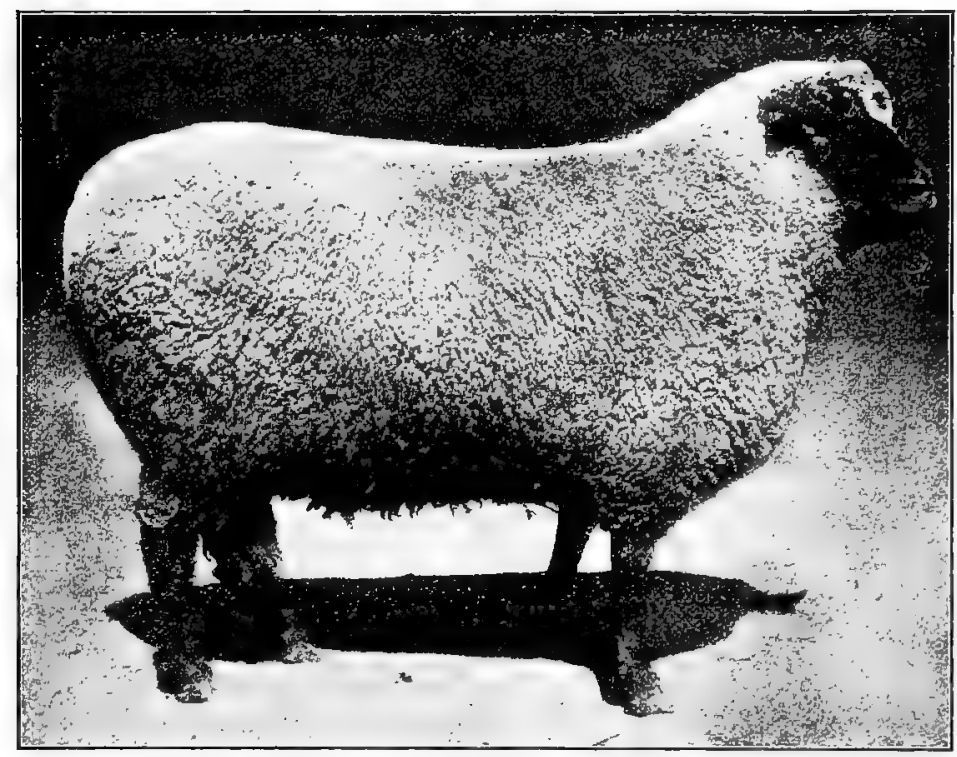

FIG. I82. An Oxford ram, two years of age, imported in 1900 by George McKerrow \& Sons of Wisconsin, a first-prize winner at six state fairs that year and five times sweepstakes ram. Photograph from the National Stockman and Farmer

and open, quite suggestive of the long-wool type, as might be expected, considering the Cotswold blood used. The modern Oxford, however, has been bred to be uniformly brown in face, and the fleece has been bred shorter and more compact, although at the present time this is essentially the largest of the middlewool breeds. The head of the Oxford is rarely wooled much below the forehead, and the ears tend to be somewhat long and thin and free of wool. As a rule Oxfords show the distinctive 
mutton form, with a strong breadth of back and excellent leg of mutton. The skin of the Oxford Down, like the Shropshire, frequently lacks color, being bluish tinted and lacking the pink color desirable. Perhaps no breed of sheep has shown greater improvement in recent years than this.

The size of the Oxford Down places it in the first rank. Rams have been shown that weighed above 400 pounds, and 275 pounds for the mature male is a weight easily attained. Mature ewes should weigh close to 200 pounds or more. In a statement in the Breeders' Gazette in I 889 , on Oxford weights, Mr. George McKerrow, a prominent breeder, gave the following figures: 2 rams, two years old, averaged 303난 pounds each; 4 yearling rams averaged 203 pounds each; 4 aged ewes averaged 2 I 5 pounds each; 5 yearling ewes 177 pounds; and 8 March and April lambs, about September I, averaged I 8 pounds each. These were not fat sheep. In the American Sheep Breeder an Ohio man writes that in September, 1890, his ewes from one to five years old averaged I93 pounds and his rams 325 pounds.

The Oxford Down as a feeder ranks deservedly high. Being quiet of temperament and of considerable size, the breed easily thrives under conditions of restraint and fattens rapidly to large size. In the Iowa fattening wether lamb test the Oxfords in one trial gained a daily average of .52 pound, and in a second trial .40 pound, requiring in the first trial 740 and in the second IO3I pounds of dry matter for each 100 pounds of gain. The Oxford carcasses did not dress out as well as most of the other breeds, those in the first trial rating 55.2 per cent and in the second 50.08, and bringing $\$ 4.50$ per hundredweight live weight in the first trial and $\$ 5.40$ in the second. The Iowa records give the Oxford about an average rating in feeding results. In the Smithfield Club Show in 1889 the Oxford wethers weighed to show a daily gain of 9.3 ounces, and the wether lambs I o ounces per day, surpassing boih Southdown and Shropshire. The general evidence shows the Oxford to be a feeder that will do well for considerable periods, and such as the market readily purchases.

The Oxford Down cross-bred or grade has long met with favor, but of late has rapidly grown in the esteem of American sheep men. From the first this merit of the Oxford was extolled; it 
is a cross-bred that feeds rapidly to advantage on a variety of lands. The large size and heavy shearing quality of this breed has attracted our farmers, so that pure-bred rams are in demand to grade up flocks with Merino or common ewes. This produces offspring of excellent mutton qualities, shearing large fleeces and meeting with popular favor. This demand is not restricted to America. The English writers state that Oxford rams are in special favor in Germany for crossing on Merino ewes, where

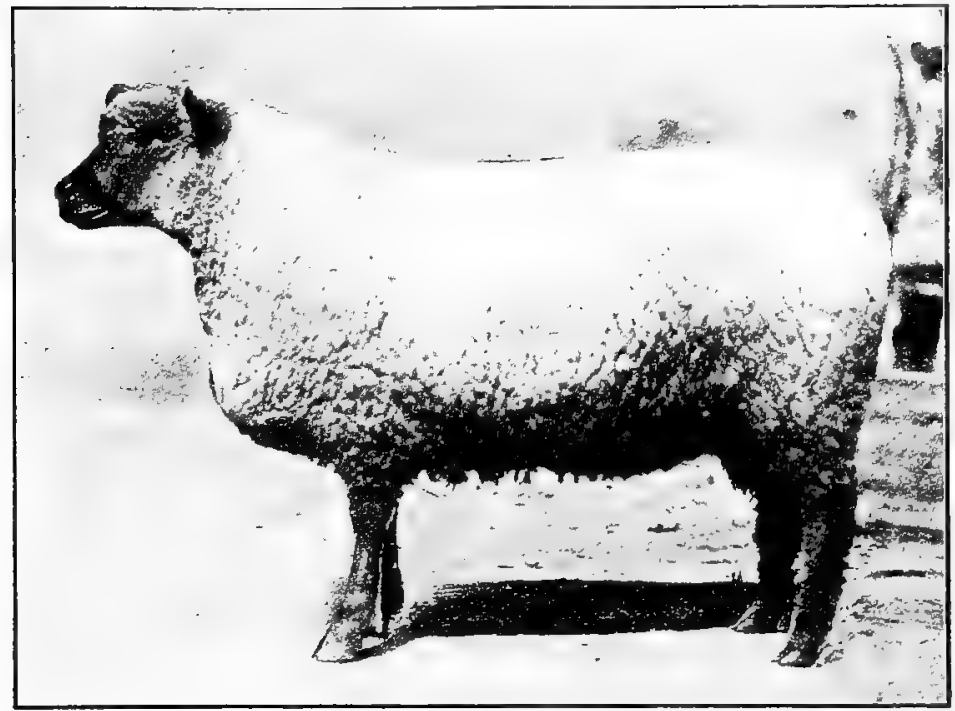

FIG. 183. The grand-champion Oxford ewe at the Louisiana Purchase Exposition, 1904, and first in class at six state fairs. Owned and exhibited by George McKerrow \& Sons of Wisconsin. Photograph from the National Stockman and Farmer

they are considerably used. In Scotland the use of Oxford rams on Cheviot ewes or cross-bred ewes is attracting favorable attention. At the Scottish National Fat Stock Show in I 899 the Oxford crosses took all the prizes in a class of twenty-five entries, a remarkable showing.

The 0xford as a wool producer is in special favor to-day. Shearing a heavy fleece of combing wool, which tends to coarseness and length of staple, it thus satisfies the demand of the 
farmer for weight. In I 860 Lawrence Smith of Massachusetts stated that his flock of store and breeding ewes usually sheared from 5 to 7 pounds, with his rams' fleeces sometimes weighing Io pounds. Thirty years later an Ohio breeder wrote that his Oxford Down flock sheared an average that year of I I pounds I 4 ounces per head. In the Iowa breed test the Oxford wether lambs in one trial sheared I I pounds and in another 8 pounds, the fleeces bringing $\$ I .44$ and $\$ I .16$ respectively, materially excelling all other middle-wool breeds. A high-class Oxford Down flock should shear a fleece averaging close to twelve pounds unwashed wool.

The prolific quality of the 0xford Down has long caused favorable comment among the breeders of this class. Twins are fairly

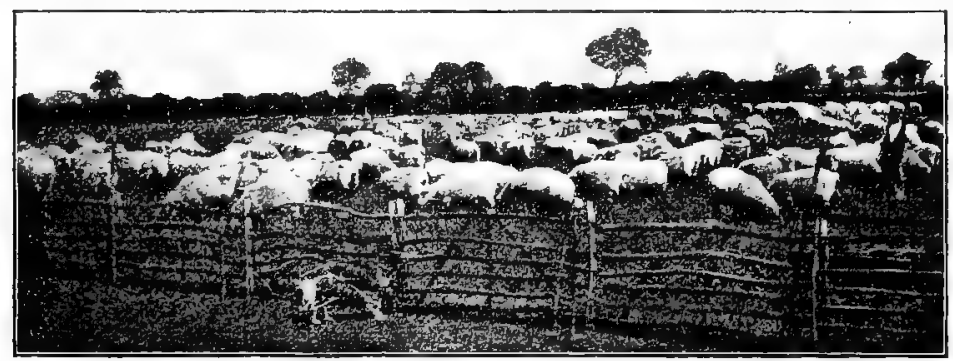

FIG. I84. Oxfords on pasture on the farm of George Adams, Faringdon, England. Photograph by the author

frequent and the ewes usually make good mothers and furnish ample milk to the lambs. The ewes, however, probably do not rank with the Shropshire in producing twins.

The distribution of the Oxford Down is very widespread. Originally confined to Oxfordshire, it is now found in about a score of counties in England, as well as in Scotland, Wales, and Ireland. So great has the breed grown in favor in recent years that it has become very widely distributed, flocks now existing in Germany, France, Sweden, Switzerland, Russia, Brazil, Argentina, Australia, New Zealand, Canada, the United States, and elsewhere. While the Oxford is not suited to range conditions, it nevertheless seems to thrive under a variety of soil and climate, though it is best suited to the more level or slightly rolling 
lands. In the United States there are Oxfords in many states, although Illinois, Ohio, Indiana, Wisconsin, and New York have noted flocks, as well as Ontario, Canada, where the breed has long met with favor.

Organizations for the promotion of Oxford Down sheep first came into existence in I884, when the American Oxford Down Sheep Record Association was established. This association published its first flock book in 1883 and has since then up to 1906 issued ten volumes, including the registration of about 35,500 rams and ewes. In 1888 The Oxford Down Sheep Breeders' Association was organized in England, and the first volume of their flock book appeared in 1889, in which fifty-four flocks were registered. Since then the English Association, up to 1905, has published seventeen flock books.

The prices paid for 0xford Down sheep have not ranged very high. In I 860 R. S. Fay had a sale at Lynn, Massachusetts, when the prices ranged from $\$ 7.50$ to $\$ 51.00$ a head. The annual Oxford Ram Fair in England shows something of prices current for this breed. In 1900 at this sale the highest price paid was 42 guineas $(\$ 210)$ for a yearling ram, and 50 yearlings from the flock of Worley \& Son averaged slightly over $\$ 50$ per head. In 1903, 60 rams sold by Mr. George Adams averaged 8 guineas $(\$ 40)$. The same year, at the sale of J. T. Hobbs, at Cirencester, the draft from his flock averaged in excess of $\$ 75$ per head, one ram bringing 58 guineas $(\$ 290)$. In 1876 T. S. Cooper of Pennsylvania showed the ram Freeland at the Centennial Exposition at Philadelphia, a famous prize winner there and in England, which he hired of A. F. M. Druce of England for $\$ 425$. 


\section{CHAPTER LIII}

\section{THE HAMPSHIRE DOWN}

The native home of the Hampshire Down breed of sheep is in south-central England, in the county of Hampshire, which, on its southern border, touches the English Channel. Like all of south England, the climate is temperate and rather moderate the year round. The land is rolling, with the downs more or less crossing the county. The soil is of a chalky character and is none too fertile, producing short, fine grass, and suited to wheat, while roots do well on the better lands.

The origin of the Hampshire Down sheep traces back to at least two sources, crossed with improved stock. In the counties of Hampshire and Wiltshire, and also to some extent in other near-by counties, were large, slow-maturing, white-faced, narrowbacked, fine-fleeced sheep with horns, known as Wiltshires. The horns turned back behind the ears and about the cheeks, from which peculiarity they were known as "crooks." There were no other sheep like them in England, and by 1837 they had practically disappeared as a result of crossing. In the county of Berks there was also another old type with horns, strong and vigorous, with dark face and legs. Early in the last century these two types were crossed again and again with the Southdown. About I 835 the sheep of Hampshire and Wiltshire generally showed Southdown type and character, and they were exhibited at the Royal Agricultural Society Show at Oxford in 1840 as West Country Down sheep, which name they long retained. From this stock was evolved the present type known as Hampshire Down.

The early improvement of the Hampshire Down is largely due to Mr. William Humphrey of Oak Ash, Newbury, Hampshire, and Mr. James Rawlence of Bulbridge, Wilton, the same county. Besides these Messrs. Stephen King, William King, Moore of 
Littlecott, Edward Waters, Frank Budd, Saunders of Watercombe, Canning of Chisledon. Ferris of Manningford, Alfred Morrison, James Read, and Bennett of Chilmark were prominent early breeders. Mr. Humphrey, however, is the most important of these, being essentially the great Hampshire Down improver, with Mr. Rawlence a most important later factor. About I834 Humphrey began gathering up as choice a flock as possible of West Country Down ewes, breeding to them rams of the same class. In 1842 he became impressed with the improved breeds at the royal show at Oxford, notably the Cotswolds, and believed that his sheep might be improved by crossing. Consequently he obtained a choice Southdown ram from Jonas Webb and crossed on his ewes with much success. Later he obtained other rams, three in all, the only outside ones ever used in his flock. At first he had difficulty in loss of size, but he culled out the finerboned, smaller ewes and bred only the larger, more robust ones, using choice cross-bred rams of his own breeding. Mr. Humphrey was very particular about

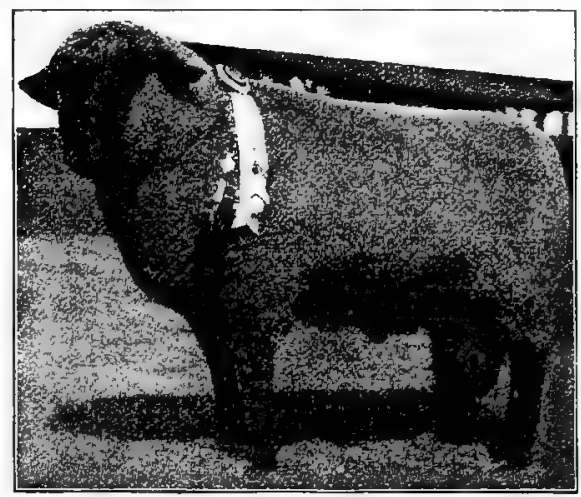

FIG. 185. The Earl 4442, grand-champion Hampshire ram at the Louisiana Purchase Exposition, 1904. Shown by John Milton of Michigan. Photograph by the author

his sires and the ewes they were bred to, selling all undesirable ewes to the butcher. He died in 1868, when his flock, one of very superior merit, was dispersed. Mr. James Rawlence bred rather differently, beginning with the Sussex breed, crossing the larger and more robust ewes with the West Country Down or Hampshire Down rams. He frequently used rams of Mr. Humphrey's breeding, and later bought Hampshire ewes to which he bred rams of his own stock. By using new blood gradually, and practicing careful selection, Mr. Rawlence developed a flock of high merit. From these two flocks has come the best of Hampshire Down stock. 
The introduction of the Hampshire Down of the modern type to America probably first occurred in I855, when Thomas Messenger of Great Neck, Long Island, New York, imported a small flock. But little, however, was done to introduce more Hampshires prior to I880. In I88 I Henry Metcalf of Canandaigua,

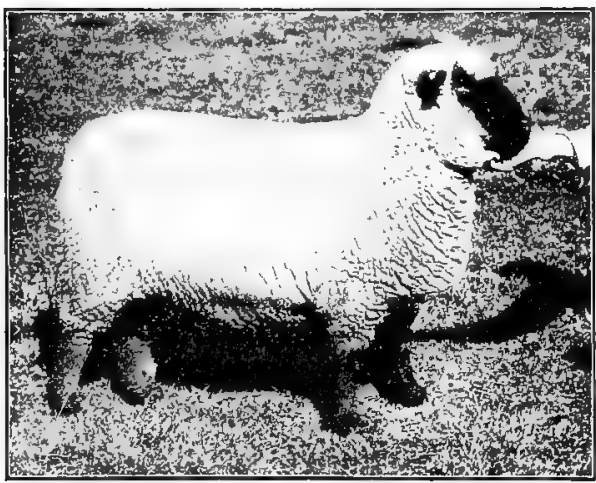

FIG. I86. A yearling Hampshire Down ewe, firstprize winner wherever shown, and first in a pen of three at the Royal Agricultural Society of England Show, 1904. Imported and exhibited by Chilmark Farms, New York. Photograph from Charles V. Phelps, Superintendent

New York, imported the ram Shepherd's Pride 2d. About I 883 the breed was introduced into Michigan, and in 1885 found its way into Ohio, Wisconsin, and elsewhere.

Characteristics of the Hampshire. The head is very dark brown or almost black in color, is rather large, and frequently has a pronounced Roman nose. The lips and nostrils are black. The ears are large, of a dark mouse color behind, and are more pointed than with Shropshire or Southdown. In the best types the ears lean outward slightly. The neck tends to be a bit long, lacking the compactness of the Southdown; yet Wrightson, the best British authority on this breed, states that it is thick and muscular and is considered to be a point of special excellence and importance. He further states that the shoulder tops are wide, and that the girth behind the shoulders and of the entire fore end must be well marked to secure any attention either in the prize or sale ring. This breed has been criticised by Wallace, who states that a conspicuous defect in ordinary specimens is a falling away behind the shoulder. The type of body and general carcass is common with accepted standards for other mutton breeds. The legs are dark brown in color, like the face; in fact the color is so deep a brown that it may almost be regarded as black. In further reference to 
these breed characteristics Wrightson makes the following interesting comments upon the sources of their inheritance.

The slightly Roman character of the face and the fine wool have no doubt partly been derived from the old Wiltshire horned sheep. . . . The quality of the flesh and the color have come through the Southdown, but the color has been deepened by selection. The length of ear has probably been derived from an alliance with the Cotswold.

The size of the Hampshire Down is large, being second only to the Oxford Down, although Wrightson classes the Hampshire as the largest of the middle-wool breeds. Mature rams should weigh about 250 pounds and ewes 190 or so. J. H. Taft of Michigan made an importation of ewes which in fair flesh averaged from 175 to 200 pounds, while lambs of his own raising at about ten months old weighed an average of $113 \frac{1}{2}$ pounds. James Wood of New York, one of the best American authorities on the breed, states that mature rams weigh 300 pounds and ewes something over 200, but these must be above average specimens.

The Hampshire Down as a mutton sheep ranks high. It has long been a popular breed in the English market, and, beginning nearly twenty years ago, met with favor in the American early lamb market, largely due to the importations and popularizing methods of James

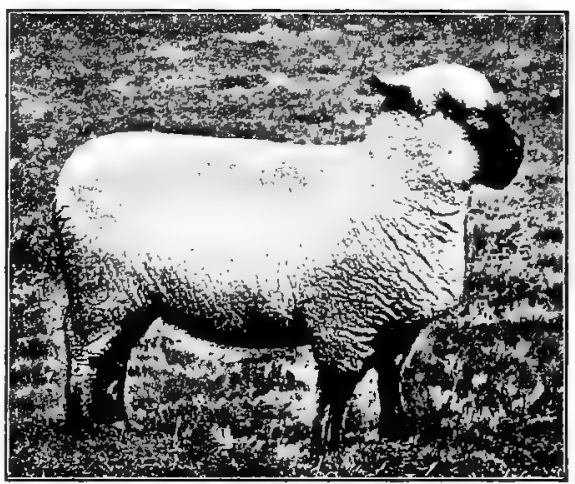

Frg. 187. A two-year-old Hampshire Down ewe, first and champion at seven American fairs in 1904. Owned and exhibited by Chilmark Farms, New York. Photograph from Charles V. Phelps, Superintendent Wood of New York. Almost nothing has been done in experimentally feeding sheep of this breed in America. In England Lawes and Gilbert secured fair results.

The Hampshire Down for early lambs has been regarded as of special merit. The lambs mature early and fatten easily, and 
as the early lamb buyer has long preferred the dark face, the Hampshire especially supplies this demand.

The Hampshire Down for crossing or grading is valued by lamb producers in particular. In England it is customary to draft from the flock the old ewes and sell them at fairs, after which Cotswold or light-faced rams are bred to them. The result of the cross fatten rapidly, and if kept till yearlings produce a large amount of mutton and wool. It is said that large numbers of Hampshire rams are sold into Lincolnshire, where they are bred to old Lincoln ewes for producing fat lambs or wethers. The Hampshire also crosses well on the Leicester. The Hampshire ram, used on grade Merinos or pure-breds, produces the dark face and superior mutton type of early lamb. This is one of the most popular crosses in America for using Hampshire blood.

The Hampshire Down as a wool producer does not rank high. The fleece is of medium length but lacks either Southdown or Shropshire quality, and for the size of sheep shears rather light, yielding about seven pounds of unwashed wool per head for the flock.

The Hampshire as a grazer has recognized merit in England, where flocks are generally grazed in summer within hurdles, a condition to which they are well suited. They graze together, often in semicircles, and pasture closely. In Hampshire and Wiltshire a large number of sheep are maintained upon the land. Wrightson notes that his summer flock on the College Farm of six hundred acres at Downton, with a favorable lambing season, consists of from 1250 to I 300 sheep and lambs, besides a dairy of 30 cows and young stock, a very superior showing.

The fecundity of the Hampshire, while not of the highest, is distinctly superior. In 1903 the English association kept a lambing record of 37 flocks comprising 15,482 ewes. These reared 18,462 lambs, or 119.17 per cent, while only 2.21 per cent of the lambs dropped were lost. In a similar record for 1902 the percentage raised was $1 \mathbf{1 6 . 8 2}$. This speaks well for the fecundity and maternal character of Hampshire ewes.

The distribution of the Hampshire is widespread. In 1903, for example, exports were made from England to the United States, Canada, Mexico, Argentina, Uruguay, Chile, Australia, 
New Zealand, South Africa, Germany, Russia, Hungary, Portugal, Jamaica, and elsewhere. In England the breed is found in a score of counties, though chiefly in Hampshire, Wiltshire, Dorset, Sussex, Surrey, and vicinity. In the United States it has a small local distribution, being most common in New York, Pennsylvania, Ohio, and Indiana, where prominent flocks are kept. Small flocks also are kept in Canada, in Ontario and Quebec. The breed is suited to rolling lands producing abundant grazing, rather than hilly country.

Hampshire sheep associations exist in England and America. The Hampshire Down Sheep Breeders' Association of England was organized in I889, and has published seventeen volumes of the flock book. Volume XIV shows a membership of 360 and the registration of 212,000 head in flock form, of which about 210,000 are females. The Hampshire Down Sheep Breeders' Association of America was also organized in 1889 , the first flock book being published in 1890 . Up to 1905 eight volumes have been issued and 4900 rams and 11,501 ewes recorded.

The prices received for Hampshire sheep, especially in England, present a high average. In 1903 Waters and Rawlence sold at public sale about 2500 head, which generally brought good prices. At the Earl of Carnavon sale one ram brought about $\$ 550$, and 100 yearling ewes averaged about $\$ 35$ each. At J. Flower's Chilmark sale and ram letting two rams were let at I35 guineas (\$675) each, the record for the past thirty-two years, with several ram lambs selling for from 34 to 76 guineas (\$ 170 to $\$ 380$ ). This was one of the memorable sales of the breed. 


\section{CHAPTER LIV \\ THE DORSET HORN}

The native home of Dorset Horn sheep, sometimes called in England Somerset and Dorset sheep, is in the counties of central and southern England, but notably Dorset, Somerset, and Wiltshire. The land here is generally rolling in localities, rather hilly, and tends to a clayey or chalky character. Roots and small grains, especially wheat and grass, are the staple crops, these doing well on the better lands. The climate is very tem-

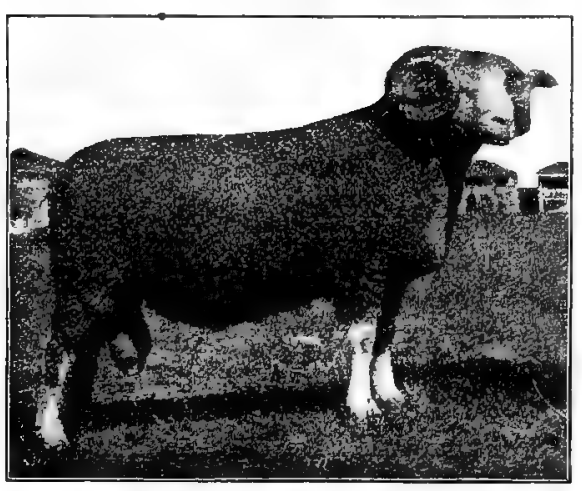

FIG. 188. A Dorset ram, first prize in class at several state fairs in 1898 , shown by Tranquillity Farm of New Jersey. Photograph by the author perate and well suited to outdoor life the entire year.

The origin of the Dorset Horn seems to be from old native stock of Dorset and Somerset counties especially. The general evidence of British authorities is that this is the only horned breed with white face and leg in Britain, and that this characteristic has been long preserved. In 1842 Professor Low wrote that in Dorset from time immemorial there had existed a breed of sheep with horns common to both sexes, having white face and legs, low shoulders, broad deep loins, long but not coarse limbs, black lips and nostrils, though sometimes flesh-colored, and possessing fine wool. In the adjoining county of Somerset was a rather larger type of much the same breed, lanker in form, longer wooled, and with pink or flesh-colored nose, by which they were known as "Pink-Nosed 
Somersets," which fattened to greater weight and had larger lambs than the sheep of Dorsetshire. Low further comments on the encroachment of the Southdown and Leicester on the Dorset territory, stating that pure-bred flocks were becoming scarce, owing to the crossing of these breeds. In fact, he stated that the breed was gradually diminishing and was in danger of being extinguished. In 1856 Professor Wilson, another British authority, writes that "the practice of crossing with the Southdown is becoming very general." In this same connection Youatt, in I 837, comments on the use of Devonshire Knots and Leicesters on Dorsets, but says the cross was not successful. However,

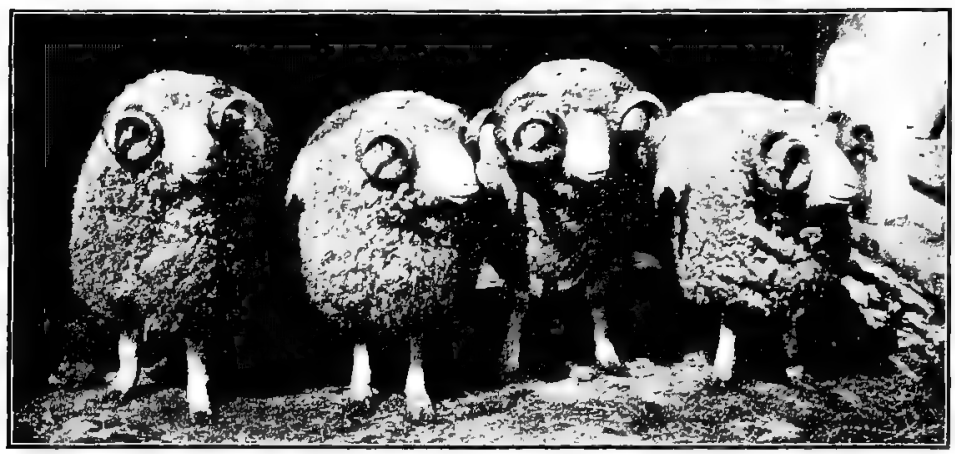

FIG. I89. Dorset rams owned by J. L. Henderson \& Son, of Pennsylvania. Photograph from the National Stockman and Farmer

some flocks were apparently kept free from crossing, notably on the isle of Portland, where about 4000 sheep of a small Dorset type existed in I840. The general improvement of the breed as a whole was secured by selection on the part of various breeders in the western part of Dorset, but especially by Richard Seymour of Bradpole, who between 1830 and 1840 perhaps had the best flock extant. Among some of the other early prominent breeders were Matthew Paul, John Pope, John Pitfield, the Messrs. Davy, William Way, and Thomas Chick. Between I 860 and I885 the breed was much improved by Henry Mayo of Coker's Frome.

The introduction of the Dorset to America is very recent, being the last of the well-known breeds brought from England to this country. The first Dorsets shown in the United States were 
some ewes and lambs exhibited in 1885 at the American Fat Stock Show at Chicago by E. and A. Stanford of Steying, England. The first owned in this country were purchased in March, 1887, by William Daley of Lockport, New York, from Valancey E. Fuller of Canada. In May, I887, E. F. Bowditch of Framingham, Massachusetts, made an importation, he being a specialist in early-lamb raising. The following month of June Adin Thayer, of Hoosic Falls, New York, imported 12 head. This same year, I887, Woodward \& Jaques of Lockport, New York, and R. J. Buck of Bridgeton, New Jersey, made importations, and the following year, in July, Rutherford Stuyvesant of New Jersey imported 2 rams and 28 ewes from the English flocks of John and William Kinder. In September, I889, Mr. T. S. Cooper of Coopersburg, Pennsylvania, imported I 53 head, mostly from the flock of Thomas Mayo, and again in $189 \mathrm{I}$ brought over 204 more head. The sheep imported by Mr. Cooper were very superior and were sold and distributed among numerous breeders, especially in the east.

Characteristics of the Dorset sheep. Both males and females have horns, those on the male curving backward and around spirally, while those on the ewes curve outward, down, and forward, with tips rising about level with the eye, perhaps turning in slightly. The face, legs, and hoofs are white. The nostrils are also white, face strong, with considerable breadth between the eyes. Compared with the ideal mutton sheep the neck and body tend to be long and rangy, and there is hardly the spring of rib and levelness of back most desirable. The head should have a short foretop of wool, the back part of the head below the ear should be wooled, and the body generally be well covered with a fine fleece, extending down to knees and hocks.

The size of the Dorset is from medium to heavy among the middle-wool breeds. Mature rams in fair flesh should weigh about 225 pounds and ewes I65 pounds. In some cases, however, much larger weights are secured. Mr. T. S. Cooper selected a large type in his importations. One two-year-old ram attained a weight of 317 pounds and a yearling 287 pounds, while ram lambs weighed I 84 and 164 pounds at five months one week old. These were mostly first-prize winners. Three first-prize 
yearling ewes at the I 889 royal show weighed at shearing time 262, 245, and 222 pounds respectively, and in August each dropped twin lambs. These, however, were excessive weights.

The Dorset as a mutton producer cannot be placed in the front rank. The meat of the wether is of fair quality when not overfat, while fat lambs rank very well indeed. In the dressed carcass the Dorset does not reach the best standard. In the Iowa station breed tests, in the first trial with fattening wether lambs, the Dorsets dressed 52.6 per cent carcass, being valued at $\$ 3.75$ per hundred, the poorest record made by ten breeds; while in the second trial they dressed 54. I I per cent, being surpassed only by the Southdown, the carcass selling at $\$ 5.50$ a hundred, compared with $\$ 5.75$ for Southdown and $\$ 5.60$ for Shropshire. Under fair conditions Dorset mutton will rank as about medium in quality.

The Dorset as a feeder will do well. The lambs grow rapidly, and with abundance of feed may be turned on the market at an early age. The breed stand s confinement and

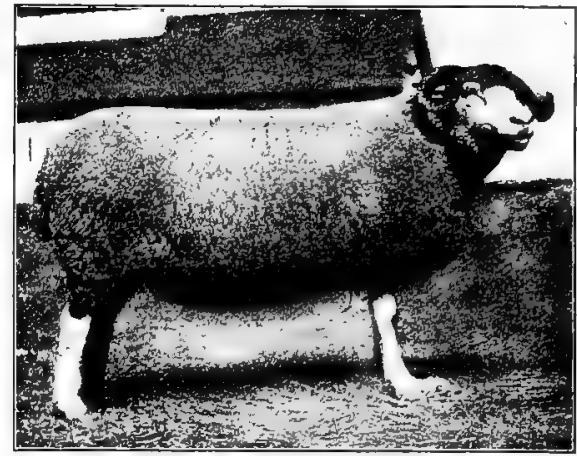

FIG. I9o. A Dorset ewe of unusual merit. First prize at several state fairs in 1898 . Shown by Tranquillity Farm of New Jersey. Photograph by the author

folding well. In the Iowa breed test the fattening Dorset lambs made an average daily gain of .48 and .43 pound in the first and second trials respectively, requiring 785 and 989 pounds of dry matter for roo pounds of gain.

The Dorset as an early-lamb producer has great distinction, having long been famous in this regard over other British breeds. The ewes will breed during much of the year, so that they have a special value for producing Christmas lambs. It has long been customary in England to breed the ewes in June and July to lamb in November and December, furnishing early lambs for the London market. In the United States, owing to the hot summers, the ewes are more readily bred from the middle of March 
into May. The lambs fatten rapidly and soon attain good weights. In England November or December lambs are generally sold fat in March and April, when they weigh 40 to 44 pounds in the dressed carcass, according to Thomas Chick, long a well-known Dorset breeder.

The fecundity of the Dorset is very fair. Not only will the ewes produce lambs twice a year if desired, but they frequently produce twins, while triplets are not rare. The general evidence from all sides shows the Dorset Horn to be one of the more prolific breeds. The evidence given in the Dorset Horn flock

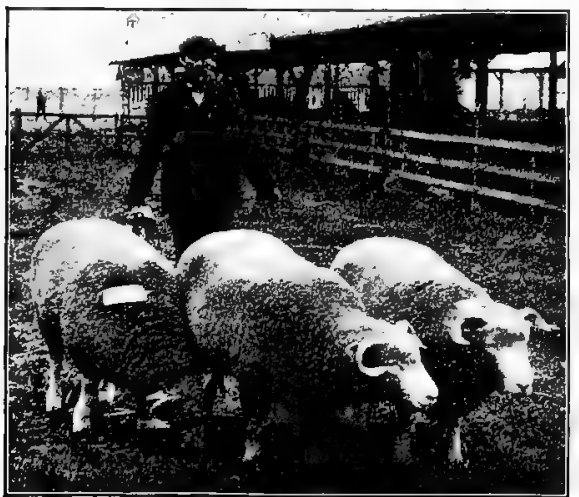

FIG. IgI. The first-prize pen of Dorset ewe lambs at the Royal Agricultural Society of England Show, 1904. Photograph by H. B. Arbuckle, from the National Stockman and Farmer books, however, does not show the breed to be so prolific at one lambing as is the Shropshire. The dams make excellent mothers and produce a large amount of milk, oftentimes drying off with difficulty.

The Dorset Horn for grading or crossing has a special value, if mutton production is the thing sought. Shropshire or Southdown rams on old Dorset Horn ewes will produce very high-class

lambs with dark faces, just what the market wants. A grade or cross from Merino stock meets with favor in America. In discussing this subject Messrs. Wing and Miller state that a Merino grade from large, roomy Merino ewes and a blocky vigorous Dorset ram will prove a surer breeder, if possible, than the pure-bred Dorset ewe. There are not many growers of hothouse lambs but what prefer Dorset grades from Merino foundation to any other ewe, the pure-bred not excepted. These ewes are again bred to pure-bred Dorset rams, and the result is a very blocky, easily fattened lamb. These grade ewes are also better milkers than the pure-breds. 
The Dorset Horn as a wool producer is open to material improvement. Mature rams will shear about 9 pounds and ewes about 6 pounds of unwashed wool. Twenty imported sheep of J. B. Henderson of Pennsylvania are credited with shearing an average of 10 pounds each. The fleece of the Dorset has improved in weight and quality. Wrightson states that fifty years ago it was computed as averaging $3 \frac{3}{4}$ pounds, whereas now (1895) a breeding flock of ewes will clip from 5 to 6 pounds of wool, and yearling ewes from 6 to 7 pounds, while rams will clip 8 to 2 pounds each, all these weights following brook washings. Dorset sheep have too short a fleece and show too little wool on the under side of the body. The quality of the staple is of medium grade, being neither fine nor coarse.

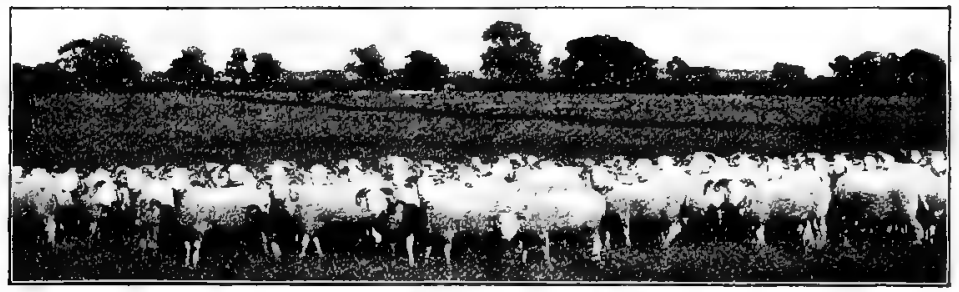

FIG. 192. A view in Dorsetshire, showing part of the Flower flock of Dorsets soon after shearing. From a photograph by $\mathrm{H}$. B. Arbuckle, from the National Stockman and Farmer

The popularity of the Dorset outside of its native home is rather restricted. It is shown at fairs or shows in but a very limited way, either in England or the United States, and the public is not generally familiar with the breed. In spite of this fact it is a mutton sheep of much merit, entitled to greater recognition, and for early lambs is of much value. With an improved capacity to produce wool, it no doubt will meet with more favor.

Dorset horns as a protection from dogs. Early advocates of the breed argued that the Dorset by means of its horns would protect itself better from dogs than would hornless sheep, but this claim has been very generally discarded in recent years, as not being worthy of special distinction.

The distribution of the Dorset Horn is not as widespread as most other British breeds. In England it is found most 
abundantly in Dorset and Somerset counties, especially on the islands of Wight, Purbeck, and Portland, where superior flocks may be found. In 1903, at the annual meeting of the Dorset Horn Association, 46,878 head were reported in Dorset, 9458 in Somerset, and 6728 on the Isle of Wight, these all being registered sheep. At the annual sale of Dorsets at Dorchester as many as I 5,000 head are sold. The breed has not been taken up with much activity abroad. In the United States high-class flocks are found in New York, New Jersey, Pennsylvania, Ohio, and Connecticut, but the breed is found in many other states and also in Canada. Dorsets have also been exported to Australasia and other British provinces. The breed seems well adapted to the level or slightly rolling lands where food is abundant. It has also thrived in the Allegheny mountain region under conditions of good grazing.

Organizations of the Dorset Horn sheep breeders were perfected in I 891 in both England and the United States. In England the Dorset Horn Sheep Breeders' Society gives official supervision to the breed. This association issued its first flock book in 1892 , and up to 1905 has published fourteen volumes, registering some 1800 rams. In I 89 I the Dorset Horn Sheep Breeders of America organized and established a flock book, publishing the first and second volumes in one in I 894. Owing to a disagreement among the members, in I 897 the Continental Dorset Club was organized, with headquarters in Ohio. This club published its first flock book in 1900 , and in 1905 issued its third volume. 


\section{CHAPTER LV}

\section{THE CHEVIOT}

The native home of the Cheviot breed of sheep is in the border country between England and Scotland, especially in the counties of Roxburgh (Scotland) and Northumberland (England). The country is hilly or mountainous, rising to an elevation of nearly 3000 feet in the section known as the Cheviot Hills. The hillsides are free of timber, excepting in the case of small artificial plantings, but are covered with short, nutritious grass. The climate is moist and rough, snow falling frequently in winter, although not usually attaining much depth.

The origin of the Cheviot is obscure, like most other breeds. Cheviots have been bred in the border country from very early times. In $\mathrm{r} 791$ David Irving published a letter in the Annals of Agriculture relating to experiments by him on Cheviots, commencing in 1777 . The Cheviot has been crossed more or less with Black Faced Highland, Leicester, and Merino, but the character of the breed has undergone great changes through careful selection, for the influence of the breeds mentioned has not been notable. In 1796 Naismyth wrote that the Cheviot was well polled, was smooth and white of face and leg, or somewhat mixed with black or brown. There was a tendency to too much leg, the shoulders were thin in some individuals, and the fleece was generally close and even, the wool soft and fine, from two to three and one-half inches long. He further says : "The same kind of sheep have fed in this district (Cheviot Hills) from time immemorial; nor does anybody allege that they were even natives of any other region." The British Wool Society over a century ago did much to popularize the breed, and at one time it became generally distributed over Scotland. The improvement of the Cheviot was gradually brought about by the breeders in general, although after the middle of the eighteenth century 
a Mr. Robson, by use of sheep from Lincolnshire, is credited with much improving the breed. In the last century $\mathrm{Mr}$. Thomas Elliott of Under Hindhope, Jedburgh, was a famous breeder and improver.

The introduction of the Cheviot to the United States first occurred in 1838 , by Robert Youngs of Delhi, Delaware County,

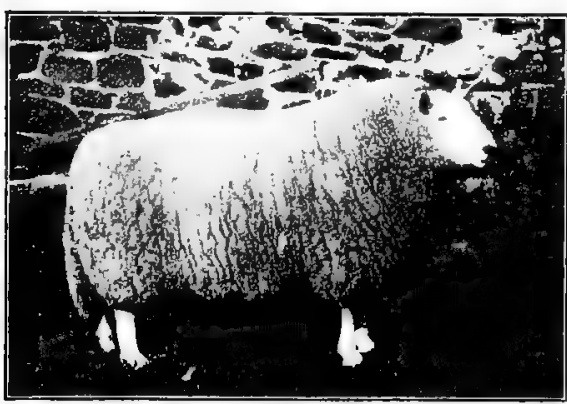

FIG. I93. Trinlieknowe ( 1327 ), a Cheviot show and stud ram owned by J. R. C. Smith, Mowhaugh, Scotland. Photograph from the owner

New York. They had some time previously been imported into Canada by a Mr. Pope of Cookshire, Quebec. In I 842 George Lough and a Mr. Davidson of Delaware County, New York, made importations. In $\mathrm{r} 845 \mathrm{~T}$. J. Carmichael imported three rams and six ewes to Jefferson County, Wisconsin. Cheviots were introduced into Pennsylvania in 1889 by T. M. Patterson, into Illinois in I 888 by E. Pumphrey, and into Indiana in I $89 \mathrm{I}$ by H. H. Keim.

Characteristics of the Cheviot. The head is usually hornless and is covered with hard, white, short hair to behind the ear and around the jaw. The lips and nostrils should be black, though frequently they are mottled flesh colored and black. The nose should be broad, with a Roman curve to a slight degree. The head is short and broad between the prominent, large eyes. The ears are white and free from wool, and are thinner and longer than the Shropshire ear. The Cheviot shoulder is lighter than with lowland breeds, and the body lacks the breadth of the Shropshire and Southdown. The skin is unusually pink and rich in color. The fleece covers the body and extends up the neck to behind the ears, forming a sort of collar, and covering the legs to knees and hocks. The fleece is of the middle-wool, combing class, is neither fine nor coarse of staple, and averages about four inches long. Sometimes the wool on the lower, back part of the thigh is long and tends to be hairy, a very objectionable feature. The head and ears often have small black spots which are no disqualifications of purity. Reddish or sandy hair also occasionally occurs 
on face and legs. This is strongly objected to, and after January I, I905, all rams possessing reddish hair, or well-defined horns became ineligible for registration. Horns occur occasionally on the rams, but are becoming more and more rare. The hoofs should be black. The temperament of the Cheviot is a striking characteristic. He carries himself with an uplift of head and alertness of ear and general style very distinctive of the breed, and one of its greatest charms.

The size of the Cheviot is medium, comparable with the Shropshire for weight. Mature rams weigh about 200 pounds, with 225 a standard, and ewes from 150 to 160 pounds. But few rams exceed 225 pounds, though ewes frequently surpass I60 pounds. The best type of Cheviot calls for a compact, heavyweighing sheep of much quality.

The Cheviot as a mutton producer stands high. In England the mutton of this breed, which is rarely too fat and which has very superior quality, ranks in the first class. External fat is not abundant, but there is a clesirable proportion of lean to fat. Professor Wallace of Scotland states that ewes fed on turnips twelve to fourteen weeks, and wethers from the hills at three years weigh, killed and dressed, 60 to 70 pounds. Wethers a year younger, fed turnips, weigh about the same.

The Cheviot as a grazing sheep is unsurpassed. On its native hills it subsists entirely on pasture,

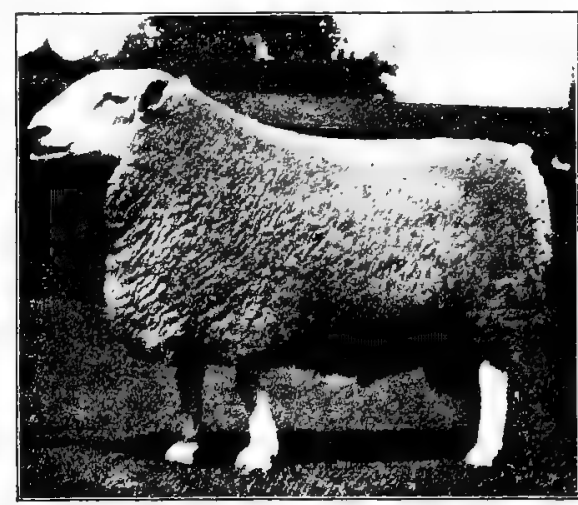

FIG. 194. Victor 2532, grand-champion Cheviot ram at the Louisiana Purchase Exposition, 1904. Owned and exhibited by H. H. Keim, Ladoga, Indiana. Photograph by the author excepting for hay which may be fed during excessive snow when the grass is covered. Ordinarily the Cheviots paw aside the thin covering of snow on the hillsides and thus secure winter grazing. No breed is more essentially a grazing sheep. 
The Cheviot as a wool producer is only fair. The fleeces lack weight, although having very satisfactory quality, the wool bringing a price equal to any of the medium class. Twenty-five Cheviot breeders give the average weights of fleeces in their flocks as ranging from $7 \frac{3}{4}$ to I I pounds per fleece for rams, and 6 to 9 pounds for ewes. Wallace states that a good average clip for ewes is $4 \frac{1}{2}$ to 5 pounds of washed wool. Formerly Cheviot fleeces appeared somewhat open and long, and the breed has ignorantly been referred to by some as a long wool, whereas it is a true middle wool. In American flocks the fleece is being

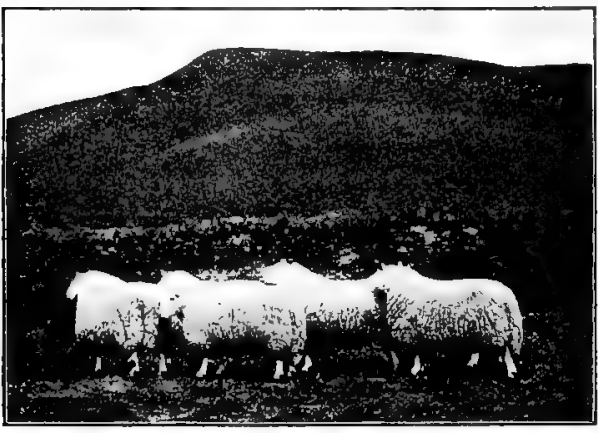

FIG. 195. Cheviot rams, the first-prize pen at the

Royal Agricultural Society of England Show, 1900. Owned and exhibited by John Elliott, Under Hindhope, Jedburgh, Scotland. Photograph by the author bred to be more compact and heavier, with a length averaging as near four inches as possible. Cheviot wool is valued by buyers, and in scouring tests at the Michigan Experiment Station the wool of this breed shrunk less than that of any other.

The prolific character of the Cheviot is above average. The author has secured figures concerning 228 ewes which in one season dropped 353 lambs, approaching one and one half lamb per ewe. The ewes are good mothers and produce as a rule ample milk for the lambs.

The hardiness of the Cheviot is one of its strong characteristics. For generations raised on the hills, rarely seeing the inside of a shed or barn, summer or winter, it has from very force of circumstances developed into the hardiest of the middle-wool breeds. The lambs are vigorous from birth and seem well suited to severe conditions of environment. On their native hills Cheviots, as a rule, receive no grain unless they be rams or show sheep.

The cross-bred or grade Cheviot has much merit as a mutton producer. The use of Border Leicester or Lincoln rams on aged 
Cheviot ewes has been practiced for a great many years in the border country, such half-breds having a comparatively high value. Where half-bred ewes are bred to Leicester or Lincoln rams they are termed "three-part-bred." Oxford Down rams are also used on Cheviot ewes with success. Both of these crosses produce very rapid-fattening lambs, giving a leaner and better quality of flesh, dressing out I6 to I 8 pounds to the quarter at about I 2 months old. Cheviot rams have not been used extensively in crossing, but, when used on Merino grade ewes, produce an easierfattening lamb of more salable type.

The Cheviot as a range sheep is of peculiar character. This breed does not flock in the ordinary manner, each sheep moving about independently, thus scattering to a considerable extent. On the Scotch hillsides one sees no evidence of flocking, such as the Merino exhibits. There are but few of these sheep on the western range, but if the natural hardiness of

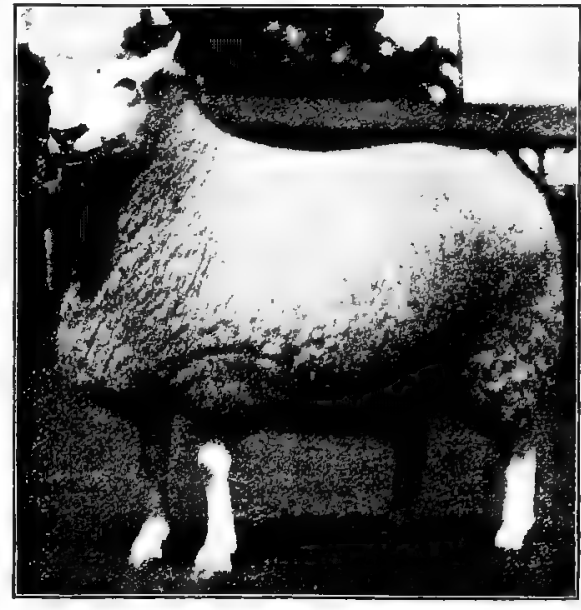

FIG. 196. A Cheviot ewe, a frequent prize winner in 1903 . Owned by Fred Hartman of Indiana. Photograph by the author the Cheviot could be combined with reasonable restriction of movement, it would serve a valuable purpose to the ranchman.

The distribution of the Cheviot is mainly in England, Scotland, and North America. In a considerable territory in the border country in Britain there are many large flocks, men counting their holdings by thousands, this being the one breed in evidence on these hills. Cheviots are chiefly bred in Roxburgh, Dumfries, Peebles, and Sutherland counties, Scotland, and in Northumberland County, England. They are also bred to a small extent in Ireland and have been exported to New Zealand. In Canada flocks exist in Quebec and several other provinces, while in the United 
States the breed has been pretty well distributed from Tennessee north, from the Atlantic to the far West. There are many flocks in eastern New York and northern Indiana, with excellent flocks in Ohio, Illinois, Vermont, Tennessee, Wisconsin, and many other states.

Cheviot sheep breeders' organizations exist in Britain and the United States. The Cheviot Sheep Society of Great Britain was organized in I89I, Volume I of the flock book appearing in

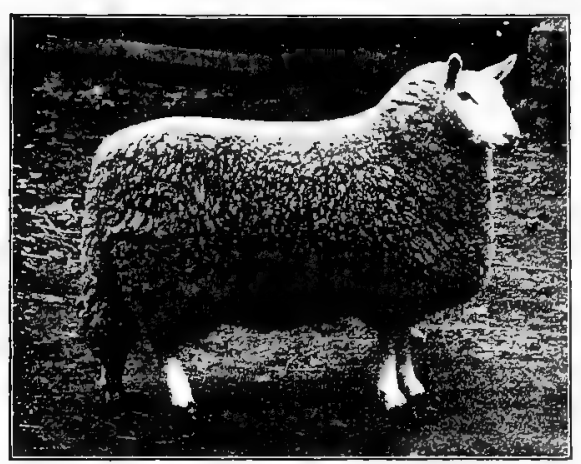

FIG. I97. A Cheviot yearling ewe, first prize in class at the Edinburgh Show, Scotland, 1904. This is a fine example of Cheviot style and character. Bred and exhibited by J. R. C. Smith, Mowhaugh. Photograph from the owner I893, there having been published thirteen volumes up to 1904 , registering 1665 rams, ewes not being recorded. In 1891 the American Cheviot Sheep Breeders' Association was organized in New York State. Owing to disaffection among the members, in 1894 the National Cheviot Sheep Society was organized in Indiana. In 1900 these organizations amalgamated, forming the American Cheviot Sheep Society, incorporated under the laws of New York. Each of the old associations published one flock book, while the new society in I 90 I published another, as Volume III.

High prices for Cheviot sheep have been paid in Scotland. Each year at Hawick annual ram sales are held on a large scale, thousands of sheep being sold and many high prices paid, with good averages. At this sale in 1903 five breeders sold rams at prices ranging from $\$ 150$ to $\$ 575$ each. At a sale in 1865 at Beattock 165 Cheviot rams owned by Mr. Oliver of Hawick brought over $\$$ I 2,000 , one three-year-old bringing $\$ 775$ and a two-year-old \$605. In 1902 Mr. J. R. C. Smith of Yetholm, Scotland, purchased the ram Ambush (I 545) for about $\$ 600$. In the United States no such high prices have yet prevailed, $\$$ I 00 being about a maximum. 


\section{CHAPTER LVI}

\section{THE SUFFOLK DOWN}

The native home of Suffolk sheep was in southeastern England, in the counties of Suffolk, Norfolk, Essex, and Kent, on the chalk hills and undulating clayey lands.

The original stock of the Suffolk Down sheep was the old Norfolk and Suffolk heath sheep. These had a long, slender carcass, says Youatt, long legs, horns, and a black face. The fore quarters were deficient, the shoulders low, and the withers sharp. The hind quarters were fairly well developed. The fleece was short and fine and weighed light. The breed was hardy and prolific. These sheep were crossed with Southdown and Hampshire rams, although English Suffolk Down breeders assume the breed to have been maintained fairly pure since I 8 IO. The Southdown blood bred off the horns, improved the form, and gave a better carcass and earlier-maturing, easierfattened sheep than the Norfolk, while the Hampshire blood gave size and weight. Mr. George Dobito of Ludgate, Suffolk, was one of the most important improvers of the Suffolk Down in the last century. The breed was first exhibited under this name in I 859 at the show of the Suffolk Agricultural Association and was not recognized by the Royal Agricultural Society until I 886 .

The introduction of the Suffolk Down sheep to America is very recent. In I $888 \mathrm{Mr}$. M. B. Streeter of Brooklyn, New York, made an importation of prize-winning stock, and the same year Mr. B. D. Sewell of Frederickton, New Brunswick, imported 20 ewes. In 1892 the Iowa Suffolk Sheep Society imported 2 rams and 20 yearling ewes and placed them on the farm of G. W. Franklin, the secretary of the society, at Atlantic, Iowa. These three importations were from the flock of Joseph Smith of Hasketon, Suffolk, England, and contained numerous valuable prize winners. 
Characteristics of Suffolk Down Sheep. The head is hornless and is a distinct black color, more so than with any other British breed, and inclines to be long. The ears are also black and tend to be large. The neck is moderately long, the body inclines to be rangy but with well-sprung rib, the chest is broad and full, and the legs black in color. The fleece is moderately short and fine and covers the body and neck to head, not as a rule passing over the forehead. The legs are wooled to knees and hocks.

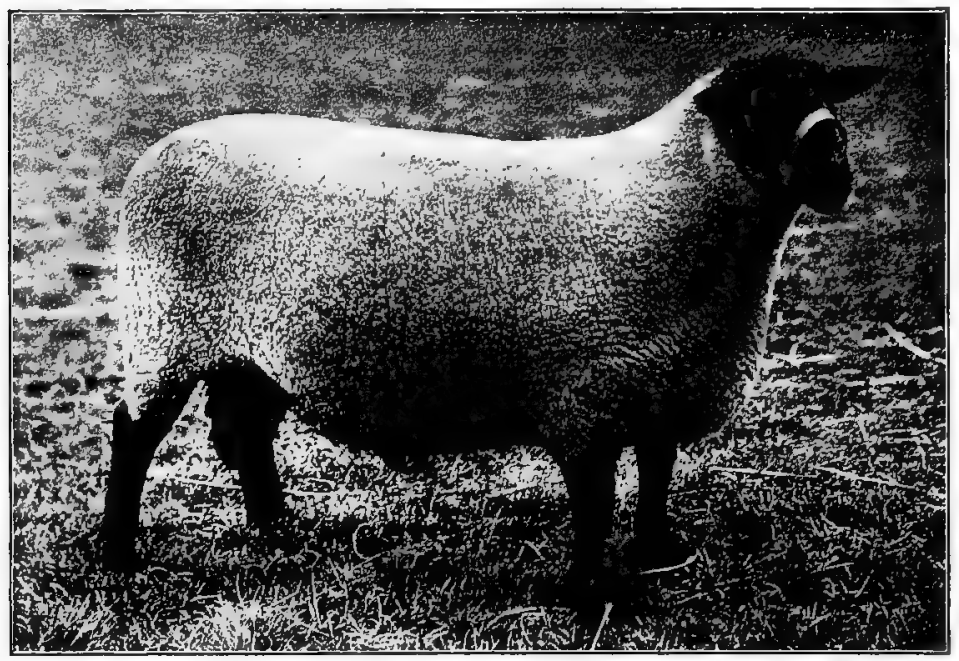

FIG. I98. Playford Model (7731), first-prize Suffolk ram at the Royal Agricultural Society of England Show, 1904. Owned by S. R. Sherwood, Playford, England. Photograph from William Cooper \& Nephews, Berkhamsted, England

The breed rather resembles the Hampshire Down but for the bareness of head. The Suffolk is said to be very hardy and is quite exempt from foot rot. -

The size of the Suffolk Down is nearly equal to the Hampshire, and is greater than the Shropshire. It is stated that mature rams of $\mathrm{Mr}$. Sewell weighed from 200 to 240 pounds, while one of the imported yearling ewes of Mr. Streeter weighed 200 pounds and a ram lamb nine months old 195 pounds. The average Suffolk possesses a weight popular with American stockmen. 
The Suffolk Down as a mutton sheep has high rank, evidently possessing good qualities secured from Southdown blood, the fat and lean being well placed and in good proportion, and the grain and flavor superior.

The Suffolk Down as a feeder also ranks well. It has been kept under conditions of moderate grain ration with considerable grazing, showing fair feeding returns. In experiments on fattening wether lambs at the Iowa Experiment Station the Suffolks gained rather faster per day than the Shropshire or Southdown in each trial, averaging .55 pound and .40 pound daily gain in two trials. They dressed out in carcass 53.6 and 52.54 per cent, and the carcasses were valued at $\$ 4.25$ and $\$ 5.00$ per hundred, a materially poorer showing, however, than most of the other breeds made.

The Suffolk Down cross-bred or grade is comparatively unknown in North America, but in South America has been used on Merino grades to produce good mutton sheep. The rams on common ewes should improve the mutton value.

The Suffolk Down as a wool producer is open to objection. Mr. Streeter, in a letter to Ezra Carman in I892, says, "I think "these sheep have just one fault, - they are not heavy shearers and they are somewhat leggy and bare of wool underneath." $\mathrm{Mr}$. Sewell reports clipping nine pounds per fleece on the average, which is a very fair showing.

The fecundity of Suffolk Down ewes is advocated as a valuable point in behalf of the breed. Twins are common and triplets not uncommon. In the spring of 1891,32 ewes of Mr. Sewell raised 58 lambs, while the same year 5 imported ewes of $\mathrm{Mr}$. Streeter produced I I lambs, and the same ewes 14 in 1892. According to returns made to the Suffolk Flock Book Society of England, the number of lambs reared to June I, I903, was 140.66 per cent per Ioo ewes, as compared with 136.16 in 1902 and an average of $\mathbf{1 3 2 . 9 7}$ per cent for the previous sixteen years. It is almost unnecessary to say that the ewes make good nurses.

The distribution of Suffolk Down sheep is mainly in southeastern England, notably in Suffolk and Norfolk, and in various other counties. In 1903 exports from England were made to Germany, France, Spain, Denmark, South Africa, New South 
Wales, South Australia, New Zealand, Canada, and Jamaica. The breed is also in other countries. In the United States Suffolks have almost no record, barring a few isolated flocks. They are especially suited to low or slightly rolling lands of good grazing character. In the United States breeders of Suffolk Downs are almost unknown. In the great sheep shows of the country the breed is practically unrepresented. Even professional showmen do not exhibit Suffolks, and no classes are provided for them. From the show-ring point of view they are quite attractive and would add materially to the interest attached to our sheep exhibitions, notably at state fairs and the International Live Stock Exposition.

Organizations for promoting Suffolk Down sheep were first established in 1886, when the Suffolk Down Sheep Society organized, publishing its first flock book in I887. In 1892 the American Suffolk Flock Registry Association was organized, with headquarters at Des Moines, Iowa. Up to 1905 this association had published no flock book. 


\section{CHAPTER LVII}

\section{THE TUNIS}

The native home of the Tunis breed, often referred to as FatTailed Sheep, is in northern Africa, in Tunis, a French province of some 45,000 square miles bordering the Mediterranean Sea. Much of the land is hilly, some of it bordering the desert of Sahara, the climate is warm, and the main crops produced are wheat and barley. This breed is found mainly in the upland region.

The origin of Tunis sheep is unknown, but the type has no doubt existed for centuries in Tunis and the associated section of northern Africa sometimes termed Barbary.

The introduction of Tunis sheep to America is said to date back to 1799, when the Bey of Tunis, at his request, allowed General William Eaton, then United States consul at Tunis, to ship from that country to the United States several "broadtailed Barbary or Mountain Tunis sheep," only one pair of which survived the voyage. These were placed in the hands of Judge Richard Peters, on his farm near Philadelphia, where they increased in number, the rams being used on native American ewes also. The original ram was later used in Lancaster County, Pennsylvania, on the farm of General Hand. It was soon discovered that they produced superior mutton, and sheep of Tunis stock came into demand. In $\mathrm{I} 807$ or 1808 Commodore Barron of the United States Navy imported some Tunis sheep to Virginia and the District of Columbia. Later President Jefferson had a ram and ewe brought over on a government vessel, and in I 825 some thirteen were landed at New York. A pair of these was sent to General Van Rensselaer of Albany. From the early stock, descendants of the Peters breeding it is claimed, flocks were established in South Carolina by Colonel Richard Singleton and in Georgia by Richard Peters. These sheep increased in number, but the Civil War nearly exterminated them. Most of 
the importations were unsuccessful, owing to the apparent physical disability of the ewes to breed on account of the tail interfering with service. A few sheep of this breed from Columbia, South Carolina, were shown in I 893 at the World's Columbian Exposition at Chicago, following which Mr. J. A. Guilliams of Indiana purchased from these, and later Charles Roundtree of the same state visited South Carolina, purchasing ten of the flock of twenty-five head there owned. Since then Mr. Roundtree Ilas been the chief promoter of this breed.

Characteristics of Tunis sheep. To begin with, this sheep, even to-day, is not well fixed in type and breed markings. In general

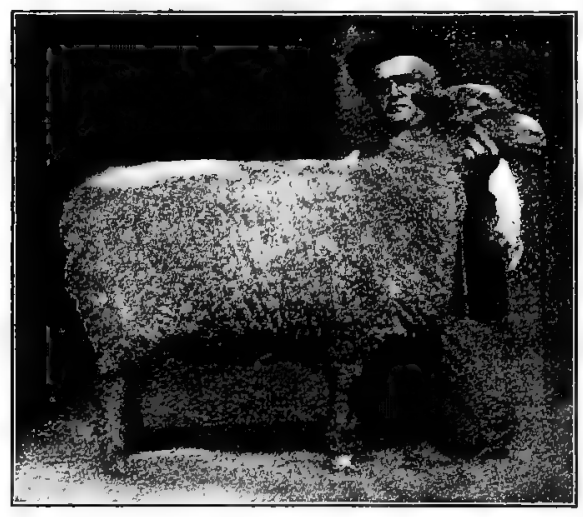

FIG. 199. A lunis ewe shown at the Louisiana Purchase Exposition, 1904, by Charles Roundtree of Indiana, who is holding the sheep. Photograph by the author the head is hornless with both sexes, and covered with hair of a tawny or yellow-brown color, the legs also being of much the same shade. Some faces, however, are solid color of brown and others are mottled brown and white. The ears are large, broad, pendulous, covered with fine hair, and are brown, white, or brown and white. The tail is broad, perhaps measuring five inches at maturity, is thick and moderately long, though the fleshy part is carried down only six or eight inches at maturity. This tail is usually cut off when the lamb is very young, and so does not appear as an important feature in the sheep. Left on, it becomes difficult to breed the ewes. At the end of the rump at the tail head there is more fullness and heaviness than exists with other docked sheep, to a notable degree. The neck tends to be long, the body of recognized mutton form, though inclined to be leggy. The fleece is of excellent quality, being soft, fine, and fairly compact, covering the body excepting the head from forehead down, and averages about three inches 
long, but varies notably in color. One animal may have a clear white fleece, another a prevailing reddish tint, while in another reddish fibers may be generally interspersed among the white. The young lambs when dropped are of various colors, - white, red, tawny, and mottled, but this generally changes to a uniform color with maturity. Aside from conformation of head, ear, and tail, the Tunis breed shows more variation than any other on the American market. In temperament they appear mild and easy to handle.

The size of Tunis sheep varies considerably, but rams are expected to weigh I 50 pounds or more and ewes 120 pounds and upward, according to the standard of the Tunis Association.

The Tunis as a mutton sheep has met with much favor. Early writers bear evidence of a high regard for the breed or its crosses for mutton in the markets of Philadelphia and vicinity. The claim has been made by the few promoters of the breed that on grass alone they will make excellent and fat mutton. In August, 1900, four grass-fed ewes, four years old, sold by Charles Roundtree, had a gross weight in the Union Stock Yards of 470 pounds. They dressed to average about 16 pounds for the hind quarter and $17 \frac{1}{3}$ pounds for the fore quarter, and dressed out 56 per cent, an exceptionally good showing. The writer has examined Tunis lambs in October, said to have had no food but grass, which were in splendid flesh for killing. On various occasions Tunis grade lambs fed by Charles Roundtree have topped the Chicago market the day of sale, and have received much favorable stock-yards comment. On August I I, I 900, two lambs I 50 days old weighed 200 pounds gross and dressed 57.6 per cent.

Cross-bred or grade Tunis sheep, sired by Tunis rams, are regarded as superior mutton sheep in the market, possessing the easy-fattening characteristics of the pure-bred.

The Tunis for early lambs has special qualifications. The pure-bred or cross-bred ewe will breed at various seasons of the year, and may be mated in spring to drop lambs in the fall for the Christmas market. The lambs fatten rapidly, and if with dark faces are well suited to the eastern market demand. Doubtless their use for early lambs will materially increase. 
The Tunis sheep as a wool producer has merit, yet the variable color of the fleece is objectionable. Tunis breeders claim that they shear from 6 to 12 pounds, and Professor Shaw credits them with $7 \frac{1}{2}$ pounds wool. In an address before the Philadelphia Society for Promoting Agriculture, in I810, Judge Peters gave the average weight of the washed fleece at 5 to $5 \frac{1}{2}$ pounds, some flocks averaging 6 , with individuals of pure blood yielding as high as Io pounds, and it is questionable if the breed has changed much in wool production since. The staple is of gond quality and is comparable in fineness with the standard combing wools.

The fecundity of the Tunis sheep ranks high. Twins are frequent, and as the ewes will breed twice a year if clesired, the flock may be rapidly increased if physical conditions do not interfere.

The distribution of Tunis sheep is widespread, yet but few flocks of importance exist, the larger ones being in Indiana and Ohio. Flocks have also been established in South Africa and Australia, and in various parts of the United States. The breed is well suited to warm latitudes, where it seems to thrive. It is also claimed that it will do well on low ground of marshy tendency.

The American Tunis Sheep Breeders' Association was organized in Indiana in 1896 for maintaining a flock book and promoting the breed, but up to 1905 no flock book had been published. The first rule of the standard adopted by the association allows twenty points for pedigrees extending back unbroken to Judge Richard Peters's stock or to direct recent importations from Tunis. 


\section{CHAPTER LVIII}

\section{THE LEICESTER ${ }^{1}$}

The native home of the Leicester breed of sheep is in the county of Leicester in central England. Here the land is gently rolling, the soil clayey and fertile, and grass, small grains, and roots grow abundantly. The climate is moist much of the year and fairly temperate, even in winter.

The origin of the Leicester as a breed is obscure, further than that a long-wooled, large, coarse, narrow-backed, slow-feeding, leggy type had been bred in the county of Leicester from time immemorial. This was the old Leicester sort.

The first improvement of the Leicester began with Robert Bakewell, who lived at Dishley Hall, near Loughborough, in Leicestershire. Bakewell was born in 1726 and began to experiment with and improve the sheep of his county just prior to I760. He purchased the best specimens of the breed to be obtained in the community, practiced rigorous selection, did much in-and-in breeding, and finally produced a remarkable improvement, so that sheep of his breeding became known as Dishley or Bakewell sheep. He converted the Leicester into a broad-backed, thick-fleshed, easy-feeding, early-maturing breed, with small bones and much less offal than in the old sort. Bakewell had a collection of bones and meat in pickle, which represented selections from time to time from animals of his own breeding, by which he studied the improvement made. Marshall, who lived in Bakewell's time, stated that he kept four points in view, - (1) breed, (2) utility of form, (3) quality of flesh, and (4) propensity to fatten, the three latter depending on the first. Bakewell attained such fame in improving these sheep, as well as Longhorn cattle and other stock, that he was often termed the father of improved live-stock husbandry. People visited him

1 The word "Leicester" is pronounced as though spelled "Lester." 
from various parts of England and Europe, and paid him large sums for the hire of his rams, he being the first person to establish this custom. An item in the Annals of Agriculture in 1787 reports him letting three rams for I 200 guineas $(\$ 6000)$, and that he had been offered rooo guineas for twenty ewes and refused it. Bakewell died in I795. The Leicester as improved by him retains to-day many of the original characteristics, though it may be somewhat smaller and more refined. His

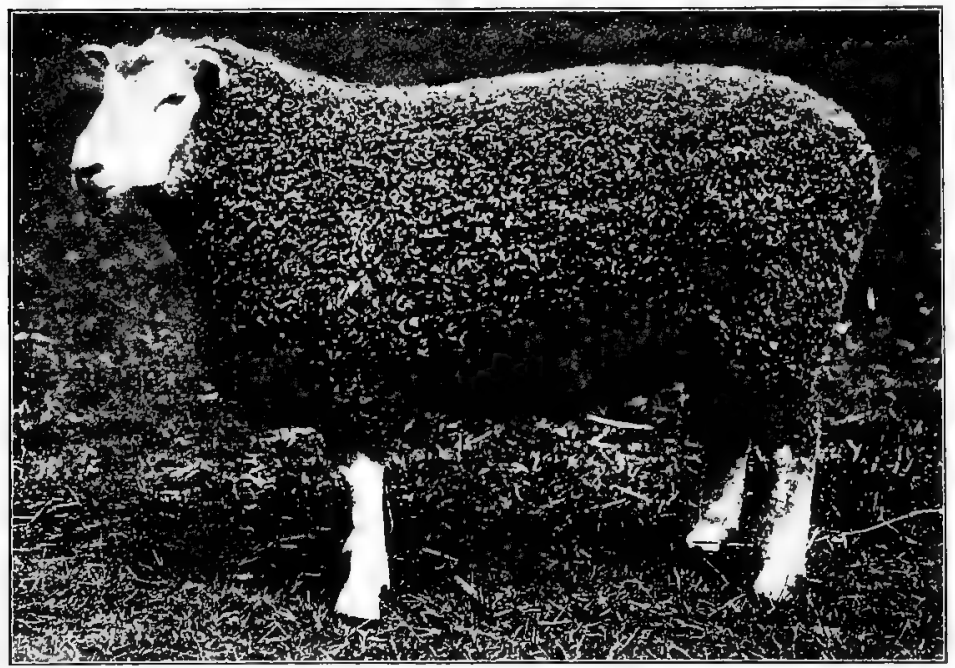

FIG. 200. A Leicester yearling ram, first prize in class at the Royal Agricultural Society of England Show, 1904. Exhibited by E. F. Jordan. Photograph from William Cooper \& Nephews, Berkhamsted, England

method of close breeding eventually reduced the fecundity, vigor, milking capacity of the ewes, and weight of wool. Breeders since his day have continued the practice of selection, and early in the last century practiced much in-and-in breeding.

The introduction of Leicester sheep to America occurred early in the history of the United States. Previous to the war of the Revolution some of the so-called Dishley or Bakewell sheep were brought, most of them smuggled, into the colonies, especially New Jersey and Virginia. As early as I800 the New Leicester was known about Philadelphia, though not of pure 
breeding. About I799 or I 800 the first pure-breds brought to America were imported to Quebec, Canada, by Reverend Mr. Toofy. In 1806 John Hart of Cheshire, Massachusetts, secured a ram, and about 1805 or 1806 Captain Beanes of New Jersey brought some pure-bred rams and ewes from England and disposed of them to a retired ship captain, George Farmer, living near New Brunswick, New Jersey. These Beanes Leicesters were carefully and successfully bred and attained a wide reputation, Captain Farmer selling some rams for as much as $\$ 1000$ per head. From New Jersey and other states came a large demand for sheep from the Farmer flock. Miles Smith, a neighbor of Farmer, and Joseph Cooper of Flemington, New Jersey, also became prominent breeders. The craze for Merino sheep, however, was on in America, and by 1818 , when Farmer died, there were no pure Leicesters on his or Smith's farms. During the War of 1812 Christopher Dunn established the first pure-bred

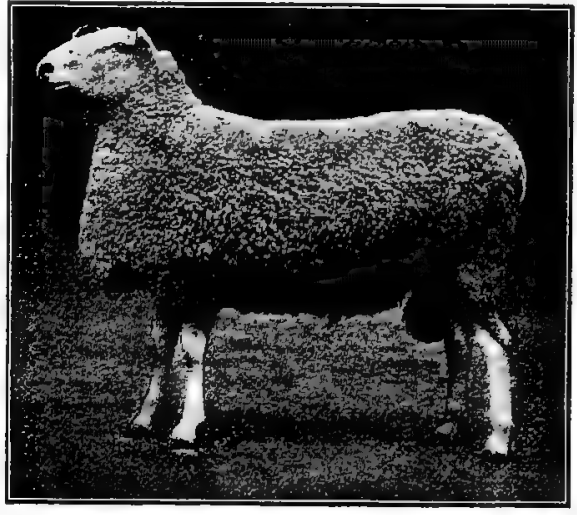

FIG. 201. A Border Leicester ram owned by Alexander Cross, Knockdon, Kilmarnock, Scotland. Photograph by the author flock of this breed in New York, near Albany, they being stock destined for Canada, but captured by an American privateer. There were importations to New York in 1826 by J. S. Skinner, in I 83 I by D. Stockdale, and in 1835 by John Baker. The first Leicesters which found their way to Ohio were brought here in 1834 by Isaac Maynard of Coshocton County, who also brought other breeds for trial. Henry Parsons of Massillon in I 840 had a large flock of breeding ewes.

There are two types of Leicester sheep, the Bakewell or true Leicester and the Border Leicester.

The Bakewell type of Leicester in general appearance is white in color, large, long-wooled, very wide of back, and tends to be long 
of leg. The head from the ears forward is covered with a soft white hair, the skin having a slight bluish tint and small black spots often occurring on head and ears. The face is of medium length, the nose is frequently Roman in form, with black skin at muzzle, and the ears are thin, somewhat large, and delicate, standing more or less erect. Neither rams nor ewes have horns. The ncck tends to be short and is not much elevated in carriage. The body is very wide of rib but often lacks in depth, the proportion of breadth to depth being striking. The breast is usually quite prominent, both in extension and thickness, and the hind quarters frequently are not so large as they should be, being peaked. The legs tend to be long and fine of bone. The temperament is quiet and gentle, such as might be expected with the large breeds. The flcece is excellent for coarse wool, medium long, and usually lies over the body in fine spiral locks. Usually no wool extends bcyond the ears, and the legs are not commonly wooled below knee and hock.

The size of the Leicester is large, though this is the smallest of the long-wooled breeds. Average-sized mature rams weigh from 225 to 250 pounds and the ewes from 175 to 200 pounds.

The pure-bred Leicesters as mutton producers do not rank high. When mature they are too large for common market demands, and unless killed before twelve months of age produce too fat a mutton. Neither is the quality quite equal to the best standard. Wrightson states that the Leicester is best fattened when from twelve to fifteen months old, when the carcass weighs about eighty to one hundred pounds. At three of the American Fat Stock Shows held at Chicago the following figures were secured, showing the best records made by Leicester fat wethers. Age 969 days, weight 300 pounds, average gain per day from birth .3 I pound

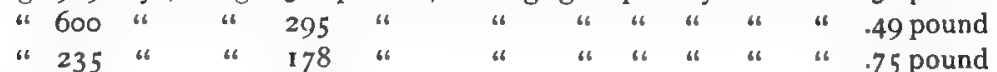
In feeding experiments at the Ontario Agricultural College the better Leicester high-grade, fat, shorn yearlings weighed 242 pounds and made an average daily gain of .54 pound.

Cross-bred or grade Leicesters are regarded with favor by some superior sheep feeders. A compact, easy-feeding Leicester ram, used on ewes of Merino character, will sire sheep of more scale 
and easier fattening quality than where Merino rams are used. In France a type of Leicesters termed Dishley Merinos has been developed by using Leicester rams on a Merino ewe foundation, these sheep now showing little of Merino character. Robert Taylor of Nebraska has used Leicester rams on middlewool ewes on the western range with signal success. In both I 903 and I $904 \mathrm{Mr}$. Taylor won the grand championship at the International Live Stock Exposition on car-load show of lambs, these being a cross of Leicester rams on grade Hampshire ewes. In fact, it is conceded that, cross-bred Leicester mutton is produced more economically, matures earlier, and is of better quality than the pure-bred, although the size is somewhat lessened. In this connection it is interesting to note that the Leicester as improved by Bakewell has served a most important part in improving some of the British breeds in the days of early development, its blood being freely used on the Southdown, Cotswold, Lincoln, Shropshire, and Hampshire foundations.

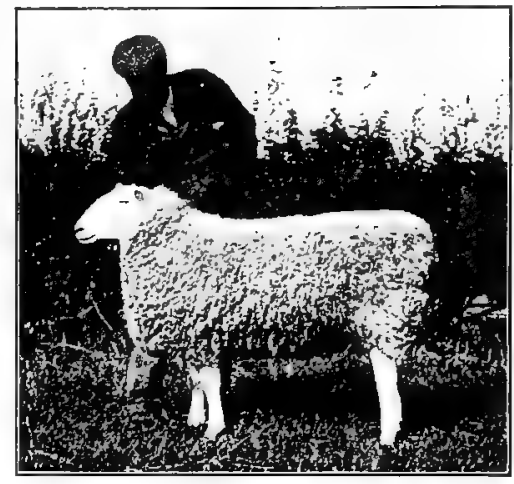

FIG. 202. A very choice Border Leicester ram bred by Mr. Smith of Leaston, Scotland. Sold in rgor for $£ \mathbf{1 2 2}$ $(\$ 600)$. Photograph from the owner, J. R. C. Smith

The Leicester as a wool producer yields a fine grade of long wool. Randall states that after the first shearing it will average about 6 inches long and will weigh 6 pounds. Professor Shaw states that the fleece should average from 9 to I I pounds weight, while the I 894 edition of the Complete Grazicr, by Youatt, places it at an average of 7 pounds. George Benedict of Nebraska, a breeder of pure Leicesters, in I 893 wrote, "The average weight of fleeces for ten years is I I pounds." The fleece of the Leicester being naturally fine and open weighs comparatively light. If grade Leicester ewes are bred to middleor fine-wool rams, the fleece of the offspring is commonly finer, more compact, and shears heavier than that of the pure-bred. 
The breeding qualities of the Leicester are only moderate. None of the largest breeds are strongly prolific, and no doubt the early policy of very close in-and-in breeding followed by Leicester breeders injured the fecundity of the breed. Careful

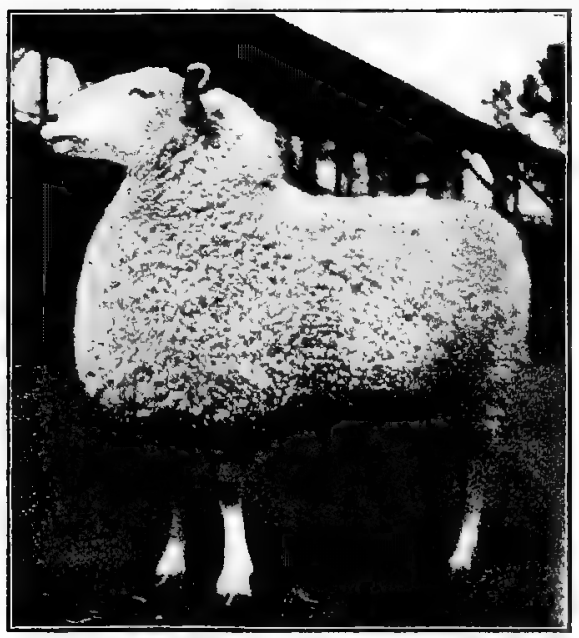

FIG. 203. Grand-champion Leicester ewe (Border Leicester) at the Louisiana Purchase Exposition, 1904. Owned and exhibited by A. W. Smith, Maple Lodge, Ontario. Photograph by the author management will no doubt secure fair results. Mr. Benedict, above referred to, reports I 36 per cent increase in his Leicester flock.

The Leicester as a grazing or range sheep ranks as only fair. Leicesters will not flock equal to the Merinos. They require better range and more abundant pasture, are not suited to rough ground, and in winter lack the constitution to withstand roughing it without shelter. The open fleece is objectionable where much snow or cold rain prevails.

In the so-called corn belt, where properly protected, with abundance of roughage, grain, and roots, this breed may do very well.

The popularity of the Leicester in America to-day is quite secondary, although in the middle of the last century it was looked on with favor in the eastern states. Very few are now owned in the United States, notwithstanding the extended history of the breed here. A few are kept for show purposes and some for cross-breeding, but this large type does not suit the modern demand for a hardy, smaller class of quick-feeding sheep, not too fat when finished. More Leicesters are fed in Canada than elsewhere in America.

The distribution of the Leicester is wide. Since the days of Bakewell it has been more or less distributed over Europe, Australia, New Zealand, Tasmania, and North America. It is not a 
common breed to-day, however, in any part of the world, even in England, its native home. There are small flocks kept in each of the Canadian provinces, but more in Ontario than elsewhere. In the United States the breed is mainly represented in Michigan, Pennsylvania, Oregon, Nebraska, Iowa, and Illinois.

Organizations in behalf of Leicester sheep date back considerably over a century. In the time of Bakewell the Dishley Society was organized to support this great breeder in establishing a new breed. This society had various meetings and adopted different resolutions. No. 4, passed in I 790, provided that "secrecy be kept by all members respecting the business of these meetings, except to absent members." Resolution No. I 3 provided that " no member shall let a ram, share or part of a ram, to any ram breeder residing within thirty miles of Leicester, not being a member, who hired a ram of Mr. Bakewell last season, I789." This society existed many years and was very influential. At the present time there is a Leicester Sheep Breeders' Socjety in England. In this country we have the American Leicester

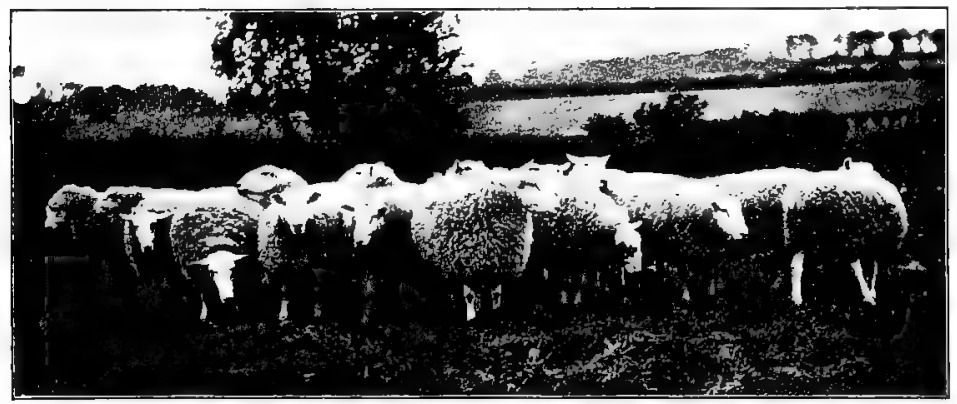

FIG. 204. A group of Border Leicester yearling rams owned by J. R. C. Smith, Scotland. Photograph from the owner

Breeders' Association, established in I 888, which has issued four volumes of flock books up to I904, registering about 7000 head.

The Border Leicester breed of sheep belongs to the Leicester family, but differs from it somewhat in type. The origin of the Border Leicester has been credited to the Culley brothers, who first used Leicester rams (obtained from Bakewell) on Teeswater ewes. Some authors have regarded the Border Leicester 


\section{6}

SHEEP

as originating from a cross of Leicester rams on Cheviot ewes, the result of the cross finally assuning a pure form of a variety of the Leicester. In 1767 the Culleys moved into northern Northumberland county, England, to Fenton, near Wooler, among the Cheviot Hills in the border country between England and Scotland. In this region they developed the Border Leicester, which became very popular. In 1806 they retired and their flock was dispersed, being purchased by various breeders. There are to-day flocks in the border region directly descended from Culley rams. The Mertoun flock of Lord Polwarth, said to have been established in 1802 , has long been and is to-day perhaps the most famous in Britain.

The characteristics of the Border Leicester sheep in comparison with the Bakewell Leicester are interestingly shown by Professor Wrightson as follows :

The differences between the Leicester and Border Leicester are to be chiefly seen in the head, which in the Border Leicester is white and boldly carried, the nose slightly aquiline, the muzzle full, the nostrils wide, and the ears erect. The head is clean and free from wool, as is pretty well shown by the fact that they suffer from flies settling on their polls in summer. The English Leicester, unless trimmed and shaved for show, usually carries a tuft of wool on his head, which protects it from flies, and he is also wooled in the shanks. The English Leicester has a bluish-white face, whereas the Border Leicester's face is clear white. In carcass the Border Leicester is the larger and longer, and the belly is not quite so full in outline, being carried rather more lightly.

It may also be added that the flesh at the nose is black, that black spots frequently occur in the white hair on head and ear, and that this is a heavier, more leggy type than the Bakewell Leicester.

Border Leicester rams crossed on Cheviot ewes make a cross which has long met with much favor in the British market. In the hill country the half-breds and three-quarter-breds feed extremely well on rather scant fare oftentimes, and produce a strictly choice mutton. Each year in the hill country between Scotland and England large numbers of cross-bred sheep of this stock find their way into the best British trade.

The Society of Border Leicester Sheep Breeders has an organization in Britain, but in America the Border type is registered in the American Leicester flock book. 


\section{CHAPTER LIX}

\section{THE COTSWOLD}

The name Cotswold is derived from a combination of circumstances. In early times sheep were folded in shelters locally known as "cots" or "cotes," and were pastured on the wild, treeless hills of the region, which were termed "wolds," from which the name Cotswold was evolved.

The native home of the Cotswold sheep is in central southwestern England, in the county of Gloucester, which touches salt water on its lower side leading up from the Irish sea. The Cotswold hills extend southwesterly nearly through and to the southern borders of the county. These hills are of variable soils, often poor in quality, gravelly or clayey in character with much lime, grow a short pasturage, and yield moderate crops of wheat and roots. The climate is moist and temperate, well suited to large sheep, especially on the lowlands.

The Cotswold is of ancient lineage. In $1464 \mathrm{King}$ Edward IV of England, says Stowe in his Chronicles, granted permission "for certain Coteswold sheep to be transported into the country of Spaine, which have there since mightily increased and multiplied to the Spanish profit." In 1842 Low wrote that Cotswold sheep irhabited the district beyond the memory of the living generation. However he believed that this breed was developed from a large type common in Warwick and Oxford counties adjoining, which it in some respects resembled. It is improbable that the Cotswold has a long ancestry on the hills of Gloucester, for a big breed of this type would not naturally thrive on hills comparatively poor in production. Yet the region in which this sheep developed became a noted wool-producing section, dating back to days of Roman conquest in the second century. Gervase Markham, writing in the sixteenth century, referred to Cotswold sheep as having long wool and large bones. It is generally 
conceded that the breed of to-day is much improved over the old type, this improvement having been largely secured by using Leicester rams on Cotswold ewes. So indiscriminately were they used between I 780 and I 820 that we are told not a Cotswold flock was spared. The Leicester blood reduced the size and constitution, but improved the symmetry, producing better bodies, finer wool, more quality, and earlier-maturing sheep. During the last century the families of Smith of Bibury, Hewer

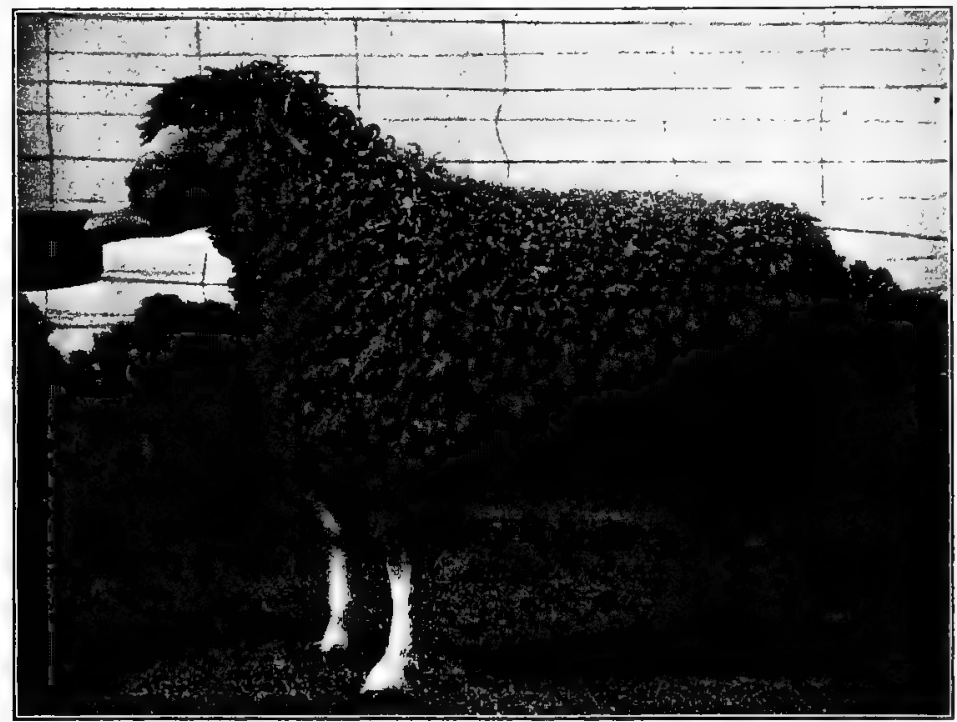

FIG. 205. Houlton's 945-392 50, an imported Cotswold yearling ram, owned by the Ohio State University. This ram is in thin flesh with about five months of fleece. Photograph by the author

of North Leach, Lane, and Garne materially improved the breed by judicious selection and some in-and-in breeding. On the dispersion of the Hewer flock various breeders purchased and established flocks which are numbered among the important ones of to-day in England.

The introduction of Cotswold sheep to the United States probably first occurred in $\mathrm{I} 832$, when $\mathrm{Mr}$. C. Dunn, who lived near Albany, New York, imported a ram. In 1834 Isaac Maynard of Coshocton County, Ohio, brought the first Cotswolds 
to that state, but within three years most of these had died. In 1840 W. H. Sotham imported a flock of I9 to New York, near Albany, for which he paid $\$$ I IO each. This same year Erastus Corning and Mr. Sotham made two large importations of a crossbred Cotswold-New Leicester sheep from the Hewer flock at North Leach, Gloucestershire. In I836 J. C. Haviland of Duchess County, New York, began breeding Cotswolds, and continued his flock many years. In I 837 they were first brought to Kentucky, where they were popular for many years and seemed well suited to the conditions there. Along in the early forties there were a number of flocks of Cotswolds in the Atlantic coast states, where they met with some favor, if on the more fertile lands. With the depreciation of Merino values about I 870-1875 Cotswold and other mutton sheep grew in favor and considerable flocks developed in the Mississippi Valley states.

Characteristics of the Cotswold. The head of the Cotswold is a distinguishing feature, being horn-

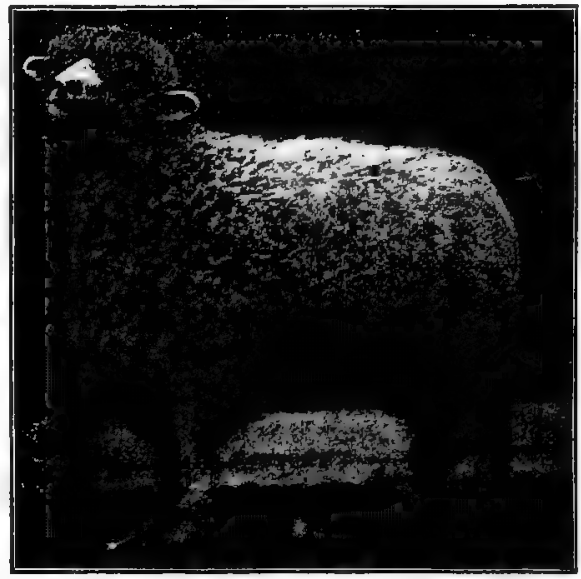

FIG, 206. A very choice Cotswold ewe, winner of first prize in class at the Ohio State Fair in 1905 and sweepstakes Cotswold ewe at the Illinois State Fair, rgo6. Owned by Wilson Bros. of Indiana. Photograph by the author less, usually white, but frequently slightly mixed or spotted with gray or brown, is dark at the nostrils, broad between muzzle and eyes, having a tendency to a Roman nose, and with curls or locks over the forehead, often extending to the nostrils. This forelock is rather a distinctive feature of this breed. The back carries the same great breadth as the Leicester and Lincoln, though the body often lacks depth and appears leggy, especially behind. The heart girth is often striking, showing much thickness. Fream states that at a show some years ago in England two of the winning two-year-old rams girthed five feet and five feet four inches 
respectively. The fleece covers the body in rather large locks or curls, very similar to the Lincoln, naturally parting along the back and hanging down the sides to considerable length. The legs have much the same color marking as the head. In quality this breed ranks well, and in general appearance has a carriage which Cotswold men regard as distinguished. Professor Wrightson states that

the Cotswold was often described by the late Professor Coleman when teaching at the Royal Agricultural College [which is in the Cotswold district of England], as a sheep which could "look over a hurdle," that is, carried his head high and well poised on a somewhat erect neck. This is said to be accompanied with a tendency to be "ewe necked " and low in the rumps, or "down at both ends," as I have heard Professor Coleman repeatedly say. He knew the Cotswold sheep well, and was himself a Cotswold man, so his opinion carries weight. These faults have been corrected in the best flocks there can be no doubt, but they exist in second-rate animals, as is most evident in rough weather, when the animals are viewed at a disadvantage.

In carriage the Cotswold is a sheep of dignified appearance, with considerable alertness of expression.

The size of the Cotswold is large, ranking very close to the Lincoln and often equaling it. A mature Cotswold ram in moderate flesh should weigh from 250 to 275 pounds, and the ewe from 200 to 225 pounds. Select show animals often weigh much more.

The Cotswold as a mutton sheep is rather ordinary. The quality of the mutton is inferior in sheep two years old or over, the fiber lacking fineness and the percentage of external fat too great on well-fed animals. The Cotswold is most desirable for the table up to twelve months of age, producing a very good grade of lamb.

The Cotswold as a feeder ranks well. In various feeding experiments the wethers have made heavy gains. In 1852 Sir John B. Lawes reported on important sheep-feeding experiments at Rothamsted, in which he showed that forty-six Cotswold lambs made a total gain of 29283 pounds between December I and April I 7, a weekly increase per head of 3 pounds $2 \frac{1}{2}$ ounces, and an increase for each 100 pounds live weight weekly of 2 pounds 2 ounces. Twenty of these lambs, fasted weight, dressed out $6 \mathrm{I} .48$ per cent. In extended experiments by this investigator 
the best results in feeding were secured on the Cotswold, giving a more economical production than on the Leicester, Hampshire, Sussex, or cross-breds. At the Iowa experiment station, in two breed trials with fattening lambs, the Cotswold made the heaviest gain, averaging .62 and .50 pound daily respectively, consuming less dry matter to secure a pound of gain than any other breed in each trial. In per cent of dressed carcass the Cotswold lambs showed an average of 54.9 and 53.57 respectively, a fair record. From figures collated by Henry of records at the American Fat Stock Shows at Chicago between I 879 and I882, Cotswold wethers showed the following gain from birth:

\begin{tabular}{|c|c|c|c|c|c|c|}
\hline \multicolumn{4}{|c|}{ YEAR } & \multirow{2}{*}{$\frac{\text { AGB }}{933 \text { days }}$} & \multirow{2}{*}{$\frac{\text { AVERAGE WEIGHT }}{28 \mathrm{I} \text { pounds }}$} & \multirow{2}{*}{$\begin{array}{c}\text { Average Daily Gain } \\
\text {-3I pound }\end{array}$} \\
\hline 1881 & . & . . & & & & \\
\hline 1878 & . & . . & . & 535 “ & 220 & $.4 \mathrm{I}$ \\
\hline 1878 & . & . & . & 170 & 152 & .89 \\
\hline
\end{tabular}

The general testimony is that the Cotswold is a superior feeder, and Wallace writes that it is well suited for feeding on stiff land, even when pretty wet, although the last part of the statement is very questionable.

The value of the Cotswold in crossing and grading is moderate. Used on native sheep or grade Merinos, extra scale and better mutton quality may be obtained, with more fleece. Formerly Cotswold rams were considerably used in the central west on common ewes, but the demand for a smaller type of mutton and a compact fleece caused the discontinuance of this practice.

The Cotswold as a grazing sheep ranks high where pastures are abundant, but on hilly or rough land it is not a satisfactory breed. This breed does best in the northern plain sections of America, where plenty of grass, roots, and grain may be grown. From its quiet temperament and heavy weight, like the other longwool breeds, it may be fed to great advantage on rape or turnips for a limited time, on restricted areas within hurdles.

The breeding qualities of the Cotswold are fairly good, though some authorities rank the breed as superior in this respect. None of the large breeds, however, are strongly fecund, though they are excellent nurses and produce large lambs. 
The Cotswold as a w0ol producer, as has already been designated, has long had high rank. The fleece is of a lustrous character with a tendency to coarseness, and on mature sheep may attain a length of 12 to 14 inches, but is somewhat shorter than that of the Lincoln. Eight to ten inches is a usual length. Many flocks show an average weight of fleece of over Io pounds. George S. Baber of Kentucky for years kept about forty breeding ewes, which averaged 10 pounds of wool per head. For years C. L. Day of Wisconsin had a large flock and the fleeces averaged about II pounds each. Wallace places the yield of fleece for ewes at 6 to 8 pounds, and Wrightson says that in "crack" flocks the fleeces may run to $93^{\frac{1}{3}}$ pounds, and many fleeces have been shown weighing close to I4 pounds, but these are exceptional. In selecting breeding rams one well covered on belly and scrotum should be sought, shearing a heavy, relatively compact fleece, showing plenty of crimp and quality.

The distribution of the Cotswold has been rather widespread in the past. It has seemed particularly suited to Gloucestershire and adjoining sections of England, and while flocks exist outside of that locality, the breed is not common. It has been exported to Australia, New Zealand, France, Germany, Russia, Canada, and the United States. In this country it has had a wide distribution, and twenty-five years ago was a prominent breed in some sections, notably Ohio, Indiana, and Kentucky. At the present time Wisconsin and Ohio have superior breeding flocks, but Ontario, Canada, leads in this respect. The demand for smaller mutton with less external fat and for a medium or fine wool has materially injured Cotswold development in America.

Organizations for promoting Cotswold sheep are maintained in England and America. The Cotswold Sheep Society of England was organized in 1892 , and has published a number of volumes of its flock book. The American Cotswold Sheep Association was organized in 1878 , and has published twelve volumes of flock books up to 1905 , registering nearly 35,000 sheep. 


\section{CHAPTER LX}

\section{THE LINCOLN}

The native home of Lincoln sheep is in the county of Lincoln, on the east coast of England by the North Sea. The soil is of a clayey character. The land is slightly hilly in places, but also has considerable lowlands of rich pasturage. The small cereals, grass, and roots are the staple crops. The climate is moist and fairly temperate, though rather cold alongshore in winter.

The origin of the Lincoln dates back very many years. There had long existed in Lincolnshire a large, coarse type of sheep much like the old Leicester, with white face and legs, heavy head, large neck and prominent dewlap, long and hollow of back, with flat ribs but good loin and deep belly. The skin was especially thick, the fleece long and coarse, the size very large, and the flesh coarse and inferior. This old-fashioned type was improved by the use of Leicester rams of the new sort, such as Bakewell had produced. Much jealousy had existed between Leicester and Lincoln breeders in those days, and the Lincoln gradually developed into the largest, longest fleeced breed of sheep in Britain. The early type was slow to mature, but Leicester blood produced quicker feeders and generally improved the symmetry and quality. The breed, however, did not have a wide reputation like the Leicester, and until the middle of the last century was known but little outside of Lincolnshire.

The introduction of Lincoln sheep to America dates back over a century. Prior to 1796 it is stated that some of the old Lincolns were taken to Massachusetts, but, not thriving on the hills, were generally abandoned. In I825, however, A. A. Lawrence of the same state "imported 6 Southdowns and ro Lincolnshires." In I 829 Mr. Pickering, also of Massachusetts, imported two rams and two ewes. It is reported that during the ocean voyage a fleece of 19 pounds was removed from one 
of the rams. In 1834 Isaac Maynard brought the first Lincolns to Ohio from the east. At Buffalo it is said he was offered $\$ 500$ for his Lincoln ram. In I 836 Leonard D. Clift of Carmel, New York, imported some Lincoln sheep. One pair was sold to go to Virginia and one to Ohio for $\$ 250$ each. Later importations were made by $\mathrm{Mr}$. Clift. The Lincoln has since then been brought occasionally to the United States, though in but a small way.

Characteristics of Lincoln sheep. The color of the Lincoln is white, although the face frequently has a grayish or darker shade along the bridge of the nose. The head is large and hornless, is often broad between muzzle and eyes, tending to Roman character, the ears are large and broad and are dotted or mottled in color. The Lincoln has a very broad, level back, is covered with a firmer flesh than the Leicester, and shows a greater comparative depth of rib than that breed, not appearing so leggy.

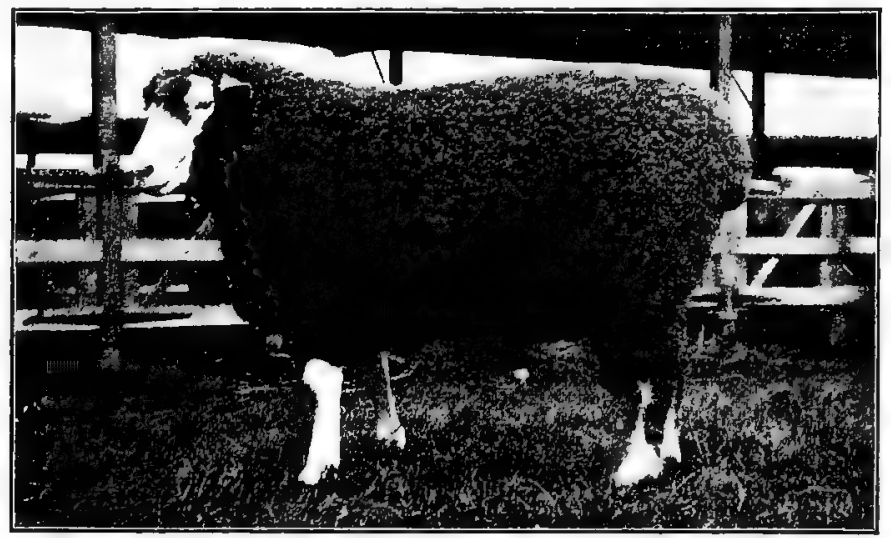

FIG. 207. Dowsby 350 Guineas, first and champion Lincoln ram at the Royal Agricultural Society of England Show, 1897. Bred by Henry Dudding, owned and exhibited by S. E. Dean \& Sons, Dowsby Hall, Folkingham, England. Photograph by the author

The rump is broad and level, and the hind quarter of a thick, meaty character as a rule, and when heavily fed this is often patchy. The legs are in suitable proportion to the rest of the body, but appear rather large and coarse. The sheep in general appearance impresses one as massive. The wool covering is in rather coarse 
spirals or curly locks which naturally part along the back and hang down to considerable length on the sides. A short foretop, or group of locks, occurs in good specimens of the breed, more than with Leicesters and less than with Cotswolds.

The size of the Lincoln represents the largest of the British breeds of sheep, though Wallace states that it does not exceed

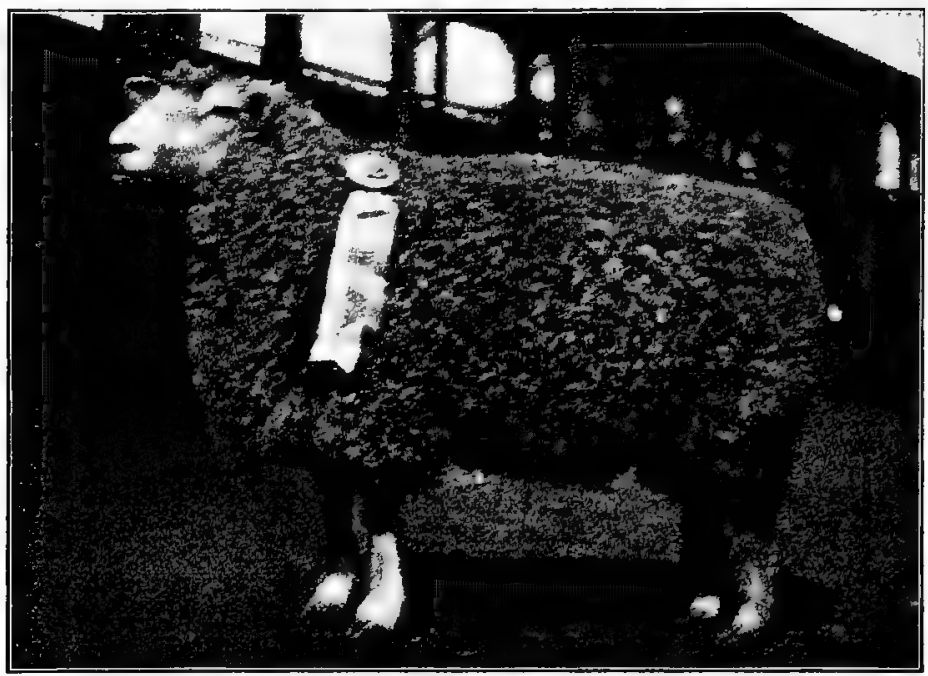

FIG. 208. Gibson's $155-10858$, grand-champion Lincoln ram at the Louisiana Purchase Exposition, 1904. Owned and exhibited by J. T. Gibson, Denfield, Ontario. Photograph by the author

the Cotswold. The author has seen a Wensleydale ram that was comparable with the larger Lincoln. The average Lincoln, however, probably weighs heavier than does the average of any other breed. Rams of this breed sometimes attain a weight of nearly 400 pounds, and when in good flesh will easily weigh very nearly 300 pounds, while the ewes average close to 275 pounds when mature.

The Lincoln as a mutton producer does not rank high. The size is too large, too much fat is produced, and the quality is not the best. When killed during the lamb period a more acceptable class of meat is produced. While the carcass dresses out very well, there is too great a degree of waste in fat and bone to suit 
modern trade. In feeding experiments at the Iowa experiment station Lincoln wether lambs in one trial made an average daily gain of .55 pound and in another trial of .46 pound. The price paid for the carcass was $\$ 4.50$ and $\$ 5.25$ per hundred, compared with $\$ 4.75$ and $\$ 5.75$ respectively, the highest price paid. The Lincolns dressed out 55.7 and 51.08 per cent in the carcass, which was about an average of the breeds tested. Comparatively few feeding experiments with Lincolns are recorded.

The Lincoln as a feeding sheep ranks very well. With suitable and abundant food it matures early and will fatten rapidly. Its temperament is very quiet and docile, well suited to folding or the feed lot.

The Lincoln as a grazing sheep is best adapted to moderately dry upland meadows, where food is abundant. In the hill country the breed has never made a success and has not secured a foothold. Some English writers have called attention to the eminent fitness of the Lincoln to the meadows of Lincolnshire, but further note the fact that they soon deteriorate in most other parts of England. In the Argentine, where great pastures of superior quality exist, Lincolns are at present meeting with much favor.

The cross-bred or grade Lincoln is to-day an important factor in the British mutton market. A large number of Lincoln rams are used on the common ewes of the Argentine or on the grade Merino ewes of Australia. A visit to the yards at Birkenhead, England, where shiploads of live sheep are received from the Argentine, shows the prevalence of ' Lincoln blood. These crosses, or grades, make a big, growthy lamb which fattens easily and furnishes a large chop or leg of mutton, more acceptable in the English than in the American market. Lincoln rams have been used to some extent on Merino grade ewes on our western ranges, yet not in a large way.

The Lincoln as a wool producer is of special interest. No breed probably furnished so long a fleece. Wrightson reports samples of Lincoln wool in his possession $2 \mathrm{I}$ inches long. The rules of the National Lincoln Sheep Breeders' Association require a growth of at least eight inches of fleece during one year. The weight of the fleece, which is naturally coarse, may in the case 
of a ram reach 30 pounds. The average weight of fleeces on Lincoln wether lambs in the Iowa feeding experiments was I 2.9 and 10.4 pounds respectively, the heaviest of the ten breeds under trial, and yielding the largest income from sale, viz., $\$ 1.79$ and $\$ 1.56$ respectively. A mature ewe should produce close to I 5 pounds, and a ram 18 to 20 pounds. In fineness of quality this ranks slightly better than the Leicester. Compared with the Leicester fleece it is longer, is in larger spirals or curls, and

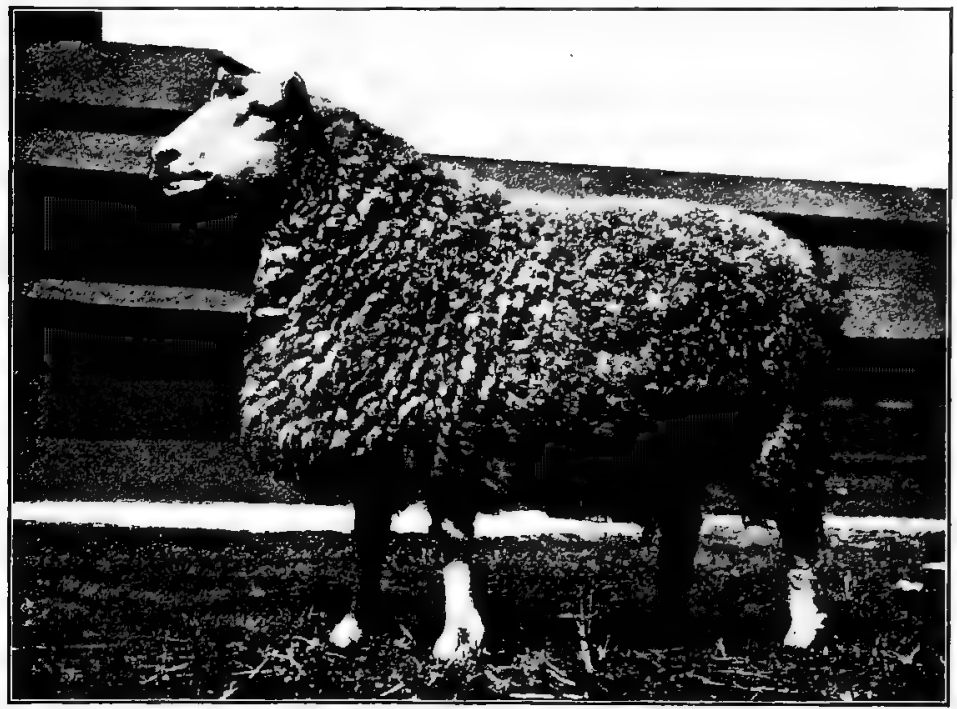

FIG. 209. A Lincoln ewe, first prize in class at the Ohio State Fair, 1905. Owned and exhibited by J. R. Bickett, Xenia, Ohio. Photograph by the author

covers the belly better. Wrightson states that the wool is very bright and lustrous when shorn, giving the name "luster wool." This feature, however, disappears when the sheep are bred away from their native county. The massing of the wool in flakes or strands upon the animal is characteristic of the breed, but the fiber is hair-like and "lashy" if separated and compared with the fiber of Merino wool.

The breeding quality of the Lincoln is not of the first rank. Ewes are good mothers but produce only a fair amount of milk and are not of more than average fecundity. 
The distribution of the Lincoln is largely limited to Lincolnshire and adjoining east counties in England, while it has been extensively exported to Australia, New Zealand, South Africa, Argentine Republic, Russia, Canada, and the United States. At the present time an extensive trade exists between British breeders and South American buyers, Lincoln rams being heavily shipped to the Argentine. In the United States the breed has never secured much foothold, neither has it seemed so well adapted to our conditions as to those of Canada or England. Lincoln sheep are mainly kept in Ontario and other Canadian

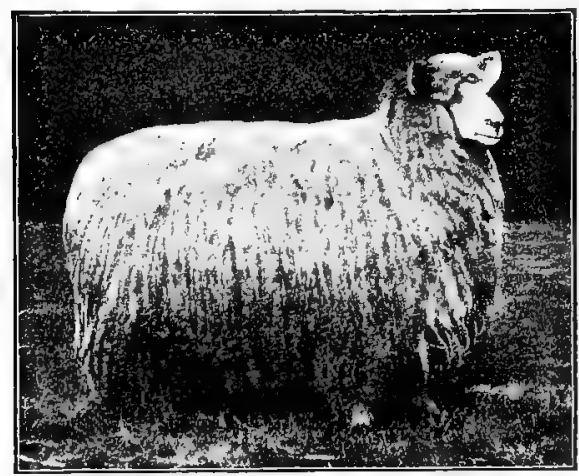

FIG. 2IO. A Lincoln ewe lamb of very superior character at the Royal Agricultural Society of England Show, 1904. Her fleece swept the ground. Photograph by H. B. Arbuckle, from the National Stockman and Farmer provinces, and in Michigan, Wisconsin, Illinois, and Ohio, several flocks being kept in each of these states. Sheep of this large type cannot thrive satisfactorily during the hot, dry summers so common in the central United States. No doubt they will do better on the upper Pacific coast, in Oregon and Washington, where the climate more nearly resembles that of England.

Organizations to promote Lincoln sheep interests exist in England and America. The Lincoln Long-Wool Sheep Breeders' Association, with headquarters in England, in the native county of the breed, supervises the welfare of these sheep in Great Britain. This association was organized in 1892, and has published I 5 volumes of flock books up to Igo6. The National American Lincoln Sheep Breeders' Association was organized in I89I, and has published two flock books up to 1906.

The important breeders and improvers of Lincolns are still to be found in Lincolnshire. Mr. Henry Dudding of Riby Grove, Great Grimsby, Lincolnshire, is the most distinguished improver of to-day, and has done much for the breed. The Dudding family 
have bred these sheep for one hundred and fifty years, and have won the highest honors attained by the breed, and maintain the largest flock in the county. S. E. Dean \& Sons are also very prominent breeders in Lincolnshire, having a large flock of superior sheep from which extensive exportations are made.

The prices paid for Lincolns are among the highest realized for any breed of sheep. Since the South Americans and Australians began to purchase rams for home trade high prices have ruled, the supply being limited. The ram sales of Lincolnshire are now world famous. On July 26, I898, Mr. Henry Dudding's sale established a new record for England. One ram sold for $\mathcal{E}_{1050}$ (\$5 I 20), and 52 rams brought an average of $£ 86$ I9 s. $(\$ 423.50)$. At the I905 sale of $\mathrm{Mr}$. Dudding a new record was made, 3 I yearling rams bringing $£ 280 \mathrm{I} 8 \mathrm{~s}$, and average of about $\$ 440$ each. The second-prize ram of the Royal Agricultural Society Show of 1905 brought $\$ 2500$, while another ram sold for $\$ 2100$. Again, in I 906, the annual sale of Mr. Duding at Riby broke all previous records and proved of international interest. One ram sold for $£$ I 522 IOs. (about $\$ 7600$ ), the highest price on record. In all 56 yearling rams realized over $\$ 42,000$, or brought an average of over $\$ 750$. Twenty-three yearling ewes averaged about $\$ 85$. Each year the Dudding sale attracts world-wide attention. 


\section{CHAPTER LXI}

\section{THE KENT OR ROMNEY MARSH}

The native home of the Kent sheep is in southeastern England in the county of Kent, in the district known as Romney Marsh. This is a low, level, marshy, alluvial plain about on sea level, the sea being held back by strong walls. The climate is moist and

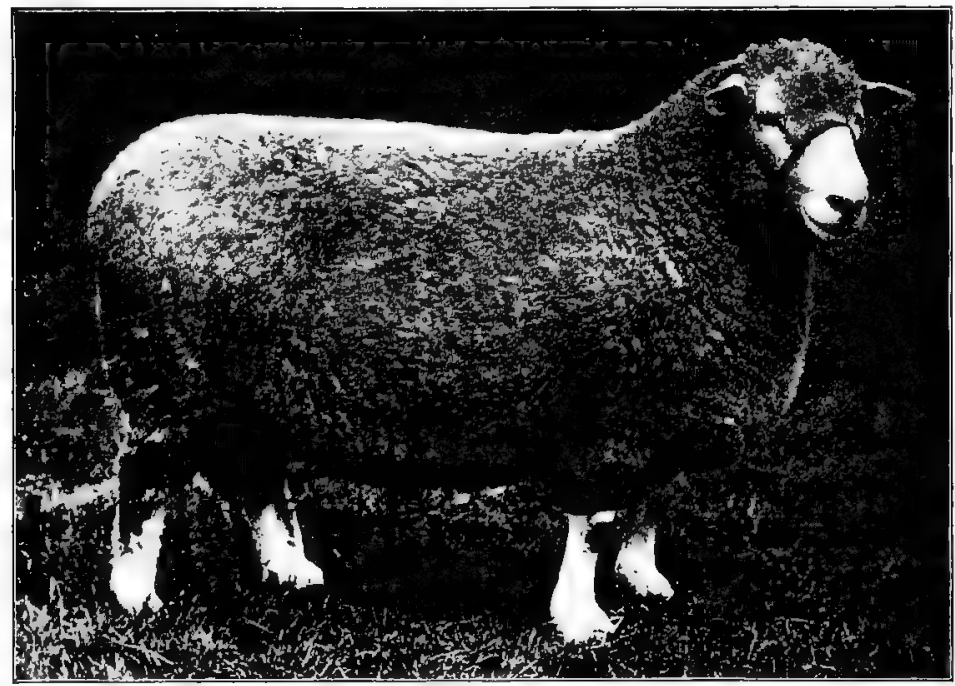

FIG. 21 I. A Kent or Romney Marsh ram, first prize in class at the Royal Agricultural Society of England Show, 1904. Owned and exhibited by Charles File. Photograph from William Cooper \& Nẻphews, Berkhamsted, England

mild and the region sparsely settled. Here a comparatively large number of sheep are maintained on the land.

The early type of Kent sheep was rather comparable with other breeds in being deficient in rib, heavy of bone, long of leg, and coarse of wool. In 1855 , referring to these as Romney Marsh sheep, Professor Wilson thus describes the breed: 
The head and legs are white; the head long and broad, with a tuft of wool on forehead ; no horns ; neck long and thin ; breast narrow with moderate fore quarters; the body long with flattish sides and sharp chine; loins wide and strong; the belly large; thighs broad and thick; and legs and feet large, with coarse bone and muscle. They are very hardy and are well adapted for the bleak and exposed district of the Romney Marshes. They also bear stocking closer than other breeds, as it is not unusual to see six or eight fattening sheep placed to the acre. The improved breed produces sheep ready for market at from two to three years old, weighing from 120 to 140 pounds. The fleece is valuable, weighing on the average eight pounds.

The modern type of Kent sheep is a decided improvement over the breed as described by Wilson. The head is white and is frequently bare of wool and also hornless. Careful selection and breeding has reduced the size somewhat, but has produced a sheep more compact of frame and more easily fattened than the old sort. The back is broader, the ribs are longer, the coupling shorter, and the leg of mutton heavier and of excellent quality. In the improvement of the breed the fleece has been refined to a marked degree. The adaptability of the Kentish sheep to lowlying lands has caused it to be regarded with favor in eastern England and in some other sections, for it seems freer from foot rot than most breeds; in fact, it is claimed that this breed on Romney Marshes is not affected with this disease at all.

The Kent sheep in America is almost unknown. A few individuals have been brought here in the past, but the importations have not succeeded in obtaining a permanent and satisfactory foothold. In 1904 a few poor specimens were imported and exhibited at the Louisiana Purchase Exposition at St. Louis, but persons familiar with the breed criticised them severely. There is no question but what Kent sheep have merit in their native county, and are suited to certain regions in the United States. In Australia the breed has met with favor and is imported to the British colonies to some extent. 


\section{CHAPTER LXII}

\section{THE BLACK FACED HIGHLAND}

The native home of Black Faced Highland Sheep is the more elevated section of Scotland, especially in the Highlands, in the counties of Perth and Dumbarton. Here this breed has been bred on the heather-topped hills, where the winters are rough and cold, for certainly one hundred and twenty-five years or more.

The origin of the Black Faced Highland Sheep is unknown. Sheep of this sort have been known for a long period of time in

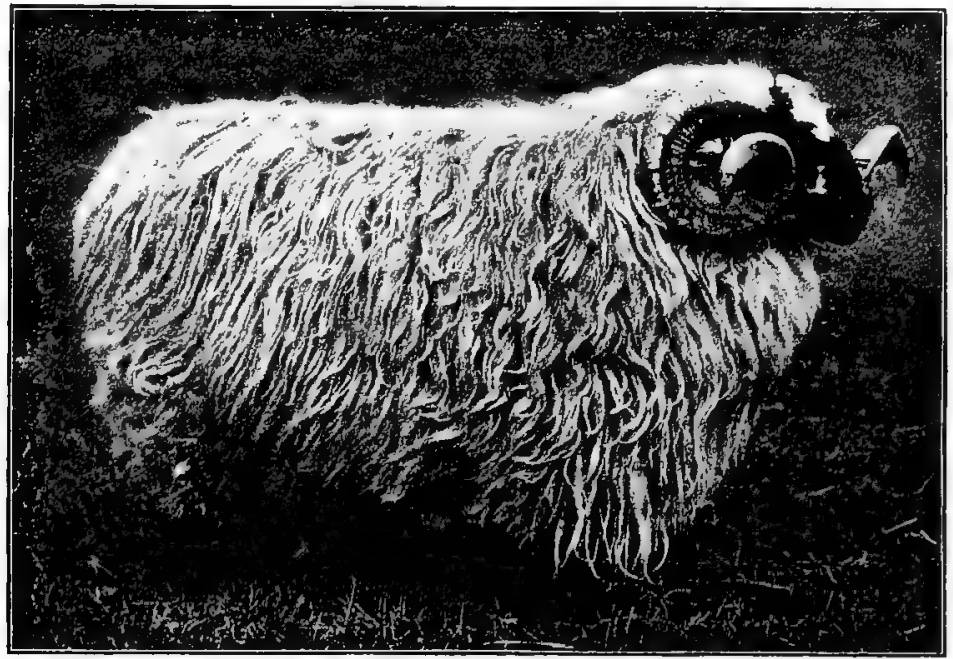

FIG. 212. A Black Faced Highland ram, first prize in class at the Royal Agricultural Society of England Show, Ig04. Photograph from William Cooper \& Nephews, Berkhamsted, England

the Highlands, where in earlier days they were not very popular. The fact that this breed was extremely hardy and could endure on the higher mountains even better than the Cheviot gave it a foothold a half century or so ago, which it has since held. 
The introduction of Black Faced Highland sheep to America first occurred in June, I86I, Hugh Brodie importing one ram and two ewes for Brodie \& Campbell, New York Mills, New York. In 1867 this flock and its increase was purchased by T. L. Harison of Morley, St. Lawrence County, New York. Isaac Stickney of New York also imported a small flock about I867 for his farm in Illinois. Other than these very few of these sheep have ever been brought to America.

Characteristics of the Black Faced Highland sheep. Both sexes have horns, those of the males being rather large, taking one or two spiral curves. The ewes' horns are small, thin, and curved,

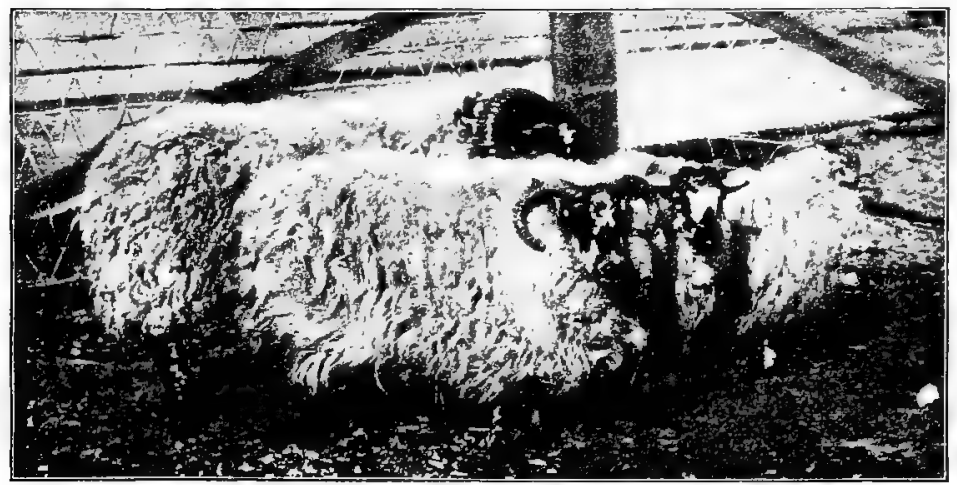

FIG. 213. A group of Black Faced Highland sheep. Photograph by H. B. Arbuckle, from the National Stockman and Farmer

but not spiral. The face is covered with hair, not wool, of either a solid black or a mottled white and black color. The nose is strong and prominent, the nostrils wide and black, and the ears short and small. The body is that of the typical mutton sheep, though not of heavy flesh type. The fleece is very long and coarse, often kempy, and very loosely covers the body. The breed belongs to the long-wool group, and the fleece is specially used in making carpets and coarse woolen goods. In temperament the breed is very wild and independent, quite unlike the heavier lowland sheep. In size Black Faced sheep are small to medium.

The special value of the Black Faced Highland sheep is based on its hardy character and ability to withstand very rough 
exposure in winter in mountain regions where food is scarce; and also for its mutton, which is popular in the British market because of its superior flavor and fine quality and grain. The fleece is not very valuable, and on ewes averages $3 \frac{1}{2}$ to $4 \frac{1}{2}$ pounds unwashed.

Cross-bred or grade Black Faced Highland sheep meet with favor in Scotland, giving a heavier fleshed type with the good quality of mutton of the pure-bred. Robert Wallace states that the produce of a Black Faced ewe by a Leicester ram is called a "cross" or "mule," and by a Cheviot ram a "half long." The latter name is given because a Black Faced is sometimes termed the "short" sheep and a Cheviot the "long" sheep. As ewes these sheep of mixed breed are good milkers.

The distribution of Black Faced Highland sheep is mainly over the Highlands of Scotland and in a small degree on the higher of the mountain regions of north England. Large numbers are bred in the Highlands, and this with the Cheviot occupies most of the space at the Scotch shows. There is no flock-book society to promote the breeding of this sheep.

The special field for Black Faced Highland sheep in America should be the mountain regions east and west, but more especially the higher sections of the lower Alleghanies, where grass grows in abundance. The Cheviot, however, is almost equally hardy and is far better suited to the American market. 


\section{CHAPTER LXIII}

\section{THE ANGORA GOAT}

The native home of the Angora goat is in the district of Angora in Asia Minor. Angora, the principal city, is about 220 miles south by southeast of Constantinople, Turkey. This is a mountainous region 2000 to 4000 feet high, lying south of the Black Sea, forty degrees north latitude passing through it at Angora 200 miles from the sea. The climate has wide extremes of heat and cold. The rainfall is rather variable but light. The soil is frequently poor and free of vegetation. Forests occur to a considerable extent also. It is probable that this goat has inhabited this region for many centuries, dating back to days before the Christian era.

Several varieties of goat in Angora are reported, each located in a special district. These according to Gatheral are the following: (a) Yavan-Ova, having a heavy, lustrous fleece; (b) Chorba, producing a very soft, fine mohair; (c) Chubouk-Ova, remarkable for length and fineness of fiber; $(d)$ Ayash, white of fleece, but lacking luster ; (e) Joevas, having a bright, showy, but kempy fleece. Other varieties are also referred to.

The introduction of the Angora goat to America dates back to I 849, when the Sultan of Turkey presented Dr. James B. Davis of Columbia, South Carolina, with nine choice animals. These were long known as Cashmere gats, -but evidence seems to show that they were true Angoras. TKese goats and their progeny were sold later to various people, but especially to Colonel Richard Peters, who bought in I 854. They were shown quite extensively and attracted much attention. From the Davis importation flocks became established over considerable territory in many states. In I 863 large flocks were reported in Georgia, Tennessee, Kentucky, Indiana, Illinois, Texas, Kansas, Iowa, Michigan, Minnesota, Missouri, Ohio, Maryland, New 
York, and Massachusetts. A number of other importations followed that of I849. In I 86 I Mr. W. W. Chenery of Belmont, Massachusetts, made two importations, and later others in 1866 and I867. About I 867 Messrs. I. S. Diehl and C. S. Brown imported 160 head and placed them on the farm of Mr. Brown at Newark, New Jersey. A number of other importations followed the above, notably that of John S. Harris of California in I 876

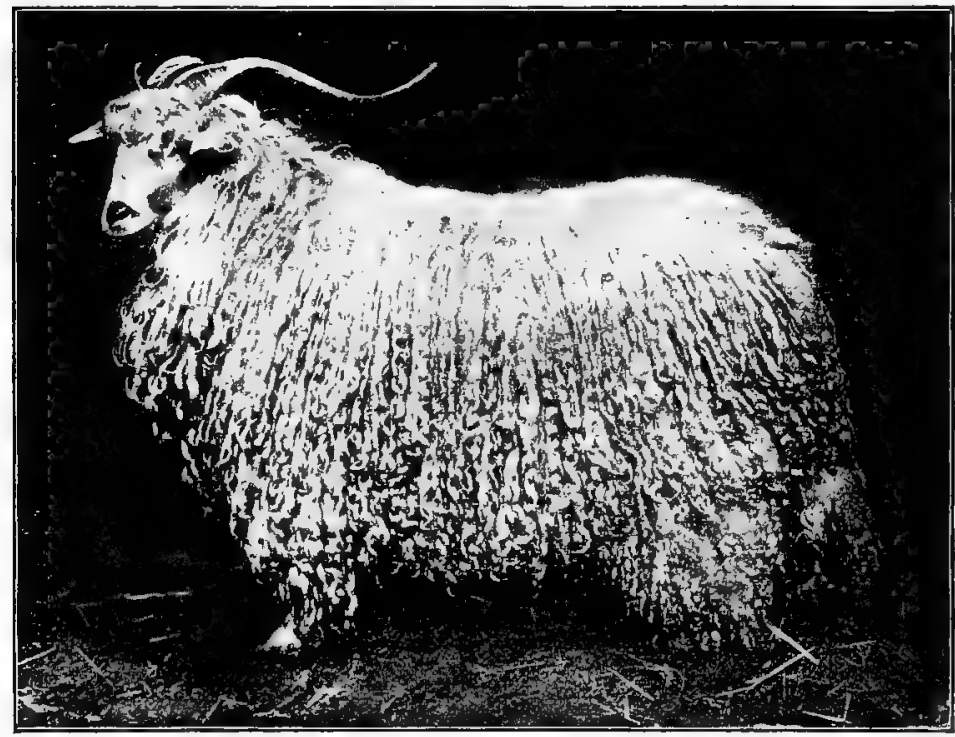

FIg. 214. Hobson's African, first in aged Angora buck class at the Lewis and Clark Exposition, Portland, Oregon, 1905. Weight of fleece $18 \frac{1}{2}$ pounds at thirteen months old, selling for $\$ 1.50$ per pound. At head of the flock of William Riddell \& Sons, Monmouth, Oregon. Photograph from L. A. Webster

and Dr. W. C. Bailey of California in I90I, both of which gentlemen made personal selections in Asia Minor.

A description of the Angora goat of improved type is quoted from the late Professor George F. Thompson, a well-known American authority on this animal:

The Angora goat is smaller than the ordinary common goat. It weighs from 60 to 100 pounds, although some are frequently found that weigh considerably more, especially if fat. The back should be straight, with 
shoulders and hips of equal height. A sloping rump is very objectionable. The chest should be broad, indicating good constitution, and the body round, legs short and strong. The head should not droop, but be clean-cut, with bright eye and broad muzzle; avoid a pinched nostril. The horns are grayish, never black; in the buck they are heavy, with an inward twist, inclining backward and to the outside. The doe's horns rise immediately upward and backward, slightly outward, with very little inclination to twist. In most animals the ears are pendent and from six to eight inches long, with an average width of about two inches, and well pointed. In some animals the ears are fox-like, - short, pointed, and pricked. There appear to be no other differences between the goats having the different kinds of ears.

The fleece of the animals should be pure white, although there are colored Angoras. No colored spots on the skin should be tolerated. The fleece should cover the entire body, - as dense on the belly and neck as on the back and sides; should extend to the ears and jaw. While some are breeding for the topknot and for mohair on the face and lower legs, this is not an evi-

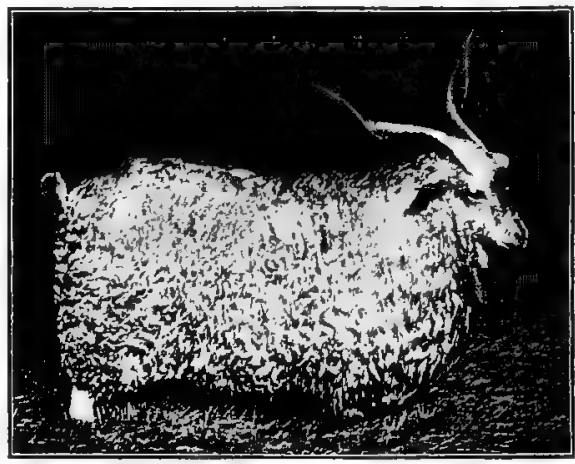

FIG. 215. Pasha Columbia, a great Angora sire and show buck, costing $\$$ ro50, at the head of the flock of Mrs. M. Armer, Kingston, New Mexico. Photograph from the National Stockman and Farmer dence that the animal is better than another that may not have the head and face covered. The mohair should grow to the length of about ten inches during a year, and hang in tight ringlets or wavy curls. The curl should extend entirely up to the skin.

The Angora goat sheds its fleece each spring if not shorn. Some are hornless, though such are rather uncommon. The Angora has no strong musky odor, like the common goat, excepting in the case of the male during the breeding season.

The fleece of the Angora goat is commercially known as mohair. It differs from wool in having no exterior scales and not possessing the felting quality. Mohair is somewhat coarser than fine wool, but it is longer and much stronger. An average fleece weighs about three pounds. Riddle \& Sons of Monmouth, Oregon, report that their buck Sultan, sweepstakes at the Lewis and Clark Exposition in 1905 , sheared a fleece weighing $18 \frac{1}{2}$ 
pounds, which they claim makes it the heaviest fleece on record. This mohair lies over a short coat of hair known as kemp, which is hard and white, sometimes attaining a length of four inches. Kemp is a very objectionable fiber, as it is coarse and will not take the dyes used with mohair. Its presence in American flocks is materially due to the influence of common goat blood on which the Angora has been much crossed in the past. Very careful selection of breeding sires helps to greatly reduce this difficulty.

The prices of mohair differ according to the demand and quality. In Bradford, England, the mohair manufacturing center of

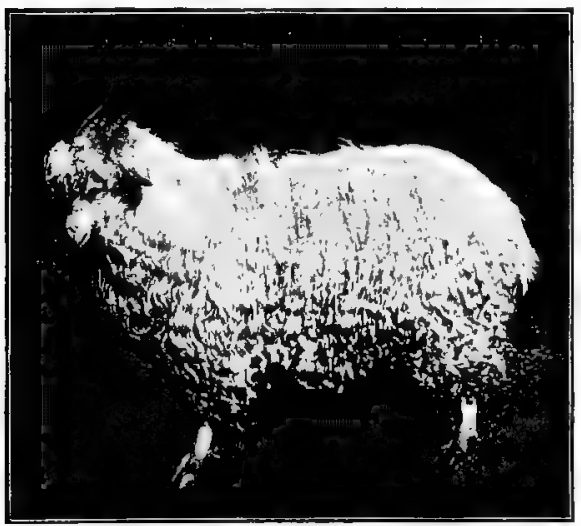

FIG. 216. Aztec 10664, the champion Angora goat of the 1902 shows. Bred by D. C. Tay. lor \& Son and sold for \$1 400 to Kemble Bros. of Iowa. Photograph from the National Stockman and Former the world, the price has ranged from 23 to 92 cents a pound since 1856 , though during the past twenty-five years it has ranged low rather than high. In I90 I the average price in the United States was about 25 cents. Late in 1905 choice combing mohair was quoted in Chicago at 34 to 36 cents a pound.

The value of the Angora as a mutton producer is not regarded commercially as very important. The flesh of the fat young Angora makes excellent mutton, although comparatively few find their way into the markets. Sold in the stock yards Angoras usually bring a lower price than sheep. Some Angora breeders are enthusiastic over the superior quality of the mutton. Wethers may be shorn for some years and then fattened and sold for mutton.

The Angora as a renovator of brush land has a distinct value. The goat is naturally a browser and not a grazing animal. In brush lands he is in his element. He eats the slender tips and twigs and destroys young trees and brush very effectually. In Michigan, Wisconsin, and some other states large tracts of 
brush land have been pastured to flocks of goats, which have materially reduced the cost of clearing the land for farm purposes.

The distribution of Angora goats is very widespread. They are found in various parts of the world, but especially in Asia Minor, South Africa, and the United States. With reasonable care they seem adapted to a wide range of climatic conditions, and do well in the dryer southwestern states and in Wisconsin and the colder, moister north. A dry climate, however, seems to offer the best condition of health. At the present day Angora goats are found in nearly every state in the country, with very large flocks in New Mexico, Texas, and the southwest.

The prolificacy of the Angora goat is not marked. Rarely more than one kid is dropped a year, though twins occur. Thompson states that on the southwestern ranches the average percentage of kids is about 70, with instances of flocks attaining I 20 per cent.

The price for Angora goats varies greatly. Many have changed hands on western ranches at two or three dollars a head, but very high prices have been paid. Pure-bred, fair specimens have sold at prices comparable with sheep of average breeding character. In 190I, at the Kansas City Goat Show, the buck Columbia Pasha changed hands for $\$ 1050$, while the next year Mr. A. Kemble of Iowa paid \$1400 at the same show for the buck Aztec. Still later, in 1903, at the Kansas City Show, the buck Dick Junior, sweepstake of the show, sold for \$ $\$ 300$. Lazarus, that sold in 1900 for $\$ 700$, was a famous show buck and proved to be a breeder of much merit. The highest price ever paid for a doe in America was $\$ 900$ for Oregon Beauty, champion yearling at Kansas City in 1905.

The American Angora Goat Breeders' Association promotes the interest of the breed. This is a young organization with its membership mainly distributed in the far West. Goats are registered much as in other pure-bred live-stock associations. 


\section{CHAPTER LXIV}

\section{THE MILCH GOAT}

The goat as a milk producer has long had a recognized place among the poorer people of the various countries of the world. Among common goats a yield of a quart a day is not uncommon. Some breeds of goats are quite heavy producers of milk, as will be shown further on. Goats' milk is quite white in color and contains about four and one-half per cent of fat and somewhat more albumen than cows' milk. Where goats are properly kept, under clean conditions, and the milk properly drawn and cared for, no unpleasant flavor or odor is connected with it.

Varieties of milk producing goats occur in several countries, some of which are specially bred for their value as milkers. The common goat seen in America and the Angora produce milk, but milking families of these have not as yet been much developed. The following are the leading breeds of milch goats.

The Maltese goat is especially bred on the island of Malta in the Mediterranean Sea. The island of 95 square miles supports a population of about 200,000 people, and nearly 30,000 goats and 900 cows are used in milk production. Maltese goats are usually hornless, the body is compact, and the legs short. The ears are carried rather horizontally and are fairly long. In color they are usually white, with some red markings, and have long hair. The udders are very large, of much capacity, and come quite near to the ground. This is one of the best milking breeds of goats. They milk for quite a long period, and the better individuals produce from three to four quarts a day. Whether this breed would do well in the cold sections of America, where much moisture is prevalent in winter, is not yet demonstrated. In the summer of 1905 the late Professor G. F. Thompson of the United States Department of Agriculture went to Malta and imported to this country 68 of these goats, and their adaptability 
to American conditions will be studied. Some Maltese goats were taken to Canada a few years ago, where it is said they have done very well.

The Toggenburg goat. This breed is raised more particularly in the Toggenburg Valley in Switzerland, where it has been bred for centuries. This goat is a medium brown in color, with a white band passing along down each side of the face from eyes to mouth. The breed is rather slender and lean of body and neck. Horns may or may not occur, though it is regarded as a

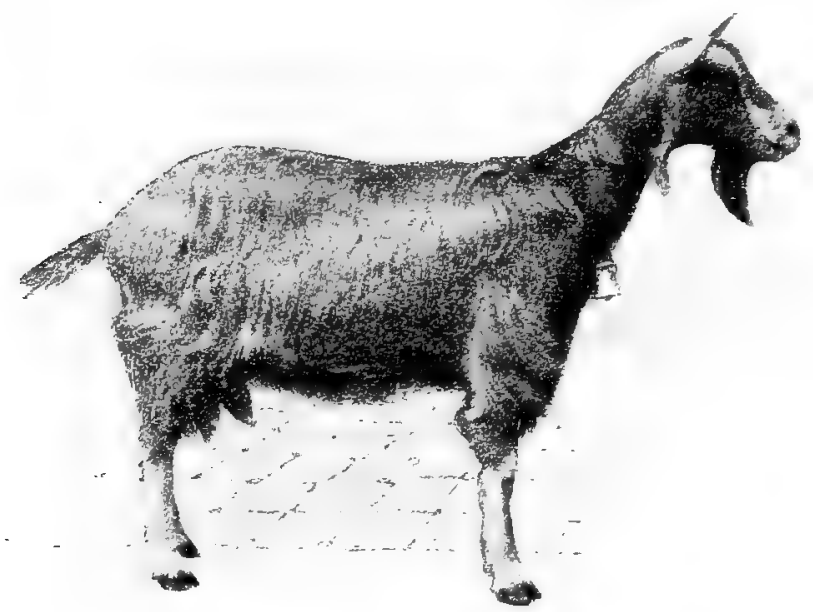

FIG. 217. A Toggenburg milch goat. Photograph from the American Sheep Breeder

hornless breed. The ears are of moderate size and are usually carried somewhat erect. The males have a coarse beard and are rather more free of offensive odor than male goats of other breeds. The breed differs in character of coat of hair, some animals having a rough, long coat, others a short one, and still others one of a medium character. The udder seems capable of great capacity. When full it is carried high between the legs and has large, long teats. Many of these goats produce from four to five quarts of milk a day, while the best produce from five to six or even seven quarts. The breed is regarded as very 
hardy, and it is thought will be well suited to the more elevated regions in America.

The Saanen goat derives its name from the Saanen Valley in Switzerland. It is the largest breed of that country, is lean and lank, is pure white or creamy white of color, and in general has short hair over the body excepting along the spine and at flanks and lower thighs. Thompson says :

The does are especially beautiful, with slim, long, graceful necks and clean, breedy-looking heads. The head of the buck is decidedly masculine, but does not have the serious look of the Toggenburger. The breast is well developed; as a rule the udder is very pretty and carried high. This is considered a hornless breed, but, as with the Toggenburgers, occasionally one is found with horns.

There are many fine milkers in this breed, though the average will not show to quite so good an advantage as the Toggenburg. Peer states that "the best of them are probably the best in the world, giving from five to six quarts per day of the very best quality." Thompson gives a record of 10 goats which made annual records ranging from 423 to 95 I quarts.

The Appenzell goat is a breed also found in the Toggenburg Valley, Switzerland. The color is usually white, though some are dark or spotted. It is a breed that weighs about I Io pounds, ranks next to the two described breeds as a milker, and is very hardy.

The Schwarzthal goat is especially found in the Canton Valais, Switzerland, and in the Rhone Valley. It is also known as the Glazier goat. This is a rather large breed of striking appearance, with horns and tuft of long hair on the forehead, and slender legs. The front part of the body to back of the shoulders is black, while the balance of the body is white. The front hoofs are black and the hind ones are yellow. This is an extremely hardy breed, perhaps the toughest of any. It does not yield as heavily of milk as some other breeds.

The Langensalzaer goat is bred in the central part of Germany, in and about Thuringia. There are several types and colors. The better sort is a very good milker.

The Nubian goat is found in Nubia, Upper Egypt, Abyssinia, and also in South Africa. It is very large and has long legs. The head is of striking appearance, being almost always hornless, 
and has a remarkable Roman face with depressed nostrils. The lower jaw extends beyond the upper, showing the teeth. The ears are frequently very large, long, and droopy, or they may be short and pointed. The color is very bright brown or black. The hair is short on some specimens and long on others. The udder is large and the lobes are deeply divided, with very goodsized teats. This is one of the highest types of milch goats, is credited with as much as ten to twelve quarts of milk a day, and is said to rarely give less than four quarts per day. This breed has been crossed on other goats to special advantage. Nubian goats are very docile. They lack hardiness, being quite unable to withstand cold.

There are numerous other breeds of milch goats found in various parts of the world.

The American Milch Goat Record Association was organized on November 12, 1903, to promote the establishment of a milch-goat industry in

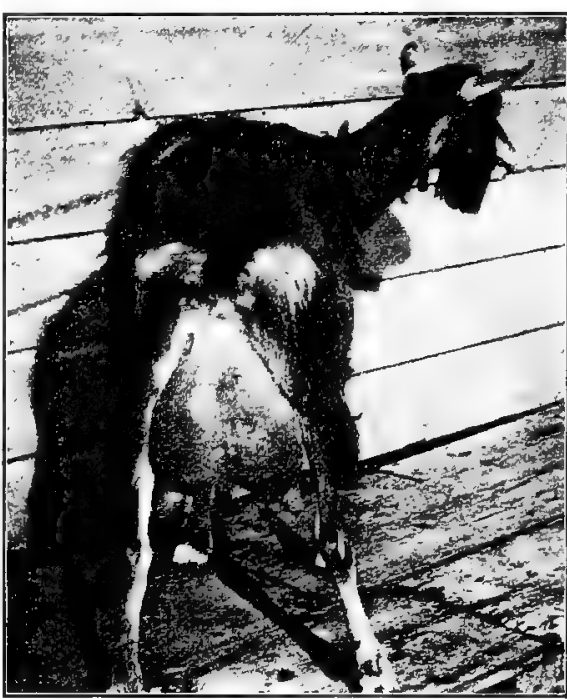

FIG. 218. Phyllis, an imported Toggenburg doe, showing a very great development of the udder. Photograph from Professor F. K. Cooke, Winnetka, Illinois

America. At the second annual meeting of this association, in December, 1905, it was decided that milch goats imported hereafter must be accompanied by a certificate satisfactory to the secretary as to their breeding and country of origin, and that from the year 1906 the qualification for native milch goats should be one quart of milk a day to entitle them to registry.

The period of lactation of the goat varies according to the breeding and care. The common goat of this country produces milk from three to five months. In Europe, with the distinctly milking breeds, the period is more extended. There the plan is 
to have one doe come fresh in the spring and milk for about six months, where two are used in the family, having the other kid in the fall. This provides a supply of milk for the entire year.

The fecundity of the milch goat. Does usually drop two kids at one time, and occasionally three. It is stated by Thompson that there is a record of a Nubian goat which dropped eleven

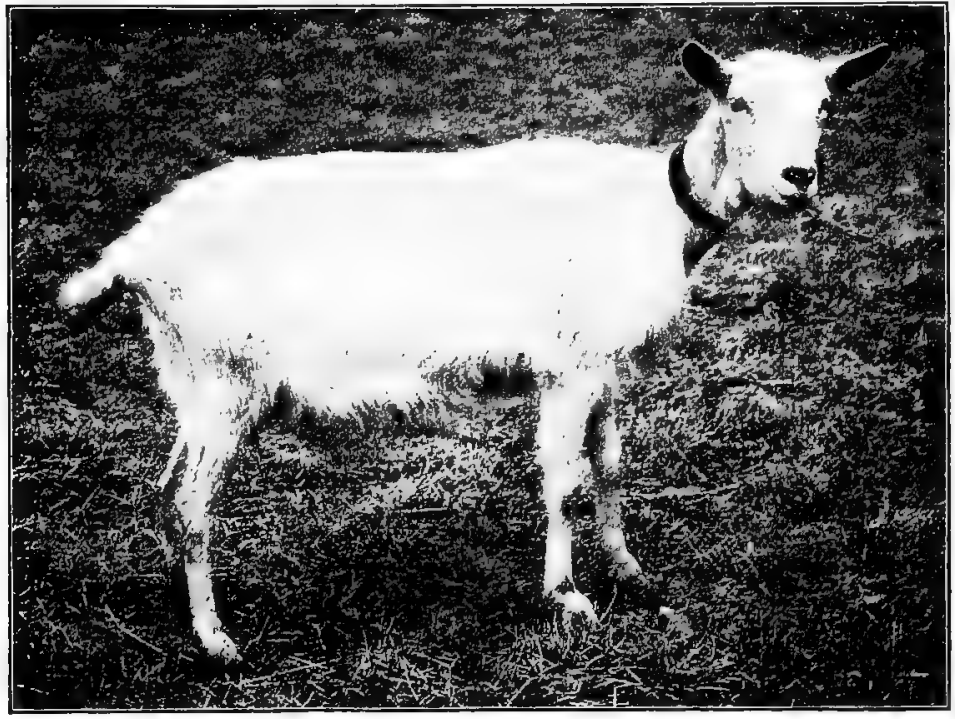

FIG. 219. Marina, an imported Saanen doe, owned by Professor F. K. Cooke, Winnetka, Illinois. Photograph from the owner

kids within twelve months. The period of pregnancy is five months, as with sheep.

The age attained by milch goats naturally varies. They have been known to live to be sixteen years old, but will probably attain to ten or twelve years of age with reasonable care. The doe is in her prime at from five to seven years of age.

The prices for milch goats are rather indefinite. American goats are to be bought at all sorts of prices from $\dot{p}_{2}$ up to $\$ 10$, depending upon the value to the owner. The best milkers of Malta sell at $\$$ I 8 to $\$ 25$, those of Switzerland at about $\$ 20$. Peer states that Toggenburg does at one to two years old cost from $\$$ I 2 to $\$$ I 5 per head before dropping their kids. In Syria 
and Egypt they fetch as low as $\$ 4$. In England prices rule high for milch goats, ranging up to as high as $\$ 40$ for selected homebred, or to $\$ 100$ for the pure Toggenburger. At the present time a great deal of attention is being devoted to the milch goat, and this may result in materially higher prices.

Importations of milch goats to America began in 1893 , when Mr. W. A. Shafor of Ohio brought to this country four Toggenburg goats which he purchased in England. In May, I904, Mr. F. S. Peer of New York imported I6 Toggenburg and Io Saanen goats to this country for Messrs. W. J. Cohill of Maryland, R. N. Riddle of New Jersey, W. M. Decker of New York, and S. K. Bayley of Massachusetts. Mr. Cohill also secured two goats from Carl Hagenback at the World's Fair, St. Louis, in 1904, that Hagenback had brought from the Black Forest of Germany. These are supposed to be Schwarzwald goats. In rgo5 Professor Thompson imported 68 Maltese goats, as noted on a preceding page. 


\section{A FEW REFERENCE BOOKS ON SHEEP AND GOATS}

Those marked with a are especially recommended.

William L. Black, A New Industry, or Raising the Angora Goat. Texas, I89o. T. Вонм, Die Schafzucht, 2 vols. Berlin, 1883.

*E. A. Carman, H. A. Heath, and John Minto, Special Report on the History and Present Condition of the Sheep Industry of the United States. Washington, 1892 .

Le Four, Le Mouton. Paris, N.D.

*Bryan Hook, Milch Goats and their Management. London, Igoz.

Mentzel, Die Schafzucht. Berlin, 1892.

L. A. MorRell, The American Shepherd. New York, 1846.

Stephen Powers, The American Merino. New York, 1887.

Henry S. Randall, The Practical Shepherd. Rochester, 1863.

Henry S. Randall, Fine Wool Sheep Husbandry. New York, 1868.

* Henry S. Randall, Sheep Husbandry. New York, 1883.

Dr. O. Rohde, Die Schafzucht. Berlin, 1879.

*S. C. C. Schreiner, The Angora Goat. New York, 1898 .

JAmeS ScotT, Black Faced Sheep. Edinburgh, 1888.

W. S. Spooner, The Sheep: History, Structure, Economy, Disease. London, 1888.

Henry Stewart, The Shepherd's Manual. New York, 1890.

*Hen ry Stewart, The Domestic Sheep. Chicago, 1898.

*G. F. Thompson, A Manual of Angora Goat Raising. Chicago, 1903.

*G. F. Thompson, Information Conceming the Milch Goat. Washington, 1905.

JoHN Usher, The Border Breeds of Sheep. Kelso, 1893.

-J. E. Wing, Sheep Farming in America. Chicago, 1905.

Dr. William A. Rushworth, The Sheep. Buffalo, 1899.

"John Wrightson, Sheep: Breeds and Management. London, 1893.

*William Youati, Sheep: Their Breeds, Management, and Diseases. London, 1837 . 


\title{
PART IV-THE PIG
}

\author{
CHAPTER LXV \\ THE AMERICAN TYPE OF PIG
}

The type of swine most valued in the United States possesses great compactness of form, breadth of back, fullness of ham, shortness of limb, and is capable of fattening rapidly and maturing early. It is a type that in its highest-fed and most popular form contains a large amount of fat, especially in leaf lard and external covering. It represents the extreme development of meat production, and, as ordinarily corn fed in the states, is not looked upon with favor by people of other countries. It is often referred to as the lard type of pig, from its natural heavy fat production. In this connection it may be said that while this type is quite generally popular and approved of, the character and degree of fleshing is materially influenced by the sort of food fed. Even those breeds recognized as of the bacon type, kept and fed under the conditions of the corn belt, undergo a gradual evolution toward the type most popular in this country, losing much of the bacon-producing attributes. In connection with a consideration of this type it is to be borne in mind that the fattest specimens do not represent the best type. A pig may easily be made overfat. It would be in the interests of swine in general, if judges at shows deprecated and turned down excessively fat animals and placed suitable emphasis on breeding stock or fat stock, according to its purpose and merit.

The general appearance of the pig should be compact and thick of body, involving shortness of head, broad back, strong hams, deep body, short legs, and plenty of quality, as shown in abundance and fineness of hair and strong bone and joints. The temperament should be mild yet active, for the disposition has much 
to do with determining whether the animal is a desirable breeder or feeder. Size or weight have a bearing on the market price, and pigs of this type for size weigh heavy. Generally speaking, at the present time the average weight of the pig sold on the market ranges about 225 pounds.

The head is short and broad in the best specimens, without much length of snout. Between the eyes the width should be fair in proportion to the rest of the head. Excessive fat about the eyes is quite undesirable. The ears should be placed well on the head, be neatly attached, and show refinement in quality of hair and texture. A large ear is undesirable, one of medium

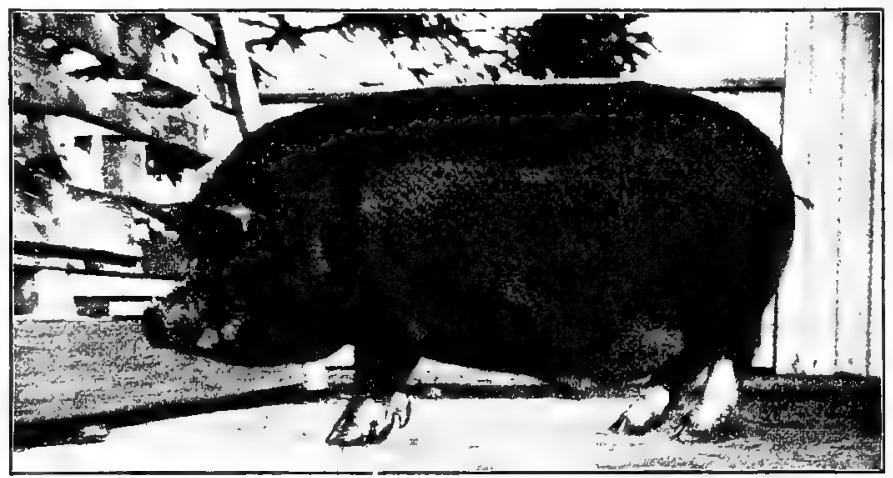

FIG. 220. A type of the fat or lard hog, a cross-bred Berkshire-Poland China, bred by the Ohio State University. Photograph by the author

size and neatly pointed being preferred. A smooth, round jowl, full and firm, yet not heavily fat and fabby is desirable. Wrinkles or seams on any part of the head are distinctly objectionable.

The neck should not be long, but rather broad and short, with a smooth blending at head and shoulder. The tendency is toward a narrow neck on top; too much width or depth does not often occur.

The breast and chest indicate constitution. When the breast is wide and deep, the breastbone carried well forward, and the curve about the chest good and strong both above and below, plenty of room for the heart and lungs is shown. A narrow chest is inconsistent with vigorous development and good feeding qualities. 
The shoulders should fit smoothly back into the body, showing no roughness or openness at the top. A smooth, broad, evenly fleshed shoulder on the fat pig is most desirable from the market point of view. The mature boar will show some thickness and heaviness of skin here at the "shields," those parts inherited from the wild boar as a protection in fighting. It is objectionable, however, even with the boar, to have notable thickness of shoulder, as this is quite liable to be transmitted.

The front legs should show good position, superior bone, and shortness. Standing in natural position, viewed from in front, the legs should stand just under the shoulders, the knees straight, the toes directing forward, the entire position indicating easy posture. Pigs of narrow heart girth, at least of the floor of the chest, usually stand with the knees close together and are what is sometimes termed "knock-kneed." From one side the leg should come down true and plumb from the center of the shoulder, standing strong on the toes, with pasterns fairly erect and dew claws (the rudimentary toes on back of leg) well above the ground. A strong, well-sustained pastern is important. If the foot is weak and the pasterns badly depressed the animal shows a tendency to support its weight improperly. A clean, smooth, hard bone, with strong, yet not coarse joints, represents the better leg development. Too fine and small a bone is often seen with pigs when they really should have a heavier bone to properly support the weight.

The back and loin of the American type of pig in most favor is of medium length, has a slight arch from front to rear, the ribs are well sprung, and the loin is broad and thick. In the case of breeding stock the back may not appear wide, although feeding would soon give it considerable breadth. The width should be carried the entire length from shoulders to hips, offering excellent room for covering. As one views the back from front or rear, the width is carried uniformly. A tapering from front to rear is not in good form, indicating heaviness of shoulder and lightness of loin. As one views the back from the side, it should run rather parallel with the lower line. A droop is quite common, but this is the result of a weak back and so is objectionable. 
The hips, rump, and ham involve the highest-priced meat on the modern porker. The hips should be neatly placed and not prominent, and should be smoothly covered with flesh. The rump has a tendency to be droopy, with the tail set low, although good form calls for a long, broad, somewhat level rump, thickfleshed, with the tail neatly attached fairly well up. Below the rump the hams carry down fairly straight behind or with some outward curve, then rounding into the lower thigh and twist above the hocks. A high-class ham viewed from behind is thick at the edge and low at twist, with considerable depth from the tail to the point where the hams join at twist. From the side the relative length is long from the hip point to lower corner of ham, while considerable side breadth shows, with a strong, well-turned lower thigh and hock joint.

The hind legs in natural position should have strong hocks, wide and muscular, yet not fat, standing well apart when viewed from the rear, so that the legs appear quite plumb from that point. Viewed from the side the hocks should seem deep and the legs below carried down straight, with the pig standing strong on the toes. All the features of quality, bone, and strength of position desirable in the front legs are equally desirable in the hind legs.

The sides from shoulder to hind flank and ham require a long, well-arched rib. This furnishes a body of ample digestive or breeding capacity. Not only should the sides be deep, but the lower part of the body in good formation will be wide, thus preserving a good line from front to hind flank. Such a body as this, full and thick at the flanks, is associated with the animal of easy fattening power.

The fleshing quality of the pig is most important. If an animal is well fleshed, the back, sides, shoulders, rump, and hams will be uniformly covered with meat, which will feel mellow yet firm, and not harsh and hard to the touch of the hand. The skin will be free of scurviness or roughness, and wrinkles will be quite lacking. This smoothness of covering is equally essential with the fat pig or breeding animal. Wrinkles often occur about the jowl or head and along the sides, furnishing decided obstacles to high-grade work in dressing the carcass at slaughter. 
The hair of the pig indicates quality. A reasonable degree of fineness is desirable, this being associated with animals that dress out well in killing. Large, coarse bristles go with heavy joints and much bone and offal. Curly hair is often seen on the pig, but straight coats are more popular. The hair should not only be of good quality but also of a fair degree of abundance.

The disposition of the fat type of pig is usually quiet and docile. Among individuals of the same breed, those which flesh up most readily and respond to feeding quickest, as a general thing are of the most quiet temperament. It is doubtless true also that the American breeds of swine differ to some extent in disposition and easy feeding quality. The Poland-China for example, is notable for its quiet and phlegmatic habits. As feeding progresses and the animal enters the fat stage, there is a natural tendency to become sluggish and sleep a great deal. This results in lack of vigor and strength a-foot. To avoid this, persons who fit hogs for the show ring compel the animals to exercise to a certain extent each day for some time prior to and during the show season. The more active temperament, of some breeds, however, notably those of the bacon type, do not usually require any special exercise. 


\section{CHAPTER LXVI}

\section{THE BERKSHIRE}

The native home of the Berkshire pig is England, and more especially the counties of Berkshire and Wilts in the southcentral part. The climate is mildly temperate, the land more or less undulating, and the soil quite commonly a clay-loam, and the crops the small grains, roots, and grasses. As a whole the climate is very favorable to swine husbandry. The neighboring counties of Leicester and Stafford have also been prominently associated with the development of the breed.

The foundation stock of the early Berkshire. In 1789 Culley wrote:

The most numerous breed of hogs in this island is that excellent kind generally known by the name of the Berkshire pigs, now spread through almost every part of England, and some places of Scotland. They are in general reddish brown, with black spots upon them, large ears hanging over their eyes, short-legged, small-boned, and exceedingly inclined to make readily fat.

$\mathrm{He}$ also testifies to the large weight of the breed, and mentions one referred to by Young weighing over I I 30 pounds, and to another still larger. Laurence, in I 790, agrees with Culley excepting in bone, which he states was large, while he also adds that the muzzle turned up.

The early improvement of the Berkshire was due to the use of Chinese, Siamese, and Neapolitan blood. In I 842 Professor Low wrote:

The Berkshire breed has, like every other, been crossed and recrossed with the Chinese, or Chinese crosses, so as to lessen the size of the animals and render them more suited to the demand which has arisen for small and delicate pork.

This crossing was regarded as necessary to prevent degeneration in shape and quality. 
The characteristics of the old type of Berkshire, after the addition of foreign blood, were greatly improved. About I 830 they were classed as large, and, Youatt says, were sandy or whitish brown, spotted regularly with dark brown or black. The body was free of bristles and was covered with long, thin, and somewhat curly hair. The ears were erect and fringed with long hair, the head and snout were short, the body thick and compact, the legs short, the skin thin, the flesh of good flavor, and the bacon superior. At this time the breed was regarded as one of the best in England, due to early maturity, easy fattening, small bone, hardiness, and the prolificacy of the females.

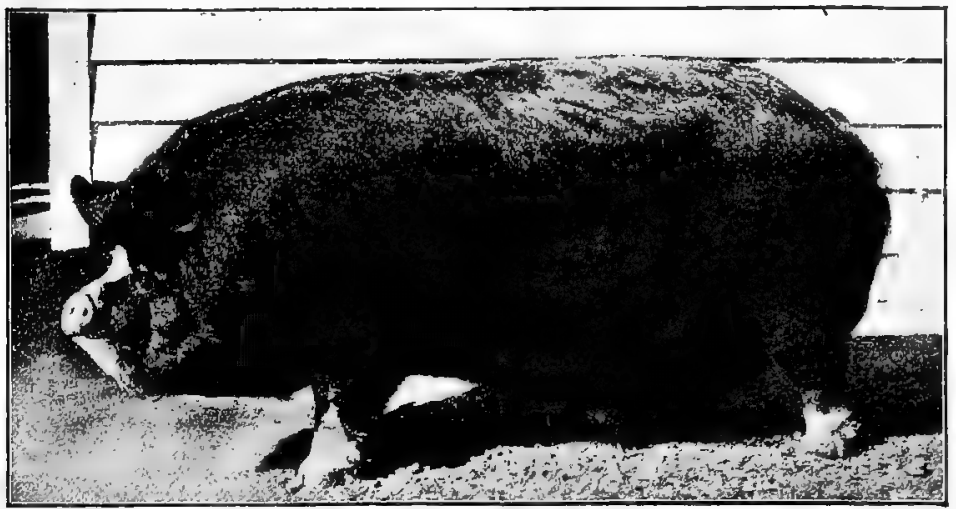

FIG. 221. Masterpiece 77000, second-prize Berkshire boar at the Louisiana Purchase Exposition, 1904. Sold by A. J. Lovejoy \& Son, Roscoe, Illinois, for $\$ 2500$ to W. S. Corsa of Illinois. One of the most famous sires of to-day. Photograph from Professor William Dietrich, Illinois University

According to various early authorities there must have been considerable variation in color, size, and type of the early Berkshire.

Prominent improvers of the early Berkshire were Richard Astley of Oldstonehall, who is credited by Professor Low as being the great improver of the breed, and Lord Barrington, who died in 1829. Sidney, who was a leading pig authority, in I 860 wrote that Lord Barrington did a great deal toward improving the Berkshire breed, the improved stock of that time nearly all tracing back to his herd. The methods of these two breeders do not seem to have been made public, and little is known of 
them. A half century ago William Hewer of Sevenhampton, Wiltshire, was a leading breeder and improver.

Important modern improvers of the Berkshire in England as well as America are worthy of record here. In England, Russell Swanwick at Cirencester and the late Heber Humfrey at Abingdon for years bred with signal ability and did much for the breed. In America N. H. Gentry of Sedalia, Missouri, has long held a most distinguished place as a Berkshire breeder. In a list of prominent American breeders during the last twenty-five years of the nineteenth century high place should be accorded to the names of James Riley and I. N. Barker of Indiana, M. K. Prine of Iowa, A. J. Lovejoy of Illinois, and J. G. Snell of Ontario, Canada.

The introduction of the Berkshire pig to America first took place in 1823 , according to A. B. Allen, who credits John Brentnall,

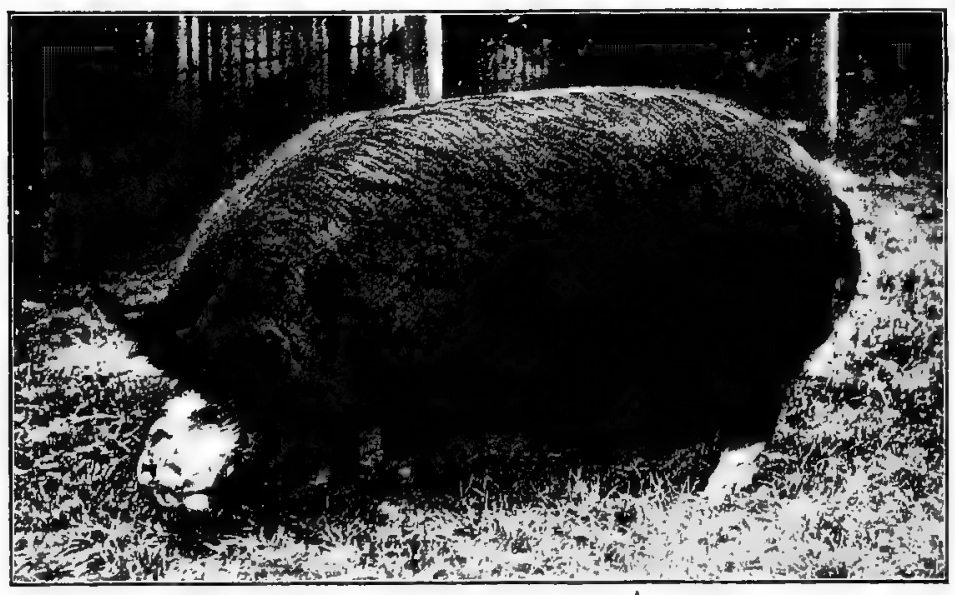

FIG. 222. Lyneham Lad, first-prize aged Berkshire boar at the Royal Agricultural Society of England Show, 1904. Owned and exhibited by Sir Alexander Henderson. Photograph from William Cooper \& Nephews, Berkhamsted, England

an English farmer, who settled in the English neighborhood in New Jersey, with this importation. In I 832 Sidney Hawes, another English farmer, brought some Berkshires to America and settled near Albany, New York. Allen states that he owned pigs descended from each of these importations. In I838 a few 
pigs of the breed were imported to Canada. In I 839 Messrs. Bagg and Wait, English farmers who had settled in Orange County, New York, made a large importation, and this firm made several other importations later on. In I84I A. B. Allen brought over forty head after carefully examining British herds, and later made other importations and did much to popularize the breed.

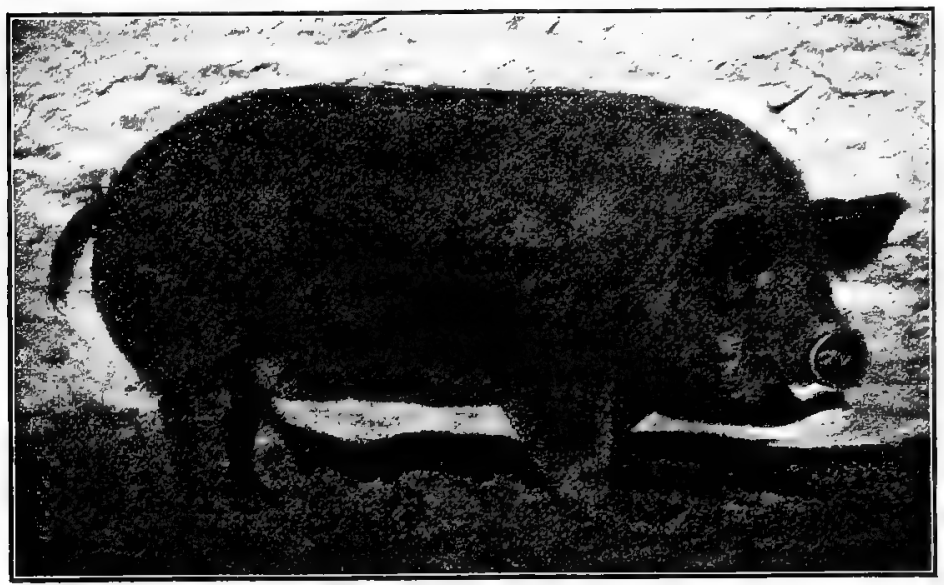

FIG. 223. University Lee 72621, second-prize Berkshire boar in class over six and under twelve months at the Ohio State Fair, 1902. Sire of the grandchampion pen of barrows at the International Live Stock Exposition, I go5. Bred by J. M. Hodson of Ohio, and used in the herd of the Ohio State University. Photograph by the author

The Berkshire soon moved west. In 1835 a boar and sow were brought to Butler County, Ohio, from Albany, New York, while the Bagg and Wait importations soon found a market in Kentucky, Tennessee, Missouri, and the South.

Important families of Berkshire pigs are worthy of note. Among these are the Duchess, of which Royal Duchess 900 by Othello 259 is the founder; the Sallie, descended from Sallie I by Duke of Gloucester I; the Charmer, descended from Royal Charmer 9082 by Exor 3891 ; the Lee, descended from Minnie Lee 14606 by Exor 3891 ; the Nora, descended from Nora B. 14052 by Liverpool Bob IO4I7. In these families will be found the names of many of the most illustrious animals of the breed that have lived in America. 
Famous Berkshire boars in the history of the breed in America make up an extended list. Among those prominent mainly for their influence on the breed are Othello 259, Lord Liverpool 22 I, Charmer's Duke I3360, Longfellow I6835, Baron Lee IV 33446, Lord Premier 50001, Governor Lee 47971, Combination 56028, Royal Windsor 22889, Model Duke I7397, Columbia's Duke 33855, and Masterpiece 77000. Of these Longfellow is regarded by many as the most distinguished sire of all, the greatest Berkshire boar that was ever bred in America, in his overshadowing influence on the breed.

Characteristics of the Berkshire pig. The face of the modern Berkshire should be of medium length and gracefully dished; excessive dish of face is not to be encouraged. The ears are carried erect or pointed slightly forward, often drooping considerably with age. The typical Berkshire back is not so broad as that of the Poland-China, but is quite level and of moderate breadth, with considerable length of side, the ribs being fairly arched and long. The rump should be rather long and level, with the tail set high, though there is some tendency to shortness and droopiness. In the correct type the entire back outline shows less arch than is characteristic of some of the other breeds, with squareness at the hind quarter. The jowl is only moderately full, the shoulders of medium thickness and breadth, and the hams rather deep and thick, well turned in the twist, though not excessively so. The legs should be fairly short, though frequently individuals are too leggy. The bone is of fair quality, and Berkshires probably stand as well on their feet as any of the breeds of to-day.

The color of the Berkshire has changed somewhat from early times. A black body generally, with a white streak in the face, more or less white on the tail, and four white feet make up the "six white points" generally characteristic of the breed. White frequently occurs, however, on the jowl or on the front arm or at the armpit by the shoulder. These colors need not occur in this exact degree, and if a white spot occur on the body elsewhere, there is no clause to disqualify in the American Berkshire Herdbook. The color markings of English show Berkshires were studied by Mr. Heber Humfrey some years ago at the Royal Show at Windsor. Quoting from Mr. Humfrey's report: 
We examined every Berkshire in the show. Taking them at all ages, there were 139 animals. We took the generally accepted standard of "four white feet, white tip of tail, more or less white in face, and a little or not, as the case may be, under the jowl, on the point of the elbow, or inside the ear," and we found on looking through our notes that we had marked 1 Ig down as within the limits of this standard. Only half a dozen were described as having serious defects in the marking; the remaining 14 had only a single small spot, generally on the shoulder or between the ears; one or two were on the sides, but several of them not large enough to attract notice if we had not been looking for them. Out of the half dozen which we thought might be ruled out of competition, only one had a second objection: this was a spot on the front and another on the back of the ham; the second had a large sandy and white spot on the bottom of the shoulder; a third had a black foot ; Nos. 4 and 5 had black tails, and the 6 th a white ear.

The writer knows of a registered boar in service with a white spot of three inches diameter on the back, and within recent years has seen a boar in the show ring and in service with hair noticeably tinted copper color. While these are only fancy points, uniformity of breeding would be promoted by the adoption of fixed standards of color markings, disqualifying when the color fell without the limitations. The British Berkshire Society in 1893 suggested that judges disqualify pigs notably irregular in marking or with black face or foot.

The size of the Berkshire pig may by classed as medium to large. In 1842 Low wrote that "the true Berkshires are of the larger races of swine." In 1893 Professor Long wrote:

Thirty years ago ... some of Mr. Sadler's prize pigs under seven months old weighed 240 pounds each, although they were turned out into an orchard daily while fattening. The same gentleman exhibited, and won the first prize at Baker Street with a fat pig which weighed 856 pounds, the length of her body being 6 feet 4 inches and her girth 7 feet 6 inches. At that time, however, the ordinary weight of a well-bred Berkshire bacon hog was, when ready for the butcher, about 50 stone of 8 pounds ( 400 pounds), but for the curing of the best hams these were generally considered a little too large.

The Berkshire is often advertised under the name "Large English Berkshire," but in England but one Berkshire breed exists, and the title "Large English" is rather uncalled for and somewhat misleading. Young pigs at six months old should easily weigh 175 pounds, and at one year about 300 pounds. The ordinary mature boar in breeding condition should weigh 500 
pounds, and the sows 400 pounds. Lord Premier 5000 I at seven years old weighed 890 pounds, King Lee 27500 at ten months weighed 420 pounds, while the famous Longfellow 16835 at I7 months weighed 726 pounds.

The adaptability of the Berkshire to environment is of the first class. The breed is found growing successfully and meeting with favor in the colder, more northerly sections of America, where the winters are severe, and in the warmer southwest and

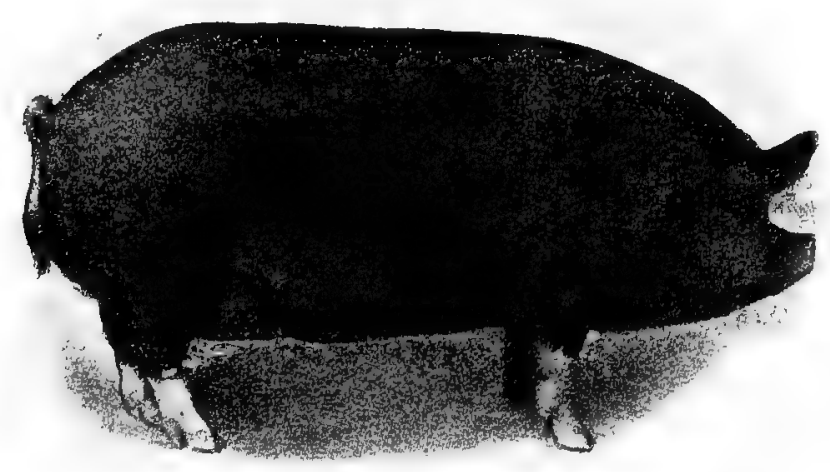

FIG. 224. A yearling Berkshire sow, a prize winner at the Toronto Exposition, 1905. Owned by William Wilson, Brampton, Ontario. Photograph from Professor G. E. Day

more temperate regions. Walker, however, in discussing the adaptability of the Berkshire to climate says:

As far as our own actual experience goes, Berkshires do not prove nearly so profitable in the north of England and in Scotland as in the south, and this harmonizes with our remark that they love warmth and a genial clime.

In spite of this opinion it is doubtless true that no breed of swine is bred and fed under more varied conditions with the success that is attained with the Berkshire.

The early-maturing qualities of the Berkshire are very good. There are those, however, including the author, who do not give them first rank in this respect. Individual Berkshires may fatten rapidly and mature early, but in a broad comparison of breed 
maturity the Poland-China would have the advantage, while many would accord first place to the Duroc-Jersey and Chester White.

The Berkshire as a grazing pig ranks high wherever fairly tried. On the clover fields of the middle West they thrive to perfection, while rape pasture in the more northerly sections seems well suited to them. In general pasturage in America Berkshires quite hold their own. Writing of the Berkshires as foragers, Walker states that they are hardly surpassed so long as in a temperate climate. He says :

You may see herds of a score or two each, any year towards October, running over the wide stubble fields on the borders of Wiltshire, nearly average pork, and yet they have made their growth and their flesh pretty much on waste material, i.e. shed corn, weeds, roots, pasturage, and so on.

The Berkshire as a feeder and fattener has had extensive trial both in Europe and in America. In the records made a high place has been accorded the breed. Numerous American experimental stations have used pigs of the breed in feeding experiments from which the following records are quoted. In 23 trials, involving I23 Berkshires fed at eight institutions in the United States and Canada, it required 369 pounds of feed for each Ioo pounds of gain in live weight, the Tamworth, Chester White, and PolandChina surpassing the Berkshire in this respect. In breed tests at the Iowa Experiment Station the Berkshire made an average daily gain of .98 pound, the Poland-China .90, and the Chester White .89 pound, the cost per 100 pounds gain being $\$ 2.33$, $\$ 2.23$, and $\$ 2.46$ respectively. At the Ontario Agricultural College the average of trials for four years show almost identically the same daily gains, requiring a less amount of meal than any other breed, that is, $378 \frac{3}{4}$ pounds for Ioo pounds of gain. At the Massachusetts Experiment Station seven Berkshires, fed I 40 days, made an average daily gain of I. 16 pounds each, requiring 289 pounds of feed for Ioo pounds gain. From the records quoted above or published elsewhere it may be seen that the Berkshire as a feeder ranks well, though the average of breed trials do not give it first place. Among British authorities on swine Professor Long takes high rank, and in his Book of the Pig he writes of "its comparative slowness as a feeder," and says that it is generally found that a fast-feeding Berkshire has not 
only alien blood in its veins, but that, when killed, it exhibits far too large a proportion of fat.

The quality of Berkshire pork, viewed from the standpoint of the American market, is of the very best class. Fed in the same manner, in comparison with the Poland-China, Chester White, and Duroc-Jersey, the Berkshire will show a class of meat with a larger percentage of lean than any of them. In feeding experiments conducted by the author at the Indiana station, in a comparison of Berkshires and Poland-Chinas bearing on the influence of food on carcass, the larger percentage of lean to fat in the

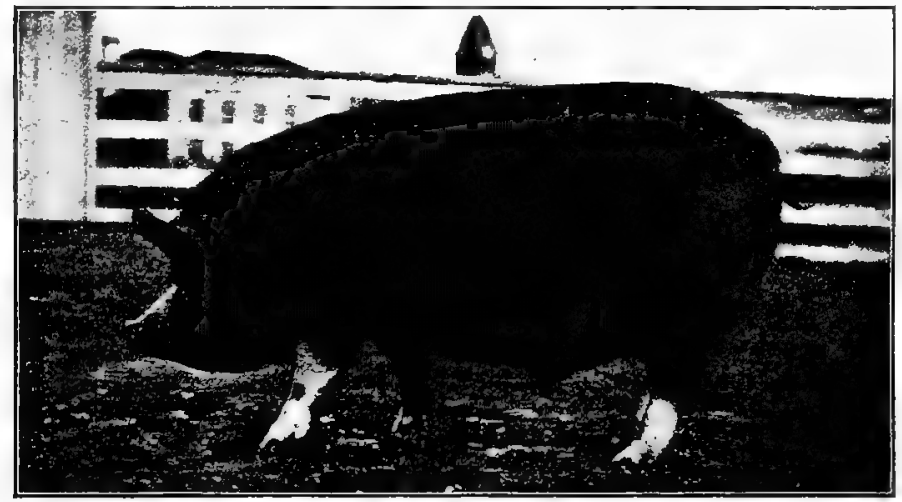

Fig. 225. A pure-bred Berkshire barrow, bred by the Ohio State University, one of the grand-champion pen at the International Live Stock Exposition, Chicago, 1905. Photograph by the author

Berkshire was strikingly shown. The meat of this breed has a fine grain and, when not all corn fed, a desirable blending of fat and lean. In certain localities where select sausages are made Berkshire pork has been relied upon for securing superior quality. Where properly fed this breed makes a bacon pig of high class, and is so regarded in Great Britain, though it may not be the equal of the Large Yorkshire or Tamworth in this respect.

The cross-bred or grade Berkshire, where fair samples of pigs are used in breeding, merit high praise. A cross of Berkshire boar on Poland-China sows produces offspring that feed rapidly and sell well, the two breeds blending admirably. This cross gives more vigor and a better feeder. Also a cross of the 
Berkshire on the Chester White female is productive of a better feeder than the sire, with a class of pork superior to that of the dam. The great value of the Berkshire in crossing is amply demonstrated from the fact that the blood of the breed has been used to improve that of other breeds for over a century, and no doubt has done much to help the most prominent breeds of to day in their early stages. Sidney states that Fisher Hobbs, who did much in improving British pigs, used the Berkshire as a cross on his Essex pigs, and thereby size and condition were materially affected. In fact, so strong was the Berkshire influence that some twenty-eight years after the cross was made some

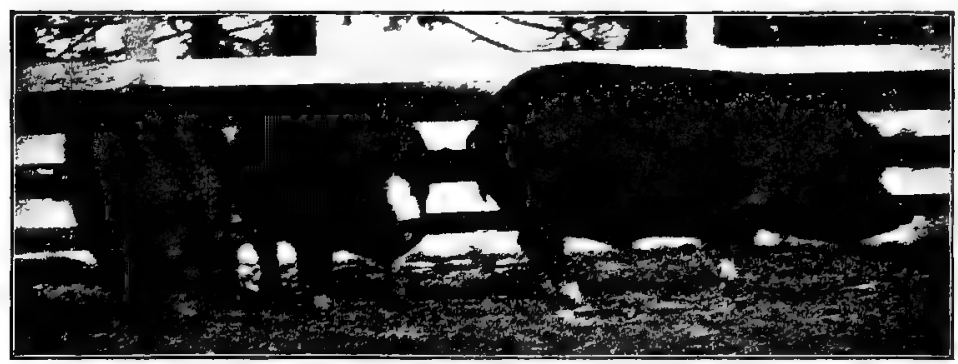

Fig. 226. Three pure-bred Berkshires, the pen of grand-champion barrows over all pure-breds, grades, and crosses at the International Live Stock Exposition, Chicago, 1905. Bred and exhibited by the Ohio State University. Photograph by the author

of the young Essex reverted to their alien ancestor, and were, in reality, exact types of the true Berkshire pig. Mr. W. H. Wykes, an experienced breeder, according to Long, finds that the best crosses are made by the Berkshire on the Black Suffolk and the Tamworth. The value of the Berkshire boar in grading up a herd is unquestioned. Feeders of such blood always command the top market price in America.

The fecundity and prolificacy of the Berkshire is of a fair degree of merit. An extensive study of the relative prolificacy of three breeds of swine (the Berkshire, Poland-China, and Chester White) by Dr. A. W. Bitting shows that the average size of 400 Berkshire litters was 8.22 pigs, while 600 Chester White litters averaged 8.96 pigs and I086 Poland-China litters averaged 7.45. These records were based on herdbook figures of sizes 
of litters. There are many large litters of Berkshire pigs, and litters of ten are not uncommon. Walker states that about seven or eight at a farrow are reckoned an average family for even the older sows. William Ashcroft, a successful English breeder, is quoted by Professor Long as saying that the tendency to produce medium litters, of say six to eight, may be corrected by breeding less closely. "If unrelated stock pigs are used," says Ashcroft, "the litters will come pretty regularly twice a year, and average about eight to eleven." In the United States the tendency with the heavily corn-fed sow is to produce smaller litters than would be the case with a less-fattening diet. In general the Berkshire is not lacking in fecundity. As nurses and mothers the sows may be regarded as in the first class.

The prepotency of the Berkshire is of high merit. Being one of the oldest breeds, long bred with care, its prepotency has become well established. No breed of swine has a more beautiful conformation, and where bred pure this is easily transmitted from generation to generation.

The style and finish of the Berkshire are worthy of comment. By many it is rightly regarded as the aristocrat of the swine family. The symmetrical outline, with pricked-up ear and wellturned head, give an attractive finish and style which assists materially in making this breed popular with many people.

The distribution of the Berkshire pig is very widespread. It is found in various parts of England, although more generally in the south section. It is also found to some extent in Scotland, Wales, and Ireland. On the continent of Europe the breed is not so common, although it has been more or less exported to the various European countries. In the British provinces of Canada and Australasia the Berkshire is common. In the United States no breed is more widely distributed than this, and it is generally found all over the Union, although it is perhaps most common in New York, Pennsylvania, Ohio, Indiana, Michigan, Wisconsin, Illinois, Iowa, and Missouri.

Organizations for the promotion of the Berkshire pig exist in England and the United States. The American Berkshire Swine Breeders' Association was organized in 1875 at Springfield, Illinois, since which time to January, 1906, twenty-five 
herdbooks have been published, including the registration of 90,000 pigs. The National Berkshire Record Association was organized March I, 1893, at Indianapolis, Indiana. This society up to 1905 had published seven herdbooks, including the registration of about 9000 animals. This organization is now defunct. The British Berkshire Herdbook, published by the British Berkshire Society, first appeared in I 885. Twenty volumes have thus far appeared, registering about I0,000 animals.

High prices for Berkshire pigs have been paid to a limited degree. In I $889 \mathrm{Mr}$. N. H. Gentry sold the yearling boar Model Duke 17397 at private sale to Andrew Smith of California for $\$ 750$. Mr. Gentry paid $\$ 700$ for Lord Liverpool 22 I in England, and states that he sold about $\$ 7000$ worth of his direct offspring, and also received about $\$ 500$ in cash for his services on sows sent him by breeders from all over the country. Along in the seventies the boar Robin Hood 801 was sold for $\$ 1400$ by T. S. Cooper of Pennsylvania to W. C. Norton of Pennsylvania. The three-year-old boar Columbia's Duke 33855 sold at the Reuben Gentry auction on November I6, I898, at Springfield, Illinois, for \$1 200 to Berry \& Juneman of Barclay, Illinois, the highest price ever paid at auction for a Berkshire pig up to that time. In $1903 \mathrm{Mr}$. G. C. Council of Illinois paid Mr. N. H. Gentry $\$ 1500$ for the boar Lord Premier 5000 I by Baron Lee IV 33446. This boar died in 1905, after which Mr. Council bought Premier Longfellow 68600 of Mr. Gentry for $\$ 2000$. In $1905 \mathrm{Mr}$. A. J. Lovejoy of Illinois sold the boar Masterpiece 77000 to W. S. Corsa of the same state for $\$ 2500$. In the summer of 1906 James Qurollo of Missouri sold to F.W. Morgan of Wisconsin the Berkshire boar Lord Bacon 874I 5 for $\$ 3000$. This boar was sired by Speculator $8008 \mathrm{I}$, a son of Masterpiece. On August 29, I906, at the auction sale of G. C. Council of Illinois, the boar Lord Premier's Rival 92805 sold for $\$ 3200$ to I. L. Weirick of the same state. Lord Premier $2 \mathrm{~d}$ 92708 at the Council sale was sold to Overton Hall Farm of Tennessee for $\$ 1600$, the highest price yet paid for a Berkshire under I 2 months of age. Many Berkshire pigs have changed hands at $\$ 100$ to $\$ 500$ per head. 


\section{CHAPTER LXVII}

\section{THE POLAND-CHINA}

The locality in which the Poland-China pig originated is in Butler and Warren counties in southwestern Ohio. This is an undulating region with a prevailing clay-loam soil, excepting in the river bottom. The Great Miami flows through Butler County, the valley of which is twelve miles wide and very fertile. The Little Miami River drains the greater part of Warren County. Corn, wheat, oats, grass, and clover are grown extensively in these two counties, which cover about 850 square miles. Hamilton County, Ohio, and Union and Wayne counties in Indiana were also associated with early Poland-China development. All these five counties are grouped together. The climate is fairly temperate both summer and winter, typical of the central West, east of the Mississippi.

The origin of the Poland-China pig is not clearly understood. In the past considerable discussion has taken place concerning the accuracy of statement of various persons regarding the blood used in the early days of the formation of the breed. Radical difference of opinion has existed on this point. In important essentials the history of the establishment of the breed is very well understood.

The early breeds or types of swine of the Miami Valley were known as the Warren County pig, the Russian, Byfield, Big China, Irish Grazier, and Berkshire. Each of these and perhaps others assisted in forming the Poland-China breed. Previous to I 816 two breeds were known in the Miami Valley, the Russian or Russia and the Byfield.

The Russian pig is described as generally white, with long, coarse hair, a long and coarse head, with a narrower ear than the common pigs of the region had. The breed possessed a superior length and height, the bone was large and fine, and 
the pigs stood well on their feet, and were quiet of temperament. These pigs sometimes reached large size.

The Byfield pig was of two types, both being white in color. One was very large, with long, flat sides and heavy, lopped ears; the other was more refined, with small ears pointing noseward, with broad back, deep chest, large jowl, short nose, dish face, and thin hair.

Previous to 1816 the Russian and Byfield breeds were very generally bred and their blood mingled with the common pigs of the community.

The Big China breed of pigs was introduced into the Miami Valley in $18 \mathrm{I} 6$, one boar and three sows having been brought from Philadelphia by John Wallace, a trustee of the Shakers'

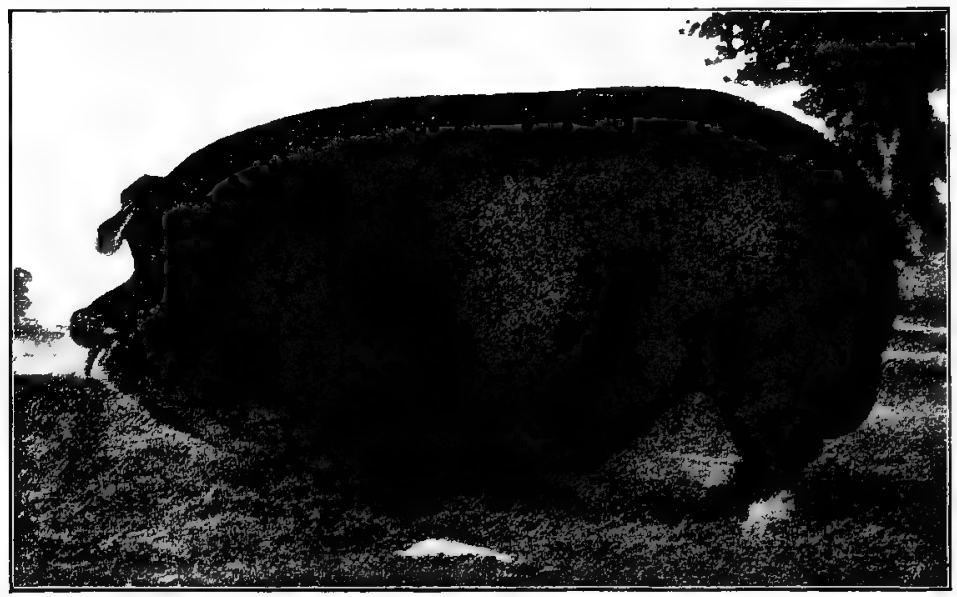

FIG. 227. Globe Perfection, first-prize Poland-China boar in the yearling class at the Ohio State Fair, I905. Bred and exhibited by Edward Klever \& Mather, Bloomingburg, Ohio. Photograph by the author

Society of Union Village, Warren County, whose members had much to do with the development of the Poland-China breed. The boar and two sows were white, while one sow had some sandy spots in which were small black spots. This was a medium-sized breed of unknown ancestry, of fine form, small head and ears, short legs and fine bone, and superior feeding qualities. Shepard thinks this may have been the Grass breed 
known in Maryland, Virginia, or Pennsylvania, or the Bedford or Parkinson hog. Used on the Russian and Byfield crosses the Big China produced very superior feeders and much improved the character of Miami Valley pigs, resulting in what became widely and favorably known as the Warren County hog. Between 1816 and 1835 the swine industry of southwestern Ohio had a great impetus, due to the beneficial effects of this cross.

The Berkshire as an element in Poland-China evolution first attracted attention in 1835 , when Munson Beach of Lebanon, Warren County, introduced some pigs of this breed from New York State. These Berkshires had erect ears, were stylish in appearance, and at once met with much favor. Others soon introduced Berkshires, and up to 1842 they were extensively used on the Miami Valley pigs. The Berkshire gave more symmetry, greater activity, more quality, and the black color to the Warren County hog.

The Irish Grazier as a factor in Poland-China history was introduced into Warren County by William Neff of Cincinnati, who imported from Ireland in the fall of 1839 . This was a white, thinly-haired hog, varying somewhat in size and type. The Neff stock had an erect ear, a long body with superior back, excellent legs, and very fine hams. For several years Irish Grazier stock was mingled with the Miami Valley mixture, but the pure-bred stock soon became extinct, not, however, until it had assisted in the improvement of the Warren County hog. Mr. Cephas Holloway, who from 1813 for very many years lived in the Shaker community at Union Village, stated that "the two breeds - the Berkshires and Irish Graziers - were extensively used in making crosses by our best breeders of swine in Warren, Butler, Hamilton, Clinton, and Montgomery counties." In I87 I Mr. Tytus, an extensive pork packer from 1836 to I 860 , said, "The Warren County breed was greatly improved by crossing with the Berkshire and Irish Grazier." From I 845, at least, up to the present time, it is claimed, no foreign blood has been used in the development of the Warren County pig, or what later became known as the Poland-China.

The adoption of the name Poland-China has an important history. The name "Poland" or "Poland and China " had been given 
to herds of Miami Valley pigs by certain breeders as early as along in the sixties. Mr. Ayers McCreary and Mr. D. M. Magie claimed that their pigs were a combination of Poland and Big China blood. Mr. A. C. Moore of Illinois, who formerly lived in Ohio, also termed his pigs Poland and Chinas. These men in particular, and some others, claimed that a Poland breed of pigs had been used, presumably introduced to America by Polish settlers. Much controversy developed over the accuracy of the claim that such a breed as Poland had ever been used in Warren County. More or less investigation followed, and no satisfactory evidence seemed to support the claim. Evidence was secured, however, to show that in one neighborhood an individual used the word Poland "to designate the progeny of a particular animal that had been obtained from Asher Asher, who was a Polander by birth and who many years ago resided for a time in Butler County, some five or six miles south of Monroe." After an investigation of this subject of origin of the breed a committee reported to the National Swine Breeders' Convention at Indianapolis, Indiana, in November, 1872 , on the origin of the PolandChina breed, and the report was accepted. In this report no recognition was given to the influence of Poland blood, but the committee recommended that "in view of the difficulties in making a change in the name of any breed, that the said name of Poland-China be recognized as the accepted name of said breed."

The improvers of the Poland-China pig in the earlier days of its development represented numerous intelligent farmers and stockmen particularly in the Miami Valley. The Shakers of Union Village in Warren County were most prominent in this work, and the herds of various breeders who later obtained distinction traced back to Shaker breeding. John Harkrader of Springboro, Warren County, who has been classed as one of the originators of the breed, developed a herd generally recognized as being of great merit, from which descended much prepotent blood. Most prominent among the promoters of the breed forty years ago were D. M. Magie of Oxford, Butler County, Ohio, who claims to have originated the Poland-China; Alexander Young and James Duffield of Somerville and John Irvin of Darrtown, all of 
Butler County, Ohio ; and A. C. Moore of Canton, Illinois. Magie and Moore extensively advertised the breed and did much to bring it before the public. The herds of L. N. Bonham, established at Oxford in I87I; of Edward and J. M. Klever at Bloomingburg, established in 1873 ; of James Hankinson, Carlisle Station, established in 1870 ; of W. C. Hankinson at Blue Ball, established in 1857 or 1858 ; of J. Douthett at Xenia, Greene County, established in 1863 ; and of Noah Coler \& Son at Liberty, established in 1868 , were prominent among the Ohio herds of influence thirty years or more ago.

Poland-China sows of note date back many years. The following were early foundation sows: Bessy Pugh 88, Lady Pugh 516, Lady Rue 518, Old Warner Sow 7 14, Queen Duffield 804, Queen of Black Bess Tribe 808, White Bess 1000, and White Face I002. In addition to these early ones of special prominence are F's Black Bess 304, foundress of the noted Black Bess family ; The Old Harkrader Sow 950 ; Graceful I 5 54, foundress of the Graceful family; Beauty $255^{8}$, dam of Tecumseh 4339 and foundress of the Tecumseh family; Cora Shellenberger 2880, dam of Success I 999, a famous sire ; Lady Duffield 3776 , dam of Tom Corwin $2 \mathrm{~d} 2037$, foundress of the Corwin family; Bess Stribbens I 168, foundress of the U. S. family; Sunshine 96I40, dam of the noted Ohio boar Ideal Sunshine 37885 ; Bessie Wilkes 80820 , dam of Chief Perfection 32199 , the head of the Perfection family; and Galena 993 I6, a famous show and brood sow of recent years. Much of the best PolandChina blood traces back to The Old Harkrader Sow 950.

Poland-China boars of note make up a long list. Especially prominent among these as great sires are Alex No. I, Butler 93, John 3d 3II, World Beater 12I3, Perfection 447, Young Perfection 631, Old Sweepstakes 253, Success 1999, Tom Corwin 2d 2037, Give or Take I585-1667, Tecumseh 4339, Ideal Black U. S. 29505, Ideal Sunshine 37885, Chief Perfection 3993 I, and Chief Perfection 2d 42559 A-45395. The last-named is regarded by many as the greatest Poland-China sire in the history of the breed. Farrowed in 1896 , he was still in active service in 1905, with a long list of distinguished progeny and their descendants. 
of more recent boars the following are quite celebrated animals: Perfect Perfection 8097I, Thickset 7122I, Perfection I Know 77521, Perfection E. L. 71635, and High Roller 84255 .

Characteristics of the Poland-China pig. The head is of medium length and breadth in good specimens, with a rather full jowl below. The face is classed as straight, the nose and space from below the eyes to nostrils being free of dishing. The cheeks tend to be rounding and full and frequently are somewhat seamed. The ears should be fine and break over at the top third into a

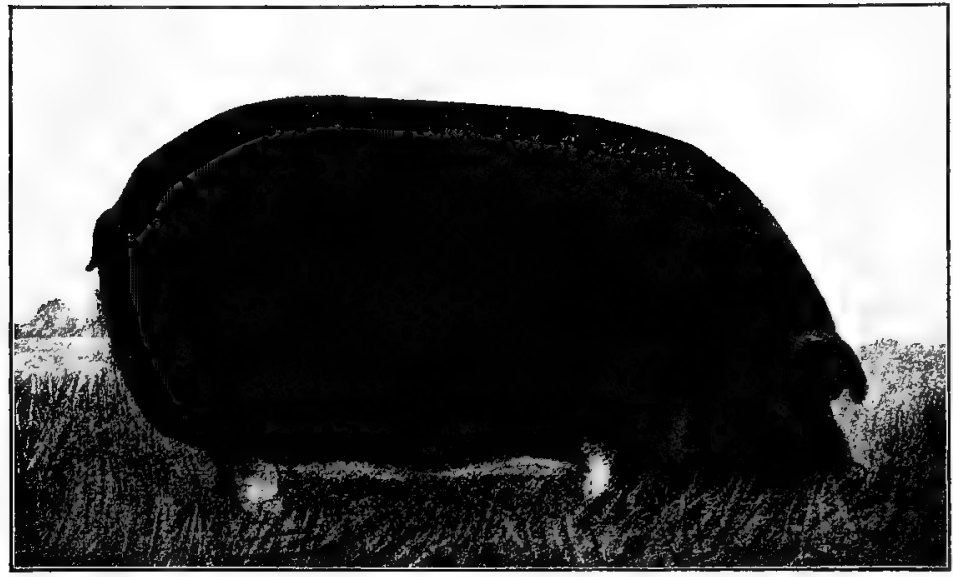

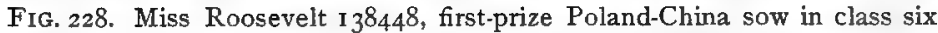
months or under at the Louisiana Purchase Exposition in 1904. Shown by Shellenberger \& Keller of Ohio. First prize in class at Ohio State Fair, 1905. Owned and exhibited by Charles E. Keller, Newark, Ohio. Photograph by the author

neat droop ; thick, heavily attached ears are objectionable. The neck of the Poland-China tends to be short and thick, the shoulders a bit prominent but well covered, the back strongly supported with a gradual yet moderate arch the entire length, the loins and ribs being thickly covered, wide, and strikingly arched in wellfattened specimens. The sides have but a moderate length, with an excellent depth. The rump is of medium length but is frequently somewhat low, so that the entire upper line of the pig from ear to tail has a more curved outline than some other breeds. The hind quarter is characterized by great thickness of flesh, the 
hams being thick for the entire length from top to bottom, with a full, deep twist between. The legs are shorter with this breed than with some others, but too refined a bone and not the strongest of pasterns are common. When heavily fed and made to carry much weight for the age, the feet are frequently poorly supported at the toes. Taking the entire form into consideration, no breed shows such compactness and great meat-producing capacity on such short legs as does the Poland-China. Its most characteristic features to the onlooker are the color, straight nose, droopy ear, very broad and curved back, superior hams, and short legs.

The color of the Poland-China pig has undergone something of an evolution. Originally the use of white pigs formed a leading feature in the development of the breed, but the advent of Berkshire blood caused a change to a darker type. Thirty years ago large white or sandy markings were common on the body. Twenty-five years ago many "spotted" pigs were registered in the Olio Poland-China Record, although at this time black pigs with white points were receiving special attention. The older breeders were attached to the lighter colors, but the solid black color with white feet, tail, and face met with show-ring favor and attained a popularity which has held up to date, although white elsewhere argues no impurity of blood. This uniform color marking is said to be largely due to the influence of the boar Tom Corwin $2 \mathrm{~d} 2037$.

The size of the Poland-China pig classes it among the middleweight breeds. Formerly very large weights were attained, but the modern demand for a more refined and smaller market type has caused the development of less scale. Pigs fed for market will easily attain 200 pounds at six months, while 250 pounds is not a rare weight with good feeders. Boars at one year old should weigh about 300 pounds, and sows 250 to 275 . At full maturity boars should easily weigh 500 pounds and sows 400 pounds in breeding form. Among some of the well-known Poland-China boars Chief I Know I I 992 weighed 650 pounds, Model Boy I 3959650 pounds, and Lookout 32451700 pounds in breeding form at maturity.

The adaptability of the Poland-China to environment is at least medium. On the lower lying lands within the corn belt 
in the Mississippi Valley it has prospered exceedingly. In the rougher, cooler sections in the northeast or on the more hilly lands it has not done so well. As a breed, however, it readily adapts itself to a range of conditions comparable with other breeds.

The early-maturing qualities of the Poland-China are of the first rank, and it has long been famous for this quality. No other breed will finish off so early in fat form as will this. In an address on the Poland-China, Mr. L. N. Bonham, a leading authority on the breed said :

To show that this breed had, in $\mathrm{I} 870$, attained unsurpassed excellence in their readiness to fatten at any age, and their rapid growth, we quote the weights of two lots of pigs fattened when eleven months old.

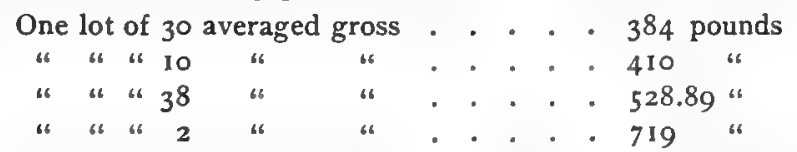

The net average of this last lot of 40 pigs was 531 pounds.

In the change in the market from a larger, older type of fat hog to a smaller, younger one weighing about 225 pounds the Poland-China has been a leading element in meeting the new demand. On the great Chicago hog market Poland-China blood to-day is a most prominent and leading feature, due largely to the ability of feeders to mature this breed early. So strongly has this habit become fixed that a tendency exists with breeding stock to mature too early and so not attain the most desirable scale and size.

The Poland-China as a grazer is well suited to blue grass and clover pastures, where it has long been a common figure in the middle West. The general custom of the western farmer is to pasture his pigs in the summer season, and this breed long ago showed its suitability for this purpose, keeping easily with little grain.

The Poland-China for feeding and fattening is the most popular and common breed at this time in America. What has already been stated shows that the early-maturing qualities have a valuable application in the feed lot or stye. As based on extensive feeding experiments, the breed will show unusually good gains at very fair cost. In 22 tests involving 96 pigs at eight experiment stations and agricultural colleges, as reported by Rommel, it 
required 357 pounds of feed for Ioo pounds of gain with the Poland-China, surpassing the Berkshire, Large Yorkshire, and Duroc-Jersey. At the Iowa Experiment Station, in a breed trial including sows and pigs before and after weaning, it cost $\$ 3.15$ per IOO pounds of gain before weaning and $\$ 2.23$ after weaning with the Poland-China, materially surpassing the Berkshire, Chester White, Duroc-Jersey, and Tamworth, being excelled by the Yorkshire only. In feeding trials at the Ontario Agricultural College the Poland-China made an average daily gain of .9 pound,

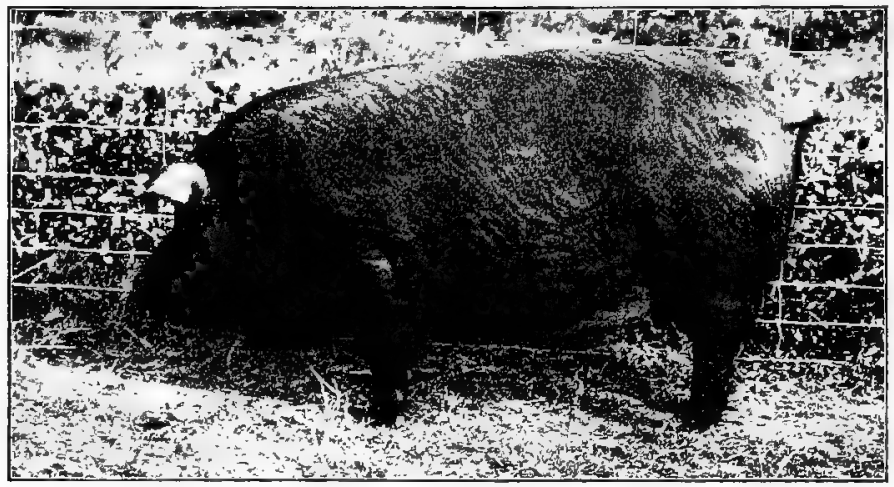

FIG. 229. Orpha 62532, an excellent Poland-China sow formerly owned by the Illinois University. Photograph from Professor William Dietrich

requiring $40 \mathrm{I} \frac{3}{4}$ pounds of grain for $\mathrm{I}$ oo pounds of gain. In the Ontario trials the economy of gain by the Poland-China was the poorest of any breed, which is rather an unusual result. The following figures, published by Henry in Feeds and Feeding, indicate the value of the Poland-China as a feeder.

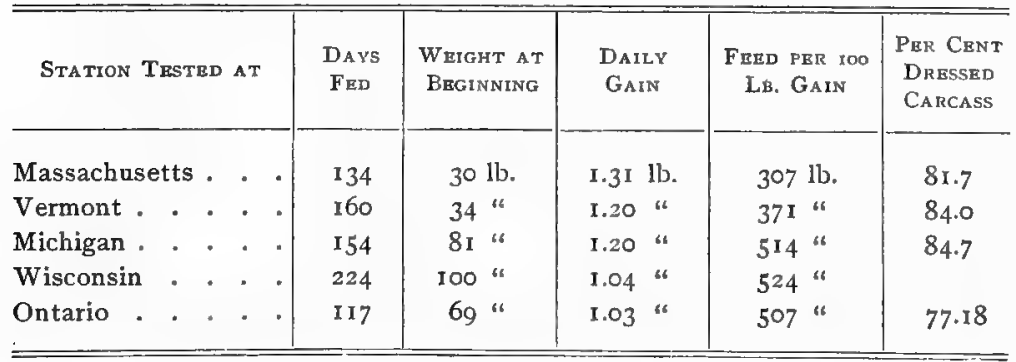


These figures are very creditable. It is noteworthy that the per cent of dressed carcass secured by the Michigan station slightly excelled all other breeds at the different stations.

The character of Poland-China meat has been subject to criticism from certain sources during the past few years. The export trade has called for a lean type of bacon, such as is only produced by a lean type of pig, or one that is fed a nitrogenous ration. The Poland-China produces rather more external fat than do most other breeds. This is readily seen in comparing the carcasses of pigs of this breed with those of other breeds. There is more lard, more mechanically separable fat, and a greater thickness of surface fat. In a carcass study of the Poland-China and Berkshire made by the writer this was clearly shown. This has also been demonstrated at the Wisconsin station, where the loin fat of the Poland-China was 1.75 inches thick, the back 2.5 inches, and the shoulder 2.75 inches, exceeding in thickness both Berkshire and Yorkshire. The American trade, however, does not object to this fat, nor is the price paid by the packer any less. So far as the grain and quality of Poland-China meat is concerned, when not too fat it compares very favorably with the Chester White and Duroc-Jersey. Fed on a nitrogenous ration, the Poland-China produces a very acceptable carcass for the Ameriean market.

The cross-bred or grade Poland-China is the most popular pig of to-day. Pure-bred sires on common sows furnish the large majority of the porkers which find their way to the great markets of this country. These pigs fatten rapidly, mature early, and the females show more vigor and greater breeding power than the pure-breds. Poland-China boars crossed with Duroc-Jersey, Berkshire, or Chester White sows produce offspring which feed better and more rapidly than the pure-breds. If Poland-China sows seem to lack in prolificacy, a cross with a boar of one of the other breeds mentioned will increase the size of litter. The writer has also obtained high-class feeding pigs by mating Large Yorkshire boars to Poland-China sows. This cross fed rapidly and carried ample flesh, yet did not become too fat, dressing out a choice carcass.

The lack of fecundity and prolificacy of the Poland-China has subjected this breed to much criticism of late years. Formerly, 
when the type was larger, it is probable that the sows may have produced somewhat larger litters than at the present time. The smaller, fat type of sow will not breed so easily or have such large litters as the larger, more rangy sort. Many breeders of recent years have seriously criticised the fecundity and reproductive power of this breed, and no doubt the great increase in the herds of Chester Whites and Duroc-Jerseys is due to dissatisfaction with the Poland-China as a breeder. There is no doubt but what the average sow of the breed produces smaller litters than any other breed well known in our feed lots. Dr. Bitting has shown this to be true in his herdbook record study, in which he shows that the average size of 1086 Poland-China litters was 7.45 pigs each, 400 Berkshires 8.22 pigs, and 600 Chester Whites 8.96 pigs. In a study made by the writer of the litters of I 300 Poland-China brood sows, farrowing 9335 pigs, the average size of litter was 7.4 pigs, essentially the same result as secured by Dr. Bitting. Mr. George M. Rommel, in I 906 , published a study of Poland-China fecundity, based on herdbook records covering the years I882-I886 and I898-1902. Over 50,000 litters were considered, including 103,458 pigs for $1882-1886$ which averaged 7.04 pigs per litter, and 299,324 pigs for $1898-1902$ which averaged 7.52 pigs per litter. These figures seem to show a slight gain rather than loss in the prolificacy of this breed.

The distribution of Poland-China swine is mainly through the Mississippi Valley states, notably Ohio, Indiana, Illinois, Iowa, Missouri, Kansas, and Nebraska. The breed is common also in other states. Among pigs of this class, in Canada, heavy fat producers are not popular and have but slight hold. The breed has been introduced abroad in a small way. In $1877 \mathrm{Mr}$. D. M. Magie sent three head to Joseph Munson, Jr, at Liverpool, England, and in 1898 twelve head were sent to Russia, six from the Iowa Agricultural College and six from H. G. McMillan of Iowa. The breed, however, has never met with much favor outside of the United States. This is due to the fact that a leaner type of pork is required elsewhere.

Organizations for the promotion of Poland-China pigs are strong and influential. The Ohio Poland-China Record Association was organized at Dayton in 1878 , although the first volume of the 
Ohio Poland China Record was published in 1877 by Carl Friegau and M. J. Lawrence. Twenty-six volumes of this record have been published as a full set. The American Poland-China Record Company was organized in January, 1878, at Cedar Rapids, Iowa, publishing the first volume of their herdbook in 1879 , since which it has published about forty volumes. The Central Poland-China Association was organized in February, I880, at Indianapolis, publishing its first volume the same year. The Northwestern Poland-China Swine Association was organized at Washington, Kansas, in $188 \mathrm{I}$. The Standard Poland-China Record Association was organized in 1887 at Marysville, Missouri, publishing the first volume of its swine record that year, having published about twenty volumes since that time. The Southwestern Poland-China Record Association was organized at Ripley, Tennessee, in I 896 . Two small herdbooks have been published, including nearly 2000 registrations. Several hundred thousand Poland-China hogs have been registered, the American, Standard, Central, and Ohio associations each doing a large business. Recently an effort has been made to amalgamate all the different Poland-China associations into one: This resulted in the consolidation in 1905 of the Ohio and Central Poland-China associations, under the name of the National Poland-China Record.

The high prices paid for Poland-China pigs surpass those paid for any other breed of swine. Some of the highest reputed prices paid occurred in the summer of 1903, when at auction sales held in Indiana a number of pigs were sold to companies of buyers on a shares basis. For example, two men owned a half interest in a boar, which they sold by shares, ten shares being issued. Each owner reserved one share and then offered the other eight at auction. Thus ten men came into ownership of a boar, eight giving security in notes or cash, usually the former. By such a plan eight shares of interest in the boar Chief Perfection 2d were sold in July, 1903, for $\$ 13,850$, eight men bidding off the shares at sums ranging from $\$$ I 500 to $\$ 2000$ each. On the basis of purchase the boar was valued at $\$ 34,625$, an absurd proposition on the face of it. Such sales for a season made a great furor, but soon became discredited and were discontinued. Among noteworthy sales of regular form is that of King Medium 
on December 23, I 896, which sold for $\$$ I 025 , the highest auctionsale price to that date. Happy Union 345 I I at the Howard \& McAllister sale in Iowa, in I 897 , sold for $\$ 4000$ to the Happy Union Stock Company. The same year Look Me Over 19417, another boar, sold for $\$ 3600$ at the Hart \& Minnis sale at Edinburg, Illinois, to the Look Me Over Breeding Association at Stanberry, Missouri. In February, 1897, at the Johnston sale in Iowa, the four-year-old boar Lookout 28901 brought $\$ 1600$. One of the most notable recent sales is that of Meddler 99999, sold in 1905 to Edward Ware for $\$ 3000$. Numerous boars of the breed have sold at prices from $\$ 500$ to $\$ 1000$ per head. Of high-priced sows, Minnie's Model I02806 sold at \$1310, Hadley's Half Sister 87840 sold at $\$ 650$, and Moorish Maid $8 \mathrm{I} 624$ and Klever's Choice 74256 , each sold at $\$ 600$, are famous examples. During the winter of $1896-1897$ such a boom in Poland-China prices occurred as to cause a protest from the wiser breeders of the country. Men attended auction sales and purchased at prices far above the intrinsic value of the animals bought. A craze for pedigree seemed to prevail and many animals sold at high 'figures that were unworthy a place in a creditable breeding herd. Better judgment soon prevailed, however, and breeders returned once more to a more reasonable basis of values. 


\section{CHAPTER LXVIII}

\section{THE CHESTER WHITE}

The original type of Chester White pig first became prominent in Chester County, Pennsylvania. Long ago there existed in both Chester and Delaware counties a large, coarse, white pig. It has even been assumed that the original stock of this sort came over with the early colonists, possibly at the time of William Penn. Captain James Jeffries of Westchester, Pennsylvania, in a voyage to England early in the last century (I820), secured a pair of white pigs, male and female, from Bedford County, England. These pigs have been referred to both as Bedfordshire and Cumberland breeds, though the former is the usually accepted title. The boar, which was retained by Captain Jeffries, had been a prize winner in England, and, used on the old white type in Pennsylvania, had a distinctly refining influence. This Jeffries boar was white, though he had bluish or blackish skin spots, and a broad back, excellent hams, short legs, and a refined head with droopy ears. Following the Jeffries importation, Harvey Atwood of Delaware County, Pennsylvania, imported some white Chinese stock from England. This was a sway-backed sort, with short legs, short face, droopy ears, and having black, blue, and sandy spots in the hair, and possessing excellent feeding and maturing qualities. The stock from Jeffries and Atwood were blended together along with the common white pigs of the region, and from this has come the first strain, if it may be so termed, of the Chester White blood.

The origin of the so-called Improved Chester White goes back to England also. This has a special application to what is known as Todd's Improved Chester White, and is based on a statement by S. H. Todd, and adopted January I6, I90I, by the American Chester White Record Association. This is the most detailed information published concerning the ancestry of the improved breed. 
In $1827 \mathrm{~W}$. K. Townsend of East Haven, Connecticut, imported from England some Norfolk Thin Rind pigs. These were black dotted with white, or white belted with black, and were blocky of type, short-legged, fine of hair, and vigorous. Kneeland Todd and his brother Isaac bought a boar of this breed, and a white sow of medium size of a breed known locally in Connecticut as the Grass breed. No doubt this sow was an Irish Grazier. In 1830 the Todd brothers removed from Connecticut to Ohio and brought these two pigs with them. These were bred together in Ohio with considerable success, producing pigs

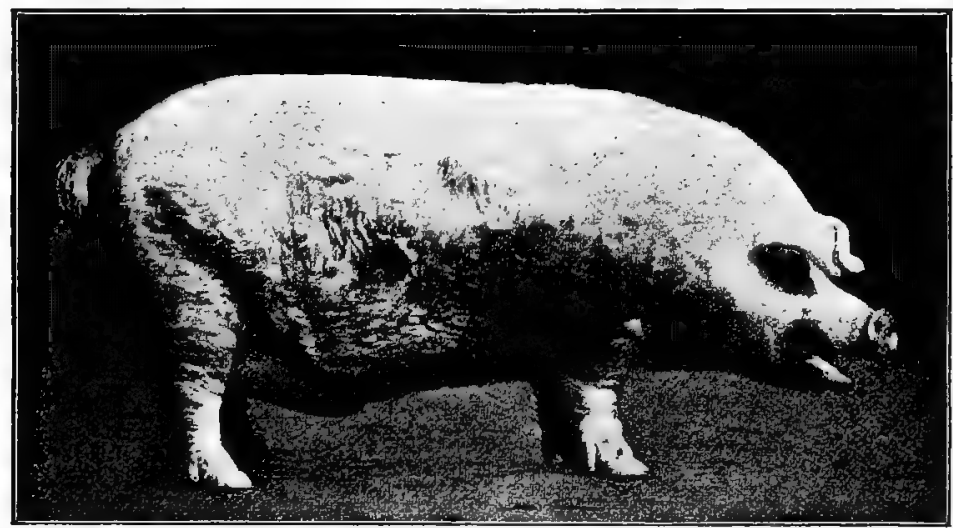

FIG. 230. Jackson Chief 4759, grand-champion Chester White boar at the Louisiana Purchase Exposition, 1904. Bred and exhibited by L. L. Frost of Missouri. Photograph from the National Stockman and Farmer

that would dress 365 pounds at nine months of age. In 1833 Joseph Haskins removed from Massachusetts to Wakeman, northern Ohio, and took with him a pair of pigs, a boar of the Byfield breed, and a sow pig similar to the one brought from Connecticut by the Todds. The Todd and Haskins pigs were bred back and forth until I848. That year Isaac Todd bought from Joel Meade of Norwalk, Ohio, a large white boar which the seller called the Large Grass breed. This was used in his herd on account of its good-feeding and early-maturing quality. In I862 Isaac Todd secured a so-called Normandy boar of unknown breeding, white in color, said to be of French ancestry. 
This nicked well with his stock, and he produced superior feeders and handsome pigs, with which he attained show-ring success. At the second state fair held in Ohio Isaac Todd with this stock vanquished all competitors in the show ring. In 1865 Todd first introduced Chester White blood in his herd with satisfactory results. At this period his son, Seth $H$. Todd, took up the work. More Chester White blood was used, and in I 867 the son bought a pair of pure-bred Chester White pigs of George B. Hickman. These were used in the herd and the boar proved a most successful sire. From this period on, for about forty years, Mr. S. H.

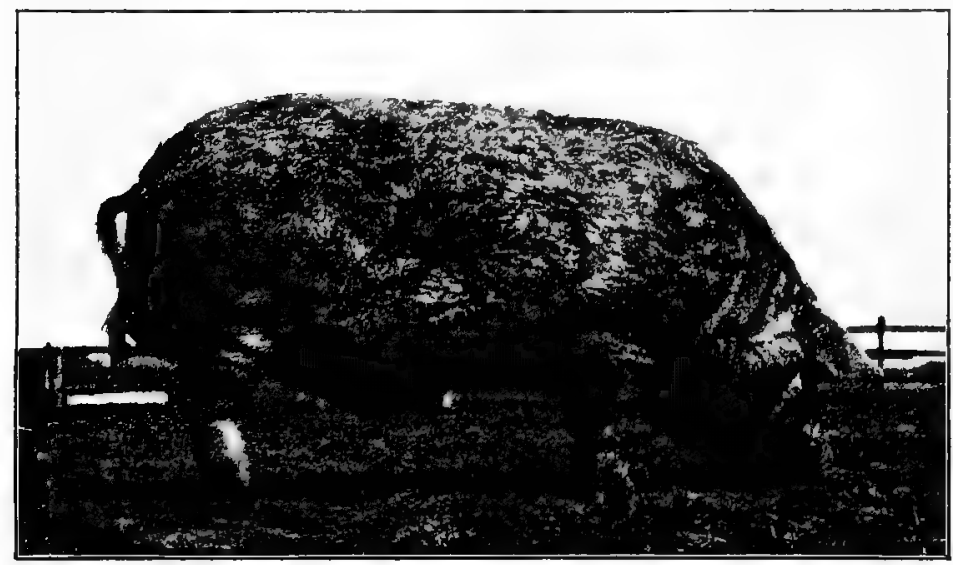

FIG. 23I. Purdue Beeler 4755, a Chester White boar owned for some time by Purdue University, and an excellent show boar and sire. Photograph by the author

Todd bred and improved the Chester White and played a leading part in its development. The claim has been made that PolandChina blood has been used in the improvement of this breed, but this Mr. Todd says "is entirely false" in its application to his own breeding. He rather attributes it to a reversion to the black color found in the Thin Rind or Bedford hog. Besides S. H. Todd, Thomas Wood of Chester County, Pennsylvania, has been an important improver of the breed.

The origin of the Ohio Improved Chester White is credited to Mr. L. B. Silver. This person lived at Salem, Ohio, and became interested in improved breeds. In 1865 he made a trip through 
the eastern states to study the pure breeds of swine. The Chester White impressed him most, so that he purchased a specimen and began breeding. Mr. Silver endeavored to establish a uniform type of large size, with superior quality, such as most nearly approached his ideal. From his breeding is descended what is known as the Ohio Improved Chester White (O. I. C.) strain, and all animals known now as O. I. C. W. must trace back to his herd to be eligible for registration in the herdbook promoting this family.

Characteristics of the Chester White As its name implies, this breed is pure white in color of hair, although small black or bluish-black spots occur on the skin to a more or less extent. Such spots do not disqualify, but are not desirable in fixing breed character. The head has a straight face, the nose often tends to be long and narrow, and the ears are drooped forward, breaking over one third to one half the length. Thick, heavy ears are not uncommon. The body carries a back line of good width with a tendency to be somewhat arched, though not undesirably so. The depth of body is usually excellent and the shoulders show smooth and strong, but the hams may be improved in the lower thigh. The legs may be short, but they are rarely supported on the toes with strength, the Chester White being characteristically weak of pastern, the toes being too much spread and bent and the dewclaws too low down. This weakness is due no doubt to the early-maturing, rapid-fattening quality of the breed, the weight being too great for the feet to properly sustain. This calls for more strong bone in the make-up of the Chester White. The quality of hair is about medium, with a tendency to coarseness, while curly hair is not uncommon. The modern specimen of the breed shows a finer hair than did the older type. A tendency on the part of this as well as other white breeds is to sun scald and scurfiness of skin, especially in the West, when exposed to a hot sun and dry weather. In temperament the Chester White is excellent, being quiet and well suited to feeding.

The size of the Chester White places this breed in a high rank. Formerly it was the largest breed in the country, and specimens were exhibited weighing over Iooo pounds. The tendency of 
modern breeding has been toward refinement and smaller size, so that the Chester White does not naturally develop excessive size. Mature boars in fair flesh should weigh about 600 pounds and sows 450 , while barrows at six to eight months should feed to weigh 350 pounds.

The Chester White as a feeder ranks high. The barrow of this breed will compare favorably with any breed in returning results for grain fed. The writer has supervised the feeding of many Chester Whites at the Indiana Experiment Station, when very rapid and profitable fattening resulted, average gains of one pound

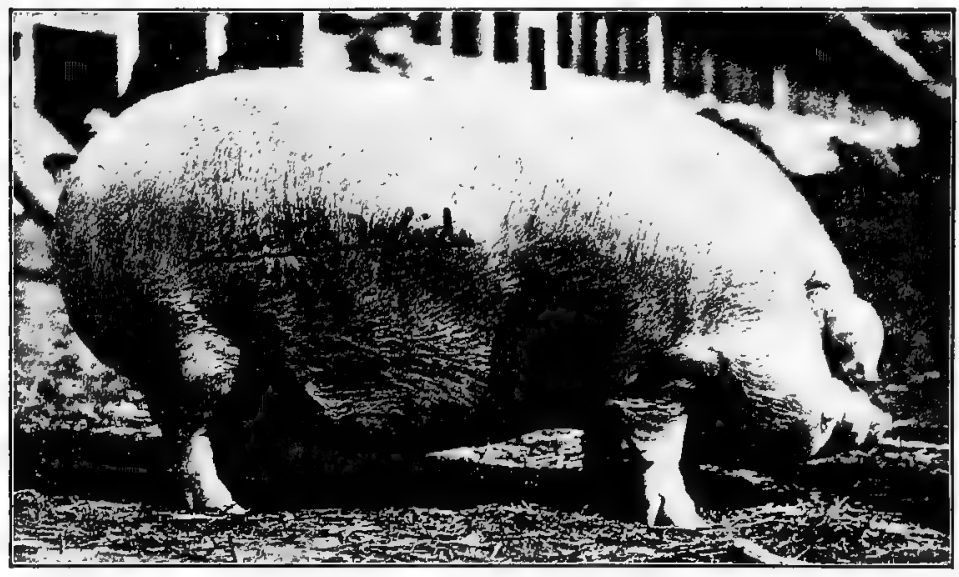

FIG. 232. A Chester White sow owned by W. A. Huber of Iowa.

Photograph from the National Stockman and Farmer

live weight from less than three pounds of grain having been made daily in feeding experiments of several months' duration. In breed tests with pure-breds at various stations the Chester White has made a good record. At the Vermont station in a I 72 days' test Chester Whites made an average daily gain of I.36 pounds, dressing out 84.5 per cent carcass. At the Maine station a daily average of I.I 5 pounds was secured for I4O days, and of I.05 pounds for I 7 days at the Ontario Agricultural College, dressing out 77. Io per cent carcass. In other experiments at the Ontario Agricultural College Professor Day reports that it required 3.37 pounds food for a pound of gain with Chester 
Whites, compared with 3.I 8 for the Berkshire, that breed doing best in this respect.

The breeding qualities of the Chester White rank high, and it may be regarded as one of the most prolific of the heavier-fleshed type of pigs. The general evidence shows the Chester White sow to produce larger than average litters. In I 897 Dr. A. W. Bitting made a careful study of the size of litters of the Chester White, Berkshire, and Poland-China, as based on herdbook records. A total of 2083 litters were studied, showing 8.96 pigs per litter for the Chester White, 8.22 for the Berkshire, and 7.45 for the

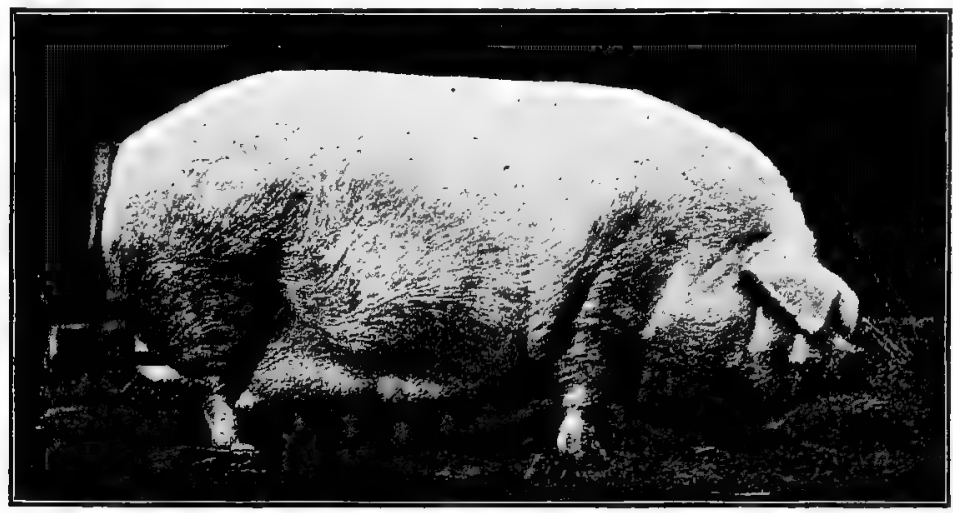

FIG. 233. Barget C. 12954, first-prize Chester White sow at the Ohio State Fair, 1905, and a winner at various other fairs. Owned and exhibited by W. J. Cherry, Xenia, Ohio. Photograph by the author

Poland-China. Of these the Chester White raised to weaning 7.62, the Berkshire 7.17, and the Poland-China 6.14 of a total of I600 litters raised. This is a distinct showing in behalf of the Chester White. The sows as a rule have excellent udders and make very satisfactory mothers, equally good with any other breed of this class.

The cross-bred or grade Chester White makes a superior feeder, and sows from pure-bred sires are prolific above the average. The Chester White and Poland-China. cross to make better butchers' hogs than either of the pure-breds, feeding faster and having more scale than the Poland-China. High-grade Chester Whites are very prolific, and the fat pigs are appreciated by 
buyers. The pure-bred used on the smaller class gives more scale to the progeny. To have the most satisfactory specimens the Chester White should be crossed on pigs possessing superior bone and feet. A writer in the National Stockman and Farmer, in 1898 , reports on a three-quarters bred Chester White sow, five years old, that raised 78 pigs in this time, or nearly 20 pigs a year for four years.

The quality of Chester White pork may be regarded as good. The breed, however, carries much fat and will not produce a high-class bacon, as based on the English market; neither under ordinary conditions will the meat be quite the equal in percentage of fat to lean, as will the Berkshire.

The Chester White as a grazing pig will do well on pasture, making a good showing on alfalfa, the clovers, or rape, comparing favorably with the other breeds.

The distribution of the Chester White is very widespread, the breed being common in the eastern United States and in Ohio, Irdiana, Michigan, Illinois, Iowa, and some other states. During the past ten years the breed has grown much in favor, as is evidenced by the large increase in Chester Whites at the fairs. The breed also has something of a foothold in Canada, especially in Ontario. It seems well adapted to the corn-belt states, while it has long been a favorite in Pennsylvania and the East, where it is kept under more restricted conditions of confinement. They have also been distributed some in the South, where they are reported as well adapted to the environment, notably in West Virginia, South Carolina, and Mississippi.

Organizations to promote Chester Whites. There are four associations for registering and promoting Chester White interests. These are as follows: The American Chester White Record is an outgrowth from the Chester White Record Association, organized in 1885 "for the purpose of making and maintaining a registry of the Todd Improved Chester White Swine," with headquarters at Columbus, Ohio. Four volumes of Todd's Improved Chester White Swine Record were published, the first appearing in 1885 . In 1894 the articles of incorporation were changed to read American Chester White Record Association, and Volume $\mathrm{V}$ was designated American Chester White Record. 
Up to I905 ten records had been published, registering about Io,000 animals. The Ohio Improved Chester White Swine Breeders' Association was organized in 1897 at Cleveland, Ohio. Six records have thus far been published. The Standard Chester White Record Association was organized in 1894 at Indianapolis, Indiana. Volume I appeared in 1895, and thus far ten volumes have been published up to I906. The National Chester White Record Association was organized years ago and long led an inactive existence. The headquarters for this organization have been in Pennsylvania.

The prices paid for Chester Whites have not been affected by inflation conditions, as has occurred with other breeds. While the Chester White is an old breed and is well known over a large portion of the country, it has played a modest part during the more recent years when boom prices might have been anticipated. Breeders have mainly depended upon private sales, and very high-class animals have been purchasable at from $\$ 50$ to $\$$ roo per head. In $1893 \mathrm{Mr}$. S. H. Todd sold the boar pig Banker 2293, that was first in class at the World's Columbian Exposition at Chicago, for $\$ 50$. This, according to $\mathrm{Mr}$. Todd, is the highest price paid for a Chester White up to that time, and so far as the writer can learn it has not been equaled since. 


\section{CHAPTER LXIX}

\section{THE DUROC-JERSEY}

The occurrence of red or sandy-colored pigs in America dates back many years. When pigs of this color were first imported is not recorded. A number of so-called breeds of red pigs were kept early in the last century, and from these it has been assumed the present-day red American pig, the Duroc-Jersey, is descended.

The Guinea breed of pigs is frequently referred to in agricultural writings of a half century or more ago. In that section of western Africa known as Guinea, slave-trading ships secured cargoes for American ports. Here existed a red or sandy breed of swine, which no doubt found its way to our shores. Youatt states that these pigs were "large in size, square in form, of a reddish color, the body covered with short, bristly hair, and smoother and more shiny than almost any other variety of the porcine race." W. $\mathrm{H}$. Montgomery in 1852 wrote that the Red Guinea hog was imported into his county in Iowa in 1849 from Steuben County, New York. A correspondent of the American Farmer states that the African or Guinea breed was brought to America as early as I804 or possibly earlier.

The Portuguese breed of pigs was imported from Portugal by Daniel Webster, about I 852, for his farm in Massachusetts. They arrived at New York about the time of Webster's death, and his heirs disposed of them to S. W. Jewett of Middlebury, Vermont, and A. E. Beach of New York. They were dark red in color, and in form resembled the Chinese pig. Red pigs from the Webster importation and ancestry were distributed over several states east and south.

Spanish red pigs were imported by Henry Clay in 1837 , four in number, and taken to his farm, Ashland, at Lexington, Kentucky, where they bred and successfully increased. This stock met with favor and was considerably distributed south, notably 
in Kentucky and Virginia. These had erect ears and were of a red color.

The Berkshire as a source of red swine early occupied a place of prominence. Half a century ago Berkshires were more or less red in color, and the breed had been imported for many years even then. Eminent authorities think that much of the DurocJersey pig is descended from the sandy-colored Berkshire.

The Jersey Red breed of pigs was for many years a favorite one in New Jersey and the East. They were very large and coarse, weights of 500 to 600 pounds being common, with specimens exceeding 1000 pounds. In reporting on this breed to the National Swine Breeders' Convention in I872, Colonel F. D. Curtis stated that D. M. Brown of Windsor, New Jersey, had known of them back to nearly 1832. In neighborhoods they were bred very uniformly, the color usually being a dark red, although in some sections they were light, sandy, and often "patched with white."

The characteristics of the Jersey Red as agreed upon by the National Swine Breeders' Convention in 1872 were as follows:

A good specimen of a Jersey Red should be red in color, with a snout of moderate length, large lop ears, small head in proportion to size and length of body. They should be long in the body, standing high and rangy on their legs ; bone coarse, hairy tail and brush, and hair coarse, inclining to bristles on the back. They are valuable on-account of their size and strong constitution and capacity for growth. They are not subject to mange.

About 1870 Joseph B. Lyman, then agricultural editor of the New York Tribune, it is said first named the breed Jersey Reds. Previous to this period they had been commonly called Red hogs and Durocs. In recent years this breed as described has become insignificant and has relapsed into obscurity.

The Duroc breed of red pigs is said to have been established by Isaac Frink of Milton, Saratoga County, New York. In I823 he obtained a red boar pig from a litter of ten, the product of a pair of red pigs purchased in I 822 by Harry Kelsey of Florida, New York, from persons either at Oyster Bay, Queens County, New York, or imported from England, concerning which point there is doubt. Mr. Kelsey owned the famous stallion Duroc, and the pigs in question were known simply as red pigs. 
Mr. Frink called his boar and descendants Durocs, in honor of the horse. This boar was crossed on common sows, and many of the offspring resembled him, being long and deep of body, lop-eared, heavy of shoulder and ham, quiet of disposition, and making rapid growth. The Durocs were finer in bone and carcass than the Jersey Reds. In I 830 William Ensign of Stillwater, Saratoga County, secured a pair of red pigs from Connecticut, where they were known as Red Berkshires, getting more the next year, and breeding and distributing them considerably. The Frink and Ensign families of Durocs became very popular.

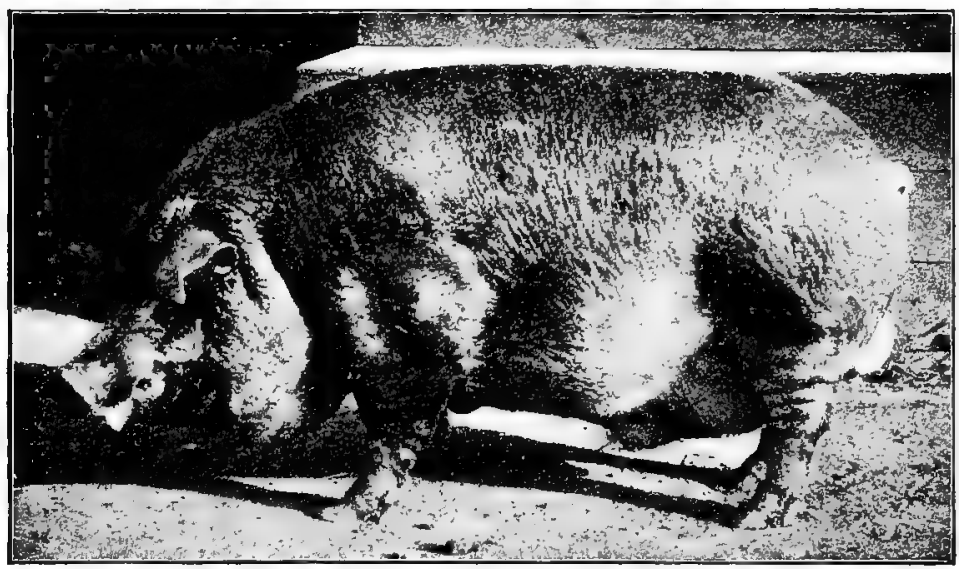

FIG. 234. Ohio Chief 8727 , first-prize aged Duroc Jersey boar at the Louisiana Purchase Exposition, 1904. Bred and exhibited by S. E. Morton \& Co., Camden, Ohio. Photograph from Professor William Dietrich

The origin of the Duroc-Jersey pig is the result of the amalgamation of the blood of these red breeds or families above referred to. Colonel F. D. Curtis of Saratoga County, New York, long a breeder and familiar with existing conditions, did much to promote improvement of this breed during the stage of amalgamation. Mr. William $\mathrm{H}$. Holmes also was a leading breeder and improver in Colonel Curtis's time. The Durocs of New York, the Red Berkshires of Connecticut, and the Red Rocks of Vermont, as they were called, were of the same general type. Some system in breeding was attempted, and in 1877 the breeders of Washington and Saratoga counties in New York met and decided 
what the characteristics of the best type of this red pig should be. This standard, which was published in the agricultural press, was the first thing of the kind printed regarding red pigs, and was essentially the one adopted by the National Swine Breeders' Convention in 1872 . In 1885 Colonel Curtis wrote that the breeders of the so-called Red Berkshire and Red Rocks cordially united with the New York men, and the Duroc-Jersey standard was universally accepted by the best breeders of all the red hogs of America.

The improvement of the Duroc-Jersey began with the union of the breeders' interests. It resulted in a pig of some less scale than the Jersey Red, lacking its coarseness, having a better quality of flesh, feeding easier, and maturing more reaclily at a younger age. Instead of developing a big hog, one of medium scale was regarded as preferable. The standard of the old type of I3erkshire closely resembled the Duroc-Jersey of twenty years ago. Since then the Berkshire has perhaps become more refined than before, and the Duroc-Jersey has kept pace with Berkshire evolution.

Men prominent in improving and advertising the Duroc-Jersey are of rather recent years. There were numerous excellent breeders in New York, Connecticut, and Vermont, who sought to improve the breed. Mr. William M. Holmes of Greenwich, Washington County, New York, was long an industrious student of the breed, but Colonel F. D. Curtis of Charlton, Saratoga County, was not only a prominent breeder of Duroc-Jerseys but he was also a natural organizer and leader and actively promoted the breed for many years. Besides Holmes and Curtis, S. E. Morton of Ohio, George W. Stoner, Thomas Bennett, and J. M. Stonebraker of Illinois, William Roberts of Iowa, and C. H. Searle of Nebraska did much for the breed from about the year I 880 .

Duroc-Jersey pigs of distinction first became prominent with the appearance of the breed at the important exhibitions, notably in the early eighties. Among the prominent show and breeding boars between 1880 and 1885 were Major 17, Climax 21 , Phil D I67, Richard III I 8 I, John Jordan 297, and King Stoner I65 I. Of the sows of that period the following may be mentioned: Holmes' Ruby 70, Lulu 76, Bess III 82, Mona II 90, Mojeska 96, Bessie Ioo, Valleria 200, Lou Edna 226, and Red Stumpy 
926. In more recent years Hoosier King 3205, Col. M. 3285 , Storm King 3377, Walt's Col. 5795, Ohio Chief 8727, and Top Notcher 8803 , have attained distinction as boars of great merit.

Characteristics of the Duroc-Jersey pig. The head is usually regarded as small in proportion to the size, the face is either straight or very slightly dished, and the nose of medium length, being neither short nor long. The ears are of medium size and droop forward, the top third more or less breaking over. The back inclines to considerable width in contrast to length, showing a wide spring of rib with a slight tendency to arch, though

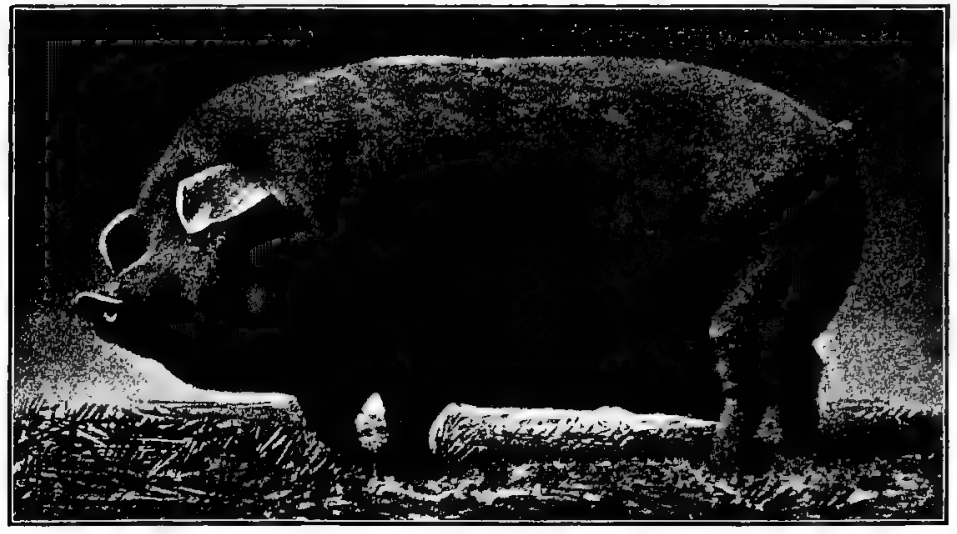

F1G. 235. Cedar Vale Queen 7th, the champion Duroc-Jersey sow at the Indiana State Fair, 1905. Bred and exhibited by Watt \& Foust, Cedarville, Ohio. Photograph by the author

not to so great a degree as with the Poland-China. The body often shows unusual depth. The shoulders and hams are rather heavy and thick fleshed, the latter especially so, and low in the twist. The legs in the modern Duroc-Jersey are short and the bone good, yet a tendency to too much refinement is manifest. Weak pasterns are becoming too common with this breed, notwithstanding the inheritance of strong legs from the old Jersey Red. The body as a whole, back of the ears, to-day resembles the Poland-China more than the Berkshire. The color of the Duroc-Jersey is red, although the shades vary from light to dark. Young pigs are usually a bright red, and with age the 
tint changes. Some pigs are a cherry red, a popular color, while others are yellowish red or a shade of chestnut. A very dark red or shady brown, very light or pale red, and black spots on the body skin, are objected to by breeders. Black spots on the belly and legs are not desired but are admissible.

The size of the Duroc-Jersey is somewhat variable, due no doubt to the commingling of the blood of the large Jersey Red and the smaller, more refined red breeds. For animals in fair show condition the American Duroc-Jersey Swine Breeders' Association offers the following weights in its published standard: Boars two years old and over should weigh 600 pounds; sows of same age and condition, 500 pounds; boars 12 months, 350 pounds; sows, 300 pounds; boars and sows six months of age, I 50 pounds. Many large animals of the breed are found to-day. Mr. S. E. Morton, owner of the boar Ohio Chief 8727 , states that, properly fitted, he could easily be made to weigh over 1000 pounds. No doubt the breed averages somewhat smaller than it did a quarter of a century ago, due in part to the general market demand for a smaller class of hogs.

The environment best suited to the Duroc-Jersey is on the farms of the middle West, within the corn belt, where clover pasture is also a feature of swine husbandry. Here the breed is found to-day in its most perfect form. In the warm climate of the South, however, the Duroc-Jersey has met with great favor, not seeming to be unfavorably affected by the dry, warm summers, especially as regards skin troubles. In Canada the breed has but a small foothold, due to the demand for the bacon type of pig.

The maturing qualities of the Duroc-Jersey are distinctly high class. Pigs easily mature at six months of age to dress out 175 pounds. At the Iowa Agricultural Experiment Station nineteen pigs at an average of 214 days weighed an average of 197 pounds each. These are not unusual records and are such as may be secured by any competent feeder with fair representatives of the breed. From the breeders' standpoint the DurocJersey presents no essential advantage over other popular breeds in regard to the sows or boars reaching early breeding form.

The Duroc-Jersey as a feeder may naturally be classed with the Poland-China, Berkshire, and Chester White. In the 
Mississippi Valley states it has been well received by the feeders, especially in recent years; yet when it comes to cost of production in gain, published breed tests of experiment stations make the Duroc-Jersey a comparatively costly feeder. Rommel quotes the results of eleven different feeding tests at various experiment stations, in which it is shown that it required 4 I 8 pounds of feed for IOO pounds of gain live weight by the DurocJersey, 49 more than were required by the Berkshire, 6 I more than the Poland-China, and 7 I more than the Chester White. At the Iowa Experiment Station, however, the cost for Ioo

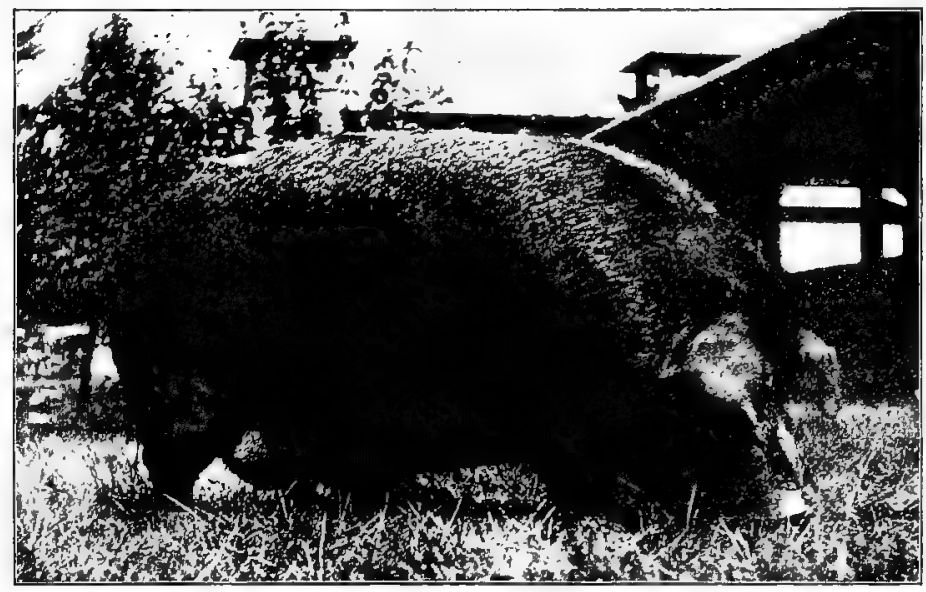

FIG. 236. Col. Gladness I3577, first-prize Duroc-Jersey boar at Ohio State Fair, 1906. The owner refused $\$ 500$ for this pig at the time of the show. Owned and exhibited by A. E. Foster, New Salem, Ohio. Photograph by the author

pounds of gain with Duroc-Jerseys was $\$ 2.27$, compared with $\$ 2.33$ for the Berkshire and $\$ 2.46$ for the Chester White. In several years of testing at the Ontario Agricultural College the Duroc-Jersey more than held its own with the Poland-China.

The Duroc-Jersey as a grazer seems suited to such pasture as other breeds will do well on, and for this reason is a favorite to-day with many farmers. On both blue grass and clover it thrives well.

The slaughter test of Duroc-Jersey pigs is essentially typical of that of the corn-fed hog of the Mississippi Valley. In feeding 
trials of breeds of swine at the Iowa station, where the carcasses of each breed were carefully studied, the Duroc-Jersey yielded less lard than any other breed except the Chester White. There was a total of 20.35 pounds lard and more total guts than any other breed excepting Berkshire, though the difference was not great. In killing, the Yorkshires led with 79. I 8 per cent dressed meat and the Duroc-Jerseys fifth with 77.05 per cent.

The quality of Duroc-Jersey meat may at least be regarded as good, compared with Poland-China or Chester White, when the same kind of food is used. Duroc-Jersey pigs are not discriminated against in the market, although the class of pork produced by them in the corn belt is not the equal of that resulting from less corn feeding. For many years the red hogs of Saratoga County, New York, commanded a premium in the Albany market, then a great pork-packing center. This was due to the superior excellence of Duroc meat, produced from rations of potatoes, oats, and peas and clover pasture.

The cross-bred or grade Duroc-Jersey pig is finding its way extensively into the market. Among farmers pigs from common sows sired by Duroc-Jersey boars feed well. They not only feed well, but if mated with Poland-China blood, produce increased size of litters as a result. The cross on Poland-China or Berkshire stock will be harmonious, if such a cross is desired. It is better, however, to use the Berkshire male on the DurocJersey female, to secure the highest-class meat.

The breeding characteristics of the Duroc-Jersey are considered distinctly superior. Twenty years ago Colonel Curtis wrote that young sows had from seven to ten pigs and old sows from ten to eighteen, while twelve and fourteen strong pigs at one litter were not at all uncommon. Rommel, in a report on Duroc-Jersey fecundity, published in I906, based on herdbook figures, shows that $2 \mathrm{I}, 652$ litters, comprising 200,574 pigs, averaged 9.26 pigs per litter. This is a most excellent record and reflects great credit on the prolificacy of this breed.

The distribution of the Duroc-Jersey is now very widespread. It has long been a popular breed in New York, New Jersey, Virginia, and certain sections of the South. In recent years it has grown much in favor in the Mississippi Valley, although bred 
here for a long time in a limited way. At present the breed is in much favor in Ohio, Indiana, Illinois, Iowa, Nebraska, and Michigan. Each year an increase of interest is shown in the auction sales of the pure-breds and in the exhibits made at the fairs.

Organizations to promote Duroc-Jersey pigs date back to I 883 , when the American Duroc-Jersey Swine Breeders' Association was established, the first annual meeting being held at Chicago, November 15-I6, I 883, at which time Colonel F. D. Curtis of New York was elected president and C. H. Holmes of Iowa secretary. In 1885 this association published its first herd

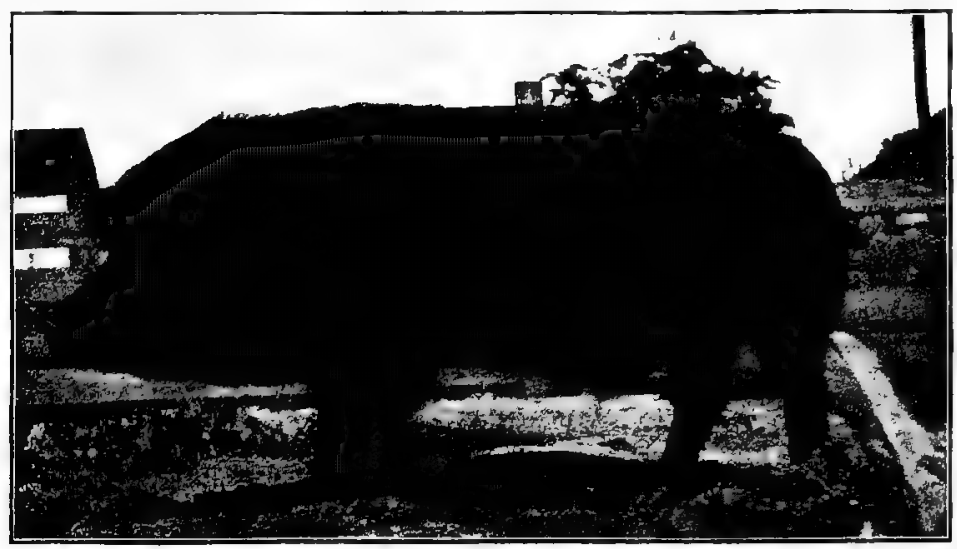

FIG. 237. A yearling Duroc-Jersey boar owned by E. S. Kelly of Ohio. Photograph by the author

record, since which time to 1904 fifteen rolumes had been issued, including the registration of about 6500 boars and I 5,000 sows. On November 20, I891, the National Duroc-Jersey Record Association was organized at Geneseo, Illinois, with J. M. Stonebraker of Illinois as president and G. W. Philippo of Illinois as secretary-treasurer. This association published Volume I of its herd record in I893, since which time a total of 19 volumes have been issued to 1906 , including the registration of many thousands of boars and sows. A capital $A$ after the registration number of a Duroc-Jersey pig indicates its registration in the American Association, and an $N$ in the National Association. Each of these organizations has been very prosperous. 


\section{CHAPTER LXX}

\section{THE CHESHIRE}

The native home of the Cheshire pig is Jefferson County, New York, in the north-central part of the state, on the eastern shore of Lake Ontario. The climate is quite cold and rough in winter, and the conditions as a whole are not ideal for swine raising.

The origin of the Cheshire dates back to about 1855. The cause for the use of the name of the breed is unknown. About I 855 Messrs. Hungerford and Brodie of Jefferson County imported from England a Yorkshire boar of the large or middle class. This was used upon sows in the county, and soon after White Suffolk blood was mingled with the descendants of this boar. Early in the sixties A. C. Clark of Belleville and S. P. Huffslater of Watertown began to show pigs of this class at the fairs. Later, in I $870, \mathrm{Mr}$. Clark won the Packer's Prize of $\$ 500$ for the best pen of pigs exhibited at a fair at St. Louis, Missouri. The name Cheshire, or Jefferson County, was officially adopted in 1872 by the Swine Breeders' Convention at Indianapolis, Indiana. The evidence indicates that the breed is the result of constant crossing and breeding of Large Yorkshires and White Suffolks to the white pigs in Jefferson County. In 1876 Colonel F. D. Curtis, a prominent New York live-stock authority, wrote Mr. F. D. Coburn that he knew "of but one breeder of Lhese pigs in Jefferson County." Mr. J. H. Sanders bred these pigs pure for about seven years in Iowa, and wrote Mr. Coburn as follows :

I produced all the different types of the Yorkshire from the Large York down to the Lancashire Short-face.... The type which I finally succeeded in fixing upon the Cheshires, as bred by me, was almost identical in size, form, and quality with the most approved Berkshires. Indeed, so marked was this resemblance in everything but color that they were often facetiously called "White Berkshires." 
About I $873 \mathrm{E}$. W. Davis began to improve this pig and added much to the permanence of type.

Characteristics of the Cheshire. This breed closely resembles in form the Yorkshire of the middle class. The face while dished is not extremely so, and the ears, which are small and fine stand erect or point slightly forward. The back is wide and very slightly arched, the Cheshire scale of points requiring it to be "long, broad, and straight nearly to root of tail." The body as a whole has considerable length but often lacks depth. The

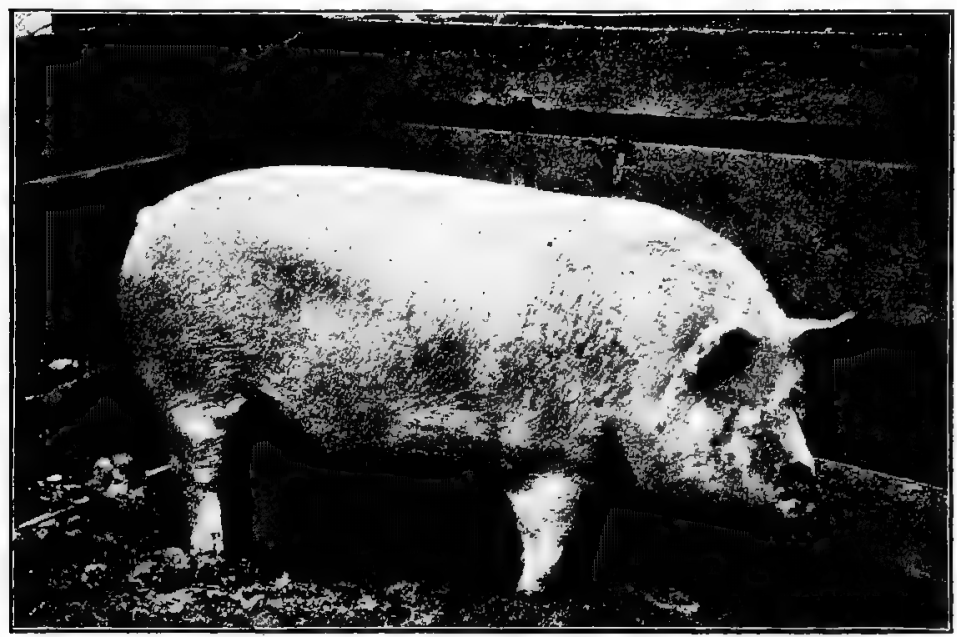

FIG. 238. A Cheshire barrow, one of a pen exhibited by Cornell University at the International Live Stock Exposition, 1905. Weight at eight and one-half months 353 pounds. Bred by E. S. Hill, Freeville, New York. Photograph from Mr. Hill

shoulders and hams are regarded as of the thick-fleshed, welldeveloped sort. The legs show considerable refinement of bone, frequently to an undesirable extent. The feet and pasterns are only moderately strong. The color of the hair and skin is white. Black spots may occur on the skin of pure-breds, and while objectionable do not disqualify. Both skin and hair are regarded as of superior quality by those who are familiar with the breed.

The size of the Cheshire pig is about medium, though it has been classed by Professor Shaw as the smallest of the middle-sized 
breeds. This is hardly in accordance with the standards of the Cheshire Swine Association. The standard of excellence in Volume I of the herdbook states that when grown and well fattened the hogs should show a dressed weight of from 400 to 600 pounds. That represents a heavy-weight hog. There are said to be numerous instances on record of pigs dressing over 400 pounds when nine months old. The Cheshire barrows shown at the International Live Stock Exposition in 1905 were a heavy-weight lot and gave no impression of being of a small breed. One of these at eight and one-half months weighed 353 pounds. The Cheshire is said to weigh heavy for its size. Mr. A. H. Bates, once a prominent breeder of swine, has the following to say in a letter which is quoted from the Cheshire Herdbook:

I find that buyers are not able to guess the weights of Cheshires. One lot of thirteen culls I offered at $325 \mathrm{lbs}$. each. The buyers thought they would not weigh over $300 \mathrm{lbs}$. They averaged 390 each. Another lot of twenty culls I offered at $150 \mathrm{lbs}$. average. They weighed $185_{2}^{1} \mathrm{lbs}$. on the average. I have found it will not do to sell Cheshires by guess.

The quality of Cheshire meat ranks high. Sanders, writing of those he bred, stated that " their meat was most excellent, tender, and juicy." Others have rendered similar testimony. The flesh is fine grained, and, with hogs not fed too much corn, is of a desirable bacon type.

Cross-bred or grade Cheshires are not common, but are looked upon with favor in some localities. Where superior and prepotent boars are kept they may be used on common sows to material advantage, securing a high class of pork.

The Cheshire as a feeder is not well known. But few have been tried in the great swine-producing sections of the country. Only experiment stations in the eastern states have fed Cheshires experimentally. The Maine station reports in 1890 a comparison of breeds of swine, Cheshires gaining daily 1.23 pounds, Yorkshires 1.14, Chester Whites 1.08, Poland-Chinas I.OI, and Berkshires 1.Oo. Two pigs of each breed were used, one of each sex, and they were fed from five to eight weeks. The Berkshires ate the least food to make a pound of gain, and the Cheshires the most. Experiments in $189 \mathrm{r}$ at the Maine 
station also showed more food required for the growth of the Cheshire than for that of other breeds.

The fecundity of the Cheshire is above medium, the sows breeding readily and producing fairly large litters, especially as commonly fed in the eastern states.

The Cheshire as a grazer is not well known, for it has been in the main a stye-fed breed. It should, however, do well on good pastures. Shaw credits the breed with fair grazing qualities. The fact that the Cheshire has never secured much of a hold in the great swine-producing sections of our country, although introduced there, would argue that it had not satisfactorily adapted itself to western conditions.

The Cheshire Swine Breeders' Association, organized in I 884 in New York State, promotes the purity and welfare of this breed. The association published its first volume of a herd record in I 889, since which three others have been issued up to and including $\mathrm{I} 906$.

The distribution of the Cheshire pig is mainly in the eastern United States, with New York the leading state interested in the breed. Herds are also owned in the New England states, Pennsylvania, Ohio, and elsewhere, though in but a slight degree.

The popularity of the Cheshire is distinctly local, it being one of the least-known breeds in America, being rarely seen on the market or at agricultural fairs west of New York. The late S. M. Shepard, a well-known western judge and authority on swine, states that following the exhibit of Clark at St. Louis in I 870 the breed did not gain much in favor beyond the state of its origin. 


\section{CHAPTER LXXI}

\section{THE VICTORIA}

The origin of the Victoria breed of pigs is accredited to two sources, which are as follows:

I. The Davis Victoria pig. George F. Davis of Dyer, Lake County, Indiana, combined the blood of the Poland-China, Berkshire, Chester White, and Suffolk, crossing these and then practicing careful selection to secure a definite type. This work

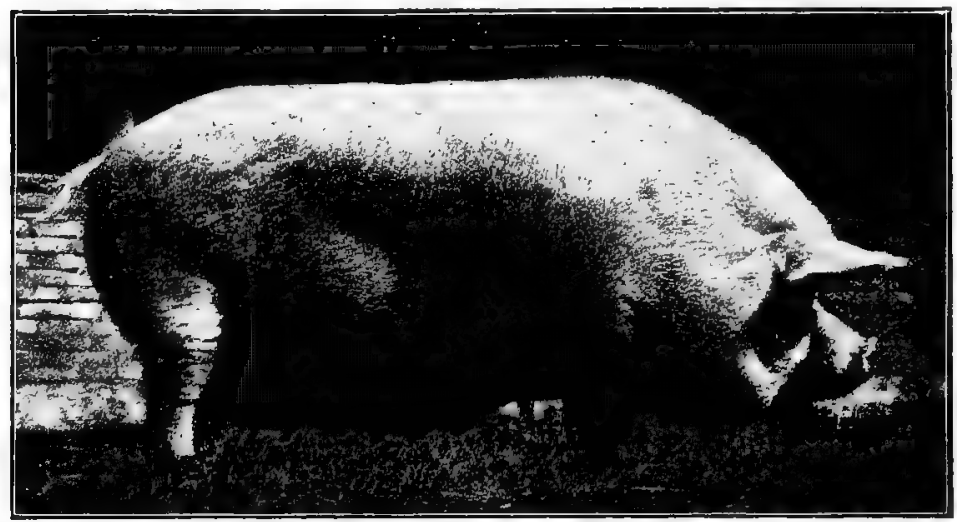

FIG. 239. A Victoria sow, first in class at the Ohio State Fair, 1905. Bred and exhibited by George Ineichen of Indiana. Photograph by the author

began about 1870 . The descendants of this breeding represent the present-day Victorias in this country.

2. The Curtis Victoria pig originated with Colonel F. D. Curtis of Kirby Homestead, Saratoga County, New York, about 1850. The native hog containing a strain of the Irish Grazier and the Byfield breed were first used, and their descendants were crossed on the Yorkshire. What was termed Suffolk blood was also used, but this was probably the Yorkshire or a close relative. Careful 
selection by Colonel Curtis, who was a prominent stockman in his day, resulted in the development of a white breed much after the Middle Yorkshire type, with slightly dished face and erect ear. The Swine Breeders' Convention at Indianapolis in 1872 approved of a committee report commending the Victoria. In this it was stated that pigs of this breed if pure should have a direct descent from a sow named Queen Victoria, which may be regarded as the mother of the family and from which the breed probably takes its name. So far as the writer is aware the Victoria stock of Curtis ancestry is now no longer in pure-bred existence.

Characteristics of the Victoria pig. The head is moderately broad, the face has a medium dish, the ear is of small to medium

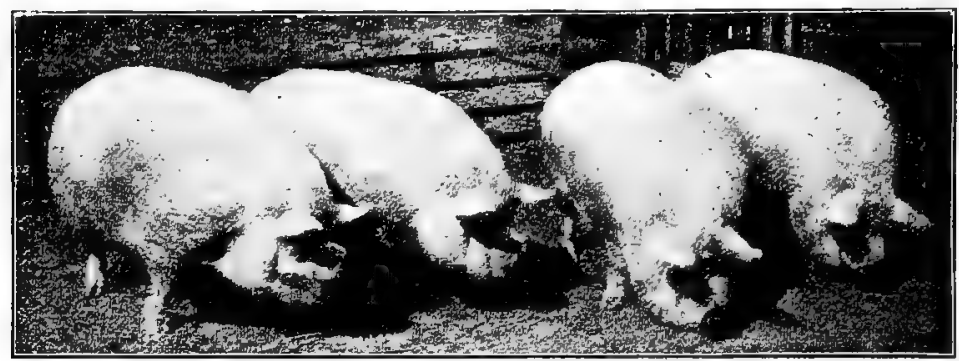

FIG. 240. A group of prize-winning Victorias, bred and exhibited by George F. Davis \& Son, Dyer, Indiana. Photograph from the National Stockman and Farmer

size and is carried very erect. The body is broad and deep, the back level, and the tail set on at a line nearly with the level of back. The shoulders and hams carry a considerable thickness and fullness, and the length and depth of side meat is very good. The length of leg is only moderate, and the quality of bone and hair is fair. In general conformation one is reminded of the Middle White of England.

The size of the Victoria places it in the medium group with the Poland-China and Berkshire. At maturity the sows should weigh 450 pounds and the boars 600 . The average weights for Victorias shown at the American Fat Stock shows at Chicago from 1878 to I $88 \mathrm{I}$ inclusive were $460 \frac{1}{2}$ pounds for sows one year and under two, 331 pounds for sows under one year, and 326 pounds for barrows between six months and one year old. 
The adaptability of the Victoria is to the middle West where good pasture is provided and plenty of grain always available for finishing.

The Victoria as a feeder has not been extensively tried. Mr. Davis, the originator, fed and showed these pigs with much success for many years, beginning with local fairs in Indiana and Illinois in 1878. From observations by the writer, however, no special advantage seems to exist in the pigs of this breed as feeders. In fact it may be questioned if the Victoria will feed equal to the standard, popular breeds of the present day.

The quality of Victoria pork will rank well among other breeds. At the American Fat Stock Show at Chicago the breed has killed out well in the carcass tests. In I 882 at this show the prizes for the best carcasses of swine were awarded on Victorias exhibited by Scheidt \& Davis of Indiana.

The cross-bred or grade Victoria pig is not well tried in the American feed yard and its value is not commonly known. The breed is not yet well suited to crossing with pure-breds, owing to its own comparatively recent origin, but the grade should sell satisfactorily on the market.

The breeding qualities of the Victoria are very good and they produce fair-sized litters, in fact the claim is made that large litters are common.

A special argument in behalf of the Victoria has been that as a white breed it is not so susceptible to skin disease, such as sunburn, mange, itch, etc., as are other white breeds, especially in the South and Southwest.

The promotion of the Victoria pig is championed by the Victoria Swine Breeders' Association, organized in Indiana in $\mathbf{1} 886$. In 1887 the first volume of the Victoria Swine Record was issued, containing IO3 registrations.

The distribution of the Victoria pig is mainly in Indiana, Ohio, and Illinois, though herds also exist in various other Mississippi Valley states in a small way. The breed is not growing rapidly in public favor and is shown but little at live-stock shows and agricultural fairs. 


\section{CHAPTER LXXII}

\section{THE ESSF,X}

The native home of the Essex pig is in the county of Essex in eastern England, lying just northeast of London. The land is level or rolling and the climate temperate and moist.

The early native type of Essex pig is said to have been of mixed color, black and white, with white shoulders, nose, and legs. It was roach-backed, flat-ribbed, had long legs, a sharp head, was coarse in bone, was a large feeder, and had a nervous disposition.

The improvement of the Essex pig was first secured by Lord Western, formcrly an Essex squire, who, when in Italy in 1830 , purchased a pair of black Neapolitans, male and female, and brought them to England. The Neapolitan was then crossed

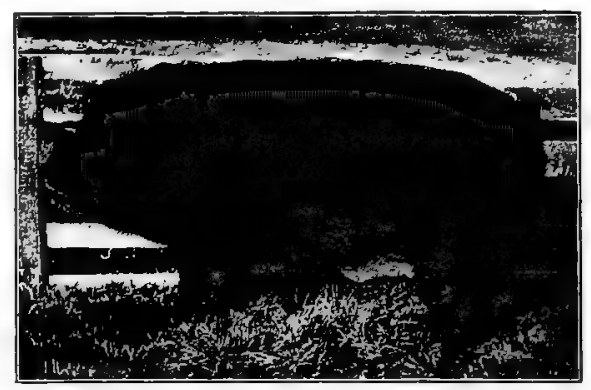

Fig. 241. An Essex boar owned by Joseph Featherstone \& Son of Ontario. Photograph from Professor G. E. Day

upon some well-selected pigs such as were common in Essex, with most satisfactory results. It is also thought that Black Suffolk and Berkshire blood was used. The white coloring was entirely removed and a black Essex-Neapolitan pig of improved form resulted, with shorter head and legs, more quality, and fattening much more readily. These improved pigs were very popular for a time. They were inbred, however, at least in Lord Western's hands, and became of enfeebled constitution, lacking in fecundity and in size.

The establishment of the Improved Essex breed was accomplished by Mr. Fisher Hobbes of Boxted Lodge, a tenant of 
Lord Western. Even prior to 1840 he began to use EssexNeapolitan boars on hardy, high-class Essex sows. By careful selection and mating he developed what became famous as the Improved Essex breed. Lord Western died in 1844, and on his death Hobbes purchased his best breeding sows. This improved form had more size and constitution than the original EssexNeapolitan, and for more than twenty years this was maintained by selection from three distinct families. In I $840 \mathrm{Mr}$. Hobbes received first prizes on a boar and sow at the Royal Agricultural Society Show at Cambridge, which gave the breed much fame. Since the time of Mr. Hobbes this breed has become distributed in England, especially in Suffolk County, adjoining Essex, where the leading breeders reside. In England to-day the Essex is generally known as the Small Black breed or Black Suffolk.

The introduction of the Essex pig to America dates back to early in the last century. The old-fashioned type of Essex, it is thought, was owned about 1820 in Massachusetts, John Prince having a cross-bred sow, part Essex, part Chinese. In I839 Henry Parsons of Canada imported and kept Essex pigs near Massilon, Ohio. In 1886 S. M. Shepard wrote that of recent years a number of importations had been made and a few herds kept in New York, Michigan, Wisconsin, Kentucky, Tennessee, and a few other states. One of the extensive breeders and importers of twenty-five years ago was William Smith of Michigan. At the present time one hears little of the breed in America, neither is it often seen in the exhibits of swine at the fairs or live-stock shows.

Characteristics of the Essez pig. This breed has certain very distinguishing features. The color is entirely black. The head is rather short, the face is slightly dished, the forehead is broad, and the ears are small, fine, and carried erect. The jowl is rather broad and full. The neck is short, the back very broad and somewhat short and strongly carried, while the sides are deep and short. The shoulders are well laid and thickly fleshed, and the hams are thick and deep and of superior merit. The legs, which tend to be rather short, show bone of fine quality. In form the Essex is distinctly of the thick-fleshed, fat, chunky sort, and perhaps no breed in England has been fattened to so 
high a degree. Owing to excessive flesh development the litters gradually became weak and enfeebled constitution finally resulted.

The size of the Essex pig is small compared with the PolandChina or Berkshire, ranking among the smaller breeds. In 1860 Samuel Sidney wrote that "with age they attain considerable weight and often make 500 pounds at 24 months old." The Emperor, a boar bred by Fisher Hobbes, Sidney states is 2 feet $8 \frac{1}{4}$ inches high at the shoulder and 6 feet I inch long. Mr. F. D. Coburn quotes William Smith, an extensive breeder of Essex in Michigan, that these pigs often reach a weight of 400 to 500 pounds. Dr. Chase of Kansas places their weight, under ordinary treatment, when full grown, at 250 to 275 pounds.

The special field for the Essex seems to be in the hands of the small breeder or feeder. This is the case in England as well as in America. The type is not so well suited to severe conditions as some other breeds.

The maturing qualities of the Essex are noteworthy, the breed having been famous for early maturity since the improvement first effected by Lord Western. Feeders easily mature at six months.

The Essex as feeders rank high in combining early maturity with great flesh production. The capacity of the breed to lay on flesh has not been placed on record by American investigators, but it has long been famous as a profitable feeding kind, although producing a fatter pork than is at present in favor abroad. The temperament of the Essex is very docile, which naturally promotes easy as well as profitable feeding.

The quality of Essex meat is fine and of excellent flavor, but a large per cent of fat to lean meat prevails, unless care is exercised in the kind of foods fed. Mr. J. A. Smith of Ipswich, England, who breeds and shows Essex, is quoted by Professor Long as saying that "one objection which is urged against the breed is their tendency to produce an undue proportion of fat, consumers complaining that the bacon is not sufficiently streaky."

The cross-bred or grade Essex pig may be of considerable comparative value: $A$ half century ago it is said that the Berkshire breed was much improved by Essex blood. In fact Essex blood, as improved by Lord Western and Fisher Hobbes, is said to have been responsible for much of the improvement through 
crossing or grading in the herds of England. It is a well-established fact that the Essex used on the coarser, rougher type imparts quality and early maturity.

The fecundity of the Essex pig became impaired by its excessive development in fat production, a criticism made against the breed years ago. Mr. Smith, already quoted, says that his pigs, when properly managed, are very prolific, fifteen or sixteen being frequently in a litter, although ten to eleven is a fair number. The breed, however, does not stand high in this respect, being ranked below the Berkshire. As nurses the Essex sows are regarded as simply medium, not as a rule yielding an abundance of milk. The fecundity of individuals and their capacity to nurse young will depend in a measure on the character of food fed and condition of body.

Organizations to promote Essex swine exist in America and England. The American Essex Association was organized in I 887 and has a small following. It has published two volumes of the herdbook and has registered about 1500 animals in these volumes. In England the National Pig Breeders' Association officially represents the breed.

The distribution of Essex pigs is quite widespread. They are found in England in a small way in various counties, notably in Essex and Suffolk. They have also been exported to France and other European countries and to Canada and Australia. In the United States a few herds are found in Michigan, Indiana, Texas, Nebraska, Alabama, Ohio, and elsewhere. The breed has met with favor in the South. 


\section{CHAPTER LXXIII}

\section{THE SMALL YORKSHIRE}

The origin of the Small Yorkshire pig, known as the "Small White" in England, is obscure. It has been assumed that it came from Chinese stock, though different to-day from the early Chinese type. Charles Mason of Chilton and Robert Colling of Darlington, Yorkshire, both Shorthorn cattle breeders, are the earliest known persons to have bred Small Yorkshires, then termed Chinese. They owned herds as early as I 8 I 8 , but nothing is known of the parent stock. Following this period the breed met with some extensive distribution in England by Shorthorn breeders.

Some strains or families of Small Whites early developed in England. A local breed, known as the Solway in Cumberland, assisted in the improvement of the Small Yorkshire, although this was descended from the Mason-Colling breeding of Small Whites. The Solway also played a part in improving the Large Yorkshire as bred by Mr. Wainman of Carhead. There existed some twenty-five or so years ago, a small white pig known as the Suffolk, which was essentially absorbed by the Small Yorkshire. In Cumberland was another type, some larger than the Small Yorkshire, but of the same general character, the blood of the two being freely mixed. Still another branch, descended from Mason-Colling stock, was known as the Windsor breed. A more modern and very popular strain was developed by Lord Ducie, which really resulted from a judicious blending of Cumberland and Small Yorkshire blood.

The introduction of the Small Yorkshire pig to America under that name occurred many years ago. In I 888 Curtis wrote that it was first brought to this country about I860, but did not attract much attention. Colonel Richard M. Hoe of New York and William H. Cole of New Jersey made importations in I872, 
I $874, \mathrm{I} 875, \mathrm{I} 876, \mathrm{I} 877$, and $\mathrm{I} 878$, and to these importations trace the best-known herds of America. Small Yorkshires were first exhibited at New York and New Jersey fairs in 1875, while in I876 they were extensively shown in Ohio, Indiana, and at St. Louis and also at the Centennial Exposition at Philadelphia.

The characteristics of the Small Yorkshire are most striking. This breed among swine is the most highly developed of any from the standpoint of "fancy" points. The head in its most fashionable form presents a remarkable development. The face is

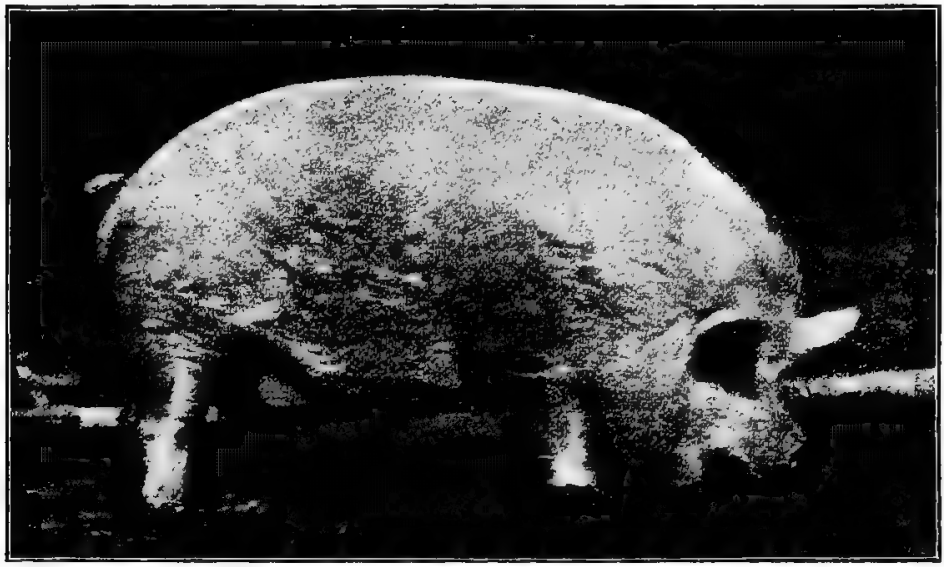

FIG. 242. A Small Yorkshire boar, first in class at the Ohio State Fair, 1905. Owned and exhibited by George Ineichen of Indiana. Photograph by the author

very short and broad, and is dished or curved to such a degree in specimens as to point the end of the nose upward. The lower jaw also is curved upward in a marked degree. In this highly dished face the eyes are often obscured by rolls of fat about the side of the head. The ears are short, fine, and erect, pointing forward. The jowl is naturally very round and highly developed. This breed is famous for great fat production; the neck short and thick, the back very broad, short, and deeply laid with fat or flesh, the tail set up well on a line with the back, the hams and shoulders heavy and full for the size, and the bone, hair, and quality quite refined. The color is entirely white except for 
black spots occasionally occurring on the skin. In referring to the characteristics of the breed Professor James Long writes:

In breeding the Small White pig the breeder should make it his aim to maintain the characteristic points of the variety, the chief of which are form (much in little), fineness of bone, quantity and quality of hair, shortness of snout, and aptitude to fatten.

As a whole pigs of this breed have great breadth and depth for their size.

The size of the Small Yorkshire ranks it as the smallest of the breeds kept in this country. The matured pig will usually weigh

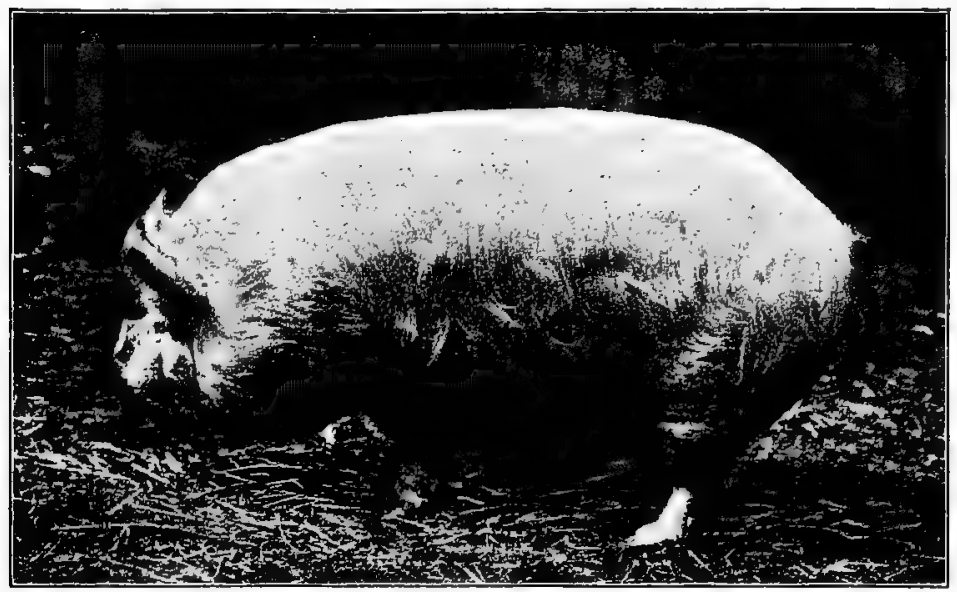

FIG. 243. A Small Yorkshire sow exhibited at the Royal Agricultural Society of England Show, I903. Photograph from Professor G. E. Day

from I 80 to 200 pounds, although Mr. Sanders Spencer has had them weigh nearly 300 pounds at fifteen months of age. Owing to the very compact form individuals weigh more than might be anticipated.

The early-maturing qualities of the Small Yorkshire are of a high order, so that the pigs may be fattened at almost any stage of development.

The Small Yorkshire as a feeder is easily fattened, but does not make large gains. This has been regarded as a superior sort for making small roasting pigs, as the young things finish off early for this purpose. Some British swine authorities claim that 
pigs of this breed can be brought to excessive fatness on less food by half than any other breed. It will not, however, increase as rapidly in actual gains as the larger breeds. At the Vermont Experiment Station Small Yorkshires made an average daily gain of 1.04 pounds live weight, having an average weight of 201 pounds after 184 days of feeding, starting at 23 pounds. It required 353 pounds of feed for Ioo pounds gain, and the carcasses dressed 84. I per cent. This record somewhat excelled that of the Berkshire.

The Small Yorkshire as a grazing pig will do extremely well, at least that is the experience in England. Professor Long states that when a Small White pig is fit for exhibition it gets very little but grass, and that he has repeatedly seen fat pigs of this breed which in summer were entirely grass-fed.

The quality of Small Yorkshire meat, while of fine grain and sweet, is not in favor to-day in Great Britain, containing as it does a high percentage of fat. Mr. John Walker, writing in 1905 in Pigs for Profit, says:

As far as quality goes these pigs are despised by the butcher because they give such a very small proportion of lean to fat that the public leaves the joints of pork on the butcher's slab, it being so leanless, while the bacon curer will have naught to do with the fat little animals.

The cross-bred or grade Small Yorkshire pig is in general an improvement over the pure-bred, if mated to a larger breed, for thereby a better grade of pork is produced and a more hardy and prolific stock results.

The fecundity of the Small Yorkshire is about medium, with a tendency to small litters, such as might be expected from a breed tending to excess of fat development. The nursing females produce but a moderate amount of milk.

The popularity of the Small Yorkshire has decreased to such an extent that it is but slightly bred to-day in England or America. As a breed it was largely developed by fanciers, often for show. Its excessive fat, however, caused it to become unpopular in the British market, where a lean type of bacon is most in favor. According to Volume XX of the National Pig Breeders' Association of Great Britain, only two or three breeders now enter their pigs, while of the Large Whites there are entered rooo out 
of I 391. This does not speak well for the popularity of the Small Yorkshire in England. In the United States the breed is very rarely seen at the live-stock shows, nor are there many breeders.

The distribution of the Small Yorkshire is mainly in England and the United States, in small herds and in a limited degree, as has been indicated. They are mainly located in the eastern United States, notably in New York, Massachusetts, and Pennsylvania, with a few small herds in the middle West.

Organizations to protect and register Small Yorkshires exist in England and America. The National Pig Breeders' Association registers in Great Britain. In the United States the American Small Yorkshire Club was organized in New York in 1878. This club has registered about 1500 pigs in the first two and only volumes of the herdbook issued. The American Yorkshire Club, organized in 1893, with headquarters in Minnesota, also registers this breed in the American Yorkshire Record, of which two volumes have been published. In the herdbooks of this club the Small Yorkshires are registered in a group by themselves, as Class A, the Large Yorkshires being in Class B. Only a few hundred of the Small Yorkshires have been registered in this club, these being mainly in the western states. 


\section{CHAPTER LXXIV}

\section{THE SUFFOLK}

Two so-called breeds exist under this name, one in America, the other in England. The American breed is white, the English black. At one time a type of small white pigs existed in England under the name of Suffolk, but it finally became absorbed with the Small Yorkshire, and to-day no such breed as a White Suffolk is recognized abroad.

The English Suffolk pig is black, and, as will be seen in the discussion of the Essex pig on page $52 \mathrm{I}$, this is known abroad as the Small Black breed, although the names Essex or Suffolk are appropriate and are used to a certain extent.

The origin of the American Suffolk pig is no doubt of Smail Yorkshire ancestry in England. This breed is said to have been imported to the United States in 1855 by John Wentworth of Illinois. The breed has never had much development in America, and so little impression has it made under the name of Suffolk that, although an association was years ago organized in its behalf, the American Suffolk is not recognized in the October, 1904, list of accredited swine-record associations of the United States Department of Agriculture.

Characteristics of the American Suffolk pig. In 1872 the National Swine Breeders' Convention at Indianapolis, Indiana, approved of the following description of the breed, which is republished here as more specific than the published standard of the American Suffolk Swine Breeders' Association.

Head small, very short; cheeks prominent and full ; face dished; snout small and very short; jowl fine; ears short, small, thin, upright, soft, and silky; neck very short and thick, the head appearing almost as if set on front of shoulders, no arching of crest ; chest wide and deep ; elbows standing out; brisket wide but not deep; shoulders thick, rather upright, rounding outward from top to elbow; crops wide and full, long ribs, well arched out 
from back, good length between shoulders and hams; flanks well filled out and coming well down at ham; back broad, level, straight from crest to tail, no falling off or down at tail; hams wide and full, well rounded out, twist very wide and full all the way down; legs small and very short, standing wide apart - in sows, just keeping belly from the ground; bone fine, feet small, hoofs rather spreading; tail small, long, and tapering; skin thin, of a pinkish shade, free from color; hair fine and silky, not too thick ; color of hair pale yellowish white, perfectly free from any spots or other color; size small to medium.

The American Suffolk pig in a breed comparison is essentially a Small Yorkshire, although the dish of face may not be always quite so pronounced as with the latter, while the size tends to be slightly larger. Otherwise the two breeds are one to all intents and purposes.

The distribution of the American Suffolk pig is mainly in the Mississippi Valley, small herds being kept in Michigan, Iowa, Illinois, and Indiana. Several hundred have been registered in Canada. Between one and two thousand American Suffolks have been registered, but thus far no herdbook of the breed has been published. 


\section{CHAPTER LXXV}

\section{THE BACON TYPE OF PIG}

The demand for the bacon type of pig comes mainly from the export trade. Only in recent years has the American swine producer had his attention actively called to this class. This has been largely due to the demand of the British market for superior bacon. Denmark, Ireland, and Canada furnish much of the bacon consumed in England and Scotland. This bacon requires a liberal

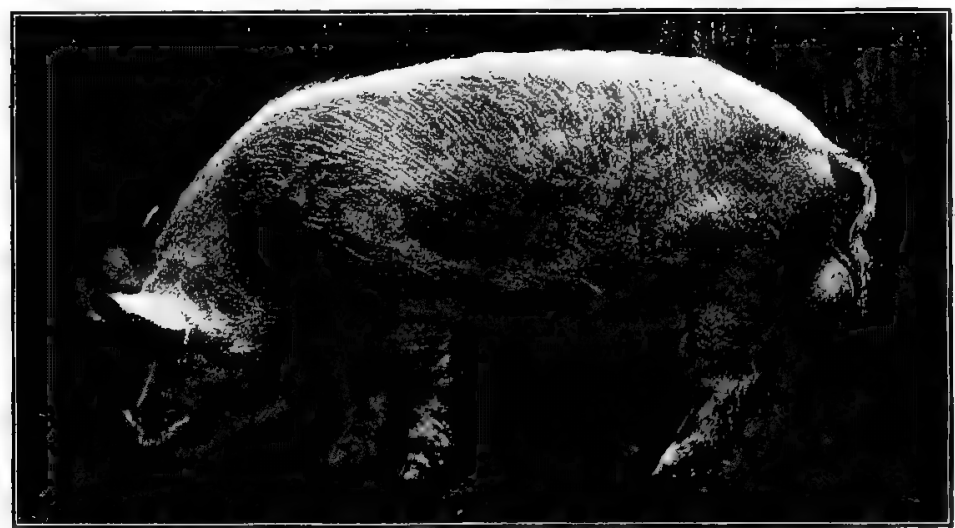

FIG. 244. Oak Lodge Royal Canadian, a Large Yorkshire boar owned by the Ontario Agricultural College, Guelph. This boar is in breeding condition only, and shows the desirable conformation of the bacon type of pig. Photograph from Professor G. E. Day

mixture of lean with fat, and suits the foreign trade much better than the fatter type produced in the Mississippi Valley. In spite of the British demand for this sort the American packers do not pay a premium for it; consequently the feeder prefers to produce the more rapid-fattening, heavier-fleshed, earlier-maturing lard type. In spite of this fact the production of bacon pigs seems 
destined to materially increase in the future in the United States, for the reason that bacon consumption is rapidly increasing.

The general characteristics of the bacon pig as compared with the so-called lard hog are as follows : back not broad, head somewhat long, side long and deep, a smoother shoulder, lighter ham, and somewhat longer leg. The general flesh covering is much less fat than with the lard type. In motion the bacon pig is animated and free of action, showing lively temperament.

The head varies rather according to breed. Excessive length is undesirable, but the Tamworth often has a very long head. A medium length of nose is preferred, while a broad forehead, with ample width between the eyes, which should be of good size and easily seen, denotes mild disposition. A deep head with strong lower jaw is preferred.

Ears of a fine quality, not large, thick, and coarse, but of moderate thickness, covered with silky hair, attached neatly well up on the head, and actively carried, are desirable.

The neck tends to be a bit long, but a medium length is sought, with not too much width, blending nicely with head and shoulders. The jowl lacks the extreme fullness found in the lard hog, and is free from wrinkles such as often occur with the heavy jowl. This part bacon-pig buyers regard as of little importance.

The shoulders lie well into the body and do not bulge out prominently, but considerable width and depth, with ample flesh covering, are most desirable. A good specimen of this type never has prominent shoulders. Some extra thickness of skin and heaviness is expected with boars, but no notable heaviness.

The fore legs should be well placed, coming down true, either viewed from front or side, the knees not "knocking in " and toes turning out, the pasterns being strongly carried, and the pig standing up in shapely form on the toes. A fine, hard bone is very important, as evidenced by clean-cut limbs and smooth joints, lacking coarseness and meatiness. A smooth, clean, hard bone is evidence of quality and is associated with the better sort of dressing out in killing.

The chest may be compared to that of the race horse. It should be deep and full, yet not too broad. As one looks at the front of the pig the breast and brisket appear full and not 
peaked. Viewed from one side the brisket projects slightly beyond the legs. A hidden, retreating brisket indicates a poor constitution.

The back should be carried level and show no sag, and the width should be uniformly maintained from shoulder to ham. A strong, nicely arched loin, as wide as any point of the back and smoothly fleshed, is important. A thickness of one and one-quarter to one and one-half inches of fat along the back is regarded as best

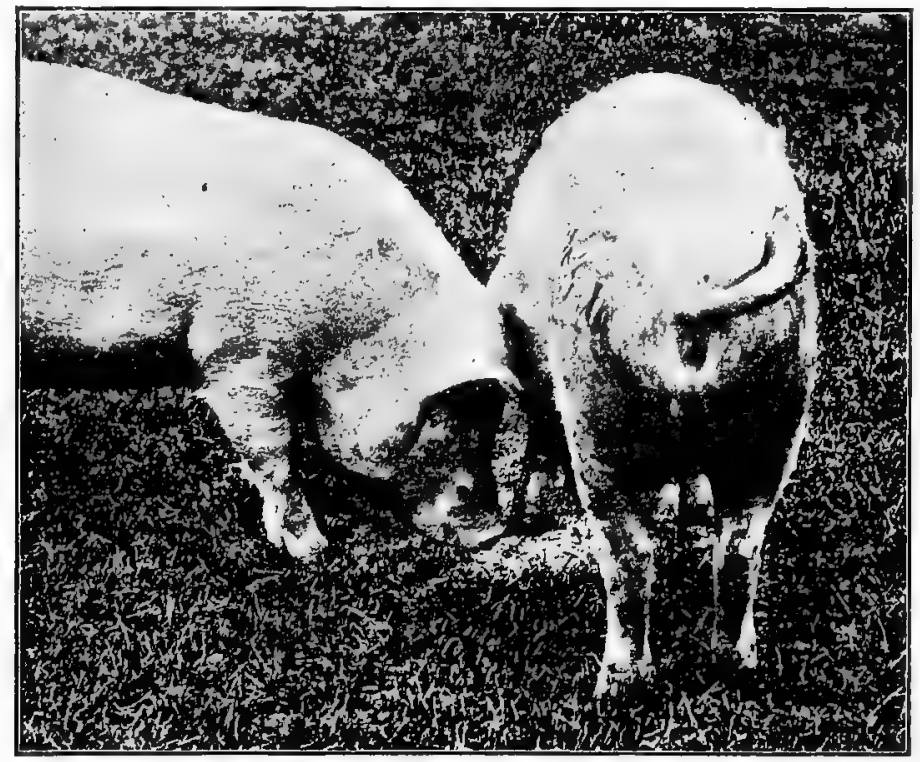

FIG. 245. A shoulder and ham view of the bacon type of pig, showing the smooth shoulder and neatly tapering ham. Photograph from Professor G. E. Day

on the finished fed pig. The back of this type has a moderately arched rib, not flat, giving a body capacity in harmony with the best feeder.

The sides are the most important feature, because from here comes the bacon so highly valued in this class. The sides must be long, evenly carried from shoulder to ham, be thick and full at flank, and of moderate depth. A very deep side provides too much belly or cheap meat. The side must be quite smooth and 
free of wrinkles, and be covered evenly with flesh. In touching on this subject the Ingersoll Packing Company of Canada says :

The packer calls for the long, lean pigs, as they are the ones that suit best and are most difficult to procure; this is the only kind that will furnish the desired "Wiltshire side," and it will also make any of the other cuts the market calls for.

The rump and hams lack the heavy development of the lard type, but a level, long, moderately broad rump is important. The hams in their lower parts should be long, gradually tapering, not necessarily split up high between, with shallow, neatly turned twist. They should also be broad from front to rear, with a medium thick covering of flesh, tapering to the hocks.

The hind legs should have all the merits of the fore legs in bone, quality, and smoothness, and in position of pasterns and toes. Besides this the hocks should be well placed, being smooth of joint and neither close nor wide behind.

The quality of the bacon pig is most important. This is seen in the clean, smooth bone and joints, and the abundant hair, lacking in coarseness, lying close to the mellow skin. Wrinkles should be lacking, and the entire body be smooth and evenly covered with flesh in breeding as well as in feeding stock.

The weight of bacon pigs most acceptable in the market is from I 70 to I 80 pounds, although 200 is not excessive. Danish bacon pigs range from 180 to 220 pounds. The larger type is not approved in Canada, the smaller being preferred.

Breeding bacon pigs should show the characteristics associated with sex, but in general the above description applies to the bacon type. The boar should have a strong, masculine head, neck, and shoulder, the sow a smaller, more refined sort, with more depth of belly than possessed by boar or barrow. 


\section{CHAPTER LXXVI \\ LARGE YORKSHIRE OR LARGE WHITE}

The ancestry of the Large Yorkshire clearly goes back over a century. Swine from time immemorial have been known in England, and a large, coarse, leggy, narrow-backed, white hog was common in early days in that country. In I 789 George Culley referred to what is no doubt parent stock of the breed, as follows :

There was a breed of large white pigs with very large ears hanging over their eyes, which a few years ago were very common in many parts of Yorkshire and Lancashire. They were very plain, thin, awkward hogs, with very long legs, but what distinguished them more was two wattles or dugs, not unlike the teats of a cow's udder, which hung down from their throats on each side.

Early in the nineteenth century Dickson wrote that the old Yorkshire breed was the worst of the large sort, being long legged and weak loined, with a constitution not of the soundest kind. These were, however, he writes, being improved by Berkshire stock. In I 842 Low wrote as follows:

In Yorkshire, Lincolnshire, Norfolk, and generally in the eastern counties there are breeds of large size, of a white color, and with pendent ears. These breeds have been cultivated with more or less care, and have all been affected in their form and characters by crossing.

The white pigs of Cumberland County were also closely related to those of Yorkshire and were much intermixed.

This old type of Yorkshire had a strong coat of white hair, some blackish or bluish skin spots covered with white hair, a large, long head, big ears, and strong bone. It was slow of maturity and was fed up to over 800 pounds.

The modernizing of the Large Yorkshire began about the middle of the nineteenth century. Sidney credits the first correct movement to improve by using white Leicesters on old Yorkshires. These Leicesters were large, with smaller heads than the Yorkshire, had erect ears, were fine of hair and light 
of bone compared with the others. This cross was improved by breeding the largest and best young sows to Small Yorkshire boars of great fattening capacity. The improvement thus effected mainly took place sixty or so years ago about the cities of Leeds, Keighley, and Skipton in the county of York, and to a considerable extent by factory hands and laborers. In I $85 \mathrm{I}$ Joseph Tuley, a weaver of Keighley, exhibited a pig at the Royal Agricultural Show at Windsor that attracted great attention, and

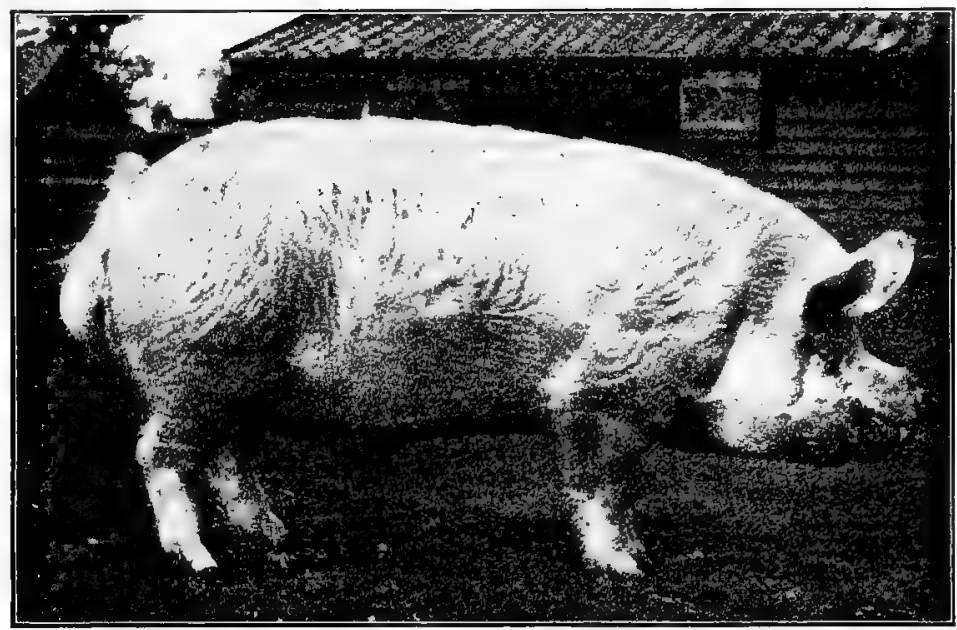

FIG. 246. Holywell Royalty II, a fine example of a Large Yorkshire bcar. Bred and owned by Sanders Spencer, Holywell Manor, St. Ives, England. Photograph from Mr. Spencer

later his strain of Large Yorkshires was very popular, and his pigs sold at high prices. At this time the pig breeders of Yorkshire and Cumberland kept pedigrees of their pigs, which they printed and made much of. The agricultural societies of the region offered prizes to promote the breed, and there was keen competition in the show ring. The various towns had agricultural societies and shows. Regarding these Sidney wrote as follows :

At these shows there is often a row of twenty or thirty fat pigs, worth from $£^{6}$ to $£^{12}$ each, all as white as soap and water can make them, stretched on beds of clean straw, with wrappers of some kind to protect them from the sun or rain, contending for the first prize, $£ 4$; second prize, $£ 3$; third prize, $£^{2}$; fourth prize, $£ \mathrm{I}$. 
At this time Yorkshire was credited with being in the first rank as a pig-breeding county, having the largest white breed in England and the largest hogs in the world.

- The early improvers of the Large Yorkshire may perhaps date from Mr. Tuley, as has been indicated. From a sow Matchless and a boar Sampson, of his breeding, came some of his best

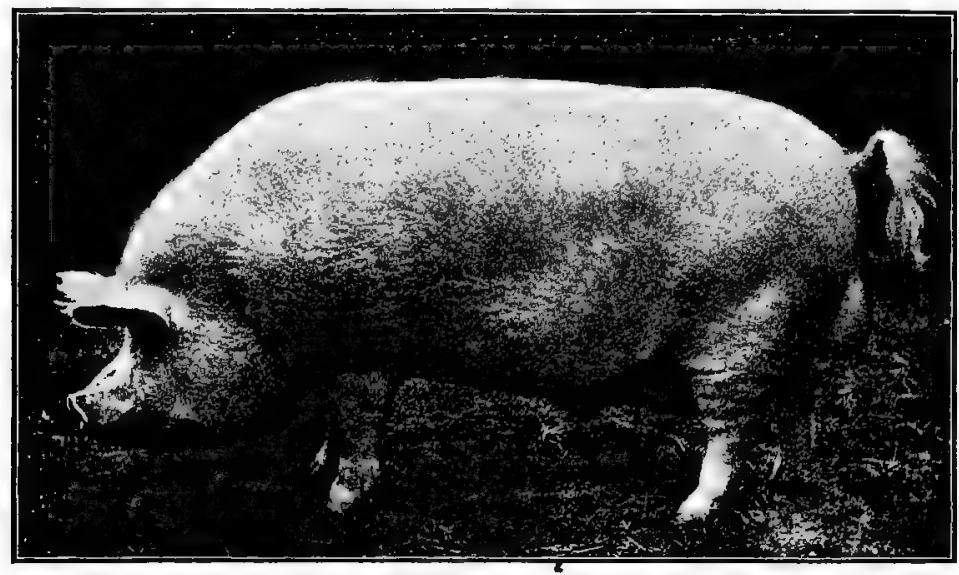

FIG. 247. Roger (7203), first-prize and champion Large Yorkshire boar, and winner of the Berkshire Society gold medal, at the Royal Agricultural Society of England Show, 1904. Owned by the Earl of Ellesmere. Photograph from William Cooper \& Nephews, Berkhamsted, England

stock. Mr. W. B. Wainman of Carhead, Yorkshire, used hogs of Tuley blood and added to the merits of the breed, for he produced stock of much quality and sent them to various parts of the world. In his herd selected pigs by careful feeding would attain a weight of about 500 pounds in twelve months. Besides Tuley and Wainman numerous others have long bred and improved this breed, notably Sanders Spencer of St. Ives, Huntingdon County, who for a half century has been a most distinguished breeder.

The important characteristics of the Large Yorkshire are as follows :

The head is medium long and should have but little upward curve. Some prefer a lengthy head, but modern ideas object to too much extension. A broad, strong underjaw is desired. 
The ears incline to be heavy and droop forward. They should be fine, of medium size, and be carried well upward and only slightly pointing forward. Loppy ears are objectionable.

The body should have considerable length. The back is not broad like that of the Poland-China, but should be of fair and uniform width with considerable depth, the sides being long and deep at the flanks, and full between shoulder and hip. From the American point of view this breed tends to have a weak loin and too narrow a back.

The hams are not expected to be extremely fat and heavy, but should be of good size and thickness, with the thighs well carried down. Thin thighs and cow hocks are very common with this type of hog.

The color of the hair should always be white on every part of the body. Bluish or blackish spots occur occasionally on the skin under this white hair, and while objected to by fanciers, do

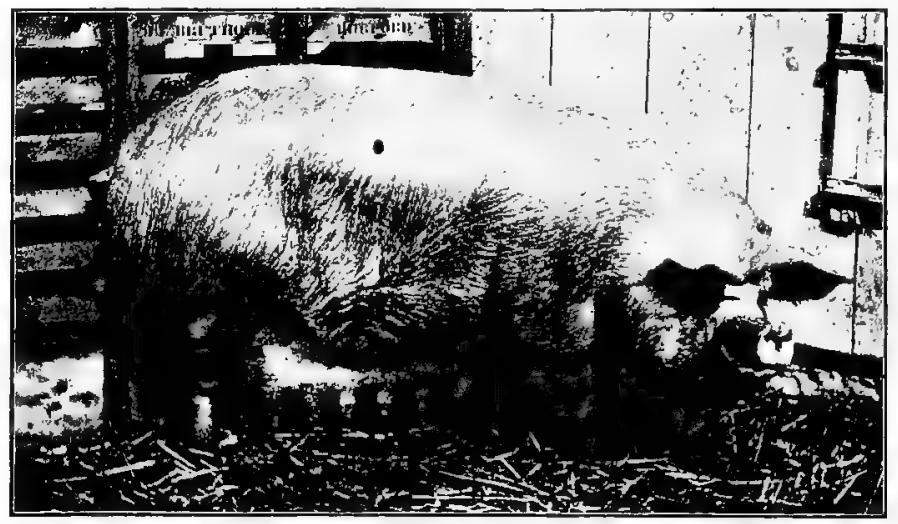

FIG. 248. Oak Lodge Julia 7 th, 2586, a Large Yorkshire sow, winner of first prize and championship at the Pan-American Exposition, I9or. Bred by J. E. Brethour, Burford, Ontario. Photograph from Professor G. E. Day

not affect purity of breeding, neither do they disqualify registration. The skin should be pink and healthy. White pigs in America, especially in the sunny West, tend to scurfiness of skin and sun scald, which causes them to be more or less unpopular.

The size of the Large Yorkshire places this breed in the first rank. Long writes of a Wainman sow that weighed 1203 pounds. 
In I90 I several sows of the breed were exhibited at the International Live Stock Exposition, which weighed over 1000 pounds each. Mr. Spencer, in reply to a letter from Professor Long, says :

The Large Whites reach, in the heaviest animals, 12 stone (I68 pounds) at six months old; at nine months, 20 stone to 25 stone (280-350 pounds); at I 2 months, 30 stone ( 420 pounds); and at 18 months, 45 stone ( 630 pounds)... Sampson VI, a boar bred and exhibited by myself, and winner at the Royal two years in succession, weighed, alive, $9_{i}^{8}$ hundredweight ( 1092 pounds) at 23 months, and was light in bone and carried but little offal.

The modern market demand, however, is for a smaller pig, and Yorkshire breeders are producing a smaller Large Yorkshire

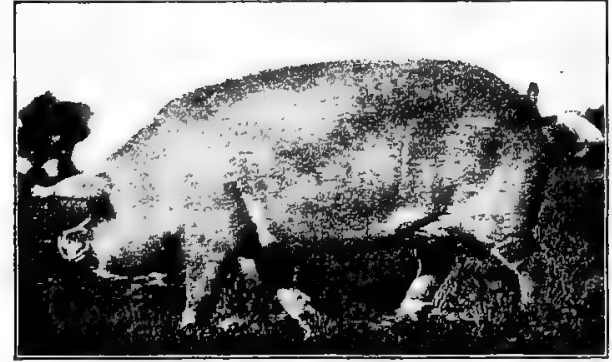

Fig. 249. Holywell Czarina, a Large Yorkshire sow on pasture at Sanders Spencer's, Holywell Manor, St. Ives, England. Photograph by the author type, but few of the big pigs appearing before the public.

The early-maturing character of the Large Yorkshire is not pronounced. Feeders in the corn belt, used to pigs that will finish off in eight months, find this breed slow to mature. The Yorkshire grows very well but does not fatten as early as the American breeds. At six months of age the Yorkshire lacks the fattened condition possessed by other breeds not of the bacon type. In fact, it never will, as a matter of inheritance, carry so much fat, for it is a leaner sort.

Large Yorkshire cross-breds are a very superior type. The Yorkshire boar bred to either Poland-China or Berkshire sows produces most excellent feeders. In experiments conducted by the author with this combination the pigs grew rapidly, fed extremely well, finished off smoothly, and produced the best sort of meat. In numerous cross-breds examined the interesting fact has been brought out that the white color of the Yorkshire is almost invariably predominant. This demonstrates the prepotency and fixity: of character of the breed. The use of Large Yorkshire boars on our typical American sows should not only 
produce most desirable feeders but should also increase the size of litters and thus improve the defective fecundity of many sows.

The Large Yorkshire as a bacon producer has special distinction. The breeders of this pig emphasize the value of this character. In Denmark, England, Ireland, and Canada, where bacon production is an important industry, the Yorkshire and its crosses is the most common blood used. The Messrs. Denny, an English bacon firm, desired to introduce the best type of bacon hog to use on the common stock of Ireland. After some experimental work with the English breeds they sent Large Yorkshires as

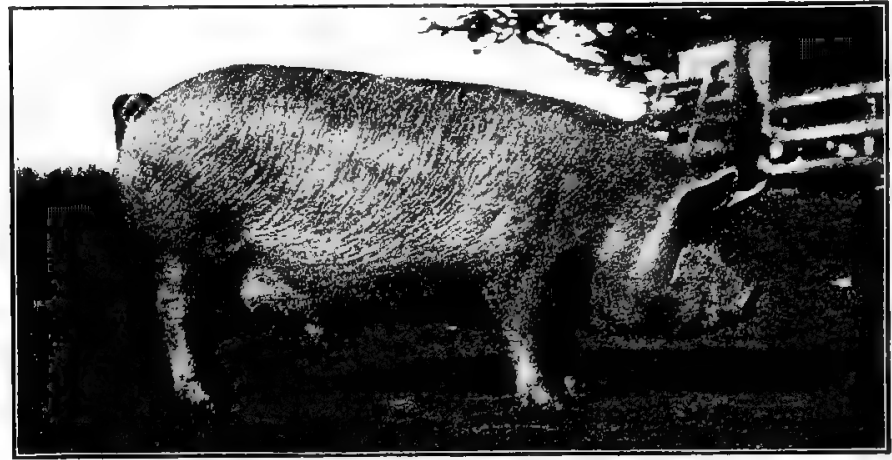

FIG. 250. A pure-bred Large Yorkshire barrow, about six months old, one of the champion pen of the breed at the International Live Stock Exposition, Chicago, 1905. Bred and exhibited by Ohio State University. Photograph by the author

the best, as they had the thickest bellies and the most streaky meat. In Denmark the Large Yorkshire boar is extensively used, in fact it is the standard for breeding to ordinary Danish sows. The William Davies Packing Company of Canada also advocate the use of Large Yorkshires and their crosses for bacon production.

Large Yorkshires dress out just fair in slaughtering. In the report of the block test at the Ontario Provincial Winter Fair in I90 I the average percentage of dressed weight of the Yorkshire carcass was 78.4. The fatter pigs dress out somewhat heavier. Mr. Spencer states that this breed will dress out 76 to 82 per cent. Yorkshires fed in the corn belt, with Indian corn as the main food, will no doubt kill out better than if fed barley, peas, 
oats, middlings, and similar foods, such as are used in Canada and Europe.

The Large Yorkshire as a prolific breed stands in the front rank. The females from very early days have been noted for producing large litters. Long refers to a sow of Wainman breeding that reared 153 pigs in 13 litters, while one of her daughters raised 33 pigs. in three litters. Richard Gibson, a prominent Canadian breeder, writes of an imported sow of his that has bred 96 pigs in three years without the least apparent injury to her constitution. James Howard, long an English Yorkshire breeder of prominence, prefers sows of this breed to have 12 teats and emphasizes the importance of her being a good milker. The sows very generally make good mothers.

The Large Yorkshires as feeders have not given equal satisfaction in America. They do not seem to eat our standard foods with the relish shown by the Poland-China or Chester White.

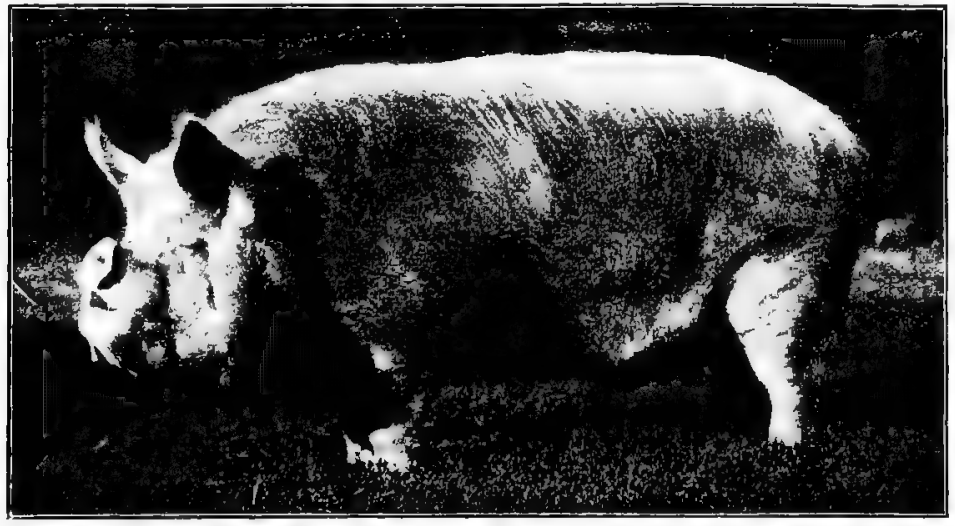

FIG. 251. Holywell Rosador, a Middle White boar, first prize at the Royal Counties Show and at the Highland and Agricultural Society of Scotland Show, 1899. Bred and exhibited by Sanders Spencer, Holywell Manor, St. Ives, England. Photograph by the author

For some years the author has bred and fed the Large Yorkshire alongside three other breeds, and in the comparison the Yorkshire was distinctly at a disadvantage as a feeder. This test included imported, Canadian, and home-bred Yorkshires. Neither does the pure-bred graze equally well with our more common breeds. 
The introduction of the Large Yorkshire to the United States occurred prior to 1840 , and in I84I a pair was imported by A. B. Allen and brought to Ohio. Undoubtedly specimens of this breed have been brought to America from time to time for over a century. In I 893 Wilcox and Liggett of Minnesota imported some of the more modern type, and from this and Canadian stock have come most of the present Large Yorkshire stock in this country. The people of Canada have been breeding Yorkshires for many years, and the most important herds in America are in that country.

The Large Yorkshire's popularity in the United States has not grown in a substantial or even satisfactory way. Undoubtedly it is a superior bacon producer, raises large litters, and is a meritorious animal. Its slow-fattening character, its usual lean and leggy type, its inferiority as a feeder, and its white color furnish

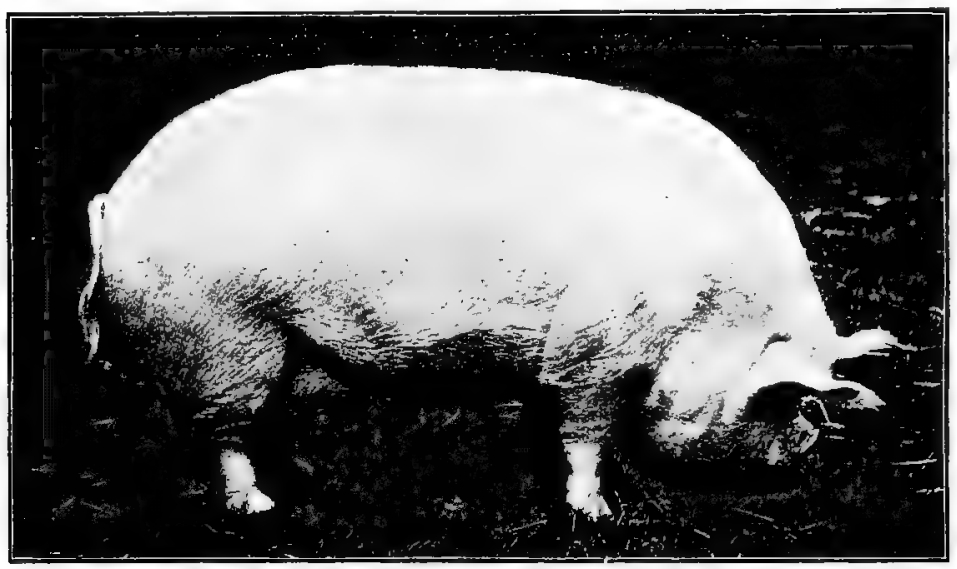

FIG. 252. Walton Jewel II, a Middle White sow, first-prize winner at the Royal Agricultural Society of England Show, 1905. Exhibited by Sir Gilbert Greenall, Bart. Photograph from Professor G. E. Day

more or less of the objection of the western pork producer. If the people of the United States really had a market for bacon that would justify the feeding of this class of hogs, no doubt the Yorkshire would be more extensively bred and fed.

The distribution of the Large Yorkshire is very widespread. Mr. Sanders Spencer has exported them to forty-six different 
countries, including Europe, Asia, Africa, Australia, and North and South America. It is the leading white breed of Great Britain, Denmark, and Canada, and is used more or less in different European and British settled countries. In the United States it is bred to a limited extent in Minnesota, Iowa, Ohio, Indiana, and other states.

The American Yorkshire Club was organized in 1893 for the promotion of the breed. The official headquarters have long been in Minnesota. Up to January I, 1905, two modest herdbooks had been published, in which was also registered a limited number of Small Yorkshires, these being grouped as Class A and the Large Yorkshires as Class B. In Great Britain all registered Yorkshires are recorded by the National Pig Breeders' Association.

The Middle White or Middle Yorkshire is of a smaller, fatter type than the Large Yorkshire. It has a more dished head, broader back, is of a fatter type, and more nearly approaches American ideals in pig form than does the Large Yorkshire. Middle Whites are not a recognized breed in America, though they are in Great Britain. Middle Whites may come from Large Yorkshire litters, being selections of the correct form, or may result from a cross of Small Yorkshire boars on Large Yorkshire sows. No doubt numerous pigs recorded in America as Large Yorkshires would be classed as Middle Whites in England. Under the circumstances it is not always easy to draw the line between the two so-called breeds. 


\section{CHAPTER LXXVII}

\section{THE TAMWORTH}

The native home of the Tamworth is the counties of Stafford, Leicester, Northampton, and Warwick in central England, but notably in Stafford. This is generally a rolling but not very hilly region, with a temperate, moist climate.

The ancestry of the Tamworth pig is obscure. Tradition and history refer to a pig of Tamworth type existing early in the last century. Most writers on the pig say but little of this breed and we know almost nothing of its early development. Spencer states that this is one of the oldest English varieties, which fed in large droves on oak and beech mast in the forests of the midland counties even before the battle of Waterloo. In an address before a breeders' association at Detroit in 1899, Mr. E. N. Ball stated that the breed was introduced into England from Ireland by Sir Robert Peel about I 8 I2, but no evidence is found elsewhere to support this statement.

The early type of Tamworth was long of leg and snout, narrow of back, and shallow of body, slow to mature, very active and hardy, and usually of a sandy or reddish color.

The improvement of the Tamworth came with the conversion of England into a cultivated region, when farmers wanted a less active type of pig. The opinion seems to prevail that this breed was mainly improved by selection, the breeders seeking to secure a quieter type, fattening more rapidly than of old and yet retain. ing the characteristic color. In I $886 \mathrm{Mr}$. F. C. Fidgeon of Tamworth, England, who had a considerable knowledge of the breed, iniormed Professor Long that in the nearly sixty years he had known the Tamworth he had never noticed so great a change as from about 1880 to 1886 .

A generation ago [he says] they were a lean pig, of a very dark red color, which never varied in shade and were provided with a very long snout. Of 
late the color has altered in shade, having become a sandy or lighter red, a point which is apparently growing in favor, although I question very much whether this color is as pure as the original dark red, for I believe it has been obtained by a not very distant cross with a white pig.

Spencer has also suggested the white cross and Neapolitan cross. For years the breed was almost unnoticed, excepting by a limited number. In comparatively recent years it has received renewed attention. for its bacon value. In i 847 a Tamworth sow won

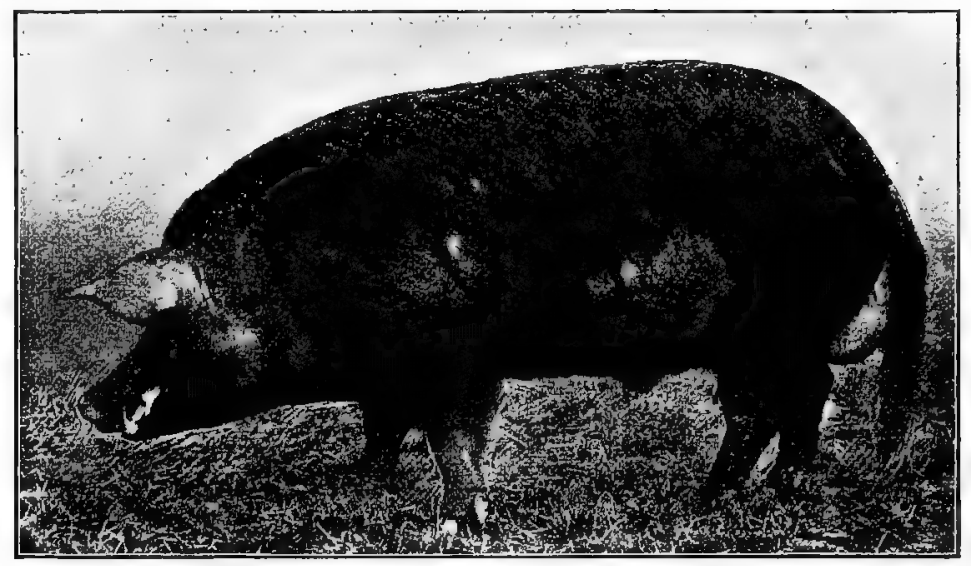

FIG. 253. A Tamworth boar, winner of first prize in class at the Royal Agricultural Society of England Show, 1904. Exhibited by Robert Ibbotson. Photograph from William Cooper \& Nephews, Berkhamsted, England

first honors at the royal show, but the breed was not given a special class recognition by the Royal Agricultural Society of England until I 885.

The introduction of the Tamworth to America is generally credited to Mr. Thomas Bennett of Rossville, Illinois, who imported some pure-bred pigs in I882. Professor Shaw states that since 1888 large numbers have been introduced into Canada. Most of the importations to the United States have been from Canada.

Characteristics of the Tamworth. The color is red, varying in shade from light to dark, "a golden red hair on a flesh-colored skin free from black" being preferred. In form the Tamworth is large, lean in type, and long in head, body, and leg. The head 
is notably long of snout, tends to be narrow with straight snout, and the face but slightly dished. The ears are large and should be erect or leaning slightly forward, not breaking over. The back is narrow and long and the sides long and should be deep, but usually are not, based on American standards. The shoulders are usually well placed and carry sufficient breadth but lack in thickness. The hams represent the lean type, lacking thickness at the twist and general development of lower thigh. The legs are long and show considerable strength, and the pasterns are well sustained, the pigs standing easily on the toes. In temperament the breed is active and almost restless, but the disposition seems mild and gentle. The National Pig Breeders' Association of Great Britain lists the following as objectionable points in the Tamworth: black hair, very light or ginger hair, curly coat, coarse mane,

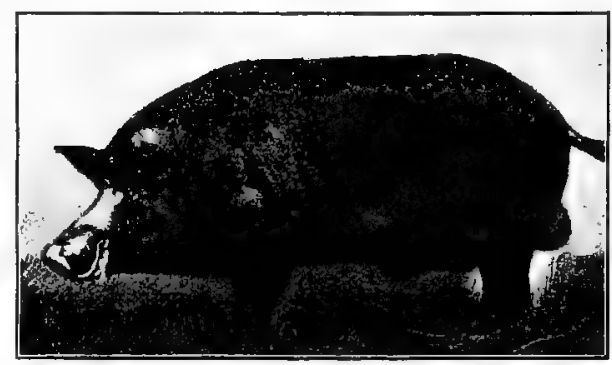

FIG. 254. A Tamworth boar: Photograph from Professor G. E. Day black spots on skin, slouch or drooping ears, short or turned-up snout, heavy shoulders, wrinkled skin, inbent knees, and hollowness at back of shoulders.

The size of the Tamworth is large, approaching, if not equaling, that of the Large Yorkshire. The Buffalo Review of August I 7 , 1899, refers to a Tamworth boar in England, under three years old, which weighed alive 1607 pounds and dressed I 330 pounds. This, of course, was abnormal. The average mature boar will probably weigh about 600 pounds and the sow 450 pounds. At six months old pigs will weigh about 175 pounds.

The Tamworth as a bacon pig ranks very high. The claim is made that, owing to dissatisfaction with the fat quality of bacon produced in the average pig in England along in the early eighties, the Tamworth came to the front to supply the necessary lean meat. The sides are long, and in good specimens deep, and have a superior admixture of lean and fat of highly acceptable 
quality. Consequently this feature of its conformation, with the lack of thick external fat, caused the recent agitation in its behalf in England and America. It is but fair to say, however, that in spite of the arguments in behalf of this as a bacon producer, it is bred only in a small way abroad, the Large Yorkshire being the leading bacon pig of both Britain and Denmark.

The maturing quality of the Tamworth is inferior, probably being less forward in development than any other breed in America. While growth is constantly made, an early-finished, matured product does not usually obtain. However, some British feeders have argued that the Tamworth will mature early. $\mathrm{Mr}$. G. M. Allender, long a famous British breeder, says, "I find that the Tamworths feed early, and I have hams now hanging which exceed 20 pounds each in weight, smoked and dried, although they were cut from pigs which were only twenty-seven weeks old." The Mitchell Brothers of Birmingham, who won first prize at the Birmingham Fat Stock Show in I884, informed Professor Long that the Tamworths they exhibited were only five and one-half months old and weighed 12 score per pig, or 240 pounds. These pigs were from a sow twelve months old at farrowing.

The feeding quality of the Tamworth is fairly good, the pig making considerable growth for the food fed. Mr. E. N. Ball of Michigan reports on three pigs about sixteen weeks old, which during ninety-seven days gained a total of 340 pounds from I 224 pounds of grain, or Ioo pounds of gain for 360 pounds of feed. Rommel of the United States Department of Agriculture, averaging the results of feeding six breeds as brought out in representative tests by experiment stations, shows that in 16 tests involving 92 Tamworths it required 344 pounds of feed for 100 pounds gain live weight. In the Iowa feeding trials on breeds three experiments were conducted, showing daily gains for Tamworths of $.77,1.00$, and 1.05 pounds respectively, the average cost per pound of gain being $\$ 2.42$, ranking fifth in cost of production among the breeds. The Iowa experiments also showed that the Tamworths dressed out in carcass very well, the average being 78.46 per cent for 14 pigs, comparing creditably with five other breeds, surpassing three of them. At the Ontario Agricultural College, in comparisons of six breeds, covering five years of 
feeding, 390.I 7 pounds meal were required for Ioo pounds gain, this being the best showing made by any breed but the Berkshire.

The cross-bred or grade Tamworth has considerable merit. Tamworth boars on Berkshire sows are a favorite cross with some feeders in England. When bacon curers complained of Berkshires fattening too heavily the Tamworth cross was resorted to with desirable results. Long reports that the Messrs. Mitchell during two years bred and fed 300 pigs, all by Tamworth boars from Berkshire and Yorkshire sows, that averaged 200 to 240 pounds weight at under nine months old. Tamworth boars,

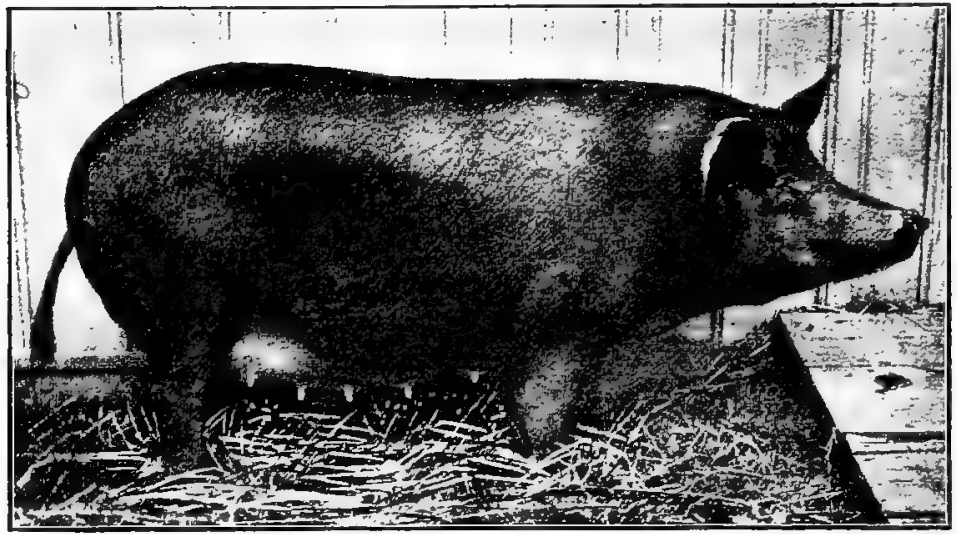

FIG. 255. A Tamworth sow, an excellent illustration of the best type of the breed. Photograph from the National Stockman and Farmer

bred on the fat type of American sows, will produce a very attractive, easy-feeding, highly-marketable porker. Used on Poland-China grades considerable success may be expected. If cross-bred females are used for breeding they will produce much larger litters than will the American breeds. The Tamworth sire is very prepotent, and reproduces his color in a marked degree.

The fecundity of the Tamworth is a striking feature of the breed. Mr. Fidgeon reports his sows generally bringing from ten to fifteen pigs at a litter. It is generally conceded in Britain that the Tamworth is unsurpassed for fecundity and size of litter. One of the quoted objections to the breed in England was that it was too prolific, the sows bringing fifty per cent too many 
young ones. It is this renovating quality of fecundity which has furnished important arguments for Tamworth breeders in behalf of the breed. The sows make good mothers and produce an abundance of milk, as might be anticipated with this type.

The Tamworth as a grazing pig or rustler has a distinct place. It was for this reason that the breed was originally highly valued, and this quality still obtains. The pigs are hardy and naturally adapt themselves to pasture and clover or rape. Such feeding is essentially better for producing bacon than fat meat.

Criticisms of the Tamworth. Several characteristics of the Tamworth have invoked much criticism in America. The long head, narrow back, and long legs are not looked on with favor by American breeders. The great mass of American stockmen will not accept this type, and do not think it a profitable feeder or desirable sort. Unquestionably it will not feed as satisfactorily for us as will our more acceptable breeds, and from past experience the general evidence shows that the buyer will not pay as much for these pigs as for the common type of the country. It is undoubtedly true that the Tamworth is more prolific and produces a better quality of bacon, but it is not yet demonstrated in the United States that this is a pig the market wants on a serious basis. In 1898 , in letters to the Kansas Board of Agriculture, Armour \& Company stated that there was no special demand for bacon hogs, while Swift \& Company said there was a growing demand, Berkshires being preferred.

The distribution of the Tamworth is very limited. The breed is kept in a small way in England, and the same applies to Canada and the United States. Specimens are not commonly shown at the important stock shows of England or in this country. The principal herds in America are found in Ontario, Canada, and in Michigan, Illinois, and Iowa in the United States.

Organizations to promote Tamworths exist in England in the authority of the National Pig Breeders' Association of Great Britain, and in America in the American Tamworth Swine Record Association, the latter being organized in Michigan in 1897. The American Association has thus far published one record. The Dominion Swine Breeders' Association of Canada also registers this breed under government supervision. 


\section{CHAPTER LXXVIII}

\section{THE THIN RIND OR HAMPSHIRE}

This breed has been known for many years in the United States under the name of Thin Rind. In I904, by official action of the American Thin Rind Record Association, this name was changed to Hampshire. The name Hampshire seems ill advised to the writer, for the reason that quite a different breed of pigs exists at present under that name in England. It is unfortunate

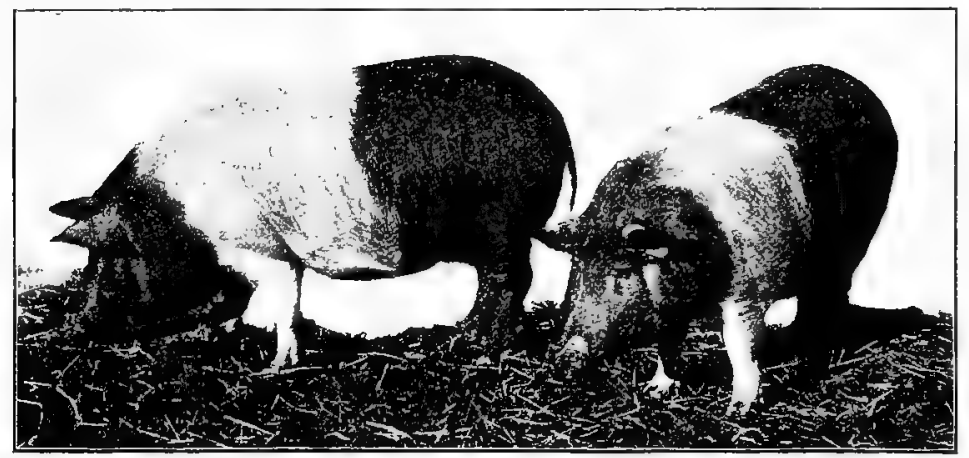

Fig. 256. A pair of Thin Rind or Hampshire pigs. Photograph from John Goodwine, Jr., Potomac, Illinois

to have the same name for two different breeds of swine, and is not justifiable. Therefore the author will make use of the word Thin Rind, which is said to have been given on account of the mellow thin skin and soft silky hair.

The origin of the Thin Rind breed of swine is quite obscure. Mr. H. F. Work states that this pig was a native of Hampshire, England, early in the last century. About 1820 to 1825 a retired sea captain named MacKay, living near Boston, Massachusetts, is said to have bought some of these pigs in England and taken them to Massachusetts, where they became popular under his name and later became known as Thin Rinds. This breed has 
long been known in Kentucky as the Thin Rind, and it has been assumed that it came from the same source as the Mackay pig. In 1835 Major Joel Garnett is said to have introduced Thin Rinds to Kentucky, having purchased from eastern persons. Some have claimed also that the ancestors of the Kentucky Thin Rind were imported prior to 1842 from Tonquin, China, by a merchant of New Orleans. The author has been unable to secure any absolute information regarding the true ancestry of this pig. No description of any breed has been found in the early English writings which will apply to the Thin Rind of 1835 .

Characteristics of the Thin Rind pig. The head is of the straight faced type, of medium size, with light jowl. The ears, though crect, incline slightly forward. The back tends to be of only medium width, not thick, and is fairly well supported. The shoulders are light and well set in, and have fair width. The body as a whole has only moderate depth and length, producing a fair side for bacon. The hams are lacking in fullness, not possessing the thickness and depth of the more popular American breeds. The legs tend to be somewhat long, but the bone is of good quality, while the pasterns and toes are usually well placed. The color of the Thin Rind is usually black, with a white belt about the body, this being known as a "listed" color, or solid black. This white band or list is from four to twelve inches wide, encircling the body just back of and about the fore legs, the latter also being usually white. In discussing the color Mr. H. F. Work says :

While the list will long be retained by many of the breeders as the most fashionable color, there are also those who try to run their herds pure black. An ideal color is made up much as one may fancy, and the "color craze" should not exclude worthy animals that are a little "off color," save where spots occur. The breeding of blacks is an absolute necessity when the listed hogs begin to show too much white, so as to narrow the belt.

The size of the Thin Rind pig does not place it among the largest breeds, it being about medium in size. Boars sometimes attain weights of 500 pounds, but usually are much smaller. The sows weigh about 300 pounds in ordinary condition. Barrows in high flesh attain a weight of 300 to 400 pounds. At the 1903 International Live Stock Exposition John Goodwine, Jr., 
won first prize for barrows with five Thin Rinds which averaged 493 pounds each at eighteen munths old, one of which won the championship in the slaughter test.

The fecundity of the Thin Rind pig is of superior character. The sows usually farrow litters of ten or twelve pigs after the first farrowing, and make excellent mothers and nurses. In this respect they rank with the most prolific breeds of American ancestry.

Grade or cross-bred Thin Rind pigs are not common. The use of the pure-bred boar on common sows will result in a more piolific stock, leaning toward the bacon type. Superior Thin Rind boars should add vigor and killing quality to the offspring of a certain class of high-fleshed sows of chunky type.

The Thin Rind as a grazer ranks high in Kentucky and elsewhere, where pigs range more or less for mast, and seek for feed in field and forest. It was this quality, together with that of fecundity, which added to the popularity of the breed where known.

The quality of Thin Rind meat is distinctly superior. Naturally the breed belongs to the bacon class, but when persistently fed corn for generations it loses some of its bacon-producing character. Yet in the slaughter tests these pigs have made a good showing. At the I90 International Live Stock Exposition at Chicago the second prize for both pens of five barrows of export bacon type, and for carcass weighing 300 pounds or over, was awarded Thin Rind barrows exhibited by Mr. Goodwine of Illinois. At the 1905 International Mr. E. C. Stone won the grand championship in barrow class over all breeds. Thin Rind meat is of excellent grain with a desirable proportion of lean to fat.

An organization to promote Thin Rind interests was incorporated by six Boone County, Kentucky, farmers in 1893 , they forming the American Thin Rind Record Association. At this time about twelve herds of swine of this breed were eligible for registration, mainly located in Kentucky and Indiana. In I904 this association changed its name to the American Hampshire Swine Record Association. No herdbook has yet been published.

The distribution of the Thin Rind breed is not extensive. It has long been bred and fed in Kentucky, and herds in a small way have been kept in Indiana and Illinois. The popularity of this breed is restricted, but has gained somewhat in recent years. 


\section{A FEW REFERENCE BOOKS ON THE PIG}

Those marked with a * are especially recommended.

JaCов Biggle, Biggle Swine Book. Philadelphia, 1899.

*F. D. Coburn, Swine Husbandry. New York, 1888.

G. E. DAY, Swine. Des Moines, I905.

JosePH HARRIs, Harris on the Pig. New York, I870.

* James Long, The Book of the Pig. London, N.D.

Dr. Georg MAY, Die Schweinezucht. Berlin, I880.

*George M. Rommel, The Hog Industry. Washington, 1904.

*S. M. Shepard, The Hog in America. Indianapolis, 1896.

* Samuel Sidney, The Pig. London, 1871.

*Sanners Spencer, Pigs: Breeds and Management. London, i 897.

John Walker, Pigs for Profit. London, I905.

*William Youatt and W. C. L. Martin, The Hog. New York, 1863.

\section{MISCELLANEOUS LIVE-STOCK BOOKS}

R. L. Allen, Domestic Animals. New York, 1859.

*John Coleman, Cattle, Sheep, and Pigs of Great Britain. Iondon, i 887.

* Јонn A. Craig, Judging Live Stock (sixth edition). College Station, Texas, I904.

George Culley, Observations on Live Stock. Dublin, 1789 .

*George W. Curtis, Horses, Cattle, Sheep, and Swine. College Station, Texas, 1888.

R. W. Dickson, An Improved System of Management of Live Stock and Cattle. London, N.D.

Sir William Jardine, The Natural History of the Ruminating Animals (The Naturalists' Library, Vol. IV). Edinburgh, 1836.

*Live Stock Journal Almanac. London, issued yearly.

*David Low, On the Domesticated Animals of the British Islands. London, 1842 .

D. G. F. Macdonald, Cattle, Sheep, and Deer. London, i 872 .

R. O. PrINGLE, The Live Stock of the Farm. Edinburgh, 1875 .

G. G. Richardson, The Corn- and Cattle-Producing Districts of France. London, N.D.

J. H. Sanders, The Breeds of Live Stock. Chicago, 1887.

*Thomas Shaw, The Study of Breeds in America. New York, I90o.

* Robert Wallace; Farm Live Stock of Great Britain. Edinburgh, 1889.

*Various Writers, The Best Breeds of British Stock. London, I898.

* William Youatt, The Complete Grazier (revised by William Fream). London, 1893. 


\section{N D E X}

Aberdeen Angus cattle, 213; as a dairy cow, 220 ; characteristics, 217 ; crossing or grading, 220 ; early improvers, 2 I 4 geographical distribution of, 224 ; in America, famous, 223 ; introduction to America, 216; native home of, 2!3; organizations, 224; origin, 213 ; prices brought by, 222 .

Aberdeen Angus steer at International Live Stock Exposition, 222.

Aberdeen Angus steers, 22ף; prices brought by, 223 .

Aberdeen Angus tribes in favor, 216.

Action coach horse, 62.

Aguirre Merinos, 342.

American Merino, 339; as wool producer, 349; breeding qualities, 35 I ; characteristics, 348 ; cross-bred or grade, 350; maturing qualities, 352 ; mutton qualities, $35^{\circ}$; show-ring victory, 355 ; size, 349 .

American studbook, 8o.

American Yorkshire Club, 544.

Anchitherium, 4.

Angora Goat Breeders' A ssociation, 459.

Angora goat, description, 456 ; distribution, 459; fleece of, 457 ; introduction to America, 455 ; mutton, $45^{8}$; native home, 455; prices, 459 ; prolificacy, 459 ; renovator brush land, 458 ; varieties, 455 .

Appenzell goat, $46 z$.

Arab horse, 7 ; characteristics, 12 ; crossbred, 13; families, 9; foundation, 9 ; in American history, Io; native home, 8; notable, 12; origin, 8; registration of, 13 .

A rab pony, 148.

Arab studs in England and A merica, I I.

A rabian, Darley, I 5 .

Ardennais, 113 .

Ass, the, 155; African wild, 155; ancestry of, 155; Asiatic wild, 155; characteristics, I 55 ; to America, introduction. 160 .

Australian Merinos, 344 .

Ayrshire cattle, 287 ; as beef producers, 293; as butter cows, 292; as milk producers, 29I ; characteristics, 289; cross-bred or grade, 294 ; distribution, 294 ; early improvers, 288 ; introduction America, 289 ; native home, 287 ; origin, 287 ; size, $29 \mathrm{r}$.

Ayshire herd milk records, $29 \mathrm{I}$; in public tests, 292; milk for cheese, 293 ; milk records, 292 ; organizations promoting interests, 294.

Bacon pigs, breeding, 535; weight, 535.

Bacon type pig, characteristics, 533; demand for, 532.

Bakewell, Robert, improver of Shire, I25, 429.

Bar None (2388), 128.

Barb, Godolphin, 15.

Baron's Pride (9122), : 18.

Bates, Thomas, 177 .

Beautiful Bells, 48 .

Beef animal, general appearance of, 169; quality of, 173 .

Beef cattle, fleshing of, 174 .

Beef type compared, dual-purpose and, 307 ; of cattle, 169.

Belgian Draft Horse, American Association of Importers of, 137; characteristics of, 137; cross-bred, 139; distribution, 139; exhibitions in United States, 136; history in America, 136.

Belgian horse, I 33 .

Belgium as a horse-breeding country, 133 ; draft-horse shows in, 135 ; horsebreeding methods in, 134; Official Draft Horse Society of, I33.

Bellfounder, 37, 66 .

Belted cattle. See Dutch Belted.

Benedict (10315) 9300, I1 8.

Berkshire pig, adaptability to environment, 478 ; as feeder, 479 ; as grazer, 479; as source red swine, 506 ; boars, 476; characteristics, 476; characteristics old type, 473 ; color, 476 ; cross-bred or grade, 480 ; distribu: tion, ${ }_{4} \mathrm{~S}_{2}$; early improvement, 472 ; early-maturing, 478 ; families, 475 ; 
fecundity and prolificacy, $48 \mathrm{r}$; foundation stock, 472 ; improvers early, 473; improvers, modern, 474; in Poland-China evolution, 486 ; introduction to America, 474; native home, 472; organizations for promoting, 482 ; pork, 480 ; prepotency, 482 ; prices, 483 ; size, 477 ; style and finish, 482 .

Big China pig, 485 .

Black Faced Highland sheep, characteristics, 453; cross-bred or grade, 454 ; distribution, 454 ; introduction in America, 453; native home, 452; origin, $45^{2}$; special field in America for, 454 ; special value, 453 .

Black Top Merino, characteristics, 362 ; Spanish Merino, 361.

Blake strain, I 40 .

Blythwood Conqueror (14997), 128.

Books, miscellaneous live-stock, 554 ; on cattle, reference, 332 ; on horse, reference, I67; on pigs, 554; on sheep and goats, 466 .

Booth family, 178 .

Border Leicester sheep, 435; characteristics, 436; in America, 436; organization to promote, 436 ; rams on Cheviot ewes, 436 .

Boulonnais, III.

Breton, I I 2.

Brienz 168, dairy test, 329.

British home Hackney, early, 63 .

Bronchos, 148 .

Broomfield Champion (95), I 16.

Brown Swiss cattle, 326; adaptability, $33^{\circ}$; as beef producers, $33^{\circ}$; Breeders' Association, American, 331 ; characteristics, 327 ; dairy qualities, 328 ; distribution, 330 ; in crossing or grading, 331 ; in United States, introduction, 326 ; native home, $3^{26}$; origin, 326 ; size, 328 .

Bury Chief Victor (I I 105), I 28.

Byerly Turk, I 5 .

Byfield pig, 484 .

Canadian cattle. See French Canadian. Cheshire pig as a feeder, 5I6; as a grazer, 517 ; Breeders' Association, 517 ; characteristics, 515 ; cross-bred or grade, 5I6; distribution, 517; fecundity, 517 ; meat, 516 ; native home, 514 ; origin, 514 ; popularity, 517 ; size, 5 I 5 .

Chester White pig as feeder, 501; as grazer, 503; breeding qualities, 502 ; characteristics, 500; cross-bred or grade, 502; distribution, 503; meat of, 503: organizations to promote, 503; origin Improved, 497; origin Ohio Improved, 499; original type, 497 ; prices paid for, 504 ; size, 500.

Cheviot sheep as grazer, 417 ; characteristics, 4I6; cross-bred or grade, 418; distribution, 419; for mutton, 417 ; for wool, 418; hardiness, 418 ; introduction to United States, 416 ; native home, 4I5; on range, 419; organizations to promote, 420 ; origin, 415 ; prices for, 420 ; prolific character, 4 I 8 ; size, 417 .

Clay family, 41 .

Cleveland Bay horse, 86 ; as a breed, purity, 87 ; as roadster, 90 ; characteristics, 89; distribution, 90 ; early purpose, 87 ; half-bred or grade, 90 ; in America, 88; native home, 86; origin, 86 ; studbooks, 90 .

Clyde, alias Glancer (I 53), I I 6 .

Clydesdale horse, I14; as a breed, distribution, I22 ; breeders' associations, 122 ; characteristics, II 8 ; criticisms of, 123; early history, 114; half-bred or grade, 123; high prices for, 123; introduction to America, 120 ; of merit in America, 12I; origin modern, II4; sires, important, I I 5, I I 8 ; to United States, prominent introducers of, 122 ; use English blood on, I 5 .

Coach horse, action, 62 ; sub.classes, 62.

Coates's Herdbook, 195.

Colling brothers, 176 .

Cotswold sheep, ancestry, 437; as feeder, 440 ; as grazer, 441 ; breeding qualities, 441 ; characteristics, 439 ; distribution, 442 ; for crossing and grading, 44I ; for mutton, 440; for wool, 442 ; introduction to America, 438 ; native home, 437 ; organizations for promoting, 442 ; origin name, 437 ; size, $44^{\circ}$.

Cruickshank, Amos, I79.

Dairy type compared, dual-purpose and, 307 ; of cattle, 243; quality of, 248.

Darley, Arabian, 15.

Darnley (222), I I 7 .

Dartmoor ponies, New Forest and, 148.

Davy, John Tanner, 320.

Delaine, type, maintenance, $36 z$.

Delaine, word, 357 .

Delaine Merino, 357 ; adaptability of, $3^{64}$; as a feeder, $3^{64}$; breeding quality, 364 ; cross-bred or grade, 30́4; 
Dickinson, 358 ; distribution of, 364 ; mutton value, $3^{\kappa_{3}}$; National, 359, 360 ; organizations promoting, 364 ; origin, 357 ; types, 357 ; Victor-Beall, 360 .

Denmark horse, 27.

Devon cattle, 319; as butcher's beast, 323 ; as grazers, 324 ; as milkers, 323 ; characteristics, 322 ; distribution, 324 ; early improvers, 319 ; in crossing or grading, 324 ; introduction to America, 320 ; native home, 319 ; organizations to promote, 325 ; origin, 319 ; popularity in America, 325 ; size, 323: two types, 322.

Devon oxen, 324 .

Dexter-Kerry, 303 .

Dickinson Delaine, 358 ; characteristics, 359.

Dolly Bloom 12770, 282 .

Dorset Horn sheep, as a feeder, $4 \mathrm{II}$; characteristics, 4 IO ; distribution, 413 ; fecundity of, 412; for crossing or grading, 4I2; for early lambs, 4II; for mutton, 411 ; for wool, 413 ; intro. duction to America, 409; native home, 408; organizations to promote, 414 ; origin, 408 ; popularity of, 413 ; size, 410 .

Dorset homs protection from dogs, $4 \mathrm{I} 3$.

Draft horse, action, 92; breeds French, I I 1 ; general conformation, 92 ; measurements, 97.

Draft type, 92.

Drivers of light hamess horses, 53.

Dual-purpose and beef type compared, 307 ; dairy type compared, 307.

Dual-purpose cattle, demand for, 308 ; two classes of, 307 .

Dual-purpose type cattle, 307 ; relationship size to, 308 .

Duroc breed red pigs, 506 .

Duroc-Jersey pig, as a feeder, 510 ; as a grazer, $5 \mathrm{I} 1$; breeding characteristics, 512; characteristics, 509 ; cross-bred or grade, 5 1 2 ; distinction, 508 ; distribution, 512 ; environment for, 510 ; improvement, 508; improvers, 508; maturing qualities, 510 ; meat, 512 ; organizations to promote, 513 ; origin, 507 ; size, 5 ro; slaughter tests, 5 II.

Dutch Belted cattle, 296; adaptability, 298 ; as beef producer, 298 ; characteristics, 297 ; cross-bred or grade, 299 ; dairy importance, 298; distribution, 299; introduction to America, 297 ; native home, 296 ; origin, 296 ; promotion, 299 ; records, 298.
Eclipse, I6.

Ellman, John, 378 .

England, horses introduced into, 15 ; improvement Jersey cattle in, 251; prior to Elizabeth, horse in, 14.

English-bred horses, three, 16; Merinos, 344.

Eohippus, 3.

Epihippus, 3.

Equus, 4.

Escurial Merinos, 342.

Escutcheon, 248.

Essex pigs, as feeders, 523; characteristics, 522 ; cross-bred or grade, 523; distribution, 524 ; early native type, 52I; establishment Improved, 52I; fecundity, 524; improvement, $52 \mathrm{I}$; introduction to America, 522 ; maturing qualities, 523; meat, 523 ; native home, $52 \mathrm{I}$; organizations to promote, 524 ; size, 523 ; special field for, 523 . Exmoor pony, 147 .

Fleshing of beef cattle, I 74 .

Flocks of Spain, provincial, 34I.

France, classes breeding stallions in. 76 ; horse racing in, 72 ; Percheron shows in, rog.

French Canadian cattle, 300 ; breeding, qualities, 302 ; characteristics, 300 ; distribution, 302; grazing qualities, 301 ; hardy character, 301 ; maturing qualities, 302 ; milk production by, 301 ; native home, 300 ; origin, 300 ; promotion, 302.

French Coach horse, 72 ; characteristics, 77; distribution and adaptation, 79 . grade or half-bred, 80 ; origin, 7.3 : source of stock, 73,74 ; speed records. 78.

French Draft Association, National, II 3 .

French Draft horse, 11 I ; breeds, 1 II.

French horse, history, early, 72 ; Jockey Club, 72 ; methods to promote horse improvement of, 75 ; race track, 78 .

French Merinos or Rambouillets, 344.

Fullerton, William, 2 I6.

Galliers, William, 202.

Gallipoli, 99.

Galloway bulls of distinction, 233 .

Galloway cattle, 225; American im. provers of, 233 ; as a meat producer, 230; as milk producer, 232 ; associations for promoting, 228; characteristics of, 228; criticisms of the, 229; cross-bred, 230 ; distribution of, 233 : 
hardiness of, 230 ; hide of, 230 ; improvement of, 225 ; introduction to America, 227; native home of, 225; origin of, 225 ; prepotency of the, 231 ; prices for, 233 ; size of the, 232 .

General-purpose type cattle, dual or, 307.

German Coach horse, 81 ; characteristics, 84 ; distribution, 85 ; history, 81 ; history in America, 83 ; important, 85; mares, 85 ; organization in America, 83 ; studbook, 85 ; type, 82 . German or Silesian Merinos, 343.

Germany, home horse breeding in, $8 \mathrm{r}$; records horse breeding in, 81 ; supervision horse breeding in, 82 .

Glancer (335) alias Thompson's Black Horse, 116.

Goat. See Angora.

Goat, age milch, 464; Appenzell, 46z; as milk producer, 460 ; Association American Milch, 463; fecundity milch, 464; importations America milch, 465; lactation period, 463; Langensalzaer, 462; Maltese, 460; Nubian, 462; Saanen, 462; Schwarzthal, 463 ; Toggenburg, 46r.

Goats, milk-producing, 460 ; price milch, 464 .

Godolphin, 99; Barb, 15.

Grant, Sir George Macpherson, 2 I 5.

Green Mountain Maid, 48.

Guadalupe Merinos, 34z.

Guernsey bulls of distinction, 284 .

Guernsey cattle, 276; as butter producers, 280 ; butter records, 281 , 282 ; characteristics, 278 ; cross-bred or grade, 283; distribution, 284; improvement, 276 ; in beef production, 283 ; introduction to America, 277 ; maturing character, 283 ; milk records, 279 ; native home, 276 ; organizations to promote, 285 ; origin, 276 ; size, 279.

Guemsey milk, cheese value, 282.

Guinea breed of pigs, 505.

Hackney horse, 63 ; characteristics, 68 ; color of the, 69; development of, 64 ; distribution of, 71 ; early British home, 63 ; evolution of, 64 ; half-bred or grade, 70 ; in America, 66; pony, 149; Horse Society, 71 ; soundness of the, 69 ; speed and endurance, 66 ; stock, original, 63 ; use word, 63 .

Hal family, 42.

Hambletonian Io, 38, 39 .

Hambletonian family, 37 .
Hampshire Down sheep, associations to promote, 407 ; as grazer, 406 ; crossbred or grade, 406 ; distribution, 406 ; early improvement, 402; fecundity, 406 ; for early lambs, 405 ; for wool, 406 ; introduction to America, 404; native home, 402 ; origin, 402 ; prices for, 407 ; size of, 405 .

Hampshire swine. See Thin Rind.

Harold $(3703)$, I 28.

Hereford cattle, 20I; as meat producers, 209; breeders, early, 202; nineteenth century, 203; characteristics, 206; distribution, 210 ; introduction to America, 205; native home, zor; of note in America, 206; organizations to promote, 212 ; origin, 201 ; prices for, 211.

Hereford steers in American fat stock shows, 2 Io.

Herefords of importance, foundation, 204.

Herod (King Herod), 16.

Hewer, John, 203.

Hipparion, 4 .

Hitchin Conqueror (4458), 129.

Holstein-Friesian, as producer of milk, 269 ; butter records, 271 ; milk for cheese, 272.

Holstein-Friesian bulls, great, 274 .

Holstein-Friesian cattle as butter producers, 269; breeding and maturing power, 274; characteristics, 266; distribution of, 275 ; families of prominence, 274; grade or cross. bred, 272 ; introduction to America. 264; measurements, 268 ; native home of, 264; official testing of, 270; organizations for promoting, 274 ; origin name, 264 ; records, 270 ; size of, 268 ; oxen, 273.

Honest Tom (1062), 127.

Honest Tom (1 105), 128.

Horse, connection of modern and prehistoric, 6; discovery in America prehistoric, I; distribution prehistoric, 2 ; evolution of, 2 ; man and prehistoric, 6; racing in England, 14 ; reference books on, 167 .

Horses, number of record-making, 52; prices paid for standard bred, 52 .

Hyracotherium, 3.

Improved Black Top Merino, 362 .

Indian pony, 148 .

Infantado Merinos, 342.

Irish Grazier pig, Poland-China and, 486. 
Jack, Catalonian, 157; height for, 159 ; Majorca, 158; Maltese, 156 ; Poitou, $15^{8}$.

Jacks and jennets, American Breeders' Association, 160; high prices for, 160 .

Jeffries, Thomas, 204.

Jennets, American Breeders' Association of Jacks and, 160.

Jersey bulls siring tested daughters, 261.

Jersey cattle, 249; as beef producers, 259 ; as milk-fat producers, 255 ; as producers of milk, $25^{8}$; butter records, notable, 256; characteristics, 252 ; distribution, 262 ; early maturity, 262 ; for crossing and grading, 259 ; importation to America, 252 ; in England, improvement, 25I; native home, 249 ; organizations for promoting, 263 ; origin, 249 ; prices for, 261 ; reproductive power, 262 ; size, 255.

Jersey families of distinction, 260 ; island, purity cattle on, 250 ; milk for cheese making, 258 ; type, improvement old, 250.

Jersey Red pig. See Duroc-Jersey.

John Bull (i I 69), I 27.

Justin Morgan, 39.

Keheilan, 9.

Keheilet, 9, 10.

Kent sheep, early type, 450; in America, 451; modern type, 45I; native home, 450 .

Kerry cattle, 303 ; as beef producer, 305 ; as milk producer, 304 ; characteristics, 303; distribution, 306; hardy character, 305 ; in cross-breed. ing, 306; maturing characteristics, 305; native home, 303; organization, 306 ; size, 304 ; true, 303 .

Langensalzaer goat, 462 .

Large white pig, 536 .

Large Yorkshire pig, ancestry, 536 ; as a bacon producer, 54I; as feeders, 542 ; characteristics, 538 ; cross-breds, 540 ; distribution, 543 ; early improv. ers, $53^{8}$; early-maturing, 540 ; introduction to America, 543; popularity in United States, 543; prolificacy, 542 ; size, 539 ; slaughter test, $54 \mathrm{I}$.

Leicester sheep as grazer, 434 ; Bakewell type, 43I ; Border type, 435; breeding qualities, 434 ; characteristics Border, 436 ; cross-bred CheviotBorder, 436 ; cross-bred or grade, 432 ; distribution, 434 ; for mutton, 432 ; for wool, 433; improvement, 429 ; in America, Border, 436; introduction to America, 430; native home, 429 ; origin, 429; organizations to promote, 435 ; organization to promote Border, 436; popularity, 434; size, 432 .

Lincoln sheep as grazers, 446 ; breeders and improvers of, 448 ; breeding quality, 447; characteristics, 444 ; cross-bred or grade, 446 ; distribution, 448 ; for mutton, 445 ; for wool, 446 ; introduction America, 443; native home, 443; organizations to promote, 448 ; origin, 443 ; prices for, 449 ; size, 445; Lincolnshire Lad II (1365), 127.

McCombie, William, 214.

Maltese goat, 460 .

Mambrino Chief, $3^{8}$; family, $3^{8}$.

Man and prehistoric horse, 6.

Martin's Boxer strain, 14 I.

Matchem, 16.

Merino sheep, Aguirre, 342; American, 339 ; as wool producer, American, 349 ; Australian, 344 ; Black Top Spanish, 361 ; breeding qualities American, 351 ; characteristics, 335,348 ; Class A, 333; Class B, 334 ; Class C, 334 ; conformation, 333: cross-bred or grade American, 350; Delaine, 357; distribution, 352 ; drives in Spain, annual, $34^{\circ}$; early improvers, 346 ; English, 344 ; Escurial, 342 ; exportation from Spain, 343 ; fiber, fineness, 350 ; fleece to body, relationship weight, 349; German or Silesian, 343; Guadalupe, 342 ; Improved Black Top, 362 ; Infantado, 342 ; introduction to United States, 344; mania for, 346 ; maturing qualities, American, 352 ; mutton qualities, American, 350; native home, 339; Negrette, 342; organizations to promote, 352 ; origin, 343 i origin, Delaine, 357 ; Paular, 34I ; Rambouillets or French, 344 ; rams, famous, 353 : Saxon, 343 ; size, American, 349; show-ring victory, 355; Swedish, 343; three classes, 333 ; type, 333 ; wool, 338 ; prices for, 354 i subtypes or families, 355 ; use of three classes, 335 .

Mesohippus, 3 .

Messenger, 37 .

Middle White or Middle Yorkshire swine, 544 .

Middle Yorkshire or Middle White swine, 544 . 
Milch goat. See Goat.

Milk veins, 247.

Miss Russell, 48.

Mohair, prices of, $45^{8}$.

Morgan family, 39 .

Mule, I6I; a hybrid, I6I; as carriage or saddle animal, 165; best type of, 164; characteristics, 162; color of, 164; distribution of, 161 ; endurance of, 164; in history, 161 ; Poitou, 165; raising in United States, 161; resistance to disease, 165 ; sex of, 166 ; temperament of, 164 .

Mules, classification, 163: levee, I63; lumber, 163 ; mine, 163 ; plantation, 162 ; prices paid for, 166 ; railroad, 163.

Mustangs, 148 .

Mutton conformation, 375 .

Mutton type of sheep, 375 .

National Delaine, 359, 360.

Negrette Merinos, 342 .

New Forest and Dartmoor ponies, 148.

Nivernais, 112.

Norfolk Red Polled cattle, 310 ; amalgamation Suffolk and, 310.

Nubian goat, 462 .

Ohio Importing Company, 183 .

Orloff horse, characteristics of, 54 ; color of, 56; cross American trotter and, 57 ; importations of, 56 ; origin of, 54 ; speed of, 57 ; trotter, 54 ; types of, 56 .

Orohippus, 3 .

Oxen, Devon, 324.

Oxford Down sheep, as feeders, 398 ; characteristics, 396; cross-bred or grade, 398; distribution, 400; for wool, 399; introduction to America, 396 ; native home, 395 ; organizations to promote, 401 ; origin, 395 ; prices paid for, 4 or; prolific quality, 400 ; size of, 398.

Pace, explanation of, 49 ; interchangeable, trot and, 49.

Pacer, the, 49; ancestry of the, 49.

Pacers, sires of trotters and, 47.

Pacing, brood mares, list of trotting or, 48 ; families, money-winning trotting or, 52 ; horse, conformation of, 50 ; records, $5^{I}$; standard, 50.

Packington Blind Horse, I 27.

Parahippus, 4.

Paular Merinos, $34 \mathrm{I}$.
Percheron horse, 98; Associations, American, 104 ; cross-bred or grade, 107; deterioration, 101; distribution in America, 107; early type, 100; history in United States, important, 106; improvement in France, 104; introduction to United States, 106 ; origin, 98 ; original home, 98 ; popularity of, IIO; prices paid for, IOg; Society of France, 104; type about 1877 of, 101; type of to-day, 102.

Percheron shows in France, rog.

Percheron sires, famous, 108.

Percheron studbooks, ro5.

Picardy, I1 3 .

Pig, American type, 467; bacon type, 532,533 ; books on, 554 ; breeding bacon, 535; Byfield, 484 ; disposition fat type, 471 ; fleshing quality, 470 ; general appearance, 467 ; hair, 471 ; Russian, 484 ; weight bacon, 535 .

Pilot, 42 ; family, 42 .

Pliohippus, 4 .

l'oitou, 165 .

l'oland-China, adoption name, 486 .

Poland-China pig, adaptability to environment, $490^{\circ}$; and Irish Grazier pig, 486; as feeder, 491 ; as grazer, 491 ; boars of note, 488 ; distribution, 494 ; early-maturing, 49 I ; evolution, Berkshire in, 486; characteristics, 489 ; color, 490; cross-bred or grade, 493; fecundity and prolificacy, 493; improvers, 487 ; meat, 493 ; native home, 484 ; organizations to promote, 494 ; origin, 484 ; prices for, 495 ; size, 490 ; sows of note, 488 .

Polled Durham cattle, 197; distribution of, 200; double standard, 197 ; herdbook, American, 200; origin word, I97; popularity of, 200 ; prepotency, 200 ; promotion of interests of, 200 ; requirements for registering, 199; single standard, 197.

Polo pony, 146.

Ponies, 146; New Forest and Dartmoor, 148 .

Pony, Arab, I 48 ; Exmoor, 147 ; height of, 146 ; improvement of Shetland, I 52 ; Indian, I 48; Polo, I 46 ; Welsh, 146; Welsh mountain, 147.

Portuguese pigs, 505.

Position legs horse, proper, 6r.

Prehistoric horse, 1 ; and man, 6 ; existence of, 1; color of, 5 ; connection of modern and, 6 .

Premier (2646), 128.

Price, John, 203. 
Prince of Wales (673), 116.

Prince William (3956), I 28.

Protohippus, 4 .

Protorohippus, 3 .

Przewalskii's horse, 6.

Quartly, Francis, 319.

Racing in England, horse, I4.

Rambouillet sheep, the, 366; ancestry, 366 ; as mutton producer, $37 \mathrm{I}$; as wool producer, 372 ; breeding qualities, 372 ; characteristics, 370 ; crossbred or grade, 372 ; distribution, 373 ; early maturity, 373; French Merinos or, 344 ; hardy quality, 373 ; improvement, 367 ; introduction to United States, 368 ; native home, 366 ; grganizations to promote, 373 ; pfices for, 374 ; size of, 371 .

Red or sandy-colored pigs in Ameřex 505.

Red pigs. See Duroc-Jersey.

Red Polled cattle, 309; amalgamation Suffolk and Norfolk, 310; as beef producers, 314 ; as butter producers, 316 ; as milk producers, 315 ; characteristics, 312 ; in crossing or grading, 316 ; deficiencies of, 317 ; distribution, 318 ; groups and tribes, $3 \mathbf{I}$; introduction to America, 312; milk records, 3 I 5 ; native home, 309 ; organizations promoting, 318 ; origin, 309 ; weight, 314.

Red swine, Berkshire as source, 506.

Roadster type, 33.

Romney Marsh. See Kent.

Russian pig, 484 .

Saanen goat, 462 .

Saddle animal, mule as carriage or, 165.

Saddle horse, American, 26; Breeders' Association, American, 32 ; characteristics of, 28; foundation stock American, 27; gaits of, 28, 29; history, American, 26; influence Thoroughbred on American, 26.

Saddle horses, famous, 28 ; prices paid for, 32 .

Sandy-colored pigs in America, red or, 505 .

Saxon Merinos, 343.

Schwarzthal goat, 462 .

Scotch Clydesdale Horse Society, 122.

Shadingfield strain, I4I.

Shales, The Original, 65 .
Shetland ponies, of interest, I 54 ; prices paid for, I 53.

Shetland pony, 150; ancestry, 150; characteristics, 151 ; improvement of, 152 ; in America, use of, 153 ; native home, I50; organization, I54; type of, 150.

Shire horse, characteristics, 129 ; breed. ing in England, 124; critics in America of, 130; demand for the, 131; distribution of the, I3I ; early history, 124; importations to America of, 130; importers of, 132 ; in crossing, use of, 131; in show ring, 132 ; modern, I26; old-fashioned, I25; organizations to promote the, 13I ; origin of, 124; Robert Bakewell, im. prover of, 125; Society, I3I ; stallions, important, 127 ; varieties of the, 126.

Shorthom cattle, as butcher's beast, 187; as milk producer, 190; at Louisiana Purchase Exposition dairy test, 192; breeders, other important, 180; characteristics, 184 ; color of, 186; dairy records, 191; grading or crossing, 189; herdbook, American, 195 ; imported to America, first, 183 ; improvers of the, 176 ; origin of, 175 ; original home of, 175 ; quality of, I 87 ; steers at Internationa] Exposition, 188; steers in show ring, I 88 .

Shorthorns in America, men who have promoted, I96; of interest, individual foundation, 180 ; prices received for, 193.

Shropshire sheep as grazer, 392 ; characteristics, 389 ; cross-bred or grade, 39 r ; distribution of, 393 ; early improvers, 388 ; early-maturing, 392 ; fecundity of, 391 ; for general purpose, 393i for mutton, 390; for wool, 392 ; introduction to America, 388 ; native home, 387 ; organizations to promote, 393 ; origin, 387 ; prices for, 394 ; size of, 390 ; vigor of, 393 .

Silesian Merinos, German or, 343.

Small white swine, strains or families, 525 .

Small Yorkshire pig, as a grazer, 528; characteristics, 526; cross-bred or grade, 528 ; distribution, 529 ; earlymaturing, 527 ; fecundity, 528; introduction to America, 525; meat, 528 ; organizations to promote, 529 ; origin, 525 ; popularity, 528 ; size, 527 . 
Southdown sheep, 378; adaptability of, $3^{84}$; as feeder, 383 ; breeding qualities, 384 ; characteristics, 381 ; criticism, 385; cross-bred or grade, 384 ; distribution, 385 ; early improvers of, 378 ; for wool, 384 ; introduction to America, 381 ; mutton, 383 ; native home, 378 ; nobility breeding, 380; organizations promoting, 385 ; original stock, 378 ; prices for, $3^{86}$; size of, $3^{82}$.

Spain, annual Merino drives in, 340; exportation Merinos from, 343; provincial flocks of, $34 \mathrm{I}$; sheep husbandry in, 339 .

Spanish Merino, Black Top, 361 .

Spanish red pigs, 505 .

Spanish sheep, two groups, 340.

Standard-bred horses, prices paid for, 52 .

Standard-bred trotter, what is a, 44 -

Standard Delaine, 360.

Standard pacing, 50.

Studbook, Thoroughbred, 24.

Suffolk and Norfolk Red Polled Cattle, amalgamation, 310.

Suffolk Down sheep, as feeder, 423; characteristics, 422 ; cross-bred or grade, 423 ; distribution, 423 ; fecundity, 423; for mutton, 423 ; for wool, 423; introduction to America, 421 ; native home, $42 \mathrm{I}$; organizations to promote, 424 ; size, 422 ; origin, 421 .

Suffolk horse, characteristics, I42; cross-bred, 145: distribution, 145; draft horse, I44; early career, 140 ; fecundity and longevity of, I45 ; foreign blood to improve, 140 ; foundation, I 40; history modern, I4I ; in America, history, I 42 ; native home of, 140 ; studbook, 145.

Suffolk pig, characteristics, American, 530; distribution, American, 531 ; English, 530; in breed comparison, 531 ; origin, American, $53^{\circ}$.

Suffolk Red Polled cattle, 309.

Sussex cattle, 234; beef properties, 235; characteristics, 234 ; cross-bred and grade, 236; distribution, 236 ; early-maturing and grazing value, 236 ; introduction to America, 234; milkgiving qualities, 235 ; native home, 234 ; origin, 234 ; promotion of, 237 ; size, 235 .

Swedish Merinos, 343.

Swine, of Miami Valley, 484 ; type valued in United States, 467 .

Swiss chle, races, 326. See Brown Szeiss,"s, "s, $s, " s, " s, " s, " s$
Tamworth pig, ancestry, 545 ; as bacon, 547 ; as a feeder, 548 ; as a grazer, 550; characteristics, 546 ; criticisms, 550 ; cross-bred or grade, 549; distribution, 550 ; early type, 545; fecundity, 549; improvement, 545 ; introduction America, 546; maturing quality, 548 ; native home, 545 ; organizations to promote, 550 ; size, 547.

Thin Rind pig, as a grazer, 553; characteristics, 552; distribution, 553; fecundity, 553; grade or cross-bred, 553 ; meat, 553 ; organizations to promote, 553 ; origin of, 551 ; size, $55^{2}$.

Thoroughbred horse, I4; color of, 21 ; conformation of, 20 ; distribution, 21 ; height, 21 ; influence on American saddle horse of, 26 ; origin of, 17 ; speed of, 22, 23; studbook, 24 ; temperament, 21 ; weight, 21 .

Thoroughbred sires, famous, 24, 25 .

Thoroughbreds, importations to America of, 19; names famous, 17 ; prices of, $2 \mathrm{I}$; prominent American, 19; prominent British, 18.

Toggenburg goat, $46 \mathrm{I}$.

Tom Hal, 42.

Tomkins family, 202.

Trot, explanation of, 49 .

Trot and pace interchangeable, 49.

Trotter, American, 36; cross of Orloff and American, 57 ; definition standardbred, 44; in America, early use, 36; speed of the, 46 ; type of American, 43.

Trotters and pacers, sires of, 47 .

Trotting, blood in America, source, 36.

Trotting families of note, 37 .

Trotting horse, history of English, 36 .

Trotting or pacing brood mares, list, 48 .

Trotting or pacing families, money-winning, 52.

Trotting records, fast, 47 .

Trotting register, 44 .

Tunis Sheep, Breeders' Association, 428 ; characteristics, 426 ; cross-bred or grade, 427 ; distribution, 428 ; fecundity of, 428 ; for early lambs, 427 ; for mutton, 427 ; for wool, 428 ; introduction to America, 425 ; native home, 425 ; origin, 425 ; size, 427 .

Turk, Byerly, 15 .

Type of cattle, beef, 169 ; dairy, 243.

Type, quality of dairy, 248 .

Udder, 246.

United States, mule raising in, 161 . 
Veins, milk, 247 .

Victor-Beall Delaine, 360.

Victoria pig, adaptability, 520; argument for, 520; as a feeder, 520 ; association for promoting, 520; breeding qualities, 520; characteristics, 519 ; cross-bred or grade, 520 ; Curtis, 518 ; Davis, 518 ; distribution, 520; origin, 518; pork, 520; size, 519 .

Watson, Hugh, 214.

Webb, Jonas, 379.

Welsh mountain pony, I47.

Welsh pony, 146.
West Highland cattle, 238; as beef producers, 240; breeders' organization, 242; breeding qualities, $24 \mathrm{I}$; characteristics, 238 ; cross-bred or grade, 241 ; distribution, 242 ; hardiness of, 240 ; introduction to America, 238; milking qualities, 241 ; native home, 238 ; origin, 238 ; size, 240 . William the Conqueror (2343), 128 . Wright strain, 141 .

Yeksa Sunbeam, 281.

Yorkshire Coach horse, 9r.

Yorkshire pig, ancestry Large, 936 ; Small, 525 . 






